Copyright: The author, Ashleigh Russell Harper, 2020.

\title{
Vegetation fires in temperate upland heaths: environmental impacts, recovery and management implications
}

Ashleigh Russell Harper

Submitted to Swansea University in fulfilment of the requirements for the Degree of Doctor of Philosophy

Swansea University

2020

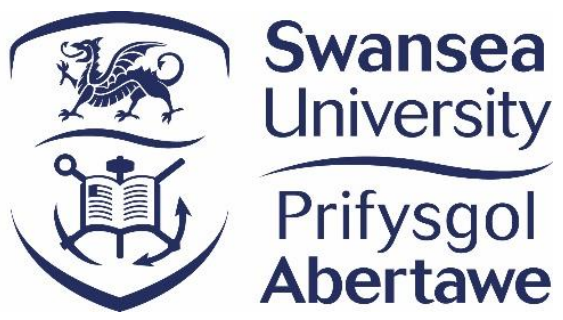




\section{Summary}

The impacts of wildfires are diverse and highly variable dependent on location, habitat type, site conditions and fire severity. Wildfire impact research is however, limited across large areas of the UK presenting an issue for the creation of effective sitespecific management planning in a number of areas and habitat types. To address this issue in the Brecon Beacons National Park (south Wales), research was conducted assessing post-fire: i) vegetation community composition; ii) soil physical and chemical properties; iii) ash chemical composition and toxicity. The primary conclusions from this research suggests vegetation community composition and soil physicochemical properties are able to recover relatively rapidly to long unburnt conditions (>11-years and >3-years, respectively) following wildfire events in dry heaths with shallow organic soils. The fast rates of post-fire vegetation recovery across the assessed sites are likely due to the species-poor, dwarf-shrub dominated, pre-fire conditions reducing the time required for the vegetation community to return to this low species diversity. Soil physicochemical properties showed limited impact from the fires, likely due to the high moisture retention of the surface organic soil layer having resulted in limited soil heating and depth penetration. Wider environmental concerns are raised by the ash composition, which showed remarkably high concentrations of potentially toxic substances such as, metallic elements (e.g. Fe, $\mathrm{Mn}, \mathrm{Pb}, \mathrm{Zn}$ and $\mathrm{As}$ ) and polycyclic aromatic hydrocarbons (PAH), compared to ash from other environments and vegetation types. These conclusions pose important questions about the future of temperate heaths, the priorities of future upland management and highlight numerous areas for further research. 


\section{Declarations and statements}

\section{Declaration}

This work has not previously been accepted in substance for any degree and is not being concurrently submitted in candidature for any degree.

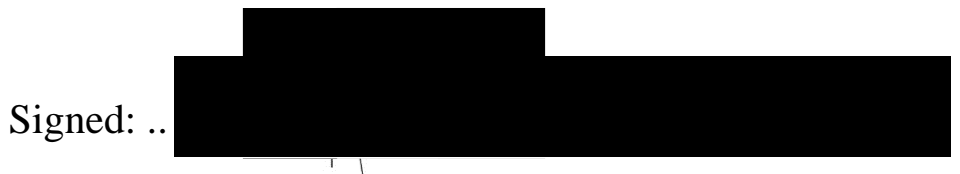

Date: $16 / 12 / 2020$

\section{Statement 1}

This thesis is the result of my own investigations, except where otherwise stated. Where correction services have been used, the extent and nature of the correction is clearly marked in a footnote(s). Other sources are acknowledged by footnotes giving explicit references. A bibliography is appended.

Signed:

Date: $16 / 12 / 2020$

\section{Statement 2}

I hereby give consent for my thesis, if accepted, to be available for photocopying and for inter-library loan, and for the title and summary to be made available to outside organisations.

Signed:

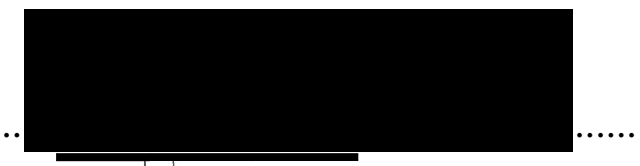

Date: $16 / 12 / 2020$ 


\section{Authorship declarations}

Paper 1: Prescribed fire and its impacts on ecosystem services in the UK

\section{Located in: Chapter 2}

Candidate contributed: The candidate led all aspects of the above publication from the conception and design to the acquisition, analysis and interpretation of data. The publication was solely drafted by the candidate. Percentage contribution: $90 \%$

\section{Co-authors contributed:}

Prof. Stefan Doerr: Contributed to the design of the work, interpretation of the data and made substantial contribution to revising the manuscript.

Dr Cristina Santin: Contributed to the design of the work, interpretation of the data and made substantial contribution to revising the manuscript.

Dr Cynthia Froyd: Contributed to the interpretation of the data and made substantial contribution to revising the manuscript.

Dr Paul Sinnadurai: Contributed to the interpretation of the data and made contribution to revising the manuscript.

All authors approved the final manuscript before publication.

We the undersigned agree with the above stated "proportion of work undertaken" for each of the above published peer-reviewed manuscripts contributing to this thesis:

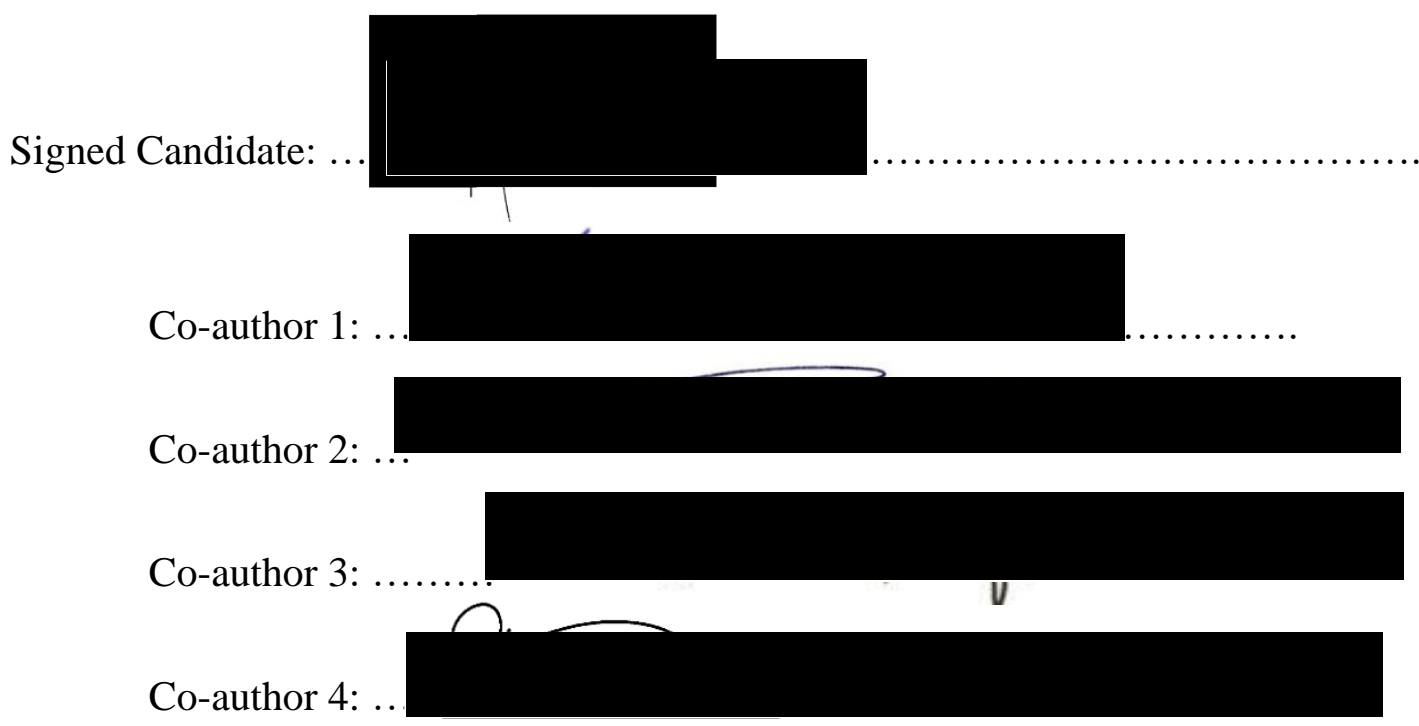


Paper 2: Chemical composition of wildfire ash produced in contrasting ecosystems and its toxicity to Daphnia magna.

\section{Located in: Chapter 5}

Candidate contributed: The candidate led all aspects of the above publication from the conception and design to the acquisition, analysis and interpretation of data. The publication was solely drafted by the candidate. Percentage contribution: $85 \%$

\section{Co-authors contributed:}

Dr Cristina Santin: Contributed to the design of the work, interpretation of the data and made substantial contribution to revising the manuscript.

Prof. Stefan Doerr: Contributed to the design of the work, interpretation of the data and made substantial contribution to revising the manuscript.

Dr Cynthia Froyd: Contributed to the design of the work, interpretation of the data and made contribution to revising the manuscript.

Dr Dania Albini: Contributed to the acquisition of laboratory data, rearing and caring for the test subjects (Daphnia magna).

Xose Luis Otero, Lucia Vinas and Begona Perez-Fernandez: All equally contributed to the acquisition of laboratory data by conducting the ash chemical characterisation tests.

All authors approved the final manuscript before publication.

We the undersigned agree with the above stated "contribution of work undertaken" for each of the above published peer-reviewed manuscripts in this thesis:

Signed Candidate:
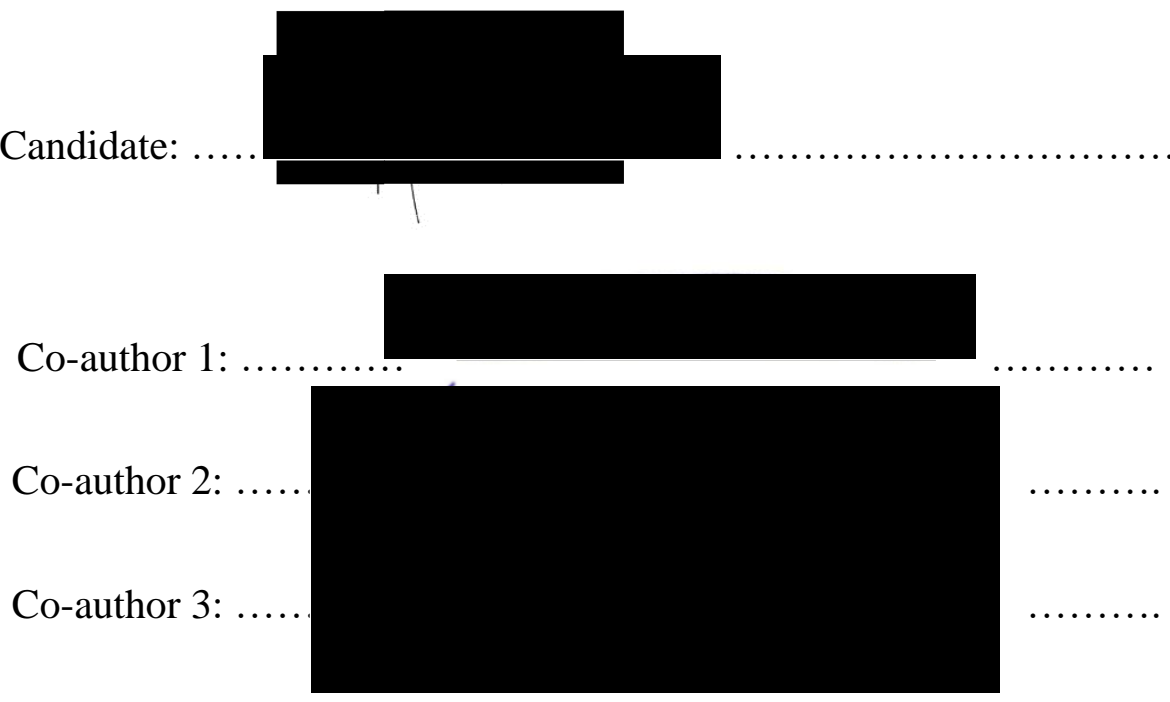
Co-author 4: ...

Co-author 5: ...

Co-author 6: ...

Co-author 7: ...

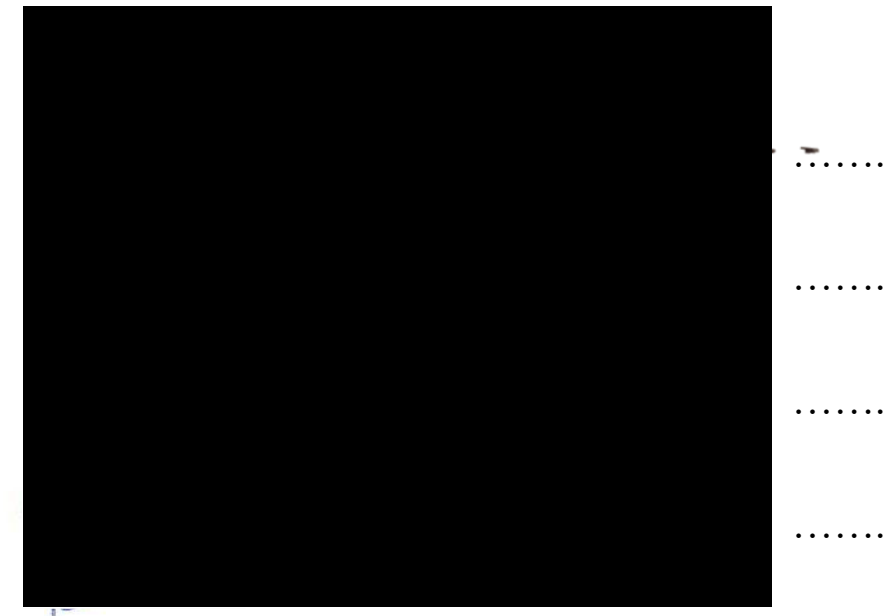




\section{Acknowledgements}

I want to thank Swansea University and the College of Science for all the support and opportunities I have received throughout my time here. In addition to guiding me through an undergraduate, masters and doctoral degree the staff in the Geography Department have inspired me with their enthusiasm and work ethic.

On a personal level, I would like to thank my three supervisors, Prof. Stefan Doerr, Dr Cristina Santin and Dr Cindy Froyd for whom I am very grateful to for this opportunity. Their continued support, encouragement and expert guidance has been invaluable. I cannot express my gratitude enough, for helping me achieve these first steps towards a scientific career. It has been a pleasure to work with such esteemed researches and lovely people.

I would also like to thank several people who have made significant contributions to chapters within this thesis. Firstly, Dr Paul Sinnudurai for providing expert advice and context helping to ground this research and firmly direct its outputs towards making prescriptive and useable land management advice (Chapters 2 and 3). I would sincerely like to thank Paul for his guidance and encouragement, and I am hugely grateful for his time and efforts.

Secondly, I would like to thank Dr Dania Albini for her practical guidance and advice during the toxicology project (Chapter 5). I had no formal background in rearing aquatic macroinvertebrates when I began this project and without your help the road would have been far more difficult and the project far less successful. Thank you.

Thirdly, I would like to extend my gratitude to Xose Luis Otero, Lucia Vinas, Begona PerezFernandez and Maria Santiso, for the laboratory analysis conducted to quantify the ash and soil chemical compositions in Chapters 4 and 5 . Your hard work and reliability were excellent and provided data sets which are integral to this thesis and the respective publications.

Last but certainly not least I would like to thank my family; Mum, Dad, Bry, Nan and Grampy, wonderful girlfriend Helen and close friends, you know who you are. Your unconditional support and encouragement throughout this process has kept me going. For all those times I asked for help and received it and especially for all those times I didn't even have to ask. These kindnesses willingly given are priceless and I am extremely lucky to have you all by my side. I would not have got this thesis through to completion with my sanity intact without you all.

I would also like to thank the examiners, Dr Emilia Urbanek and Dr Matt Davies for their substantial contributions to improving this thesis. Your time and efforts during the examination process are greatly appreciated. 


\section{Contents page}

Summary

Declarations and statements $\quad$ ii

Authorship declarations $\quad$ iii

Acknowledgements vi vi

Contents vii

List of tables $\quad$ xi

List of figures $\quad$ xiv

Abbreviations $\quad$ xvii

Chapter 1: Introduction 1

1.1. Introduction 2

1.2. Wildfire, a UK perspective 3

1.2.1. Current fire dynamics 3

$\begin{array}{ll}\text { 1.2.2. Future projections } & 7\end{array}$

1.3. Fire effects on vegetation dynamics $\quad 8$

1.3.1. Plant functional traits 9

1.3.2. Heathland: fire-adapted vegetation in the UK 10

1.4. Fire effects on soil properties 14

1.4.1. Physical properties 17

1.4.2. Chemical properties $\quad 20$

1.4.3. Biological properties 23

1.5. Fire effects on freshwater systems 26

1.5.1. Ash properties $\quad 27$

1.5.2. Contaminants in Ash 28

1.5.3. Aquatic toxicology 30

1.6. Objectives and thesis structure 31 
Chapter 2: Prescribed fire and its impacts on ecosystem services in the UK 35

2.1. Introduction 36

2.2. Current use of prescribed fire $\quad 39$

2.3. Water quality 43

2.3.1. DOC and water colouration 43

2.3.2. Water chemistry 48

2.4. Carbon dynamics $\quad 52$

2.4.1. Carbon storage $\quad 52$

2.4.2. Gaseous exchange 54

2.4.3. Carbon budgets $\quad 55$

2.5. Habitat composition and structure (biodiversity) 56

2.5.1. Flora

2.5.2. Fauna 60

2.6. Research gaps and future directions $\quad 64$

2.6.1. Spatial and temporal distribution of prescribed fire
research

2.6.2. Ecosystem services $\quad 64$

2.7. Conclusions and framework for progress 66

Chapter 3: Post-wildfire vegetation recovery in European dwarf-shrub heaths, south-western UK

3.1. Introduction $\quad 71$

3.2. Materials and Methods 73

3.2.1. Heathland classification 73

3.2.2. Study design and site selection 76

3.2.3. Fire weather conditions 78

3.2.4. Vegetation surveys $\quad 81$

3.2.5. Statistical analysis $\quad 82$

3.3. Results 86

3.4. Discussion $\quad 92$

3.4.1. Vegetation response 94 
Chapter 4: Post-fire soil physicochemical properties in European dwarfshrub heaths, south-western UK

4.1. Introduction

4.2. Materials and methods

108

4.2.1. Study area

108

4.2.2. Heathland classification

109

4.2.3. Site selection

110

4.2.4. Fire weather conditions

4.2.5. Experimental design and laboratory methods

4.2.6. Soil physical characteristics and $\mathrm{pH}$

4.2.7. Soil chemical characteristics

4.2.8. Statistical analysis

4.3. Results

4.3.1. Soil physical characteristics and $\mathrm{pH}$

4.3.2. Soil chemical characteristics

4.4. Discussion

4.4.1. Soil physical characteristics and $p H$

136

4.4.2. Chemical characteristics

4.4.3. Management implications

Chapter 5: Chemical composition of wildfire ash produced in contracting ecosystems and its toxicity on Daphnia magna

5.1. Introduction

5.2. Materials and methods 


\section{Chapter 6: Synthesis and general conclusions}

6.1. General conclusions

6.2. Summary and further research

i) Supplementary material: Chapter 2

ii) Supplementary material: Chapter $3 \quad 201$

iii) Supplementary material: Chapter $4 \quad 210$ 


\section{List of tables}

Table 2.1: Legal prescribed burn seasons with relevant legislation.

Table 2.2: Representation of the varying results presented within the UK literature on the impacts of prescribed burning on DOC and water colouration.

Table 2.3: Representation of the varying results presented within the UK literature on the impacts of prescribed burning on water chemistry.

Table 3.1: National Vegetation Classification (NVC) habitat attributes for European dry dwarf-shrub heathland (H4030).

Table 3.2: National Vegetation Classification (NVC) disturbance 76 sensitivity indicators for European dry dwarf-shrub heathland (H4030).

Table 3.3: Detailed site descriptions and burn conditions.

Table 3.4: Average site vegetation cover $(\%)$ and height $(\mathrm{cm})$ for key species and functional groups at each stage of the recovery timeseries.

Table 3.5: Details of the nested linear model of diversity as a function of the predictor site:status.

Table 4.1: Detailed site descriptions and burn characteristics.

Table 4.2: Average values for each quantified soil physical characteristic at all sampling areas and both soil depths $(0-2.5$ and $2.5-5 \mathrm{~cm})$.

Table 4.3: Average values for each quantified soil chemical characteristic at all sampling areas and both soil depths $(0-2.5$ and $2.5-5 \mathrm{~cm})$.

Table 5.1: Fire and vegetation characteristics of the six ash types used in this study.

Table 5.2: Total dry chemical composition of the six ash types tested (mg $\left.\mathrm{kg}^{-1}\right)$.

Table 5.3: Water-soluble chemical composition of the six ash types obtained by leaching tests. 
Table 5.4: Relative contribution of the 24 water-soluble ash constituents and parameters to four of the significant principle components of the six ash types derived from principle components analysis.

Table 5.5: Concentration and composition of PAHs found in each ash type $\left(\mathrm{ng} \mathrm{g}^{-1}\right)$.

Table 5.6: Immobilisation percentage of Daphnia magna at $24 \mathrm{~h}$.

Table 5.7: Immobilisation percentage of Daphnia magna at $48 \mathrm{~h}$.

Table 6.1: Thesis objectives, synthesis of key findings and further research potential.

Supplementary Full bibliography of the publications collected by this

Table 2.1: review, highlighting the focus location, topic which it is relevant to, ecosystem type and publication type.

Supplementary Species cover data for each sampling area. Cover (\%) data

Table 3.1: combines canopy and ground layer survey data averaged for each species and site. Species have been divided into functional groups for ease of interpretation.

Supplementary Details of the post-hoc pairwise ("emmeans") analysis of

Table 3.2: the linear model output to assess differences in sampling area diversity.

Supplementary Overall species scores derived by Non-metric 207 Table 3.3: multidimensional scaling analysis (NMDS).

Supplementary Details of the post-hoc pairwise analysis following the Table 3.4: vegetation community composition NMDS.

Supplementary Details of the nested linear model of bulk density (BD) as

Supplementary Details of the post-hoc pairwise ("emmeans") analysis of

Table 4.2: the linear model output to assess differences in sampling area soil bulk density (BD).

Supplementary Details of the nested linear model of water holding 
Supplementary Details of the post-hoc pairwise ("emmeans") analysis of

Table 4.4: the linear model output to assess differences in sampling area soil water holding capacity (WHC).

Supplementary Details of the nested linear model of $\mathrm{pH}$ as a function of Table 4.5: site:status and depth.

Supplementary Details of the post-hoc pairwise ("emmeans") analysis of 221

Table 4.6: the linear model output to assess differences in sampling area soil $\mathrm{pH}$.

Supplementary Details of the nested linear model of water drop penetration 225 Table 4.7: (WDPT) as a function of site:status and depth $(0,2.5 \mathrm{~cm}$ and $5 \mathrm{~cm}$ depths).

Supplementary Details of the post-hoc pairwise ("emmeans") analysis of

Table 4.8: the linear model output to assess differences in sampling area soil water drop penetration (WDPT).

Supplementary Average soil moisture expressed as volumetric water

Table 4.9: content (VWC) across all sampling areas and both soil depths (0-2.5 and 2.5-5 cm depth). 


\section{List of figures}

Figure 1.1: Annual fire statistics for the United Kingdom (2001-2019).

Figure 1.2: Distribution of wildfires across the UK between 1 January 2018 and 31 December 2019 as detected by VIIRS.

Figure 1.3: Modelled wildfire risk change in the UK (1980-2080).

Figure 1.4: Distribution of Annex 1 European Dry Heaths (4030) across the UK.

Figure 1.5: Effects of a moderate to high vegetation burn severity wildfire on above-ground vegetation in a $C$. vulgaris- $V$. myrtillus dry heath (NVC: H12).

Figure 1.6: Fire effects on the biological, chemical and physical properties of soils and their associated temperature ranges reached near the mineral soil surface.

Figure 1.7: Effects of a high to extreme soil burn severity wildfire on shallow organic layered heathland soils $(<30 \mathrm{~cm}$ organic layer depth).

Figure 2.1: Examples of the effects of different management techniques on catchment-scale vegetation structure.

Figure 3.1: Overview of the long unburnt area at Site C. Photograph taken at Mynydd Du Carn Pica, south Wales (July-2018).

Figure 3.2: Locations of the four sampling sites used in this study within the Brecon Beacons National Park (S. Wales).

Figure 3.3: Example survey plots from each sampling area. Photographs were taken of $1 \mathrm{~m} 2$ survey quadrats in late spring/early summer (May-June 2018).

Figure 3.4: Graphic representation of the "emmeans" pairwise comparison output.

Figure 3.5: Distribution of species and sites derived by Non-metric multidimensional scaling analysis (NMDS). 
Figure 3.6: Representation of group (sampling area) mean dispersions displayed as the distance between groups and the centroid: identified by the "betadisper" function in R using the TukeyHSD method.

Figure 4.1: Overview of the long unburnt area at Site A. Photograph taken at Mynydd Llangorse, south Wales (August 2018).

Figure 4.2: Soil type map of the Brecon Beacons National Park (S. Wales, UK).

Figure 4.3: Conditions at Site A following the wildfire event assessed in this study.

Figure 4.4: Graphic representation of the bulk density (BD) "emmeans" pairwise comparisons output.

Figure 4.5: Graphic representation of the water holding capacity (WHC) "emmeans" pairwise comparisons output.

Figure 4.6: Graphic representation of the $\mathrm{pH}$ "emmeans" pairwise comparisons output.

Figure 4.7: Water drop penetration time (WDPT) percentage class data for surface, subsurface $(2.5 \mathrm{~cm})$ and subsurface $(5 \mathrm{~cm})$ at each burnt area alongside unburnt area repellency for that depth stage ( $\mathrm{n}=12$ per sampling location).

Figure 4.8: Graphic representation of the water drop penetration (WDPT) "emmeans" pairwise comparisons output.

Figure 5.1: Representation of the ordination of the first two axes (PC1 and PC2) produced during the principle components analysis (PCA) of the water-soluble chemical composition of the six ash types studied.

Figure 5.2: Concentration response relationship after 24 and $48 \mathrm{~h}$ of 168 exposure.

Supplementary Overview of Site A in the Llangorse region. Polygons 
Supplementary Overview of Site B in the Cwmgiedd region. Polygons

Figure 3.2: indicate the approximate location and area of the 2015 fire event and the two sampling areas.

Supplementary Overview of Site $\mathrm{C}$ in the Glanamon region. Polygons 202

Figure 3.3: indicate the approximate location and area of the 2011 fire event and the two sampling areas.

Supplementary Overview of Site D in the Penderyn region. Polygons

Figure 3.4: indicate the approximate location and area of the 2007 fire event and the two sampling areas. 


\section{Abbreviations}

ANOVA: Analysis of variance

BBNP: $\quad$ Brecon Beacons National Park

CAP: $\quad$ European common agricultural policy

DLM: Disturbed late mature growth

DOC: Dissolved organic carbon

E.C: $\quad$ Electrical conductivity

EC10: $\quad$ Effect concentration - concentration of substance required to produce $10 \%$ of test individuals to become immobilised.

EC50: $\quad$ Effect concentration - concentration of substance required to produce $50 \%$ of test individuals to become immobilised.

ECEC: Effective cation exchange capacity

EPA: $\quad$ United States Environmental Protection Agency

GSL: Growth stages limited - not all growth stages present

LIS: $\quad$ Limited indicator species present

LOEC: Lowest observable effect concentration

NMDS: Non-metric multi-dimensional scaling

NOEC: No observable effect concentration

NVC: National vegetation classification

Olsen-P: Bioavailable phosphorus derived using the Olsen method

PAH: $\quad$ Polycyclic aromatic hydrocarbons

PC: $\quad$ Principle component

PCA: Principle components analysis 
PES: $\quad$ Payments for ecosystem services

PyC: Particulate organic carbon

PyOM: Pyrogenic organic matter

SAC: $\quad$ Special areas of conservation

SBD: $\quad$ Soil bulk density

SOM: Soil organic matter

SSC: $\quad$ Suspended sediment concentration

SSSI: $\quad$ Sites of special scientific interest

S-W: $\quad$ Shannon-Weiner diversity index

SWR: Soil water repellency

USS: $\quad$ Uneven stand structure

WDPT: Water drop penetration time

WHC: Water holding capacity

VWC: Volumetric water content

Chapter 5: Ash type abbreviations

AUS: Australian eucalypt ash

USA: American chaparral ash

CAN: $\quad$ Canadian spruce ash

URIA: Spanish heathland ash

SPA: $\quad$ Spanish pine forest ash

UK: $\quad$ British grassland ash 


\section{Chapter 1}

Introduction 


\subsection{Introduction}

Fire has been a vital natural disturbance and catalyst for landscape change on Earth since the appearance of terrestrial vegetation in the Late Silurian period (420 Ma) (Scott and Glasspool, 2006). Wildfires occur at the intersection between three key controlling factors, environmental conditions (weather), fuel availability and the sources of ignition, and are now estimated to burn 300-450 million ha annually (Moritz et al., 2005; Giglio et al., 2013). Changes in the balance of these factors means fire activity is significantly spatially and temporally variable (Marlon et al., 2008; Yang et al., 2014).

The long history of fire in many regions has meant that some vegetation communities have become highly fire-adapted. In these communities, fires play an integral part in maintaining the health and governing the function and structure of flora and fauna, as well as biogeochemical cycles (Schwilk and Kerr, 2002; Bowman et al., 2009; Bixby et al., 2015a). The current and near-future of fire regimes across the Earth's surface are, however, highly dictated by human activities and this presents a range of concerns for both naturally fire-prone and traditionally non-fire prone ecosystems (Pausas et al., 2008).

Traditionally, western Europe (e.g. UK, Germany, Belgium, Netherlands) has not been considered a fire-prone region due to its temperate climate (Scott et al., 2014). Despite this, fire still plays a defining role in the maintenance and function of some habitats (e.g. dwarf-shrub heaths) due to the prolonged use of fire in land management (Tucker, 2003a; Davies et al., 2008a). The scientific literature on the impacts of fires is, however, dominated by research from regions in which fire is a natural part of ecosystem cycles, making the need to better understand its impacts in temperate zones with anthropogenic fires, such as the UK, perhaps even greater (Glaves et al., 2013; Harper et al., 2018).

This introductory chapter offers a contextual background to fire in the UK and its impacts across three key topic areas: vegetation dynamics, soil properties and water contamination. The material aims to provide a basis for the more detailed discussions in the subsequent chapters, drawing upon UK-based research where possible, and relevant international research where required. In addition, within each subsequent chapter, the current state-of-the-art of UK research addressing each specific topic is 
included, and, in Chapter 2, a comprehensive literature review on the impacts of prescribed fires in the UK on key ecosystem services is provided. The specific objectives of this thesis and its structure are also outlined at the end of the introductory section.

\subsection{Wildfire, a UK perspective}

The term wildfire in the UK is defined as 'any uncontrolled vegetation fire which requires a decision, or action, regarding suppression' (10, para. 3.3, p. 10. McMorrow 2011). As the UK no longer has any truly wildland areas remaining wildfires are considered a semi-natural hazard due to their inescapable link with human activities, from land management practices to the social causes of arson ignitions (Gazzard et al., 2016).

\subsubsection{Current fire dynamics}

There are two primary seasons in which wildfires occur in the UK, spring (MarchApril) when dead vegetation is left after the winter freezing and drying, and summer (July-September) when hot and dry periods significantly reduce fuel moisture content (McMorrow, 2011). There is, however, substantial intra and inter-annual variability in fire seasons with abnormally low activity or no defined seasons occurring some years, particularly in wet years. This variability in fire seasons means large-scale severe wildfires are considered an intermittent issue (Gazzard et al., 2016). Fire seasons are also not solely a function of natural and climatic drivers in the UK with human factors such as, managed burning, grazing, density of ignition sources and fuel accumulation due to land abandonment or management policy complicating these relationships (Albertson et al. 2010).

Fire and rescue services in the UK attend an annual average of over 45,000 wildfires (2014-2018) accounting for a burnt area of approximately 5500 ha (2001-2019) (Crowhurst, 2015; Forestry Commission, 2019; European Commission, 2020a). The vast majority of these fires are, however, very small with, for example, statistics retrieved from the fires attended in Wales estimating only $2 \%$ of wildfires burnt an area $>1$ ha (Fire and Rescue Service, 2020). These $2 \%$ of fires account for $96 \%$ of the 
total area burnt (1223 ha per annum in Wales) (2009-2019) (Fire and Rescue Service, 2020). The Forestry Commission further estimates $49 \%$ of these fires burnt an area $<5$ $\mathrm{m}^{2}$ (Forestry Commission, 2019). This is likely due to not only the relatively small and discontinuous mosaic of available fuels but also because of the efficiency at which fire and rescue services suppress wildfires (McMorrow, 2011).

Fire data provided by the European Commission's Global Wildfire Information System (GWIS) and European Forest Fire Information System (EFFIS) estimates the UK experienced an annual average of 35 wildfires ( $>30$ ha approx.) and a burn area of 6172 ha between 2001-2019 (Figure 1.1) (European Commission, 2020a, 2020b). These statistics are derived from MODIS and VIIRS satellite data which have a spatial resolution capability of $500 \mathrm{~m}$ and $375 \mathrm{~m}$, respectively (Giglio et al., 2018; European Commission, 2020a). This data provides an overview of the occurrence of large-scale wildfires in the UK and highlights the significant inter-annual variability.

Periods of widespread fires tend to cluster over short periods (2-3 months), often concentrated in particularly dry years such as 2003, 2011 and 2018 (Figure 1.1) (European Commission, 2020b). Notable examples of particularly severe fires are, the Swinley Forest fire in May 2011 and the Saddleworth Moor fire in June 2018 (BBC News, 2011, 2019). The Swinley Forest fire occurred at the end of an extremely dry spring season and burnt an area of 110 ha of managed pine forest. This endangered major transport infrastructure and a large residential area just 50 miles west of London (BBC News, 2011; Veeraswamy et al., 2018). The Saddleworth Moor fire occurred at the start of the summer season during unusually high temperatures, following a dry spring, and consumed an 1800 ha area of moorland east of Manchester (BBC News, 2019). This fire took weeks and assistance from the army to extinguish, having substantial implications for air and water quality in the surrounding area. Large-scale fires such as these are estimated to cost up to $£ 1$ million in suppression costs alone with the fire rescue services spending, on average, $£ 55$ million per year on wildfire response costs (McMorrow et al., 2009; Gazzard et al., 2016). 


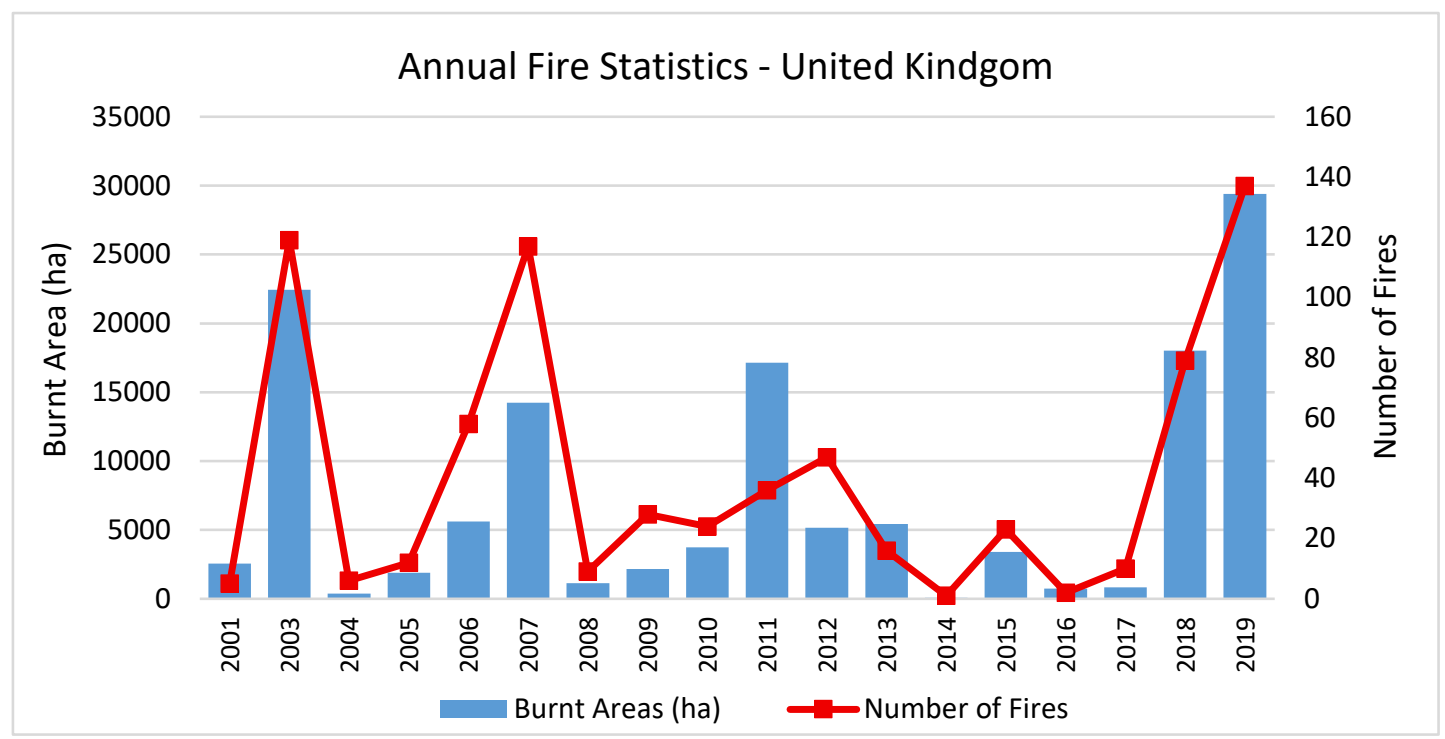

Figure 1.1: Annual statistics of fires $>30$ ha for the United Kingdom (2001-2019) as provided by the European Commission's Global Wildfire Information System (GWIS) and European Forest Fire Information System (EFFIS) derived from NASA's MODIS and VIIRS satellite data (European Commission, 2020a, 2020b).

The vast majority of wildfires in the UK take place in grassland and shrubland habitats, predominately on arable land and urban greenspaces according to Fire and Rescue Service data (Forestry Commission, 2019; Fire and Rescue Service, 2020). The pattern of this majority of fires shows a concentration of fire activity around the fringe of urban areas, along the rural-urban interface, often following valleys and transport routes (e.g. south Wales) (Jollands et al., 2011; Davies and Legg, 2016).

This spatial distribution is strongly influenced by the close proximity of these areas to human populations and thus the predominant sources of wildfire ignitions, arson and accidental. Primary causes are thought to be arson, bonfires, barbecues, cigarettes or sparks from vehicles, powerlines and military exercises (Gazzard et al., 2016). Reliable forensic evidence is, however, rare and very few convictions are pursued as it is hard to prove liability. These ignition types add an additional element of sociocultural complexity to understanding the wildfire phenomenon in the UK. The prevalence of arson ignitions is also unlikely to change until greater value or sense of ownership over environmental assets is felt by the wider population.

The distribution of larger wildfires ( $>30 \mathrm{ha}$ ) across the UK is, however, dictated by an additional set of factors as opposed to just close proximity to human settlements 
(European Commission, 2020b). Figure 1.2 shows larger fires occur across the UK but generally cluster in a few specific regions, Northumberland, North York Moors, Pennines, Peak District, south Wales and the Cairngorms (McMorrow, 2011; European Commission, 2020b). Primarily this is because these National Parks provide wide open vegetated spaces in which fires are able to spread without being met by urban disruptions (acting as fire breaks). In addition, National Parks are designed to accommodate human access and thus the potential for arson or accidental ignitions is relatively high (e.g. bonfires, barbecues and cigarettes). Also, the terrain in National Parks often makes it more difficult for Fire and Rescue Services to successfully suppress fire events and they are often left to run until natural or created fire breaks prevent further spread, enabling larger scale fires. These areas also tend to be dominated by heathland and moorland habitats, some of which are particularly fireprone (Calluna vulgaris-dominated habitats) (Figure 1.4) (McMorrow, 2011).

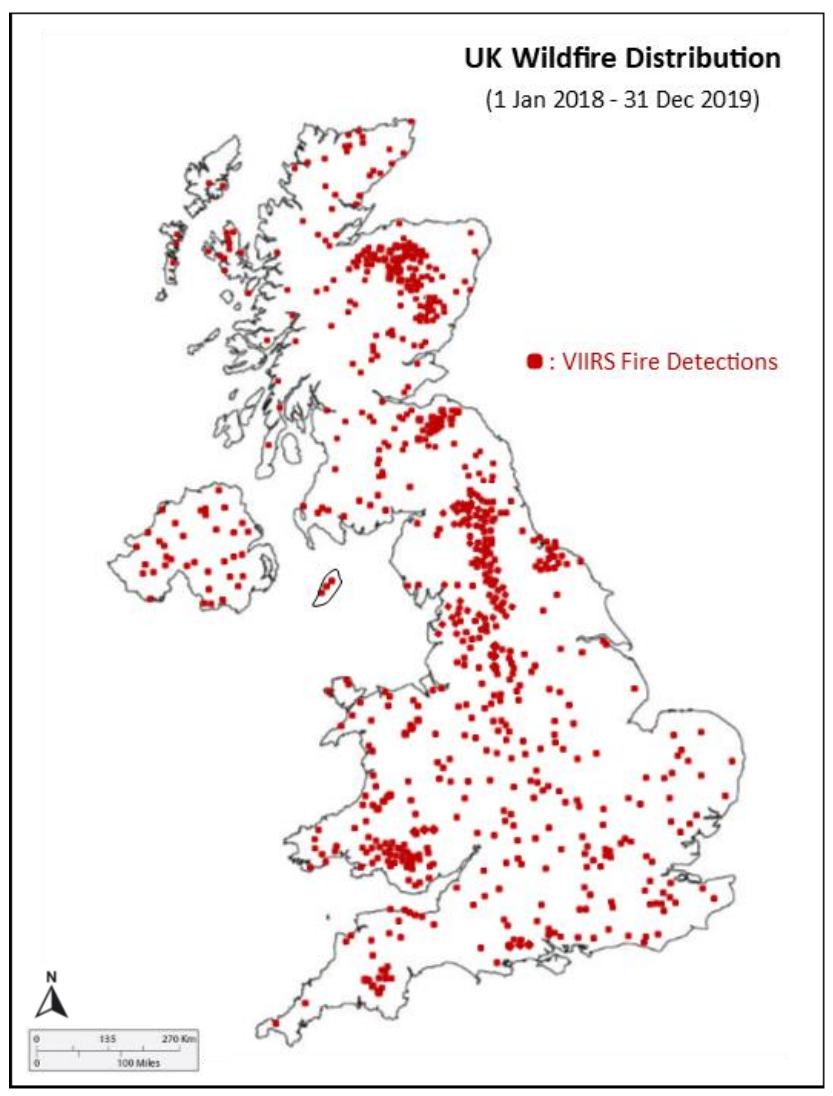

Figure 1.2: Distribution of wildfires across the UK between 1 January 2018 and 31 December 2019 as detected by VIIRS (Visible Infrared Imaging Radiometer Suite). Each circle represents one fire event (European Commission, 2020b). 


\subsubsection{Future projections}

In the UK, climate changes are expected to cause a number of substantial shifts in seasonal and regional weather patterns. These changes are estimated to manifest as enhanced seasonality with an increase in summer temperature and reduction in summer rainfall, coupled with an increase in winter rainfall (Jenkins et al., 2009; Albertson et al., 2010). These changes have been projected to increase wildfire risk in the UK by approximately 30-50\% by 2080 according to the McArthur Fire Danger Index (Figure 1.3) (Moffat et al., 2012). This increase in risk is likely to be regionally variable with the largest increase in the south-east of England and extending into south Wales (Figure 1.3).

These results, however, need to be interpreted with caution as they provide only change in annual average values and the coarse resolution of soil and land cover data used to produce the fuel (biomass) component of the model, a key element of wildfire risk, is likely poorly represented. Estimates can therefore only provide a national-scale indication of the possible changes in UK wildfire risk (1980-2080).
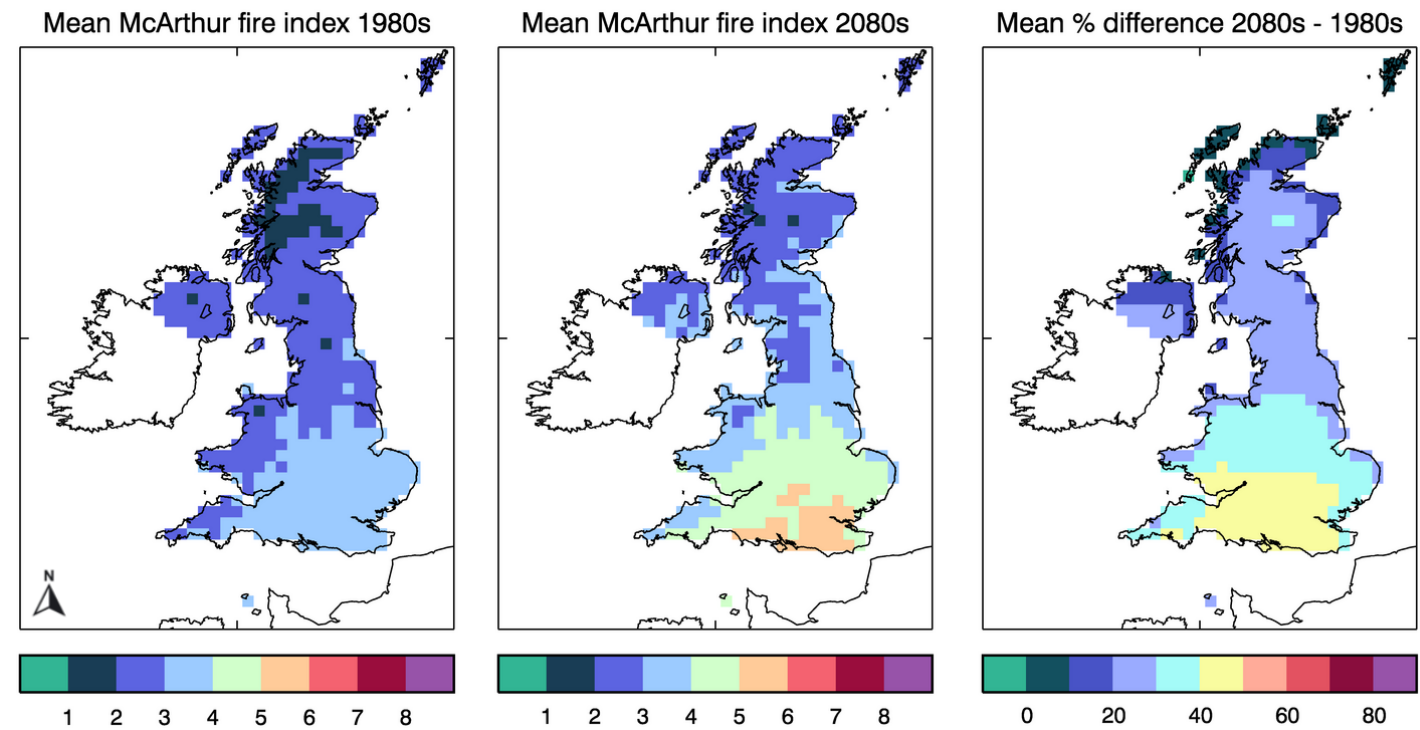

Figure 1.3: Modelled wildfire risk change in the UK (1980-2080) estimated using the McArthur Fire Danger Index using UKCP09 Regional Climate Model data. Scale represents the level of fire risk with 1 being low risk and 8 being high risk. Taken from (Moffat et al., 2012). 
Recent data (2000-2018) suggests fire regimes across the globe are now inescapably influenced by human activities and future scenarios predict an approaching shift towards an indirectly anthropogenic-driven global fire regime dictated by temperature increases and subsequent regional drying (IPCC, 2000; Pechony and Shindell, 2010). Studies modelling future wildfire projections based on climate scenarios have come to the general consensus that fire frequency and severity will increase in moisture-limited systems (e.g. forests). The opposite is, however, likely to occur in fuel-limited systems with increasing fuel limitation and aridity (Andela et al., 2017; Rogers et al., 2020). It is also likely to become particularly difficult to deal with increasing wildfire frequency and severity given the reduction in the influence of direct human activities (Krawchuk et al., 2009; Pechony and Shindell, 2010; Jolly et al., 2015).

Predictions consistent with this overall trend of increasing fire activity are perhaps already being experienced in the UK with 2018 and 2019 having particularly severe wildfire seasons (Figure 1.2) (European Commission, 2020b). In 2019, the unusually dry and warm weather saw a record number of major wildfires, surpassing the previous highest number of large wildfires ever recorded in one year by early April (Annual total 137 wildfires over $>30$ ha) (Figure 1.1) (European Commission, 2020b). The increasing occurrence of major wildfires has also been reported in regions across the globe from the U.S., South America, central Asia, southern Europe, Australia and southern Africa (Liu et al., 2010; Pechony and Shindell, 2010; Wang et al., 2017; Wotton et al., 2017).

\subsection{Fire effects on vegetation dynamics}

Vegetation dynamics include a range of components vital to the capacity of habitats to respond to changes in environmental conditions and fire regimes (Oliver et al., 2015). Vegetation community composition and structure are key biotic characteristics influencing biogeochemical processes and thus, affecting a range of ecosystem services (e.g. biodiversity, water quality and carbon capture) (Hooper et al., 2005; De Deyn et al., 2008). Short and long-term vegetation community response to fires are highly variable across different habitat types, and successional trajectories are dictated by a range of factors such as: site characteristics (e.g. topography, aspect, and disturbance history); fire severity; vegetation community composition (e.g. species, 
age, structure and condition); post-fire disturbance and pre- and post-fire weather conditions (Tucker, 2003a; Ward et al., 2007). The impacts of fire on vegetation can also be examined from a number of perspectives, from the response of individual plants to populations, species, communities, ecosystems or landscapes across both fireprone and non-fire-prone habitat types.

\subsubsection{Plant functional trails}

Vegetation has a range of adaptations to survive and even thrive after fire events, and recovery rates can be rapid in some ecosystems (Cerdà and Doerr, 2005; Granged et al., 2011a; Velle et al., 2012). There are a number of mechanisms controlling vegetation regeneration patterns post-fire, including the location of plant growth points, the susceptibility of growth points to fire, and the capacity of species to reestablish from re-sprouting (re-sprouter species) and seedling (seeder species) growth (Mohamed and Gimingham, 1965; Bond and Midgley, 2001; Lamont et al., 2011).

Of these regeneration mechanisms, post-fire re-sprouting (vegetative regeneration) is the most rapid form of recovery by species able to maintain some part of the plant tissue alive and intact through fire events, initiating new shoot growth from dormant buds (e.g. from epicormic, lignotuber, rhizome and roots) (Clarke et al., 2013). There are many examples of pyrophytic re-sprouter species across the globe in rainforests (Poorter et al. 2010), conifer forests (Dietze and Clark 2008; Shibata et al. 2016), savannas (Lawes et al. 2011) and desert shrublands (Nano and Clarke 2011). This form of recovery is ideal for rapidly and aggressively colonising post-fire vegetation gaps, particularly in fertile competitive environments, to limit the space and resources for slower non-re-sprouting species (Pausas and Keeley, 2014).

Post-fire seeding (non-re-sprouting species) is a much slower vegetation recovery strategy and is more dependent on longer fire return intervals, due to the longer reestablishment times required for vegetation to regrow from seed (Pausas and Keeley, 2014). These species also rely on the ability to produce a fire-resistant seed bank or hold seeds at canopy level, which germinate vigorously in response to fire events (Pausas and Keeley, 2014). Germination of this kind can be triggered in response to both heat and smoke (combustion chemicals) (Keeley et al., 2011). 
There are several key types of seeding strategies: (i) Facultative seeders are capable of both means of regrowth and are able to re-sprout and germinate post-fire (Marais et al., 2014); (ii) Obligate seeders which are unable to re-sprout and therefore, rely on post-fire seedling germination to regenerate (Keeley et al., 2011); and (iii) Post-fire colonisers which are not able to persist through fire events but which instead rely on post-fire seed dispersal from adjacent unburnt patches for recovery (Marais et al., 2014; Pausas and Keeley, 2014).

The differences between these regeneration strategies affect the ability of plant species to recovery following fire disturbances and therefore, has consequences for overall vegetation community composition in habitats with varying compositions of resprouter and non-re-sprouter species (Clarke et al., 2013). For example, as a generalisation, a large proportion of obligate seeding species within a given habitat often produces an even-aged population structure. The dominance of re-sprouting species in a given habitat more often produces a diverse-age structured assemblage (Pausas and Keeley, 2014). Although there has been debate within the literature, it is now widely agreed the presence of fire adaptive traits suggests plants are adapted to fire regimes rather than to fire itself (Keeley et al. 2011). This means the effects of fire on vegetation dynamics are strongly influenced not only by species types and fire severity but also by fire return period (Keeley et al., 2011).

\subsubsection{Heathland: fire-adapted vegetation in the UK}

The term heathland refers to a range of habitats, all with a number of key commonly held characteristics (Fagúndez, 2013). From an ecological and physical perspective, these open habitat types are dominated by dwarf shrub species such as, Calluna vulgaris (L.) Hull (hereafter C. vulgaris) and Erica spp. and develop over nutrientpoor, shallow (<50 cm) and acidic soils (JNCC, 2009). Heathlands are widespread across the UK and are particularly common in Wales, throughout the Pennines and Peak District, and across Scotland (Figure 1.4). Under natural circumstances heathlands are mainly successional and therefore, are often replaced by woodlands, except at altitudinal and latitudinal limits such as the west of Ireland and Northern Scotland where they can be climax assemblages (Fenton, 2008). 
In a more modern context, heathlands are largely semi-natural communities created and maintained by forest clearance, grazing and prescribed burning. These habitats are thus considered plagioclimaxes, as they are being prevented from developing to their full climatic climax community by human activities (Fagúndez, 2013; Glaves et al., 2013). These areas are of particular cultural and social importance in the traditional landscapes of the UK (Figure 1.4) and continental Europe (Stokes et al., 2004; Fagúndez, 2013; Glaves et al., 2013).

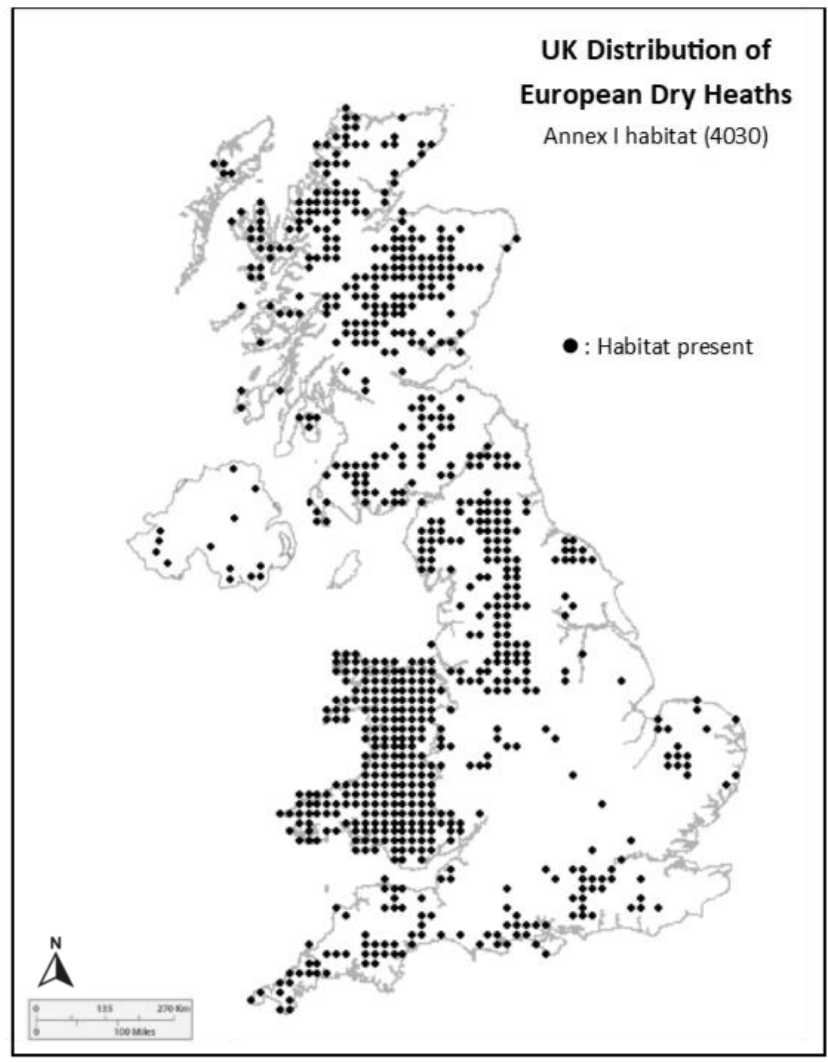

Figure 1.4: Distribution of European Dry Heath (Annex 1) across the UK. Each circle represents a $10 \mathrm{~km}^{2}$ area in which European dry heath habitat is known and/or predicted to occur (JNCC, 2019a).

Heathlands contribute substantially to many ecosystem services such as food provision, water supply, carbon storage, recreation and biodiversity (Wessel et al., 2004; Webb, 2008; Ward et al., 2009). The importance and vulnerability of these habitats, however, have been highlighted in recent decades as a result of continued habitat loss and degradation (De Graaf et al., 2009). The encroachment of urban development, afforestation and agricultural practices as well as, recreational disturbances, air pollution, successional pressure, excessive drainage and changes to fire regimes pose a considerable threat to heathland habitats (García et al., 2013). $C$. 
vulgaris-dominated heaths, for example, are now internationally scarce and over $80 \%$ of lowland heath in the UK have been lost in the last two decades (Averis et al., 2014). Substantial portions of remaining heathland habitat in the UK now occur within National Parks (Figure 1.4) (JNCC, 2019a). Large areas of heathland habitat in Europe, and similar heathland type habitats in Australia and North America, are now also protected as a result of similar factors (Allen, 2008; Pywell et al., 2011; Fagúndez, 2013; García et al., 2013).

Over the last millennium, heathland habitats across the UK have been significantly influenced by fires with burning occurring on 30-40-year cycles (Stokes et al., 2004). In recent decades, there have been a number of concerns about the potential of climatic and environmental changes to increase the occurrence and severity of wildfires in the UK (Albertson et al., 2010). Increased occurrence and/or severity of uncontrolled fires could potentially have significant implications for vegetation dynamics in heathlands. Previous studies have assessed a range of fire impacts on heathland vegetation, from the impacts of stand-age on post-fire regeneration (Kayll and Gimingham, 1965; Mohamed and Gimingham, 1970), vegetation community dynamics and species responses to fire (Gimingham et al., 1981; Hobbs \& Legg 1983; Mallik and Gimingham, 1983) and the implications of different burn regimes on biodiversity (McVean, 1959; Stevenson and Rhodes, 2000; Robertson and Barton, 2001). Despite the lengthy history of research on fire impacts on UK heathlands there is still limited research on how vegetation response varies across biotic and abiotic gradients and variations in fire severity. Furthering our understanding of the impacts of wildfires is, therefore, vital to safeguard key ecosystem services (Davies et al., 2013; Grau-Andrés et al., 2019a).

The fuel source for wildfires in heathland habitats primarily comes from within the dwarf-shrub canopy, provided by a combination of living vegetation and suspended dead material, as opposed to from a build-up of litter at the ground level. It is, therefore, common for even moderate burn severities to substantially reduce or completely remove canopy-level vegetation (Figure 1.5) (Scott, 2000). Early research on heathland fires suggests temperatures between $340^{\circ} \mathrm{C}$ to $440^{\circ} \mathrm{C}$ at the ground level are capable of destroying most $C$. vulgaris stems but likely not to prevent vegetative 
regeneration, depending on the maturity of the stand (Whittaker, 1961; Kayll and Gimingham, 1965).

After moderate vegetation burn severity fires, successional patterns are often similar between relatively healthy heathland habitats, depending on population dynamics relative to water and nutrient availability (Clement and Touffet, 1990; Scott, 2000).

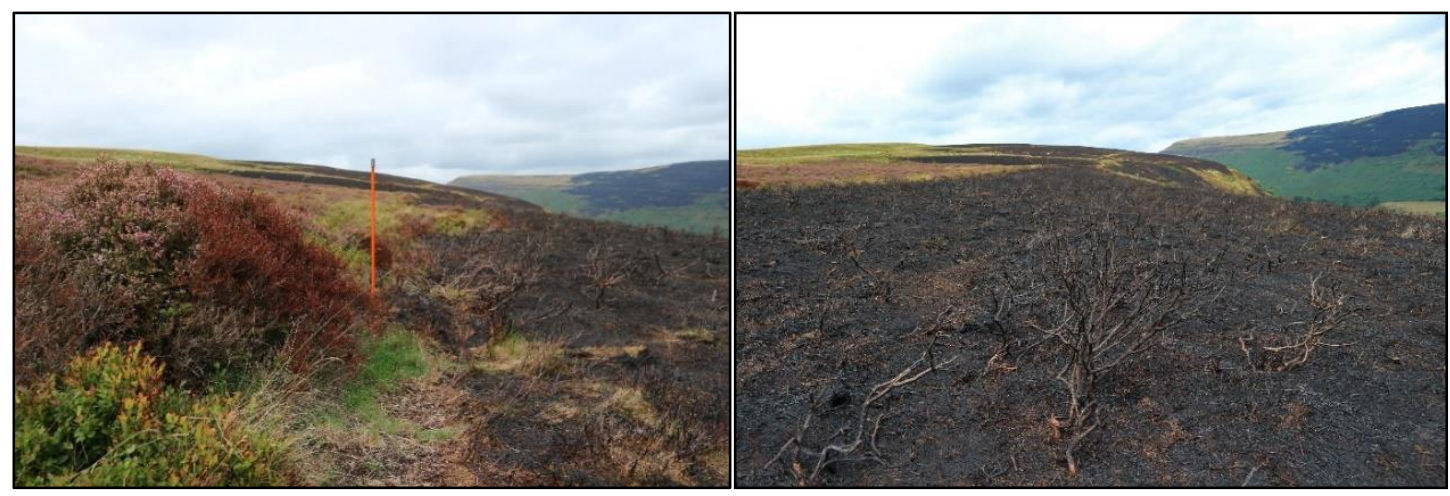

Figure 1.5: Effects of a moderate to high vegetation burn severity wildfire on above-ground vegetation in a C. vulgaris-V. myrtillus dry heath (NVC: H12).

In a broad context, vegetation recovery in healthy successional heathlands can be defined by the balance of functional groups (e.g. graminoids, ericaceous shrubs, mosses, lichens and liverworts), with recovery trajectories often progressing towards pre-fire control characteristics (Stewart et al., 2004; Harris et al., 2011a). Early postfire recovery (<5-years) is often dominated by graminoid species (e.g. Agrostis spp. and Nardus stricta L.) due to the relative speed of regenerative growth via surviving stem bases (Whittaker, 1961; Brys et al., 2005). In the medium to long-term (5-8 years) however, ericoid species (e.g. C. vulgaris or Vaccinium myrtillus L.) (hereafter, $V$. myrtillus) progressively outcompete other functional groups and often begin to dominate assemblages if no further disturbances occur (Chapman et al., 2009; Harris et al., 2011a; Milligan et al., 2018).

A key factor in the recovery of dwarf-shrub dominated heathlands is the average stand age stand when a fire event occurs. It is well-established that vegetative regeneration of $C$. vulgaris, for example, is significantly hindered as plant age and maturity increases. Kayll and Gimingham (1965) found that when burning a range of different aged $C$. vulgaris stems at $400^{\circ} \mathrm{C}$, there was a significantly higher proportion of stems 
displaying vegetative regeneration in the younger age group (12 years old) as compared to the older age groups (17 and 24 years old). Even under moderate burn severities, $C$. vulgaris older than 15 years tends to lose its ability to vegetative regenerate (Mohamed and Gimingham, 1970). This can have a significant impact on the dynamics of post-fire heathland recovery.

In the case of less favourable pre- and post-fire conditions or high fire severities, postfire heathland recovery can be substantially hindered. Areas with unusually low soil organic matter content, low soil nutrient conditions, monospecific dominance (e.g. of C. vulgaris, Molinia caerulea (L.) Moench or Polytrichum commune Hedw.) and consisting largely of older-aged shrub species (>15 years) are likely to be particularly affected (Maltby et al., 1990; Legg et al., 1992; Davies et al., 2010). In these cases, recolonisation of vascular plants can be substantially slower with limited growth for $>10$ years (Maltby et al., 1990; Velle et al., 2012).

Increased burn severity also has the potential to change plant functional balances and alter ecosystem function as a whole (Grau-Andrés et al., 2019a). Changes to burn severity and return intervals can lead to the homogenisation of vegetation communities or the conversion of heathlands to grassland habitats, negatively affecting their conservation value and resilience (Oliver et al., 2015). If temperatures exceeding $200^{\circ} \mathrm{C}$ are experienced within the surface soil substantial damage is also caused to the seed bank. C. vulgaris seeds, for example, have been observed to be killed at $200^{\circ} \mathrm{C}$ with germination significantly hindered at much lower temperatures depending on the length of exposure (e.g. $120^{\circ} \mathrm{C}$ for $>30$ seconds). Charring of C. vulgaris seeds is also lethal, even if accompanied by non-lethal temperatures (Whittaker and Gimingham, 1962).

The impacts of, often low severity, controlled burns (prescribed fires) on vegetation community composition and structure are not addressed further in this introductory section as they are covered in detail in Chapter 2.

\subsection{Fire effects on soil properties}

Soil is considered to be the natural feature at the Earth's surface formed from the combination of mineral and organic material and consists of a variety of physical, 
chemical and biological properties (Santín and Doerr, 2016). The importance and extreme diversity of soils make them among the Earth's most valuable resources, and they represent the largest terrestrial organic carbon store, directly supporting the presence and growth of terrestrial vegetation (Scharlemann et al., 2014; Santín and Doerr, 2016). Fires can cause a number of considerable changes in soil properties and understanding these impacts are crucial to assuring the protection, quality and sustainability of this fundamental resource (Figure 1.6) (González-Pérez et al., 2004; Certini, 2005; Zavala et al., 2014).

The effects of fire on soil properties are highly dependent on the often large spatialtemporal changes in temperature and heating duration of soils within fire events (Certini, 2005). The higher the temperature and the longer the heating duration (residence time) the greater the depth of heat penetration and the more severe the subsequent impacts (Figure 1.6) (Santín and Doerr, 2016). Heat penetration in soils is, however, subject to steep temperature gradients as soils are generally poor conductors of heat (Mataix-Solera et al., 2011). In predominantly mineral soils, for example, temperatures at $5 \mathrm{~cm}$ depth rarely exceed $150^{\circ} \mathrm{C}$ during fire and no heating occurs at $>20 \mathrm{~cm}$ in most cases (DeBano 2000).

In general, heat tends to be transported faster and penetrates deeper in more moist soils (Campbell et al., 1994). The latent heat of vapourisation, however, prevents soil temperature exceeding $100^{\circ} \mathrm{C}$ until all moisture is removed, temperatures typically then rise to $>200^{\circ} \mathrm{C}$ (Campbell et al., 1994). The duration of soil heating is, therefore, considered the most significant component affecting the extent of soil damage at depth (Certini 2005).

Available research on the impacts of wildfires on shallow heathland soils in the UK is very limited. The following subsections, therefore, provide an introduction to the impacts of fire on soil properties more broadly, using relevant UK research where possible (e.g. Grau-Andrés et al. 2018, 2019). This provides important background and context to the heathland-specific content discussed in Chapter 4. 


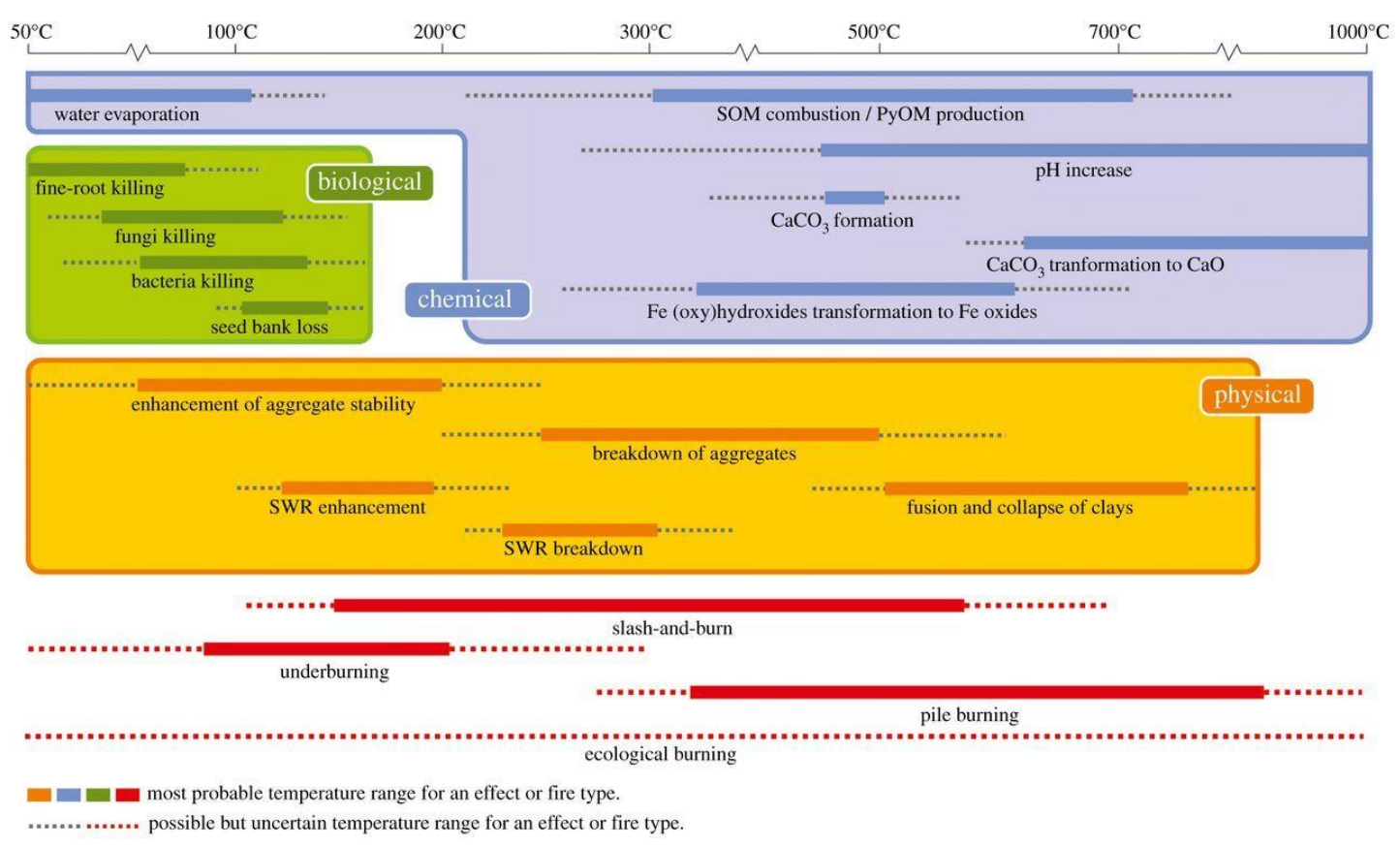

Figure 1.6: Fire effects on the biological, chemical and physical properties of soils and their associated temperature ranges reached near the mineral soil surface. The temperature scale is nonlinear. SOM: soil organic matter; PyOM: pyrogenic organic matter; SWR: Soil water repellency. Taken from Santín and Doerr (2016).

When direct measures of fire intensity (sensu Keeley (2009) a measure of the timeaveraged energy flux) are not available, estimates of fire severity can be used to describe the degree to which a fire has impacted a given ecosystem (Keeley, 2009). 'Fire severity' and the related term 'burn severity' are defined here as the impact of fire on a given ecosystem from the loss of or change in above- and belowground organic matter (Keeley, 2009).

As a result of the broad nature of this definition the term 'soil burn severity' is also used here to specifically refer to the degree of loss or decomposition of soil organic matter or deposition of ash from the combustion of aboveground biomass (Lewis et al., 2006). This is perhaps particularly important to contextualise the use of the word severity in relation to soils as within a given fire event the degree of combustion of organic matter can be substantially different between the above-ground vegetation and underlying soil. 


\subsubsection{Physical properties}

One of the most researched fire effects on soil physical properties is its influence on water repellency. Soil water repellency (hydrophobicity) is the increase in the ability of soils to resist wetting due to the partial combustion of soil organic matter causing redistribution or concentration of hydrophobic substances in the soil and improvement in the bonding of these substances with soil particles (Zisman, 1964). It was thought the heating of any hydrophilic soil with a greater than $2-3 \%$ component of organic matter would create water repellency, it has, however, been also observed to either enhance or reduce water repellency in already repellent soils (DeBano, 1991; Hubbert et al., 2006; Jordán et al., 2011).

The creation of water repellency can result in a number of major consequences for catchment hydrology and geomorphology as well as plant growth and overall ecosystem function via reduced infiltration capacity, increased overland flow, uneven wetting patterns, creation of preferential flow and accelerated erosional processes (Imeson et al., 1992; Doerr et al., 2000). Fire is a commonly cited trigger of hydrophobicity and a number of species common to British heathlands are associated with the creation of water repellency, e.g. C. vulgaris (Mallik, 1985), Vaccinium spp. (Richardson and Hole, 1978) and Agrostis spp. (Wilkinson and Miller, 1978).

The effects of soil burn severity are crucial to the creation, or destruction of water repellency in soils as demonstrated in Figure 1.6. During very low-severity fires such as some management burns where soil surface temperatures remain less than $100^{\circ} \mathrm{C}$, there is thought to be minimal to no effect on soil water repellency assuming the soil retains some moisture (Santín and Doerr, 2016). At burn severities in which the soil surface temperature reaches $100-200^{\circ} \mathrm{C}$, the enhancement of soil water repellency is possible as organic substances in the topsoil begin to volatilise and condense, coating soil mineral particles causing the reduction of soil permeability (Mataix-Solera et al., 2011; Santín and Doerr, 2016). The extent of volatilisation and subsequent hydrophobicity at these temperatures is dependent on heating duration, fuel type and soil moisture content (Zavala et al., 2014). It is not until burn severities produce soil surface temperatures in excess of $300^{\circ} \mathrm{C}$ that hydrophobic substances and bonds breakdown, and soil water repellency is destroyed (Mataix-Solera et al., 2011). 
Soil aggregate stability (structural stability) is another physical property of soil potentially impacted by fire activity (Certini, 2005). Soil aggregate stability is a measure of the associated stability of individual particles within a given soil and therefore its overall structural resilience when subject to external forces (MataixSolera et al., 2011). Aggregate stability is dictated by soil granulometric composition, soil biology and soil physic-chemical properties and it is considered a parameter reflecting overall soil health (Jordán et al., 2011). Soil aggregation often varies seasonally and annually, disintegrating and re-aggregating regularly in response to a range of factors (Mataix-Solera et al., 2011).

In a review by Mataix-Solera et al. (2011) three common patterns of soil burn severity dictated change in aggregate stability are proposed: i) soils containing high clay content as the principle binding agent (calcium carbonate, $\mathrm{Fe}$ or $\mathrm{Al}$ oxides) tend to significantly increase in aggregate stability as severity increases, ii) soils in which organic matter is the primary cementing substance coupled with low water repellency (hydrophilic soils) initially increase in aggregate stability from low to moderate soil burn severity (up to $170^{\circ} \mathrm{C}$ ). Significant structural degradation and subsequent breakdown of aggregate stability, however, occurs above $220^{\circ} \mathrm{C}$ in these soil types and, iii) soils with a sandy composition in which organic matter is the primary binding agent but are already hydrophobic decrease in aggregate stability with increasing soil burn severity.

The impacts of fire on soil aggregate stability are also highly variable with soil burn severity playing a key role. Impacts are also highly dependent on the type of soil and the main binding agents present (e.g. organic matter), determining the specific onset temperature of stability enhancement or breakdown (Jordán et al., 2011). In general, low-severity fires $\left(25-200^{\circ} \mathrm{C}\right)$ do not cause significant changes in soil aggregate stability, however, when soil hydrophobicity is created as a result of burning, aggregate stability often increases (Terefe et al., 2008; Mataix-Solera et al., 2011). At high soil burn severities, soil aggregate stability can be substantially changed dependant on soil type. Responses varying from the breakdown of aggregates as a result of the destruction of organic matter to enhanced aggregation if certain minerals (e.g. Fe or $\mathrm{Al}$ oxides) are prevalent in the soil causing recrystallization (Guerrero et al., 2001; Campo et al., 2008). 
Other notable aspects of soil physical properties affected by fires identified in the literature are bulk density and particle-size distribution (Certini, 2005). Bulk density is strongly linked to soil aggregate stability and follows similar patterns of response to fire (soil burn severity). Bulk density generally increases as a result of the collapse of aggregates, decrease of organic matter and the reduction in soil aggregate stability as well as the incorporation of ash into the soil profile filling available gaps (Durgin and Vogelsang, 1984; Giovannini et al., 1988). Consequently, soil permeability and porosity decrease, implying a decrease in soil water holding capacity and increased surface run-off and erosion (Fayos, 1997; Martin and Moody, 2001).

Particle-size distribution does normally not directly change as a result of fire events, however, the incorporation of ash into the soil profile and increased post-fire erosion rates can preferentially remove fine particulate material affecting the overall distribution of particle-sizes (Mermut et al., 1997; Oswald et al., 1998).
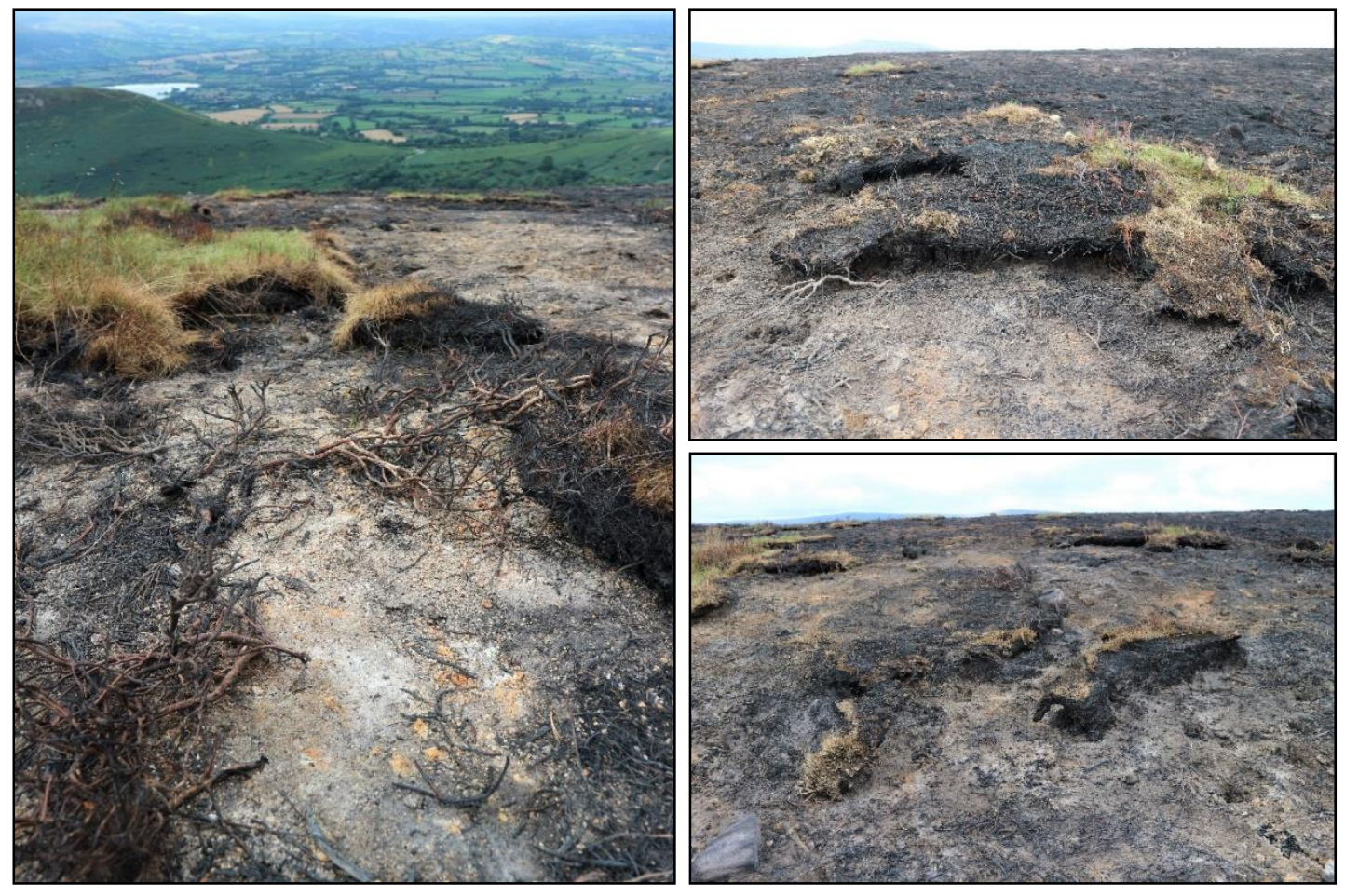

Figure 1.7: Effects of a high to extreme soil burn severity wildfire on shallow organic layered heathland soils ( $<30 \mathrm{~cm}$ organic layer depth). Two weeks of smouldering combustion causing almost complete removal of the organic soil layer and exposing the underlying mineral soil. Photographs taken at Mynydd Llangorse, south-east Wales (July-2018). 


\subsubsection{Chemical properties}

Perhaps one of the most intuitive and important impacts of fire on soil properties is its effect on organic matter quantity and quality. Soil forms the largest pool of carbon on the Earth's surface ( 2400 Pg C to 2 m depth) (Yousaf et al., 2017). As a result, changes to this store could have significant effects on the global carbon balance and climate change (González-Pérez et al., 2004; Scharlemann et al., 2014). The effects of fire on soil organic matter content are highly variable ranging from total destruction of organic matter to partial scorching depending on a number of factors such as burn severity, soil type, soil moisture and the characteristics of burnt material (Figure 1.7) (Verma and Jayakumar, 2012). It is, therefore, difficult to predict the impacts of fire on soil organic material, however some broad generalisations are possible.

At lower temperatures $\left(100-200^{\circ} \mathrm{C}\right)$ the distillation of volatiles begins alongside the loss of organic carbon from the soil surface (Giovannini and Lucchesi, 1997). Above $200^{\circ} \mathrm{C}$ the charring of organic carbon starts along with the breakdown of lignin and hemicellulose, and at temperatures $>300^{\circ} \mathrm{C}$ major structural changes begin along with the increase in the production of aromatic structures (González-Pérez et al., 2004). Combustion during wildfire is often incomplete forming a range of fire-derived (pyrogenic) organic solid compounds. Fire can, therefore, produce a substantial amount of new carbon forms in addition to thermal modification of existing carbon within an ecosystem (Mataix-Solera et al., 2008; Santín et al., 2016). Fires are, therefore, able to cause a substantial rearrangement of ecosystem carbon forms (Schulze et al., 2000; Santín et al., 2016).

In the UK, we have little knowledge on the impacts of severe wildfires on soil carbon storage and there is no research based in open heathland ecosystems (shallow organic soils: <50 cm) (Figure 1.7) (Davies et al., 2013). In organic soils more generally, Davies et al. (2013) assessed the impacts of a smouldering summer wildfire on carbon loss primarily in an area of ca. 14 ha of Pinus contorta plantation in the Cairngorms National Park (Scotland). During this fire, and subsequent smouldering combustion, $96 \pm 15 \mathrm{t} \mathrm{ha}^{-1}$ of carbon was lost equivalent to between $0.1-0.3 \%$ of the carbon sequestered annually by British upland peats (Worrall et al., 2003). This value of carbon loss is within the range of those reported in other wildfire soil carbon consumption studies in peatlands in North America (15-25 $\left.\mathrm{t} \mathrm{ha}^{-1}\right)$ and Northern Europe 
and Asia (17-23 t ha-1). These estimates are, however, likely greater than the losses experienced in shallower heathlands soils with their lower carbon stocks (Davies et al., 2013).

There is a notable breadth of literature on the impacts of prescribed burns (low soil burn severity) on total moorland carbon dynamics in the UK which is not addressed here as it is discussed in detail (including carbon storage, gaseous exchange and carbon budgets) in Chapter 2.

Soil $\mathrm{pH}$ is another soil chemical property influenced by soil heating during fire events and can have considerable implications for habitat function (e.g. vegetation type and water quality) (Verma and Jayakumar, 2012). Soil pH often shows limited direct response to fire activity at low to moderate soil burn severities, however, considerable increases can occur as a result of high-severities (soil temperatures $>450-500^{\circ} \mathrm{C}$ ) (Arocena and Opio, 2003; Boerner et al., 2009). Increases in soil pH are primarily as a result of the incorporation of ash into the soil surface due to the strong alkalinity of some ash types (Molina et al., 2007; Schafer and Mack, 2010). During instances of complete combustion increases in soil $\mathrm{pH}$ can also occur due to the denaturation of organic acids and the resultant release of bases, producing an increase in soil base saturation (Macadam, 1987; Certini, 2005). In an investigation into topsoil after severe burning in California, Ulery et al. (1993) found $\mathrm{pH}$ could increase by as much as three units shortly after burning, in this case as a result of the production of $\mathrm{K}$ and $\mathrm{Na}$ oxides, hydroxides, carbonates and calcite which could promote alkaline conditions for up to 3 years post-fire.

Fires also have repercussions for the concentration and distribution of soil nutrients, particularly nitrogen (N) and phosphorus (P) (Knicker, 2007). The concentration of soil organic $\mathrm{N}$ and its response to fire is directly related to the degree of soil heating during fire events and thus the level of N volatilisation (Covington and Sackett, 1992; Boerner et al., 2009). A significant proportion of organic $\mathrm{N}$ survives during lower soil burn severity fires (soil temperature $<200^{\circ} \mathrm{C}$ ) as the degree of volatilisation is limited due to minimal organic matter consumption (Turner et al., 2007). During fire events in which moderate to high soil burn severity (soil temperature $>200^{\circ} \mathrm{C}$ ) occurs, a considerable portion of organic $\mathrm{N}$ can be lost as combustion converts organic $\mathrm{N}$ into inorganic forms, such as Ammonium (Certini, 2005). 
During burning, inorganic $\mathrm{N}$ can also be released from dead plant material where it is previously found in non-bioavailable forms (Rivas et al., 2012). These changes are largely restricted to the soil surface $(0-5 \mathrm{~cm})$ (Prieto-Fernandez et al., 1993). Fire also has indirect implications for soil $\mathrm{N}$ levels as nitrification conditions, the breakdown of ammonium $\left(\mathrm{NH}_{4}{ }^{+}\right)$into nitrates $\left(\mathrm{NO}_{3}{ }^{-}\right)$, are usually improved as a result of burning, especially in burnt acid soils (Knicker, 2007; Boerner et al., 2009). Decreasing acidity, as a result of soil $\mathrm{pH}$ change, enhances soil microbial activity and improves nitrogen fixation, enabling $\mathrm{N}$ levels to be quickly restored, except under severe conditions leading to nitrogen leaching or destruction of soil microbial communities (Raison et al., 2009; Rivas et al., 2012).

Several studies in forested and shrubland habitats reported immediate post-fire decreases in soil organic $\mathrm{N}$ and a corresponding increase in $\mathrm{NH}_{4}{ }^{+}$levels, with $\mathrm{NO}_{3}{ }^{-}$ concentrations not recovering until >1-year post-fire (Covington and Sackett, 1992; Knicker, 2007; Rau et al., 2007). Both forms of inorganic N disappeared in the soil surface five years post-fire (Covington et al., 1991; Covington and Sackett, 1992). A multi-decadal (65-year) study of post-fire soil total $\mathrm{N}$ levels across grassland, broadleaf and needle-leaf forests found that repeated and frequent burning produced a long-term decline (34\%) in surface $\mathrm{N}$ levels, with particular impacts on grassland and broadleaf forests (Pellegrini et al., 2018).

Losses of phosphorus (P) during combustion because of volatilisation are often small in comparison to $\mathrm{N}$ losses (volatilisation at $200^{\circ} \mathrm{C}$ ) as $\mathrm{P}$ volatilisation occurs at higher temperatures $\left(>700^{\circ} \mathrm{C}\right)$ (Raison et al., 2009; Schafer and Mack, 2010). Regardless of soil heating or ecosystem type, it is estimated that half as much $\mathrm{P}$ is lost to the atmosphere in comparison to $\mathrm{N}$ and thus post-fire soil surfaces often contain high $\mathrm{P}$ concentrations and low $\mathrm{N}$ concentrations. Fire can, therefore, have a notable effect on the relative availability of soil N:P (Schafer and Mack, 2010).

Soil $\mathrm{P}$ appears to be one of the only elemental components whose post-fire increase is consistently proportional to soil burn severity, with severe burning releasing $\mathrm{P}$ via combustion of organic matter and mineralisation but limited losses due to its high volatilisation temperature (Capogna et al., 2009). Soil heating also directly modifies soil $\mathrm{P}$ by converting organic $\mathrm{P}$ into the more enriched bioavailable orthophosphate (inorganic phosphorus) (Certini, 2005). 
Concentrations of orthophosphate commonly increase immediately post-fire due to this direct pyro-mineralisation however, its residence time can be limited as it preferentially, and often rapidly, binds to $\mathrm{Al}, \mathrm{Fe}$ and $\mathrm{Mn}$ oxides in acidic soils and $\mathrm{Ca}$ minerals in more alkaline soils (Caon et al., 2014; Hinojosa et al., 2016). Soil pH is, therefore, a key factor in the form and availability of $\mathrm{P}$ in post-fire soils and as a result is subject to significant variability due to, for example, fire severity, vegetation/litter type, soil composition (Certini, 2005). Combustion of organic matter also releases $\mathrm{P}$ in ash which can be lost (e.g. runoff or wind-blown) or redistributed into the soil (e.g. leached) (Caon et al., 2014). In a shrubland ecosystem in western USA, orthophosphate increased immediately post-fire in the soil surface and remained elevated for two years (Rau et al., 2007).

The impact of fire on other chemical elements and micronutrients such as, Magnesium, Calcium, Potassium, Iron, Manganese and Zinc is limited and due to the variability of the possible impacts of fires and influencing parameters (soil type, soil $\mathrm{pH}$, vegetation type, burn characteristics) it is difficult to draw broad conclusions. Furthermore, it remains largely unclear as to what degree fire-driven changes in nutrient availability will limit future plant productivity or biogeochemical cycles (Pellegrini et al., 2018).

\subsubsection{Biological properties}

In terrestrial ecosystems, soil organisms are vital for the regulation of biogeochemical cycles due to their role in the decomposition of organic matter and recycling of nutrients (Bárcenas-Moreno et al., 2011). Soil microbes and invertebrates are, therefore, of key importance to post-fire soils and vegetation recovery as these organisms help to dictate soil structure and health by regulating soil aeration, penetrability, moisture and nutrient status (Mataix-Solera et al., 2009). Soil heating during fire events can have an impact on soil biological properties affecting the abundance and diversity of soil-dwelling invertebrates and microbial communities (Certini 2005).

Fire can have both direct impacts on soil organisms via soil heating and indirect effects by modifying soil properties and vegetation. Those impacts are highly variable depending on factors such as fire severity, soil properties and post-fire conditions as well as the type of soil organism (Mataix-Solera et al., 2009). Perhaps the two primary 
factors influencing microbial and invertebrate communities during fires are soil burn severity and soil moisture, which affect the degree of soil heating and the depths of penetration (Bárcenas-Moreno and Bååth, 2009; Holden et al., 2016).

Immediately post-fire (<6-months), soil microorganisms are often significantly reduced in biomass as peak temperatures during fires in the first few centimetres of the soil often exceed those required to kill microbial organisms (approx. $>60^{\circ} \mathrm{C}$ ) (DeBano et al., 1998). Effects on microorganisms during fires, therefore, appear to have a direct correlation to soil burn severity with increasing burn temperatures resulting in decreasing diversity and abundance (Holden et al., 2016). Varying burn severities appear to alter microbial community diversity with, in particular, changes in water availability influencing species competition and favouring xerotolerant species, reducing overall diversity (Capogna et al., 2009).

After the immediate post-fire period ( $>6$-months), however, fires producing moderate to high soil burn severities have been found to cause increases in microbial abundance and diversity given favourable recovery conditions (e.g. soil moisture) (Capogna et al., 2009). In Mediterranean shrub, maquis and American prairie ecosystems, favourable recovery conditions resulted in fungal species density reaching and exceeding pre-fire levels between 6 to 12 months post-fire (Wicklow, 1988; Bartoli et al., 1991; Capogna et al., 2009). An investigation by D'Ascoli et al. (2005), following the initial post-fire decrease in microbial biomass, found quantities increase compared to control levels within the first 3 months post-fire. Fire is thought to change the ability of carbon utilisation and improve soil nutrient conditions enabling increases in soil microorganism biomass and diversity (Wang et al., 2016).

In the case of severe fire events, topsoil can become completely sterilised of all soil biota, although this is rare (Certini, 2005). In forested ecosystems, Prieto-Fernández et al. (1998) recorded almost complete destruction of microbial biomass immediately post-fire and a reduction in abundance still evident after 4-years of recovery in the surface soil $(0-5 \mathrm{~cm})$. This lengthy recovery could be as a result of organic pollutants incorporated into the soil during combustion (e.g. Polycyclic aromatic hydrocarbons, dibenzofurans and polychlorinated dibenzo-dioxins) or simply by limited plant primary productivity or variable habitat fire dependence/sensitivity (Kim et al., 2003). 
Within microbial communities, bacterial species are thought to recover more rapidly than fungal species after soil heating. Fungal species are often more temperaturesensitive in comparison to bacterial species as bacterial spores are able to withstand much higher temperatures (D’Ascoli et al., 2005; Wang et al., 2016). Bacterial species are also able to recover to higher levels compared to fungi likely due to interspecies competition and fire-induced increase in $\mathrm{pH}$ favouring bacterial growth (BárcenasMoreno and Bååth, 2009; Rousk et al., 2009). At lower temperatures $\left(<200^{\circ} \mathrm{C}\right)$ only minor differences are evident in the inhibition of fungal and bacterial communities (Bárcenas-Moreno and Bååth, 2009).

The impacts of fire are generally less pronounced on soil invertebrates in comparison to microorganisms due to their higher mobility levels (Certini, 2005). Despite this, the level of mobility of different invertebrate species greatly varies and so too does their vulnerability to fire (Coyle et al., 2017). Detritivore species, for example, are at particular risk from fire as these litter/surface-dwelling organisms can be dramatically reduced in abundance during combustion if the majority of the litter layer is consumed (Radea et al., 2010). Smaller soil invertebrates such as mites and collembolans may be more fire resilient as they live and are able to move further down in the soil profile in response to disturbances (Barratt et al., 2006; Malmström et al., 2009).

The initial response of soil invertebrate abundance and diversity to fire is highly variable but is significantly correlated with soil heating (Certini, 2005; Coyle et al., 2017). Composition and abundance changes can last from a few months in mite species to up to a decade in some collembolan communities, with recovery dictated by soil properties, plant recovery and species disturbance tolerance and recolonization strategies (Jung et al., 2010; Malmström, 2012).

Indirectly, a number of factors can also acutely affect the recovery of particular invertebrate species dependant on their life-history traits and changes in inter and intraspecific competition. For example: detritivore recovery will be closely affected to the rates and type of plant and litter reestablishment; fungivores by the response of soil fungal communities; and predators by the recovery of their favoured prey species (Buddle et al., 2006; Coyle et al., 2017). This close dependence on other habitat traits means long-term fire recovery in soil invertebrates is difficult to assess as changes may not be a direct response to the fire disturbance itself and rather may reflect changes in 
plant communities during successional stages and the quality and quantity of organic matter inputs (Radea et al., 2010).

Despite the limitation of data on the impacts of wildfires on soil fauna, it is clear that, whether low or high soil burn severity, all fires result in some physical, chemical and biological changes in soils and have the potential to influence soil faunal communities (Zaitsev et al., 2016; Coyle et al., 2017).

\subsection{Fire effects on freshwater systems}

It is well-established that wildfires can lead to considerable changes in hydrological and geomorphological processes due to their direct effects on vegetation cover, soil properties and atmospheric inputs (Shakesby, 2011). Among the indirect effects are the incorporation of ash into the soil surface and its subsequent run-off and erosion into freshwater systems (Smith et al., 2011). During wildfires, combustion of fuels releases a wide range of organic and inorganic compounds some of which are concentrated into wildfire ash left on the ground post-fire (Bodí et al., 2014). The postfire erosion and mobilisation of ash and burnt soils pose a number of considerable risks for freshwater systems from, substantial inputs of suspended sediment, nutrients, trace elements and metal contaminants threatening water quality, drinking water supplies and aquatic biota (Smith et al., 2011; Bladon et al., 2014; Nunes et al., 2018).

Despite the concerns outlined above, research interest has only recently focused on the linkage between ash production and composition and its impacts on on-site and downstream water quality (Nunes et al., 2017, 2018). Given the potentially substantial influence of ash on catchment water quality this section focuses on outlining the current knowledge in this emerging body of literature and provides context to the assessment of ash toxicology in Chapter 5.

A comprehensive summary of the effects of relatively low severity (prescribed) fires on water quality more broadly in the UK has also been provided in Chapter 2. 


\subsubsection{Ash properties}

Wildfire ash is formed during the combustion of fuels, such as biomass, necromass and soil organic matter, and is a heterogeneous material composed of a complex mixture of organic and inorganic material (Bento-Gonçalves et al., 2012). Its composition is primarily made up of pyrogenic organic carbon, oxides and hydroxides, nutrients, major and trace metals and other possible contaminants (Abraham et al., 2017). Ash is typically non-cohesive, has a low density, and is not attached to the soil, facilitating its mobilisation and transport (Bodí et al., 2014; Abraham et al., 2017).

In general, ash formed during low-moderate burn severities (typically reaching $<450^{\circ} \mathrm{C}$ ) represent forms of incomplete combustion, is often organic-rich, primarily formed of pyrogenic carbon, dark in colour, of low density and produces a relatively thick ash layer (Bodí et al., 2011, 2014; Pereira et al., 2014). At higher burn severities (typically reaching $>450^{\circ} \mathrm{C}$ ) the combustion of organic matter is substantially higher reducing the organic component of ash and producing a lighter coloured, higher density and often thinner ash layer (Pereira et al., 2012; Bodí et al., 2014). In forested areas, with high fuel loads, the resultant wildfire ash layer can be $2-10 \mathrm{~cm}$ thick and equates to $1-5 \mathrm{~kg} \mathrm{~m}^{-2}$ of ash. Ash layers have, however, been recorded as exceeding $20 \mathrm{~cm}$ depth in some instances (Doerr et al., 2008; Gabet and Sternberg, 2008). Ash is usually characterised by high alkalinity and electrical conductivity (Plumlee et al., 2007; Granged et al., 2011a; Silva et al., 2015).

The primary inorganic constituents of wildfire ash are calcium $(\mathrm{Ca})$, silicon $(\mathrm{Si})$, potassium $(\mathrm{K})$ and magnesium $(\mathrm{Mg})$ and to a lesser extent sulphur (S), sodium $(\mathrm{Na})$ and phosphorus $(\mathrm{P})$ in addition to major and trace elements, such as lead $(\mathrm{Pb})$, iron $(\mathrm{Fe})$, copper $(\mathrm{Cu})$, aluminium $(\mathrm{Al})$, manganese $(\mathrm{Mn})$, nickel $(\mathrm{Ni})$, Zinc $(\mathrm{Zn})$ and mercury (Hg) all in varying quantities (Pitman, 2006; Plumlee et al., 2007; Bodí et al., 2014; Silva et al., 2015; Nunes et al., 2017). Although the primary components of wildfire ash are similar, the quantity of each element is highly variable and is dictated by factors such as fire severity, fuel type (plant species), vegetation structure and degree of combustion (combustion completeness) (Bodí et al., 2014). Khanna et al. (1994), in an assessment of Eucalyptus litter ash, found considerable variations in the quantity of chemical elements, for example, N, P and Al concentrations were 300$14,000 \mathrm{mg} \mathrm{kg}^{-1}, 160-12,000 \mathrm{mg} \mathrm{kg}^{-1}$ and 1000-18,000 $\mathrm{mg} \mathrm{kg}^{-1}$, respectively. 
The residence time of ash layers at burnt sites is often short as it is easily mobilised and transported by wind and rainfall-induced surface runoff (overland flow). Ash is, therefore, a key component of the post-fire hydrogeomorphology of burnt catchments (Doerr and Cerdà, 2005). Cerdà and Doerr (2008) observed that rainfall of $153 \mathrm{~mm}$ over 6 days following a fire events in an Aleppo pine forest (eastern Spain) almost entirely removed a $36 \mathrm{~mm}$ ash layer within 3 weeks. Ash is also able to alter soil hydrological behaviour in a number of ways by creating a distinct layer above the soil surface which can function in different ways depending on, for example the differences in ash physical and chemical properties, the depth of the ash layer, soil type and postfire rainfall characteristics (Bodí et al., 2014; Abraham et al., 2017). The impact of ash on hydrological processes are, however, complex and changes in post-fire runoff and transport can be contradictory with, for example ash increasing overland flow in some cases (Woods and Balfour, 2010) and decreasing it in others (Cerdà and Doerr, 2008; Bodí et al., 2012).

\subsubsection{Contaminants in ash}

There are a number of constituents in wildfire ash which are of particular environmental concern due to their toxicity and tendency to bioaccumulate, in particular, metals and polycyclic aromatic hydrocarbons (PAHs) (Vila-Escalé et al., 2007; Campos et al., 2012; Oliveira-Filho et al., 2018).

Metals are a naturally occurring part of aquatic systems and are usually gradually released from soils and rocks via leaching. Some metals, such as $\mathrm{Cu}, \mathrm{Zn}$ and $\mathrm{Fe}$ are essential to the protein structure and gene regulation of living organisms (Smith et al., 2011; Abraham et al., 2017). The mobilization of other non-essential metals such as $\mathrm{Hg}, \mathrm{Cd}$ and $\mathrm{Pb}$ can cause significant noxious effects on aquatic organisms by displacing these essential metals and disrupting enzyme function (Gifford et al., 2004; Smith et al., 2011). Wildfire ash represents an additional diffuse source of metals into aquatic systems and elevated concentrations of even essential metals can have toxic implications (Gifford et al., 2004).

Metal contaminants are notably persistent in freshwater systems as they tend to accumulate in aquatic organisms and sediments (Abraham et al., 2017). These contaminants are also virtually non-degradable and able to persist in freshwater 
systems once the majority of the ash has been removed (Abraham et al., 2017). During an assessment of runoff contamination loads following five Californian scrubland wildfires between 2003 and 2009, Stein et al., (2012) found mean $\mathrm{Cu}, \mathrm{Pb}$ and $\mathrm{Zn}$ concentrations were between 112 and 736-fold higher in the burnt catchments in comparison to unburnt controls. Despite limited observations of trace element concentrations in freshwater systems across a range of ecosystems after wildfire events, most found high elevated levels (above respective guidelines) of $\mathrm{Fe}, \mathrm{Al}, \mathrm{Mn}$, $\mathrm{As}, \mathrm{Pb}$ and to a lesser extent $\mathrm{Cu}, \mathrm{Zn}$ and $\mathrm{Hg}$ (Khanna et al., 1994; Ferreira et al., 2005; Plumlee et al., 2007; Smith et al., 2011; Abraham et al., 2017).

Polycyclic aromatic hydrocarbons (PAHs) are a form of pyrogenic carbon produced by combustion in wildfires and released into the atmosphere or deposited into ash and soils. Concerns around PAHs mobilisation into freshwater relates to their potential toxicity, carcinogenicity, environmental persistence and tendency to bioaccumulate (Olivella et al., 2006; Vila-Escalé et al., 2007). In post-fire environments, these compounds can be transported into surface waters via runoff and direct fallout or leached into groundwater systems. Wildfires are also able to mobilise pre-existing PAHs within habitats, deposited by atmospheric deposition, industrial effluents, wastewater discharges and oil spills (Vila-Escalé et al., 2007).

Few studies have examined PAHs outputs from wildfire events although those that have observed notable post-fire increases in freshwater systems (Bundt et al., 2001; Olivella et al., 2006; Vila-Escalé et al., 2007; Rey-Salgueiro et al., 2018). Olivella et al. (2006) for example, reported a downstream increase ranging from 2-336 $\mathrm{ng} \mathrm{l}^{-1}$ onemonth post-fire in Catalonia, Spain.

The post-fire quantity of PAHs in ash, soils and aquatic systems appears highly variable and within ash itself, fire severity and the level of combustion completeness is thought to be a major determining factor in the quantity and composition of PAHs (Vila-Escalé et al., 2007; Chen et al., 2018). Lower severity burns (i.e. more incomplete combustion) promote the production of PAHs, with significantly higher PAH content in black ash in comparison to white ash (Silva et al., 2015; Chen et al., 2018). Values presented by Olivella et al. (2006) testing wildfire ash from pine and oak forests found 1-19 $\mathrm{ng} \mathrm{g}^{-1}$ ash, whereas Silva et al. (2015) assessing dry wildfire ash from a eucalypt forest (Portugal) found $1100 \mathrm{ng} \mathrm{g}^{-1}$ ash and Santín et al. (2017) 
analysing PAHs in pine forest ash produced by wildfire and slow pyrolysis found between 1000-50,000 $\mathrm{ng} \mathrm{g}^{-1}$ ash.

Once released into surface water systems, PAHs are subject to a variety of transformative processes and can have a range of different interactions with ash, sediments and aquatic organism's dependent on their physicochemical properties (Olivella et al., 2006). PAHs can volatilise, oxidise, photodegrade or biodegrade as well as bind to sediment particles or accumulate in biota. PAHs in aquatic systems are primarily found sorbed to particles due to their high affinity for organic carbon and relatively low solubility (Chen et al., 2018). Frišták et al. (2019) found particularly methylated aromates bind to insoluble carbon fractions or get trapped in microporous structures of pyrogenic material and therefore, likely have limited bioavailability.

\subsubsection{Aquatic toxicology}

The post-fire release of soluble elements and particulate matter from eroded ash and soils into freshwater systems can increase water turbidity, $\mathrm{pH}$, organic matter, suspended sediment, conductivity and depletion of dissolved oxygen, among other effects (Smith et al., 2011). Previous studies across the world have linked post-fire rainfall and surface runoff with the transport of particles downstream posing a considerable threat to aquatic systems and drinking water (Ferreira et al., 2008; Smith et al., 2011; Prats et al., 2014). Ash is, however, rarely examined as a distinct part of post-fire sediment and few studies have characterised wildfire ash composition in detail (Bodí et al., 2014). These factors result in key environmental concerns as to the extent to which wildfire ash may pose a diffuse contamination threat to freshwater systems (Costa et al., 2014; Nunes et al., 2017, 2018).

The impacts of ash on freshwater systems are, however, not limited to changes in water quality and increasing recognition is being given to the impacts of ash on aquatic biota. Despite the limited literature on this topic detrimental effects of ash contamination have now been observed in fish (Nunes et al., 2017; Oliveira-Filho et al., 2018; Gonino et al., 2019a), amphibians (Pilliod et al., 2003), macroinvertebrates (Brito et al., 2017), algae (Campos et al., 2012), and phytoplankton (Earl and Blinn, 2003). 
Key studies to date assessing the impacts of ash contamination on aquatic organisms have reported highly variable impacts between different ecosystems, types of ash, fires and species (Campos et al., 2012; Silva et al., 2015; Brito et al., 2017; Oliveira-Filho et al., 2018). Silva et al. (2015) and Campos et al. (2012) for example, studied Eucalyptus ash and found no significant impact on the planktonic crustacean Daphnia magna reproduction or immobilisation rates over chronic (21 days) and acute (46 h) exposures respectively. Toxicity was however observed using the same ash on several lower trophic species, the bacteria Vibrio fischeri, algae Pseudokirchneriella subcapitata and the macrophyte Lemna minor.

A similar study by Brito et al. (2017) testing the toxicity of Brazilian Cerrado ash over acute exposures $(48 \mathrm{~h})$ found significant toxicity on the planktonic crustacean Ceriodaphnia dubia and the fish Danio rerio, but no significant impact on the mollusc Biomphalaria glabrata. Gonino et al. (2019b) also observed negative impacts of wildfire ash (Brazilian sugarcane ash) on several species of native fish (Astyanax lacustris, Moenkhausia bonita and Microplecostomus forestii) over 24-h acute exposures but not for two non-native fish species (Oreochromis niloticus and Poecilia reticulata).

This limited assortment of literature demonstrates the variability and complexity of influencing factors in relation to the effects of ash contamination on aquatic biota. Further studies on the mobilisation of ash into freshwater systems are, therefore, of high importance to understanding to full implications of fire on water quality.

\subsection{Objectives and thesis structure}

Understanding the impacts of fires on terrestrial and aquatic systems is crucial for informing effective policy and land management. This is particularly vital in naturally non-fire-prone regions like the UK where the existing knowledge is quite spatially and temporally limited and given the expected increase in wildfire risk predicted as a result of climate change. To help fill vital gaps in the often-limited fire impact research specific to UK temperate ecosystems, the goal of this thesis was to investigate and evaluate the role of fires in altering vegetation dynamics, soil properties and water quality in upland heaths. A set of research projects were designed and implemented within the three key topic areas (vegetation dynamics, soil properties and water 
quality), including the assessment of post-fire vegetation and soil recovery in temperate upland heaths and the chemical characterisation of ash and its subsequent water contamination potential. To address these diverse general aims, four specific objectives were defined and are addressed in this thesis:

1. Clarify the current state-of-the-art of prescribed fire impact research within the UK in order to identify key areas requiring further research and aid the contentious debate around the use of fire in land management.

2. Evaluate the impacts of fires on vegetation community composition and diversity in upland heaths, assessing dynamics of post-fire recovery.

3. Investigate the effects of fires on soil physical and chemical properties in areas of upland heath with shallow organic layered soils.

4. Characterise the chemical composition of ash generated in a range of habitats, placing UK ash into a broader global context. In addition, to assessing the potential toxicity of these ash types on aquatic organisms.

The data presented within this thesis aims to provide a valuable contribution to inform future land management decision-making within the Brecon Beacons National Park (south Wales), and more broadly across the UK and other temperate ecosystems likely to experience shifting land-use patterns and changing fire regimes in the future. This thesis is, therefore, composed of six chapters, with the first and final chapters providing a general introduction and a final synthesis and concluding remarks, respectively. The remaining four chapters represent individual research projects, two of which are published in international journals.

Chapter 2 provides a critical review of the published work relating to the impacts of prescribed fire on water quality, carbon dynamics and habitat composition and structure (biodiversity) in the UK, in addition to highlighting future research priorities. Its primary aims are to provide guidance based on the current state-of-the-art for researchers, landowner, managers and policymakers on the potential effects of the use of fire in management and to inform the wider, contentious, debate about the place of fire in modern conservation and land management in temperate ecosystems. In direct relation to the thesis, this review provides a firm contextual background to the impacts of low severity fires in the UK on key ecosystem services and an insight into current land management techniques as well as the academic discussion around them. 
Chapter 3 represents a study examining post-fire vegetation community compositional and structural recovery across four heathland sites within the Brecon Beacons National Park (South Wales). This provides insight into vegetation dynamics at four stages of post-fire recovery $(<1,3,7$ and 11-years elapsed time-since-fire). European heathlands dominated by the ericoid shrub $C$. vulgaris are of high conservation value and international significance and are often subjected to both wild- and prescribed fires in the UK. Very limited vegetation recovery research has, however, been conducted in these habitats, particularly in Wales. This chapter, therefore, aims to address this research gap and provide spatial and habitat-specific information to aid land management decision-making.

Chapter 4 provides a study assessing the impacts of fire on soil properties across four heathland sites within the Brecon Beacons National Park. This provides insight into soil physicochemical properties at four stages of post-fire recovery $(<1,3,7$ and 11 years elapsed time-since-fire). The same sites were used in Chapter 3 and Chapter 4. A range of parameters are assessed from physical properties (e.g. bulk density, water holding capacity, $\mathrm{pH}$ and hydrophobicity) to detailed chemical characterisation, including total carbon $(\mathrm{C})$, total nitrogen $(\mathrm{N})$, bioavailable phosphorus $(\mathrm{P})$, aluminium $\left(\mathrm{Al}^{+3}\right)$, calcium $\left(\mathrm{Ca}^{+2}\right)$, magnesium $\left(\mathrm{Mg}^{+2}\right)$, potassium $\left(\mathrm{K}^{+}\right)$and sodium $\left(\mathrm{Na}^{+}\right)$. This enables an assessment of fires impacts in this seldom studied habitat type (temperate heathlands on shallow organic layered soils) and location (Wales).

Chapter 5 assesses the chemical composition of ash generated in six contrasting and globally distributed vegetation types (UK grassland, Spanish pine forest, Spanish heathland, USA chaparral, Australian eucalypt forest and Canadian spruce forest) and its associated toxicity on the sensitive aquatic indicator species Daphnia magna Straus (hereafter D. magna). As a result of the non-existent research on ash chemical properties in the UK, this chapter aims to provide a detailed chemical characterisation of a set of globally distributed ash types in order to place UK ash into the broader context of global fire research, in a directly comparable manner. This chemical characterisation provides the quantification of ash organic and inorganic components including potential contaminants (e.g. metals and PAHs). Acute (48 h) toxicity tests were also conducted for all ash types using the indicator species D. magna in order to evaluate the relationship between chemical composition and toxicity and its implication for water contamination potential. 
To incorporate the material published in different academic journals into this thesis, chapters have been re-formatted to provide consistency and extended to reduce the amount of supplementary material required. To ensure ease of referral, references have been combined and placed at the end of the thesis. Despite all efforts to maintain a more traditional thesis structure apologies must be made for the remaining repetition between chapters which inevitably results from this chosen format. 


\section{Chapter 2}

Prescribed fire and its impacts on ecosystem services in the UK

Published in: Science of the Total Environment (2018) 624, 691-703. (DOI:

https://doi.org/10.1016/j.scitotenv.2017.12.161) 


\subsection{Introduction}

Fire is an important ecological process for many ecosystems and has played a complex role in shaping landscapes across the globe (Bixby et al., 2015a). Throughout the last millennium, humans have used fire as a means of clearing land, facilitating hunting, and maintaining favourable grazing and leisure habitats (Goodfellow, 1998; Worrall et al., 2010a). During the last century, prescribed fire (i.e. controlled or management burning) has been used increasingly as a management tool across parts of the Mediterranean, and the seasonally dry regions of Australia and North America to control natural fire regimes and reduce the risk of severe wildfires spread by managing fuel loads (Burrows and McCaw, 2013; Fernandes et al., 2013; Ryan et al., 2013). The scientific literature on prescribed fire is dominated by research from these regions where fire is also part of the natural ecosystem cycles. Management burning, however, is also a common practice in non-fire prone ecosystems in the world's temperate zones (e.g. New Zealand, Tasmania, Northern Europe, South America and East Asia) (Holden et al., 2007), and the need to fully understand its impacts maybe even greater. The UK uplands have been burnt by humans for millennia (Worrall et al., 2010a). This paper aims, therefore, to provide (i) a comprehensive review of the existing knowledge on the impacts of this practice on key ecosystem services and (ii) to identify future research directions, with a focus on providing guidance to land managers and policy makers on the potential effects of the use of burning.

Early evidence of human management burning in the UK begins in the late Mesolithic/early Neolithic times (approx. 4000 years ago) as a hunting strategy and for clearing land (Fyfe et al., 2003; Tucker, 2003a). By the late medieval period, burning was recorded as a common land management practice, notably in southern England and Scotland (1300s) (Rackham, 1986; Fyfe et al., 2003). It was not until the mid- $19^{\text {th }}$ century, however, that the use of burning for habitat management spread as a result of grouse moors (Worrall et al., 2010a). Over the last 150 years, this practice has taken the form of rotational prescribed burning (Davies et al., 2008a). Rotational prescribed burning consists of using deliberately ignited fires to create a mosaic of burnt patches of different ages. This produces a diverse vegetation structure, allowing the regeneration of younger, more palatable shoots (Worrall et al., 2010a). Burning occurs over a variety of patch sizes with individual patches being burnt on cycles of between 8 to 25 years, although rotations are highly variable and often irregular. Some 
burning, however, ideally takes place within a given area every year (Davies et al., 2008a). This is deemed beneficial for the productivity of livestock-grazing pasture and increasing red grouse populations for sports shooting where relevant (Worrall et al., 2010a).

Upland habitats form the primary focus of this review. In the UK, prescribed burning is conducted almost entirely in upland areas, focused on controlling the density, structure and age of Calluna vulgaris (L.) Hull (hereafter C. vulgaris) and Molinia caerulea (L.) Moench (hereafter M. caerulea) dominated communities (Tucker, 2003a). Upland areas are categorised as areas above the upper limits of agricultural enclosure, between 250-600 m altitude, depending on climatic conditions (Reed et al., 2009). Uplands cover approximately one-third of the land surface in the UK and support a diverse range of semi-natural habitats (Reed et al., 2009). These incorporate a range of ecosystem types from blanket bog, heathland and grassland assemblages, containing a variety of both vegetal and animal species (rare and priority conservation species; e.g. Hen harrier - Circus cyancus Linnaeus, Black grouse - Lagopus lagopus scoticus Latham and Sphagnum spp.) and different operating land management practices (e.g. burning, grazing, cutting and predator control) (Natural England, 2001).

It is widely established that these upland regions provide a range of 'ecosystem services' (i.e. services the environment provides for the well-being of humans) benefiting multiple stakeholders (provisioning services; food, fuel and freshwater. Regulating services; water regulation, climate regulation. Supporting services; nutrient cycling, primary production.) (Reid et al., 2005; Reed et al., 2009). As a result, a large portion of upland habitats fall within areas awarded with special conservation and research significance (e.g. National Parks; Sites of Special Scientific Interest (SSSI); Special Areas of Conservation (SAC)) (Tucker, 2003a).

There are concerns around the application of prescribed burning in these important upland ecosystems in the UK. Burning has been implicated in several potentially negative impacts on the health and diversity of upland habitats (Ramchunder et al., 2009; Davies et al., 2016). In recent decades, the use of prescribed fire in the UK has become a source of heightened controversy with negative public opinion fueled by opposition from popular media (Monbiot, 2016). This highlighted several important limitations within the subject knowledge and resulted in land managers requesting 
further clarification on the impacts of prescribed burning. This, in addition to several other driving forces, has produced a substantial increase in research output with $77 \%$ of the literature captured for this review being published since 2000, 37\% since 2010 . It is, therefore, timely to review these areas of focus (water quality, carbon dynamics and habitat composition and structure) not least to also provide a synthesis for land managers in the UK and in regions with comparable ecosystems.

Three key aspects of ecosystem services form the focus of this review due to their vulnerability and the significance of potential impacts:

i) Water quality: A prominent concern for the management of upland catchments as they provide $70 \%$ of the UK's freshwater resource and are heavily regulated and monitored (Bonn et al., 2009).

ii) Carbon storage: Upland areas in the UK are vitally important for carbon storage with $3000 \mathrm{Mt}$ carbon estimated to be stored in moorlands alone, equating to a globally significant carbon store over 6 times the gaseous carbon emitted by the UK in 2015 (DBEIS, 2017; SEERAD, 2007).

iii) Habitat composition and structure (biodiversity) ${ }^{1}$ : Globally rare fauna and flora are found in the UK uplands with a variety of UK BAP (Biodiversity Action Plan) Priority Habitats and $75 \%$ of the total area of the world's natural heather moorland (Tucker, 2003a). ${ }^{1}$

These three aspects of ecosystem services have been consistently cited as important features needing to be closely monitored when implementing burn practices. All of which require further research to clarify possible impacts (Tucker, 2003a; Ramchunder et al., 2009; Worrall et al., 2010a; Glaves et al., 2013; Brown et al., 2015; Davies et al., 2016).

To collect the relevant literature used in this review searches in scientific journals were conducted using several online databases, assessing articles at title and abstract level (Scopus, Web of Science and Google Scholar). These searches were conducted using a range of general fire search terms from 'fire', 'burn', 'prescribed fire', 'managed fire' and 'muirburn': a set of general locational search terms including, 'UK', 'Britain',

\footnotetext{
${ }^{1}$ In this review the broad term of habitat composition and structure has been used instead of biodiversity as the relevant literature discussed includes the assessment of widely different levels of biodiversity.
} 
'England', 'Scotland' and 'Wales': and a large number of topic specific terms including 'water quality', 'water chemistry', 'run-off', 'flora', 'fauna', 'biodiversity' and 'carbon dynamics'. The inclusion criteria used for screening the subsequent search results were studies with a clear focus on prescribed, managed or controlled fires, with at least one sampling site based within the UK and focused on any aspect of water quality, carbon or biodiversity (flora and fauna). No formal grading of the quality of studies was conducted, due to time constraints, although notable methodological differences (issues) are highlighted in the text, where relevant.

Extensive searches for non-peer reviewed work through key UK agency sites were also undertaken resulting in an overall bibliography of 95 publications (Natural England, Natural Resources Wales, Scottish Environmental Protection Agency, Forestry Commission, Yorkshire Water, Severn Trent Water, and Welsh Water). Nonpeer reviewed literature was screened using the same selection criteria as the peerreviewed research with additional consideration of potential author and organisational conflict of interest.

Of the 95 publications identified, 64 were peer-reviewed research papers, 10 peerreviewed review papers and 21 agency reports. A systematic outline of the captured publications is given in the supplementary information (Supplementary Table 2.1). Despite best efforts it must, however, be noted that this is not likely an exhaustive list of all publications relating to the impacts of prescribed fire on all aspects of water quality, carbon dynamics and habitat composition and structure in the UK. This is due to the difficulties in collating literature on such a diversity set of topic areas and the availability and access to, particularly older research (pre-1980), in online databases.

The following section provides a brief overview of the current use of fire in the UK, which is followed by sections on the three key ecosystem services. The final two sections highlight the major research gaps and suggest future directions followed by the overall conclusions and a framework for progress.

\subsection{Current Use of Prescribed Fire}

In modern terms a prescribed fire is any supervised burn conducted to meet specific land management objectives (Santín and Doerr, 2016). The current practice of 
prescribed burning (also referred to as management or controlled burning, swaling or muirburning) has been created using a combination of traditional knowledge and practical experience combined with modern technology and scientific research (Fernandes and Loureiro, 2010). The global distribution of the use of prescribed burning is highly variable and the development of effective practices has been quicker in more fire-prone and fire adapted regions (Australia, USA and Canada) due to the greater need to control fuel loads (Goldammer and Bruce, 2004). In highly fire-prone regions prescribed burning is integral to sustaining healthy ecosystems (Burrows and McCaw, 2013; Gharun et al., 2017).

In areas where the use of prescribed fire is well established often proactive burn strategies are employed to protect communities and the environment. For example, in Victoria (south-eastern Australia) the location and burn rotational length are predetermined depending on the main management objective (wildfire risk reduction, vegetation management and/or biodiversity) (Burrows and McCaw, 2013). Short rotations (<4-years) are used in areas within a close $(\sim 5 \mathrm{~km})$ radius of human settlements to protect life and assets. Longer rotations are employed in lower risk areas further away from human settlements. The current management policy aims to burn approximately $2000 \mathrm{~km}^{2}$ per year $(8 \%)$ of the forested area to effectively manage fuel loads (Burrows and McCaw, 2013). In highly fire-prone regions such as, Australian Eucalyptus forests and North American tallgrass prairies burn rotations can be as short at 2-3 years, resembling return periods close to a natural wildfire regime (Burrows and McCaw, 2013; Valkó et al., 2014).

In contrast, the use of prescribed burning is prohibited in most or all circumstances in several non-fire prone European countries despite burning being a traditional part of their land management (Valkó et al., 2014). These countries include, Estonia (Liira et al., 2009), Germany (Kahmen et al., 2002), Sweden (Antonsen and Olsson, 2005), Switzerland (Köhler et al., 2005), the Czech Republic, Poland, the Netherlands, Romania, Ukraine, Austria and Greece (Valkó et al., 2014). This has likely resulted from the unpredictable and often negative impacts of uncontrolled burning in unregulated land clearance and vandalism (e.g. Romania, Ukraine, Austria and Greece) in addition to a lack of relevant research and operational expertise (Valkó et al., 2014). 
Prescribed burning is regulated in the UK and it is estimated on average $114 \mathrm{~km}^{2}(0.4-$ $0.6 \%$ of total cover) of upland areas are being burnt each year (Yallop et al., 2006). Evidence suggests the area of land being managed by prescribed burning has increased since the 1940s across the UK as a whole, however, trends are localised with large regional variations (Yallop et al., 2005, 2006; Douglas et al. 2015). In some areas, such as the Borders and Grampian Regions of Scotland, research shows the mean area of $C$. vulgaris burning remained similar between 1940-1988, with burning rates far below the considered optimum (every $>15$ years) (Hester and Sydes, 1992).

The typical length of burn rotations across the UK is also highly variable. It is recommended that burn rotations should not be shorter than a 15-20-year reoccurrence on UK moorland, however, local conditions and vegetation types inevitably alter the appropriate return period (DEFRA, 2007).

The timing of prescribed burning is set by principal legislation and burning practice codes, which differ across the UK (Table 2.1). Despite previous research not recommending any alterations to the existing burn restriction dates (Glaves et al., 2005), opposition is growing within the operational community. In practice, it is argued that these dates do not enable fuel loads to be effectively managed due to the highly variable weather experienced in the UK (Allen et al., 2016; Hope, 2017). Prolonged periods of wet conditions often make it difficult to meet fuel reduction objectives during the current legal burn seasons. The statutory agencies presiding over Howden Moor (Peak District), for example, had to raise the target annual burn area from $7 \%$ to $10 \%$ of the moorland area per year to compensate for a build-up of burnable heather following several years of bad weather during the prescribed burn season (2003-2005) (Allen et al., 2016). 
Table 2.1: Legal prescribed burn seasons with relevant legislation. Adapted from (Worrall et al., 2010a).

\begin{tabular}{c|cll}
\hline Region & Uplands & \multicolumn{1}{c}{ Legislation } & \multicolumn{1}{c}{ Code } \\
\hline England & $1^{\text {st }}$ October - & The Heather and Grass & The Heather and Grass Burning \\
& $15^{\text {th }}$ April & $\begin{array}{l}\text { Burning Code Regulations } \\
\text { (England) 2007 }\end{array}$ & Code (Defra, 2007) \\
Wales & $1^{\text {st }}$ October - & $\begin{array}{l}\text { The Heather and Grass } \\
\text { Burning Code Regulations } \\
\text { (Wales) 2008 }\end{array}$ & $\begin{array}{l}\text { The Heather and Grass Burning } \\
\text { Code for Wales (Welsh }\end{array}$ \\
& $31^{\text {st }}$ March & Assembly Government, 2008) \\
Scotland & $1^{\text {st } \text { October }-}$ & Hill Farming Act 1946 & Muirburn Code (SEERAD, \\
& $30^{\text {th }}$ April & & 2001) \\
Northern & $1^{\text {st }}$ September - & Game Preservation Act 1928. & The Heather and Grass Burning \\
Ireland & $14^{\text {th }}$ April & & Code (Defra, 2007) \\
\hline
\end{tabular}

There is limited data on the national extent, distribution and frequency of burning in the UK uplands. A large proportion of the available mapping studies are locally based using different methodologies making the collation of these resources difficult.

The largest single study of this kind, to date, in the UK by Douglas et al. (2015) used remotely sensed data (MODIS) to map burning for gamebird management across $\mathrm{c} 45,000 \mathrm{~km}^{2}$ of the UK, primarily in Scotland and Northern England. Across this area they detected strip burning in 8551 1-km squares, $43.6 \%$ in England, 27.6\% in Scotland and 2\% in Wales (Douglas et al. 2015). The annual number of burns across the study area increased at a rate of $11 \%$ per year from 2001 to 2011 with this trend accelerating in the most recent years. These results are similar to those estimated by smaller scale studies (e.g. Yallop et al. 2006) and suggest increases in the yearly number of burns are widespread across the UK uplands. These increases are thought to be largely due to the intensification of red grouse management in northern England (2001-2009) (Natural England, 2009). 


\subsection{Water quality}

Water quality is one of the critical issues relating to the impacts of burning on ecosystem services in the UK. It is estimated $70 \%$ of the UK`s freshwater is sourced from upland catchments (Bonn et al., 2009) and this is closely regulated by the European Water Framework Directive (Kallis and Butler, 2001). Outside the UK, many areas also heavily rely on the water provided from upland, particularly forested, catchments including one-third of the world's largest cities (e.g. Los-Angeles, Rio de Janeiro, Tokyo and Sydney) and two-thirds of municipalities in the USA (CHIFM, 2008). For this review, we identified 23 relevant peer-reviewed papers, five agency reports and six relevant peer-reviewed review papers addressing impacts of prescribed fires on water (Supp. Table 2.1). Here the assessment of water quality has been divided into two distinct categories (i) research focusing on dissolved organic carbon (DOC) and water colouration, two closely related and carbon-focused characteristics and (ii) research focusing on other aspects of water chemistry.

Throughout the water quality literature, there are three different types of water that are commonly sampled; runoff water, soil water and stream water. Runoff is the body of water that flows across the land surface in times of reduced infiltration rate or capacity, often sampled using crest-fall traps (Worrall and Adamson, 2008; Clay et al., 2010a). Soil water refers to the water contained, flowing or percolating through the upper layers of soil. Although there is no standardised definition or methodology, soil water is commonly sampled using dipwells up to one meter below the surface (Clay et al., 2010a). Sampling is also conducted on water from directly within a stream system, often $2^{\text {nd }}$ order streams, providing an indicator of the catchment scale impact of burning on water quality (Brown et al., 2013; Ramchunder et al., 2013).

\subsubsection{DOC and water colouration}

DOC is a broad classification for the quantity of organic matter at varying stages of decomposition that is dissolved in aquatic systems, often considered to be organic compounds of $<0.45 \mu \mathrm{m}$ in size (Clay et al., 2009a). Water colour is a measure of the absorbance of water at a given wavelength and refers to the humic component of DOC within a water body (Holden et al., 2012). Elevated DOC and water colouration in water supply catchments can lead to breaches in drinking water standards and have 
health implications as the chlorination of such waters can lead to the production of carcinogenic by-products (Chow et al., 2003). This can have substantial costs implications for water companies and is likely responsible for these parameters becoming dominant foci in the recent literature. DOC can also be a notable part of the carbon lost through freshwater systems, particularly in peatland catchments (Yallop et al., 2010).

Water colouration and DOC concentration research has been conducted using a range of methodologies including laboratory studies (McDonald et al., 1991), plot-scale studies (Clay et al., 2012; Worrall et al., 2013a), catchment-scale studies (Yallop et al., 2008; O’Brien, 2009; Chapman et al., 2010) and modelling studies (Grayson et al., 2008, 2012). The evidence presented from this combination of different approaches suggests, overall, that burning on moorlands can have a significant impact on DOC and water colour but results are highly likely dependant on the scale at which change is assessed (plot or catchment scale) (Yallop and Clutterbuck, 2009; Yallop et al., 2010; Grayson et al., 2012). Yallop et al., (2010) estimated prescribed burning on upland peat habitats resulted in between a 5 to 15 -fold increase in carbon exports as DOC as compared to equivalent unmanaged areas (Yallop et al., 2010). Ramchunder et al., (2013) in a comparison of streams in unburnt (3) and burnt (3) catchments over one year recorded a mean increase in DOC from $14.67 \mathrm{mg} \mathrm{l}^{-1}$ (unburnt) to $29.93 \mathrm{mg} \mathrm{l}^{-}$ ${ }^{1}$ (burnt). It has also been observed that catchments producing the highest colour concentration had been subjected to greater than $40 \%$ of the land surface area being burnt, with less colour production experienced in catchments with lower burn area cover (Grayson et al., 2012).

There are, however, a considerable number of studies that report rather different outcomes (Table 2.2) (O’Brien et al., 2006; Chapman et al., 2010; Clay et al., 2012). Several small-scale plot studies conducted on both soil water and runoff water produced inconsistent evidence with, at most, short-term ( $<1$ year) elevations in water colouration and DOC (Ward et al., 2007; Clay et al., 2009a, 2012). A plot-scale study by Clay et al., (2012) found burning on moorland did not significantly correlate with changes in the concentrations of DOC or water colour in runoff. They did, however, witness a significant correlation (increase) in water colour concentration of soil-water after a burn, only returning to normal conditions after approx. 4-5 years. 
The existing evidence suggests plot-scale and catchment-scale studies are likely to exhibit different responses to burning, with the distinction between the compositions of samples collected using different methods (runoff, soil water and stream water). Runoff and soil water measurements at the plot-scale both only represent individual expressions of catchment water discoloration at a given location. These methodological differences between catchment and plot studies have been proposed to explain the contradictory results (Holden et al., 2012), but definitive evidence of the mechanisms that might explain these differences is still lacking (Grau-Andrés et al., 2019b).

Catchment-scale studies addressing the extent to which changes propagate downstream are highly beneficial to assess the broader impacts of burning on water colour and DOC. It is, however, vitally important when conducting these kinds of studies to ensure any paired "burnt" and "unburnt" catchments are sufficiently comparable to ensure a reliable interpretation of results (Ashby and Heinemeyer, 2019b; 2019b).

A summary of the published outcomes is presented in Table 2.2. 
Table 2.2: Representation of the varying results within the UK literature on the impacts of prescribed burning on DOC and water colouration. Study details in Supp. Table 2.1.

\begin{tabular}{|c|c|c|c|}
\hline Parameter & Increase & No impact & Decrease \\
\hline \multicolumn{4}{|l|}{$\overline{D O C}$} \\
\hline \multirow[t]{4}{*}{ Runoff } & Yallop et al., 2010 & Clay et al., 2009a & \\
\hline & & Clay et al., 2010a & \\
\hline & & Clay et al., 2012 & \\
\hline & & Worrall et al., 2013a & \\
\hline \multirow[t]{5}{*}{ Soil water } & & Clay et al., 2009a & Worrall et al., 2007 \\
\hline & & Clay et al., 2012 & Worrall et al., 2013a \\
\hline & & Ward et al., 2007 & \\
\hline & & Grau-Andrés et al. & \\
\hline & & 2019 & \\
\hline \multirow[t]{3}{*}{ Stream water } & Clutterbuck \& Yallop, 2010 & Brown et al., 2013 & \\
\hline & Yallop \& Clutterbuck, 2009 & & \\
\hline & Ramchunder et al., 2013 & & \\
\hline \multicolumn{4}{|l|}{ Water colour } \\
\hline Runoff & Yallop et al., 2010 & Clay et al., 2012 & Clay et al., 2009a \\
\hline \multirow[t]{2}{*}{ Soil water } & Clay et al., 2012 & Ward et al., 2007 & Clay et al., 2009a \\
\hline & McDonald et al., 1991 & & Worrall et al., 2007 \\
\hline \multirow[t]{5}{*}{ Stream water } & Beharry-Borg et al., 2009 & Chapman et al., 2010 & \\
\hline & Clutterbuck \& Yallop, 2010 & O`Brien et al., 2005 & \\
\hline & Yallop \& Clutterbuck, 2009 & & \\
\hline & Grayson et al., 2008 & & \\
\hline & Grayson et al., 2012 & & \\
\hline
\end{tabular}

Vegetation type present in a burn area is a good example of one of the factors identified as crucial in the production of DOC and the significance of which may have been underestimated or even overlooked by earlier studies. Research into the effects of different vegetation types on DOC concentration in soil and surface water after a burn have shown statistically significant correlations (Armstrong et al., 2012; Beharry-Borg et al., 2009). Semi-natural ecosystems dominated by C. vulgaris (heather) are associated with the highest levels of DOC in comparison to sedge-dominated and mixed vegetation assemblages (Armstrong et al., 2012). This is suggested to be because of their ability to suppress the water table through evapotranspiration. 
Increased water demand by shrubby vegetation (e.g. C. vulgaris) for transpiration leads to greater depth of root systems and declines in the water table (Worrall et al., 2007). This suppression of the water table in addition to Calluna-dominance promoting the creation of peat pipes (natural tunnels/macropores created by root penetration which transport water through the soil/peat) alters the hydrological transport in Callunadominated peatlands by reducing the interaction between ground water, soil water and the water table (Holden, 2005; Miller, 2008; Clutterbuck and Yallop, 2010; Smart et al., 2013).

In addition to investigating vegetation type, cover and structure, an important aim for future research would be to quantify the impacts of a range of other influencing parameters, which are seldom considered, on levels of DOC production in different ecosystems (e.g. Burn severity, extent and properties of surface soils/peats).

It is estimated the mean DOC concentration of freshwater drainage from upland peat catchments has increased by $91 \%$ in the UK between 1988 and 2003 (Evans et al., 2005). Typically, 60-70\% of the variance in DOC concentrations in burnt peatlands over the past two decades are driven by changes in burn activity (Glaves et al., 2013). The combustion of vegetation and subsequent changes in erosional and fluvial processes, particularly on blanket bog and peatlands, are likely significant in altering DOC and water colour production but the exact causality is still not fully understood (Chapman et al., 2010).

More research is needed to investigate the mechanisms controlling the dynamics of DOC and water colouration. It is important to differentiate the changes in DOC and water colour because of burning from the background of increasing DOC concentrations in freshwater drainage evident across the whole of Northern Europe (resulting from several different climatic and atmospheric drivers, notably changes in temperature and sulphur emissions) (Freeman et al., 2001; Evans et al., 2014). Given the uncertainties in the controlling processes, information on historic DOC changes at a given site, for example through palaeolimological reconstruction techniques, could assist both in determining natural references conditions and in identifying drivers (Evans et al., 2005).

Despite the importance of this area of study, there are still ongoing debates on the impacts of prescribed fires on the range of key physical and chemical parameters for 
water quality. The current literature contains many contradictory research findings, likely an indicator not only of the complexity of this area of research but also of the limited number of studies (e.g. Table 2.2). This presents opportunities for further study in the UK and is also cited as an area requiring global attention, with additional studies required in a range of geographic areas and biomes (e.g. tropical South America, Africa, Asia, Australia, boreal regions, temperate rainforests, grasslands and semi-arid savannas) (Bixby et al., 2015a).

\subsubsection{Water Chemistry}

Water chemistry is another important aspect when considering the impacts of burning on freshwater systems. The removal of vegetation and litter cover by burning, the creation of ash and the increased vulnerability of soils to erosional processes often results in elevated deposits of nutrients and metals into stream and ground-water systems (Tucker, 2003a; Bodí et al., 2014; Abraham et al., 2017). Elevations in the concentration of nutrients and metals can have significant effects on water quality with the potential to breach legal regulations and pose a health risk in water supply catchments. Over the last two decades, fires have affected the water supply in major world cities such as, Denver (USA), Sydney, Adelaide and Melbourne (Australia), increasing metal and sediment concentrations to substantially above World Health Organisation drinking water guidelines (Abraham et al., 2017).

Water chemistry studies in the UK are conducted using a range of methods (Table 2.3). Most studies follow either plot-scale or catchment-scale sampling methodologies (Worrall et al., 2010a). At the plot-scale, experimental blocks are used with a combination of dipwells for soil water sampling and crest-fall traps for runoff sampling (Worrall and Adamson, 2008; Clay et al., 2010a). Catchment-scale studies have often employed direct river sampling techniques using continuous sensors with dataloggers and physical water sample extraction for laboratory analysis (Brown et al., 2013; Ramchunder et al., 2013). Studies have also monitored indicator species such as macroinvertebrates as an indirect assessment of stream chemical properties (Brown et al., 2013; Ramchunder et al., 2013). 
Table 2.3: Representation of the varying results presented within the UK literature on the impacts of prescribed burning on water chemistry. $(\mathrm{SSC}=$ Suspended Sediment Concentration, Total $\mathrm{P}=$ Total Phosphorus). For study details see Supp. Table 2.1.

\begin{tabular}{|c|c|c|c|}
\hline & Increase & No impact & Decrease \\
\hline \multicolumn{4}{|l|}{$\begin{array}{l}\text { Stream water / } \\
\text { Runoff }\end{array}$} \\
\hline \multirow[t]{2}{*}{ pH } & Ramchunder et al., 2013 & & Brown et al., 2013 \\
\hline & & & Clay et al., 2010a \\
\hline SSC & Ramchunder et al., 2013 & & \\
\hline Nitrates & Ramchunder et al., 2013 & Brown et al., 2013 & Clay et al., 2010a \\
\hline Calcium & Clay et al., $2010 \mathrm{a}$ & & Brown et al., 2013 \\
\hline Chloride & Ramchunder et al., 2013 & Brown et al., 2013 & \\
\hline Magnesium & & Brown et al., 2013 & Clay et al., $2010 \mathrm{a}$ \\
\hline Sodium & & Brown et al., 2013 & Clay et al., 2010a \\
\hline Sulphate & & Brown et al., 2013 & Ramchunder et al., 2013 \\
\hline \multirow[t]{2}{*}{ Aluminium } & Brown et al., 2013 & & Clay et al., 2010a \\
\hline & Ramchunder et al., 2013 & & \\
\hline Manganese & Brown et al., 2013 & & \\
\hline Iron & Brown et al., 2013 & & \\
\hline Silicon & Brown et al., 2013 & & \\
\hline \multicolumn{4}{|l|}{ Soil water } \\
\hline pH & Clay et al., 2010a & & \\
\hline Nitrates & & Worrall \& Adamson, 2008 & \\
\hline Total P & & & Worrall \& Adamson, 2008 \\
\hline Potassium & Clay et al., 2010a & & \\
\hline \multirow[t]{2}{*}{ Calcium } & & & Clay et al., 2010a \\
\hline & & & Worrall \& Adamson, 2008 \\
\hline Chloride & & & Clay et al., $2010 \mathrm{a}$ \\
\hline Magnesium & & & Worrall \& Adamson, 2008 \\
\hline Sodium & Clay et al., 2010a & & Worrall \& Adamson, 2008 \\
\hline Sulphate & & Worrall \& Adamson, 2008 & \\
\hline \multirow[t]{2}{*}{ Aluminium } & Clay et al., 2010a & & \\
\hline & Worrall \& Adamson, 2008 & & \\
\hline Iron & Clay et al., $2010 \mathrm{a}$ & Worrall \& Adamson, 2008 & \\
\hline
\end{tabular}


The current knowledge suggests after a burn soil water experiences an increase in aluminium $(\mathrm{Al})$, iron $(\mathrm{Fe})$ and sodium $(\mathrm{Na})$ and a decrease in calcium $(\mathrm{Ca})$ and chlorine (Cl) (Worrall and Adamson, 2008; Worrall et al., 2010a) (Table 2.3). Similarly, runoff water has been observed to experience an increase in $\mathrm{Al}$ and Fe following a burn (Brown et al., 2013; Ramchunder et al., 2013). A comparison of the chemical composition of water from 5 streams in unburnt and 5 streams in burnt peatland catchments in northern England by Ramchunder et al., (2013) detected an average increase in $\mathrm{Al}$ from $0.10 \mathrm{mg} \mathrm{l}^{-1}$ (unburnt) to $0.30 \mathrm{mg} \mathrm{1-1}$ (burnt) and increase in $\mathrm{Fe}$ from $0.39 \mathrm{mg} \mathrm{l}^{-1}$ (unburnt) to $26.13 \mathrm{mg} \mathrm{l}^{-1}$ (burnt) over 1 year. The overall findings on water chemistry are, however, based on a limited number of studies, some of which do not entirely agree (Table 2.3). The evidence for the response of other metals (magnesium, potassium, manganese) and nutrients (chloride, phosphates and nitrates) are insufficient to form any reasonable conclusions (Table 2.3). It is again also likely the methodological differences between catchment and plot scale studies could explain the contradictory results across these chemical parameters (Holden et al., 2012).

The occurrence of large-scale catastrophic wildfires is rare in the UK (i.e. extreme severity, large extent) with severe fires only causing an intermittent problem. Despite this, climate change is expected to increase the vulnerability of UK ecosystems to wildfires, and examples of high-impact fires have occurred over the last decade (e.g. Swinley Forest in 2011) (Gazzard et al., 2016).

In regions where they do occur increases in nutrients and metals into stream systems can be substantial, particularly in forested areas (Tecle and Neary, 2015; Nunes et al., 2017). Global incidences of these types of fires demonstrate the potential severity of the impacts of fire on water quality providing useful context for the future of fire impacts in the UK. The Rodeo-Chediski fire in Arizona (USA) 2002, for example, burnt 189,648 ha of forested land in an upland area, resulting in a 4000\% rise in stream peak flow (Gill, 2004; Tecle and Neary, 2015). The fire also produced a 2-month rise in stream phosphorus levels (reaching $39 \mathrm{ml} \mathrm{L}^{-1}$ - Environmental Protection Agency (EPA) drinking water guideline - $0.1 \mathrm{mg} \mathrm{L}^{-1}$ ) and a 5-month rise in iron levels (3000\% above the EPA drinking water guideline) (Tecle and Neary, 2015). These levels are dangerously high and present a major problem for drinking water supplies in the surrounding area. 
There is a lack of data on the impacts of burning on stream chemical properties within the UK and further research is required (Ramchunder et al., 2009; Worrall et al., 2010a). The response of both nutrients and metals in runoff, soil water and stream water following a burn are not well understood and results appear to be highly species specific (Clay et al., 2010a). Worrall and Adamson (2008) suggest the hydrological impacts experienced by burnt catchments dictate the changes in these parameters.

A potential hydrological consequence of burning highlighted in the literature is changes to the source waters affecting the composition of runoff and soil water (Worrall et al., 2010a). Decreases in the depth of the water table, for example by up to $26 \%$ on 10-year burn cycles, can reduce the importance of base-rich ground waters (e.g. $\mathrm{Ca}, \mathrm{Mg}$ ) in soil water, due to changes in evapotranspiration (influenced by vegetation cover and type - see section 3.1) (Worrall et al., 2007; Clay et al., 2009b). Changes at the soil surface from the generation of hydrophobic compounds, intensification of soil crusting and/or the quality and quantity of organic matter available following a burn also leads to a divergence in runoff and soil water composition (Clay et al., 2010a). Increased separation of these two water-transport pathways allows runoff water at the surface to become more dilute with rainwater and its components, whilst soil water under the surface becomes less dilute (Worrall et al., 2010a). Further research is needed to fully understand these underlying mechanisms and to separate the impacts of burning from other factors which can influence water table depth, such as drought.

Several key limitations have been identified in the previous two sub-sections from the lack of mechanistic understanding to the limited number of studies currently available on the impacts of prescribed fire on water quality. The factors influencing the creation and transport of water pollutants because of burn management, for example, appear to be complex and varied. The influence of in-situ vegetation cover (Armstrong et al., 2012), weather, burn regime and hydrological dynamics (Worrall and Adamson, 2008) are also important factors but often not fully considered. The wide range of sampling techniques, time and geographic scales used in the research published thus far is not helpful for directly comparing results. In many cases this limits the ability to draw firm conclusions, highlighting the need for greater standardisation of methodologies across water quality research. 
In addition, the geographic distribution of the research collected on the impacts on water quality is significantly restricted, with over $80 \%$ originating from northern England. Although this region contains a large proportion of the UKs upland moor and peatland areas, it is vital the spatially sensitive nature of these parameters be reflected in the distribution of research. It is widely suggested that all forms of research need to be expanded across the full range of UK ecosystems with interest on water supply catchments (Holden et al., 2012; Glaves et al., 2013; Brown et al., 2015; Davies et al., 2016).

\subsection{Carbon Dynamics}

Prescribed burning affects several aspects of the carbon cycle and the literature provides strong evidence for this (Imeson, 1971; Kinako and Gimingham, 1980; Ward et al., 2007; Allen et al., 2013). Most of the carbon-focused literature has investigated the impacts of burning in peatlands on DOC concentrations, as discussed in section 3. Other key themes identified include carbon sequestration (Garnett et al., 2000; Ward et al., 2007) and carbon storage (Farage et al., 2009; Allen et al., 2013) as well as some more recent attempts to model full carbon budgets (Worrall et al., 2010b). We identified 37 relevant publications on the impacts of burning on carbon dynamics (27 peer-reviewed papers, 4 peer-reviewed review papers, and 6 agency reports).

\subsubsection{Carbon storage}

Burning on peatlands reduces above-ground carbon stocks through the combustion of vegetation (Ward et al., 2007; Glaves et al., 2013). Several studies have attempted to quantify the above-ground carbon loss in peatland ecosystems in the north of England. These studies estimate carbon losses by sampling biomass in selected plots/quadrats and calculating the difference between areas burnt and equivalent unburnt areas in similar C. vulgaris dominated habitats (Ward et al., 2007; Allen et al., 2013). Ward et al., (2007) estimated a $56 \%\left(88 \mathrm{~g} \mathrm{C} \mathrm{m}^{-2}\right)$ reduction in above-ground carbon on a 10year burn cycle for their peatland study area at Moor House (Pennines, North England). It is, however, important to recognise that even if the amount of aboveground carbon reduction can be substantial, this reduction may not be significant in 
relation to total ecosystem carbon storage, as the majority of carbon in peatland ecosystems is stored below-ground (Ward et al., 2007).

Some research has suggested prescribed burning can also reduce the rate of peat accumulation and below-ground carbon storage in comparison to non-burning management (Garnett et al., 2000; Ward et al., 2007; Marrs et al. 2019a). Ward et al., (2007), for example, estimated a loss of $167 \mathrm{~g} \mathrm{C} \mathrm{m}^{-2}$ from the peat surface under regular burning regimes (10-year rotations) in a peatland ecosystem (Moor House, North England). Garnett et al. (2000) also found there was significantly less carbon in the peat formed under a regime containing burning (10-year rotations) in comparison to one that did not include burning (Burnt $=3.1 \pm 0.4 \mathrm{~kg} \mathrm{C} \mathrm{m}^{-2}$ and not burnt $=5.4 \pm 0.6$ $\mathrm{kg} \mathrm{C} \mathrm{m}^{-2}$ ). Marrs et al. (2019a), also in an assessment of carbon sequestration at Moor House (North England), found burning reduced peat accumulation rates by $4.9 \mathrm{~g} \mathrm{~m}^{-2}$ $\mathrm{yr}^{-1}$ per each additional burn, in their sample area, over a 100-year period (unburnt $=$ $\left.123 \mathrm{~g}_{\text {peat }} \mathrm{m}^{-2} \mathrm{yr}^{-1} ; 47 \mathrm{~g} \mathrm{C} \mathrm{m}^{-2} \mathrm{yr}^{-1}\right)$.

The weight of evidence for this conclusion is, however, limited in the UK. Notably, Garnett et al., (2000) acknowledged their study was unable to determine the main influencing processes as the data used was unable to establish the burn history of the peat formed before the study began. Potential financial (funding via DEFRA and the Heather Trust) and non-financial (author affiliation to the Heather Trust, DEFRA and The Game and Wildlife Trust) competing interests, and issues with the broader comparability of study sites have, however, been raised in relation to Marrs et al. (2019a) (Baird et al., 2019; Marrs et al. 2019b).

These results are also at odds with several studies, such as, Clay et al., (2010b) who found burning to significantly decrease the carbon loss from a catchment comparing burnt (117.8 $\left.\mathrm{g} \mathrm{C} \mathrm{m}^{-2} \mathrm{yr}^{-1}\right)$ and unburnt (156.7 $\mathrm{g} \mathrm{C} \mathrm{m}^{-2} \mathrm{yr}^{-1}$ ) catchments. They suggest that burning reduces carbon loss by increasing primary productivity and reducing net respiration of ecosystems. A recent study by Heinemeyer et al. (2018) also concludes all their sampling sites (blanket bogs in Northern England) showed considerable net carbon accumulation during active grouse moor management periods with higher accumulation coinciding with periods of more frequent burning (10-15-year burn rotations). Heinemeyer et al. (2018) suggest charcoal inputs from burning are a crucial factor dictating the impact of fire on peat carbon accumulation. Charcoal can have 
direct and indirect impacts on decomposition processes; namely charcoal production increasing peat bulk density, converting otherwise decomposable carbon into an inert carbon pool, altering peat moisture and possibly negatively impacting soil microbial activity (Heinemeyer et al., 2018). Potential competing interests have also been highlighted here with financial and non-financial author ties to The Moorland Association and The British Association for Shooting and Conservation.

Research from fire-prone ecosystems in the USA have also shown wildfires that lead to organic matter loss in mineral soils (via soil heating) can reduce soil aggregate stability enhancing the vulnerability of soils to post-fire runoff and erosion (Neary et al., 2005); however, direct effects of prescribed fires on organic matter of mineral soils are usually very minor (Santín and Doerr, 2016).

Some studies have attempted to combine these aspects of carbon storage and estimate the total loss of carbon from the peat surface and above-ground vegetation resulting from prescribed burning (Garnett et al., 2001; Ward et al., 2007). Over a 10-year burn rotation in peatland, these studies produced estimates of carbon loss of $25.5 \mathrm{~g} \mathrm{C} \mathrm{m}^{-2}$ $\mathrm{yr}^{-1}$ by Ward et al., (2007) and $73 \mathrm{~g} \mathrm{C} \mathrm{m}^{-2} \mathrm{yr}^{-1}$ by Garnett et al., (2001), both from study areas at Moor House National Nature Reserve, North Pennines. Clearly further studies are required to assess the longer-term impacts of burning on carbon over several burn cycles and in other areas.

\subsubsection{Gaseous exchange}

Research investigating the fluxes of gaseous carbon are vital to parameterise climate change models as well as, to understand the effects of prescribed burning on carbon cycling (Grace, 2004); however, the exchange of gaseous carbon (fluxes of $\mathrm{CO}_{2}$ and $\mathrm{CH}_{4}$ ) at sites managed by prescribed burning has received limited attention within the UK with few studies adding to the body of knowledge (Allen, 1964; Grace, 2004; Ward et al., 2007). Fluxes in $\mathrm{CO}_{2}$ have been shown to be significantly affected by the prolonged use of prescribed burning on peatland ecosystems. Early laboratory experiments simulating heather burning estimate that $61-68 \%$ of original vegetation carbon is released to the atmosphere during combustion (Allen, 1964). Over relatively short burn rotation (10-years) the gross $\mathrm{CO}_{2}$ fluxes of both photosynthesis and respiration have been shown to increase, relative to unburnt treatments. This represents 
an acceleration of carbon processing rates (Ward et al., 2007). Fluxes of this kind are responsive to the vegetation changes attributed to burn management but are also strongly correlated with seasonal changes in climate, particularly temperature (Ward et al., 2007).

\subsubsection{Carbon budgets}

In recent years, considerable attention has turned to estimating complete carbon budgets, mostly using modelling approaches (Farage et al., 2009; Clay et al., 2010b; Worrall et al., 2010b). Clay et al., (2010b) used both fluvial (DOC, particulate organic carbon - POC, excess dissolved $\mathrm{CO}_{2}$ ) and gaseous parameters (Methane, net ecosystem respiration of $\mathrm{CO}_{2}$ and uptake of $\mathrm{CO}_{2}$ by primary productivity) to estimate a carbon budget for the widely researched Trout Beck catchment in the North Pennines. This study found the catchment to be a net source of carbon under all management techniques. 10-year burn rotation plots equated to an average source of $109.6 \mathrm{~g} \mathrm{C} \mathrm{m}^{-2}$ $\mathrm{yr}^{-1}$ and 20-year plots $125.9 \mathrm{~g} \mathrm{C} \mathrm{m}^{-2} \mathrm{yr}^{-1}$ (Clay et al., 2010b). However, burning did significantly decrease the magnitude of the carbon source in comparison to the unburnt plots (average of $156.7 \mathrm{~g} \mathrm{C} \mathrm{m}^{-2} \mathrm{yr}^{-1}$ ). The influence of burn rotational length is evidently a key determinant on the carbon budget.

Worrall et al. (2010b) derived from a meta-analysis of carbon research that prescribed burning is likely not to benefit the carbon budget. Based on the current literature, however, estimating total ecosystem carbon budgets is difficult as the limited number of UK studies leads to large uncertainties and subsequent models will be substantially affected by the differences in the estimates of parameters between studies and sites (Glaves et al., 2013). It is clear, burning affects the processes controlling carbon budgets in peatlands. Moorland management including the use of prescribed burning, however, may not have a substantially detrimental effect on the carbon balance of upland areas if burning is conducted using appropriate fire regimes tailored for the chosen catchment (Farage et al., 2009). It is also important to consider the relatively small loss of carbon from prescribed fires as a necessary and beneficial reduction in fuel load, reducing the probability of a wildfire which would have a more detrimental effect on the carbon budget (McMorrow et al., 2009). 
There are several additional limitations upon the current state of knowledge relating to the carbon dynamics of prescribed burn management. The continued theme of the limited geographic distribution of research across the UK is also an important issue for the assessment of carbon dynamics. Much of the carbon-focused research again originates from the Pennines (North England) which is not directly applicable to UK upland ecosystems, as a whole. More research is therefore, required to extend the geographic distribution of research across a more representative sample of upland ecosystems.

Few studies have directly related differences in burn characteristics (e.g. severity) to the effects on carbon dynamics within the UK context (Glaves et al., 2013). Potentially important aspects of the full carbon budget are also rarely considered in the UK literature, such as the production of pyrogenic carbon (PyC; charcoal) (Worrall et al., $2013 \mathrm{~b}$ ), which is more resistant to degradation than original biomass and lead to longterm carbon sequestration (Santín et al., 2016). Actually, a substantial portion, around $13.5 \%$, of the organic carbon accumulated in northern peatlands during the Holocene may have originated from PyC (Leifeld et al., 2017). Research conducted in Australian Eucalyptus spp. forests has demonstrated a significant increase in PyC in the surface soil $\left(0.4 \mathrm{Mg} \mathrm{ha}^{-1}\right)$ and litter $\left(0.3 \mathrm{Mg} \mathrm{ha}^{-1}\right)$ following prescribed burning (Krishnaraj et al., 2016). To improve the accuracy of carbon budget estimates in UK ecosystems, additional factors such as PyC production must be fully considered in future research.

\subsection{Habitat composition and structure (Biodiversity)}

There are many ways of defining and approaching the topic of biodiversity across the relevant literature but in this review, biodiversity is considered through the broader term of 'habitat composition and structure'. In this review habitat composition and structure (biodiversity) is defined both as a regulator underpinning ecosystem processes and directly as an ecosystem service itself (sensu. Mace et al., 2012). In much the same way as biodiversity, habitat composition and structure can also be considered an indication of the health of a system.

In this section, the impacts of prescribed burning on habitat composition and structure has been split into two distinct categories; the effects on flora (vegetation) and fauna (animals). We identified 33 peer-reviewed papers, 2 peer-reviewed review papers, and 
14 agency reports providing insights into these parameters. The UK uplands contain many vital habitats (EC Annex 1 priority habitats and UK BAP habitats) for both flora and fauna of national and global conservation significance, such as Heather moorland, active Blanket bog, European dry heaths (Tucker, 2003a). The impacts of burning on these habitats is an important discussion but crucially one that must assess the tradeoffs of the use of fire in management.

\subsubsection{Flora}

The use of fire in land management has a range of complex impacts on the local flora from the initial combustion of vegetation during a fire to the redistribution of the balance of competitive advantage and changes in successional stages (Tucker, 2003a; Ward et al., 2007). Much of the regeneration depends on the pre-fire conditions of vegetation, the length of burning rotation and the fire conditions on a given burn day (Tucker, 2003a; Davies et al., 2010). As a result, the responses to fire in the UK uplands are highly variable.

The available literature suggests burning produces an initial period of dominance of graminoid species such as, M. caerulea, Trichophorum cespitosum (L.) Hartm. or Eriophorum vaginatum L. and, at least an initial, decline in dwarf shrub cover and diversity on blanket bog and wet heathland (Marrs et al., 2004; Stewart et al., 2004; Ward et al., 2007). Ward et al., (2007) investigated the long-term impacts of repeat burning on peatland vegetation using the results of a 50-year old field experiment at Moor House (North Pennines). They found burning increased graminoid biomass by $88 \%$ and reduced the biomass of bryophytes by $91 \%$ and shrubs by $51 \%$ in the initial period of regrowth, typically $10-15$ years.

There is also strong evidence that $C$. vulgaris declines during this initial graminoiddominant phase but typically then increases with time (McFerran et al., 1995; Stewart et al., 2005). Bracken fern is also one of the species that can increase in abundance in this early period following vegetation burning (Glaves et al., 2005). Caution must be taken, however, when forming generalisation as impacts will differ on individual circumstances (e.g. habitat type, weather, and burn dynamics). At some locations in the Peak District for example, under favourable conditions, C. vulgaris has been observed to return just one year after a fire event. 
A prominent objective of prescribed burning in UK is to rejuvenate plant species such as $C$. vulgaris (heather). This improves the productivity of grazing pastures and creates a mosaic pattern of $C$. vulgaris stands that increase the capacity of grouse on grouse moors (Tucker, 2003a; Jones, 2005; Chen et al., 2008). As a result, C. vulgaris is perhaps the most commonly cited target species with regards to burn management. Some argue current burn practices reinforce the dominance of $C$. vulgaris creating habitats relatively low in species diversity (McVean and Ratcliffe, 1962; Lindsay, 2010). The presumption that current vegetation type and structure (i.e. at the time of burning) is what is ecologically best and should be maintained is also subject to continued debate (Worrall et al., 2010a).

After burning and the initial decline in C. vulgaris (because of its relatively slow recovery rates), it often increases over a considerable period (15-20-years or longer), dominating particularly in drier sites where the rejuvenation of moss and Sphagnum spp. are inhibited (Ward et al., 2007; Harris et al., 2011a). This regeneration pattern highlights the importance of implementing site-appropriate burn rotational lengths to maintain the graminoid-Calluna balance and prevent loss of peat-forming Sphagnum spp. in areas managed for traditional purposes (Grazing pasture and grouse moors) (Harris et al., 2011b). In general terms, burning too frequently is thought to dramatically reduce $C$. vulgaris cover, damaging the ecosystem and likely leading to conversion to a grassland habitat (Tucker, 2003a). If burn rotations are too long, $C$. vulgaris is likely to dominate at the expense of other species creating a monoculture (Tucker, 2003a).

In other ecosystems elsewhere, for example in North America, Australia and South Africa, overly long burn rotations resulting from fire suppression have been documented to allow the encroachment of woodland species into grassland and savanna habitats in addition to an increased risk of catastrophic wildfires from fuel build-up (Ratajczak et al., 2012; Valkó et al., 2014).

Sphagnum spp. is a group of bryophyte species important to the creation and maintenance of bog and peatland habitats and they are shown to have variable responses to fire (Lee et al., 2013). The variable responses of Sphagnum spp. to burning likely reflects differences in individual burns and species of Sphagnum but it can be said with a reasonable degree of certainty that high Sphagnum cover and 
diversity is characteristic of less-modified and less-disturbed peatland ecosystems (Littlewood et al., 2010; Worrall et al., 2010a; Glaves et al., 2013). Despite this, some species of Sphagnum (e.g. Sphagnum capillifolium) appear capable of recovering relatively rapidly following low-moderate severity fires (Lee et al., 2013; Grau-Andres et al., 2017; Taylor et al., 2017). Lee et al. (2013) also states an open canopy and reduced cover of $C$. vulgaris aids the recolonization and growth of some Sphagnum species post-fire (e.g. S. capillifolium).

There is also evidence from sites outside the UK suggesting that some species of Sphagnum (e.g. S. balticum and S. magellanicum) can recolonize effectively after burning in Sphagnum-dominated peatlands depending on site wetness (i.e. hydrogeological setting) (Sillasoo et al., 2011; Lukenbach et al., 2015). Lukenbach et al. (2015) in a study of post wildfire moss recovery in Alberts boreal peatlands (Canada) do, however, acknowledged that peatlands in late successional stages and those located in areas not well connected to groundwater flow are vulnerable to the detrimental effects of fire on Sphagnum.

The processes dictating the changes in Sphagnum cover require further detailed study in the UK. Current burn policy airs on the side of caution and discourages burning on blanket bogs until there is greater clarity in the literature to recommend otherwise (SEERAD, 2001; DEFRA, 2007; Welsh Government, 2008).

A notable proportion of the current literature associating the declines in particular species to the use of prescribed burning are not directly investigating the impacts of burning and rather making observational correlations in order to explain their results (Worrall et al., 2010a). These types of studies often acknowledge the potential influence of other factors (e.g. overgrazing, pollution and drainage) in these results and are only able to provide anecdotal rather than direct evidence of the impacts of fire. This evidence may still be valuable but must be treated with caution.

To truly justify the use of fire for the purposes of vegetation management more studies need to be conducted directly addressing the benefits/drawbacks of burning in comparison to other techniques (e.g. cutting, layering or grazing) (Figure 2.1) (Lunt et al., 2010). Few studies have focused on habitat composition or biodiversity as a whole and instead monitor the impacts of burning on one species or group of species. 

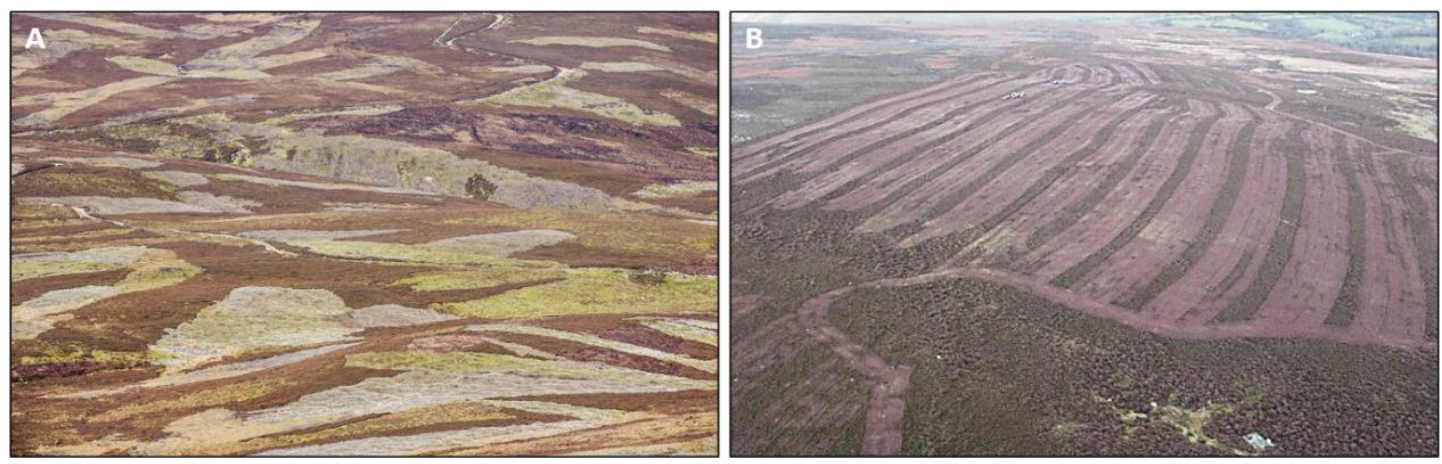

Figure 2.1: Examples of the effects of different management techniques on catchment-scale vegetation structure. $\mathrm{A}=$ Mosaic pattern of prescribed burning created by Grouse moor management in northern Scotland (photo by Peter Cairns). B = Strip pattern of heather harvesting fuel management technique in the Brecon Beacons National Park.

\subsubsection{Fauna}

Fauna, in much the same way as flora, has a range of complex responses to the use of fire in UK upland habitats. The literature captured for this review contains several key areas of focus; birds, aquatic macroinvertebrates and terrestrial invertebrates.

In England, 35\% of the moorland designated with site of special scientific interest (SSSI) status is based on ornithological features (Stroud et al., 2001). There are many breeding bird species in the UK that are globally significant (Hen Harrier - Circus cyaneus, Merlin - Falco columbarius Linnaeus, Golden Plover - Pluvialis apricaria Linnaeus, Lapwing - Vanellus vanellus Linnaeus, Curlew - Numenius arquata Linnaeus, etc.) (Tucker, 2003a). Breeding birds, therefore, constitute a prominent research focus into the effects of prescribed burning on fauna. Grant et al., (2012) noted burning affects birds primarily by the destruction of nests during burns and by changing the habitat (vegetation structure and condition as well as, availability of plant and invertebrate food sources). Most of these important species require short (mean height $<10 \mathrm{~cm}$ ) open areas of vegetation for nesting, hunting and feeding. These behavioural preferences mean species such as Red grouse (Lagopus lagopus scotica), Golden plover, Curlew and Stonechat (Saxicola torquata Linnaeus) appear to benefit from prescribed burning as it provides optimal habitat conditions with varied vegetation ages and heights (Thompson et al., 1995; Tharme et al., 2001; Daplyn et al., 2006; Pearce-Higgins and Grant, 2006). Tharme et al. (2001) estimated densities 
of Curlew and Golden plover were two and five times higher, respectively, on grouse moors as on other moors.

Red grouse are a key species which rotational patch prescribed burning is specifically designed to benefit for the purpose of game shooting on grouse moors (Robertson et al., 2017). As such, the rotational burning of vegetation covered a 34\% larger area of moorland designated as grouse moors in comparison to other moorland areas (Tharme et al., 2001). Brown and Bainbridge (1990) estimate 5-15\% (0.66 and 1.7 million ha) of the UK uplands are managed for grouse shooting. The creation of fresh palatable shoots of C. vulgaris for food and taller/older sections for nesting and shelter is highly beneficial to grouse (Glaves et al., 2013; Calladine et al., 2014; Robertson et al., 2017). As such, Red grouse numbers have been observed to be twice as high on grouse moors than other moorland areas (Tharme et al., 2001).

Other species of bird, however, do not appear to benefit from prescribed burning as they are commonly associated with different sets of vegetation characteristics (Tharme et al., 2001; Daplyn et al., 2006). Whinchat (Saxicola rubetra Linnaeus) are associated with tall or dense vegetation types (Bracken - Pteridium aquilinum (L.) Kuhn) and Skylarks (Alauda arvensis Linnaeus) with grassland vegetation with an open structure incorporating sedge and moss cover, both of which are not promoted by burn management (Pearce-Higgins and Grant, 2006). As a result, they are estimated to be 3.9 and 2.1 times less abundant on grouse moors, respectively (Tharme et al., 2001). Tucker, (2003) also suggests burning is detrimental for Short-eared Owls (Asio flammeus Pontoppidan), Hen Harriers and Merlin if patches of older heath are not retained for nesting purposes.

Many of the bird-focused studies used in the interpretation of the impacts of prescribed burning are not able to differentiate the impacts of burning on the densities of moorland birds from the impacts of other management practices often used simultaneously on grouse moors (e.g. predator control). There is strong evidence of a correlation between the severity of burning and/or predator control on the densities of some species of moorland birds (Smith et al., 2001; Tharme et al., 2001). As it is unclear in these studies what proportion of changes to bird densities are caused by burning alone as opposed to the control/reduction in species that predate these smaller birds (Red Fox - 
Vulpes vulpes Linnaeus, Stoat - Mustela ermine Linnaeus, Cow - Corvus corone Linnaeus, Raptors) their results must be evaluated accordingly.

Few studies directly focus on the impacts of burning on birds and rather focus on the impacts of grouse moor management or vegetation structure in general (Smith et al., 2001; Tharme et al., 2001; Calladine et al., 2014; Douglas et al., 2017). The influence of different aspects of grouse moorland management on bird assemblages were assessed by Littlewood et al., (2019) and found a positive relationship between the abundance of three ground nesting birds (Golden Plover - Pluvialis apricaria Linnaeus, Curlew - Numenius arquata Linnaeus and Common Snipe - Capella gallinago Linnaeus) and predator control. Evidence for the effects of burning on the same three species were, however, weak (Littlewood et al., 2019).

The breeding behaviour of bird species has had a substantial effect on the timings of the legal burn seasons set across the UK (Section 2). Bird species that are ground or vegetation-nesting would be put under significant threat if prescribed burns occurred during nesting seasons. A review by Glaves et al., (2005) compiled a list of the date of first eggs laid by potentially vulnerable species and found that by the end of the current English burn season (15 ${ }^{\text {th }}$ April) 56\% of Lapwing, 39\% of Snipe (Gallinago gallinago Linnaeus), 26\% Stonechat and 24\% of Golden Plover had attempted their first nest. They go on to contextualise this as representing only a 1-2\% chance of first nests being lost to burning and therefore, justifying the current regulatory dates. This potential vulnerability is an example of why prescribed burning needs to be tailored to specific locations, with burning avoiding nesting seasons and locations to reduce potential impacts.

Invertebrates, both aquatic and terrestrial, have been seen to be directly and indirectly influenced by prescribed burning (Usher, 1992; Ramchunder et al., 2013) (MacDonald and Haysom, 1997). In addition to the direct combustion of terrestrial invertebrates during a fire, there is strong evidence to suggest that invertebrate density and community composition are significantly influenced by the changes in vegetation structure (McFerran et al., 1995; Eyre et al., 2003). Typically, species that prefer open ground environments such as, ground beetles and surface-active spiders tend to benefit from burning (Eyre et al., 2003). It is also proposed that species diversity and richness increase in habitats with a range of vegetation at different heights created by rotational 
burning practices (McFerran et al., 1995). Coulson, (1988) suggested that under 'good practice` burning terrestrial invertebrates are relatively effective at recolonizing areas as most are highly mobile. The timescale of recovery for various invertebrate species are seldom studied and have not been accurately quantified but are likely influenced by the burn rotational length, burn severity, vegetation dynamics and prevailing meteorology.

Studies investigating the impacts of burning on aquatic macroinvertebrates are useful for their insights into water quality. However, relatively little is known about the impacts on whole invertebrate assemblages in upland habitats (moorland/peatland) making this a key area for future research. There is currently evidence from a few studies that the use of prescribed burning in peatland catchments correlates with changes in aquatic macroinvertebrate assemblages (diversity and composition) (Brown et al., 2013; Ramchunder et al., 2013). Ramchunder et al., (2013) investigated the difference in macroinvertebrate assemblages over the course of one year between $2^{\text {nd }}$ order streams in unburnt and burnt catchments in northern England and found no statistically significant difference in total abundance (unburnt $=2296$ individuals per $\mathrm{m}^{2}$, burnt $=2182$ indiv. per $\mathrm{m}^{2}$ ). A significant decrease in species richness (unburnt $=$ 32 indiv. per $\mathrm{m}^{2}$, burnt $=20$ indiv. per $\mathrm{m}^{2}$ ) was, however, found. Significant decreases were also reported in taxonomic richness by Brown et al., (2013). Changes in community composition often display a reduction in the density of $\mathrm{pH}$ and sedimentsensitive species such as, Ephemeroptera which presented a significant decrease in abundance (unburnt $=1061$ indiv. per $\mathrm{m}^{2}$, burnt $=271$ indiv. per $\mathrm{m}^{2}$ ) in Ramchunder et al., (2013). Along with an increase in more resilient species such as Chironomidae (unburnt $=568$ indiv. per $\mathrm{m}^{2}$, burnt $=1075$ indiv. per $\mathrm{m}^{2}$; Ramchunder et al., 2013) and Nemouridae (Brown et al., 2013).

In contrast to the assessment of terrestrial invertebrates by Coulson, (1988), aquatic macroinvertebrates may experience longer recovery times in overall diversity if increased sedimentation disrupts feeding processes and fills interstitial spaces, potentially damaging filter feeding invertebrate taxa (Ramchunder et al., 2013).

We found no studies on the impacts of amphibians, reptiles or mammals within UK upland areas. Research from North America and Australia demonstrate prescribed burning has the potential to affect the overall abundance and diversity of species of 
amphibian (Schurbon and Fauth, 2003; Perry et al., 2012), reptiles (Gorissen et al., 2015; Harper et al., 2016) and mammals (Burrows and McCaw, 2013; Lashley et al., 2015; Harper et al., 2016) and this should constitute a key area for future study in the UK.

\subsection{Research gaps and future directions}

\subsubsection{Spatial and temporal distribution of prescribed fire research}

The geographic distribution of research on prescribed fire in the UK is rather limited. Of the work examined here, $46 \%$ originates from northern England with $15 \%$ dedicated to, or including, data from one single catchment, Trout Beck at the Moor House Nature Reserve, in the North Pennines. Overall, England comprises 52\%, Scotland $18 \%$, Wales $3 \%$ and Ireland $1 \%$ of the captured literature. $26 \%$ of publications included multiple focus areas not confined to one specific area. This has likely resulted from the relatively small number of research papers in this field and because a large proportion of UK upland moors are in the north of England.

The research conducted at Moor House has substantially advanced our understanding of prescribed fire, however, it currently provides a bias towards a catchment that may not be representative of the broader context of the UK (Holden et al., 2012). Hence the need to expand all types of relevant research into a more representative distribution of locations and ecosystems remains (Brown et al., 2015; Davies et al., 2016). This should include efforts to quantify and monitor the distribution of the use of prescribed burning across the UK. In this context, the fact that $77 \%$ of relevant work in the UK has been published since 2000 , with $37 \%$ since 2010 is encouraging. The relatively short time period over which an increased focus has been given to prescribed fire impact research, however, has meant that long-term assessments remain rare.

\subsubsection{Ecosystem services}

The body of knowledge on the impacts of burning on water quality has grown rapidly over the past few decades, with research expanding in numerous directions (Section 3). Despite this, further research is needed on all aspects of the impacts of prescribed 
burning on water quality, with a focus on water supply catchments (Brown et al., 2015). Water originating from within the Brecon Beacons National Park for example, supplies $90 \%$ of the drinking water to the wider urban area of Cardiff (Wales) (population of approx. 850,000) making water quality of substantial management importance (BBNPA, 2015). There is a lack of data on the impacts of burning on stream physicochemical properties (Ramchunder et al., 2009). This is perhaps a primary factor in the lack of consensus on the responses of soil and stream hydrology and nutrient cycling to burning. Future research should address this issue with a focus on understanding the underlying mechanisms and the provision of ecosystem services, particularly water quality from peatland systems (Worrall et al., 2010a). Expansion of studies investigating the extent to which water quality changes propagate downstream is also required to provide a wider environmental perspective of the impacts of burning (Brown et al., 2015). It is also important to further contextualise changes in water quality by extending studies investigating stream ecosystems. Relatively little is currently known about changes in the community composition of aquatic indicator species (e.g. macroinvertebrates, macrophytes) because of burning (Glaves et al., 2013; Ramchunder et al., 2013). Further investigation is also required on the effects of differences in the characteristics of burn patches such as size, shape, location, distribution, on water quality, chemistry and flow in peatland watercourses (Glaves et al., 2013).

Regarding impacts of burning on carbon dynamics, a prominent concern is the narrow geographic distribution of current research highlighted above, which limits the applicability of the findings given the diversity of terrain in the UK subjected to prescribed burning. In addition, few studies have directly related differences in burn characteristics, such as burn severity, to the effects on carbon dynamics within the UK (Glaves et al., 2013). This area of research would provide important context also globally to the effects of using prescribed fire in temperate climates. Furthermore, potentially important aspects of the full carbon budget are seldom considered in the UK literature. A lack of information exists on gaseous exchange and the production of char/PyC in the surface soil and litter following prescribed burning (Worrall et al., 2013b; Krishnaraj et al., 2016). Greater consistency in the methods used to monitor and estimate carbon balances would also enable more accurate comparative assessments. 
Regarding habitat composition and structure, research is required across a more representative distribution of UK ecosystems directly focusing on the impacts of fire to separate them from other factors such as grazing, cutting, predator control, habitat type (Smith et al., 2001; Tharme et al., 2001). Including assessments of habitat biodiversity, as opposed to focusing on one or two individual species, are also important to further our understanding. To fully assess the value of fire for the purposes of vegetation management, more studies need to be conducted directly addressing the benefits of burning in comparison to other techniques such as cutting or layering (Lunt et al., 2010). There is also a notable lack of studies addressing the impacts on amphibians, reptiles or mammals within UK upland areas. Future research should progress in these new directions to provide a greater knowledge of ecosystem responses to fire. Research from outside of the UK can provide a useful context in these areas (Schurbon and Fauth, 2003; Perry et al., 2012; Gorissen et al., 2015; Lashley et al., 2015; Harper et al., 2016), but its applicability to the UK needs to be validated.

Cutting across the topic areas summarized above, a more detailed and consistent recording of site vegetation type, structure, composition and condition as well as surface topography and burn characteristic (type, intensity, severity) would substantially enhance the value and comparability of studies (Glaves et al., 2013). It is vital that future research strives to make the differences between the impacts of well managed and controlled uses of fire on ecosystem services in contrast to the impacts of more severe or poorly conducted prescribed burns.

\subsection{Conclusions and Framework for progress}

Both prescribed and wildfires currently play a significant role in shaping ecosystems across the globe (Bixby et al., 2015a). In many fire-prone regions, the use of prescribed burning is well established and integral to sustaining healthy ecosystems and protecting communities from catastrophic wildfires (Burrows and McCaw, 2013). In North America and Australia, for example, a large body of research underpins the effective use of prescribed fire to reduce accumulated biomass, support target species, manage open landscapes and control invasive species (Fuhlendorf and Engle, 2001; Cummings et al., 2007; Ryan et al., 2013; Valkó et al., 2014). In the UK and large 
areas of Europe where fire does not serve such wide social and infrastructural needs, there is growing debate over the use of fire in land management. Opposition continues to question whether its role is an overall benefit. Current fire management practices in the UK uplands are closely regulated and it is estimated only $0.4-0.8 \%$ of upland areas are burnt each year (Yallop et al., 2006) mostly to maximise the productivity of $C$. vulgaris, red grouse and sheep.

The application of burning in the UK uplands has not dramatically changed throughout its modern usage (i.e. last 150 years) despite substantial changes in the environment and economy of the uplands. Taking inspiration from the effective use of prescribed fire in other regions (North America and Australia), the use of fire in the UK does not need to be limited to grouse moor management and agricultural land clearance if it is able to address any other desirable management objective. Habitat-specific research like that carried out in fire-prone regions needs to be conducted in areas relevant to Western Europe's humid temperate environment and different socioeconomic background to fire use to enable the appropriate use of prescribed fire in the UK. Landowners and managers need a greater level of certainty on the advantages and disadvantages of prescribed burning in different habitats, with historic perspectives of burning for biodiversity versus burning for productivity still prevalent.

The length and placement of prescribed burning seasons is an issue in the UK and one which could and should be subject to consideration in the devolved administrations as an easy step towards the better management of fuel loads. Dry springs coupled with an increase in illegal arson during the past decade (particularly in South Wales) have led to significant pressure being put on regional fire services (Jollands et al., 2011). This pressure has led to specialist task forces (specific wildfire response and prescribed burn management training for regional fire services) needing to be established, more equipment (assess to off-road response vehicles and helicopters) being deployed and closer co-operation between relevant agencies (Fire services, environment agencies, land managers and research institutes). More needs to be done to ease the financial and infrastructural strain on fire services resulting from accumulated fuel loads facilitating arson and wildfires (Section 2).

There is a potential blurring of the lines between controlled burns for land management purposes and for the purposes of mitigating the extent, likelihood and impact of illegal 
arson fires. If a consensus emerges where conservation burns in vulnerable ecosystems are more damaging than beneficial to biodiversity, water quality and/or carbon storage, there may remain a need to reduce the fuel load for wildfire prevention by other means until a beneficial cultural change leading to fewer fires by arson and accidental ignitions has been achieved.

Conservation land managers are caught in a paradigm. They maintain valued anthropogenic ecosystems that reflect past cultural and legislative requirements, whilst being uncertain of the long-term ecological resilience of ecosystems in a changing climate, culture and policy environment. Empirical, objective data is lacking in many areas and more needs to be understood about the long-term impacts of burning in addition to a range of other pressures facing upland systems (industrial pollution, acid rain deposition, historic overgrazing, human footfall and shifting weather patterns). When investigating the impacts of relatively long burn rotations (10-20 years) it is crucial that research includes data from the full post-burn recovery period and longerterm studies including more than one rotation are highly beneficial. Achieving this kind of long-term impact monitoring is, however, difficult and for the current knowledge to be significantly advanced more research areas need to be set aside (by National Parks or land owners) and partnerships with academic institutes set up specifically to target long-term research (e.g. Trout Beck, Moor House Nature Reserve).

When evaluating the current body of literature on the impacts of fire and the health and state of ecosystems in the UK it is important to acknowledge a key consideration to frame future progress. The biodiversity that remains at the present day has hung on in response to numerous pressures and it is often evaluated based on what is present now, after considerable human influence, rather than what was there before or what might come in the future. This feature of landscapes in the UK poses a range of open questions relating to what the 'natural' state of a given area is? What land-use type has/is an area intended for and what does a desirable or necessary future state of a chosen landscape look like (Worrall et al., 2010a)? There are perhaps no correct answers to these questions and differing opinions help to fuel the continued debate around the use of prescribed burning in land management (Davies et al., 2016). It is, therefore, imperative that no one group, or opinion be allowed to drive the debate 
around what we want from our landscapes in the future. A collaborative effort incorporating the full range of stakeholders must be prioritised.

Prescribed burning, under a changing climate, could either be a useful land management tool or a highly damaging process if implemented without sufficient impact research. This uncertainty around the impacts of prescribed burning has resulted in the national policy approach primarily focusing on suppressing the occurrence of fire in all forms (e.g. prescribed fire and wildfire) to avoid any potentially detrimental impacts (Gazzard et al., 2016). Although this may be appropriate in a densely populated country, there are considerable dangers around allowing fuel loads to build up. It is well documented in fire-prone regions that allowing fuel to accumulate under policies of suppression leads to increasing vulnerability to severe wildfires (Ryan et al., 2013). If the UK is not able to produce sufficient scientific evidence to inform management, climate predictions and international context suggests wildfires could become a major risk to water supplies, carbon storage and biodiversity. In addition to increasing the already high priority civil risk of wildfires and causing significant financial implications.

Creating and implementing progressive and adaptive management practices, including fire where sufficiently beneficial, supported by robust scientific evidence should be the primary focus of future research and policy (Allen et al., 2016; Davies et al., 2016). 


\section{Chapter 3}

Post-wildfire vegetation recovery in European dwarf-shrub heaths, south-western UK. 


\subsection{Introduction}

European heathlands dominated by the ericaceous shrub Calluna vulgaris (L.) Hull (hereafter $C$. vulgaris) are widespread across the UK and are of high conservation value and national cultural importance due to their traditional socioeconomic use and global rarity (Thompson et al., 1995; Glaves et al., 2013). Despite formerly extending over large areas of Europe, dwarf-shrub heathlands are now mainly confined to the British Isles and coastal regions of western Europe (JNCC, 2008). It is estimated around $25 \%$ of C. vulgaris dominated heathland was lost in England and Wales between 1947 and 1980 and $>25 \%$ of what remains is classified as in unfavourable condition (JNCC, 2019b). These losses in habitat cover and health are thought to result from a number of factors such as changes in fire regimes and grazing pressures, forest planting, nutrient deposition, succession and excessive drainage (García et al., 2013; JNCC, 2019b).

Dwarf-shrub heathlands are primarily semi-natural habitats in the UK and were created as a result of woodland clearance and the exposure of these areas to rotational burning and grazing practices (Thompson et al., 1995). These practices, in the uplands, produce dwarf-shrub dominated, open and structurally diverse heathland habitats designed to best support sheep grazing and the sport shooting industry (e.g. densities of red grouse or red deer) (Tucker, 2003a; Allen et al., 2016). These habitats, therefore, represent plagioclimax communities and due to their fundamental reliance on human intervention to maintain habitat form, they are not self-sustaining (Dodgshon and Almered, 2006). Changes in management practices and fire regimes can, therefore, have significant implications for vegetation community composition and biogeochemical processes. Impacting a range of important ecosystem services such as biodiversity (Littlewood et al., 2010), water quality (Clutterbuck and Yallop, 2010; Holden et al., 2012), carbon storage (Gray and Levy, 2009), provision of food and recreation (Fagúndez, 2013).

Biogeochemical processes in heathlands are generally recognised to be affected by vegetation community composition and more specifically the differences in functional traits of the dominant plant species present (Hooper et al., 2005; De Deyn et al., 2008). Traditional rotational burning practices (i.e. prescribed burning) are designed to have limited impact on community composition and, if conducted correctly in dwarf-shrub 
heathlands, are likely to cause only slight changes in the balance of plant functional types (graminoids vs ericaceous species) and structural profile (shrub age) in the shortto medium-term (DEFRA, 2007; Harris et al., 2011a). Higher severity fires, however, have a much greater capacity to significantly alter vegetation community composition and habitat function due to elevated fuel consumption, and soil surface and belowground heating.

Higher severity fire events in heathland habitats are thought to further differentiate community composition in comparison to lower severity burns (Davies et al., 2010; Grau-Andrés et al., 2019a) with the potential to significantly reduce diversity and recovery rates (Burkle et al., 2015; Kettridge et al., 2015). High to extreme severity fire events usually occur during severe warm and dry conditions. Fires occurring during these conditions have been found capable of killing stems, preventing resprouting, causing serious depletion of seed banks (Legg et al., 1992; Davies et al., 2008a), substantially removing ground moss cover and subsequently increasing erosion rates (Legg et al., 1992), and disrupting carbon accumulation processes (Kettridge et al., 2015).

In dwarf-shrub heathlands fire severity is also thought to be more sensitive to fuel moisture content, and thus drought conditions, than in wetter peatland habitats (GrauAndrés et al., 2018). C. vulgaris-dominated heathland communities may, therefore, be at greater risk of the most severe impacts of wildfires in comparison to wetter habitat types (e.g. peatlands), in the context of future climate changes (Sulwiński et al., 2017; Grau-Andrés et al., 2018). Enhanced seasonality resulting from warmer summer temperature, lower summer rainfall and higher winter rainfall are projected to increase wildfire risk in the UK by between $30-50 \%$ by 2080 with the most pronounced increases occurring in southern England and south Wales (Albertson et al., 2010; Moffat et al., 2012). These climate changes are also likely to reduce the biogeographic area of key species, such as $C$. vulgaris, with altitudinal and latitudinal contraction restricting their range, further impacting heathland communities, particularly in southern England and south Wales (Normand et al., 2009; Moffat et al., 2012; Chambers et al., 2013).

There is, however, relatively limited research specific to the impacts of wildfires on dry heathland vegetation in the UK. The majority of literature focuses on low severity 
and small-scale prescribed and experimental fires in peat-dominated ecosystems, notably in the north of England and in Scotland (Harper et al., 2018). This presents an issue for the creation of effective, site-specific management strategies in dry heathland habitats in areas such as southern UK and comparable regions elsewhere in Europe. Filling the gaps in the spatial and habitat coverage in wildfire vegetation recovery research across the UK, is, therefore, vital for planning and promoting site-specific mitigation and remediation strategies to safeguard ecosystem services (Albertson et al., 2010; Fagúndez, 2013).

This study aimed to assess post-fire vegetation recovery in dwarf-shrub heaths across four sites within the Brecon Beacons National Park, south Wales (UK). This provides insight into post-fire recovery at four time-intervals, $<1,3,7$ and 11-years elapsed time-since-fire, each with a paired long unburnt area where no burning had occurred for at least 25-years. Recovery was then assessed in relation to the difference between each burnt area and its paired unburnt conditions. The overall aims were to (i) determine the impacts of wildfires on vegetation community composition and diversity in dwarf-shrub heaths, (ii) evaluate the degree of recovery at each of the four timeintervals and, (iii) assess the implications of the findings for management practices in this and comparable habitats elsewhere.

\subsection{Materials and Methods}

\subsubsection{Heathland classification}

European dry heathlands (European Habitats Directive Annex I habitat type: H4030) typically occur on freely draining, acidic and often nutrient-poor mineral or shallow organic layered $(<0.5 \mathrm{~m})$ soils and are dominated by ericaceous dwarf-shrubs such as C. vulgaris and Vaccinium myrtillus L. (hereafter V. myrtillus). In the UK, these habitats are typically found in upland areas between the alpine or montane zone (600$750 \mathrm{~m}$ ) and the line-of-enclosure for agricultural land (approximately 250-440 m) (Rodwell, 1991). Dry heathlands encompass a range of National Vegetation Classification (NVC) plant communities and the primary dominant species $(C$. vulgaris) is often found in combination with, for example, gorse (Ulex gallii Planch), bilberry (V. myrtillus) or Erica spp. although other species can be locally important. Twelve NVC types meet the definition of European dry heath including, C. vulgaris - 
Festuca ovina heath (H1), C. vulgaris - Ulex gallii heath (H8), C. vulgaris - Erica cinerea heath (H10) and C. vulgaris - V. myrtillus heath (H12) (JNCC, 2008, 2009, $2019 \mathrm{~b}$ ). In the UK, dry heathlands are now thought to cover $<8000 \mathrm{~km}^{2}$ and are primarily distributed across Scotland, northern England and throughout Wales (JNCC, 2019b).

Several attributes for upland habitats in the Common Standards for Monitoring Guidelines (JNCC, 2009) constitute key habitat features used to assess dry dwarf-shrub heath conditions (H4030). Within the context of wildfire impacts, several of these target attributes provide relevant markers of post-fire recovery and as such are outlined in Table 3.1 (Target conditions) (JNCC, 2009). Contextual information has also been provided on a set of sensitivity criteria, outlining characteristics or features which, if present in dry dwarf-shrub heathland areas, create high sensitivity to further disturbances such as wildfires (Table 3.2) (JNCC, 2009). The target condition requirements (Table 3.1) and sensitivity indicators (Table 3.2) are discussed through this paper in direct relation to fire activity and recovery, however, they are all more broadly applicable to a range of disturbance types (e.g. grazing, air pollution and succession).

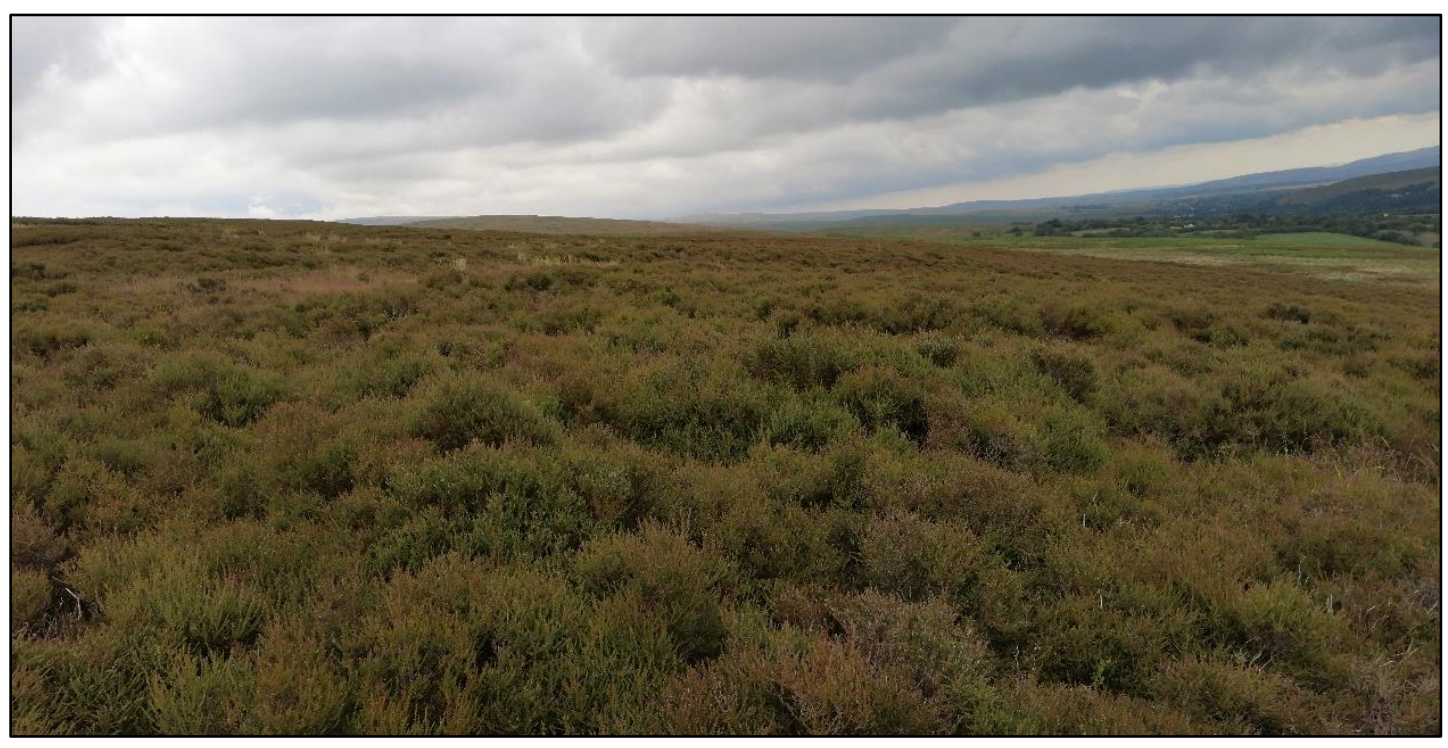

Figure 3.1: Overview of the long unburnt area at Site C. Photograph taken at Mynydd Du Carn Pica, south Wales (July-2018). 
Table 3.1: National Vegetation Classification (NVC) habitat attributes for European dry dwarf-shrub heathland (H4030). Table modified from JNCC Common Standards Monitoring Guidelines for Upland Habitats to display key habitat attributes used in the assessment of habitat condition in European dry dwarf-shrub heaths (JNCC, 2009). Specific focus has been given to aspects that may relate to fire effects and recovery. Dry dwarf-shrub heathland: $C$. vulgaris - V. myrtillus (H12), examined in this study, is included within Annex I type: European dry heathland (H4030).

\begin{tabular}{|c|c|c|}
\hline Attributes & Target Condition & Comments \\
\hline Dwarf-shrub cover & $\begin{array}{l}\text { At least } 25 \% \text { of dwarf-shrub cover } \\
\text { should be group (i) indicator species. } \\
\text { Less than } 50 \% \text { of dwarf-shrub cover } \\
\text { should be group (ii) indicator } \\
\text { species. }\end{array}$ & $\begin{array}{l}\text { Indicator species } \\
\text { (i) C. vulgaris, Erica spp., } \\
\text { Empetrum nigrum and } \\
\text { Vaccinium spp. } \\
\text { (ii) Genista anglica, Myrica } \\
\text { gale, Salix repens and Ulex } \\
\text { gallii. }\end{array}$ \\
\hline Species frequency & $\begin{array}{l}\text { At least one species of moss or non- } \\
\text { crustose lichen must be present. } \\
\text { Less than } 10 \% \text { cover made up of } \\
\text { bracken. } \\
\text { - Less than } 20 \% \text { cover made up of } \\
\text { scattered native trees and scrub. } \\
\text { Less than } 10 \% \text { cover consisting of } \\
\text { Juncus effuses. }\end{array}$ & $\begin{array}{l}\text { Moss and lichen indicator } \\
\text { target must be excluded in } \\
\text { recently burnt areas. }\end{array}$ \\
\hline $\begin{array}{l}\text { Vegetation } \\
\text { disturbance }\end{array}$ & $\begin{array}{l}\text { - All growth phases of } C \text {. vulgaris } \\
\text { should occur throughout the area. } \\
\text { - At least } 10 \% \text { of the } C \text {. vulgaris } \\
\text { should be in the late mature growth } \\
\text { phase. } \\
\text { - Should be no signs of recent burning } \\
\text { within 'sensitive areas'. }\end{array}$ & $\begin{array}{l}\text { Burning should not have } \\
\text { entered further than } 25 \mathrm{~m} \\
\text { inside the given habitat, or it } \\
\text { is considered damaging. }\end{array}$ \\
\hline Physical structure & $\begin{array}{l}\text { - Less than } 10 \% \text { of ground cover } \\
\text { should be disturbed bare ground*. }\end{array}$ & $\begin{array}{l}\text { Excluding recently burnt } \\
\text { ground. } \\
\text { *Emphasis is on disturbed } \\
\text { rather than bare. Substrate } \\
\text { may be covered but only by } \\
\text { an algal mat. Surface must } \\
\text { not be broken and/or } \\
\text { imprinted by hoof marks, } \\
\text { footprints or vehicle tracks. }\end{array}$ \\
\hline
\end{tabular}


Table 3.2: National Vegetation Classification (NVC) disturbance sensitivity indicators for European dry dwarf-shrub heathland (H4030). Table taken from JNCC Common Standards Monitoring Guidelines for Upland Habitats to display key area sensitivity indicators highlighting features that, if present, significantly increase area sensitivity to further disturbances. Dry dwarf-shrub heathland: $C$. vulgaris - V. myrtillus (H12), examined in this study, is included within Annex I type: European dry heathland (H4030).

\section{Area disturbance sensitivity indicators}

(a) Vegetation severely wind-clipped, mostly forming a mat less than $10 \mathrm{~cm}$ thick.

(b) Areas of thin soils (>5 cm depth).

(c) Hill slopes greater than $26^{\circ}$ and all sides of gullies

(d) Ground with abundant Sphagnum spp., liverworts and/or lichen cover.

(e) Areas of noticeably uneven structure at a spatial scale of $1 \mathrm{~m}^{2}$ or less. Unevenness (e.g. commonly found in old heather stands) will relate to distinct, often large, spreading dwarf-shrub bushes. Dwarf-shrub canopy will not be completely continuous. Layering likely to be present and may be common.

(g) Areas with hagging or erosion gullies, and within 5-10 meters of a watercourse.

\subsubsection{Study design and site selection}

Habitat type (vegetation cover) data for the Brecon Beacons National Park, and site visits, were used to identify upland areas complying with the following physical criteria: dry dwarf-shrub heath (containing sections of National Vegetation Class (NVC) H12 - Calluna vulgaris - Vaccinium myrtillus habitat) (JNCC, 2009) where $C$. vulgaris is a keystone species, elevation (300-550m), topography (containing plateaued sections, $<10^{\circ}$ slope), low grazing pressure (approx. $<1 \mathrm{ha}^{-1}$ year $^{-1}$ ), recreational walking pressure (low) and soil type (acid upland soils with moderate to high surface carbon content) (Cranfield University, 2018; UK Soil Observatory, 2018). This information was then overlaid with wildfire data derived from National Park Authority burn map records and archived Landsat 1-8 and Sentinel 2 imagery (accessed via USGS LandsatLook) to locate areas which have experienced wildfires $\left(>1 \mathrm{~km}^{2}\right.$ ) over the last decade (and not burnt again since). 
Combining this information resulted in a set of four burnt areas being chosen for inclusion in this study with a post-fire recovery time of <1-year (Site A), 3-years (Site B), 7-years (Site C) and 11-years (Site D) (Figure 3.2; Table 3.3). The same selection criteria were then used to locate long unburnt areas at each site, in close proximity to each burnt area, but not directly affected by fire for a minimum of 25-years. When locating each long unburnt area, particular care was taken to assess why a given fire may have terminated where it did (e.g. topography, habitat type, obstruction or via human extinguishing) to ensure the selection of sufficiently comparable unburnt areas. Each long unburnt area was located as close as possible to its paired burnt area whilst ensuring this did not represent a substantial change in conditions (e.g. vegetation composition or soil type) (Supp. Figure 3.1-3.4).

The combination of burnt and long unburnt areas within each site enabled burnt area vegetation to be assessed against a closely located unburnt assemblage. Recovery was then able to be assessed in relation to the time taken to return to unburnt conditions within each site. These paired burnt and unburnt areas were deemed sufficiently comparable for use in this study as a result of their compliance with the chosen selection criteria (e.g. similar elevation, topography, soil type and grazing and recreational pressure). Statistical analyses also suggest there are no significant differences when comparing between control unburnt area diversity ( $\mathrm{S}-\mathrm{W}$ diversity) at all sites, or between vegetation community composition (derived from species occurrence and cover data) at Site A, B and C. The long unburnt area at Site D did however significantly differ in community composition from the long unburnt areas at Sites A, B and C (see subsection 3.2.4).

Weather records from a monitoring station in the central Brecon Beacons (NGR = 2877E, 2261N; Altitude $331 \mathrm{~m})$ indicated this area's annual mean (2000-2018) daily temperature to be between $8-9^{\circ} \mathrm{C}$, mean daily high summer temperatures of $18-19^{\circ} \mathrm{C}$, mean daily low winter temperature $1-4^{\circ} \mathrm{C}$ and mean annual precipitation was between 1030 and $1696 \mathrm{~mm}$. The underlying geology of the sites surveyed here are primarily sandstone formations ranging from South Wales lower coal measures sandstone (Sites B and C) to Twrch formation sandstone (Site D) and Senni formation sandstone (Site A) (British Geological Survey, 2018). 


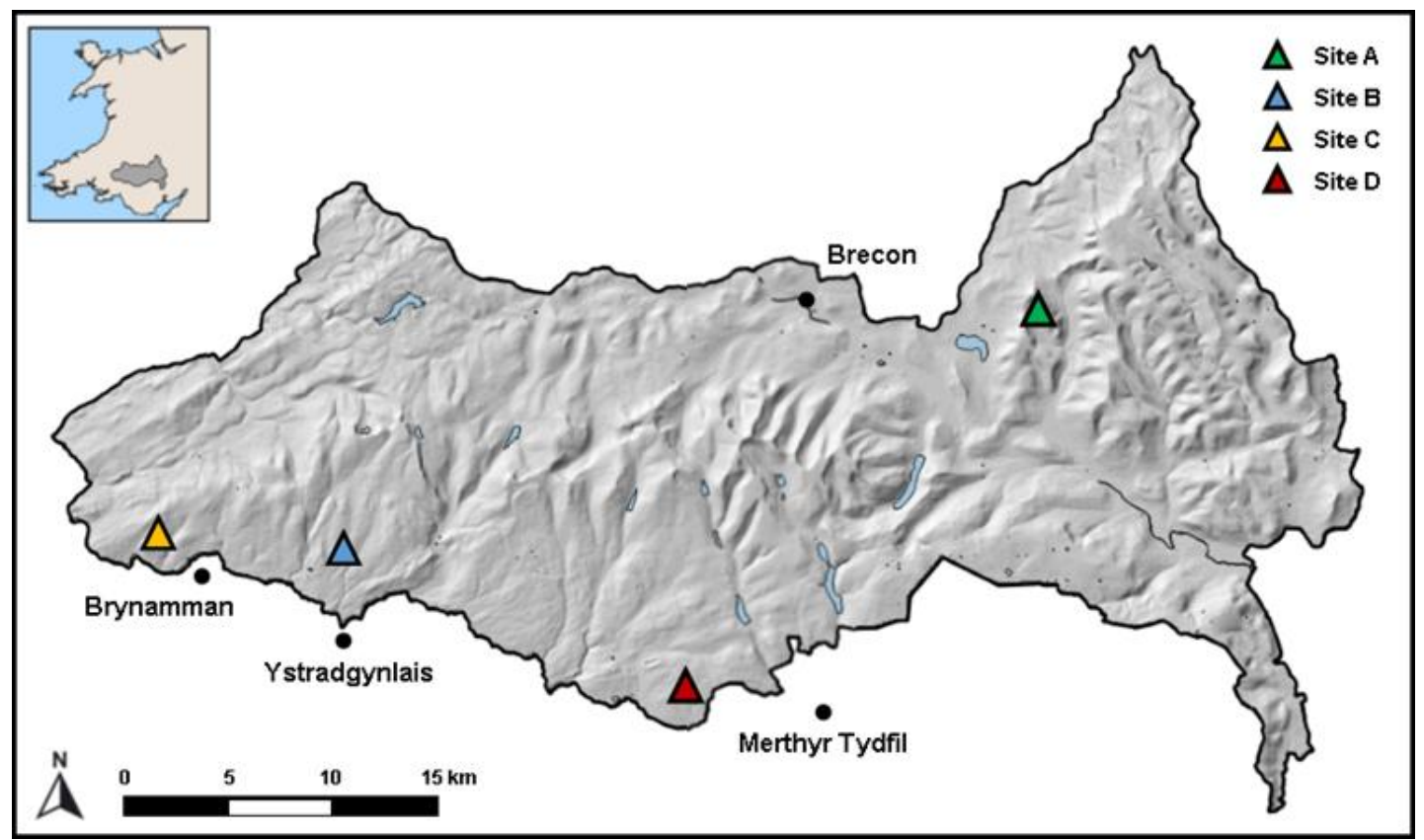

Figure 3.2: Locations of the four sampling sites used in this study within the Brecon Beacons National Park (S. Wales). See Supplementary Material Figure 3.1-3.4 for further detail.

\subsubsection{Fire weather conditions}

Fire severity could not be directly monitored for each fire event within this space-fortime substitution methodology. To address this, estimates of burn conditions and fire behaviour have been calculated for each of the four fire events to help assess their comparability and to contextualise subsequent differences in vegetation dynamics. To conduct these analyses a component of the Canadian Forest Fire Danger Rating System (CFFDRS) was used to produce estimates of (De Groot, 1998; De Jong, 2016):

- Fine fuel moisture content (FFMC) - a numerical rating for the moisture content of the surface litter layer (including mosses and other fine fuels).

- Duff moisture code (DMC) - indicates the moisture content of the upper-most loosely compacted organic layer (approx. $<10 \mathrm{~cm}$ depth).

- Drought code (DC) - indicates the moisture content in the deeper more compact organic matter layers (approx. 10-20 cm depth).

- Initial spread rate (ISI) - indicates the expected rate of fire spread using a combination of FFMC and wind speed.

- Fire weather index values (FWI) - a numerical rating for the fire frontal intensity estimated by combining the ISI with a weighted combination of DMC and DC. 
FWI provides a good general indicator of overall fire danger conditions (i.e. potential fire severity).

Full analytical details are provided in subsection 3.2.5.

These estimates suggest burn conditions were relatively similar for each of the four fire events particularly in relation to FFMC, a crucial determinant of burn severity, and FWI, an important proxy for wildfire risk (Table 3.3). Conditions were, however, considerably drier during the 2018 fire event with elevated DMC and DC in comparison to the other fires (Table 3.3). Vegetation burn severity and combustion completeness are, therefore, likely to have been higher during the 2018 fire (Site A).

This information coupled with the almost total removal of vegetative cover, but limited combustion of topsoil in most areas following the 2018 fire (Site A), suggests these fire events were likely of moderate to high vegetation burn severity but low soil burn severity. A systematic guide to interpreting burn conditions using the CFFDRS, based on fires in Alaskan forests, suggests continuous fire spread begins to occur at FFMC $>80$ but extreme fire behaviour generally only occurs at FFMC >92, DMC >60, DC $>300$ and FWI >25 (Alexander and Coles 2001). It is also thought the duff layer is unlikely to experience prolonged combustion at DMC $<20$, with considerable combustion not likely until DMC >40 (Alexander and Coles 2001; Davies et al. 2013). These thresholds have been found to be broadly comparable to UK heathland habitats (Lawson et al. 1997; Davies et al. 2013; Davies and Legg, 2016).

It is, however, evident the ability of these index values to predict or forecast fire risk and severity are variable between regions, times of year and for different habitat types (Davies and Legg 2016). These results, therefore, need to be treated with a degree of caution and used only as a 'best possible estimate' and means of qualitative comparison within this study, as opposed to a depiction of actual burn conditions.

Pre-fire above-ground fuel loads were estimated to be between $1.5-2.2 \mathrm{~kg} \mathrm{~m}^{-2}$ across the sites using the vegetation data collected from the control long unburnt areas (e.g. mature stands with average C. vulgaris cover of $64 \%$ and height $70 \mathrm{~cm}$ ) and information from studies in similar C. vulgaris dominated habitat types (Figure 3.1) (Davies, et al. 2008, 2009; Grau-Andrés et al. 2018). 
Table 3.3: Detailed site descriptions and wildfire burn conditions. Burn conditions include estimates of: fine fuel moisture content (FFMC), duff moisture code (DMC), drought code (DC), initial spread rate (ISI) and fire weather index values (FWI). Soil organic depth average (standard deviation), estimated using field rod depth measurements. Vegetation classification and area health are based on a set of habitat-specific criteria outlined in Table 3.1 and Table 3.2. The following abbreviations have been assigned to the key mandatory requirement or sensitivity indicators: USS $=$ Uneven stand structure; GSL $=$ Growth stages limited (not all growth stages present); LIS = Limited indicator species present; DLM = Disturbed late mature growth (JNCC, 2009).

\begin{tabular}{|c|c|c|c|c|}
\hline & & Burn conditions & $\begin{array}{l}\text { Organic soil depth } \\
\text { average }(\mathrm{cm})\end{array}$ & $\begin{array}{l}\text { Vegetation } \\
\text { classification }\end{array}$ \\
\hline \multirow[t]{2}{*}{ 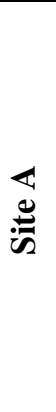 } & $\frac{\vec{d}}{\stackrel{\vec{d}}{v}}$ & $\begin{array}{ll}\text { - } & \text { Burned July } 2018 \\
\text { - } & \text { FFMC: } 85.5 \\
\text { - } & \text { DMC: } 35.7 \\
\text { - } & \text { DC: } 212.7 \\
\text { - } & \text { ISI: } 4.2 \\
\text { - } & \text { FWI: } 8.6\end{array}$ & $30(9.5)$ & $\begin{array}{ll}\text { - } & \text { LIS } \\
\text { - } & \text { GLS }\end{array}$ \\
\hline & $\begin{array}{l}\vec{E} \\
\text { हे } \\
\text { है }\end{array}$ & Unburnt for $>25$ years & $40(6)$ & $\begin{array}{lc}\text { NVC H12 } \\
\bullet \quad \text { USS } \\
-\quad \text { GSL }\end{array}$ \\
\hline \multirow[t]{2}{*}{ 里 } & 岂 & $\begin{array}{ll}- & \text { Burned April } 2015 \\
\text { - } & \text { FFMC: } 86.9 \\
\text { - } & \text { DMC: } 16.2 \\
\text { - } & \text { DC: } 39.3 \\
\text { - } & \text { ISI: } 5.6 \\
\text { - } & \text { FWI: } 7.8\end{array}$ & $35(10.3)$ & $\begin{array}{ll}\text { - } & \text { LIS } \\
\text { - } & \text { GLS }\end{array}$ \\
\hline & 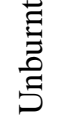 & Unburnt for $>25$ years & $41(11)$ & $\begin{array}{l}\text { NVC H12 } \\
\bullet \quad \text { USS }\end{array}$ \\
\hline \multirow[t]{2}{*}{$\begin{array}{l}\text { U } \\
\text { 㻤 }\end{array}$} & 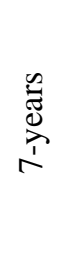 & $\begin{array}{ll}\text { - } & \text { Burned April } 2011 \\
\text { - } & \text { FFMC: } 88.8 \\
\text { - } & \text { DMC: } 19.7 \\
\text { - } & \text { DC: } 58.7 \\
\text { - } & \text { ISI: } 5.9 \\
\text { - } & \text { FWI: } 9.6\end{array}$ & $28(12)$ & $\begin{array}{l}\text { NVC H12 } \\
-\quad \text { DLM }\end{array}$ \\
\hline & $\begin{array}{l}\vec{E} \\
\text { है } \\
\text { है }\end{array}$ & Unburnt for $>25$ years & $21(3.4)$ & $\begin{array}{l}\text { NVC H12 } \\
\bullet \quad \text { USS }\end{array}$ \\
\hline \multirow[t]{2}{*}{ 里 } & 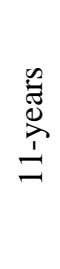 & $\begin{array}{ll}\text { - } & \text { Burned April } 2007 \\
\text { - } & \text { FFMC: } 86.7 \\
\text { - } & \text { DMC: } 16.8 \\
\text { - } & \text { DC: } 64.1 \\
\text { - } & \text { ISI: } 5.4 \\
& \text { FWI: } 8.5\end{array}$ & $42(10.8)$ & NVC H12 \\
\hline & 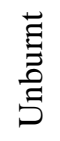 & Unburnt for $>25$ years & $51(7.3)$ & $\begin{array}{l}\text { NVC H12 } \\
-\quad \text { USS } \\
-\quad \text { GSL }\end{array}$ \\
\hline
\end{tabular}




\subsubsection{Vegetation surveys}

Vegetation surveys were conducted in each burnt area (elapsed time since burning, $<1$, 5, 7 and 11-years) and the four paired long unburnt areas (>25-years unburnt) (Figure 3.2; Figure 3.3). They were conducted using a random quadrat $\left(1 \mathrm{~m}^{2}\right)$ sampling method at each site within a chosen $100 \times 100 \mathrm{~m}$ section (fitting the original selection criteria) (Harris et al., 2011a; Whitehead and Baines, 2018; Grau-Andrés et al., 2019a). In each burn area, the sampling location was located towards the centre of each burnt area. Little is known about the diversity and structure of edges created by wildfires, however, it is relatively well established that edge effects created by other factors (e.g. cutting, agriculture, disease, topography) can cause notable abiotic and biotic differences in plant communities as a result of, for example, changes in light, temperature, moisture and wind (Harper et al., 2004; Ries et al., 2004). These edges were, therefore, excluded to avoid possible edge effects and their potential variation (Braithwaite and Mallik, 2012).

Surveys were carried out in 24 quadrats per site (12 in each burnt area +12 in each long unburnt) (96 total). The following was recorded within each quadrat; (i) identification of all flora to species level (if flora was significantly damaged, dry or grazed and identification to species level was not possible, it was recorded as its broad functional group, e.g. feather moss $\mathrm{n} / \mathrm{a}$ or lichen $\mathrm{n} / \mathrm{a}$ ) (ii) percentage cover of each species, estimated visually within a $1 \mathrm{~m}^{2}$ quadrat (iii) maximum height of each species, measured using a meter rule (iv) overall sward height, estimated using a meter rule (v) percentage of exposed ground, estimated visually within a $1 \mathrm{~m}^{2}$ quadrat and (vi) notation of any evidence of additional disturbance (grazing or disease). Three depth measurements were also taken, using a standard soil depth probe, within each of the vegetation survey quadrats to assess the vertical extent of the organic soil profile (Table 3.3). 


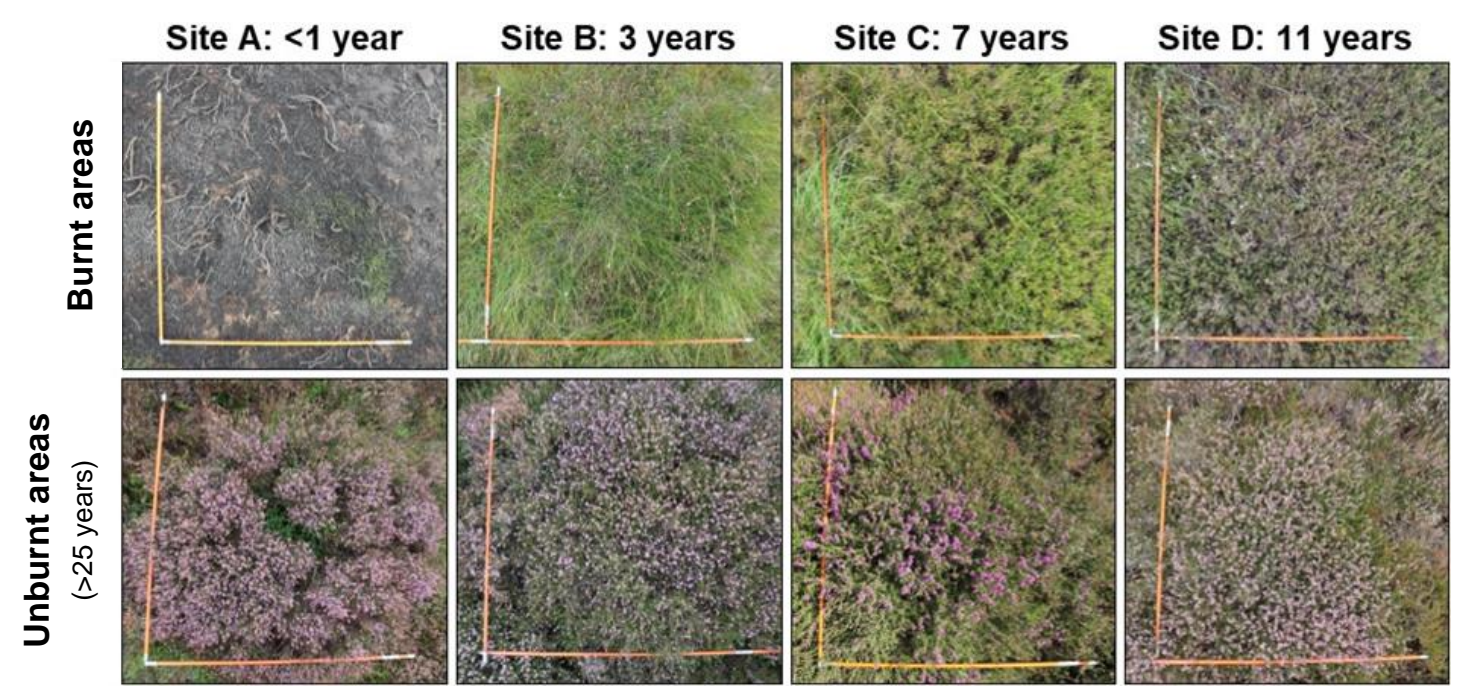

Figure 3.3: Example survey plots from each sampling area. Photographs were taken of $1 \mathrm{~m}^{2}$ survey quadrats in late spring/early summer (May-June 2018). Burnt areas (top) running from $<1$-year to 11-years post-fire (left to right) and the paired long unburnt area for each site directly below (all $>25$ years post-fire).

\subsubsection{Statistical analysis}

Fire weather index values were calculated using the "cffdrs" package in $\mathrm{R}$ version 4.0.2. (Wang et al. 2017). This package enables the calculation of the two main components of the Canadian Forest Fire Danger Rating System (CFFDRS) (Van Wagner and Pickett, 1985), the Fire Weather Index (FWI) System and the Fire Behaviour Prediction (FBP) System. The analyses conducted here focused on the calculation of five of the components produced by the FWI System (Van Wagner, 1987), three fuel moisture codes: Fire Fuel Moisture Code (FFMC), Duff Moisture Code (DMC) and Drought Moisture Code (DC), and two fire behaviour indexes; Initial Spread Index (ISI) and Fire Weather Index (FWI) (Table 3.3).

To calculate these code and indices values the FWI System (using function "fwi") required daily noon weather observation data: temperature $\left({ }^{\circ} \mathrm{C}\right)$, relative humidity $(\%)$, wind speed $(\mathrm{km} / \mathrm{h})$ and 24-hour rainfall $(\mathrm{mm})$ from a closely located monitoring station. The data used here was provided by the Met Office from a monitoring station in the northern Brecon Beacons (Sennybridge: NGR 2894E 2417N, Altitude 407 metres). In addition to the latitude and longitude of the monitoring station to assess whether day length adjustments are required to correctly parameterise the "fwi" function. To calculate the moisture code values accurately 3 -months of daily weather 
data were provided prior to each individual fire event. Moisture code values are cumulative, i.e. reliant on the previous days moisture values, and sufficient data is, therefore, required to ensure output values are unaffected by the initial default fuel moisture values used by the "fwi" function (e.g. FFMC=85, DMC=6, DC=15).

The CFFDRS provides a globally applicable means of assessing fire weather conditions and is widely used as a tool in fire management, alert systems and active fire growth and intensity predictions (Lawson and Armitage, 2008; de Jong et al. 2016; Wang et al. 2017). This method also provides a standardised means of contextualising burn conditions and fire severity in studies assessing historic fire events such as this (Davies and Legg, 2016; Davies et al. 2013).

Vegetation community composition and diversity were analysed using the "vegan" package in $\mathrm{R}$ version 4.0.2., unless stated otherwise (Dixon, 2003; Oksanen et al., 2019).

Occurrence and percentage cover values for all species in each quadrat and area were used to calculate an overall diversity value for each quadrat and area using the Shannon-Wiener index (S-W) (function "diversity", Index = "Shannon"). The S-W function is employed here as a simple measure of diversity which incorporates both community species richness, e.g. the number of species present, as well as species abundance, defined by cover, (community evenness) information (Hill, 1973; Heip et al., 1998). This is vital for assessing post-fire disturbance recovery largely dictated by the development and interaction between key species across these relatively speciespoor heathland sites.

Linear regression (function " $\mathrm{lm}$ ") was then used to assess the interaction between 'site' (Site A, B, C, D) and 'status' ('burnt' or 'long unburnt') with diversity (S-W). Two primary questions were being assessed through this analysis; i) do burnt and unburnt area diversity differ between each site (e.g. Site A burnt vs Site B burnt) and ii) do burnt and unburnt area diversity different within each site (e.g. Site A burnt vs Site A unburnt). To address these questions, a nested model design was chosen to account for possible pseudoreplication within the analyses. This is required as only one sampling area is provided per burnt age (Site A: <1-year, Site B: 3-years, Site C: 7-years and Site D: 11-years post-fire), and individual quadrats within each sampling area do not 
represent independent observations (all within a single fire event). The treatment term 'status' (burnt or long unburnt) is, therefore, confounded with 'site'.

Model residuals were subsequently checked visually to ensure normality assumption had been met (using scatter and Q-Q plots). A Shapiro-Wilks test (function "shapiro.test" - "MASS" package) was also conducted to numerically assess residual normality. Residual distribution was assumed normal based on resulted p values $>0.05$. In addition, a Bonferroni Outlier Test (function "outlierTest" - "car" package) was conducted to determine if there were any outlying observations within the model regression which might suggest miscoding, invalid data or incorrect model conceptualisation (Weisberg, 2014; Fox \& Weisberg, 2019b). This test uses the t distribution to assess if the models highest studentised residual value's outlier status is statistically different from the other observations in the model. No studentised residual outliers were identified with Bonferroni p-values $<0.05$.

To explore the interaction between diversity and status:site identified within the model, an analysis of variance table was produced for the model residuals to identify the level of interaction significance (i.e. extract test statistics and p-values). The function "Anova" ("car" package) was used to conduct a type III variance test (Fox \& Weisberg, 2019b). Type III tests, in contrast to the more traditional type I or II, are conducted in light of interaction terms (e.g. nesting) as well as all effects within the model. This is crucial for maintaining consistency with the nested design and to account for repeated measures data (Hand \& Taylor, 1987; Fox, 2016). Post-hoc pairwise tests were then conducted to pinpoint specific differences in within-group heterogeneity (extent of change in community composition within an environment; Jost, 2007). To do this, the "emmeans" function was used ("emmeans" package) as it allows testing within a nested structure, whilst automatically correcting for multiple comparisons (Searle et al. 1980; Lenth et al. 2018). Correction was conducted using the Tukey method.

Non-metric multi-dimensional scaling (NMDS) was conducted in R using the function "metaMDS" to visualise changes in vegetation community composition (Kruskal, 1964). NMDS is commonly regarded as the most robust unconstrained ordination method in community ecology and uses random starts to attempt to find a stable scaling solution (Minchin, 1987; Faith, 1987). No data transformation was conducted on the 
species abundance data prior to analysis. By default, the "metaMDS" function performs Wisconsin double standardisation, additional square root transformation is also applied if values are particularly large, this is sufficient for treating data of this kind (Bray and Crutis, 1957; Oksanen, 1983). Standardisation of community ecology data in this way focuses the subsequent analyses on relative change in species by neutralising the influence of overall species abundance (Jackson, 1997).

In order to perform any distance-based multivariate analyses data must also be converted into a dissimilarity-matrix. Within the "metaMDS" function the "bray" distance metric was chosen as it often provides the best results when using community ecology data such as the species abundance data used here (Bray and Curtis, 1957; Faith, 1987). Scree plots of stress against number of dimensions indicated 3-D NMDS solutions were the best compromise between interpretational ease and ordination accuracy. A solution was found after 59 tries with a final NMDS stress value was 1.5 which is considered to indicate an adequate representation of the community composition (McCune et al., 2002).

The scaled NMDS results were then fitted to vectors (function = "envifit"; perm =999) to assess the significance of the variables using permutation tests. This enables a set of scores to be assigned to each species which when plotted produce arrows showing the direction, gradient and degree of correlation between species and sites. NMDS was used as it optimises the goodness of fit in relation to the scaling of data points (Kruskal, 1964; Milligan et al., 2018; Grau-Andrés et al., 2019a; Noble et al., 2019). Ordination non-metric goodness of fit here was $\mathrm{r}^{2}=0.975$ (linear fit: $\mathrm{r}^{2}=0.851$ ).

In addition, permutational multivariate analysis of variance (permanova) was used to test for differences in community composition using the "adonis" function in "vegan" (Anderson, 2001). For consistency, permutations were constrained to account for the nested structure of the data, using the "strada" argument, so permutations only occur within and not between sampling sites (Site A, B, C, D). The extent of change in community composition was then investigated by calculating pairwise differences in within-group heterogeneity, using the function "betadisper" and the Tukey-HSD method (Anderson, 2006). 


\subsection{Results}

Throughout the study, 36 different species were recorded (Supp. Table 3.1). Of these species, 11 were found exclusively in the long unburnt sampling areas, such as the tree species, Quercus robur L. and Sorbus aucuparia L.; the mosses, Sphagnum fallax H.Klinggr, Sphagnum palustre L.; and the lichen, Cladonia chlorophaea L.. Six species were exclusively found within the burnt sampling areas, such as the graminoids; Juncus acutiflorus Ehrh. ex Hoffm., and Juncus squarrosus L., and mosses; Campylopus introflexus (Hedw.) Brid., and Sphagnum tenellum (Brid.) Brid. The additional 19 species including, the ericaceous shrubs $C$. vulgaris, and $V$. myrtillus, and the graminoid species Agrostis capillaris L. and Eriophorum vaginatum L. were found in at least one long unburnt and one burnt area. The most commonly occurring species were the dwarf-shrub species: $C$. vulgaris and V. myrtillus and the moss species Hypnum jutlandicum Holmen \& E.Warncke which were present at all sampling areas. Full species occurrence and cover data are provided in Supp. Table 3.1. A summative version has been provided in Table 3.4.

Table 3.4: Average vegetation cover $(\%)$ and height $(\mathrm{cm})$ for key species and functional groups at each sampling area. Cover and height data represent combined canopy and ground layer survey results averaged across all quadrates for each site. Overall, Shannon-Wiener (SW) diversity index values are provided for each area with standard deviation values.

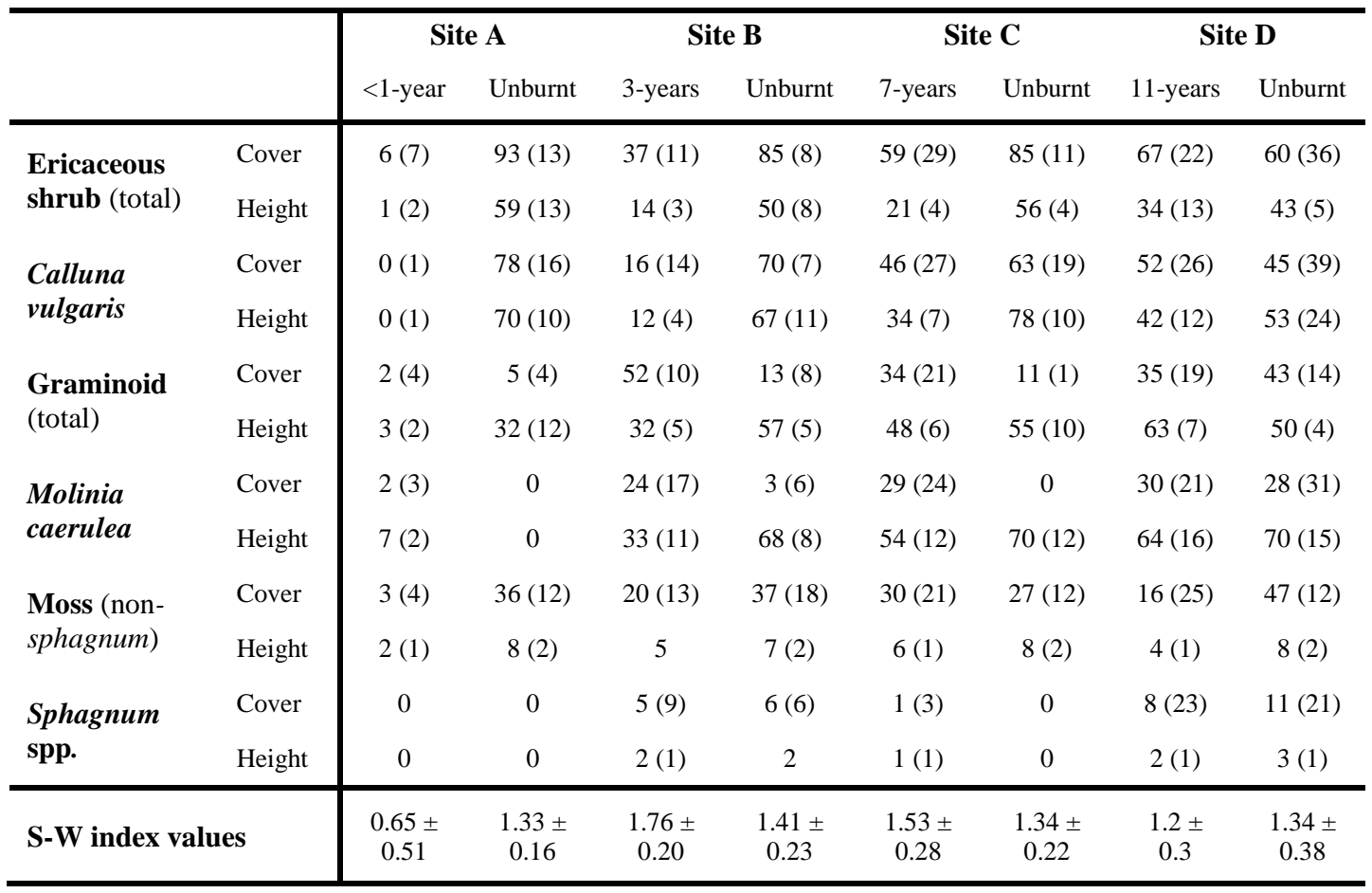


Species percentage cover and height data highlight a number of potentially key aspects of post-fire recovery and the competitive balance between species functional groups (Table 3.4). For example, the percentage cover and height of total ericaceous shrub species increased sequentially between each burnt area from Site A $(6 \%$ and $1 \mathrm{~cm})$ to Site D (66\% and $34 \mathrm{~cm})$ (Table 3.4). The abundance of graminoid species was variable across the sampling areas (Table 3.4). The lowest overall abundance (cover) was, again, found in the burnt area of Site A ( $2 \%)$ and the highest in the burnt area of Site B (52\%). Whilst ericaceous species appear, on average, more abundant across the burnt sampling areas, in contrast, graminoid species are more abundant, on average, across the long-unburnt areas (Table 3.4).

Moss species (non-Sphagnum) in general also appear less prevalent in the most recently burnt sampling area (Site A) and progressively more abundant in the burnt areas of Site B and Site C, and across the long unburnt sampling areas. Of these moss species, feather mosses were the most dominant, with Hypnum jutlandicum occurring at every sampling location and Rhytidiadelphus squarrosus (Hedw.) Warnst., and Pleurozium schreberi (Brid.) Mitt. occurring at seven and six of the eight study areas, respectively.

The overall presence of Sphagnum spp. is limited across these sampling areas with no species occurring with any regularity (Table 3.4). Sphagnum subnitens was the most common, occurring in isolated small patches in three of the eight areas; the burnt area at Site B and the burnt and unburnt areas at Site D (Supp. Table 3.1). This is perhaps to be expected as most species of Sphagnum are not commonly found in dry heathland habitats with consistent cover only to be expected within wetter peaty habitats (Noble et al., 2019).

Shannon-Weiner (S-W) diversity index values suggest these sites are all relatively species-poor with low diversity values across the burnt and unburnt sampling areas (SW: 0.65-1.76) (Table 3.4). The lowest diversity values were present within the most recently burnt area at Site A $(S-W: 0.65 \pm 0.51)$ with the highest values in the burnt area at Site B (S-W: $1.76 \pm 0.20)$ (Table 3.4).

The nested linear model conducted using the S-W diversity index values found an interaction between diversity and site:status at the $95 \%$ confidence level $\left(\mathrm{r}^{2}=0.48\right.$, df $=7, \mathrm{p}$-value $=<0.05)($ Table 3.5). This analysis identified the burnt area of Site A and 
Site B as having significant associations between diversity and the predictor variable site:status (Table 3.5). Notably no significant association was found between diversity and site:status between the four long unburnt areas (Table 3.5). The variance in diversity ascribed by the model as related to the site:status interaction explains $48 \%$ of the overall variance (model $\mathrm{r}^{2}=0.48$ ). A considerable proportion of the data variance, therefore, remains unidentified and should be taken into consideration when interpreting the results.

Table 3.5: Details of the nested linear model of diversity as a function of site:status (see subsection 3.2.5. for full analytical details). Adjusted $R^{2}$ was 0.48 and $p$-value of $<0.05$ on 7 degrees of freedom. The notation * indicates significant p-value interaction at the $95 \%$ confidence level.

\begin{tabular}{l|cccc} 
& Estimate & Std. Error & t-value & p-value \\
\hline SiteA: Burnt & -0.70 & 0.13 & -5.32 & $<0.05^{*}$ \\
SiteA: Unburnt & -0.02 & 0.13 & -0.14 & 0.89 \\
SiteB: Burnt & 0.40 & 0.13 & 3.02 & $<0.05^{*}$ \\
SiteB: Unburnt & 0.07 & 0.13 & 0.53 & 0.60 \\
SiteC: Burnt & 0.14 & 0.13 & 1.07 & 0.29 \\
SiteC: Unburnt & -0.10 & 0.13 & -0.78 & 0.44 \\
SiteD: Burnt & -0.15 & 0.13 & -1.15 & 0.26 \\
SiteD: Unburnt & 0.02 & 0.13 & 0.32 & 0.54 \\
\hline
\end{tabular}

To explore the model interaction between diversity and site:status an analysis of variance test (function "Anova") and subsequent post-hoc pairwise comparisons were conducted to identify specific differences in sampling area diversity. The analysis of variance results suggest there is a significant difference in sampling area diversity based on the site:status interaction (Sum.Sq $=8.25, \mathrm{df}=7, \mathrm{~F}$-value $=11.39, \mathrm{p}$-value $=$ $<0.05$ ). Pairwise comparisons (function "emmeans") identify the burnt area at Site A as significantly different in diversity (S-W diversity) from all other burnt and unburnt sampling areas (Figure 3.4; Supp. Table 3.2). Significant difference also occurred between the burnt area at Site B and the burnt area at Site D, and the unburnt area at 
Site C (Figure 3.4; Supp. Table 3.2). All other sampling area pairwise comparisons were deemed not to be statistically different, including between the four long unburnt areas (Figure 3.4).

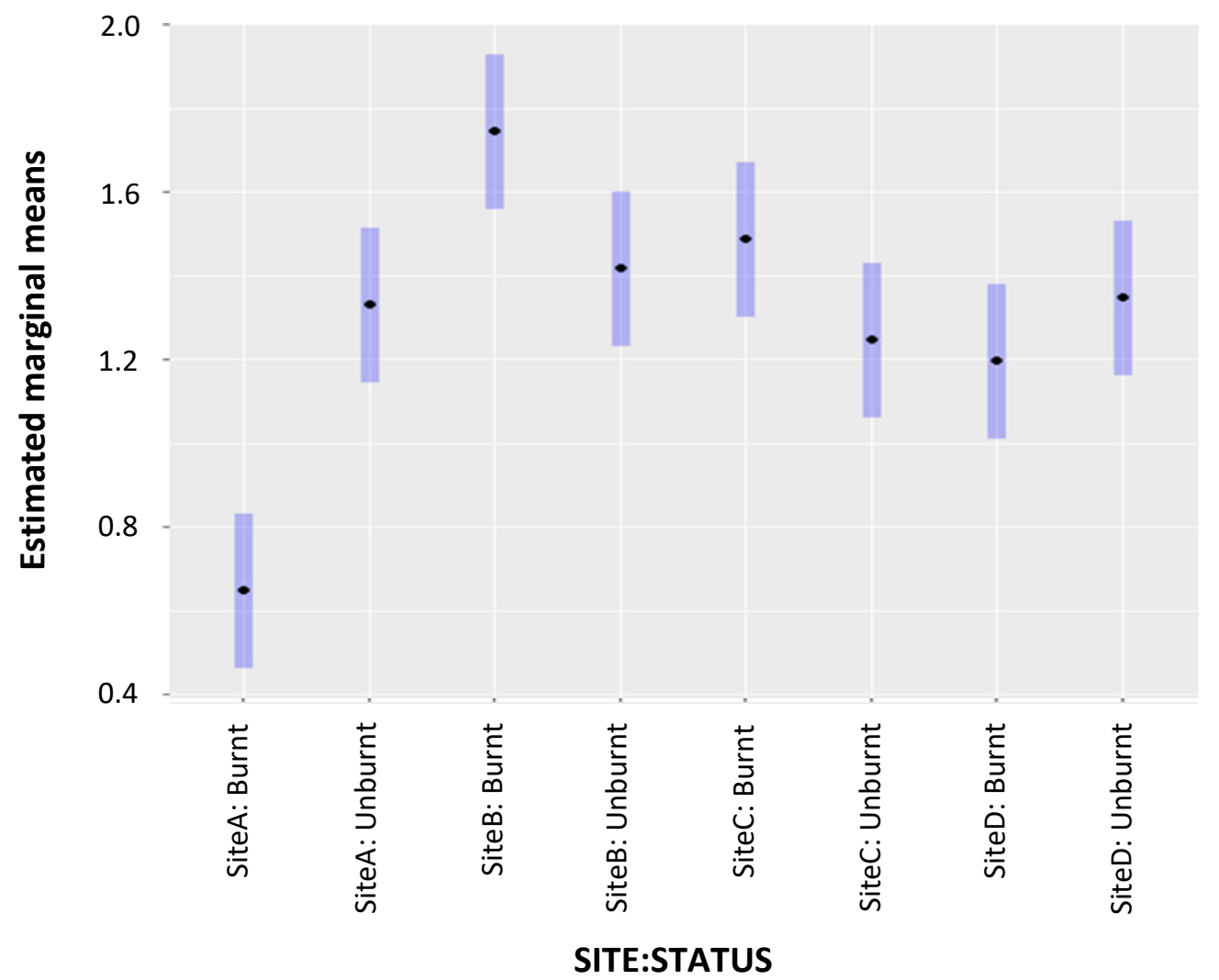

Figure 3.4: Graphic representation of the "emmeans" pairwise comparison output. Estimated marginal means plotted with 95\% confidence intervals (highlighted in blue) to assess differences in area diversity (S-W diversity). Sites with overlapping confidence intervals are judged to the statistically similar at the $95 \%$ level.

To assess vegetation community composition more broadly, non-metric multidimensional scaling (NMDS) was conducted to highlight the association of particular species with sampling areas (Figure 3.5). Generally, species with low NMDS1 values but high NMDS2 values are associated with the unburnt areas, particularly at Sites A and B. This directional orientation is most strongly associated with species such as, the dwarf-shrub $C$. vulgaris $(\operatorname{Pr}=<0.05)$, and the moss species Rhytidiadelphus squarrosus (Hedw.) $(\operatorname{Pr}=<0.05)$ and Pleurozium schreberi (Brid.) $(\operatorname{Pr}=<0.05)$ (Figure 3.5; Supp. Table 3.3). Conversely, species with high NMDS1 values and low NMDS2 values are more closely associated with the burnt sampling 
areas, particularly at Sites B and D. This directional orientation is most strongly associated with species such as, the dwarf-shrub Erica tetralix L. and the grass species Molinia caerulea (L.) Moench (hereafter M. caerulea) $(\operatorname{Pr}=<0.05)$ and Trichophorum cespitosum (L.) Hartm. ( $\operatorname{Pr}=<0.05)$ (Figure 3.5; Supp. Table 3.3).

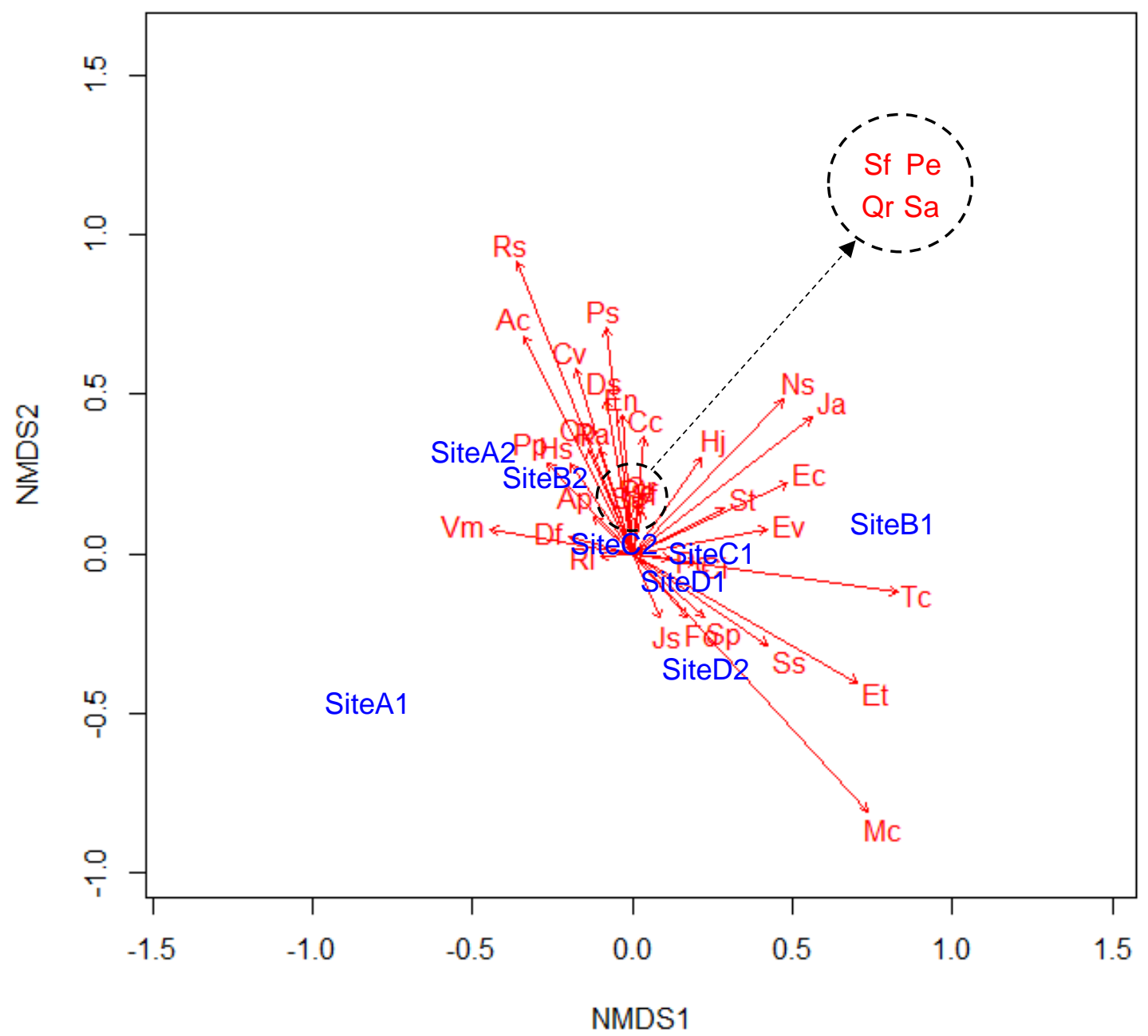

Figure 3.5: Distribution of species and sites derived by Non-metric multidimensional scaling analysis (NMDS). Sampling areas (in blue) are labelled using the site letter (A-D) followed by their status (1=Bunrt; $2=$ Unburnt). Species are ordinated in relation to their occurrence and cover across the sampling areas. Species abbreviations are as follows: Calluna vulgaris $(\mathrm{Cv})$, Empetrum nigrum (En), Erica tetralix (Et) Erica cinerea (Ec),Vaccinium myrtillus (Vm), Molinia caerulea $(\mathrm{Mc})$, Eriophorum vaginatum (Ev), Festuca ovina (Fo), Nardus stricta (Ns), Agrostis capillaris (Ac), Juncus acutiflorus (Ja), Juncus squarrosus (Js), Trichophorum cespitosum (Tc), Deschampsia flexuosa (Df), Sphagnum subnitens (Ss), Sphagnum tenellum (St), Sphagnum fallax (Sf), Sphagnum palustre (Sp), Campylopus introflexus (Ci), Aulacomnium palustre (Ap), Polytrichum commune (Pc), Dicranum scoparium (Ds), Pleurozium schreberi (Ps), Hypnum jutlandicum (Hj), Pseudoscleropodium purum (Pp), Rhytidiadelphus loreus (Rl), Rhytidiadelphus squarrosus (Rs), Racomitrum lanuginosum (Ra), Hylocomium splendens (Hs), Cladonia chlorophaea (Cc), Cladonia portentosa (Cp), Potentilla erecta (Pe), Sorbus aucuparia (Sa) and Quercus robur (Qr). 
To assess the significance of these distance-based differences in species and sampling areas, permutational analysis of variance tests (permanova) (function "adonis") were conducted, using a nested site:status interaction (using the "strada" argument within "adonis"). The analysis of variance results suggest there are significant differences in sampling area vegetation community composition $(\mathrm{Sum} . \mathrm{Sq}=9.49, \mathrm{df}=7, \mathrm{~F}-\mathrm{value}=$ 9.93, $\mathrm{r}^{2}=0.44, \mathrm{p}$-value $=<0.01$ ). Pairwise comparisons (function "betadisper": "Tukey-HSD") were used to further explore this significant result by identifying significant differences in mean dispersion between sampling areas (Figure 3.6 and Supp. Table 3.4).

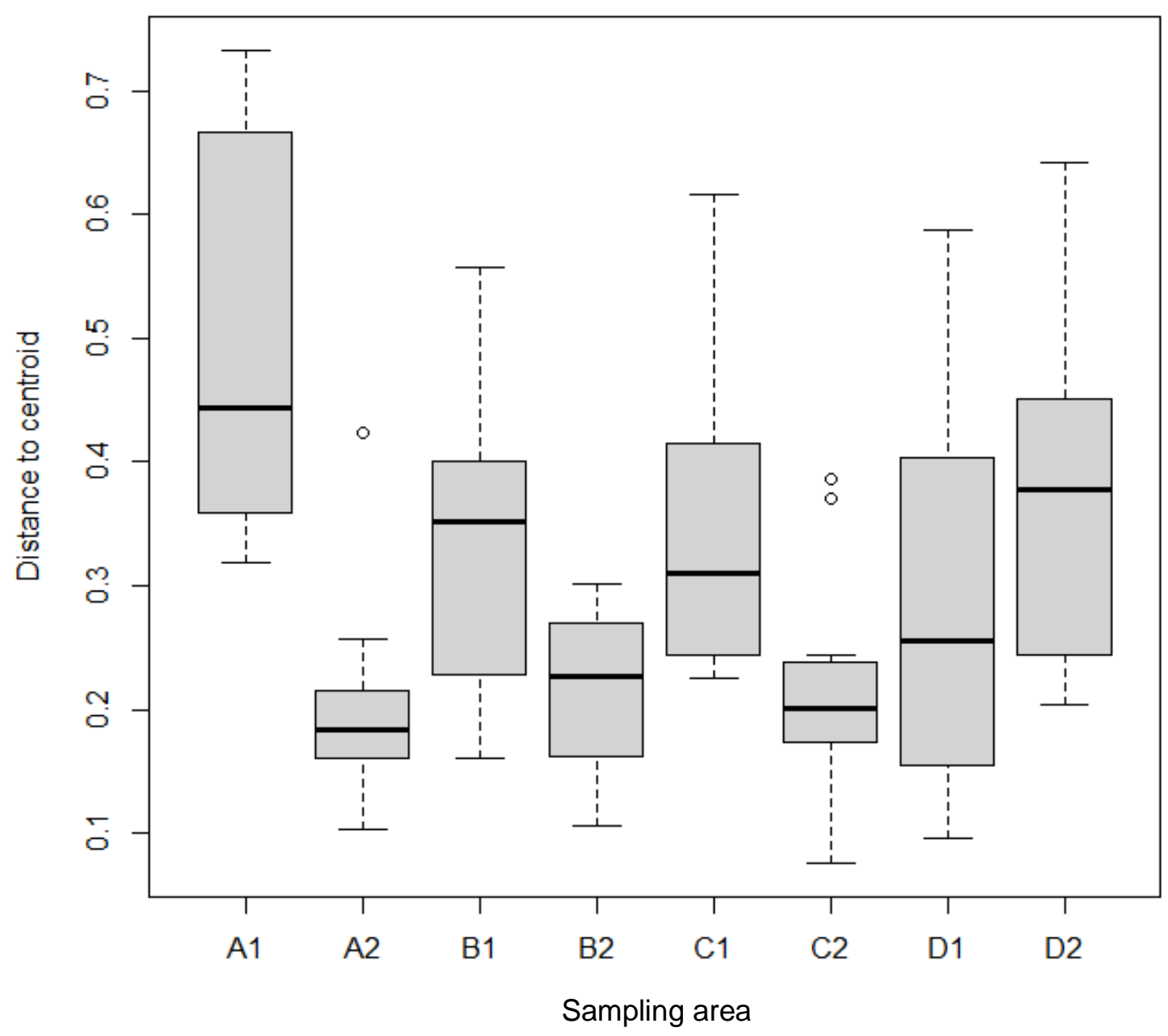

Figure 3.6: Representation of group (sampling area) mean dispersions displayed as the distance between groups and the centroid: identified by the "betadisper" function in R using the Tukey-HSD method. These dispersions are used to test for significant differences between sampling area vegetation community composition. Samplings areas are displayed using the site letter (A-D) followed by their status (1=Burnt: $2=$ =Unburnt). 
Similar to the analyses conducted using the area diversity data ( $\mathrm{S}-\mathrm{W}$ diversity), the burnt area at Site A is significantly different from most other sampling areas in relation to community composition. The exception to this being the unburnt area at Site D (Figure 3.6 and Supp. Table 3.4). The unburnt sampling area at Site D also produced several other significant pairwise differences when compared with the other unburnt areas (Sites A, B and C), in addition to with its paired burnt area (Supp. Table 3.4). No significant pairwise differences were identified when comparing between the other long unburnt areas (Sites A, B and C). While the burnt and unburnt areas significantly differed within Site A and D, no significant differences were found when comparing between the two samplings areas within Site B and C (Figure 3.6 and Supp. Table 3.4).

\subsection{Discussion}

The use of space as opposed to time by which to assess change is a commonly used strategy in ecology, particularly when assessing lengthy processes (e.g. vegetation recovery/succession) (>10 years) which are not feasible within most research setups (e.g. time, resource or funding limited). This approach, however, makes several key assumptions which are important to outline before 'diving into' the following discussion and interpretation of results. These include the assumption that the chosen sampling locations are; geographically but not environmentally distinct, control (long unburnt) and treatment (burnt) areas are sufficiently comparable (e.g. similar predisturbance conditions), and, in the case of fire ecology, burn conditions for each fire event are also comparable (Ashby and Heinemeyer, 2019a).

To address these assumptions several key features were incorporated into the study design. Firstly, all sampling areas were chosen in compliance with a selection criteria, providing consistency in relation to for example, area elevation, topography, soil type and grazing and recreational pressure (See subsection 3.2.2. for full details). These criteria help to limit, as much as possible, the influence of geographic and environmental variables on heathland vegetation community composition. The importance of the comparability of sampling sites within space-for-time substitution studies has been a notable source of contention in the field of fire science in recent years (Ashby and Heinemeyer, 2019a; 2019b; Brown and Holden, 2019). 
Secondly, to reduce the likelihood of significant environmental differences between the (burnt)(treatment) and long unburnt (control) areas, a long unburnt area was located at each site to enable burnt area recovery to be assessed against a closely located unburnt assemblage (Supp. Figure 3.1-3.4). It must be acknowledged that this does not guarantee control and treatment areas had similar pre-disturbance conditions, even within the same site, due to the environmental heterogeneity of most ecosystems (Johnson \& Miyanishi, 2008; Pickett, 1989). It does, however, removed the need for potentially problematic cross-site (between-site) comparisons in order to assess the degree of burnt area recovery.

Thirdly, as burn conditions aren't able to be directly measured within a space-for-time approach, they were quantified here using the Canadian Forest Fire Weather Index (FWI) System. The FWI system allows estimates of fine fuel moisture content (FFMC), duff moisture code (DMC), drought code (DC), initial spread rate (ISI) and fire weather index values (FWI) to be produced using historic weather data (e.g. precipitation, air temperature, wind speed and relative humidity) (See subsection 3.2.4. for full details). Whilst direct measurements of burnt conditions are highly desirable and FWI estimates do not prove, or disprove, comparability of the assessed fire events, they do crucially enable an adequate means of comparing historic fire events.

Finally, statistical analyses were conducted to assess the comparability of sampling areas to contextualise the results and inform subsequent interpretations (See subsection 3.2.5. for full details). Due to the time constraints of this project, and the common pitfalls of conducting ad hoc monitoring of natural events such as wildfires, no replication of burn treatments were available (e.g. only one sampling area per burn age; $<1,3,7,11$-years post-fire). This means careful consideration was given to the statistical analyses (e.g. utilising a nested analytical design) and inferences that can be drawn from these data (e.g. by comparing with-in, and not between, site heterogeneity) to avoid potential pseudoreplication (Oksanen 2001; Schank and Koehnle 2009; Ramage et al. 2013).

Despite these efforts to ensure conditions were conducive to comparable sampling areas and fire events, it is acknowledged that the results of chronosequence studies are not as reliable or accurate as those produced through controlled experimentation as some differences in site histories and burn characteristics are inevitable (França et al., 
2016). It is also important to acknowledge that these limitations do not preclude studies of this kind from providing useful insight if conducted appropriately (Ashby and Heinemeyer, 2019b). In this study, a true time-series or chronosequence of vegetation recovery cannot be produced due to the lack of burn treatment replication (e.g. only one sampling area per burn age; <1, 3, 7, 11-years post-fire). Long-term change can, however, still be interpreted based on the difference between burnt and unburnt area conditions within each site based on the age of each burnt area.

\subsubsection{Vegetation response}

Vegetation community response to wildfire across the dwarf-shrub heaths studied here suggests post-fire recovery is dictated by the growth strategies of two key functional groups: graminoids and ericaceous shrub species (Table 3.4). This pattern can be broken down to three common phases of disturbance recovery (Harris et al., 2011a), i) the early pioneer re-establishment phase, (ii) the building phase and (iii) the mature successional phase. This post-fire successional pattern is reasonably well established in heathland habitats, in the UK, and they often follow similar post-fire recovery trajectories towards their pre-fire conditions (Stewart et al., 2004; Ward et al., 2007; Harris et al., 2011a).

In the burnt area of Site A ( $<1$-year post-fire), pioneer graminoid species such as Agrostis capillaris, Deschampsia flexuosa (L.) Trin. and M. caerulea make up a relatively considerable portion of the vegetation assemblage (Table 3.4). These species appear to have re-sprouted within the burnt area producing shoots up to $5 \mathrm{~cm}$ in height within the first year (Supp. Table 3.1). This suggest the burnt area of Site A falls within the initial stage of post-fire recovery, the early-pioneer re-establishment phase. Initial fast recovery of these species is likely due to the speed of vegetative regeneration and the ability of early-colonist species to rapidly-produce shoots from meristems below the soil surface (Hobbs and Gimingham, 1984). Species such as Agrostis spp., Nardus spp. and D. flexuosa have all been cited as having positive short-term responses to burning in heathlands in other regions in the UK (Hobbs and Gimingham, 1984; GrauAndrés et al., 2019a) and in similar heathland habitats in southern Norway (Velle and Vandvik, 2014). 
In the burnt area of Site B (3-years post-fire), M. caerulea and Nardus stricta had established themselves to, on average, 24 and $16 \%$ ground cover, respectively, with $52 \%$ total graminoid cover and an average height of $32 \mathrm{~cm}$ (Table 3.4; Supp. Table 3.1). These species, again, appear able to re-establish relatively quickly in comparison to other species types (e.g. ericaceous shrub and moss species) during the early years of post-fire recovery. In addition to their ability to rapidly regrow due to the speed of vegetative regeneration, the substantial removal of other vegetative cover during fire events such as these maximises light availability and reduces interspecific competition for these early-colonist species positively influencing recovery success (Hobbs and Gimingham, 1984; Velle et al., 2012; Grau-Andrés et al., 2019a). In particular, the success and recovery rate of early-colonising graminoid species has been directly linked to the degree of ericaceous shrub removal and the subsequent recovery rate of C. vulgaris (Grau-Andrés et al., 2019a). More broadly, the most successful graminoid species during this early recovery stage (e.g. $M$. caerulea here) depends on a combination of factors including, the disturbance type, composition of the available seed bank or seed dispersal ranges, environmental conditions and soil characteristics.

There is a notable absence of ericaceous shrub species cover in the burnt area at Site A (<1-year post-fire) and limited recovery in the burnt area at Site B (only $16 \% C$. vulgaris cover in the burnt area at Site B: 3-years post-fire) in comparison to long unburnt conditions (Table 3.4). This could perhaps be as a result of fire's ability to inhibit the primary regrowth functions (e.g. seeding and vegetation regeneration) of key species such as $C$. vulgaris (Velle and Vandvik, 2014). Vegetative regeneration has been demonstrated to be significantly inhibited after the burning of mature $C$. vulgaris stands (>15-years) slowing the recovery process (Kayll and Gimingham, 1965; Davies et al., 2010). Limited vegetative regeneration of $C$. vulgaris was observed in the most recent burnt area (burnt area at Site A: <1-year post-fire) suggesting a mature stand (>15-years) was likely the primary fuel source for this wildfire event.

Seedling recruitment, particularly in C. vulgaris, is also often inhibited following wildfire if soil heating has reduced surface soil moisture content (Britton et al., 2003; Calvo et al., 2005). Given the almost total removal of above-ground vegetative cover observed in the burnt area at Site A, it is likely soil heating would have temporally reduced soil surface moisture content in these shallow organic layer heathland soils 
( $<50 \mathrm{~cm}$ organic depth), further inhibiting initial C. vulgaris recovery rates (Kettridge et al., 2015; Grau-Andrés et al., 2018).

The efficiency of ericaceous shrub regrowth strategies and recovery rates are highly spatially variable and dependent on specific site conditions (e.g. fire severity, post-fire weather conditions, soil organic depth, remaining and adjacent seed banks, elevation, aspect and latitude, amongst others) (Legg et al., 1992; Chapman et al., 2009; Calvo et al., 2012; Milligan et al., 2018; Grau-Andrés et al., 2019a). Inhibited C. vulgaris recovery after wildfire in $C$. vulgaris dominated habitats has been observed across Europe, from northern England to southern Norway and northern Spain, often as a result of poor seedling recruitment, limited vegetative regeneration and interspecific competition (Maltby et al., 1990; Calvo et al., 2005; Velle et al., 2012).

The burnt area at Site B (3-years post-fire) is significantly different when compared with the burnt area at Site A ( $<1$-year post-fire) in relation to diversity and vegetation community composition. This difference perhaps suggests the burnt area of Site B could represent the canopy building phase of disturbance recovery. This difference is characterised by the re-establishment of ericaceous species (e.g. C. vulgaris and $V$. myrtillus), creating a more balanced community (graminoid - ericoid balance). Cover values of graminoid and ericaceous species in the burnt area of Site B (3-years postfire) were 52 and $37 \%$ (Table 3.4).

C. vulgaris also has a number of fire-adaptive traits which can aid its re-establishment in burnt heaths (Davies et al., 2010). These traits range from the stimulation of seedling growth by heat, smoke and smoke derived solutions (Måren et al., 2010; Calvo et al., 2012) to the positive influence of the almost total removal of ground cover reducing the physical barrier to seedling growth and the removal of $C$. vulgaris litter which is auto-toxic to its own seeds (Bonanomi et al., 2005; Davies et al., 2010).

As dwarf-shrub heathlands progress towards maturity the cover of graminoid species, often, declines in favour of increasing ericaceous shrub species cover (Mallik and Gimingham 1983; Hobbs and Gimingham 1984; Calvo et al. 2012; García et al. 2013). Across the burnt areas assessed here overall graminoid species cover is greater, in comparison to the cover of ericaceous species, at Site A and B $(<1$ and 3-years postfire) but lower at Site C and D (7 and 11-years post-fire) (Table 3.4). These differences could result from the greater period of post-fire recovery at Site C and D. The precise 
values of ericaceous and graminoid species could, however, also be influenced by differences in, for example, site grazing pressures which were not able to be directly quantified here.

The success of one graminoid species, M. caerulea, however, does not align with the overall shift from graminoid to ericaceous species dominance across the assessed sites (Table 3.4). The cover of $M$. caerulea across the burnt areas, instead of reducing, increases in cover from $24 \%$ at Site B (3-years post-fire) to $29 \%$ at Site C (7-years post-fire) and $30 \%$ at Site D (11-years post-fire) (Table 3.5). M. caerulea was, therefore, significantly oriented in the average direction of the burnt areas by the NMDS analysis (Figure 3.5; Table 3.6).

Whilst the abundance of $M$. caerulea was higher in the burnt areas of Site B and C, in comparison to the unburnt areas at these sites, it was found at comparable levels in both the burnt $(30 \%)$ and unburnt $(28 \%)$ areas of Site D (Table 3.4). This perhaps highlights a fundamental difference between the pre-fire assemblage at Site D, when compared to the other sites. This could suggest the occurrence and cover of $M$. caerulea in the burnt area of Site D is not as a direct response to the assessed fire event. This is also likely a key factor in the significant differences in community composition found between the unburnt area of Site D when compared to the unburnt areas at Site A, B and C (Figure 3.6 and Supp. Table 3.4).

The relatively limited coverage of $M$. caerulea at the most recently burnt sampling area (Site A: <1-year post-fire) is perhaps due to the limited occurrence and cover of any species at this stage or simply because of its absence at Site A pre-fire (cover of M. caerulea in the unburnt area at Site $\mathrm{A}=0 \%$ ) (Table 3.4).

The perennial tussock grass $M$. caerulea has a high phenotypic plasticity in relation to nutrient turnover and productivity. Increased post-fire soil nutrient (e.g. nitrogen and phosphorus) levels are thought to enable $M$. caerulea to grow more successfully than other graminoid species if it appears in the seed bank or surrounding area (Aerts and de Caluwe, 1989; Aerts et al., 1990; Brys et al., 2005). The results presented here provide some evidence supporting $M$. caerulea's positive relationship with fire and its invasive advantage in burnt habitats (Site B and C) (Figure 3.5) (Marrs et al., 2004; Jacquemyn et al., 2005). As a result of this competitive advantage, M. caerulea has spread throughout disturbed heathlands across Europe in recent decades. This poses a 
major threat of permanently altering habitat composition in dwarf-shrub heaths, potentially converting $C$. vulgaris-dominated heaths into grasslands (Table 3.5) (Marrs et al., 2004; Brys et al., 2005; Friedrich et al., 2011).

Anecdotal accounts suggest $M$. caerulea dominance is a particularly prominent issue in Wales and southern England, in comparison to more northerly latitudes. This may also be evident in the establishment of $M$. caerulea in the unburnt area of Site D with over $65 \%$ of the total graminoid cover consisting of $M$. caerulea (overall cover: $28 \%$ ), perhaps as a result of an earlier disturbance (Table 3.5). Although M. caerulea itself is not directly mentioned in the JNCC Common standards monitoring guidelines target attributes for dry heathland (Table 3.1) (JNCC, 2009), it has been suggested <20\% cover could represent an appropriate threshold level for favourable dry heath habitat conditions (Glaves, 2015). High cover values of $M$. caerulea are also likely to result in other attribute targets being failed and hence also resulting in unfavourable heathland condition (Table 3.1) (Glaves, 2015).

A primary feature of vegetation community composition in the latter time intervals in this study is the increased dominance of ericaceous species, particularly $C$. vulgaris (in the burnt area at Site $\mathrm{C}$ and the four unburnt areas: 11- >25-years). This trajectory at a given site takes heathland habitats into a low diversity $(\mathrm{S}-\mathrm{W}=1.34)$ mature, towards degraded, successional phase, as seen in all long unburnt areas surveyed $(>25$ years post-fire) (Table 3.5). Degraded conditions in this context refer to areas of dry heathland which do not meet one or several of the habitat condition targets outlined in Table 3.1 (JNCC, 2009). These conditions are often present in dwarf-shrub dominated areas which have progressed to a state in which stands are, on average, more than 30 $\mathrm{cm}$ in height with well-established woody stems $(>1 \mathrm{~cm}$ diameter) and forming a layered canopy with gaps and scattered dead material producing an accumulating fuel load (JNCC, 2009).

Across the long unburnt areas average $C$. vulgaris cover was $64 \%$ creating large areas of complete cover at canopy level (Figure 3.2; Table 3.4). The continued dominance of $C$. vulgaris at the canopy level causes increased ground shading and progressively prevents successful growth of other species (Hobbs and Gimingham, 1984). This results in a significant positive association of $C$. vulgaris with the long unburnt areas in the NMDS ordination (Figure 3.5; Supp. Table 3.3). This is a commonly cited 
relationship in fire-affected heathland and moorland habitats in the UK. Sustained increases in $C$. vulgaris cover and height have been observed through $>20$-years postfire, limiting all other species to $<40 \mathrm{~cm}$ height and 20-25 years after burning (Chapman et al., 2009; Harris et al., 2011a; Milligan et al., 2018). This is also a key issue in estates, particularly in the north of England and Scotland, where grouse shooting practices and the associated $C$. vulgaris-favoured burning regimes have been abandoned.

Other ericaceous species, such as V. myrtillus and Erica spp., are thought to have distinct post-fire recovery patterns, from $C$. vulgaris, as a result of their seeds being more temperature tolerant and/or they benefit more from heat pulses that help break dormancy (Grau-Andrés et al., 2019a). High fire severities have been linked to the increasing abundance of, for example, E. cinerea in some heathland habitats due to their larger average seed size, suggesting higher temperature tolerance (Tavşanoğlu and Pausas, 2018; Grau-Andrés et al., 2019a). The results here do show a quicker recovery towards unburnt conditions or preferential occurrence of other ericaceous species (e.g. V. myrtillus) in more recently burnt areas. This dynamic is, however, difficult to assess more broadly in areas dominated to such an extent by $C$. vulgaris pre-fire, as there is relatively limited coverage of other ericaceous species (Table 3.4).

\subsubsection{Recovery dynamics}

The results presented in this study found diversity (S-W diversity) and vegetation community composition were indistinguishable from unburnt conditions at Site B, C and $\mathrm{D}$ suggesting these heathland habitats were able to recovery in as little as 3-years post-fire (Figure 3.4 and 3.6). Despite this, the burnt areas at Site B and C still fellshort of key habitat attribute requirements used to assess favourable habitat condition and vegetation disturbance in European dry heath (JNCC, 2009). For example, not all growth phases of $C$. vulgaris are present and less than $10 \%$ of $C$. vulgaris is at the mature growth stage in both burnt areas (Table 3.1) (JNCC, 2009). These factors, therefore, suggest optimum habitat conditions, combining recovery to unburnt area diversity and community composition as well as favourable stand conditions (e.g. stand height and maturity) occurred in the burnt area of Site D (11-years post-fire) (Table $3.1 ; 3.3$ ). 
The vegetation assemblage at Site D is at 11-years post-fire which is at the lower end of recovery times estimated by other studies in similar $C$. vulgaris-dominated habitats across the UK (DEFRA, 2007; Harris et al., 2011a). The Heather and Grass Burning Codes for Wales and England for example, suggests optimum diversity and structure is reached between 10-20 years following low severity prescribed burning in $C$. vulgaris dominated habitats (DEFRA, 2007). Other studies such as Harris et al. (2011) for example, place optimum recovery, return period length, at $c .20$ years post-fire for the $C$. vulgaris dominated moorland surveyed after a low severity prescribed burn. Low-severity prescribed fires are also thought to be much less likely to have substantial and lasting impacts on vegetation and recovery rates are therefore assumed to be quicker in comparison to following higher severity fire, such as those assessed here (Table 3.3) (Glaves et al., 2013; Harper et al., 2018; Grau-Andrés et al., 2019a).

The relatively quick recovery of Site $\mathrm{D}$ to unburnt conditions within 11-years post-fire could result from the condition of its unburnt area and the way in which recovery has been assessed. The unburnt area at Site D, and all other unburnt areas sampled, had particularly low diversity (S-W diversity) and presented signs of being in structurally degenerate condition (Table 3.1 and 3.5) (JNCC, 2009). This is perhaps due to a lack of recent disturbances which are key to maintaining favourable conditions in these plagioclimax communities (JNCC, 2009). Assuming pre-fire conditions were similar to that of all the long unburnt areas, it is likely to take less time to recovery towards pre-fire (control) conditions, what is being assessed, if pre-fire conditions were already species-poor and dominated by a small number of prominent fire-adapted species (e.g. C. vulgaris). Long unburnt area conditions were found to be statistically similar to their paired burnt areas at Sites B, C and D in relation to diversity (S-W diversity) and Sites B and C in relation to vegetation community composition (Supp. Table 3.2 and $3.4)$.

During an extensive assessment of dry heathland habitat condition within the Snowdonia National Park (north Wales), utilising the same JNCC monitoring guidance utilised here (Table 3.1 and 3.2), it was concluded $76 \%$ was in unfavourable condition (Gritten, 2012). It is considered likely this level of degradation and trend in the decline of dry heath condition is an all-Wales phenomenon although no similar assessment is currently available for the Brecon Beacons National Park (south Wales) (Gritten, 2012). It is, therefore, plausible that post-fire recovery rates such as this may be more 
common than the academic literature suggests across dwarf-shrub heathlands in Wales and more broadly across the UK, given comparable pre- and post-fire conditions. This raises a wider question about the way in which recovery is assessed in dry heathlands (i.e. against control or pre-fire conditions) given that they are often of similar low species diversity and in unfavourable condition. Even under favourable conditions, dry heaths across the UK are often dominated by dwarf-shrub species, such as $C$. vulgaris and $V$. myrtillus in the south and west, and in the north occasionally by Juniperus communis (Rodwell, 1991; JNCC, 2008; Velle and Vandvik, 2014).

In the wider European context similar recovery rates have, however, been observed in C. vulgaris dominated habitats in northern Spain (highest diversity values between 7 14-years post-fire) (Calvo et al., 2012). In addition to faster recovery towards pre-fire conditions following severe wildfire events in C. vulgaris - Erica spp. heathlands in southern Spain (Granged et al., 2011a), C. vulgaris dominated heathlands in central Norway (Velle et al., 2012) and dwarf-shrub scrubland in eastern Spain (Cerdà and Doerr, 2005) taking as little as 2-years to return to pre-fire cover levels. Low overall diversity, a dominance of fire-adapted species and/or post-fire precipitation are cited as key explanations for the relatively fast recovery rates in these studies.

The overall vegetation response to fire observed here appears within the range of that observed by other comparable studies suggesting the presented results are generally applicable to similar heathland habitats. These results, therefore, may provide some useful insight into the impacts of wildfire on vegetation community composition in the seldom studied dry dwarf-shrub heathland habitat type and geographic location of south Wales (UK).

\subsubsection{Implications}

The results presented in this study suggest dry heathland habitats dominated by fireadapted species, such as $C$. vulgaris, can recover relatively quickly (approx. 7-11 years) following wildfire events, despite almost total removal of above-ground vegetation cover. This seems a positive outcome for the health and function of upland heaths, suggesting extreme fire severities, higher than those experienced here are required to substantially inhibit recovery towards unburnt conditions in the medium to long-term. This recovery, however, represents a trajectory towards low diversity, 
structurally degenerate and often unfavourable habitat conditions, as seen across the long unburnt sampling areas. Management intervention is, therefore, required to recreate or maintain favourable habitat conditions in these plagioclimax communities even under current climatic conditions.

Climate changes in the UK over the coming decades are expected to enhance seasonality, increasing summer temperatures, reducing summer rainfall and increasing winter rainfall (Albertson et al., 2010). These changes are projected to alter the biogeographic range of plant species and increase the risk of wildfires (Albertson et al., 2010). A number of aspects of post-fire recovery discussed here (e.g. C. vulgaris dominance, stand structure, invasive encroachment of $M$. caerulea and succession of tree species $S$. aucuparia and $Q$. robur) highlight key concerns over the future status of dry heathland habitats in the UK, given their inherently low ecological resilience and the expected pattern of future wildfire activity change (Worrall et al., 2010a).

It is relatively well-established in heathland habitats that vegetation dynamics depend on the interaction between species attributes and climatic conditions (Clément and Touffet, 1981). Although this is generally similar of most habitats in the UK, evidence suggests heathlands are particularly vulnerable to changes in wildfire activity due to their often-low species diversity, the dominance of woody ericaceous shrub species, accumulated fuel loads and shallow organic layered soils $(<50 \mathrm{~cm})$. These factors produce a susceptibility to relatively fast moisture loss of vegetation during drought conditions and thus increase the likelihood of higher burn severity (Grau-Andrés et al., 2018, 2019a).

Maximum temperatures at the soil surface under high fire severity conditions are also thought to be significantly higher in heathland habitats in comparison to wetter moorland/peatland sites due to the often-low fuel moisture and limited protective ground litter and moss coverage (Grau-Andrés et al., 2018). Shallow, lower organic content soils are also significantly less effective at insulating against soil heat penetration than moister, peaty soils (Davies et al., 2010). Higher soil surface temperatures and greater heat depth penetration in heathlands in comparison to wetter moorland/peatland habitats under the same climatic conditions and fire severity, therefore, increase the risk of critically damaging plant tissues, seed banks, soil 
properties and post-fire recovery capacity (Granström and Schimmel, 1993; Schimmel and Granstrom, 1996; Grau-Andrés et al., 2019a).

These factors pose questions about the long-term vulnerability of dry heathland habitats and the degree to which an increasing prevalence of severe wildfire may threaten key ecosystem services (e.g. carbon storage, water quality and biodiversity) (Marrs et al., 2004; Brys et al., 2005; JNCC, 2008; García et al., 2013). Severe wildfire events across the UK following prolonged droughts in recent years have intensified the need to understand the effects of wildfires on $C$. vulgaris dominated heathlands and create effective management strategies (Grau-Andrés et al., 2019a).

Identifying appropriate land management or remediation strategies for degenerate dwarf-shrub heath is often particularly difficult. The inherently low ecological resilience of these habitats coupled with the projected climatic and socioeconomic changes produces a range of competing opinions on their appropriate future form and usage, leading to a contentious land management debate. The legacy of maintaining upland heath plagioclimaxes, traditionally-managed specifically for certain human needs (e.g. grazing and hunting), where natural aspects have been deliberately excluded (e.g. pioneer tree species or wildlife, such as predatory mammals, birds and competitive wild herbivores) are likely to increasingly conflict with other priorities of nature recovery, and climate change mitigation and adaptation.

In areas, such as the Brecon Beacons National Park, where under-grazing and accumulating fuel loads are a notable issue, long-term resilience and reducing wildfire risk should form key management priorities. The way in which this management is approached should inevitably be highly site-specific, however, strategies aimed at creating and maintaining upland structural heterogeneity, at the landscape scale, could perhaps form a positive step towards reaching longer-term resilience. In addition to the implementation of re-wetting programs to restore degraded areas of former wet heathland and reduce the rate of fuel moisture loss during drought conditions.

\subsection{Conclusion}

The results presented here suggest optimum habitat conditions combining diversity (SW diversity) and stand structure (e.g. height/age profile), occurred between Site C and 
D (7-11 years post-fire), along with the return of mosses (non-Sphagnum) to unburnt area cover values and the re-establishment of lichen and flowering plant species. Dry dwarf-shrub heathlands, therefore, appear able to recover towards long unburnt conditions relatively quickly (<11-years), following wildfire events despite almost total removal of above-ground vegetative cover. This finding is in contrast to some post-fire vegetation recovery rates estimated in wetter moorland or peatland habitats (>20 years) (Maltby et al., 1990; Legg et al., 1992; Harris et al., 2011a). 
Chapter 4

Post-fire soil physicochemical properties in European dwarf-shrub heaths, south-western UK. 


\subsection{Introduction}

Soils are considered one of the Earth's most valuable non-renewable resources. They represent the largest store of terrestrial organic carbon and directly support the presence and growth of terrestrial vegetation (Scharlemann et al., 2014; Santín and Doerr, 2016). The large diversity of soils makes them an essential part of numerous supporting, regulating and provisioning ecosystem services (Pausas and Keeley, 2014; Santín and Doerr, 2016). The ability of soils to sustainably provide these ecosystem services is fundamentally reliant on their health and functionality and thus the factors which influence these (e.g. land-use, perturbation regimes, erosion rates, hydrology) (Zavala et al., 2014).

Fire is one of the main perturbations in the Earth system (Bowman et al., 2009) and it is well-established to have the potential to cause considerable changes to soil physical and chemical properties, such as altering soil nutrient availability, organic matter content, microbiology and hydrological functions (Certini, 2005; Brown et al., 2015). Understanding these impacts and how they differ between soil types and fire dynamics is crucial for protecting this vital resource (González-Pérez et al., 2004; Certini, 2005; Zavala et al., 2014).

European dry heathlands are amongst the ecosystem types in Europe that commonly experience fire (Fagúndez, 2013; Schepers et al., 2014; JNCC, 2019b). They are defined as areas of shallow organic layered, often acidic, soils dominated by dwarfshrub species such as, Calluna vulgaris (L.) Hull (hereafter C. vulgaris) and Vaccinium myrtillus L. (hereafter V. myrtillus) (Rodwell, 1991). These are cultural landscapes, created, over millennia, by the clearance of forest and repeated burning and grazing and as such are considered fire-adapted plagioclimaxes (Tucker, 2003a; Allen et al., 2016). Over recent decades, changes in fire regimes, as well as successional pressures and excessive drainage, have posed considerable threats to heathland habitats (De Graaf et al., 2009; García et al., 2013). Currently $>25 \%$ of dry heath in the UK is considered to be in unfavourable condition based on assessments of vegetation composition and structure, with this percentage rising to $75 \%$ in some regions (JNCC, 2019b, 2019a).

Despite dry dwarf-shrub heaths being fire-adapted habitats, their reliance on specific controlled fire regimes to maintain vegetation composition and structure makes them 
fundamentally lacking resilience. Resilience in the context is referred to as the ability of vegetation or soils to recover and maintain their structural and functional integrity following pulse-like disturbances, such as fires (Grubb and Hopkins, 1986; BlancoCanqui and Lal, 2010). As a result, there are growing concerns the projected increase in the occurrence and severity of wildfires across the UK, and elsewhere in Europe, could take fire regimes sufficiently outside the conditions to which heathlands are adapted, causing major implications for their function (Moffat et al., 2012; Davies et al., 2013; Kelly et al., 2018; Grau-Andrés et al., 2019a). This raises important questions as to the potential impacts of these changes on heathland soils (Kelly et al., 2018). The majority of current fire impact research in the UK is, however, focused primarily on assessing the impacts of prescribed fires on vegetation dynamics in habitats with peaty soils (Glaves et al., 2013; Harper et al., 2018). Relatively little work has been conducted assessing the impacts of typically more severe wildfire events, particularly on shallow organic layered heathland soils, such as in dry dwarf-shrub heaths.

Fire influences soil properties through several primary mechanisms, ranging from the direct heating of top-soils, altering the molecular structure and solubility of some of its chemical constituents, the deposition and incorporation of fire-modified organic material into the surface soil, to changing the soil's physical structure and hydrological function (Certini, 2005; Clay et al., 2009b). The effects of fire on soils are dependent on a number of factors relating to both the soil type and characteristics (e.g. physical structure, chemical composition, moisture content) and fire dynamics (e.g. intensity, temperature reached and duration) (Zavala et al., 2014; Santín and Doerr, 2016).

When direct measures of fire intensity (sensu Keeley (2009) a measure of the timeaveraged energy flux) are not available, estimates of fire severity can be used to describe the degree to which a fire has impacted a given ecosystem (Keeley, 2009). In the case of soil, severity includes the degree of loss or decomposition of soil organic matter or deposition of ash from the combustion of aboveground biomass (Lewis et al., 2006). Whilst low severity fires, by definition, do not have significant impacts on soils properties, more severe fires have a much greater likelihood of affecting a wide range of soil physical (e.g. texture, structure, water holding capacity) and chemical properties (e.g. pH, nutrient availability, organic matter content), in some cases in an irreversible way (Certini, 2005). 
Of what research currently exists in temperate heathland soils within Europe, no detectable changes in soil physicochemical properties or no changes persisting longer than 1-year post-fire are common place following low severity prescribed fires (Mohamed et al., 2007; Granged et al., 2011a; Gómez-Rey et al., 2013; Fonseca et al., 2017; Francos et al., 2018). A number of studies have also observed relatively limited impacts on soil physicochemical properties following higher severity wildfire events in temperate heathlands within Europe (Gómez-Rey and González-Prieto, 2014; Kelly et al., 2018). Kelly et al. (2018), for example, recorded no observable difference in a suite of soil parameters (e.g. pH, total $\mathrm{N}$, total C, K, Mg and bioavailable P) 15-18 months after a wildfire in the top $5 \mathrm{~cm}$ of soil in a dry heathland in Ireland. GómezRey and González-Prieto (2014) found no detectable difference in soil physicochemical properties (e.g. pH, Ca, P, Mn, Na, K, Al and Fe) 1-year after a shrubland wildfire in the top $2 \mathrm{~cm}$ of soil in NW Spain.

Further work to expand the habitat coverage of impact research is required to better understand the impacts of fire on soil physicochemical properties between fire severities and habitats across the UK, and other European temperate regions. With particular focus on the seldom studied shallow organic layered heathland soils to best inform future land-management practices.

In order to address this, the following study aims to (i) determine the impacts of wildfires on a range of soil physical and chemical properties in dwarf-shrub heaths, (ii) evaluate the degree of recovery at four post-fire time-intervals $(<1,3,7$ and 11years) and, (iii) assess the implications of the findings for management practices in this and comparable habitats elsewhere. A set of four dwarf-shrub heathland sites within the Brecon Beacons National Park (Wales, UK) were used to provide insight into post-fire recovery at these four time-intervals $(<1,3,7$ and 11 -years elapsed timesince-fire). Each site with a burnt and paired long unburnt area where no burning had occurred for at least 25-years. Impacts and recovery were then assessed in relation to the difference between conditions in each burnt area compared with its within-site long unburnt area. 


\subsection{Materials and methods}

\subsubsection{Study area}

The Brecon Beacons National Park consists of a predominantly upland landscape spanning a $1350 \mathrm{~km}^{2}$ section of south and mid-Wales (UK). The park ranges from an altitude of 300 to $800 \mathrm{~m}$ containing a variety of habitat types from ancient deciduous woodland and coniferous plantations, to expanses of open grassland and heathland. Vast areas of the park are now, however, highly modified habitats influenced by a range of factors, such as agricultural and land management practices (grazing and burning), as well as climate changes. As a result, species-poor grassland and shrubland habitats are now prevalent throughout the park. The sites used in this study consist primarily of dwarf-shrub heathland (European Habitats Directive Annex I habitat type: H4030), and are dominated by $C$. vulgaris and V. myrtillus, particularly in the longunburned areas.

There are three primary soil types dominating the National Park; Stagnosols which are soils with stagnating water and structural or textural discontinuity, Cambisols which are relatively young soil with little profile development, and Podzols which are soils set by Aluminium and Iron chemistry. Isolated pockets of Histosol soils with thick organic layers are also present, notably in the central and north-eastern sections of the park (UK Soil Observatory, 2018) (Figure 4.2). Site specific soil type information is provided in subsection 2.2 (Figure 4.2; Table 4.1).

The underlying geology of the Brecon Beacons National Park is diverse containing a range of siltstone, mudstone and sandstone sedimentary bedrock formations (e.g. Millstone grit or Old Red Sandstone) (British Geological Survey, 2018). The sites used in this study reside primarily above sandstone formations (see Table 4.1 for site specific information). No superficial geological deposit records exist for the sites used in this study (British Geological Survey, 2018).

The climate in this southern region of Wales is humid temperate with year-round rainfall. Weather records from a monitoring station in the central Brecon Beacons $($ NGR $=2877 \mathrm{E}, 2261 \mathrm{~N} ;$ Altitude $331 \mathrm{~m})$ (2000-2018) indicates annual average precipitation ranges from $1030-1696 \mathrm{~mm}$, with an average of $3.5 \mathrm{~mm}$ per day in late summer (July-August) and of $6.5 \mathrm{~mm}$ in late winter (December-January). The average number of days with precipitation over $1 \mathrm{~mm}$ per year is 170 (2007-2018). Summer 
air temperatures reach a daily average of $18-19^{\circ} \mathrm{C}$ (June-August) with daily average winter lows of $1-4^{\circ} \mathrm{C}$ (November-January) (2007-2018).

\subsubsection{Heathland classification}

European dry heaths (European Habitats Directive Annex I habitat type: H4030) occur across Wales and the Brecon Beacons National Park, typically on freely draining, acidic and often nutrient-poor mineral or shallow peaty $(<0.5 \mathrm{~m})$ soils (JNCC, 2019a). These areas tend to be dominated by ericaceous dwarf-shrubs such as $C$. vulgaris and $V$. myrtillus and are found between the alpine or montane zone $(600-750 \mathrm{~m})$ and the line-of-enclosure for agricultural land (approximately 250-440 m) (Rodwell, 1991). Twelve NVC habitat types satisfy the classification of European dry heath including, C. vulgaris - V. myrtillus heath (H12), C. vulgaris - Festuca ovina heath (H1), C. vulgaris - Ulex gallii heath (H8), C. vulgaris - Erica cinerea heath (H10) and C. vulgaris - V. myrtillus heath (H12) (JNCC, 2008, 2009, 2019b). In the UK, dry heathlands now cover $<8000 \mathrm{~km}^{2}$ and are primarily distributed across Scotland, northern England and throughout Wales (JNCC, 2019b). For further habitat classification details please refer to Chapter 3.

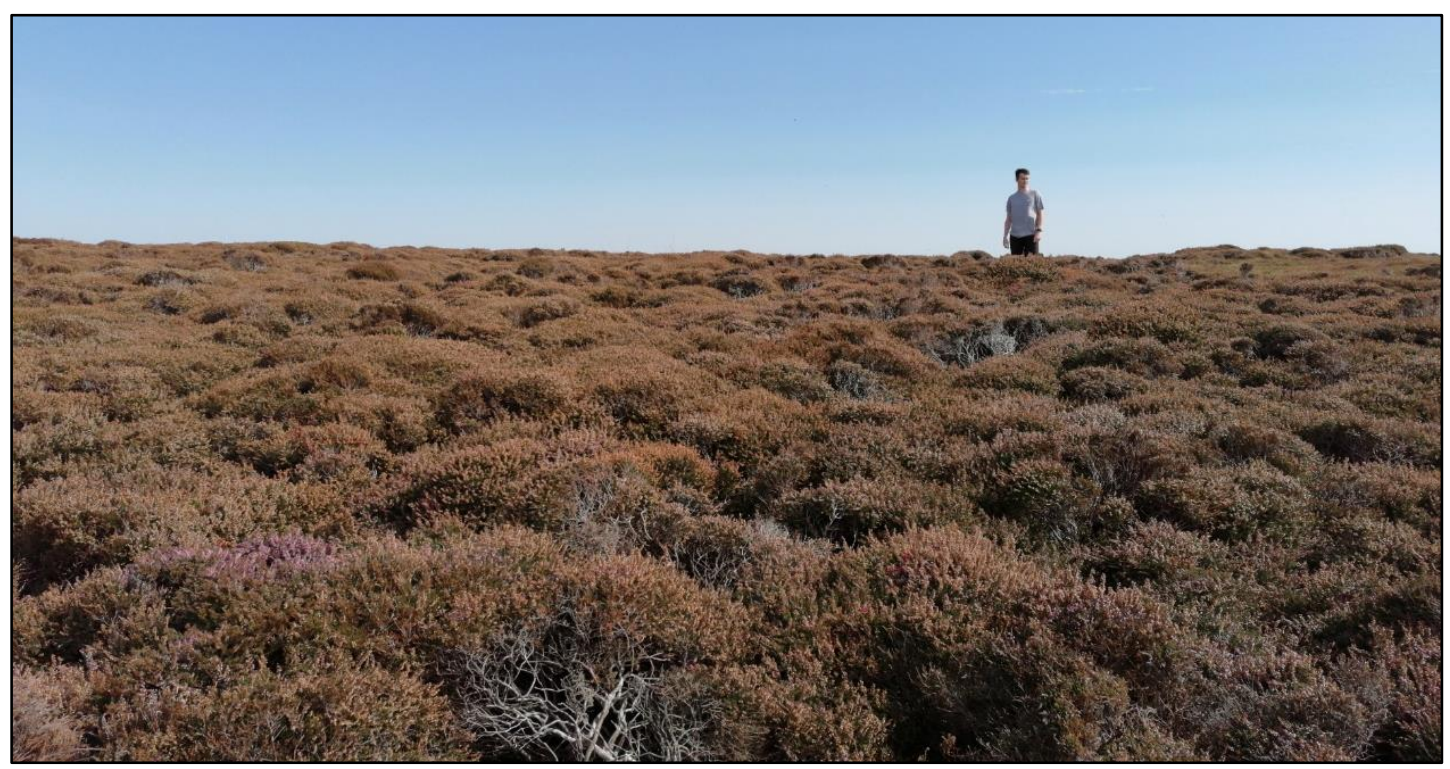

Figure 4.1: Overview of the long unburnt area at Site A. Photograph taken at Mynydd Llangorse, south Wales (August 2018). 


\subsubsection{Site selection}

To select the sites used in this study a range of data, and site visits, were used to identify upland (300-600 m) areas within the Brecon Beacons National Park complying with a set of environmental criteria. These criteria comprised of: soil type (acid upland soils with a shallow surface organic layer $<50 \mathrm{~cm}$ ), low grazing pressure (approx. $<1 \mathrm{ha}^{-1}$ year $^{-1}$ ), recreational walking pressure (low), topography (containing plateaued sections $<10^{\circ}$ slope) and a habitat type comprising primarily of European dwarf-shrub heath (e.g. NVC H12 C. vulgaris - V. myrtillus heath) (JNCC, 2009; British Geological Survey, 2018; Cranfield University, 2018).

These environmental criteria were then overlaid with wildfire data from the past 25years to locate areas which have experienced a significant wildfire $\left(>1 \mathrm{~km}^{2}\right)$ and not burnt again, in addition to unburnt areas which have not experience any fire activity over this period. Wildfire data was obtained from National Park records and archived Landsat 1-8 and Sentinel 2 imagery (accessed via USGS LandsatLook). This information identified a collection of eight appropriate areas, four burnt areas at various stages of post-fire recovery time: <1-year (approx. 3 months) (Site A), 3-years (Site B), 7-years (Site C) and 11-years (Site D), and four paired long-unburnt (>25years) areas, one for each burnt area (Table 4.1; see also map in Figure 3.2, Chapter 3). When locating each long unburnt area, particular care was taken to assess why a given fire may have terminated where it did (e.g. topography, habitat type, obstruction or via human extinguishing) to ensure the selection of sufficiently comparable unburnt areas. Each long unburnt area was located as close as possible to its paired burnt area whilst ensuring this did not represent a substantial change in conditions (e.g. vegetation composition or soil type) (Supp. Figure 3.1-3.4).

These sites all represent areas of freely draining sandy to loamy shallow soils, are highly acidic and have moderate to high organic matter content at the soil surface (UK Soil Observatory, 2018). Site A is within an area of Cambisol soils and Sites B, C and D are within Podzol soils (Table 4.1; Figure 4.2). Geologically, these sites reside primarily above quarzitic sandstone formations ranging from South Wales lower coal measures sandstone (318-319 million years old) (Sites B and C) to Twrch formation sandstone (319-329 million years old) (Site D) and Senni formation sandstone (393411 million years old) (Site A) (Table 4.1) (British Geological Survey, 2018). 


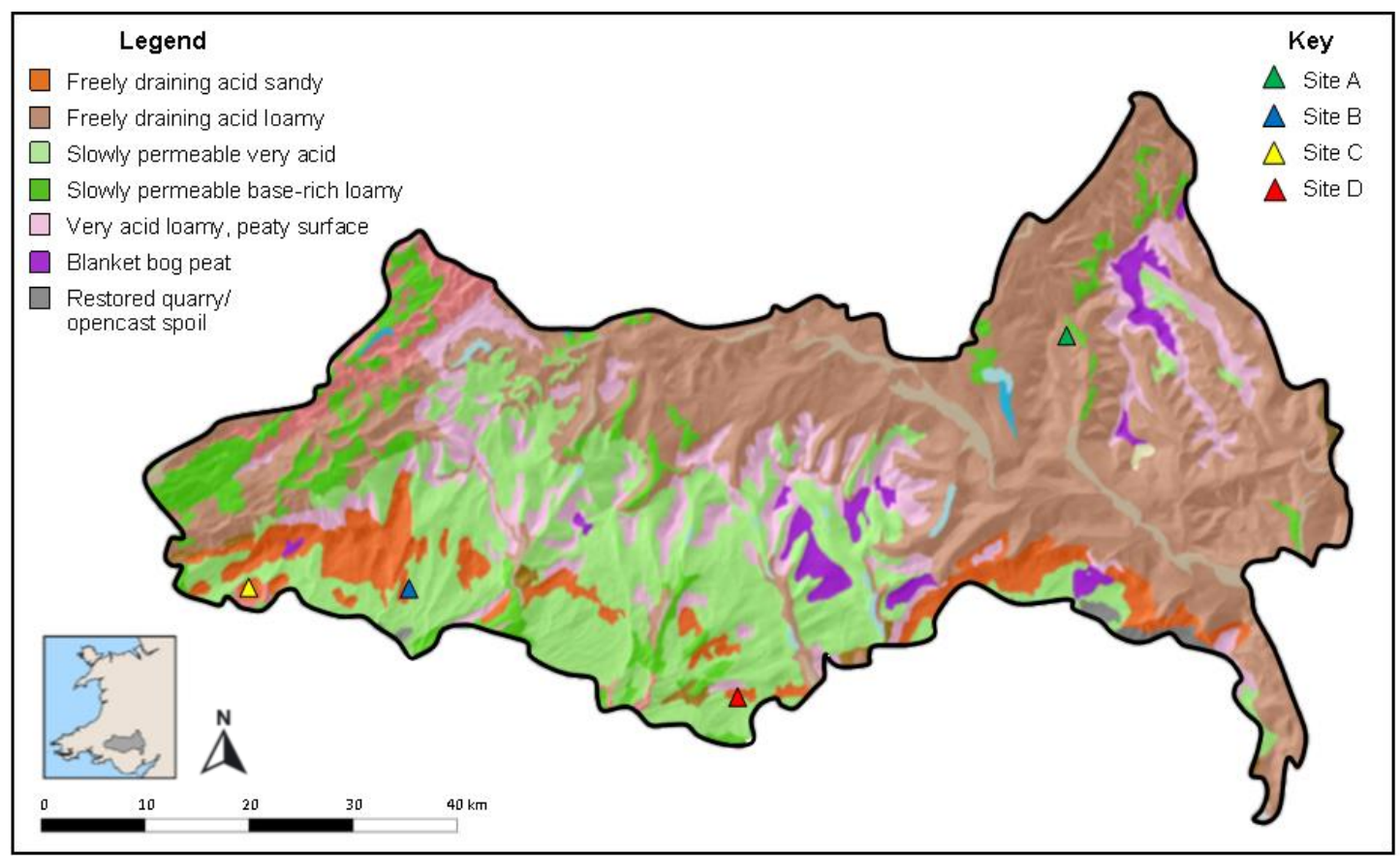

Figure 4.2: Soil type map of the Brecon Beacons National Park (S. Wales, UK). Locations of the four sampling sites used in this study are also highlighted. See Supplementary Material Figure 3.1-3.4 for further site detail.

These sites were chosen for inclusion in this study based on their compliance with the selection criteria (e.g. similar elevation, topography, soil type, vegetation cover, grazing and recreational pressure) and similarity of habitat type (i.e. vegetation community composition and diversity) established in Chapter 3. Statistical analyses conducted in Chapter 3 suggest there are no significant differences when comparing between long unburnt area diversity (S-W diversity) at all sites, or between vegetation community composition (derived from species occurrence and cover data) at Site A, B and C. The unburnt area at Site D did, however, significantly differ in community composition from the unburnt areas at Sites A, B and C (see Chapter 3: subsection 3.2.4).

\subsubsection{Fire weather conditions}

Fire severity could not be directly monitored for each fire event within this space-fortime substitution methodology. To address this, estimates of burn conditions and fire behaviour have been calculated for each of the four fire events to help assess their comparability and to contextualise any subsequent differences in soil physical and 
chemical properties. To conduct these analyses a component of the Canadian Forest Fire Danger Rating System (CFFDRS) was used to produce estimates of (De Groot, 1998; De Jong, 2016):

- Fine fuel moisture content (FFMC) - a numerical rating for the moisture content of the surface litter layer (including mosses and other fine fuels).

- Duff moisture code (DMC) - indicates the moisture content of the upper-most loosely compacted organic layer (approx. $<10 \mathrm{~cm}$ depth).

- Drought code (DC) - indicates the moisture content in the deeper more compact organic matter layers (approx. 10-20 cm depth).

- Initial spread rate (ISI) - indicates the expected rate of fire spread using a combination of FFMC and wind speed.

- Fire weather index values (FWI) - a numerical rating for the fire frontal intensity estimated by combining the ISI with a weighted combination of DMC and DC. FWI provides a good general indicator of overall fire danger conditions (i.e. potential fire severity).

These estimates suggest burn conditions were relatively similar for each of the four fire events particularly in relation to FFMC, a crucial determinant of burn severity, and FWI, an important proxy for wildfire risk (Table 4.1). Conditions during the fire events at Sites B, C and D all displayed DMC values $<20$ and DC values $<100$ which suggests moisture levels would have likely limited combustion within the surface duff layer and prevented combustion within the deeper more compact organic layers (Alexander and Coles 2001; Davies et al. 2013).

Moisture levels were, however, notably lower during the fire event at Site A with elevated DMC (35.7) and DC (212.6) in comparison to the other fires (Table 4.1). Whilst this increases the probability of combustion in the duff and the surface organic soil layers during the fire event at Site A, high to extreme fire behaviour is thought not to occur until DMC >60 and DC >300 (Alexander and Coles 2001). This information coupled with the almost total removal of vegetative cover, but limited combustion of topsoil observed in most areas following the 2018 fire (Site A), suggests these fire events were likely of moderate to high vegetation burn severity but low soil burn severity. 
Pre-fire above-ground fuel loads were estimated to be between $1.5-2.2 \mathrm{~kg} \mathrm{~m}^{-2}$ across the sites using the vegetation data collected from the long unburnt areas (e.g. mature stands with average $C$. vulgaris cover of $64 \%$ and height $70 \mathrm{~cm}$ ) and information from studies in similar C. vulgaris dominated habitat types (Figure 3.1) (Davies, et al. 2008, 2009; Grau-Andrés et al. 2018).

Full analytical details are provided in subsection 4.2.8.
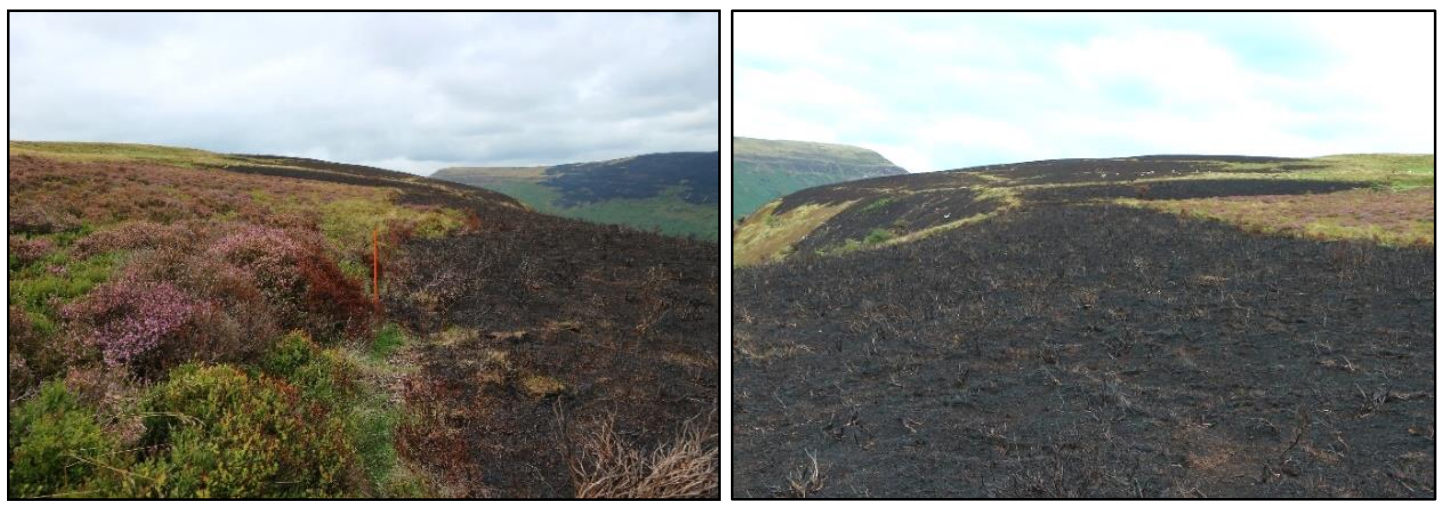

Figure 4.3: Conditions at Site A following the wildfire event assessed in this study. Almost total removal of above-ground dwarf-shrub heath vegetation (NVC H12) but limited soil organic matter combustion (Low soil burn severity). Photo taken July 2018. 
Table 4.1: Detailed site descriptions and wildfire burn conditions. Burn conditions include estimates of; fine fuel moisture content (FFMC), duff moisture code (DMC), drought code (DC), initial spread rate (ISI) and fire weather index values (FWI) derived from weather data from a monitoring station in the northern Brecon Beacons (Sennybridge). Soil organic depth average (standard deviation), estimated using field rod depth measurements. Soil type and bedrock geology have also been included (British Geological Survey, 2018; UK Soil Observatory, 2018).

\begin{tabular}{|c|c|c|c|c|c|}
\hline & & Burn conditions & $\begin{array}{c}\begin{array}{c}\text { Organic soil } \\
\text { depth average } \\
\text { (cm) }\end{array} \\
\end{array}$ & Soil type & $\begin{array}{l}\text { Bedrock } \\
\text { geology }\end{array}$ \\
\hline 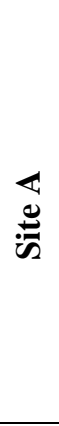 & 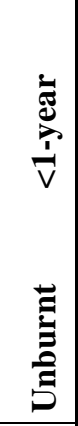 & $\begin{array}{l}\text { - Burnt July } 2018 \\
\text { - FFMC: } 85.5 \\
\text { - DMC: } 35.7 \\
\text { - DC: } 212.6 \\
\text { - ISI: } 4.2 \\
\text { - FWI: } 8.6 \\
\text { Unburnt for }>25 \text { years }\end{array}$ & $\begin{array}{l}30(9.5) \\
40(6)\end{array}$ & $\begin{array}{c}\text { Freely } \\
\text { draining acid } \\
\text { loamy soils. } \\
\text { Cambisol soils }\end{array}$ & $\begin{array}{l}\text { Senni } \\
\text { formation } \\
\text { sandstone }\end{array}$ \\
\hline$\stackrel{\infty}{\infty}$ & 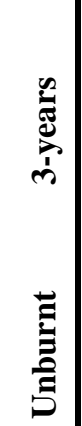 & $\begin{array}{l}\text { - Burnt April } 2015 \\
\text { - FFMC: } 86.9 \\
\text { - DMC: } 16.2 \\
\text { - DC: } 39.3 \\
\text { - ISI: } 5.6 \\
\text { - FWI: } 7.8 \\
\text { Unburnt for >25 years }\end{array}$ & $\begin{array}{l}35(10.3) \\
41(11)\end{array}$ & $\begin{array}{c}\text { Freely } \\
\text { draining acid } \\
\text { loamy and } \\
\text { sandy soils. } \\
\text { Podzol soils }\end{array}$ & $\begin{array}{c}\text { South Wales } \\
\text { lower coal } \\
\text { measures } \\
\text { sandstone }\end{array}$ \\
\hline 导 & 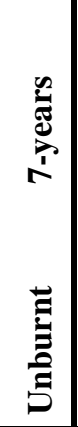 & $\begin{array}{l}\text { - Burnt April } 2011 \\
\text { - FFMC: } 88.8 \\
\text { - DMC: } 19.7 \\
\text { - DC: } 58.7 \\
\text { - ISI: } 5.9 \\
\text { - FWI: } 9.6 \\
\text { Unburnt for }>25 \text { years }\end{array}$ & $\begin{array}{l}28(12) \\
21(3.4)\end{array}$ & $\begin{array}{c}\text { Freely } \\
\text { draining acid } \\
\text { loamy and } \\
\text { sandy soils. } \\
\text { Podzol soils }\end{array}$ & $\begin{array}{c}\text { South Wales } \\
\text { lower coal } \\
\text { measures } \\
\text { sandstone }\end{array}$ \\
\hline 竞 & 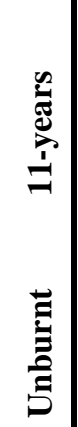 & $\begin{array}{l}\text { - Burnt April } 2007 \\
\text { - FFMC: } 86.7 \\
\text { - DMC: } 16.8 \\
\text { - DC: } 64.1 \\
\text { - ISI: } 5.4 \\
\text { - FWI: } 8.5 \\
\text { Unburnt for }>25 \text { years }\end{array}$ & $\begin{array}{l}42(10.8) \\
51(7.3)\end{array}$ & $\begin{array}{c}\text { Freely } \\
\text { draining acid } \\
\text { loamy and } \\
\text { sandy soils. } \\
\text { Podzol soils }\end{array}$ & $\begin{array}{l}\text { Twrch } \\
\text { formation } \\
\text { sandstone }\end{array}$ \\
\hline
\end{tabular}




\subsubsection{Experimental design and laboratory methods}

To investigate the impacts of fire at these sites, soil core samples were collected at each of the four selected burnt areas (elapsed time since burning, <1, 5, 7 and 11years), in addition to at the four long unburnt areas (>25-years unburnt).

Sampling locations were identified using a random quadrat $\left(1 \mathrm{~m}^{2}\right)$ sampling method in each area using areas fitting the original selection criteria (Harris et al., 2011a; Whitehead and Baines, 2018). In each burn area the sampling location was located within the burnt perimeter but away from the edge of each burn extent to avoid possible fire edge effects (Braithwaite and Mallik, 2012). Little is known about the differences in impacts of the edges created by wildfires, however, it is relatively well established that edge effects created by other disturbances such as, cutting, agriculture, disease and topography can cause notable abiotic and biotic differences in overlying plant communities (Harper et al., 2004; Ries et al., 2004). These changes are dictated by, for example, changes in light, temperature, moisture and wind (Harper et al., 2004; Ries et al., 2004). Due to the potential of differences in these factors also causing changes in soil physiochemical properties, sampling locations were excluded from fire edge areas (approximately >10 m) (Braithwaite and Mallik, 2012).

Soil cores were collected using 5 x $5 \mathrm{~cm}$ sampling cylinders at 30 locations per site between June and November 2018 (15 in each burnt area +15 in each unburnt area) (120 total). One soil core was collected from within each of the randomly selected vegetation quadrats surveyed in the previous chapter (Chapter 3). Surface litter was removed before inserting the cores into the soil surface. Samples were then sealed and transported to cold storage $\left(4^{\circ} \mathrm{C}\right)$ before analysis. All soil cores were subsequently divided into two depth categories, $0-2.5 \mathrm{~cm}$ and $2.5-5 \mathrm{~cm}$ to allow for the extent to which fire impacts penetrate into the soil profile to be assessed (60 per site: 240 samples in total).

To provide contextual information about the vertical extent of the organic soil layer three soil depth measurements were also taken, using a peat depth rod, around each core sampling point (Table 4.1). 


\subsubsection{Soil physical characteristics and $p H$}

Three parameters were selected for soil physical characterisation because of their importance for soil health as well as, for their association to fire impacts (Certini, 2005). Despite not being a 'physical' characteristic of soil, $\mathrm{pH}$ has also been included as a fourth parameter in this subsection purely for methodological consistence within this study. pH was assessed here using the same number of samples as the three other physical characteristics, and thus statistically analysed in a similar manner. This is in contrast to the remaining chemical characteristics (see subsection 4.2.8). These analyses were conducted using 24 of the soil core samples from each site (12 in each burnt area +12 in each unburnt area), accounting for 192 samples in total once cores were subdivided into the two depth categories $(0-2.5 \mathrm{~cm}$ and $2.5-5 \mathrm{~cm})$. Analyses were conducted within a constant temperature room set at $20^{\circ} \mathrm{C}$ (45-55\% relative humidity) and were as follows;

(i) Hydrophobicity: assessed using water drop penetration time tests (WDPT) at the surface $(0 \mathrm{~cm}), 2.5 \mathrm{~cm}$ and $5 \mathrm{~cm}$ depths. The $5 \mathrm{~cm}$ WDPT tests were conducted using the base of each core (Wessel, 1988; Doerr et al., 1998). First, core samples were allowed to equilibrate from field moist conditions within a constant temperature room for $24 \mathrm{~h}$ to reduce variations in preceding atmospheric humidity (Doerr et al., 2002; Doerr et al., 2006). Weighing the samples at this point allowed soil water content of each core to be calculated subsequently. This enabled its potential in influencing water repellency to be examined (Supp. Table 4.9). Five individual drops of distilled water (approximately $0.05 \mathrm{ml}$ each) were applied to the soil surface of each sample using a syringe. Time taken for each drop to completely penetrate was then recorded. Penetration times were then collated into time-intervals as outlined by Bisdom et al. (1993). This allowed sample classification into a set of widely used repellency persistence classes with ascribed descriptive ratings from wettable $(\leq 5 \mathrm{~s})$, slight (6-60 s), strong (61-600 s), severe (601-3600 s) and extreme (>3600 s). The median of the five class readings was used as representative of the repellency level of that sample (Doerr et al., 2006). 
(ii) Water holding capacity (WHC): Gravimetric soil water content (or WHC) was calculated after allowing cores to fully hydrate from the base with distilled water over a minimum of $24 \mathrm{~h}$ (or until fully saturated, i.e. constant weight. Max 72 h). Once saturated, cores were allowed to gravitationally drain (until constant weight) before being weighed to derive the maximum amount of water retained by the soil (Gardner, 1986; Campbell and Campbell, 2005; Voroney, 2019). Soil cores were subsequently oven dried at $105^{\circ} \mathrm{C}$ for $24 \mathrm{~h}$, or until constant weight, to derive the weight of the soil when dry (Schafer and Mack, 2010). The following equation was used: Water holding capacity (\%) $=[$ mass of saturated soil $(g)-$ mass of dried soil $(g)] \times 100$.

(iii) Soil bulk density (SBD): weight of the dry soil cores was taken from the previous step, derived from oven drying soil cores at $105^{\circ} \mathrm{C}$ for 24 $\mathrm{h}$, or until constant weight. Soil bulk density was then calculated using the dry sample weight and the known volume of the core steel cylinder (Walter et al., 2016; Al-Shammary et al., 2018). The following equation was used: Bulk density $\left(\mathrm{g} / \mathrm{cm}^{3}\right)=$ mass of dry soil $(\mathrm{g}) /$ soil volume $\left(\mathrm{cm}^{3}\right)$.

(iv) $\mathrm{pH}$ : conducted using a subsample of each original soil core after the samples, in field moist conditions, had been allowed to equilibrate within a constant temperature room for $24 \mathrm{~h}\left(20^{\circ} \mathrm{C}\right.$ and $45-55 \%$ relative humidity). Subsamples were used for the $\mathrm{pH}$ testing to ensure results were not affected by any of the other analytical processes (e.g. ovendrying). This soil was placed in a 1:2.5 (soil:distilled water) (w/v) solution, shaken for $30 \mathrm{~s}$ to homogenise then allowed to stand and settle for 10 minutes (Granged et al., 2011a; Valkó et al., 2016). pH was then derived using a standard soil $\mathrm{pH}$ probe (Thomas, 1996; Schafer and Mack, 2010).

\subsubsection{Soil chemical characteristics}

In addition to $\mathrm{pH}$, eight soil chemical parameters were assessed here based on their importance for soil health, biogeochemical processes and overall soil functioning, as 
well as for their association with fire impacts (Rydin and Jeglum, 2006; De Graaf et al., 2009). These include total carbon (C) and total nitrogen (N) as well as, bioavailable phosphorus (Olsen-P), aluminium $\left(\mathrm{Al}^{+3}\right)$, calcium $\left(\mathrm{Ca}^{+2}\right)$, magnesium $\left(\mathrm{Mg}^{+2}\right)$, potassium $\left(\mathrm{K}^{+}\right)$and sodium $\left(\mathrm{Na}^{+}\right)$. These analyses were conducted using six of the soil core samples from each site ( 3 in each burnt area +3 in each unburnt area). Once subdivided into the two depth categories $(0-2.5 \mathrm{~cm}$ and $2.5-5 \mathrm{~cm})$ this accounted for 12 samples per site, 48 in total. Each sample was sieved to $<2 \mathrm{~mm}$ and homogenised before analysis to ensure each subsample used during the following procedures represents a mean value for that sample. Chemical analysis was conducted as follows;

i) Total carbon and nitrogen: Total $\mathrm{C}$ and $\mathrm{N}$ concentrations were measured using a total combustion analyser (LECO TruSpec CHN Elemental Analyzer). To do this, $\sim 100 \mathrm{mg}$ of ground soil from each sample was placed into a tin foil cup and then into the total combustion analyser. Samples enter a high-temperature furnace, allowing the sample to combust. The combustion converts carbon into $\mathrm{CO}_{2}$ and nitrogen in $\mathrm{N}_{2}$. The quantity of these gases can then be detected, using an IR sensor for $\mathrm{CO}_{2}$ and a thermal conductivity detector for $\mathrm{N}_{2}$ (Sparks et al., 1996).

ii) Bioavailable phosphorus (Olsen-P): Bioavailable phosphorus was measured using the Olsen-P method (Olsen et al., 1954). To do this, 2.5 $\mathrm{g}$ of the soil from each sample was added to $0.5 \mathrm{~g}$ active carbon (previously washed). Then $50 \mathrm{ml}$ of sodium bicarbonate $(0.5 \mathrm{~N})$ reagent, adjusted to $\mathrm{pH} 8.5$, was added to start the phosphate extraction. Once mixed, this solution was placed in a centrifuge for 30 min then filtered to separate the soil particles from the solution. $5 \mathrm{ml}$ of the extracted solution was then combined with $0.5 \mathrm{ml}$ of sulfuric acid $(5 \mathrm{~N})$ and left for $24 \mathrm{~h}$ to liberate $\mathrm{CO}_{2} .2 .5 \mathrm{ml}$ of colour solution (sulfuric and ascorbic acid) was added for $1 \mathrm{~h}$ to form a blue complex. Olsen-P was then estimated by the level of light absorption of this complex at 880 nm using a colorimeter (Model Jasco V630) (Kelly et al., 2018). Olsen$\mathrm{P}$ has a long history of usage as an index of soil-available $\mathrm{P}$ and is able to be successfully used on both acid and calcareous (alkaline) soils as 
the extractant $\left(\mathrm{NaHCO}_{3}\right)$ acts through $\mathrm{pH}$ and ion effects (Kamprath and Watson, 1980; Cox, 1994; Schoenau and O’Halloran, 2008).

iii) Effective cation exchange capacity (ECEC): $\mathrm{Ca}^{+2}, \mathrm{Mg}^{+2}, \mathrm{~K}^{+}, \mathrm{Na}^{+}$and $\mathrm{Al}^{+3}$ cation concentrations were analysed using a Flame Atomic Absorption Spectrometer (Perkin Elmer PinAAcle 500) (Helmke and Sparks, 1996; Sparks et al., 1996). To do this $5 \mathrm{~g}$ of soil from each sample was added to $25 \mathrm{ml} 1 \mathrm{M}$ ammonium acetate, mixed and left for $24 \mathrm{~h}$. Next, $75 \mathrm{ml}$ of the same solution was added and then filtered to complete to extraction. $\mathrm{Mg}^{+2}, \mathrm{Ca}^{+2}$ and $\mathrm{Al}^{+3}$ were then measured using atomic absorption spectrophotometry. $\mathrm{K}^{+}$and $\mathrm{Na}^{+}$were measured using atomic emission spectrometry (Chapman, 1965; Murphy and Riley, 1986; van Reeuwijk, 2002). The concentrations of these cations were then used to calculate ECEC, the following equation was used: Effective CEC $($ ECEC $)=$ Exchangeable base cations $($ meq/lo0g $)+$ Exchangeable acid cations $(m e q / 100 g)$. E.g. $E C E C=(C a+M g+K+$ $\mathrm{Na})+\mathrm{Al}$

\subsubsection{Statistical analysis}

Fire weather index values were calculated using the "cffdrs" package in $\mathrm{R}$ version 4.0.2. (Wang et al. 2017). This package enables the calculation of the two main components of the Canadian Forest Fire Danger Rating System (CFFDRS) (Van Wagner and Pickett, 1985), the Fire Weather Index (FWI) System and the Fire Behaviour Prediction (FBP) System. The analyses conducted here focused on the calculation of five of the components produced by the FWI System (Van Wagner, 1987), three fuel moisture codes; Fire Fuel Moisture Code (FFMC), Duff Moisture Code (DMC) and Drought Moisture Code (DC), and two fire behaviour indexes; Initial Spread Index (ISI) and Fire Weather Index (FWI) (Table 3.3).

To calculate these code and indices values the FWI System (using function "fwi") required daily noon weather observation data: temperature $\left({ }^{\circ} \mathrm{C}\right)$, relative humidity $(\%)$, wind speed $(\mathrm{km} / \mathrm{h})$ and 24-hour rainfall $(\mathrm{mm})$ from a closely located monitoring station. The data used here was provided by the Met Office from a monitoring station in the northern Brecon Beacons (Sennybridge: NGR 2894E 2417N, Altitude 407 
metres). In addition to the latitude and longitude of the monitoring station to assess whether day length adjustments are required to correctly parameterise the "fwi" function. To calculate the moisture code values accurately 3 -months of daily weather data were provided prior to each individual fire event. Moisture code values are cumulative, i.e. reliant on the previous days moisture values, and sufficient data is, therefore, required to ensure output values are unaffected by the initial default fuel moisture values used by the "fwi" function (e.g. $\mathrm{FFMC}=85, \mathrm{DMC}=6, \mathrm{DC}=15$ ).

The CFFDRS provides a globally applicable means of assessing fire weather conditions and is widely used as a tool in fire management, alert systems and active fire growth and intensity predictions (Lawson and Armitage, 2008; de Jong et al. 2016; Wang et al. 2017). This method also provides a standardised means of contextualising burn conditions and fire severity in studies assessing historic fire events such as this (Davies and Legg, 2016; Davies et al. 2013).

The effect of burning on the soil physical characteristics bulk density (BD), water holding capacity (WHC), soil hydrophobicity (WDPT) as well as on $\mathrm{pH}$ were examined using several techniques and packages within $\mathrm{R}$ version 4.0.2. (Fox and Weisberg, 2019a). Two general questions were being assessed through these analyses; i) do burnt and unburnt area soil characteristics differ within each site (e.g. Site A burnt vs Site A unburnt), and ii) do burnt and unburnt area soil characteristics differ between each site (e.g. Site A unburnt vs Site B unburnt)

Initial exploratory analyses (e.g. histograms and Shapiro-Wilks normality tests) found each of the response variables were non-normally distributed with varying distribution types (e.g. varying degrees of positive or negative skewness). In order to provide consistency across the analyses of these data, each response variable was subjected to data transformation. To identify the most appropriate transformation for each variable the function "bestNormalize" ("bestNormalize" package) was employed (Medina et al. 2019; Peterson, 2019).

The "bestNormalize" function implements repeated cross-validations to estimate the Pearson's P statistic, divided by its degrees of freedom, (i.e. the 'normality statistic') for multiple transformation types (e.g. arcsine, Box-Cox, Exp(x), Log, orderNorm, sqrt $(x+a)$ and Yeo-Johnson) (Medina et al. 2019). The function is designed to identify and perform the transformation that produces the lowest $\mathrm{P}$ statistic and, therefore, 
returning the 'most normal' dataset. Normality in this context refers to the transformed values following a Gaussian distribution (Peterson, 2019). The orderNorm transformation was subsequently selected as the most appropriate transformation for the $\mathrm{pH}$ and WHC datasets, and the Box-Cox transformation was selected for the BD and WDPT datasets (Box and Cox, 1964; Peterson and Cavanaugh, 2019). Data transformations are commonly used in soil science when dealing with skewed nonnormal datasets. The transformed variables were then checked for normality using histograms and Shapiro-Wilks normality test (function "shapiro.test" - "MASS" package).

In keeping with the analytical approach in Chapter 3 (subsection 3.2.5.), linear models (function "lm") were used to assess the now normalised response variables within a nested model structure. A nested structure was imposed throughout to ensure the predictor "Status" (Burnt or Unburnt) was confounded within "Site" (Site A-D) (hereafter; site:status interaction). This design was chosen primarily as only one sampling area is provided per burn age (Site A: <1-year, Site B: 3-years, Site C: 7years and Site D: 11-years post-fire) and therefore, there is no true treatment replication within the study.

Once regression analyses were conducted, model residuals were checked visually to ensure normality assumption had been met (using residual and Q-Q plots). In addition, Bonferroni Outlier tests (function "outlierTest" - "car" package) were conducted to determine if there were any outlier observations within the model regression which might suggest miscoding, invalid data or incorrect model conceptualisation (Weisberg, 2014; Fox \& Weisberg, 2019b).

To explore interactions found between the response (BD, WHC, WDPT and $\mathrm{pH}$ ) and predictor variables (site:status and Depth) within the computed models, analysis of variance tests were conducted to assess the level of significance of these interactions (i.e. extract test statistics and p-values). The function "Anova" ("car" package) was used to conduct type III variance tests (Fox \& Weisberg, 2019). Type III tests, in contrast to the more traditional type I or II, are conducted in light of interaction terms (e.g. nesting), as well as all effects within the model. This is crucial for maintaining consistency with the nested design and to account for repeated measures data (Hand $\&$ Taylor, 1987; Fox, 2016). 
Post-hoc pairwise comparisons were then conducted, where significant results were obtained, to examine the source of differences within the data. To do this, the “emmeans" function was used ("emmeans" package) as it allows testing within a nested structure, whilst automatically correcting for multiple comparisons (Searle et al. 1980; Lenth et al. 2018). Correction was conducted using the Tukey method.

Due to the limited amount of soil chemical data able to be obtained within this study ( $n=3$ per sampling area and soil depth), in contrast to the soil physical data ( $n=12$ per sampling area and soil depth), no quantitative analyses were conducted using the soil chemical data. A sample size of $n=3$ is too small to reliably assess variance or conduct inferential statistics. This source of post-fire soil information will therefore be examined qualitatively for the remainder of this study, helping to contextualise discussion and/or infer area conditions.

\subsection{Results}

The depth measurements taken across the sampling sites assessed show organic soil layer depth averaged between $21 \pm 3.4$ to $51 \pm 7.3 \mathrm{~cm}$ depth. All soil core samples ( 5 x $5 \mathrm{~cm}$ cores) were, therefore, collected within the organic soil layer (Table 4.1). This is important for the interpretation of the following results, particularly as it separates these samples from the largely mineral soils found in heaths elsewhere.

\subsubsection{Soil physical characteristics and $p H$}

Average soil bulk density (BD) values within the soil surface layer $(0-2.5 \mathrm{~cm})$ in the burnt areas ranged between $0.1 \pm<0.1 \mathrm{~g} \mathrm{~cm}^{-3}$ in Site B (3-years post-fire) and $0.3 \pm$ $0.1 \mathrm{~g} \mathrm{~cm}^{-3}$ in Site A $(<1$-year post-fire). In the unburnt sampling areas, BD similarly varied from between $0.2 \pm 0.05 \mathrm{~g} \mathrm{~cm}^{-3}$ in Site B and $0.3 \pm 0.1 \mathrm{~g} \mathrm{~cm}^{-3}$ in Site A (Table 4.2). At the subsurface ( $2.5-5 \mathrm{~cm}$ depth), BD values across the burnt areas ranged from $0.2 \pm 0.1 \mathrm{~g} \mathrm{~cm}^{-3}$ at Site B (3-years post-fire) to $0.4 \pm 0.2 \mathrm{~g} \mathrm{~cm}^{-3}$ at Site A $(<1$-year postfire) (Table 4.2). In the subsurface unburnt areas BD values similarly ranged from 0.3 $\pm 0.1 \mathrm{~g} \mathrm{~cm}^{-3}$ in Site B to $0.4 \pm 0.2 \mathrm{~g} \mathrm{~cm}^{-3}$ in Site A (Table 4.2). 
Table 4.2: Average values for soil bulk density (BD), water holding capacity (WHC) and $\mathrm{pH}$ at all sampling areas ( $\mathrm{n}=12$ per sampling location) and both soil depths $(0-2.5$ and $2.5-5 \mathrm{~cm}$ depth). BD is given in $\mathrm{g} \mathrm{cm}^{-3}$ and WHC as percentage (\%). Standard deviation for each value is provided in brackets. Site identification divided into: Site $=$ Site A, B, C, D; Status $=$ Burnt $(<1,3,7,11$-years post-fire), Unburnt ( $>25$ years post-fire); Depth $=0-25 \mathrm{~cm}, 2.5-5 \mathrm{~cm})$.

\begin{tabular}{|c|c|c|c|c|c|c|c|c|c|}
\hline & & \multicolumn{2}{|c|}{ Site A } & \multicolumn{2}{|c|}{ Site B } & \multicolumn{2}{|c|}{ Site C } & \multicolumn{2}{|c|}{ Site D } \\
\hline & & $<1$-year & Unburnt & 3-years & Unburnt & 7-years & Unburnt & 11-years & Unburnt \\
\hline \multirow{3}{*}{ 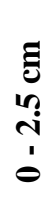 } & $\mathrm{BD}$ & $0.3(0.1)$ & $0.3(0.1)$ & $0.1(<0.1)$ & $0.2(0.1)$ & $0.2(<0.1)$ & $0.2(0.1)$ & $0.2(0)$ & $0.2(<0.1)$ \\
\hline & WHC & $46.3(24)$ & $66.6(12)$ & 72.7 (13) & $70.8(9)$ & $71.8(14)$ & $62.3(19)$ & 72.1 (13) & $68.8(18)$ \\
\hline & $\mathrm{pH}$ & $4.9(0.4)$ & $3.7(0.4)$ & $4.2(0.2)$ & $3.7(0.3)$ & $4.5(0.1)$ & $4.5(0.2)$ & $4.4(0.1)$ & $4.3(0.3)$ \\
\hline \multirow{3}{*}{$\begin{array}{c}\text { J } \\
\text { in } \\
\text { in } \\
\text { in }\end{array}$} & $\mathrm{BD}$ & $0.4(0.2)$ & $0.4(0.2)$ & $0.2(0.1)$ & $0.3(0.1)$ & $0.2(0)$ & $0.4(0.1)$ & $0.3(<0.1)$ & $0.3(0.1)$ \\
\hline & WHC & $39.3(19)$ & 48.4 (18) & $66.4(12)$ & 60.7 (13) & $62.1(15)$ & 37.4 (14) & $71.3(9)$ & $63.3(15)$ \\
\hline & $\mathrm{pH}$ & $4.2(0.3)$ & $3.7(0.4)$ & $4.2(0.1)$ & $3.9(0.8)$ & $4.4(0.1)$ & $4.5(0.2)$ & $4.2(0.3)$ & $4.4(0.2)$ \\
\hline
\end{tabular}

Regression of the BD data suggests there are interactions between the response and predictor variables within the data $\left(\mathrm{lm}: \mathrm{r}^{2}=0.52, \mathrm{df}=15\right.$, p-value $\left.=<0.05\right)($ Supp. Table 4.1). The model explains to majority of the variance within the response variable (lm: $\mathrm{r}^{2}=52$ or $52 \%$ ), and analysis of variance test found significant interactions between BD and site:status (Anova: Sum.Sq $=71.4, \mathrm{df}=7, \mathrm{~F}$-value $=19.7$, $\mathrm{p}$-value $=<0.05$ ), and depth (Anova: Sum.Sq $=25.7$, df $=1, \mathrm{~F}$-value $=49.7$, -value $=<0.05$ ). A considerable proportion of variance, however, remains unexplained by the model and provided predictor variables (i.e. site:status and depth). No significant interaction was found between BD and site: status:depth (Anova: $\mathrm{Sum} . \mathrm{Sq}=2.8, \mathrm{df}=7, \mathrm{~F}$-value $=0.8$, p-value $=0.6$ ).

Pairwise comparisons found no significant differences when comparing surface BD between the burnt and unburnt areas within each site (Figure 4.4; Supp. Table 4.2). Significantly lower BD was found in the burnt areas of Site B and C in comparison to their within-site unburnt areas in the subsurface soils (Figure 4.4; Supp. Table 4.2). These within-site comparisons are the means by which the impacts of the chosen fire events on soil conditions are evaluated within this study. The primary source of the interactions in the BD data appears to reside from comparisons between sites and depths as opposed to within-site differences. For example, pairwise differences in BD 
occurred at the surface with higher BD in the burnt area of Site A in comparison to Site B, and in the unburnt area of Site A in comparison to Site D. At the subsurface, significant differences were also apparent with higher BD in the burnt area of Site A in comparison to Site C (Figure 4.4; Supp. Table 4.2).

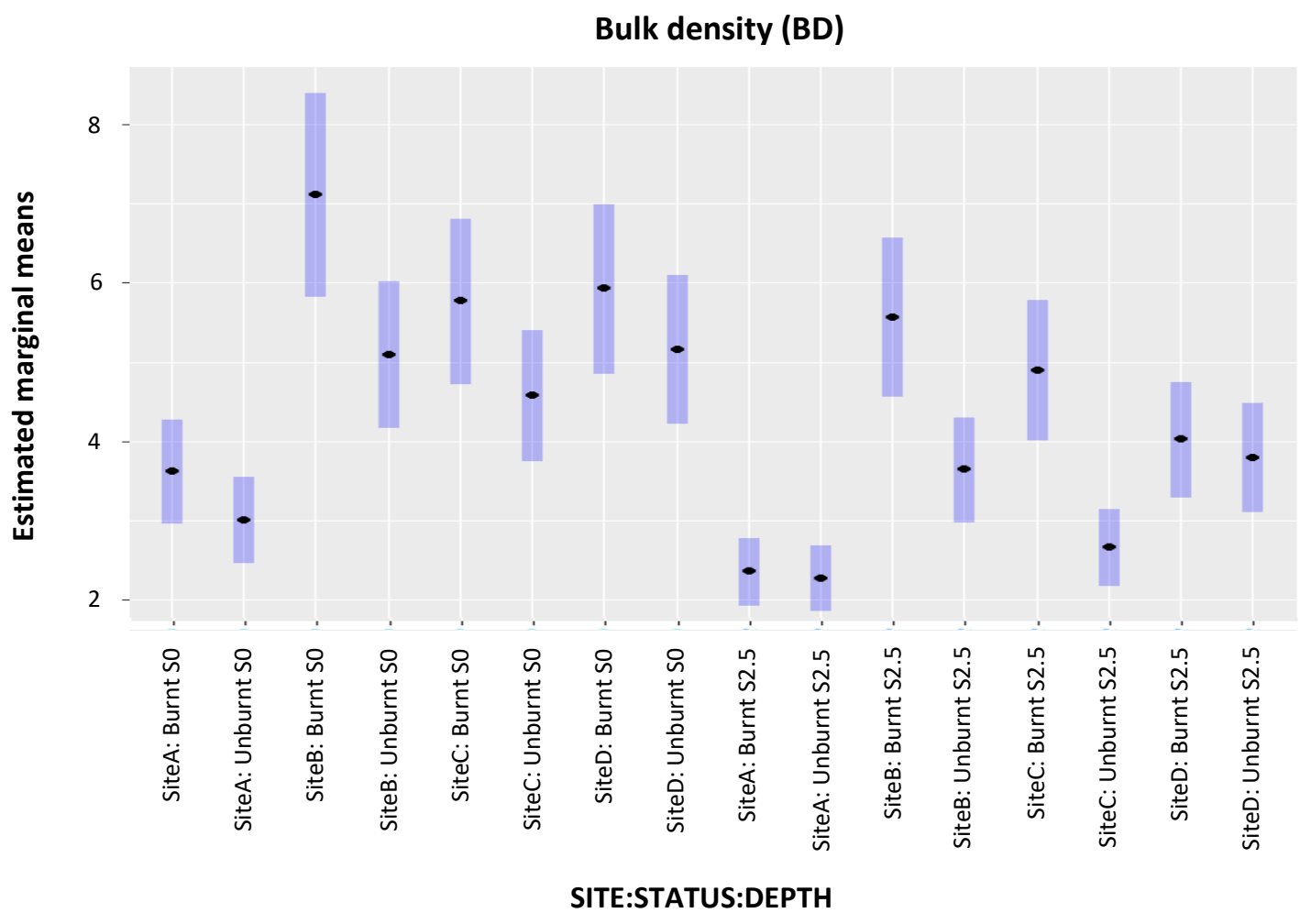

Figure 4.4: Graphic representation of the bulk density (BD) "emmeans" pairwise comparisons output. Estimated marginal means plotted with $95 \%$ confidence intervals (highlighted in blue) to assess differences in area bulk density. Areas with overlapping confidence intervals are judged to the statistically similar at the $95 \%$ level. Site $=$ SiteA, SiteB, SiteC, SiteD; Status = Burnt, Unburnt; Depth = S0 (surface layer), S2.5 (subsurface $2.5 \mathrm{~cm}$ ).

Water holding capacity (WHC) average values in the burnt areas, at the soil surface, ranged between $46.3 \pm 24 \%$ in Site A (<1-year post-fire) and $72.7 \pm 13 \%$ in the Site B (3-years post-fire). In the unburnt areas average WHC values ranged between $62.3 \pm$ $19 \%$ in Site C and $70.8 \pm 9 \%$ in Site B (Table 4.2). At the subsurface WHC values in the burnt areas ranged between $39.3 \pm 19 \%$ at Site A ( $<1$-year post-fire) and $71.3 \pm$ $9 \%$ at Site D (11-years post-fire). In the subsurface unburnt areas, WHC ranged from $37.4 \pm 14 \%$ in Site C to $63.3 \pm 15 \%$ in Site D (Table 4.2). 
Regression of the WHC data suggests there are interactions between the response and predictor variables within the data $\left(\mathrm{lm}: \mathrm{r}^{2}=0.52\right.$, df $=15$, $\mathrm{p}$-value $\left.=<0.05\right)$ (Supp. Table 4.3). The model, again, explains to majority of the variance within the response variable $\left(\mathrm{r}^{2}=52\right.$ or $\left.52 \%\right)$, however, a considerable proportion of variance remains unexplained by the site:status and depth interactions. Analysis of variance found significant interactions between WHC and site:status (Anova: $\mathrm{Sum} . \mathrm{Sq}=71.3 \mathrm{df}=7$, F-value $=19.5, \mathrm{p}$-value $=<0.05)$, and depth $($ Anova: $\mathrm{Sum} . \mathrm{Sq}=25.2, \mathrm{df}=1, \mathrm{~F}$-value $=$ 48.2, $\mathrm{p}$-value $=<0.05)$. No significant interaction was found between WHC and site: status:depth (Anova: Sum.Sq = 2.6, df = 7, F-value =0.7, p-value=0.7).

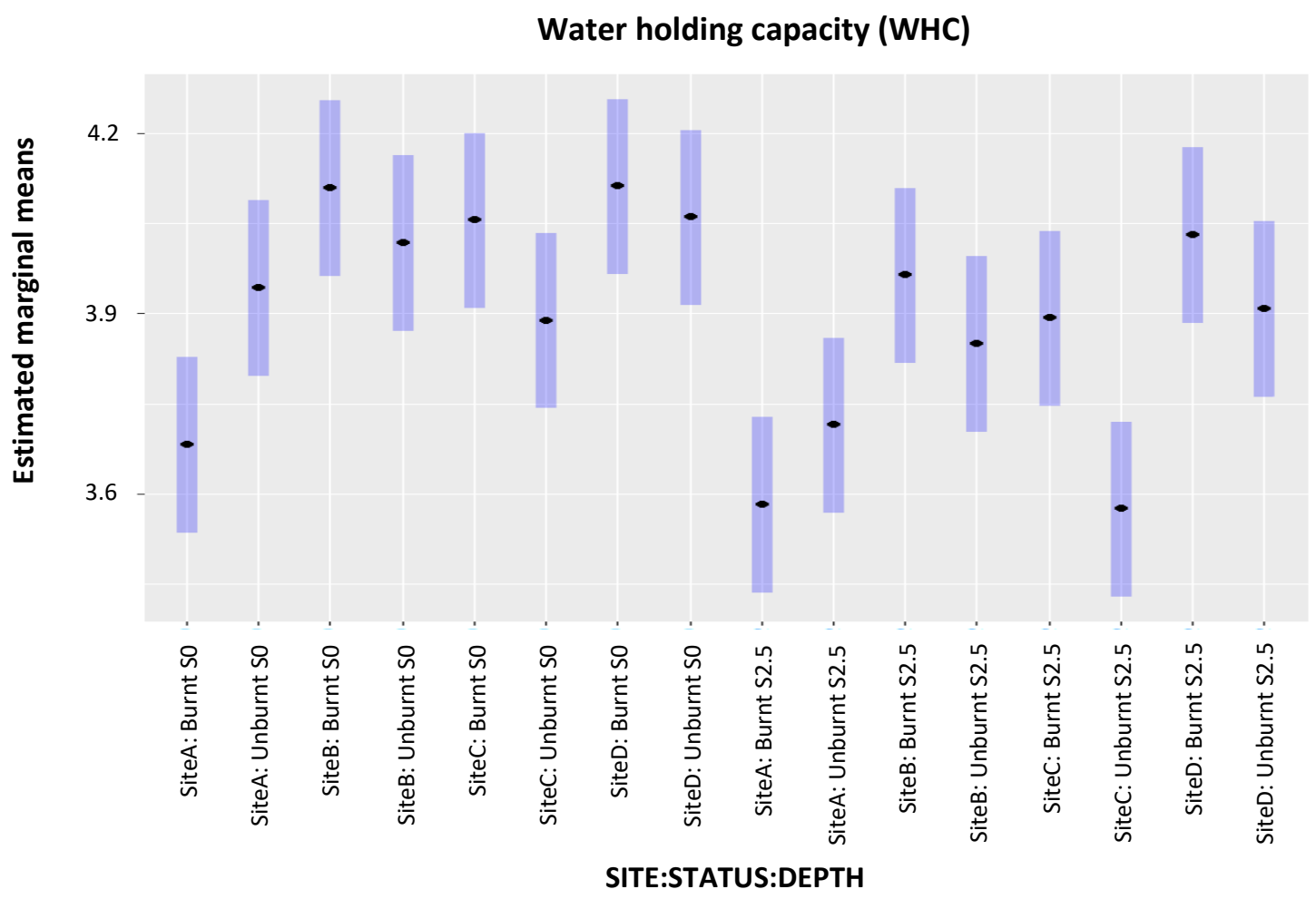

Figure 4.5: Graphic representation of the water holding capacity (WHC) "emmeans" pairwise comparisons output. Estimated marginal means plotted with 95\% confidence intervals (highlighted in blue) to assess differences in area water holding capacity. Areas with overlapping confidence intervals are judged to the statistically similar at the $95 \%$ level. Site $=$ SiteA, SiteB, SiteC, SiteD; Status = Burnt, Unburnt; Depth = S0 (surface layer), S2.5 (subsurface $2.5 \mathrm{~cm}$ ).

Subsequent pairwise comparisons found no significant differences when comparing WHC between the burnt and unburnt areas within each site at both surface and 
subsurface soil depths (Figure 4.5; Supp. Table 4.4). No significant differences were also found when comparing between the unburnt sampling areas at both soil depths (surface or subsurface) (Figure 4.5; Supp. Table 4.4). The primary source of the identified interactions in the WHC data, again, appears to reside from comparisons between sites and depths as opposed to within-site differences.

The average $\mathrm{pH}$ in the surface soil layer in the burnt areas ranged from $4.2 \pm 0.2$ at Site B (3-years post-fire) to $4.9 \pm 0.4$ at Site A ( $<1$-year post-fire). Across the unburnt areas average surface $\mathrm{pH}$ ranged from $3.7 \pm 0.4$ in Site A to $4.5 \pm 0.2$ in Site C (Table 4.2). The values for $\mathrm{pH}$ in the subsurface soil layer across the burnt areas ranged between $4.2 \pm 0.3$ at Site D (11-years post-fire) and $4.4 \pm 0.1$ at Site C (7-years post-fire). Across the unburnt area's pH values ranged from $3.7 \pm 0.4$ in Site A and $4.5 \pm 0.2$ in Site $\mathrm{C}$ in the subsurface (Table 4.2).

Regression analysis of the $\mathrm{pH}$ data suggest there are interactions between the response and predictor variables $\left(\mathrm{lm}: \mathrm{r}^{2}=0.66, \mathrm{df}=15, \mathrm{p}\right.$-value $\left.=<0.05\right)($ Supp. Table 4.5). The model explains to majority of the variance within the response variable $\left(\mathrm{r}^{2}=66\right.$ or $\left.66 \%\right)$. Analysis of variance tests within the model residuals identified significant interactions between $\mathrm{pH}$ and site:status (Anova: $\mathrm{Sum} . \mathrm{Sq}=103.6, \mathrm{df}=7, \mathrm{~F}$-value $=41.8, \mathrm{p}$-value $=<0.05$ ), depth (Anova: Sum.Sq $=4, \mathrm{df}=1, \mathrm{~F}$-value $=11.3$, p-value $=<0.05$ ), and site: status:depth (Anova: Sum.Sq $=14.2, \mathrm{df}=7, \mathrm{~F}$-value $=5.7$, $\mathrm{p}$-value $=<0.05$ ).

Subsequent pairwise comparisons found significant increases in $\mathrm{pH}$ in the burnt areas of Site A and B (<1-year and 3-years post-fire) in comparisons to their within-site unburnt areas at the surface and subsurface (Figure 4.6). $\mathrm{pH}$ levels were also significantly higher in the surface soil layer in the burnt area of Site A in comparison to the subsurface layer from the same area. No other significant within-site differences in $\mathrm{pH}$ were found (Figure 4.6; Supp. Table 4.6). Several significant between-site differences were, however, also evident in unburnt area $\mathrm{pH}$ comparing between the sampling sites at both the soil surface and subsurface depths (Figure 4.6; Supp. Table 4.6). 


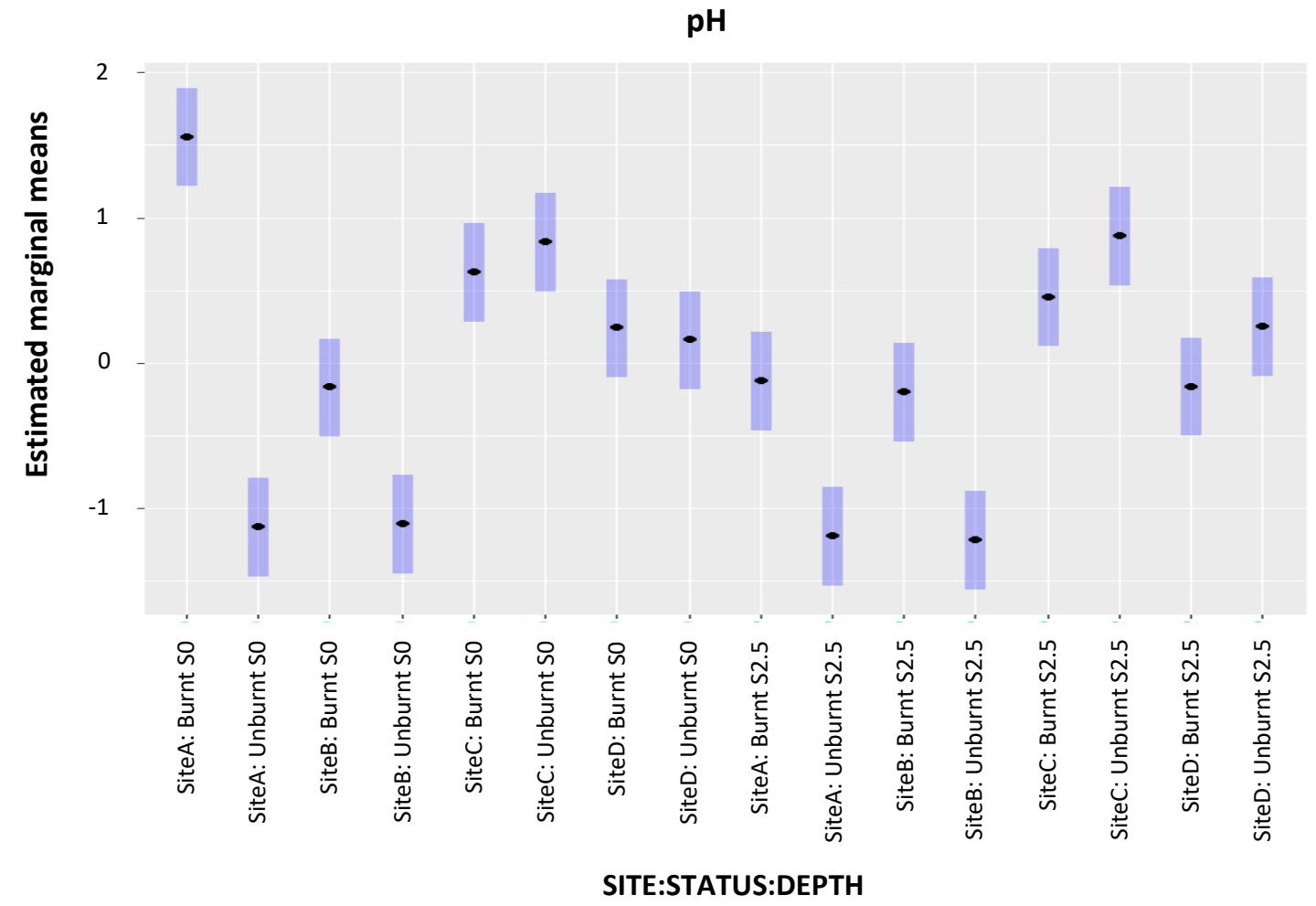

Figure 4.6: Graphic representation of the $\mathrm{pH}$ "emmeans" pairwise comparisons output. Estimated marginal means plotted with $95 \%$ confidence intervals (highlighted in blue) to assess differences in area $\mathrm{pH}$ levels. Areas with overlapping confidence intervals are judged to the statistically similar at the $95 \%$ level. Site $=$ SiteA, SiteB, SiteC, SiteD; Status = Burnt, Unburnt; Depth = S0 (surface layer), S2.5 (subsurface $2.5 \mathrm{~cm}$ ).

Soil hydrophobicity was assessed using the water drop penetration time tests (WDPT) at three depth increments, surface $(0 \mathrm{~cm}$ depth), subsurface $-2.5 \mathrm{~cm}$ depth, and subsurface - $5 \mathrm{~cm}$ depth (Figure 4.7). This is in contrast to the previously discussed soil physical characteristics which were analysed in two depth sections, surface (0-2.5 $\mathrm{cm}$ depth) and subsurface (2.5-5 cm depth). 

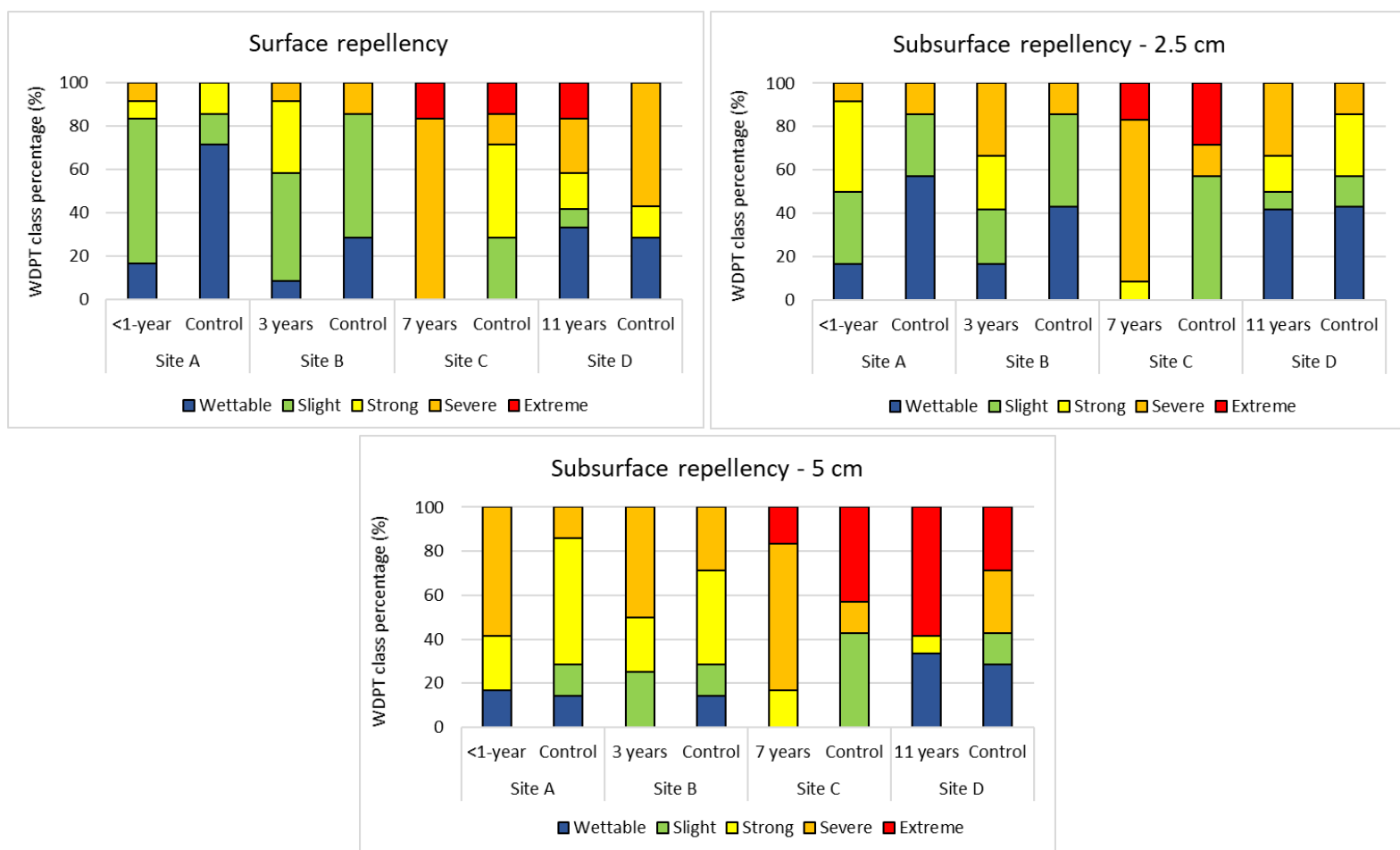

Figure 4.7: Water drop penetration time (WDPT) class data (frequency distribution) for surface, $2.5 \mathrm{~cm}$ and $5 \mathrm{~cm}$ depth at each burnt area alongside unburnt area (control) repellency for that depth ( $\mathrm{n}=12$ per sampling location). WDPT classes have been designated as follows: wettable ( $\leq 5 \mathrm{~s})$, slight (6-60 s), strong (61-600 s), severe (601-3600 s) and extreme (>3600 s) (Bisdom et al., 1993).

Regression analysis suggests there are interactions within the WDPT data explaining $33 \%$ of the total variance $\left(\mathrm{lm}: \mathrm{r}^{2}=0.33, \mathrm{~F}\right.$-value $=5.5, \mathrm{df}=23, \mathrm{p}$-value $\left.=<0.05\right)($ Supp. Table 4.7). A considerable proportion of variance within the response variable, therefore, remains unexplained by the site:status and depth interactions. Despite this, significant interactions were found between WDPT and site:status (Anova: Sum.Sq = 52.5, df $=7$, F-value $=11$, p-value $=<0.05)$, and depth $($ Anova: Sum.Sq $=27.3, \mathrm{df}=$ $2, \mathrm{~F}$-value $=20, \mathrm{p}$-value $=<0.05)$. The combined site: status: depth interaction was not significant (Anova: Sum.Sq $=7.5, \mathrm{df}=14, \mathrm{~F}$-value $=0.8, \mathrm{p}$-value $=0.7$ ).

Pairwise comparisons subsequently identified no significant differences when comparing WDPT between the burnt and unburnt areas within each site at the surface or either subsurface soil depths (2.5 and $5 \mathrm{~cm}$ depth) (Figure 4.8; Supp. Table 4.8). There also appears to be no significant differences between WDPT incrementally through the soil depths within each sampling area (comparing the surface with subsurface $2.5 \mathrm{~cm}$; and subsurface $2.5 \mathrm{~cm}$ with $5 \mathrm{~cm}$ depth). Significant differences in 
WDPT between the three soil depths reside primarily when comparing between-sites as opposed to within-sites (Figure 4.8; Supp. Tables 4.8). The WDPT in the unburnt area at Site $\mathrm{C}$ appears to be the source of multiple significant between-site differences (Figure 4.8). Water repellency appears significantly higher in the unburnt area of Site $\mathrm{C}$ in comparisons to the unburnt areas at Site $\mathrm{A}$ and $\mathrm{B}$ at the surface, and $\mathrm{A}$ and $\mathrm{D}$ in the subsurface (2.5 cm depth) (Supp. Table 4.8).

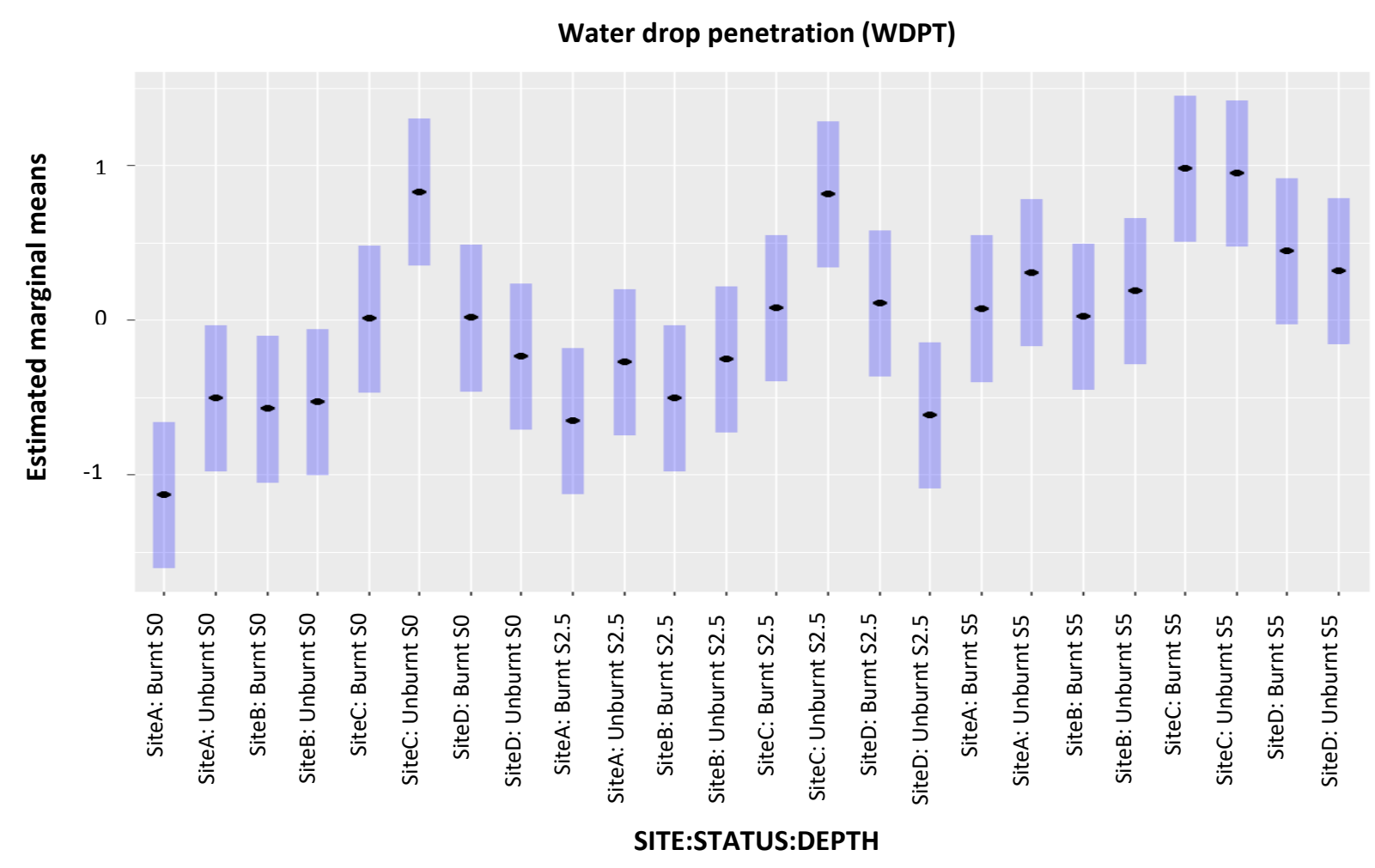

Figure 4.8: Graphic representation of the water drop penetration (WDPT) "emmeans" pairwise comparisons output. Estimated marginal means plotted with 95\% confidence intervals (highlighted in blue) to assess differences in area water drop penetration test. Areas with overlapping confidence intervals are judged to the statistically similar at the $95 \%$ level. Site $=$ SiteA, SiteB, SiteC, SiteD; Status = Burnt, Unburnt; Depth = S0 (surface layer), S2.5 (subsurface $2.5 \mathrm{~cm}$ ), $\mathrm{S} 5$ (subsurface $5 \mathrm{~cm}$ ).

Soil water contents (volumetric), derived in order to assess its potential influence on the water repellency (WDPT) levels determined on the samples, were between 16-20.2 $\%$ for the burnt sampling areas and 10.3-18.5 \% in the unburnt areas (Supp. Table 4.9). 


\subsubsection{Soil chemical characteristics}

The number of sample replicates $(n=3)$ provided for the chemical soil characteristics within this study prevents robust statistical analyses of these data. It must, therefore, be clearly stated that any of the observable differences within these data have not been statistically validated and may be as a result of chance (i.e. a product of the small sample size). Results and subsequent interpretations must be viewed in acknowledgment of this limitation. There are, however, a number of potential differences in the average quantity of some of the soil chemical components which will be discussed in the following paragraphs (Table 4.3).

Chemical characteristics appear to vary both within and between the chosen sampling areas at both soil depths (Table 4.3). Carbon content made up the single largest percentage of the elements quantified at the soil surface (range: 25-48\%) and the subsurface (range: $21-46 \%$ ). The concentrations of total carbon at both soil depths were lower in the burnt areas at Site A (surface: $30 \pm 9 \%$; subsurface $21 \pm 11 \%$ ) and Site B (surface: $46 \pm 1 \%$; subsurface: $42 \pm 0.4 \%$ ) in comparison to their respective unburnt areas (Site A surface: $32 \pm 2 \%$; subsurface: $28 \pm 2 \%$ ) (Site B surface: $48 \pm$ 1\%; subsurface: $47 \pm 3 \%$ ) (Table 4.3). Total nitrogen made up the smallest percentage of the soil composition at both soil depths (surface: 1.2 -2.2\%; subsurface: 1.3-2.6\%). This produced carbon:nitrogen $(\mathrm{C}: \mathrm{N})$ ratios ranging from $20-25$ at the soil surface and 15-26 at the subsurface (Table 4.3).

Bioavailable phosphorus (Olsen-P) at the soil surface appears variable between the sampling areas (Table 4.3). Both areas of Site A, the burnt and unburnt, recorded the highest quantities of Olsen-P with $117 \pm 63$ and $93 \pm 30 \mathrm{mg} \mathrm{kg}^{-1}$ respectively. Across the remaining surface sampling areas Olsen-P varied from $35 \pm 9 \mathrm{mg} \mathrm{kg}^{-1}$ in the burnt area at Site D to $83 \pm 9 \mathrm{mg} \mathrm{kg}^{-1}$ in the burnt area at Site B (Table 4.3). Average Olsen$\mathrm{P}$ concentrations appear higher in the burnt sampling areas, in comparison to their respective unburnt areas, at Site A, B and C at the soil surface (Table 4.3). The quantities of Olsen-P at the soil subsurface appear less variable than those at the soil surface. Concentrations in the soil subsurface ranged from $18 \pm 1 \mathrm{mg} \mathrm{kg}^{-1}$ in the unburnt area of Site A to $52 \pm 12 \mathrm{mg} \mathrm{kg}^{-1}$ in the unburnt area of Site D (Table 4.3). Olsen-P concentrations were higher in the subsurface burnt areas at Site A, B and C in comparison to in the unburnt areas at these sites (Table 4.3). 
Table 4.3: Average values for each quantified soil chemical characteristic at all sampling areas ( $\mathrm{n}=3$ per sampling location) and both soil depths (0-2.5 and 2.5-5 $\mathrm{cm}$ depth). Soil bulk density (BD) given in $\mathrm{g} \mathrm{cm}^{-3}$ and water holding capacity (WHC) given as percentage (\%). Standard deviation for each value is provided in brackets. Total carbon and nitrogen values are given as a percentage $(\% \mathrm{C}$ and $\% \mathrm{~N})$. Bioavailable $\mathrm{P}(\mathrm{Olsen}-\mathrm{P})$ is provided in $\mathrm{mg} / \mathrm{kg}$. Soluble cation concentrations are given in milliequivalents per 100 grams (meq/100 g). Standard deviation is provided in brackets. Effective cation exchange capacity (ECEC) for each sampling area are also provided in meq/100 g, along with carbon nitrogen ratios (C:N).

\begin{tabular}{|c|c|c|c|c|c|c|c|c|c|}
\hline & & \multicolumn{2}{|c|}{ Site A } & \multicolumn{2}{|c|}{ Site B } & \multicolumn{2}{|c|}{ Site C } & \multicolumn{2}{|c|}{ Site D } \\
\hline & & $<1$-year & Unburnt & 3-years & Unburnt & 7-years & Unburnt & 11-years & Unburnt \\
\hline \multirow{10}{*}{$\begin{array}{l}\text { E } \\
\text { in } \\
\text { ஸे } \\
\dot{0}\end{array}$} & $\% \mathrm{C}$ & $30(9)$ & $32(2)$ & $46(1)$ & $48(1)$ & $45(1)$ & $34(3)$ & $46(1)$ & $41(9)$ \\
\hline & $\% \mathrm{~N}$ & $1.2(0.4)$ & $1.3(0.1)$ & $2.2(<0.1)$ & $1.9(0.1)$ & $2.2(0.1)$ & $1.4(0.2)$ & $1.9(0.1)$ & $1.8(0.4)$ \\
\hline & Olsen-P & $117(63)$ & $93(30)$ & $83(9)$ & $64(16)$ & $54(23)$ & $47(4)$ & $35(9)$ & $72(37)$ \\
\hline & $\mathrm{Al}^{+3}$ & $1.2(0.6)$ & $1.9(0.5)$ & $1(0.1)$ & $1.5(0.3)$ & $1.5(0.4)$ & $3.2(1.1)$ & $2.3(0.3)$ & $1.6(0.8)$ \\
\hline & $\mathrm{Ca}^{+2}$ & $11.4(6.3)$ & $8.2(3.4)$ & $8.5(2)$ & $6.9(1.9)$ & $7.1(2.2)$ & $6.3(1.2)$ & $6.5(1.4)$ & $7.3(3.3)$ \\
\hline & $\mathrm{Mg}^{+2}$ & $4.3(1.8)$ & $3.2(1.6)$ & $6.6(1)$ & $5.3(1.5)$ & $5.4(0.8)$ & $3.8(0.9)$ & $3.9(0.8)$ & 4.1 (1.6) \\
\hline & $\mathrm{K}^{+}$ & $1.3(0.3)$ & $1.5(0.5)$ & $2.5(0.2)$ & $1.3(0.2)$ & $2.5(0.3)$ & $1.5(0.4)$ & $1.4(0.3)$ & $1.8(0.5)$ \\
\hline & $\mathrm{Na}^{+}$ & $0.6(0.2)$ & $0.4(0.1)$ & $1.3(0.1)$ & $0.9(0.1)$ & $1(0.1)$ & $0.7(0.1)$ & $0.9(0.1)$ & $0.8(0.2)$ \\
\hline & $\mathrm{C}: \mathrm{N}$ & 24 & 22 & 21 & 25 & 21 & 24 & 24 & 20 \\
\hline & ECEC & 19 & 15 & 20 & 16 & 17 & 16 & 15 & 16 \\
\hline \multirow{10}{*}{$\begin{array}{c}\Xi \\
\text { in } \\
\text { in } \\
\text { ஸ் }\end{array}$} & $\% \mathrm{C}$ & $21(11)$ & $28(2)$ & $42(0.4)$ & $47(3)$ & $40(7)$ & $24(4)$ & $46(1)$ & $32(6)$ \\
\hline & $\% \mathrm{~N}$ & $0.8(1)$ & $0.3(0.1)$ & $1.8(<0.1)$ & $1.7(0.1)$ & $1.9(0.4)$ & $2.6(4)$ & $1.9(<0.1)$ & $1.7(0.3)$ \\
\hline & Olsen-P & $45(23)$ & $18(1)$ & $44(4)$ & $35(9)$ & 48 (12) & $22(7)$ & $29(7)$ & $52(12)$ \\
\hline & $\mathrm{Al}^{+3}$ & $2.8(0.5)$ & $4.6(0.6)$ & $1.8(0.3)$ & $2.1(0.4)$ & $2.2(0.8)$ & $4.5(1.5)$ & $2.7(0.1)$ & $2.7(1)$ \\
\hline & $\mathrm{Ca}^{+2}$ & $4.9(4)$ & $1.9(0.9)$ & $4.1(0.3)$ & $4.3(0.9)$ & $4.3(0.6)$ & $2.2(1.2)$ & $3.7(0.7)$ & $4.6(1.9)$ \\
\hline & $\mathrm{Mg}^{+2}$ & $2.9(2.1)$ & $0.9(0.4)$ & $3.5(0.1)$ & $3.6(0.6)$ & $4.1(0.8)$ & $1.6(0.8)$ & $2.9(0.8)$ & $2.6(0.7)$ \\
\hline & $\mathrm{K}^{+}$ & $1(0.7)$ & $0.3(0.1)$ & $1.4(0.1)$ & $0.8(0.2)$ & $2.1(0.2)$ & $0.5(0.4)$ & $1.1(0.4)$ & $1.4(0.2)$ \\
\hline & $\mathrm{Na}^{+}$ & $0.4(0.2)$ & $0.2(<0.1)$ & $0.9(0.2)$ & $0.6(0.1)$ & $0.8(0.1)$ & $0.3(0.1)$ & $0.7(0.1)$ & $0.6(0.2)$ \\
\hline & $\mathrm{C}: \mathrm{N}$ & 26 & 21 & 24 & 26 & 21 & 15 & 24 & 19 \\
\hline & $\mathrm{ECEC}$ & 12 & 8 & 12 & 11 & 14 & 9 & 11 & 12 \\
\hline
\end{tabular}


The effective cation exchange capacity (ECEC) of both soil depths were low throughout and were within the range expected for low fertility soils (surface: 15-20 meq/100 g; subsurface 8-14 meq/100 g) (Table 4.3). The predominant base cations found in solution from the soil surface were $\mathrm{Ca}^{2+}(6.3-11.4 \mathrm{meq} / 100 \mathrm{~g})$ and $\mathrm{Mg}^{2+}(3.2$ - $6.6 \mathrm{meq} / 100 \mathrm{~g}$ ) (Table 4.3). The other soluble cations were found in lower concentrations across the surface sampling areas with $\mathrm{K}^{+}$concentrations ranging between 1.3 - $2.5 \mathrm{meq} / 100 \mathrm{~g}, \mathrm{Na}+$ between $0.4-1.3 \mathrm{meq} / 100 \mathrm{~g}$, and the acidic cation $\mathrm{Al}^{+3}$ between 1 - $3.2 \mathrm{meq} / 100 \mathrm{~g}$ (Table 4.3). The saturation of base cations (base saturation) appears to vary between the surface sampling areas but are relatively high throughout $(67-90 \%)$. In the soil surface layer, there are higher average $\mathrm{Ca}^{+2}$ and $\mathrm{Mg}^{+2}$ in the burnt sampling areas in comparison to their unburnt areas at Site A, B and C. In addition to decreases in soluble $\mathrm{K}^{+}$(Site A), $\mathrm{Na}^{+}$(Site A) and $\mathrm{Al}^{+3}$ (Site A-C) (Table 4.3).

ECEC values were lower in every sampling area at the soil subsurface in comparison to the soil surface (Table 4.3). The concentrations of $\mathrm{Ca}^{+2}$, found in the highest concentrations across the sampling areas at the soil surface, were notable lower in the soil subsurface ranging from $1.9 \pm 0.9 \mathrm{meq} / 100 \mathrm{~g}$ in the unburnt area of Site A to 4.9 $\pm 4 \mathrm{meq} / 100 \mathrm{~g}$ in the burnt area at Site A (Table 4.4). The other soluble cations were found at relatively similar concentrations between the surface and subsurface depths with $\mathrm{Mg}^{+2}$ ranging from $0.9 \pm 0.4$ to $4.1 \pm 0.8 \mathrm{meq} / 100 \mathrm{~g}, \mathrm{~K}^{+}$ranging from $0.3 \pm 0.1$ to $2.1 \pm 0.2 \mathrm{meq} / 100 \mathrm{~g}$, and $\mathrm{Na}^{+}$ranging from $0.2 \pm<0.1$ to $0.9 \pm 0.2 \mathrm{meq} / 100 \mathrm{~g}$. The concentrations of soluble $\mathrm{Al}^{+3}$ were slightly higher than at the soil surface, ranging from $1.8 \pm 0.3$ to $4.6 \pm 0.6 \mathrm{meq} / 100 \mathrm{~g}$ (Table 4.3 ).

Of these soluble cation concentrations at the soil subsurface there were higher average concentrations of $\mathrm{Ca}^{+2}$ and $\mathrm{Mg}^{+2}$ in the burnt areas at Site $\mathrm{A}$ and lower concentrations of $\mathrm{Al}^{+3}$ in all burnt areas when comparing the burnt sampling areas with their unburnt areas (Tables 4.3). Concentration of $\mathrm{K}^{+}$(Site A-C) and $\mathrm{Na}^{+}$(Site A-D) all displayed the opposite response in the subsurface soil, when compared to the surface layer, displaying higher concentrations in the burnt in comparison to unburnt areas (Table 4.3). 


\subsection{Discussion}

The use of space as opposed to time by which to assess change is a commonly used strategy in fire science, particularly when assessing lengthy processes (e.g. soil recovery) which are not feasible within most research setups (e.g. time, resource or funding limited). This approach, however, makes several key assumptions which are important to highlight before 'diving into' the following discussion and interpretation of results. These include the assumption that the chosen sampling locations are; geographically but not environmentally distinct, long unburnt (control) and burnt (treatment) areas are sufficiently comparable (e.g. similar pre-disturbance conditions), and, in the case of fire science, burn conditions for each fire event are also comparable (Ashby and Heinemeyer, 2019a).

To address these assumptions several key features were incorporated into the study design. Firstly, all sampling areas were chosen in compliance with a selection criteria, providing consistency in relation to for example, area elevation, topography, vegetation type and grazing and recreational pressure (See subsection 3.2.2. for full details). These criteria help to limit, as much as possible, the influence of geographic and environmental variables on heathland characteristics. The importance of the comparability of sampling sites within space-for-time substitution studies has been a notable source of contention in the field of fire science in recent years (Ashby and Heinemeyer, 2019a; 2019b; Brown and Holden, 2019).

Secondly, to reduce the likelihood of significant environmental differences between the burnt (treatment) and long unburnt (control) areas, a long unburnt area was located at each site. This enables burnt area conditions to be assessed against a closely located unburnt area (Supp. Figure 3.1-3.4). It must be acknowledged that this does not guarantee unburnt and treatment areas had similar pre-disturbance conditions, even within the same site, due to the environmental heterogeneity of most ecosystems (Johnson \& Miyanishi, 2008; Pickett, 1989). It does, however, removed the need for potentially problematic cross-site (between-site) comparisons in order to assess fire impacts or the degree of burnt area recovery.

Thirdly, as burn conditions aren't able to be directly measured within a space-for-time approach, they were quantified here using the Canadian Forest Fire Weather Index (FWI) System. The FWI system allows estimates of fine fuel moisture content 
(FFMC), duff moisture code (DMC), drought code (DC), initial spread rate (ISI) and fire weather index values (FWI) to be produced using historic weather data (e.g. precipitation, air temperature, wind speed and relative humidity) (See subsection 4.2.8. for full details). Whilst direct measurements of burnt conditions are highly desirable and FWI estimates do not prove, or disprove, comparability of the assessed fire events, they do crucially enable an adequate means of comparing historic fire events.

Finally, statistical analyses were conducted to assess the comparability of sampling areas to contextualise the results and inform subsequent interpretations (See subsection 4.2.8. for full details). Due to the time constraints of this project, and the common pitfalls of conducting ad hoc monitoring of natural events such as wildfires, no replication of burn treatments were available (e.g. only one sampling area per time interval; <1, 3, 7, 11-years post-fire). This means careful consideration was given to the statistical analyses (e.g. utilising a nested analytical design) and inferences that can be drawn from these data (e.g. by comparing with-in, and not between, site heterogeneity) to avoid potential pseudoreplication (Oksanen 2001; Schank and Koehnle 2009; Ramage et al. 2013). This is especially important here as it highlights significant differences in between-site unburnt area conditions for some of the chosen soil physical characteristics.

Despite these efforts to ensure conditions were conducive to comparable sampling areas and fire events, it is acknowledged that the results of space-for-time studies are not as reliable or accurate as those produced through controlled experimentation as some differences in site histories and burn characteristics are inevitable (França et al., 2016). It is also important to acknowledge that these limitations do not preclude studies of this kind from providing useful insight if conducted appropriately and transparently (Ashby and Heinemeyer, 2019b). In this study, a time-series or chronosequence of soil recovery cannot be produced due to the lack of burn treatment replication (e.g. only one sampling area per burn age; <1, 3, 7, 11-years post-fire). Long-term change can still be inferred based on the difference between burnt and unburnt area conditions within each site in relation to the age of each burnt area. This is, however, done with caution due to the identified between-site differences in unburnt area conditions for some soil physical characteristics. 


\subsubsection{Soil physical characteristics and $\mathrm{pH}$}

The results presented here show significantly higher values of soil $\mathrm{pH}$ in the burnt areas in Site A and B ( $<1$ and 3-years post-fire) at the soil surface $(0-2.5 \mathrm{~cm}$ depth) (Table 4.2), in comparison to their within-site unburnt areas. Soil $\mathrm{pH}$ values in the remaining burnt areas (Site C and D) were indistinguishable from unburnt area conditions. Post-fire increases in $\mathrm{pH}$ are well-established in a wide range of soil types (Forgeard and Frenot, 1996; Certini, 2005; Sulwinski et al., 2017). Similar results have also been observed in heath and shrubland habitats on organic and mineral soils in south western Europe and southern Australia, with significant initial increases in soil surface pH persisting for <1-3 years (Granged et al., 2011a, 2011b; Gómez-Rey and González-Prieto, 2014; Kelly et al., 2018).

Changes in soil $\mathrm{pH}$ are often primarily a result of the combustion of aboveground fuels and soil organic matter and the incorporation of ash and charcoal into the soil surface (Allen, 1964; Alcañiz et al., 2018). During the heating of aboveground fuels and soil organic matter, alkaline cations (e.g. $\mathrm{Ca}, \mathrm{Mg}, \mathrm{K}$ and $\mathrm{Na}$ ) are released as organic matter is combusted (Allen, 1964; Certini, 2005). As a result, the $\mathrm{pH}$ of the ash produced during fire events is usually alkaline or very alkaline (Harper et al., 2019). The subsequent incorporation of alkaline ash into the soil leads to an increase in soil base saturation and could perhaps be responsible for the higher $\mathrm{pH}$ level observed in the burnt areas in this study (i.e. Site A and B) (Khanna et al., 1994). The denaturation of organic acids contained within the soil is also a potential cause for changes in soil $\mathrm{pH}$. This process, however, primarily occurs when soil surfaces temperatures exceed $450^{\circ} \mathrm{C}$ (Certini, 2005), which is unlikely to have occurred for any prolonged period during the fire events assessed here.

These mechanisms perhaps also provide explanation for the significantly higher $\mathrm{pH}$ levels at the surface, in comparison to the subsurface, in the burnt area of Site A $(<1$ year post-fire) (Figure 4.6). Heat penetration in soils is subject to steep temperature gradients as soils are generally poor conductors of heat (Scott et al., 2014). Soil heating would, therefore, be greatly reduced at $2.5-5 \mathrm{~cm}$ depth limiting the potential degree of organic matter combustion and acid denaturation (Mataix-Solera et al., 2011). The deposition of ash produced during fires would also be preferentially incorporated into the top few centimetres of soil, due to closer proximity, further reducing the impacts 
on $\mathrm{pH}$ at the subsurface in comparison to the surface. Leaching and percolation would, however, cause a smaller fraction of the deposited ash to progress down through the soil profile (Francos et al., 2018).

The incorporation of pyrogenic material (charcoal) into the soil profile often has other detectable influences on soil physical properties in the form of changes in bulk density, particle-size distribution and soil colour (Smith et al., 2001; Kania et al., 2006; Santín et al., 2017;). There were, however, no significant within-site differences in soil bulk density (BD) at the surface between each burnt and its within-site unburnt area (Figure 4.4; Supp. Table 4.2). No notable accumulation of macroscopic charcoal was also observed in the burnt soil samples. Significant differences were evident in the subsurface layer, for example, between the burnt areas in Site A-C, and Sites B-C (Figure 4.4). There is no precedent within the literature to suggest these subsurface changes are a direct or indirect result of fire. These differences likely result from inevitable variations in other characteristics of these soils such as, depth of the organic horizon (O horizon), organo-mineral composition and particle-size distribution.

Another aspect of soil physical characteristics which is important for soil function is water holding capacity (WHC). Despite significant interactions between WHC with site:status and depth within the regression analysis, no significant pairwise differences were found when comparing each burnt sampling area with its within-site unburnt area or depths (Figure 4.5; Supp. Table 4.4). Pairwise differences, therefore, reside from between as opposed to within-site comparisons and due to the nested structure of this study cannot be reliably related to fire effects (i.e. as there is only one sampling area per burnt age).

It is perhaps not surprising there are no significant difference in within-site WHC as there are also no significant differences in bulk density or notable variations in carbon content using the same within-site comparisons (Figure 4.4 and 4.5; Table 4.3). Broadly it is suggested there are several ways in which fires can indirectly affect water holding capacity in soil such as, changing organic matter content, bulk density, texture and structure (Certini, 2005; Wesseling et al., 2009; Stoof et al., 2010). Prominent mechanisms include the collapse of organo-mineral aggregates due to heating and the clogging of soil pores by ash, reducing the space in which water can be stored (Martin and Moody, 2001). The observed between-site differences in WHC again likely 
resulted from variations in other characteristics of these soils such as, depth of the organic horizon (O horizon), organo-mineral composition and particle-size distribution. The response of WHC in shallow organic layered heathland soils to fire is, however, seldom assessed within the literature. Fire-induced changes in WHC are also thought to be variable between soil type, land-use and management (Batjes, 1996; Bormann and Klaassen, 2008; Katsvairo et al., 2002).

Changes in soil water repellency are one of the most researched impacts of fires across a range of habitat types and can have a substantial impact on soil hydrological function (Doerr et al., 2006; Zavala et al., 2010; Kettridge et al., 2014; Bodi et al., 2012). In the soils assessed here, there were no significant differences in within-site water repellency (WDPT), comparing between each burnt and unburnt area, and sequentially through the three soil depths (surface, subsurface $2.5 \mathrm{~cm}$ and subsurface $5 \mathrm{~cm}$ ) (Figure 4.8; Supp. Table 4.8). It is well-established that heating hydrophilic soils with a greater than $3 \%$ component of organic matter, such as the soils assessed here, can increase water repellency (Richardson and Hole, 1978; Mallik, 1985; DeBano, 2000; Kettridge et al., 2014). The effects of soil burn severity are, however, crucial to the creation of water repellency in soils and the results obtained here may give further insight into the degree of soil heating during the assessed fire events (Doerr et al., 2004; Zavala et al., 2010; Turetsky et al., 2014).

To enhance water repellency in soils such as these, soil surface temperatures would need to be elevated to between $100-300^{\circ} \mathrm{C}$. In this range all moisture is able to be removed and organic substances begin to volatilise and condense, coating soil mineral particles with hydrophobic substances and causing the reduction of soil permeability (Mataix-Solera et al., 2011; Santín and Doerr, 2016). If soil temperatures persist at $>300^{\circ} \mathrm{C}$, hydrophobic substances and bonds breakdown and water repellency is destroyed, as in extreme severity fires (Doerr et al., 2004; Mataix-Solera et al., 2011). In more organic rich peatland soils these processes are controlled primarily by fireinduced organic structural changes, improved hydrophobic molecular bonding, polymerisation or polycondensation reactions and redistribution of interstitial waxes onto soil aggregates (Savage, 1972; Franco et al., 2000; Doerr et al., 2006; Certini, 2005). 
Coupled with the calculated fire weather and burn conditions information (Table 4.1) the repellency analyses suggest temperatures of $100-300^{\circ} \mathrm{C}$ are unlikely to have been maintained at any given point at the soil surface for a prolonged period of time during the fire events assessed here. This could perhaps be due to moisture retention in the soils' organic surface layer and/or perhaps short flame residence times at the soil surface reducing the degree of soil heating (Certini, 2005; Zavala et al., 2010). Detailed studies on fire-induced soil hydrophobicity are, however, scarcer in organic rich soils (e.g. peats) in comparison to mineral soil types (Hewelke et al., 2016).

Water content is also a key factor dictating the presence of water repellency in burnt and unburnt soils (Doerr et al., 2006; Vogelmann et al., 2013). Water content was, therefore, assessed for the soil samples collected here to explore its potential effect on WDPT results. Results show volumetric soil water content values were between 10.3$20.2 \%$ (Supp. Table 4.9). These values are below the threshold above which water repellency is thought to switch in non-sandy or peaty soils ( 28-38\%) (Dekker and Ritsema, 1994; Doerr and Thomas, 2000; Moore et al., 2017). Water content at the levels found here are therefore unlikely to have had a major impact on WDPT. In addition, the range of water content values here is relatively narrow and WDPT at the higher end of the water content values were still relatively high in these samples. These factors further suggest differences in sample water content were not a major factor determining soil repellency.

\subsubsection{Chemical composition}

The effects of fire on soil chemical composition are highly complex and widely variable (Pereira et al. 2014; Sulwinski et al., 2017). These changes depend on several factors in relation to both the location (e.g. soil type and characteristics, hydrology, topography and environmental conditions) and the fire (e.g. severity, intensity and duration) (Certini, 2005; Mataix-Solera et al., 2009). One of the most widely studied effects of fire on soils is on carbon stocks, likely due to the importance of carbon in the function of natural ecosystems and the extent of the global carbon pool stored in soils ( 2400 Pg C to 2 m depth) (Yousaf et al., 2017).

Following high severity fires, it is typical to find losses in soil carbon as a result of direct combustion in organic soils (Certini, 2005; Santín and Doerr, 2019). Terefe et 
al. (2008) in a set of laboratory experiments, for example, observed significant decreases in soil organic carbon content during heating at $200-300^{\circ} \mathrm{C}$ and a complete loss at $>500^{\circ} \mathrm{C}$. Based on field observations there appears to have been minimal combustion of soil organic matter following the fire event at Site A ( $<1$-year post-fire) and assumed for the other fire event assessed in this study (Table 4.1). This is likely due to the moisture holding capacity and current moisture content of the organic surface soil layer during this fire event limiting soil surface heating and heat depth penetration. The latent heat of vaporisations prevents soil temperature exceeding $100^{\circ} \mathrm{C}$ until all moisture is removed (Campbell et al., 1994). The duration of soil heating is, therefore, considered the most significant component affecting the extent of soil damage at depth (Certini 2005). Factors such as, wind speed on these elevated (300-600 m) upland plateaus may have contributed to short flame residence times reducing the duration of soil heating.

In addition, the dense mature $C$. vulgaris vegetation creating almost total ground coverage (observed across the unburnt areas - Chapter 3) may have aided surface moss/litter and soil moisture retention (Davies and Legg, 2011). Research by Davies et al., (2009) further suggests fires in C. vulgaris-dominated areas will often burn through the canopy independently of ground-layer fuel moisture, once a fire has established. Severity and spread rates in the above-ground fuel (vegetation) are strongly influenced by the availability and moisture content of elevated dead fuels, of which there are often plenty in stands of mature to degenerate-structured $C$. vulgaris, contributing to the high vegetation burn severity discussed in Chapter 3.

The results collected here, however, do suggest total $\mathrm{C}$ concentrations were lower in the surface $(0-2.5 \mathrm{~cm})$ and subsurface $(2.5-5 \mathrm{~cm})$ in the burnt areas of Site A and B $(<1$ and 3-years post-fire), in comparison to their within-site unburnt areas (Table 4.3). This could suggest an initial post-fire decrease in $\mathrm{C}$ concentration $(\% \mathrm{C})$, perhaps as a result of the enrichment of inorganic material into the soil profile from the deposition of ash material (Santín and Doerr, 2019). The enrichment of inorganic material into the soil would not cause a decrease in the quantity of total soil carbon but would result in a reduction in the overall percentage of carbon as the fraction of inorganic material increases. Changes in soil carbon content as a result of fire are, however, highly variable and could result from differences in a range of factors from fire severity to soil type and topography (González-Pérez et al., 2004; Alcañiz et al., 2018). Small 
reductions in post-fire soil carbon concentration have also been found in other heathland soils (Granged et al., 2011b; Kelly et al., 2018).

Total nitrogen content in soils is vitally important to primary productivity and habitat function (Alcañiz et al., 2018). Nitrogen is also thought to be one of the nutrients most affected by fires (Holden et al., 2004; Alcañiz et al., 2016; Sulwinski et al., 2017). During combustion, when soil temperatures exceed $200^{\circ} \mathrm{C}$, soil nitrogen is lost as organic nitrogen volatilises (DeBano, 1991; Fisher and Binkley, 2013). The results collected here show lower total N concentrations in the burnt area of Site A $(<1$-year post-fire), in comparison to the unburnt area at this site, in the soil surface. Notably higher total $\mathrm{N}$ concentration were, however, presents in the soil subsurface comparing the burnt areas of Site A and B with their respective within-site unburnt areas (Table 4.3)

Similar to the discussion of total carbon, it is unlikely soil surface temperatures exceeded $200^{\circ} \mathrm{C}$ for prolonged periods during these fire events to cause more substantial losses of total nitrogen via volatisation. Some studies have, however, also shown increases in soil nitrogen are possible, particularly at lower burn temperatures $\left(<200^{\circ} \mathrm{C}\right)$, due to the incorporation of partially pyrolysed materials and ash into the soil (Grogan et al., 2000; Zavala et al., 2014). The limited changes observed in the proportion of total $\mathrm{N}$ and the contrast between surface and subsurface results here, mean it is difficult to directly relate these changes to fire impacts. Through the production of ash, fires are also capable of redistributing the forms of nitrogen within the soil, converting organic into inorganic forms $\left(\mathrm{NH}_{4}{ }^{+}\right.$and $\left.\mathrm{NO}_{3}{ }^{-}\right)$(Certini, 2005; Rivas et al., 2012). More detailed quantification of different forms of nitrogen, as opposite to just total nitrogen, would provide further clarity to the impacts of fire on nitrogen in these soils.

Phosphorus is an important plant macronutrient, the presence and bioavailability of which can be substantially impacted by fires and the combustion of organic matter (Venterink et al., 2009; Wang et al., 2015; Pereira et al., 2019). Whilst carbon and nitrogen start to vaporise at temperatures of around $200^{\circ} \mathrm{C}$ and losses are likely under high fire severities, nutrients such as phosphorus do not volatise until $>700^{\circ} \mathrm{C}$ (Pereira et al., 2018). Higher Olsen-P concentrations were observed in the soil surface and subsurface when comparing the burnt areas at Site A, B and C with their within-site 
unburnt areas (Table 4.3). Temperatures exceeding $700^{\circ} \mathrm{C}$ are highly unlikely to have occurred at the soil surface during the fire events assessed here.

There are two primary mechanisms by which the increases in Olsen-P in these areas may have been caused. Firstly, phosphorus bioavailability peaks at approximately $\mathrm{pH}$ 6.5 and any increase in soil $\mathrm{pH}$ in the direction of neutrality will likely have a positive effect on the quantity of bioavailable phosphorus (Certini, 2005). The significantly higher $\mathrm{pH}$ recorded in the burnt area of Site $\mathrm{A}$, in comparison to the unburnt area (Table 4.3), could perhaps have caused an enrichment of bioavailable phosphorus in this area. Secondly, the combustion of vegetation and surface soils can modify the form of phosphorus, converting organic phosphorus into orthophosphate an inorganic bioavailable form (Cade-Menun et al., 2000). The combustion of aboveground fuels during these fire events could, therefore, also cause in influx of bioavailable phosphorus into the soil profile through the deposition of ash (Smith et al., 2001; Alcañiz et al., 2018; Butler et al., 2018).

Post-fire soil enrichment of bioavailable phosphorus is, however, often short-lived (<1-year) as fires are thought to accelerate phosphorus cycling (Alcañiz et al., 2018). In acid soils in particular, orthophosphate readily binds to oxides of $\mathrm{Fe}, \mathrm{Al}$ and $\mathrm{Mn}$ helping to reduce the residence time of bioavailable phosphorus (Serrasolsas and Khanna, 1995). It would, therefore, be unusual for increases in Olsen-P to still be apparent in the burnt area of Site C (e.g. 7-year post-fire) if the primary influencing factors were fire effects. Limited research has however, been conducted on organic soils in dry dwarf-shrub heaths.

The concentrations of soluble alkaline cations such as $\mathrm{Ca}^{+2}, \mathrm{Mg}^{+2}, \mathrm{Na}^{+}$and $\mathrm{K}^{+}$also often increase as a result of fire events (Sulwinski et al., 2017; Alcañiz et al., 2018). Of these key plant macronutrients, the concentrations of soluble $\mathrm{Ca}^{+2}, \mathrm{Mg}^{+2}$ and $\mathrm{Na}^{+}$ appeared reasonably similar across the burnt vs unburnt area comparisons assessed here (Table 4.3). Higher $\mathrm{Ca}^{+2}$ and $\mathrm{Mg}^{+2}$ cation concentrations were observed in the burnt areas soil surface layer at Site A, B and C, in comparison to their long-unburnt areas. Similarly, higher values were also evident in the burnt area subsurface layer in Site A, in comparison to its within-site unburnt area (Table 4.3). $\mathrm{Na}^{+}$concentrations were consistently higher in all burnt sampling areas in the soil surface and subsurface layers. Higher concentrations of these cations in the burnt sampling areas could 
perhaps have resulted from the combustion of aboveground fuels during each fire event, and the subsequent influx of ash, rich with alkaline cations (e.g. $\mathrm{Ca}^{+2}$ and $\mathrm{Mg}^{+2}$ ), into the soil profile (Sundstrom et al., 2000; Alcañiz et al., 2018; Pereira et al., 2019). Initial increases in these macronutrients $\left(\mathrm{Ca}^{+2}\right.$ and $\left.\mathrm{Mg}^{+2}\right)$ have been well documented within the literature following low to moderate severity fires in heath and shrub habitats (Gómez-Rey et al., 2013; Gómez-Rey and González-Prieto, 2014; Xue et al., 2014; Kelly et al., 2018). The persistence of these changes, however, greatly varies within the literature ranging from rapid recovery to baseline conditions within 3 months -2 years, to increases still observable after $>10$-years post-fire (Certini, 2005; Sulwiński et al., 2017). The extent and duration of fire impacts on soils are dictated primarily by fire severity and habitat characteristics. In this instance the differences in nutrient recovery times most likely relate to post-fire soil erosion rates and solute losses, in addition to the permeability of the ash layer and the influence of vegetation dynamics on soil-plant interactions (Gómez-Rey et al., 2013; Butler et al., 2020).

The availability of soluble $\mathrm{K}^{+}$in the soil exchange, however, did not present a similar response to fire as the other alkaline cations $\left(\mathrm{Ca}^{+2}, \mathrm{Mg}^{+2}\right.$ and $\left.\mathrm{Na}^{+}\right) . \mathrm{K}^{+}$concentrations were similar between the burnt and unburnt areas at Site A at the soil surface (Tables 4.3). The remaining burnt areas, however, showed substantially higher concentrations comparing the burnt with their unburnt areas at Site B and C in the soil surface and at all burnt areas in the soil subsurface (Table 4.3). Studies in other similar heathland habitats have also shown limited to no changes in $\mathrm{K}^{+}$levels in the initial post-fire period (<1-3 years post-fire) (Mohamed et al., 2007; Gómez-Rey and González-Prieto, 2014; Kelly et al., 2018). It is, however, unclear why there would be no initial change in soil $\mathrm{K}^{+}$in the burnt area of Site A $(<1$-year post-fire) followed by a substantial increase at Sites B and C (3 and 7-years post-fire).

$\mathrm{K}+$ availability often increases in the initial post-fire period, in a similar manner to $\mathrm{Ca}^{+2}, \mathrm{Mg}^{+2}$ and $\mathrm{Na}^{+}$through the incorporation of ash into the soil profile (Alcañiz et al., 2018). After the initial post-fire period these cations then tend to decline due to leaching and runoff (Certini, 2005; Sulwiński et al., 2017). It is, therefore, likely the primary driver/s of the changes in $\mathrm{K}+$ availability observed here are not linked to fire effects at the sites. These differences perhaps result from differences in other site or soil characteristics, such as, depth of the organic horizon (O horizon), organo-mineral 
composition and vegetation community composition. In particular, plants play an active role in regulating fire-induced changes in soil chemical properties. Plant recovery rates and species composition can substantially affect the exchange of nutrients with the soil and thus the concentration of available cations within the soil across the full post-fire recovery timescale (Butler et al., 2018, 2020).

The remaining cation quantified in this study was the acid cation $\mathrm{Al}^{+3}$. The availability of $\mathrm{Al}^{+3}$ in soils is considered one of the main factors limiting fertility in acidic soils, such as those assessed here, as it impedes plant development, particularly at $\mathrm{pH}<5$ (Álvarez et al., 2005). The concentration of $\mathrm{Al}^{+3}$ is lower in the burnt areas of Site A, $\mathrm{B}$ and $\mathrm{C}$ in both the surface and subsurface soil layers (Tables 4.4 and 4.5). These lower concentrations are likely due to the significantly higher soil $\mathrm{pH}$ observed in these burnt areas (Site A and B) (Smithson et al., 2013). Increasing soil pH substantially reduces the relative solubility of aluminium with a notable change occurring between pH 3.5 and 5 (Smithson et al., 2013; Gómez-Rey and González-Prieto, 2014). The relative solubility on aluminium is very limited at $\mathrm{pH} \geq 5$ (Álvarez et al., 2005; Smithson et al., 2013). As such, reducing concentrations of soil extractable aluminium have been recorded in other studies investigating post-fire changes in similar acid soils and are also likely in other acid heathland sites in the UK (Pivello et al., 2010; GómezRey and González-Prieto, 2014).

In heathlands, the soluble form of aluminium (e.g. $\mathrm{Al}^{+3}$ ) has been shown to be toxic to a number of characteristic species, with most not able to tolerate aluminium cation saturation levels of $>15 \%$ (Kleijn et al., 2008; De Graaf et al., 2009). This threshold is exceeded in the burnt area at Site D and the unburnt area of Site C (Table 4.3). In contrast, key species such as $C$. vulgaris are relatively tolerant to soluble aluminium and higher concentrations of exchangeable aluminium in some of the areas studied here, in part, may provide explanation for the degree of observed C. vulgaris dominance (e.g. across the unburnt sampling areas) (see Chapter 3).

In addition to exchangeable $\mathrm{Al}^{+3}$ concentrations, some studies have suggested the ratio of $\mathrm{Al}$ to $\mathrm{Ca}$ is a more accurate indicator of heathland species composition and thus habitat function (De Graaf et al., 2009). This is because Ca has an ameliorating effect on Al toxicity in acidic soils and thus elevated calcium concentration can reduce the negative impacts of $\mathrm{Al}$ on seedling growth (Kleijn et al., 2008; De Graaf et al., 2009). 
In the burnt areas of Site $\mathrm{A}$ and $\mathrm{B}$ at the soil surface, reduced $\mathrm{Al}^{+3}$ concentrations coupled with elevated $\mathrm{Ca}^{+2}$ concentrations likely result in less toxic and more preferable growth conditions, for most species. This is crucial to initial post-fire vegetation recovery. In comparison, in the burnt area at Site D and the unburnt area of Site $\mathrm{C}, \mathrm{Al}^{+3}$ was elevated, and $\mathrm{Ca}^{+2}$ was reduced resulting in greater $\mathrm{Al}$ toxicity (i.e. enhancing the relative competitive ability of $C$. vulgaris) (Kleijn et al., 2008; De Graaf et al., 2009).

Combining the chemical composition data enables the calculation of effective cation exchange capacity (ECEC), an important indicator of soil function (Pereira et al., 2019). Higher ECEC are evident in the burnt areas of Site A, B and C at the soil surface and subsurface layer in comparison to in their within-site unburnt areas (Tables 4.3). This could result from the influx of base cations and the reduction in acidic cations in the burnt areas, caused by the creation and incorporation of base cation rich ash into the soil profile. In addition to the control of $\mathrm{pH}$ on element solubility (Tables 4.3). Numerous studies following low and high severity fires have recorded increases in soil exchangeable cations across a range of habitat types including, heathlands (Mohamed et al., 2007), shrubland (Gómez-Rey and González-Prieto, 2014; Shakesby et al., 2015; Fonseca et al., 2017) and forests (Kennard and Gholz, 2001; Arocena and Opio, 2003; Lavoie et al., 2010).

In general, ECEC values of 12-25 represent moderate nutrient holding capacity and, therefore, are representative of soils with relatively low fertility (Smithson et al., 2013; Cranfield University, 2018). All sampling areas in the soil surface layer presented ECEC values within this bracket (12-25) (Table 4.3). ECEC values within the soils subsurface layer were, on average, lower than at the soil surface, falling below this bracket in the unburnt areas of Site A, B, C and the burnt area of Site D. Reduced ECEC within the subsurface soil layer likely directly relates to the reduction in organic matter at this sampling depth (Santín and Doerr, 2019).

Several relevant generalisations can be made about soils with low ECEC values. Firstly, soils with low ECEC are more likely to develop deficiencies in key nutrients (e.g. $\mathrm{Ca}, \mathrm{Mg}, \mathrm{Na}$ and $\mathrm{K}$ ). Secondly, $\mathrm{pH}$ often decreases much more readily in low ECEC soils (Ketterings et al., 2007). Both of these factors relate to the susceptibility of low ECEC soils to losses of base cations via leaching. In periods of, for example, 
high nutrient inputs following major fire events, low ECEC soils are much more likely to experience large nutrient losses due to leaching, limiting the persistence of post-fire impacts on soil chemical properties (Ketterings et al., 2007). This may be a contributing factor to the relatively fast return of unburnt area conditions here, in comparison to following fires over higher ECEC peaty soils in which the retention capacity for base cations would be much greater.

Despite all efforts to ensure conditions were conducive to comparable sampling areas, sites and fire events, the limitations of using spatially distinct sites with inevitably different histories and burn characteristics must be acknowledged throughout this discussion. In particular, it must be again stated that the discussion and interpretations around the soil chemical characteristics were not able to be validated by robust statistics, due to the limited sample size $(n=3)$, and therefore, must be regarded as speculation. The overall consistency of the soil physicochemical response to fire with other similar studies, however, suggests these results are generally applicable to similar shallow organic layered heathland soils. These results, therefore, provide some valuable insight into the impacts of wildfire on a range of soil physicochemical properties in the seldom studied dry dwarf-shrub heathland habitat type and geographic location of south Wales (UK).

\subsubsection{Management implications}

When considering the implications of changes in soil physicochemical properties under future fire regime changes or respective management strategies it is important to acknowledge that dry dwarf-shrub heaths are highly specialised habitats (Thompson et al., 1995; Smith et al., 2001; Gritten, 2012). In dry dwarf-shrub heaths with strongly acidic soil ( $\mathrm{pH}<4.5)$, like most dry heaths, species are well-adapted to acidic and lownutrient conditions (e.g. C. vulgaris, Erica cinerea and Deschampsia flexuosa) (Hawley et al., 2008). Changes in these conditions as a result of wildfires and their potential to release nutrients and raise soil $\mathrm{pH}$ can, therefore, have significant impacts on their function in their current state. A sustained increase in soil nutrients and $\mathrm{pH}$ will likely favour a transition towards a more productive (i.e. biomass production) habitat, such as a grassland (Hawley et al., 2008). Molinia caerulea (L.) Moench (hereafter M. caerulea) (purple moor grass) for example, is thought to significantly 
benefit from increasing soil nutrient conditions, particularly nitrogen levels (Kirkham, 2001).

If management objectives are to retain or restore dry dwarf-shrub heaths for their range of conservation targets (e.g. C. vulgaris or wildfire and game species such as skylarks, grouse, hen harriers, merlins) then this requires the maintenance of appropriate soil conditions. Common methods for the restoration or re-creation of dry dwarf-shrub heaths and their required soil conditions include (Hawley et al., 2008): i) soil acidity and nutrient amelioration techniques (e.g. cropping and acidification techniques; sulphur and bracken chippings); ii) soil disturbance and removal techniques (e.g. ploughing, inversion and rotovation); and iii) surface and below-ground vegetation management techniques (e.g. grazing, burning, cutting and herbicide application).

If management is focused on promoting species diversity or combating the monodominance of highly competitive species such as, $C$. vulgaris, then soil conditions must also be addressed with interventions to increase soil nutrient holding capacity and $\mathrm{pH}$. There are a number of ways this can be achieved from liming to improving organic matter content and quality (e.g. restoring moss coverage) and rewetting areas of degraded or former wet heath (Hawley et al., 2008; Scott et al., 2014). The characteristic features (e.g. propensity for leaching of bases and maintenance of low $\mathrm{pH}$ conditions), particularly of podzol soil can, however, persist even through substantial land use or management changes (Hawley et al., 2008).

Evidence, however, suggests heathlands are particularly vulnerable to changes in wildfire activity due to their often-low species diversity, the dominance of woody ericaceous shrub species, accumulated fuel loads, limited protective ground litter or moss coverage, and shallow organic layered soils $(<50 \mathrm{~cm})$. These factors are thought to produce a susceptibility to relatively rapid moisture loss of soils and vegetation during drought conditions. Maximum temperature in the surface soil under the same burn conditions are, therefore, thought to be significantly higher in heathland habitats, in comparison to wetter moorland or peatland sites (Grau-Andrés et al., 2018). Shallow, lower organic content soils are also significantly less effective at insulating against soil heat penetration than moister, peaty soils (Davies et al., 2010).

In dry heaths, these circumstances dramatically increase the risk of fires critically damaging soil physicochemical properties, seed banks and post-fire recovery capacity 
if they occur during the predicted increasingly prevalent drought conditions (GrauAndrés et al., 2019a). Irrespective of the debate around the desirable future form and management of upland habitats, such as dwarf-shrub heaths, it is important to maintain or create habitats with heterogeneous structural form, where the full range of species growth phases are present, particularly of dominant species (e.g. C. vulgaris). This will help to maximise flora and faunal diversity at the landscape scale and crucially reduce the continuity of fuel loads, limiting the risk of large-scale severe wildfires.

\subsection{Conclusions}

The data collected in this study suggests these highly acidic, low fertility dry heathland soils were not substantially affected by the assessed wildfire events as regards the parameters examined here. Significant changes in soil physicochemical properties within the burnt areas which perhaps relate to fire effects were restricted to increases in $\mathrm{pH}$ at the soil surface $(0-2.5 \mathrm{~cm})$ in Site A and B $(<1$ and 3-years post-fire, respectively). This limited soil response to fire is likely due to moisture retention in the soils' organic surface layer and perhaps short flame residence times at the surface reducing the degree of soil heating.

Differences in burnt area chemical characteristics, in comparison to their within-site unburnt areas, were also apparent in the form of lower carbon content and exchangeable $\mathrm{Al}^{+3}$ concentrations, and higher base cation concentrations $\left(\mathrm{Ca}^{+2}\right.$ and $\mathrm{Mg}^{+2}$ ) and bioavailable phosphorus (Olsen-P). These differences were, however, only observable in the burnt areas at Site A and/or B ( $<1$ and 3-years post-fire) and were unable to be statistically validated due to the limited sample sizes of the chemical characteristics data. 


\section{Chapter 5}

Chemical composition of wildfire ash produced in contracting ecosystems and its toxicity on Daphnia magna

Published in: International Journal of Wildland Fire (2019) 28, 726-737. (DOI: https://doi.org/10.1071/WF18200) 


\subsection{Introduction}

Fires are a natural process in many habitat types worldwide (Bixby et al., 2015b), but they can be a social and environmental concern, potentially impacting public health, safety, infrastructure, biodiversity, land-use, water and air pollution (Bladon et al., 2014; Brito et al., 2017). Fire activity is projected to increase in many locations and ecotypes as a result of climate and societal changes, making the full understanding of their impacts crucial (Scholze et al., 2006; Chen et al., 2018).

During wildland fires, combustion of fuels releases a wide range of organic and inorganic components into the atmosphere, but also concentrates some of them into wildfire ash left on the ground (Bodí et al., 2014). Fresh wildfire ash typically consists of mineral materials and charred organic components, is non-cohesive, has a low density, and is not attached to the soil, which facilitates its mobilisation and transportation by post-fire water and wind erosion (Bodí et al., 2014; Abraham et al., 2017). The release of soluble elements and particulate matter from eroded ash and underlying soil into aquatic systems following fires can cause increases in water turbidity, $\mathrm{pH}$, organic matter, suspended sediment, conductivity and a depletion of dissolved oxygen, among other (Smith et al., 2011; Tsai et al., 2017). Ash is however, not usually examined as a distinct part of the post-fire sediment and few laboratory studies have characterised the composition of wildfire ash (Bodí et al., 2014).

The majority of the general studies into the effects of wildfire on water quality have focused on runoff amounts and nutrient levels and only more recently has increasing research attention been given to pyrolytic substances, chemical elements and biological reactivity (Shakesby and Doerr, 2006; Campos et al., 2012; Silva et al., 2015). Key areas receiving particular attention as a result of their environmental concern are the production and mobilisation of polycyclic aromatic hydrocarbons (PAHs) and heavy metals (e.g. Vila-Escalé et al. 2007; Campos et al. 2012; OliveiraFilho et al. 2018). Both present major biological concern due to their carcinogenic potential, persistence within ecosystems and tendency to bio-accumulate (Smith et al., 2011; Chen et al., 2018). These contaminants are thought to have complex impacts on water quality and the biological effects of this in aquatic systems have been observed to persist across long spatial and temporal scales (Earl and Blinn, 2003; Costa et al., 2014). 
Ash has also begun to receive increasing recognition as a source of diffuse contamination in freshwater systems with detrimental impacts on both lake and stream biota, including fish (e.g. Nunes et al. 2017; Oliveira-Filho et al. 2018; Gonino et al. 2019a), amphibians (Pilliod et al., 2003), macroinvertebrates (Brito et al., 2017) and algae (Campos et al., 2012) have all been observed. Highly variable impacts of ash contamination on freshwater biota have been reported between different ecosystems, types of ash, fires and species (Smith et al., 2011; Silva et al., 2015; Oliveira-Filho et al., 2018).

Campos et al. (2012) and Silva et al. (2015) for example, found no significant impact of eucalypt ash on the planktonic crustacean Daphnia magna reproduction or immobilisation rates over chronic ( 21 day) and acute (48 h) exposures, respectively. Toxicity was, however, observed on several lower trophic level species in these studies, the bacteria Vibrio fischeri, algae Pseudokirchneriella subcapitata and the macrophyte Lemna minor.

A similar study by Brito et al. (2017) tested toxicity over acute exposures (48 h) of three types of ash from the Brazilian Cerrado ecoregion on the planktonic crustacean Ceriodaphnia dubia, the fish Danio rerio and the mollusc Biomphalaria glabrata and found that all ash types caused toxicity to C. dubia, none impacted B. glabrata and only one type was toxic for $D$. rerio. At higher trophic levels negative impacts of Brazilian sugar cane ash have also been observed on several native fish species (Astyanax lacustris, Moankhausia and M. forestii) over $24 \mathrm{~h}$ acute exposures but not for two non-native fish species (Oreochromis niloticus and Poecilia reticulate) (Gonino et al. 2019b).

These studies demonstrate the variability and complexity of influencing factors in relation to the impacts of ash contamination on aquatic biota, highlighting the limited breadth of available research in this area (Hallema et al., 2018).

To enhance our understanding of the impacts of ash contamination on aquatic biota, this study aimed to (1) determine the chemical composition of wildfire ash produced in six contrasting ecosystems, (2) examine the ecotoxicological effect of these ash types on the freshwater indicator species Daphnia magna and (3) evaluate the relationship between chemical composition and observed toxicity and its implications for the relative water contamination potential of ash produced in these differing 
ecosystems. To the best of our knowledge this constitutes the first ecotoxicology assessment allowing the direct comparison of the composition and toxicity of ash from several globally distributed contrasting ecosystems.

\subsection{Materials and methods}

\subsubsection{Ash samples}

Six composite ash samples were collected after wildland fires, prior to any rainfall, in each of the selected ecosystems types (Table 5.1): Australian eucalypt forest (AUS), USA chaparral (USA), Canadian spruce forest (CAN), Spanish heathland (URIA), Spanish pine forest (SPA), UK grassland (UK). Fire and vegetation characteristics are summarised in Table 5.1. Each composite ash sample was sieved through a $1 \mathrm{~mm}$ mesh before chemical characterisation or use in the bioassays. 
Table 5.1: Fire and vegetation characteristics of the six ash types used in this study.

\begin{tabular}{|c|c|c|c|}
\hline $\begin{array}{c}\text { Sample } \\
\text { name }\end{array}$ & Location & Vegetation cover & Burn description \\
\hline $\begin{array}{c}\text { Australian } \\
\text { eucalypt } \\
\text { (AUS) }\end{array}$ & $\begin{array}{l}\text { West of Sydney } \\
\left(33 \circ 52^{\prime} 144^{\prime \prime} \text {; }\right. \\
150 \circ 36 ’ 01 ” \text { E) }\end{array}$ & $\begin{array}{l}\text { Open, dry sclerophyll forest with a } \\
\text { dense shrubby undergrowth. Key } \\
\text { species; ironbark (Eucalyptus. } \\
\text { fibrosa), stringybarks (Eucalyptus } \\
\text { eugenioides, Eucalyptus oblonga), } \\
\text { Banksia spp., Leptospernum spp., } \\
\text { Acacia spp. and Petrophile spp.. }\end{array}$ & $\begin{array}{l}\text { Moderate to high severity prescribed } \\
\text { fire in 2014. Fire did not affect tree } \\
\text { canopy but complete combustion of } \\
\text { understory fuels and mostly fine ash, } \\
\text { light in colour was generated (Santín } \\
\text { et al., 2018). }\end{array}$ \\
\hline $\begin{array}{c}\text { USA } \\
\text { chaparral } \\
\text { (USA) }\end{array}$ & $\begin{array}{l}\text { South western } \\
\text { California } \\
\left(34^{\circ} 25^{\prime} 14^{\prime \prime} \mathrm{N} \text {; }\right. \\
\text { 119'30'39"'W) }\end{array}$ & $\begin{array}{l}\text { Mixed chaparral with the dominant } \\
\text { species including coast live oak } \\
\text { (Quercus agrifolia), Toyon } \\
\text { (Heteromeles arbutifolia), coyote } \\
\text { brush (Baccharis pilularis), holly-leaf } \\
\text { cherry (Prunus ilicifolia) }\end{array}$ & $\begin{array}{l}\text { Large-scale, extreme high-severity } \\
\text { wildfire (Thomas fire) in 2018, } \\
\text { achieving almost complete } \\
\text { combustion of above surface fuel. }\end{array}$ \\
\hline $\begin{array}{l}\text { Canadian } \\
\text { spruce } \\
(\mathbf{C A N})\end{array}$ & $\begin{array}{l}\text { Northwest } \\
\text { Territories } \\
\left(61^{\circ} 34^{\prime} 55^{\prime \prime} \mathrm{N} \text {; }\right. \\
\left.117^{\circ} 11^{\prime} 55^{\prime \prime} \mathrm{W}\right)\end{array}$ & $\begin{array}{l}\text { Very dense tree canopy comprised of } \\
\text { mostly black spruce (Picea mariana) } \\
\text { and jack pines (Pinus banksiana) with } \\
\text { very little understory vegetation with } \\
\text { the exception of young spruce and } \\
\text { moss species. }\end{array}$ & $\begin{array}{l}\text { Very high severity experimental } \\
\text { crown fire in } 2015 \text {, all fine fuels } \\
\text { aboveground were consumed. The } \\
\text { forest floor was only slight affected } \\
(<1 \mathrm{~cm} \text { depth of burn). }\end{array}$ \\
\hline $\begin{array}{l}\text { Spanish } \\
\text { heathland } \\
\text { (URIA) }\end{array}$ & $\begin{array}{l}\text { North western } \\
\text { Spain }\left(43^{\circ} 6^{\prime} 17^{\prime}\right. \\
\left.\text { N 6 } 50^{\prime} 52^{\prime \prime} \mathrm{W}\right)\end{array}$ & $\begin{array}{l}\text { Dominant species included, heather } \\
\text { (Calluna vulgaris), western gorse } \\
\text { (Ulex gallii) and a variety of Erica spp. } \\
\text { (e.g. Erica tetralix). }\end{array}$ & $\begin{array}{l}\text { Extreme hot and dry conditions } \\
\text { producing a severe experimental fire } \\
\text { in } 2017 \text {. Combustion completeness } \\
\text { very high (most fine fuel consumed). }\end{array}$ \\
\hline $\begin{array}{c}\text { Spanish } \\
\text { pine forest } \\
\text { (SPA) }\end{array}$ & $\begin{array}{l}\text { Eastern Spain } \\
\left(40 \circ 18^{\prime} 36^{\prime} \mathrm{N} \text {; }\right. \\
1 \circ 01 ' 59 ” \mathrm{~W})\end{array}$ & $\begin{array}{l}\text { Forested area dominated by Aleppo } \\
\text { pine (Pinus halepensis). }\end{array}$ & $\begin{array}{l}\text { High-severity wildfire producing a } \\
\text { very high level of combustion } \\
\text { completeness. All surface fuel } \\
\text { consumed. }\end{array}$ \\
\hline $\begin{array}{c}\text { UK } \\
\text { grassland } \\
\text { (UK) }\end{array}$ & $\begin{array}{l}\text { South Wales } \\
\left(51 \circ 500^{\prime} 11^{\prime \prime} \mathrm{N} \text {; }\right. \\
\left.3 \circ 25^{\prime} 44^{\prime \prime} \mathrm{W}\right) \text { and } \\
\left(51 \circ 41^{\prime} 022^{\prime} \mathrm{N} \text {; }\right. \\
\left.3 \circ 38^{\prime} 37^{\prime \prime} \mathrm{W}\right)\end{array}$ & $\begin{array}{l}\text { Upland graminoid dominant areas. } \\
\text { Dominant vegetation in these species- } \\
\text { poor areas consisted of purple moor- } \\
\text { grass (Molinia caerulea), soft rush } \\
\text { (Juncus effuses), mat-grass (Nardus } \\
\text { stricta) and heath plait-moss (Hypnum } \\
\text { jutlandicum). }\end{array}$ & $\begin{array}{l}\text { Moderate severity wildfires in } 2018 \text {. } \\
\text { Consumed most above surface fuel } \\
\text { and litter but did not penetrate soil } \\
\text { surface. Composite from two fires } \\
\text { created in weight ratio 2:1 (g) of ash } \\
\text { from site one and site two, } \\
\text { respectively. }\end{array}$ \\
\hline
\end{tabular}




\subsubsection{Chemical characterisation}

Chemical characterisation of the six ash types collected was undertaken to determine the total and water-soluble concentrations of major $\left(\mathrm{Ca}, \mathrm{Cl}^{-}, \mathrm{Mg}, \mathrm{Na}, \mathrm{Si}, \mathrm{SO}_{4}{ }^{2-}, \mathrm{NO}_{3}{ }^{-}\right)$ and trace elements and compounds $\left(\mathrm{Al}, \mathrm{B}, \mathrm{Cu}, \mathrm{F}^{-}, \mathrm{Fe}, \mathrm{Ni}, \mathrm{NH}_{4}^{+}, \mathrm{As}, \mathrm{Cd}, \mathrm{Hg}, \mathrm{Pb}\right.$ and $\mathrm{PO}_{4}{ }^{3-}$ ), in addition to $\mathrm{pH}$, dissolved organic carbon (DOC) and electric conductivity. This characterisation was undertaken using established methods (Plumlee et al. 2007; Santín et al. 2015, 2018).

Total concentrations of major ( $\mathrm{Si}, \mathrm{Al}, \mathrm{Fe}, \mathrm{Ca}, \mathrm{Mg}, \mathrm{Na}, \mathrm{K}$ ) and trace elements (B, As, $\mathrm{Cu}, \mathrm{Ni}, \mathrm{Pb}, \mathrm{Cu}, \mathrm{Hg}$ ) were determined in acid extracts of the samples (9 $\mathrm{ml}$ of $\mathrm{HNO}_{3}$ $65 \%$ and $3 \mathrm{ml}$ of $\mathrm{HCl} 37 \%$ added to $0.5 \mathrm{~g}$ of ground sample) after microwave digestion (Ethos Plus Milestone microwave) at $200{ }^{\circ} \mathrm{C}$ during 50 minutes. After digestion, the extracts were completed to $50 \mathrm{ml}$ with ultrapure water (1:100 sample:solution). Certified soil standards were used to validate the method of trace metal extraction (SRM 2709a, SMR2710a, from NIST, U.S.A.), with a mean recovery rate of $>93 \%$ ) (Santín et al., 2015).

Leaching tests were carried out according to the methodology proposed by (Hageman, 2007). $3 \mathrm{~g}$ of unground ash samples were weighed into $125 \mathrm{ml}$ bottles. Then, $60 \mathrm{ml}$ ultrapure water (sample:water ratio 1:20) was added and the bottles were capped and shaken for 5 minutes. After shaking, the contents could settle for 10 minutes. The leachate was then filtered using a $0.45 \mu \mathrm{m}$ pore-size nitrocellulose capsule filter. A sub-sample of the filtrate was collected in plastic bottles and refrigerated for ion chromatography analysis. Another sub-sample of the filtrate was acidified to $\mathrm{pH}<1.5$ with suprapur grade $\mathrm{HNO}_{3}$ for atomic absorption spectroscopy and inductively coupled plasma mass spectrometry analysis.

Dissolved organic carbon (DOC) was analysed in a loop flow analysis system (Systea). Phosphate $\left(\mathrm{PO}_{4}{ }^{3-}\right)$ (given as Total Phosphorous - TP), Nitrate $\left(\mathrm{NO}_{3}{ }^{-}\right)$and ammonium $\left(\mathrm{NH}_{4}{ }^{+}\right)$concentrations in leachate extracts were determined by colorimetry (Kempers, 1974) using a Jasco V-630 spectrophotometer. Fluoride $\left(\mathrm{F}^{-}\right)$concentrations were measured using an ion-selective fluoride electrode (Metrohm $692 \mathrm{pH} / \mathrm{Ion}$ Meter). Sulfate and $\mathrm{Cl}^{-}$were determined by ion chromatography (Dionex 4500i system).

Major and trace elements in acid and leachates extracts were determined using Inductively Coupled Plasma Mass Spectrometry (ICP-MS) using a VARIAN 820-MS 
ICP-MS spectrometer, except; $\mathrm{Fe}, \mathrm{Si}$ and $\mathrm{Al}$ that were determined by atomic absorption (PerkinElmer Spectrometer 1100B).

$\mathrm{pH}$ and EC measurements were conducted on a 1:20 sample:water ratio solution (unground sample) after shaking for 5 minutes and allowing to settle for another 10 minutes (same procedure than for the leaching tests below but without filtering). $\mathrm{pH}$ was measured with a Crison micropH $2000 \mathrm{pH}$ meter, with buffer solutions of $\mathrm{pH} \mathrm{4,} 7$ and 9 and EC was measured with a Crison GLP 31 apparatus, previously calibrated with a $0.1 \mathrm{M} \mathrm{KCl}$ solution.

The concentrations of 35 PAHs were also determined according to Pérez-Fernández et al. (2015) and Viñas et al. (2009) with a GC/MS Thermo mod DSQ II (Thermo Electron Corporation, Austin, TX USA). Ash samples ( $3 \mathrm{~g})$ were extracted in Soxhlet with a 1:3 acetone:hexane mixture spiked with a mixture of six deuterated PAHs. The extracts were then cleaned-up using aluminium oxide and copper was added to remove sulphur interferences. PAHs were identified with a GC/MS Thermo mod DSQ II (Thermo Electron Corporation, Austin, TX USA). The GC (TRACE GC Ultra) was equipped with a DB-5 MS column (J\&W Scientific Folsom, CA; 0.25 mm i.d., 0.25 $\mu \mathrm{m}$ film, $60 \mathrm{~m}, 5 \%$ phenylsubtituted methylpolysiloxane phase) and helium was used as carrier gas. The operating conditions were: held at $50^{\circ} \mathrm{C}$ for $3 \mathrm{~min}$, ramped to $200^{\circ} \mathrm{C}$ at $6^{\circ} \mathrm{C} \mathrm{min}-1$ and finally to $315^{\circ} \mathrm{C}$ at $4^{\circ} \mathrm{C} \min ^{-1}$ holding that temperature for $15 \mathrm{~min}$. The sample was injected using an on-column injection system with the purge valve activated $30 \mathrm{~s}$ after the injection. Transfer line and ion source temperatures were held at $280^{\circ} \mathrm{C}$ and $220^{\circ} \mathrm{C}$, respectively. The MS was operated in the electron impact (EI) mode at $70 \mathrm{eV}$ and the spectrum divided into 8 SIM windows, each scanned for up to 7 molecular masses, previously optimized, for the corresponding analyses and the deuterated internal standards eluting in this window. Quantitation of parent and alkylated PAHs was performed using Thermo Scientific ${ }^{\mathrm{TM}}$ Xcalibur $^{\mathrm{TM}}$ software package.

Chemical and reagents used during analysis (Suprasolv grade acetone, hexane, neutral alumina (70-230 mesh) and anhydrous sodium sulphate for analysis) were obtained from Merck (Darmstadt, Germany). A standard mixture of deuterated PAHs containing naphthalene-d8, biphenyl-d10, anthracene-d10, dibenzpthiophene-d8, pyrene-d10 and benz[a]pyrene-d12 was obtained from CIL (Massachusetts, USA). A 
PAH mixture containing Naphthalene, Biphenyl, 2-Methylnaphthalene, 1Methylnaphthalene, 2,3-Dimethylnaphthalene, Acenaphthylene, Acenaphthene, 2,3,6Trimethylnaphthalene, Fluorene, Dibenzothiophene, Phenanthrene, Anthracene, 4Methyldibenzothiophene, 2-Methylphenanthrene, 2,8-Dimethyldibenzothiophene, 1,6-Dimethylphenanthrene, Fluoranthene, 2,4,7-Trimethyldibenzothiophene, Pyrene, 1,2,8-Trimethylphenanthrene,1-Methylpyrene, Benzo(c)phenanthrene, Benz(a)anthracene, Triphenylene, Chrysene, 2-Methylchrysene,7,12DimethylB(a)anthracene, Benzo(b)fluoranthene, Benzo(k)fluoranthene, Benzo(e)pyrene, Benzo(a)pyrene, Perylene, Indeno(1,2,3-c,d)pyrene, Dibenzo(a,h)anthracene, Benzo (g,h,i) perylene was prepared from mixtures from CPA Chem (Bulgaria) and Chiron (Trondheim, Norway).

For the quality assurance and quality control of analysis (QA/QC), reagents blanks were analysed, and recovery procedures checked to assure that no contamination or losses occurred during extraction or other analytical procedures. Blanks result in no detectable PAHs concentrations and average recovery of PAHs ranged from 55 to 114 $\%$ for Acenaphthylene and Acenaphthene, respectively. The method detection limits (LOD) for individual PAHs calculated using the signal-noise ratio standard deviation were in the range of 0.25 to $2.62 \mathrm{ng} \mathrm{g}^{-1} \mathrm{~d}$.w. A minimum of five levels of a PAHs mixture standards were run with every batch of samples to build the linear regression curves by plotting the peak area ratios versus each PAH concentration. Four different sediments used in the lab in various intercalibration exercises organised by Quality Assurance of Information for Marine Environmental Monitoring (QUASIMEME) were used as internal reference materials (Viñas et al., 2009; Pérez-Fernández et al., 2015).

\subsubsection{Daphnia toxicity testing}

Ecotoxicological assays consisting of acute ash exposures ( $48 \mathrm{~h}$ ) were conducted using the planktonic crustacean Daphnia magna Straus (hereafter D. Magna). This species is extensively used in ecological and toxicological studies as a sensitive indicator of the effects of contaminants on aquatic biota (OECD 2004; USEPA 2016). Daphnia spp. are also particularly relevant to freshwater lentic ecosystems (lakes, reservoirs and 
ponds) and ideal for investigating contamination potential in downstream waterbodies (Robinson and Thorn, 2009; Nikinmaa, 2014).

A monoclonal starter culture of D. magna was obtained from a long-term (2 year) rearing program. The new culture was reared and maintained according to recommended guidelines (OECD 2004; USEPA 2016), under controlled temperature $\left(20 \pm 2^{\circ} \mathrm{C}\right)$, light conditions (uniform illumination of cool-white type, approx. 5000 lux; photoperiod $16^{\mathrm{L}}: 8^{\mathrm{D}}$ ) and fed every 2 days with a distilled suspension of Pseudokirchneriella subcapitata at approximately 0.1-0.2 $\mathrm{ml}$ per Daphnid/day.

To produce the test solutions, each ash sample was combined with a culture medium (synthetic hardwater medium - ASTM 1996) at the ratio 1:10 (mass:volume) (e.g. 100 $\mathrm{g}$ of ash in $1 \mathrm{~L}$ of medium). The samples were then homogenised in an orbital shaker for $4 \mathrm{~h}$ and stored at $4{ }^{\circ} \mathrm{C}(\max 24 \mathrm{~h})$ before using in the ecotoxicological assays.

The acute toxicity tests were conducted according to the OECD 202 (OECD, 2004) guidelines, with the exception of full $\mathrm{pH}$ adjustment. $\mathrm{pH}$ was not adjusted to control levels $(\mathrm{pH} 7.2 \pm 0.2)$ in the bioassays to reproduce as close to natural conditions as possible, given $\mathrm{pH}$ is one of the most important factors affecting the toxicity and bioavailability of elements to freshwater species (Franklin et al., 2000). OECD 202 guidelines acknowledge that tests should be carried out without the adjustment of $\mathrm{pH}$, where values are within $\mathrm{pH}$ 6-9 at the highest test concentration (OECD, 2004). It is crucially important that $\mathrm{pH}$ adjustment does not cause significant changes to the test substances and due to the complex and varying compositions and reactivity of wildfire ash, potential interactions are unclear. Little is known to date on wildfire ash concentrations in water bodies, therefore, a wide range of ash concentrations was tested, trying to represent the potential variability of different natural scenarios. Six different concentrations of the ash-medium solutions were used during testing (3.12, $6.25,12.5,25,50,75 \mathrm{~g} \mathrm{~L}^{-1}$ ), plus four controls per concentration.

Tests were initiated using new-borns of less than $24 \mathrm{~h}$ old, originating from the $3^{\text {rd }}$ $5^{\text {th }}$ brood of the culture. For each ash type 150 daphnids were used. This sample size was divided into five individuals per test vessel for each concentration with four replicates and one control per concentration. The test was conducted for $48 \mathrm{~h}$ and the immobilisation of neonates was documented at $24 \mathrm{~h}$ and $48 \mathrm{~h}$. Immobilisation of neonates is defined here as individuals not able to swim within $15 \mathrm{~s}$ of gentle agitation 
of the test vessel. During this period the same temperature $\left(20 \pm 2^{\circ} \mathrm{C}\right)$ and photoperiod (photoperiod, $16^{\mathrm{L}}: 8^{\mathrm{D}}$ ) conditions as during rearing were maintained. D. magna were not fed during the acute exposure (USEPA 2016).

\subsubsection{Statistical analysis}

The water-soluble (leachates) chemical composition results were subjected to principle component analysis (PCA) (RStudio version 5.4.1) to identify constituents most strongly correlated with the different ash types. This approach to assessing the characteristic components in a given sample is widely used in environmental research when dealing with complex datasets (Brito et al. 2017). The leachates data were chosen for this analysis, as opposed to the total elements data, because this is likely the most bioavailable fraction and, therefore, the most likely to have impacted the Daphnia over an acute exposure.

To identify thresholds in the D. magna toxicity results and in agreement with standard procedures (Musset, 2006) the data were subjected to single factor analysis of variance tests (RStudio version 5.4.1). Where significant results were identified post-hoc Dunnetts analysis was used to test if the response at each concentration was significantly different to the control groups and therefore, identify critical thresholds (lethal concentrations) in the response relationships. This enables the effect concentrations $\left(\mathrm{EC}_{10}=\right.$ concentration at which $10 \%$ of individuals are immobilised and $\mathrm{EC}_{50}=$ concentration at which $50 \%$ of individuals are immobilised) for each ash to be interpolated, along with the lowest observed effect concentration (LOEC) (Musset, 2006). A significance level of 5\% (0.05) was used in all statistical tests.

\subsection{Results}

\subsubsection{Ash chemistry}

The total elemental composition of the six ash types overall contained a number of potential contaminants, but in highly variable concentrations (Table 5.2). The most abundant element in all samples was $\mathrm{Ca}\left(\right.$ range $\left.=11,800-177,000 \mathrm{mg} \mathrm{kg}^{-1}\right)$ with $\mathrm{Al}$ $\left(\right.$ range $\left.=1320-22,600 \mathrm{mg} \mathrm{kg}^{-1}\right)$ and $\mathrm{Fe}\left(\right.$ range $\left.=979-30,600 \mathrm{mg} \mathrm{kg}^{-1}\right)$ both present 
in high concentrations throughout. The elements found in the lowest total concentrations were: As (range $\left.=0.46-9.67 \mathrm{mg} \mathrm{kg}^{-1}\right), \mathrm{Cd}($ range $=0.17-1.13 \mathrm{mg}$ $\left.\mathrm{kg}^{-1}\right)$ and $\mathrm{Hg}\left(\right.$ range $\left.=0-0.05 \mathrm{mg} \mathrm{kg}^{-1}\right)$ (Table 5.2).

Table 5.2: Total dry chemical composition of the six ash types tested $\left(\mathrm{mg} \mathrm{kg}^{-1}\right)$. Abbreviation TP refers to Total Phosphorus. N.D (not detected) represents elements in concentrations $<0.01$ $\mathrm{mg} \mathrm{kg}^{-1}$.

\begin{tabular}{c|cccccc}
\hline & \multicolumn{5}{|c}{ Ash type } \\
& AUS & USA & CAN & URIA & SPA & UK \\
\hline $\mathbf{A l}$ & 7000 & 22600 & 1320 & 10000 & 32800 & 2805 \\
$\mathbf{S i}$ & 2079 & 2068 & 1782 & 2376 & 2255 & 1595 \\
$\mathbf{C a}$ & 177000 & 215000 & 163000 & 29400 & 133000 & 11800 \\
$\mathbf{T P}$ & 477 & 5342 & 5826 & 2418 & 1866 & 2645 \\
$\mathbf{N a}$ & 5043 & 4603 & 3113 & 3563 & 1123 & 663 \\
$\mathbf{M g}$ & 9900 & 22000 & 12000 & 6400 & 5500 & 2700 \\
$\mathbf{M n}$ & 510 & 710 & 830 & 1000 & 320 & 1430 \\
$\mathbf{F e}$ & 4300 & 19100 & 979 & 8600 & 30600 & 7100 \\
$\mathbf{N i}$ & 16 & 99 & 15 & 22 & 32 & 16 \\
$\mathbf{C u}$ & 21 & 52 & 29 & 40 & 30 & 50 \\
$\mathbf{Z n}$ & 144 & 112 & 144 & 101 & 172 & 181 \\
$\mathbf{A s}$ & 1.57 & 2.37 & 0.46 & 4.45 & 9.67 & 4.35 \\
$\mathbf{C d}$ & 0.17 & 0.21 & 0.22 & 0.18 & 0.26 & 1.13 \\
$\mathbf{H g}$ & $N . D$ & 0.05 & $N . D$ & 0.01 & 0.01 & 0.02 \\
$\mathbf{P b}$ & 35 & 38 & 24 & 35 & 59 & 112 \\
\hline
\end{tabular}

$\mathrm{pH}$ and electrical conductivity (EC), measured in the leachates, notably varied across ash samples, with $\mathrm{pH}$ levels ranging from moderately alkali in the UK ash (7.9), to strongly alkali in the USA ash (11.2). Equally, EC levels varied greatly from $233 \mu \mathrm{S}$ $\mathrm{cm}^{-1}$ in the SPA ash to $3880 \mu \mathrm{S} \mathrm{cm}^{-1}$ in the AUS ash. High $\mathrm{pH}$ and EC values were both characteristic features of the ash types producing immobilisation of $D$. magna tested (see Acute toxicity test section). $\mathrm{pH}$ within the bioassays themselves, however, were notably less variable (7.31-9.08, Table 5.6 and 5.7), likely due to differences in dilution between leachates and the bioassay testing, and the addition of the culture medium in the latter. 
The water-soluble (leachate) composition of the ash types were also highly variable (Table 3 ) with the most abundant components being $\mathrm{SO}_{4}{ }^{2-}$ (range $=1203-10,180 \mathrm{mg}$ $\left.\mathrm{kg}^{-1}\right), \mathrm{Cl}^{-}\left(\right.$range $\left.=228-1509 \mathrm{mg} \mathrm{kg}^{-1}\right)$ and $\mathrm{Na}\left(\right.$ range $\left.=17-3893 \mathrm{mg} \mathrm{kg}^{-1}\right)$. The minor metal and metalloids elements were similarly the components found in the lowest concentration in the leachates; $\mathrm{Cd}\left(\right.$ range $\left.=0-7 \mu \mathrm{g} \mathrm{kg}^{-1}\right)$, Ni (range $=60-844 \mu \mathrm{g}$ $\left.\mathrm{kg}^{-1}\right), \mathrm{Zn}\left(\right.$ range $\left.=0-140 \mu \mathrm{g} \mathrm{kg}^{-}\right)$and $\mathrm{Hg}\left(\right.$ range $\left.=1-2 \mu \mathrm{g} \mathrm{kg}^{-1}\right)($ Table 3$)$.

Some soluble elements occurred in particularly high levels, highlighting the variation in element content within the ash (Table 5.3). For example, in the UK sample, $\mathrm{PO}_{4}{ }^{3}$ $\left(620 \mathrm{mg} \mathrm{kg}^{-1}\right)$ and metals such as Fe $\left(4378 \mu \mathrm{g} \mathrm{kg}^{-1}\right)$ and $\mathrm{Mn}\left(9292 \mu \mathrm{g} \mathrm{kg}^{-1}\right)$ were notably high in comparison to the other ash types. There were also notably high levels of, for example, $\mathrm{Ca}\left(5864 \mathrm{mg} \mathrm{kg}^{-1}\right)$ and $\mathrm{SO}_{4}{ }^{2-}\left(32,289 \mathrm{mg} \mathrm{kg}^{-1}\right)$ in the CAN sample; B $\left(85 \mathrm{mg} \mathrm{kg}^{-1}\right)$ and $\mathrm{Na}\left(3893 \mathrm{mg} \mathrm{kg}^{-1}\right)$ in the AUS sample; and $\mathrm{Cu}\left(5158 \mu \mathrm{g} \mathrm{kg}^{-1}\right)$ and As $\left(329 \mu \mathrm{g} \mathrm{kg}^{-1}\right)$ in the URIA sample (Table 5.3).

The water-soluble concentrations of each element were relatively low when compared to the total dry concentration within each ash type (Table 5.3). On average, the proportions of water-soluble $\mathrm{Al}, \mathrm{Pb}, \mathrm{Mn}, \mathrm{Fe}, \mathrm{Zn}$ were $<1 \%$ total dry weight; $\mathrm{As}, \mathrm{Si}$, $\mathrm{Ca}, \mathrm{P}, \mathrm{Ni}, \mathrm{Cu}, \mathrm{Cd}$ were $<5 \%$ and $\mathrm{Mg}$ was $<10 \%$. The levels of $\mathrm{Na}(2-77 \%)$ and $\mathrm{Hg}$ $(5-57 \%)$ solubility were highly variable and are clearly the most overall soluble of the components analysed. 
Table 5.3: Water-soluble chemical composition of the six ash types obtained by leaching tests. Solubility of elements provided in brackets as a percentage (\%) of the total ash composition. Electrical conductivity (E.C.) given in $\mu \mathrm{S} \mathrm{cm}^{-1}$. N.D (not detected) represents components with quantities $<0.01 \mathrm{mg} \mathrm{kg}^{-1}$. The symbol (-) is used to denote values not able to be calculated due to the dry weight of the component not being tested for or the value being 0 .

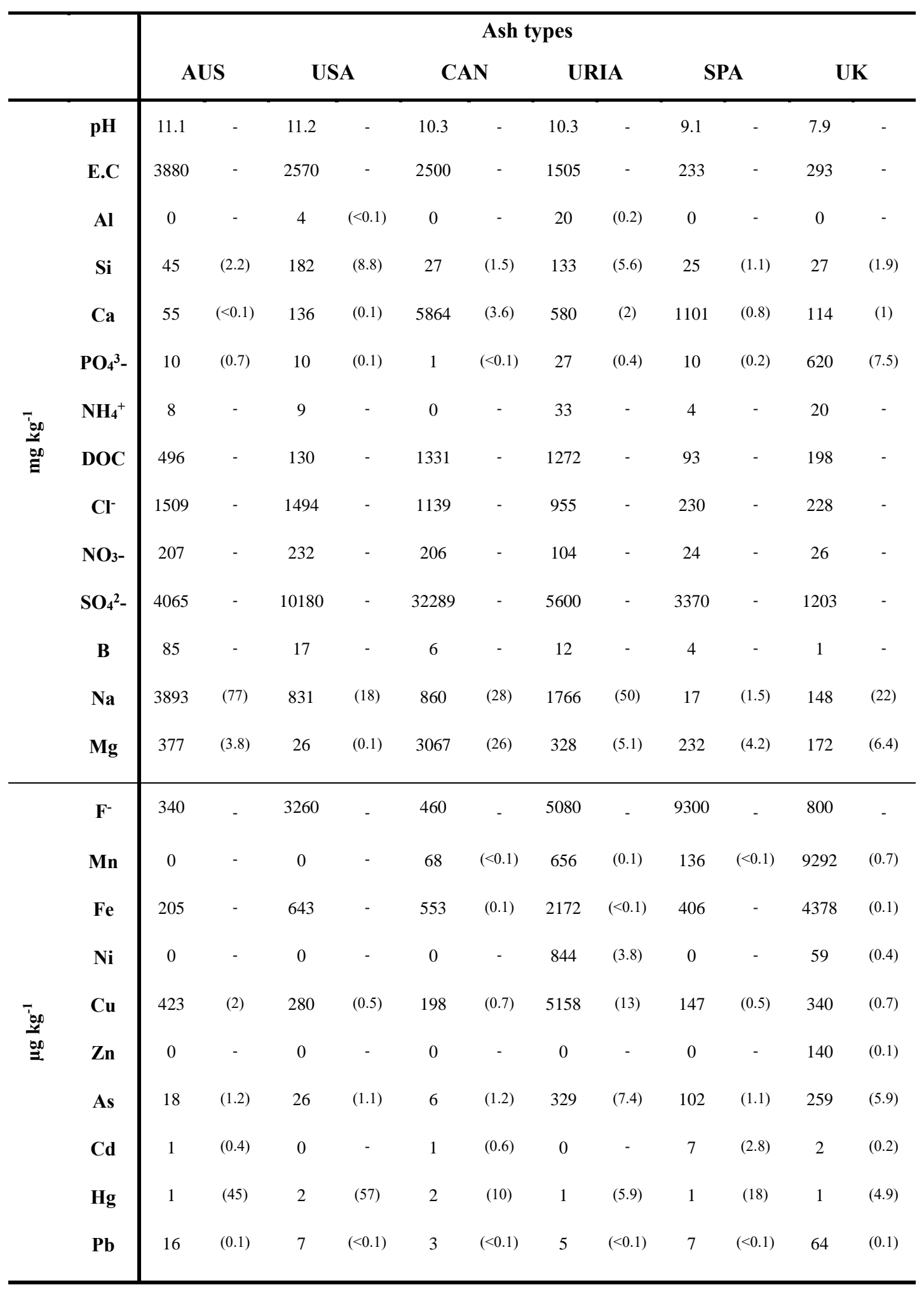


PCA identified three primary components explaining $79 \%$ of the total leachate dataset variance $(\mathrm{PC} 1=41 \% ; \mathrm{PC} 2=23 \% ; \mathrm{PC} 3=15 \%)$ (Table 5.4). $\mathrm{PC} 1$ is most strongly positively correlated with $\mathrm{Mn}, \mathrm{Fe}, \mathrm{Zn}, \mathrm{As}, \mathrm{Pb}$ and $\mathrm{PO}_{4}{ }^{3-}$ levels and most strongly negatively correlated with $\mathrm{pH}, \mathrm{EC}, \mathrm{NO}_{3}{ }^{-}, \mathrm{Cl}^{-}, \mathrm{Hg}$ and $\mathrm{SO}_{4}{ }^{2-}$ (Table 5.4; Figure 5.1). A biplot of the standardised PC1 and PC2 values (Figure 5.1) shows which components best characterised each ash type and $\mathrm{pH}, \mathrm{EC}, \mathrm{NO}_{3}{ }^{-}, \mathrm{Cl}^{-}, \mathrm{Hg}$ and $\mathrm{SO}_{4}{ }^{2-}$ were most closely correlated with the three ash types producing significant immobilisation of D. magna. Whilst, $\mathrm{Al}, \mathrm{Cu}, \mathrm{Ni}, \mathrm{NH}_{4}{ }^{+}$, As, $\mathrm{Fe}, \mathrm{Mn}, \mathrm{PO}_{4}{ }^{3-}, \mathrm{Pb}, \mathrm{Cd}$ were more closely correlated with the three non-toxic ash types (Figure 5.1).

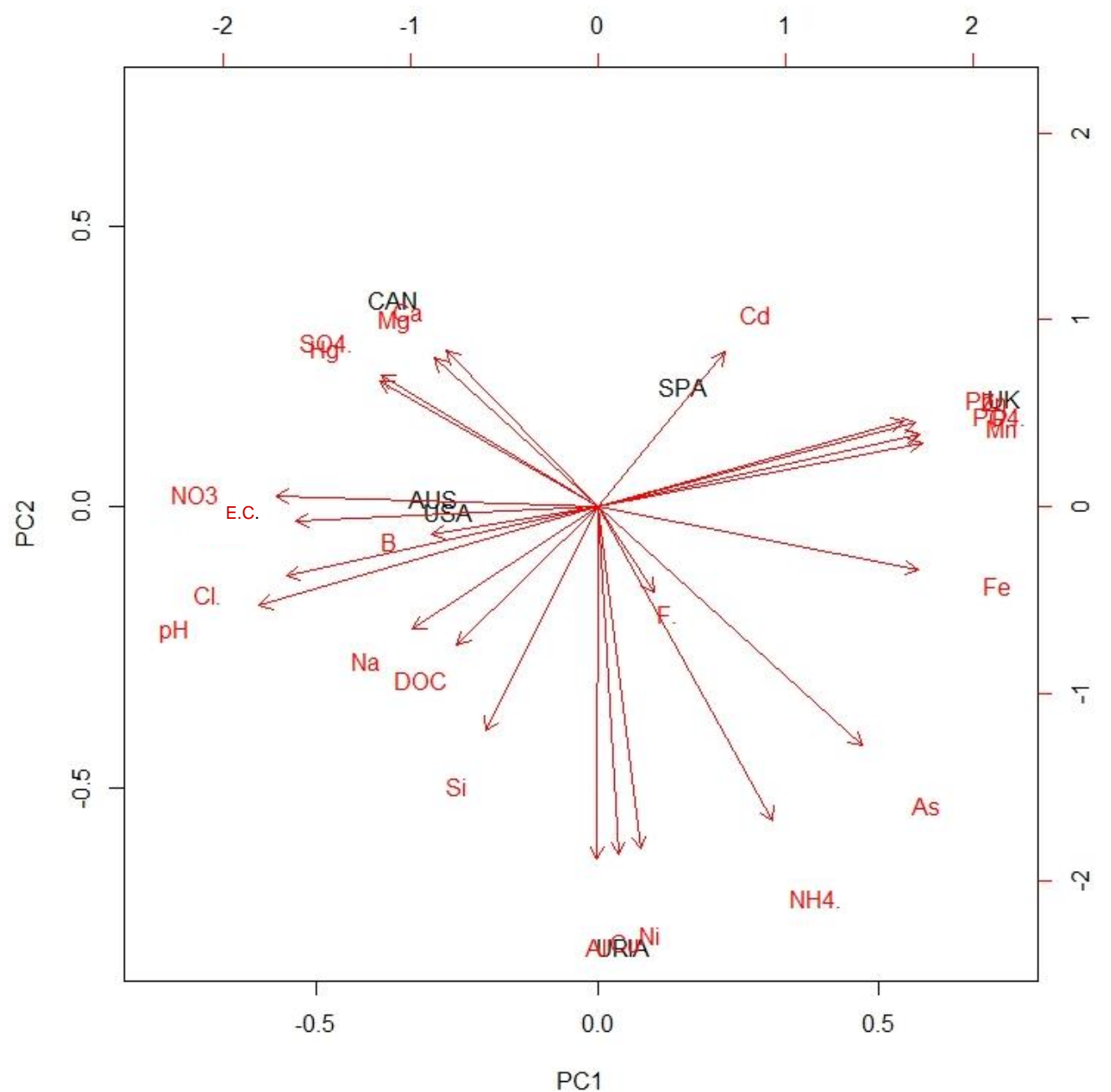

Figure 5.1: Representation of the ordination of the first two axes (PC1 and $\mathrm{PC} 2$ ) produced during the principle components analysis (PCA) of the water-soluble chemical composition of the six ash types studied. Electrical conductivity (E.C.), Dissolved organic carbon (DOC). 
Table 5.4: Relative contribution of the 24 water-soluble ash constituents and parameters to four of the significant principle components of the six ash types derived from principle components analysis. Cumulative proportion (\%) of the variance explained by each principle component also provided.

\begin{tabular}{|c|c|c|}
\hline Parameter & PC1 & PC2 \\
\hline pH & -0.29 & -0.11 \\
\hline E.C & -0.26 & -0.02 \\
\hline Al & 0.00 & -0.40 \\
\hline $\mathbf{S i}$ & -0.10 & -0.26 \\
\hline $\mathrm{Ca}$ & -0.13 & 0.18 \\
\hline $\mathrm{PO}_{4}{ }^{3-}$ & 0.27 & 0.08 \\
\hline $\mathbf{N H}_{4}^{+}$ & 0.15 & -0.36 \\
\hline DOC & -0.12 & -0.16 \\
\hline $\mathrm{Cl}^{-}$ & -0.27 & -0.08 \\
\hline $\mathrm{NO}_{3-}$ & -0.27 & 0.01 \\
\hline $\mathrm{SO}_{4}{ }^{2-}$ & -0.18 & 0.15 \\
\hline B & -0.14 & -0.03 \\
\hline $\mathbf{N a}$ & -0.16 & -0.14 \\
\hline Mg & -0.14 & 0.17 \\
\hline $\mathbf{F}^{-}$ & 0.05 & -0.10 \\
\hline Mn & 0.28 & 0.07 \\
\hline $\mathrm{Fe}$ & 0.27 & -0.07 \\
\hline $\mathbf{N i}$ & 0.04 & -0.39 \\
\hline $\mathrm{Cu}$ & 0.02 & -0.40 \\
\hline $\mathbf{Z n}$ & 0.27 & 0.10 \\
\hline As & 0.23 & -0.27 \\
\hline Cd & 0.11 & 0.18 \\
\hline Hg & -0.19 & 0.14 \\
\hline $\mathbf{P b}$ & 0.26 & 0.10 \\
\hline Cumulative prop. (\%) & 0.41 & 0.64 \\
\hline
\end{tabular}


Thirty-five PAHs were analysed across the ash types including the sixteen United States Environmental Protection Agency (EPA) priority PAHs, which provide the focus of the following discussion (Table 5.5). The total concentration of these priority contaminants ranged from $1155-14,078 \mathrm{ng} \mathrm{g}^{-1}$ ash, the highest total being found in the UK ash originating from an upland grassland ecosystem in South Wales ( $\sum 16$ EPA PAHs: 12,336 $\mathrm{ng} \mathrm{g}^{-1}$ ash) (Table 5.5). Notably high PAHs concentration were also found in the CAN ( $\sum 16$ EPA PAHs: 7,486 $\left.\mathrm{ng} \mathrm{g}^{-1}\right)$ and the SPA ash ( $\sum 16$ EPA PAHs: $4,393 \mathrm{ng} \mathrm{g}^{-1}$ ash) (Table 5.5).

The proportion of the methylated and non-methylated PAHs was very similar in all the samples with around three times more non-methylated PAHs in each ash type, except the USA ash which contained over 15 times the amount of non-methylated PAHs (Table 5.5). There was also a predominance of 2-ring PAHs in all the samples. Generally, the quantity of each ring type decreases sequentially with the number of rings, $2>3>4>5 \& 6$ with the exception of the USA sample, which had a relatively similar quantity of 3, 4, 5 \& 6 ring PAHs. The predominant 2-ring PAHs in all samples was Naphthalene. Phenanthrene was the most common 3-ring PAHs, except in the UK sample where it was Acenaphthylene. All three of these abundant PAHs (naphthalene, phenanthrene and acenaphthylene) are classified as EPA priority contaminants (Table $5.5)$. 
Table 5.5: Concentration and composition of PAHs found in each ash type (ng g-1). PAHs displayed followed with the notation * are U.S. Environmental Protection Agency priority PAHs (Keith, 2015).

\begin{tabular}{|c|c|c|c|c|c|c|}
\hline \multirow[b]{2}{*}{ PAH (ng/g) } & \multicolumn{6}{|c|}{ Ash type } \\
\hline & AUS & USA & $\mathbf{C A N}$ & URIA & SPA & UK \\
\hline Naphthalene* & 744.9 & 1148.6 & 4540.3 & 2861.4 & 1147.4 & 8010.9 \\
\hline Biphenyl & 293.5 & 654.3 & 1851.1 & 1953.3 & 1019.1 & 1677.6 \\
\hline Acenaphthylene* & 75.2 & 9.7 & 377.3 & 323.7 & 28.1 & 3337.2 \\
\hline Acenaphthene* & 13.2 & 1.9 & 84.5 & 44.3 & 9.6 & 198.2 \\
\hline Fluorene* & 18.1 & 3.4 & 99.7 & 104.0 & 26.7 & 380.4 \\
\hline Dibenzothiophene & 4.7 & 3.5 & 45.6 & 11.9 & 7.7 & 29.2 \\
\hline Phenanthrene* & 140.5 & 121.2 & 1049.5 & 487.4 & 170.5 & 1131.8 \\
\hline Anthracene* & 19.1 & 10.4 & 126.3 & 76.1 & 15.6 & 193.2 \\
\hline Fluoranthene* & 36.1 & 27.5 & 285.6 & 128.1 & 26.7 & 262.2 \\
\hline Pyrene* & 37.3 & 16.9 & 215.8 & 112.9 & 20.7 & 257.8 \\
\hline Benzo(c)phenanthrene & 2.9 & 3.0 & 12.7 & 9.7 & 2.9 & 12.7 \\
\hline Benz(a)anthracene* & 11.9 & 8.4 & 32.3 & 23.9 & 4.4 & 35.3 \\
\hline Triphenylene & 7.7 & 53.7 & 44.6 & 16.0 & 7.1 & 14.7 \\
\hline Chrysene* & 14.3 & 26.5 & 38.9 & 27.4 & 7.3 & 36.3 \\
\hline Benzo(b)fluoranthene* & 16.3 & 29.2 & 335.0 & 83.1 & 7.9 & 95.4 \\
\hline Benzo(k)fluoranthene* & 4.2 & 8.9 & 92.8 & 25.0 & 3.0 & 32.3 \\
\hline Benzo(e)pyrene & 11.3 & 44.1 & 291.8 & 90.9 & 8.8 & 57.3 \\
\hline Benzo(a)pyrene* & 7.2 & 6.1 & 74.9 & 31.7 & 2.4 & 34.2 \\
\hline Perylene & 3.4 & 1.3 & 20.1 & 14.8 & 1.9 & 13.2 \\
\hline Indeno $(1,2,3-c, d)$ pyrene* & 5.2 & 5.5 & 30.2 & 15.9 & 1.5 & 27.0 \\
\hline Dibenzo(a,h)anthracene* & 1.9 & 2.6 & 10.5 & 14.8 & 0.9 & 5.2 \\
\hline Benzo $(g, h, i)$ perylen* & 9.6 & 18.2 & 92.5 & 33.0 & 2.8 & 40.7 \\
\hline 2-Methylnaphtalene & 225.7 & 66.9 & 1702.3 & 751.4 & 274.3 & 2118.2 \\
\hline 1-Methylnaphthalene & 168.2 & 34.3 & 1204.2 & 683.7 & 318.7 & 1663.5 \\
\hline 2,3-Dimethylnaphthalene & 43.2 & 7.1 & 388.0 & 138.0 & 166.8 & 235.0 \\
\hline 2,3,6-Trimethylnaphtalene & 19.4 & 3.4 & 140.5 & 50.0 & 20.9 & 80.0 \\
\hline 4-Methyldibenzothiophene & 7.9 & 1.0 & 32.5 & 49.5 & 32.8 & 35.0 \\
\hline 2-Methylphenanthrene & 21.2 & 6.3 & 154.3 & 87.7 & 44.7 & 153.6 \\
\hline 2,8-Dimethyldibenzothiophene & 3.0 & 0.7 & 14.1 & 12.0 & 5.2 & 29.4 \\
\hline 1,6-Dimethylphenanthrene & 31.9 & 5.5 & 147.2 & 109.0 & 51.5 & 120.0 \\
\hline 2,4,7-Trimethyldibenzothiophene & 0.3 & 0.1 & 0.8 & 1.0 & 0.5 & 3.3 \\
\hline
\end{tabular}




\begin{tabular}{|c|c|c|c|c|c|c|}
\hline 1,2,8-Trimethylphenanthrene & 8.4 & 2.1 & 67.2 & 47.8 & 43.4 & 35.5 \\
\hline 1-Methylpyrene & 9.8 & 1.4 & 24.5 & 31.3 & 11.3 & 32.9 \\
\hline 2-Methylchrysene & 3.8 & 1.7 & 4.5 & 5.9 & 1.9 & 6.4 \\
\hline 7,12-DimethylB(a)A & 2.9 & 0.5 & 1728.4 & 64.2 & 90.9 & 12.5 \\
\hline$\Sigma 16$ PAHS & 1155 & 1445 & 7486 & 4393 & 1476 & 14078 \\
\hline 乏35 PAHS & 2024 & 2336 & 15360 & 8521 & 3586 & 20408 \\
\hline$\Sigma$ Methylated & 546 & 131 & 5608 & 2031 & 1063 & 4525 \\
\hline$\Sigma$ Non-methylated & 1479 & 2205 & 9752 & 6489 & 2523 & 15883 \\
\hline$\%$ Methylated & 27 & 6 & 37 & 24 & 30 & 22 \\
\hline
\end{tabular}

Table 5.5: (continued)

\subsubsection{Acute toxicity test}

High levels of D. magna immobilisation were recorded at both 24 and $48 \mathrm{~h}$ exposure for three of the six ash types tested: AUS, USA and CAN $(p<0.001$ for all three ash types) (Figure 5.2; Table 5.6 and 5.7). The response relationships identify the AUS ash as the most toxic, with a $100 \%$ immobilisation of D. magna individuals at less than 25 $\mathrm{g}$ ash $\mathrm{L}^{-1}$ within the first 24 hours of exposure (Table 6; Figure 5.2). The immobilisation effect of both the North American ash samples (USA and CAN) were relatively similar, with $48 \mathrm{~h} \mathrm{EC}_{50}$ being achieved at 20 and $26 \mathrm{~g}_{\text {ash } \mathrm{L}^{-1}}$ respectively, despite the notably different source vegetation (Table 5.7; Figure 5.2). In contrast, no significant immobilisation occurred in response to the remaining three ash types (URIA, SPA and UK) (Table 5.6 and 5.7). The UK ash did not produce any observable immobilisation across any of the test concentrations after $48 \mathrm{~h}$ of exposure. The Spanish samples (URIA, SPA) only produced small rates of immobilization at the highest concentrations (Table 5.6 and 5.7). 
Table 5.6. Immobilisation percentage of Daphnia magna at $24 \mathrm{~h}$. Estimates of Lowest Observed Effect Concentration (LOEC) (Dunnetts test; $\mathrm{p}<0.05), \mathrm{EC}_{10} *$ and $\mathrm{EC}_{50}\left(\mathrm{~g} \mathrm{~L}^{-1}\right)$. Oneway analysis of variance p-values also provided, testing if observed immobilisation of each ash type was significantly different to the control. ${ }^{*} \mathrm{EC}_{\mathrm{x}}=$ the concentration of substance required to produce $\mathrm{x} \%$ (10 or 50$)$ of the test individuals to become immobilised. The symbol (-) is used to denote values not able to be calculated.

\begin{tabular}{|c|c|c|c|c|c|c|c|c|c|c|c|c|}
\hline & \multicolumn{7}{|c|}{ Concentration $\left(\mathrm{g} \mathrm{L}^{-1}\right)$} & \multirow[t]{2}{*}{ pH } & \multirow{2}{*}{$\begin{array}{c}\text { LOEC } \\
\left(\mathrm{g} \mathrm{L}^{-1}\right)\end{array}$} & \multirow{2}{*}{$\begin{array}{c}\mathbf{E C}_{\mathbf{1 0}} \\
\left(\mathrm{g} \mathrm{L}^{-1}\right)\end{array}$} & \multirow{2}{*}{$\begin{array}{l}\mathbf{E C}_{50} \\
\left(\mathrm{~g} \mathrm{~L}^{-1}\right)\end{array}$} & \multirow[t]{2}{*}{ p value } \\
\hline & Control & 3.12 & 6.25 & 12.5 & 25 & $\mathbf{5 0}$ & 75 & & & & & \\
\hline AUS & 0 & 5 & 10 & 75 & 100 & 100 & 100 & 8.81 & 6.25 & 6.25 & 11 & $<0.001$ \\
\hline USA & 0 & 0 & 0 & 5 & 35 & 100 & 100 & 8.78 & 25 & 14 & 30 & $<0.001$ \\
\hline CAN & 0 & 0 & 0 & 5 & 10 & 100 & 100 & 8.23 & 50 & 25 & 37 & $<0.001$ \\
\hline URIA & 0 & 0 & 0 & 0 & 0 & 0 & 5 & 8.17 & - & - & - & 0.451 \\
\hline SPA & 0 & 0 & 0 & 0 & 0 & 5 & 0 & 7.88 & - & - & - & 0.451 \\
\hline UK & 0 & 0 & 0 & 0 & 0 & 0 & 0 & 7.56 & - & - & - & - \\
\hline
\end{tabular}

Table 5.7: Immobilisation percentage of Daphnia magna at $48 \mathrm{~h}$. Estimates of Lowest Observed Effect Concentration (LOEC) (Dunnetts test; $\mathrm{p}<0.05$ ), $\mathrm{EC}_{10} *$ and $\mathrm{EC}_{50}\left(\mathrm{~g} \mathrm{~L}^{-1}\right)$. Oneway analysis of variance p-values also provided, testing if observed immobilisation of each ash type was significantly different to the control. ${ }^{*} \mathrm{EC}_{\mathrm{x}}=$ the concentration of substance required to produce $\mathrm{x} \%$ ( 10 or 50$)$ of the test individuals to become immobilised. The symbol (-) is used to denote values not able to be calculated.

\begin{tabular}{c|cccccccccccc}
\hline & \multicolumn{1}{|c}{ Concentration $\left(\mathrm{g} \mathrm{L}^{-1}\right)$} & & $\mathbf{p H}$ & $\begin{array}{c}\text { LOEC } \\
\left(\mathrm{E} \mathrm{LC}_{\mathbf{1 0}}^{-1}\right)\end{array}$ & $\begin{array}{c}\mathbf{E C}_{\mathbf{5 0}} \\
\left(\mathrm{g} \mathrm{L}^{-1}\right)\end{array}$ & p value \\
& Control L & $\mathbf{3 . 1 2})$ & $\mathbf{6 . 2 5}$ & $\mathbf{1 2 . 5}$ & $\mathbf{2 5}$ & $\mathbf{5 0}$ & $\mathbf{7 5}$ & & & \\
\hline AUS & 0 & 10 & 15 & 85 & 100 & 100 & 100 & 8.93 & 6.25 & 5.5 & 9.5 & $<0.001$ \\
USA & 0 & 0 & 5 & 5 & 65 & 100 & 100 & 9.08 & 6.25 & 14 & 20 & $<0.001$ \\
CAN & 0 & 0 & 0 & 5 & 40 & 100 & 100 & 7.81 & 25 & 14 & 26 & $<0.001$ \\
URIA & 0 & 0 & 0 & 0 & 0 & 0 & 10 & 8.03 & - & - & - & 0.451 \\
SPA & 0 & 0 & 0 & 0 & 0 & 5 & 0 & 7.58 & - & - & - & 0.451 \\
UK & 0 & 0 & 0 & 0 & 0 & 0 & 0 & 7.31 & - & - & - & - \\
\hline
\end{tabular}




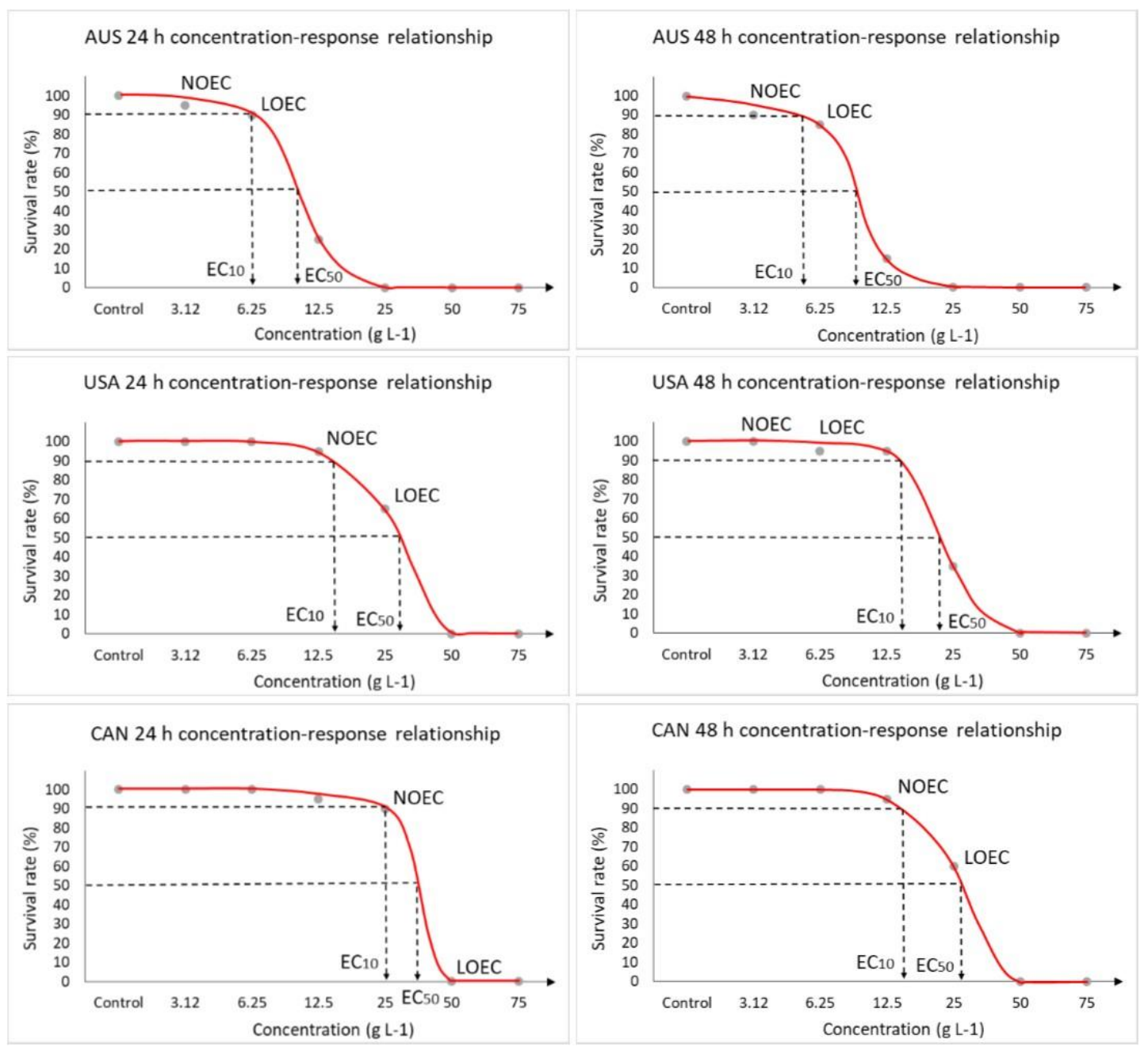

Figure 5.2: Concentration response relationship after 24 and $48 \mathrm{~h}$ of exposure. NOEC, no observed effect concentration; LOEC, lowest observed effect concentration; $\mathrm{EC}_{10}$, effect concentration at which $10 \%$ of daphnids are immobilised; $\mathrm{EC}_{50}$ effect concentration at which $50 \%$ of daphnids are immobilised.

\subsection{Discussion}

\subsubsection{Overall ash chemical properties}

The total concentration of each element within the six ash types showed a wide variability (Table 5.2). These variations might be explained by the accumulative capacity of the different vegetation types, taking up different levels of elements from the soil and surrounding environment (Peralta-Videa et al., 2009; Brito et al., 2017). Fire dynamics (e.g. burn temperature) and soil properties are also important features in the composition of elements within ash (Pitman, 2006; Bodí et al., 2014; Chen et 
al., 2018). In general, oxides and hydroxides of particularly $\mathrm{Ca}, \mathrm{Mg}, \mathrm{Si}$ and $\mathrm{P}$ tend to be abundant in wildfire ash (Pereira and Úbeda, 2010; Silva et al., 2015) as found in the ash tested here (Table 5.2).

Overall, water solubility of the studied elements in all ash types is low $(<20 \%$ except for $\mathrm{Na}$ and $\mathrm{Hg}$ ). This agrees with previous findings (Khanna et al., 1994; Santín et al., 2015; Silva et al., 2015; Brito et al., 2017). The most abundant compounds in all leachates were $\mathrm{SO}_{4}{ }^{2-}, \mathrm{Cl}^{-}$and $\mathrm{Na}^{+}$(Table 5.3), likely due to them forming very soluble salts (i.e. sulphates or chlorides). These components are thus commonly found in high concentrations in the dissolved residuals of ash (Freitas and Rocha 2011; Santín et al. 2015) (Table 5.3). In contrast, heavy metals such as $\mathrm{Cd}$, Ni and $\mathrm{Zn}$ showed the lowest concentration in the leachates due to being relatively insoluble in alkaline $(\mathrm{pH}: 8-10)$ conditions, precipitating mainly as hydroxides (Kesler, 2003; Weiner and Group, 2007). These results are similar to those found in other studies assessing post-fire runoff and ash leachates in a range of ecosystem types (Jung et al., 2009; Pereira et al., 2011) and in agreement with the general trend of alkali ( $\mathrm{Na}, \mathrm{K})>$ alkaline (Ca, $\mathrm{Mg}$ ) > heavy metals ( $\mathrm{Pb}, \mathrm{Cd}$ and $\mathrm{Hg}$ ) found by Santín et al. (2015) in eucalypt forest ash.

\subsubsection{Ash types and element solubility}

Despite the overall similarities in ash solubility in the ash leachates, there are also substantial variations among the ash types, making their chemical profiles notably different. Brito et al. (2017), assessing Brazilian Cerrado ash types, also found there were little qualitative differences in the overall composition of the different ash tested, but large variations in the concentration of the chemical elements between sampling areas.

The PCA analysis carried out allowed detection of key differences in the composition of the ash types studied here. The UK ash leachate has a distinctly soluble profile in comparison to the others. PCA analysis shows a number of heavy metals ( $\mathrm{Mn}, \mathrm{Fe}, \mathrm{Zn}$ and $\mathrm{Pb}$ ) and $\mathrm{PO}_{4}{ }^{3}$ - to be characteristic elements of the UK ash leachate (Figure 5.1). This leachate shows high concentrations of soluble $\mathrm{Fe}, \mathrm{Mn}$ and $\mathrm{PO}_{4}{ }^{3-}$ in comparison to the other ash types (Table 5.3). The pH (7.9) of the UK leachate was 1 to 3 units lower than the extracts from the other samples (Table 5.3). These less alkaline conditions 
favour the solubility of metals and $\mathrm{P}$ compared to the other samples where the metals tend to precipitate as hydroxide for values above 8-9 and the phosphate as hydroxyapatite for $\mathrm{pH}$ values >8.5 (for example see: Diaz et al. 1994; Stumm and Morgan 2013).

A characteristic component of the CAN sample (identified by PCA, Figure 5.1) was the high levels of soluble $\mathrm{Ca}$, despite the total concentration in dry ash being relatively similar to that of the AUS, SPA and USA ash (Table 5.3). It is unclear why the solubility of $\mathrm{Ca}$ is notably higher in the CAN ash in comparison to the other ash types (Jung et al., 2009; Brito et al., 2017), but that may be responsible for the reduced $\mathrm{PO}_{4}{ }^{3-}$ levels $\left(1.2 \mathrm{mg} \mathrm{kg}^{-1}\right)$ in the CAN leachate as $\mathrm{P}$ has a tendency to precipitate in the presence of $\mathrm{Ca}$ (Diaz et al., 1994). This P-Ca interaction may influence algal and cyanobacterial growth (and thus, eutrophication) by regulating P levels in freshwater systems (Bladon et al., 2008; Blake et al., 2009). In the broader context, Ca is not normally considered hazardous, but can significantly influence the overall toxicity of ash eluates (e.g. its strong relationship with $\mathrm{SO}_{4}{ }^{2}$ - leaching) (Mount et al. 1997; Tian et al. 2018). Stiernström et al. (2013) even propose that Ca might be one of the key elements responsible for the ecotoxicity of ash eluates on the crustacean Nitocra spinipes, despite $\mathrm{Ca}$ not being classified as individually ecotoxic. The high $\mathrm{Ca}$ concentration CAN ash tested here also produced significant immobilisation of $D$. magna over the 48-h exposure.

For the AUS ash sample, the levels of soluble B and $\mathrm{Na}$ are higher than in the other ash types (Figure 5.1; Table 5.3). These elements are often found in high concentrations in ash leachates (Jung et al., 2009; Pereira et al., 2011), particularly B in other eucalyptus ash tested (Freitas and Rocha, 2011). High $\mathrm{Na}^{+}$levels in freshwater systems can present an issue for water purification processes as they cannot be removed using conventional methods (Smith et al., 2011). Unlike reported by Silva et al. (2015), where the principle potential toxic components of their eucalypt ash were $\mathrm{Mn}$ and $\mathrm{Zn}$, neither of these elements were found in the eucalypt (AUS) ash analysed here. This further highlights the differences in ash composition comparing individual fire events and ecosystem types (Bodí et al., 2014).

In the URIA ash, the most defining components were $\mathrm{Cu}, \mathrm{Al}, \mathrm{Ni}, \mathrm{NH}_{4}{ }^{+}$and As (Figure 5.1). This ash contained comparatively high concentrations of, particularly, soluble $\mathrm{Cu}$ 
$\left(5158 \mu \mathrm{g} \mathrm{kg}^{-1}\right)$ and the carcinogen As $\left(329 \mu \mathrm{g} \mathrm{kg}^{-1}\right)$. Similar elevated soluble levels of $\mathrm{Cu}$ have, however, been found in mixed eucalyptus ash $\left(\mathrm{Cu}=5100-6200 \mu \mathrm{g} \mathrm{kg}^{-1}\right)$ by Santín et al. (2015). The reason for the significantly higher solubility rate of $\mathrm{Cu}$ in this heathland ash $(\mathrm{URIA}=12.9 \%$, range excluding URIA $=0.49-2.01 \%)$ is worth further consideration to identify areas or components likely to increase the risk of $\mathrm{Cu}$ contamination. The concentration of As, although elevated in the URIA (and UK) sample here, have been reported in higher quantities in a number of other wildfire ash samples (e.g. 4000 - $7300 \mu \mathrm{g} \mathrm{kg}^{-1}$ in Santin et al. (2015); $42000 \mu \mathrm{g} \mathrm{kg}^{-1}$ in Silva et al. (2015)) and despite being above the $0.01 \mathrm{mg} \mathrm{L}^{-1}$ World Health Organisations drinkingwater guideline (World Health Organization, 2011) it does not appear to cause significant immobilisation of D. magna in the URIA or UK ash.

The SPA ash has a relatively insoluble overall profile with notably high concentrations of the metals Al, Fe, $\mathrm{Zn}, \mathrm{Cb}, \mathrm{Pb}$ and the metalloid As in the dry ash (Table 5.2) but limited, to no, leaching of $\mathrm{Al}, \mathrm{Fe}, \mathrm{Zn}$ and $\mathrm{Pb}$ into the water-soluble composition (Table 3). Despite this, Cd presented as a distinct principle component of the SPA ash with a comparatively high soluble concentration $\left(7 \mu \mathrm{g} \mathrm{kg}^{-1}\right)$ and as the only sample to register a solubility percentage of greater than $1 \%(2.85 \%)$. Similar dry quantities of $\mathrm{Cd}$ were recorded by Brito et al. (2017) assessing Brazilian Cerrado ash types (0.1-0.3 mg kg$\left.{ }^{1}\right)$ but $\mathrm{Cd}$ solubility was lower in these ash types $(<0.01 \%)$.

\subsubsection{PAHs composition}

The organic fraction of ash may also contain organic contaminants of biological concern (Vila-Escalé et al. 2007; Chen et al. 2018). The data available on PAHs release following fire, however, is relatively limited (Vila-Escalé et al. 2007; Kim et al. 2011; Campos et al. 2012; Rey-Salgueiro et al. 2018).

The concentrations of PAHs found in the ash analysed here are also widely variable, with a range of $1155 \mathrm{ng} \mathrm{g}^{-1}$ in the AUS ash to $14,078 \mathrm{ng} \mathrm{g}^{-1}$ in the UK ash (16 U.S. Protection Agency (EPA) priority PAHs) (Table 5.5). The values contained within the ash tested here are substantially higher than those presented by Olivella et al. (2006) testing wildfire ash from pine and oak forests ( $\sum 12$ PAHs: $1-19 \mathrm{ng} \mathrm{g}^{-1}$ ash). The lowest concentration, found in the AUS ash type ( $\sum 16$ EPA PAHs: $1155 \mathrm{ng} \mathrm{g}^{-1}$ ash), was of a comparable level to those found by Silva et al. (2015), assessing dry wildfire ash in a 
predominantly eucalypt ecosystem in Portugal ( $\sum 16$ EPA PAHs: $1100 \mathrm{ng} \mathrm{g}^{-1}$ ash). The full range of PAH concentrations found here are within the range of 1000-50,000 ng $\mathrm{n}^{-1}$ ( $\sum 16$ EPA PAHs) found by Santín et al. (2017) analysing PAHs in pine forest floor and wood under wildfire charring and slow-pyrolysis.

The UK ash shows a much higher PAHs concentration than the other types (Table 5.5). It is unclear why this is the case as no other research has been conducted on the PAHs composition of wildfire ash originating from comparable grassland ecosystems. The type of fuel and variations in combustion temperatures and oxygen availability are thought to strongly affect the concentration and type of PAHs in ash (Enell et al., 2008; Rey-Salgueiro et al., 2018). Chen et al. (2018) found that PAHs concentrations were significantly higher in black wildfire ash (moderate burn severity) in comparison to white wildfire ash (severe burn severity). This was also true of the ash types tested here with the darker (dark grey-black) ash samples (UK, URIA, CAN) containing a much higher concentration of PAHs than the lighter (light grey-white) samples (AUS, USA, SPA) (Table 5.5). Although, variations in combustion completeness could be related to PAHs content here, the proportion of methylated PAHs in the UK ash is similar to that of the other samples tested (Table 5.5). The proportion of methylated/total PAHs is usually considered an indicator of combustion completeness as during combustion the methylated component of the compound is lost first (Keiluweit et al., 2012) (Table 5.5).

The high presence of low molecular weight and therefore, greater volatility PAHs (i.e. Nap and Phe) in the ash tested here may seem contradictory as it can be expected that these compounds would be lost during a fire. It is, however, likely that these PAHs preferentially re-condense in the ash layer and are retained in microporous structures of pyrogenic material (Santín et al., 2017). Other studies support this idea, reporting high concentrations of Naph and Phe (Kim et al., 2011) or Naph, Chry, BaA and Acy (Campos et al., 2012) from wood burning. Ash studies of beech and similar species (Bundt et al., 2001) were dominated by Nap and, to a slight extent, by BghiPer, BbF, BkF, Chry, Triph and Phe.

Caution is required when making comparisons between the PAHs values across studies as there are important variations in the methodologies employed. Some studies examine PAHs in ash (Enell et al., 2008; Silva et al., 2015) or sediment (Olivella et al., 
2006; Kim et al., 2011) and others in stream water (Olivella et al., 2006), pond water (Vila-Escalé et al. 2007), runoff water (Campos et al., 2012) or aqueous extracts (Enell et al., 2008; Silva et al., 2015) meaning concentration and compositional differences are to be expected. It is likely the high to very high PAHs concentrations recorded in the ash studied here would be dramatically reduced if the leachable fraction of the samples was tested, as opposed to total concentrations, therefore, making the portion more accessible to interact with aquatic fauna lower (Frišták et al., 2019).

\subsubsection{Implications for toxicology}

The wildfire ash analysis conducted here not only demonstrates the high variability in the concentration of chemical components of ash produced in contrasting ecosystems (Table 5.3), but also the differences in its potential toxic effects in aquatic systems (Table 5.6 and 5.7). Significant toxicity was observed on D. magna over the acute exposures for three of the six ash types tested: AUS, USA and CAN (Figure 5.2; Table $6 \& 7)$. Ash type and composition, therefore, seems crucial to the level of toxicity on cladoceran species, as also demonstrated previously (Campos et al., 2012; Silva et al., 2015; Brito et al., 2017).

The combination of the chemical data with the D. magna immobilisation results highlights a number of possible relationships (Figure 5.1). The PCA identified pH and EC as two of the parameters strongly characteristic of the three ash types causing significant D. magna immobilisation (AUS, USA, CAN) (Table 5.4; Figure 5.1). It is well established that extreme values of $\mathrm{pH}$ and $\mathrm{EC}$ have a detrimental impact on zooplankton species (Mount et al., 1997; Franklin et al., 2000; Silva et al., 2015). The $\mathrm{pH}$ values in the bioassays themselves, however, were notably lower and less variable than in the leachate results used during the PCA analysis and within a range thought acceptable for the survival of D. magna and similar cladoceran species (OECD, 2004) (Table 5.6 and 5.7). Crucially however, the relationship between $\mathrm{pH}$ and immobilisation is very similar between the leachates and bioassays $\mathrm{pH}$ results with higher $\mathrm{pH}$ values, characteristic of the ash types, producing immobilisation in $D$. magna. This perhaps suggests that $\mathrm{pH}$ has an indirect effect on D. magna immobilisation as $\mathrm{pH}$ can also influence the dissolution of elements from ash into water and therefore the relative toxic potential of other ash components (Fedje et al. 
2010). Low $\mathrm{pH}$ values, for example, encourage the leaching of oxyanion-forming (As, $\mathrm{B}, \mathrm{Cr}, \mathrm{Sb}$ and $\mathrm{V}$ ) and cation-forming elements $(\mathrm{Ca})$, and neutral $\mathrm{pH}$ greatly reduces the leaching of amphoteric elements (e.g. Al, Cd, Cu, Pb and Zn) (Fedje et al. 2010). The more neutral $\mathrm{pH}$ of the UK sample, however, does not seem to have reduced the leaching of $\mathrm{Al}, \mathrm{Cd}, \mathrm{Cu}$ and $\mathrm{Pb} . \mathrm{pH}$ has an inconsistent relationship with toxicity, and, often, results are difficult to interpret (Wilde et al., 2006; Silva et al., 2015).

The influence of key nutrients on D. magna immobilisation is perhaps less well established (Smith et al., 2011) (Figure 5.1), as ions such as, $\mathrm{Cl}^{-}$and $\mathrm{NO}_{3}$ - are required at minimum levels to support aquatic life. However, the PCA also identified high concentrations of $\mathrm{Cl}^{-}$and $\mathrm{NO}_{3}$ - as being key characteristic components of the three toxic ash types, particularly the more toxic AUS and USA ash (Table 5.4; Figure 5.1). Many anthropogenic (e.g. oil/gas production, irrigation methods and industrial/agricultural processes) and natural (e.g. sediment pore waters and burning) circumstances have been shown to increase nutrient concentrations to toxic levels (e.g. Hoke et al. 1993; Ferreira et al. 2005; Mast and Clow 2008). Scott and Crunkilton (2005) demonstrated $\mathrm{NO}_{3}{ }^{-}$produces immobilisation of D. magna at $462 \mathrm{mg} \mathrm{L}^{-1}$ with no observable effect concentration at $358 \mathrm{mg} \mathrm{L}^{-1}$. Similarly, Mount et al. (1997) estimated a concentration of $1000-2000 \mathrm{mg} \mathrm{L}^{-1}$ as the concentration of $\mathrm{Cl}^{-}$required to produce $\mathrm{EC}_{50}$ in Ceriodaphnia dubia. This suggests despite the correlations between $\mathrm{NO}_{3}{ }^{-}$and $\mathrm{Cl}^{-}$with the toxic ash types found here, the relatively low quantities of these components alone are not likely capable of causing the observed toxicity (Table 5.3). The limited number of studies focusing on $\mathrm{Na}^{+}, \mathrm{Cl}^{-}, \mathrm{SO}^{-}$and $\mathrm{NO}^{-}$exports after fire have found maximum levels sampled in ash fall well below recommended limits (Smith et al., 2011).

The relatively high PAHs concentrations found in the ash tested here appear to produce no observable toxicity on D. magna and furthermore, higher PAHs concentration seem to be associated with reduced toxicity. It has to be noted that PAHs concentrations were only determined in bulk ash samples. PAHs have limited solubility in water, particularly of the larger ring size PAHs (>3 rings) (Chen et al., 2018). The lack of relationship between high levels of PAHs and toxicity found here and in other studies (Campos et al., 2012; Silva et al., 2015) raise questions about the bioavailability of PAHs in this context. In an assessment of the methylated PAHs composition of sludgederived pyrogenic material, Frišták et al. (2019) found during pyrolysis methylated 
aromates mainly bind to insoluble carbon fractions or get trapped in microporous structures of pyrogenic material and, therefore, are unlikely to be bioavailable and hazardous to freshwater systems. This may be one reason why the PAHs concentrations are not associated with toxicity in D. magna here. The potentially more subtle and longer term impacts of PAHs on aquatic biota such as, reductions in the rate of growth, metabolic activity, reproduction or increased mutation and cancer risk (Hellou et al., 2006; Campos et al., 2012) were beyond the scope of this study. Potential synergistic, antagonistic and additive effects of the complex and variable PAHs composition of the ash types tested could also not be ruled out as a source of toxicity. Further research should be conducted investigating if these levels of total PAHs pose a greater water contamination risk from a wider ecological or drinking water perspective.

Despite the variations in ash composition and the subsequent significant differences in D. magna immobilisation, it is difficult to isolate the primary causes of toxicity. In addition to the most likely, if indirect, influential parameters, $\mathrm{pH}$ and electrical conductivity, there are also likely components that are not necessarily toxic by themselves, but could be variables influencing toxicity in certain concentrations (e.g. DOC, Na, Ca and Mg) (Freitas and Rocha, 2011; Simplício et al., 2016). Physical characteristics of the ash types may also be a possible cause of immobilisation as variations in particle size and distribution of the suspended particulate matter in the unfiltered samples used could have compromised the food intake and locomotive ability of D. magna leading to immobilisation or death (Brito et al., 2017). Even when using a standardised laboratory approach, as employed here, it remains difficult to untangle the effects of such components from those caused by other variables in such complex samples (Wilde et al., 2006; Silva et al., 2015; Brito et al., 2017).

Earlier work has suggested macroinvertebrate species such as D. magna are less sensitive to contamination than lower trophic species (Campos et al., 2012) and thus, the effects of ash contamination on these higher trophic organisms are expected to be primarily indirect through the propagation of toxicity across the food chain via bottomup, bioaccumulation processes (Abrantes et al., 2008). A few notable studies have demonstrated this premise with no observable effect of ash toxicity on daphnid survival or reproduction rates over both acute ( $48 \mathrm{~h}$ ) and chronic (21 day) exposures, but significant impacts have been observed on lower trophic species (bacteria, algae 
and macrophytes) (Campos et al., 2012; Silva et al., 2015). Understanding the mechanisms influencing the bioaccumulation/availability of ash contaminants in freshwater systems should thus be a focus of future research. The results presented here, along with other studies, appear to justify the concerns around the impacts of wildfire ash on aquatic biota and water quality even without the assessment of bioaccumulation processes (Campos et al., 2012; Brito et al., 2017).

\subsection{Conclusion}

The chemical characterisation of the six wildfire ash types shows an overall similar composition of elements, but significant variations in the concentration, reactivity and solubility of these elements. Solubility of all elements was low for all ash types comparing the total and leachate characterisation data.

The results demonstrate significant immobilisation of D. magna over acute exposure (48 $\mathrm{h}$ ) to three of the six ash types (AUS, USA and CAN). The principle characteristics of these ash types producing immobilisation, derived from PCA, were high values of $\mathrm{pH}, \mathrm{EC}, \mathrm{NO}_{3}{ }^{-}, \mathrm{Cl}^{-}, \mathrm{Hg}$ and $\mathrm{SO}_{4}{ }^{2-}$. None of these components, however, appear likely to have directly caused the immobilisation response (ecotoxicity) observed. It is perhaps more likely that these components, and possible others (e.g. Ca), have contributed indirectly to the observed toxicity. Elevated water-soluble concentrations of metal and metalloid contaminants ( $\mathrm{Mn}, \mathrm{Fe}, \mathrm{Zn}, \mathrm{Pb}, \mathrm{Cu}$ and $\mathrm{As})$ did not produce any significant inhibition and tended to be characteristic of the non-toxic ash types. The total PAHs concentrations were also not linked to significant inhibition. It continues to prove difficult to identify specific causes of toxicity in aquatic biota using test substances as complex and variable as wildfire ash.

Combining the detailed chemical characterisation of the ash types with the ecotoxicology results helps to provide further insight into the composition and variations in ash produced in contracting ecosystems and potential implications of wildfire ash contamination on the environment. A detailed understanding of the interactions and impacts of metals, nutrients and PAHs in different ecosystem types is essential for evaluating the pollution risk of fires and for informing management. The results presented here justify the concerns around the down-stream contamination potential of ash in certain ecosystems on aquatic biota and highlight the need for a 
greater understanding of possible direct/indirect chemical causalities. Further research is therefore, required in order to (i) identify and predict conditions creating certain chemical signatures in ash and (ii) to investigate the specific direct (or indirect) causality of toxicity in key groups of aquatic species. 


\section{Chapter 6}

Synthesis and general conclusions 


\subsection{Synthesis and general conclusions}

Fires are recognised as a key natural phenomenon which shape habitat function in fireprone regions across the globe (Bowman et al., 2009). Present-day fire regimes, however, represent a distinct shift towards human-driven fire regimes, dictated by a range of direct (e.g. land-use patterns, agricultural practices and cultural perspectives - ignition sources) and indirect human activities (e.g. climate changes) (Pechony and Shindell, 2010; Moffat et al., 2012). The results of this are the potential for increased frequency, severity and extent of wildfire events and a growing unpredictability of wildfire regimes (Albertson et al., 2010; Rogers et al., 2020). These changes in fire regimes can have a range of significant effects on the structure and function of many habitat types and properties, some of which could be severe and long-lasting (Velle et al., 2014; Oliver et al., 2015).

In many fire-prone regions (e.g. USA, Australia, Mediterranean basin) there is a wealth of research on the impacts of fires on ecosystem functions (Scott et al., 2014; Bixby et al., 2015a). The same cannot be said for traditionally non-fire-prone temperate regions such as the UK (Glaves et al., 2013). In traditionally non-fire-prone temperate regions natural fire regimes have not played a historic part in regulating ecosystem function and fire regimes have been human-generated for management and land clearance purposes (Scott et al., 2014). Fires in these historically non-fire-prone regions are, however, not exempt from the influence of climate changes, and fire regimes are also becoming increasingly indirectly human-driven and unpredictable (Tucker, 2003b; Albertson et al., 2010). Understanding the impacts of fires on terrestrial and aquatic systems are crucial for informing effective policy and land management, particularly in traditionally non-fire-prone regions like the UK (Harper et al., 2018).

In order to help fill the gaps in fire impact research specific to temperate ecosystems, the goal of this thesis was to investigate and evaluate the role of fires in altering vegetation dynamics, soil properties and water quality in upland heaths. A set of research projects were designed and implemented within the three key topic areas (vegetation dynamics, soil properties and water quality). These included the assessment of post-fire vegetation and soil recovery in temperate upland heaths, in addition to the chemical characterisation of ash and its subsequent water contamination potential. 
This concluding section aims to provide an integrated view of the main findings and identifies further research potential for each of these chapters (Chapters 2-5) (Figure 6.1 , along with a general synthesis of the implications for fire and land management.

\subsection{Summary and further research}

\subsubsection{Reviewing the state-of-the-art}

The first stage of this project was to clarify the current knowledge on the impacts of low severity fires, prescribed fires, on ecosystem services within the UK. This critical review of the published work focused on the three primary topic foci of this thesis, fires impacts on water quality, carbon dynamics and habitat composition and structure (biodiversity). This chapter, Chapter 2, aimed to provide a foundation from which the impacts of fire on key ecosystem services can be discussed in more detail in the subsequent chapters of this thesis. In addition to providing a stand-alone updated review on the current state-of-the-art of fire impact research in the UK.

To summarise the key findings of this substantial review, results have been condensed into a set of concise points for each topic area (Table 6.1).

\section{$\underline{\text { Habitat composition and structure }}$}

- Research in upland areas suggests burning can cause significant changes in the vegetation age, type and structure, depending on the length of burn rotations. Relatively short burn rotations (0-10-years) favour the presence of graminoiddominant habitats and longer burn rotations (>15-20-years) tend to produce ericaceous-dominant upland habitats.

- The changes in vegetation caused by burning can also influence bird diversity and abundance, benefiting particular species (red grouse, golden plover, curlew and stonechat), whilst limiting the habitat availability for other species (whinchat and skylarks).

- Burning can also change terrestrial and aquatic invertebrate community composition, reducing the abundance of pollution- and sediment-sensitive species (e.g. Ephemeroptera). 
More long-term research beyond one burn cycle is required, specifically focusing on isolating the impacts of burning from other management practices. This should include consideration of a wider range of species (e.g. amphibians, reptiles and mammals) than examined to date.

\section{$\underline{\text { Carbon dynamics }}$}

- Burning causes a short-term loss of above-ground carbon through vegetation combustion, which is normally sequestered again by vegetation regrowth.

- In some instances where fires led to deeper burning (smouldering combustion), reductions in below-ground carbon were reported.

- $\mathrm{CO}_{2}$ fluxes with the atmosphere from both plant photosynthesis and soil respiration have been found to be higher in some burned areas compared to unburnt treatments.

- Burning produces pyrogenic carbon (charred materials including charcoal) which can be an effective carbon sink in the medium- and long-term.

Prominent research published since the release of the review in Chapter 2 further challenges the widely held perception that zero burning is essential for peat growth and positive carbon accumulation rates (Heinemeyer et al. 2018: Marrs et al. 2019a). These studies both suggest appropriate prescribed burning can both mitigate wildfire risk and produce relatively fast peat growth and sustained $\mathrm{C}$ sequestration.

More data is required especially for gaseous exchanges and pyrogenic carbon production across different habitat types (peatland, moorland, grassland) to allow meaningful estimations of the effects of burning on landscape carbon dynamics.

\section{$\underline{\text { Water quality }}$}

- Fire can impact the hydrology of an area, altering the way in which water, nutrients and contaminants move through a catchment and enter stream systems.

- Burning can have a significant impact on DOC and water colour but results are highly dependent on catchment dynamics and the scale at which change is assessed. 
- The reported influence of fire on nutrient levels in soil water, runoff and stream water is highly site specific and too variable to allow broad generalizations from the limited work published to date.

- Fire has been correlated with increases in metal concentrations (e.g. iron and aluminium) in soil water, runoff and stream water in the UK, but this evidence is based on rather limited research.

The knowledge base regarding the impacts of burning within water supply catchments, specifically regarding stream ecosystems and stream physicochemical properties, needs expanding.

This review also highlights the spatial bias in the current prescribed fire impact literature in the UK. Of the research assessed at the time of the review, $46 \%$ originated from northern England with $15 \%$ dedicated to, or including, data from one single catchment, Trout Beck at the Moor House Nature Reserve, in the North Pennines. Overall, research based in England comprised 52\%, Scotland 18\%, Wales 3\% and Ireland $1 \%$ of the available literature. The remaining $26 \%$ of publications included multiple focus areas not confined to one specific area. This provides an important backdrop to the discussion of fire impacts in the UK and a justification for the locations chosen for the following chapters.

\subsubsection{Examining post-fire vegetation community composition}

To assess the impacts of fire on habitat composition and structure in more detail, Chapter 3 investigated the dynamics of post-fire vegetation recovery across a set of four dwarf-shrub heathland sites within the Brecon Beacons National Park. European dwarf-shrub heaths dominated by the ericaceous shrub $C$. vulgaris are of high conservation value and national cultural importance due to their traditional socioeconomic use and global rarity (Thompson et al., 1995; Glaves et al., 2013). These primarily semi-natural plagioclimax communities were created as a result of woodland clearance and the exposure of these areas to rotational burning and grazing practices (Thompson et al., 1995). Changes in these management practices and fire regimes could, therefore, have significant implications for vegetation dynamics and 
habitat function in dwarf-shrub heaths. There is, however, limited research on the impacts of fire in these habitats, particularly in Wales.

The results of this investigation found that, following high vegetation burn severity fires, these dry dwarf-shrub heaths recovered relatively quickly towards unburnt conditions. Optimum habitat conditions, combining diversity ( $\mathrm{S}-\mathrm{W}$ diversity) and stand structure (e.g. height and age profile), occurred in the burnt area of Site D (11years post-fire). It is likely the low diversity and fire-adapted nature of the pre-fire community composition in these sampling areas resulted in a relatively short recovery time towards unburnt conditions. It is crucial these results are not viewed as a wholly positive conclusion, as this represents the return to previously low diversity conditions, as seen across the control areas. This does not necessarily represent desirable habitat form or conditions. It does, however, suggest in this fire-adapted habitat type, higher fire severities than those experienced here are required to cause a major change in vegetation community composition in the long-term (Davies et al., 2010; Grau-Andrés et al., 2019a).

Furthermore, at the very least, mature $C$. vulgaris-dominated heathland habitats should be a key focus of long-term management strategies to proactively reduce fuel loads to prevent the occurrence of severe, large-scale wildfires (Davies et al., 2010). Further research should be carried out to continue to widen the spatial and habitat coverage of vegetation impact research across the UK. Specific focus should be given to impacts following very high to extreme severity fires, identifying thresholds of lasting detrimental impacts.

\subsubsection{Assessing post-fire soil physicochemical properties}

To expand the assessment of the impacts of fire on heathland ecosystems, Chapter 4 investigated post-fire changes in soil physicochemical properties across the same four sites as in the previous chapter (Chapter 3). The expansion of the assessment of these sites into soil properties enables a more comprehensive look at fire impacts in these seldom studied dwarf-shrub heaths and their shallow organic layered acid soils.

Results suggest most parameters of these dry heathland soils were not substantially affected by fire, perhaps due to the retention of soil moisture limiting the extent of soil 
heating during burning. Significant changes in soil physicochemical properties within the burnt areas were restricted to increases in $\mathrm{pH}$ at the soil surface $(0-2.5 \mathrm{~cm})$ in Site A and B ( $<1$ and 3-years post-fire, respectively). Differences between the burnt and unburnt sampling areas were also apparent in the form of a reduction in carbon content and exchangeable $\mathrm{Al}^{+3}$ concentrations; and increases in base cation concentrations $\left(\mathrm{Ca}^{+2}\right.$ and $\left.\mathrm{Mg}^{+2}\right)$ and bioavailable phosphorus (Olsen-P). None of these differences where, however, apparent at the sites with burnt areas aged >3-years post-fire. The latter differences were also unable to be statistically validated due to the limited sample sizes of the chemical characteristics data. Results also suggest even substantial influxes of ash are not likely to persist within the surface soil profile $(0-5 \mathrm{~cm}$ depth) in the medium to long-term due to the low nutrient holding capacity of these soil types.

Much like the post-fire vegetation recovery dynamics assessed in the previous chapter (see Chapter 3), higher fire severities than those experienced in this study would be required in these fire-adapted habitats to cause a major and lasting change in soil physiochemical properties (Davies et al., 2010; Grau-Andrés et al., 2019b).

Recent studies, however, propose heathlands are particularly vulnerable to changes in wildfire activity and not just as a result of their plagioclimax status and thus fundamental lack of resilience (Grau-Andrés et al., 2018, 2019b, 2019a). Several common habitat characteristics such as, the often-low species diversity, dominance of woody ericaceous shrubs, accumulated fuel loads, limited protective ground litter or moss cover and shallow organic layered soils $(<50 \mathrm{~cm})$ increase their vulnerability to severe fire impacts. These factors are thought to increase the susceptibility to rapid moisture loss in soils and vegetation during droughts (Grau-Andrés et al., 2018). The nature of the fuel (e.g. woody shrubs and accumulated fuel loads) and the limited ground protective cover (e.g. moss and litter cover), coupled with the potentially higher burn temperatures (fire severity) mean soil surface temperatures are likely to be significantly higher in these heathland habitats under the same burn conditions, in comparison to wetter moorland or peatland sites (Grau-Andrés et al., 2018). Shallow, lower organic content soils are also significantly less effective at insulating against soil heat penetration than moister, peaty soils increasing heat depth penetration (Davies et al., 2010). 
This context is important when assessing the broader implications of the results presented in Chapters 3 and 4. Although results show relatively rapid recovery is possible in the vegetation and soil of heathland sites after wildfires, these habitats may be particularly vulnerable to the predicted changes in future fire activity (e.g. increasing severity and frequency). This highlights the need to address the imbalance in the habitat coverage of wildfire impact research in the UK. Investigating the impacts of fire on soil and vegetation recovery rates under different burn conditions in dry heathland sites is, therefore, crucial to assessing their resilience and to inform future management decision-making.

\subsubsection{Investigating ash composition and toxicity}

The final investigation within this thesis, Chapter 5, examined the chemical composition of ash and its water contamination potential. It is well-established in the world's fire-prone regions that wildfires can considerably change the hydrological dynamics of freshwater catchments. Limited research, however, has focused on the potential impacts of wildfire ash toxicity on aquatic biota, especially within the UK.

The work in Chapter 5 assessed the chemical composition and toxicity of ash generated from wildfires in six contrasting vegetation types distributed globally (UK grassland, Spanish pine forest, Spanish heathland, USA chaparral, Australian eucalypt forest and Canadian spruce forest). Acute (48 h) immobilisation tests were conducted on the aquatic macroinvertebrate Daphnia magna, a sensitive indicator of aquatic contaminants. Results found substantial variations between the concentration, reactivity and solubility of the elemental components of the six ash types tested.

The conducted toxicity test found significant differences between the ash types. The UK and Spanish ashes had no detectable toxicity to Daphnia magna, whereas the Australian eucalypt, USA chaparral and Canadian spruce ash all caused significant toxicity (immobilisation). The principal characteristics of the ash types thought to be causing the significant toxicity were high $\mathrm{pH}, \mathrm{NO}_{3}{ }^{-}, \mathrm{Cl}^{-}$and conductivity levels. None of these components, however, appear likely to have directly caused the immobilisation response (ecotoxicity) observed. It is perhaps more likely these components have contributed indirectly to the observed toxicity. There are also components that are not necessarily toxic by themselves but could be variables 
influencing toxicity in certain concentrations (e.g. DOC, $\mathrm{Na}, \mathrm{Ca}$ and $\mathrm{Mg}$ ) (Freitas and Rocha, 2011; Simplício et al., 2016). Elevated water-soluble and total concentrations of metals (e.g. $\mathrm{Mn}, \mathrm{Fe}, \mathrm{Zn}, \mathrm{Pb}, \mathrm{Cu}$ and $\mathrm{As}$ ) and total polycyclic aromatic hydrocarbons (PAHs) were not linked to toxicity.

The results presented in this chapter, along with other studies, appear to support the concerns around the impacts of wildfire ash on aquatic biota and water quality, even without the assessment of bioaccumulation processes (Campos et al., 2012; Brito et al., 2017). It, however, continues to prove difficult to identify specific causes of toxicity in aquatic biota using test substances as complex and variable as wildfire ash. Further research should be conducted to identify and predict the conditions, locations or habitat types creating certain ash chemical signatures. In addition to investigating the specific direct, and indirect, causality of toxicity in key groups of aquatic species and if the levels of PAHs observed pose a greater water contamination risk from a wider ecological or drinking water perspective. 


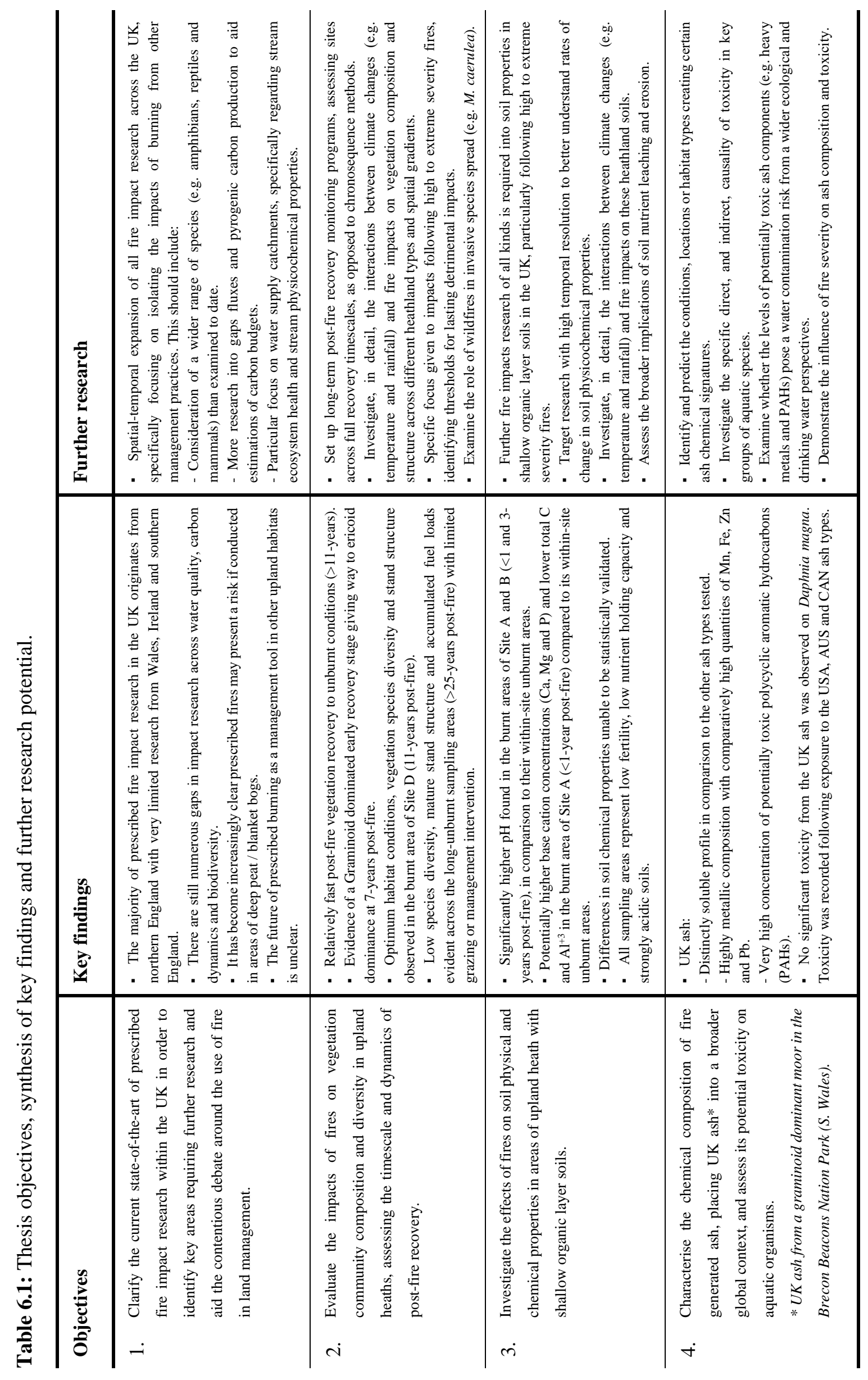




\subsection{Synthesis and management implications}

Fire has been a part of the UK uplands for centuries, implemented as a means of clearing land, facilitating hunting, and maintaining favourable grazing and leisure habitats (Goodfellow, 1998; Worrall et al., 2010a). Over the last 150 years, the use of fire has taken the form of rotational prescribed burning. This practice uses regimented ignitions, every 10-20 years, to control vegetation community composition and structure, often in C. vulgaris-dominated areas, to maximise grazing potential and grouse stocking densities (Davies et al., 2008b). This history has two particularly important implications for any discussion into the current or future form of heathland habitats and their management in the UK.

i) After a long history of fire exposure, heathland habitats are often described as 'fire-adapted', despite the lack of exposure to natural fire regimes. It is, however, important to acknowledge these adaptations are related to specific fire or disturbance regime (e.g. severity or return period).

ii) Dwarf-shrub dominated heaths are plagioclimax communities and their species composition and structure have been, and are, dictated by cultural prerogatives. As such, these habitats may be culturally significant, but they do not represent the natural form of these upland spaces.

These aspects of dwarf-shrub heaths highlight their fundamental lack of resilience, and alterations to the management practices or fire regimes across these areas will result in changes in vegetation and habitat function.

The information provided in this thesis, combined with these two contextual parameters, pose a number of implications for the future management of upland dwarfshrub heaths. Firstly, the results from Chapters 3 and 4 suggest an individual wildfire event of moderate to high severity, causing complete removal of above-ground vegetation but limited surface soil combustion, in these habitats should not be a source of too much concern from the perspective of vegetation and soil function. These chapters demonstrate a relatively fast vegetation and soil recovery to unburnt conditions (>11-years and >3-years, respectively) following these kinds of fires. 
Evidence from other studies and a fundamental lack of resilience in these heaths, however, suggests exposure to extreme severity fire or shorter fire return periods could cause major and lasting detrimental impacts on this habitat type (Rogers et al., 2020). This impresses the need for appropriate and proactive fuel management across dwarfshrub heathland sites to prevent the frequent occurrence of wildfires and particularly of extreme severity fires. It may also be prudent for management of these habitats to fully consider the degree to which fire regime changes may affect the encroachment of species with an invasive nature (e.g. Molinia caerulea (L.) Moench) or the succession towards grassland or woodland systems (Jacquemyn et al., 2005; Worrall et al., 2010a; Friedrich et al., 2011).

Concerns also arise over the ash chemical compositions reported in Chapter 5, with the UK ash containing a high concentration of potentially toxic heavy metals and PAHs. Although the UK ash, produced following a wildfire in a graminoid-dominated upland area in south Wales, did not produce any toxicity on the freshwater indicator species (D. magna), its chemical characteristics present several questions as to the wider impacts on freshwater ecology and water quality. If similar ash compositions (e.g. high heavy metal and PAH concentrations) are characteristic of fires in these habitats or this geographic area, management should strongly consider prioritising fuel management, to reduce wildfire risk, in water-supply catchments or areas in close proximity to freshwater systems (e.g. streams).

Finally, the conditions recorded across the four unburnt areas provide further evidence for the likely form of dwarf-shrub heaths under the prevailing scenario of an unmanaged retreat from traditional management practices (e.g. grazing and rotational burning) (Chapter 3). Under reduced grazing pressure and the absence of burning for $>25$-years, the unburnt areas assessed here were species-poor, dominated by $C$. vulgaris and had progressed into structurally degenerate form with an accumulating fuel load. These sites also, on average, had reduced ground moss coverage and in some areas the encroachment of tree species was evident (e.g. Quercus robur and Sorbus aucuparia).

These conditions, under most management objectives, are undesirable and increase the risk of severe wildfires (JNCC, 2008, 2009). As these habitats have been traditionally actively managed in order to produce and maintain their form, a withdrawal from 
traditional management practices should equally be viewed as an active decision on the future form of heathland habitats. If upland grazing no longer represents the financially viable prospect it once did and rotational burning is not viewed as a desirable management tool in some areas, then a conscious decision needs to be made about the future management of these sites to prevent, at the very least, fuel accumulation and increased wildfire risk.

\subsubsection{The future of upland heaths}

If the restoration and conservation of upland dwarf-shrub heaths is a desirable management outcome, for the protection of their key interest features (e.g. heather, skylarks, hen harriers), it is clear these habitats require continual management intervention to maintain their composition and form (Marrs et al., 2004; García et al., 2013; JNCC, 2019b). To do this, whilst also managing wildfire risk, strategies need to be employed to maintain structural heterogeneity, removing sections of mature growth and promoting regrowth whilst also controlling fuel loads.

The management of heaths to promote wildfire resilience in this context can be done by addressing fuel loads in several principle ways (Scott et al., 2014);

i) Biomass: reducing available biomass through burning, grazing and mechanical treatments.

ii) Vegetation type: controlling fine fuels or those with volatile biochemistry, high flammability.

iii) Vegetation continuity: maintaining heterogeneous structure and fire breaks.

iv) Habitat moisture: promoting water table levels for habitat moisture retention.

To further address wildfire risk, these strategies can be preferentially deployed in high risk areas, where habitat features suggest increased risk of high severity fires (e.g. accumulated fuel loads or flammable vegetation types) or in close proximity to key assets such as, infrastructure (e.g. roads or power and water supplies), vulnerable habitat features (e.g. areas of deeper organic matter or nesting areas for protected 
species) and human populations (e.g. homes) (McMorrow, 2011; Gazzard et al., 2016; Veeraswamy et al., 2018).

Identifying appropriate habitat management strategies in dry dwarf-shrub heaths is, however, problematic. Whilst the processes and advice on wildfire management are relatively straight forward, as outlined above, the interconnection between fire regimes and habitat composition and structure means any decision on fire management or control is also a decision on the future composition, function and usage of dry dwarfshrub heaths. Given the inherently low ecological resilience of these habitats, coupled with the projected climatic and socioeconomic changes, there are a range of competing opinions on their appropriate future form and usage (Worrall et al., 2010a; Harris et al., 2011a). This produces a contentious land management debate which has played out in academic research, popular media and political debate and encompasses the discussion around wildfire risk management (Davies et al., 2016).

Whilst the remainder of this concluding section could focus on the nuances of the debate around the desirable future form of upland heaths, it is perhaps, more prudent to discuss the key factors dictating future change, irrespective of wildfire activity.

In Wales, $83 \%$ of the land surface is managed for farming and, given the influence of farming practices in the formation and maintenance of dwarf-shrub heaths (e.g. burning and grazing), the agricultural industry has a significant influence on the future of these habitats (Downing and Coe, 2018). Furthermore, this agricultural dominance of the Welsh uplands also means, in practice, it is unrealistic to separate the planning of management regimes for the purpose of environmental benefits (e.g. wildfire risk or carbon capture) from agricultural requirements (Welsh Government, 2017).

The background of reducing profitability of upland sheep farming, the restrictions imposed on rotational burning practices and the withdrawal from the European Common Agricultural Policy (CAP) are setting a precedent for the reduction in the cover and health of upland dwarf-shrub heaths (Welsh Government, 2018). The effective management of upland heaths, and thus their future, therefore, relies heavily on the creation of new management regimes which are both beneficial to the environment and profitable for the agricultural community (Welsh Government, 2017). This requires nationally specific agri-environmental schemes or hybrid approaches offering 'payments for ecosystem services' (PES) targeting key 
environmental assets provided by heaths in a sustainable and profitable manner (Welsh Government, 2019).

Initiatives like Glastir, brought into operation in Wales in 2013, provide an example of a system in which agricultural subsidies can be provided based on contributions made towards ecosystem services (Wynne-Jones, 2013). Through Glastir, targeted habitats such as upland heaths have a number of subsidised management options from establishing and maintaining heathlands to grazing heathland pasture, protecting native species at risk (e.g. golden plover, skylark and hen harriers), reducing gorse levels in dry heaths ( $<50 \%$ cover) and heather management (burning, cutting or seed and mulch) (Welsh Government, 2019).

In light of Brexit and the withdrawal from CAP, the Welsh government have recognised the valuable opportunity to, for the first time, design a land management policy unique to Wales (Wynne-Jones, 2013; Welsh Government, 2017). This opportunity to create a new regulatory culture in agriculture replacing the basic payments and Glastri schemes could provide for the better delivery of environmental good and services (Welsh Government, 2019). The degree to which heathland interest features or uses (e.g. sheep grazing) are prioritised in the provision of agricultural payments and incentives will likely have the greatest impact on the future of upland heaths in Wales.

It does, however, appear the legacy of maintaining upland heath plagioclimaxes, are likely to increasingly conflict with the desire for a more sustainable environment and other priorities of nature recovery, and climate change mitigation and adaptation. Particularly as these habitats were designed specifically for certain human needs (e.g. grazing and hunting) and natural aspects have been deliberately excluded (e.g. pioneer tree species or wildlife, such as predatory mammals, birds and competitive wild herbivores). The proposed 'Public Goods Scheme', a more flexible replace to the Glastir system in the new Welsh land management policy, highlights reducing flood risk, decarbonisation and habitat support as its three key objectives (Welsh Government, 2018, 2019). These priorities focus primarily around the planting of trees and the restoration of water-retaining habitats such as bogs and marshy grassland, features not likely conducive to the continuation of large areas of dry dwarf-shrub heath in Wales in the long-term. 


\subsubsection{Framework for progress}

To effectively build on our current understanding, in a way that is directly focused on informing upland policy and management practices, the following key recommendations are made:

1. Learn from international context. There is potential to better incorporate the considerable depth of international expertise on wildfire resilience into UK land management policy and planning. Whilst location specific differences need to be considered, closer collaboration with land management agencies in countries with extensive experience in managing fire regimes (e.g. Spain, Portugal, USA and Australia) could significantly benefit the UK in light of anticipated future wildfire regimes changes.

2. Target habitat-specific research. More experimental burns need to be conducted specifically for research purposes in specific habitat types to provide a more representative impact knowledge base. The outcomes of such collaboration between land managers, fire services and independent research organizations would likely provide an effective way to produce the unbiased knowledge required for justifying, or discouraging, fire management strategies across the full range of UK ecosystems.

3. Prioritise long-term monitoring. It is critical that long-term research is prioritised to better understand the impacts of burning over more than one burn rotation. More areas need to be set aside by landowners or managers and monitored via long-term programmes in collaborations with research institutes (as seen at Trout Beck, Moor House Nature Reserve, north Pennines). Without these partnerships meaningful longterm research is difficult to achieve.

4. Re-evaluate prescribed burn usage and season legislation. The management of fuel loads is becoming increasingly challenging in the UK in light of climate, socioeconomic and legislative changes. If used correctly prescribed burning can be an effective fuel management tool in some habitat types and burn legislation dictating the length and placement of burn seasons should be reconsidered in the devolved UK administrations to facilitate best practice.

5. Develop sustainable and profitable agri-environmental schemes. Transition towards a system in which environmental assets are prioritised over the maintenance of cultural 
landscapes whilst ensuring the profitability of agricultural practise. Farmers should be viewed more widely as managers of a sustainable rural environment for the benefit of society, beyond food production.

6. Maintain unbiased debate. Finally, it is important the strength of feeling and opinion around future habitat form, usage and management of upland areas is rationalised based on robust scientific evidence. A collaborative effort, which includes the full range of stakeholders, is required centred on effective communication and transparency of academic research, policy and management decision making. 


\section{Appendices}

\section{i) Supplementary material: Chapter 2}

Supplementary Table 2.1: Full bibliography of the publications collected by this review, highlighting the focus location, topic which it is relevant to, ecosystem type and publication type. Some publications are relevant to multiple topics, only the primary topic is displayed. Publication type: Peer-reviewed paper (P), Peer-reviewed review (R), Agency report (AR). Literature searches were conducted using Scopus, Web of Science, Google Scholar and through key agency sites.

\begin{tabular}{|c|c|c|c|c|c|c|}
\hline Author & Date & Location & Topic & Ecosystem & Type & Title \\
\hline Allen & 1964 & N. England & Biodiversity & $\begin{array}{l}\text { Heather } \\
\text { moorland }\end{array}$ & $\bar{P}$ & $\begin{array}{l}\text { Chemical aspects of } \\
\text { heather burning }\end{array}$ \\
\hline Allen et al. & 2013 & Peak District & Carbon & $\begin{array}{l}\text { Heather } \\
\text { moorland }\end{array}$ & $\mathrm{P}$ & $\begin{array}{l}\text { Matrix modelling of } \\
\text { prescribed burning in } \\
\text { Calluna vulgaris- } \\
\text { dominated moorland; short } \\
\text { burning rotations minimize } \\
\text { carbon loss at increased } \\
\text { wildfire frequencies }\end{array}$ \\
\hline Amar et al. & 2011 & UK & Biodiversity & $\begin{array}{l}\text { Upland } \\
\text { mixed }\end{array}$ & $\mathrm{P}$ & $\begin{array}{l}\text { Exploring the relationship } \\
\text { between wader declines } \\
\text { and current land-use in the } \\
\text { British uplands }\end{array}$ \\
\hline $\begin{array}{l}\text { Armstrong et } \\
\text { al. }\end{array}$ & 2012 & N. England & Water & $\begin{array}{c}\text { Blanket } \\
\text { peat }\end{array}$ & $\mathrm{P}$ & $\begin{array}{l}\text { Multi-scale relationship } \\
\text { between peatland } \\
\text { vegetation type and } \\
\text { dissolved organic carbon } \\
\text { concentration. }\end{array}$ \\
\hline Bain et al. & 2011 & UK & Review & Peatland & $\mathrm{AR}$ & $\begin{array}{l}\text { IUCN UK Commission of } \\
\text { Inquiry on Peatlands. }\end{array}$ \\
\hline $\begin{array}{l}\text { Beharry- } \\
\text { Borg et al. }\end{array}$ & 2009 & N. England & Water & $\begin{array}{l}\text { Upland } \\
\text { mixed }\end{array}$ & AR & $\begin{array}{l}\text { Determining the socio- } \\
\text { economic implications of } \\
\text { different land management } \\
\text { strategies in Yorkshire } \\
\text { Water's catchments }\end{array}$ \\
\hline $\begin{array}{l}\text { Brown \& } \\
\text { Bainbridge }\end{array}$ & 1990 & UK & Biodiversity & $\begin{array}{l}\text { Upland } \\
\text { mixed }\end{array}$ & $\mathrm{P}$ & $\begin{array}{l}\text { Grouse moors and upland } \\
\text { breeding birds. In: } \\
\text { Thompson et al., Heaths } \\
\text { and moorland: cultural } \\
\text { landscapes }\end{array}$ \\
\hline Brown et al. & 2013 & N. England & Water & $\begin{array}{c}\text { Blanket } \\
\text { peat }\end{array}$ & $\mathrm{P}$ & $\begin{array}{l}\text { River ecosystem response } \\
\text { to prescribed vegetation } \\
\text { burning on blanket peatland }\end{array}$ \\
\hline Brown et al. & 2014 & Pennines & Water & Peatland & AR & $\begin{array}{l}\text { Effects of moorland } \\
\text { burning on the } \\
\text { ecohydrology of river } \\
\text { basins. }\end{array}$ \\
\hline Brown et al. & 2015 & UK & Review & Peatland & $\mathrm{R}$ & $\begin{array}{l}\text { Effects of fire on the } \\
\text { hydrology, } \\
\text { biogeochemistry, and } \\
\text { ecology of peatland river } \\
\text { systems }\end{array}$ \\
\hline Burch & 2008 & N. England & Biodiversity & $\begin{array}{l}\text { Heather } \\
\text { moorland }\end{array}$ & $\mathrm{P}$ & $\begin{array}{l}\text { The relationship of } \\
\text { bryophytes regeneration to } \\
\text { heather canopy height } \\
\text { following burning on the } \\
\text { north york moors }\end{array}$ \\
\hline $\begin{array}{l}\text { Chambers et } \\
\text { al. }\end{array}$ & 2007 & Wales & Biodiversity & $\begin{array}{c}\text { Blanket } \\
\text { peat }\end{array}$ & $\mathrm{P}$ & $\begin{array}{l}\text { Palaeoecology of degraded } \\
\text { blanket mire in south wales: } \\
\text { data to inform conservation } \\
\text { management }\end{array}$ \\
\hline $\begin{array}{l}\text { Chapman et } \\
\text { al. }\end{array}$ & 2009 & England & Biodiversity & $\begin{array}{l}\text { Upland } \\
\text { mixed }\end{array}$ & $\mathrm{P}$ & $\begin{array}{l}\text { Modelling the coupled } \\
\text { dynamics of moorland } \\
\text { management and upland } \\
\text { vegetation }\end{array}$ \\
\hline
\end{tabular}




\begin{tabular}{|c|c|c|c|c|c|c|}
\hline $\begin{array}{l}\text { Chapman et } \\
\text { al. }\end{array}$ & 2010 & N. England & Water & $\begin{array}{l}\text { Upland } \\
\text { mixed }\end{array}$ & $\mathrm{P}$ & $\begin{array}{l}\text { Changes in water colour } \\
\text { between } 1986 \text { and } 2006 \text { in } \\
\text { the headwaters of the River } \\
\text { Nidd, Yorkshire, UK }\end{array}$ \\
\hline Chen et al. & 2008 & N. England & Biodiversity & $\begin{array}{l}\text { Heather } \\
\text { peatland }\end{array}$ & $\mathrm{P}$ & $\begin{array}{l}\text { The impact of burning and } \\
\text { Calluna removal on below- } \\
\text { ground methanotroph } \\
\text { diversity and activity in a } \\
\text { peatland soil. }\end{array}$ \\
\hline Clay et al. & $2009 a$ & N. Pennines & Water & $\begin{array}{l}\text { Blanket } \\
\text { bog }\end{array}$ & $\mathrm{P}$ & $\begin{array}{l}\text { Effects of managed burning } \\
\text { upon dissolved organic } \\
\text { carbon (DOC) in soil water } \\
\text { and runoff water following } \\
\text { a managed burn of a UK } \\
\text { blanket bog }\end{array}$ \\
\hline Clay et al. & $2009 b$ & N. Pennines & Water & $\begin{array}{l}\text { Blanket } \\
\text { bog }\end{array}$ & $\mathrm{P}$ & $\begin{array}{l}\text { Hydrological responses to } \\
\text { managed burning and } \\
\text { grazing in an upland } \\
\text { blanket bog }\end{array}$ \\
\hline Clay et al., & $2010 \mathrm{a}$ & N. Pennines & Water & $\begin{array}{l}\text { Blanket } \\
\text { bog }\end{array}$ & $\mathrm{P}$ & $\begin{array}{l}\text { Compositional changes in } \\
\text { soil water and runoff water } \\
\text { following managed burning } \\
\text { on a UK upland blanket bog }\end{array}$ \\
\hline Clay et al. & $2010 b$ & N. Pennines & Carbon & $\begin{array}{l}\text { Blanket } \\
\text { bog }\end{array}$ & $\mathrm{P}$ & $\begin{array}{l}\text { Carbon budgets of an } \\
\text { upland blanket bog } \\
\text { managed by prescribed fire }\end{array}$ \\
\hline Clay et al. & 2012 & Northumberland & Water & Peatland & $\mathrm{P}$ & $\begin{array}{l}\text { Does prescribed burning on } \\
\text { peat soils influence DOC } \\
\text { concentrations in soil and } \\
\text { runoff waters? }\end{array}$ \\
\hline Clay et al. & 2015 & Northumberland & Carbon & $\begin{array}{l}\text { Blanket } \\
\text { peat }\end{array}$ & $\mathrm{P}$ & $\begin{array}{l}\text { Carbon stocks and carbon } \\
\text { fluxes from a 10-year } \\
\text { prescribed arning } \\
\text { chronosequence on a UK } \\
\text { blanket peat }\end{array}$ \\
\hline $\begin{array}{l}\text { Clutterbuck } \\
\text { \& Yallop }\end{array}$ & 2010 & Pennines & Water & $\begin{array}{l}\text { Upland } \\
\text { mixed }\end{array}$ & $\mathrm{P}$ & $\begin{array}{l}\text { Land management as a } \\
\text { factor controlling dissolved } \\
\text { organic carbon release from } \\
\text { upland peat soils 2: } \\
\begin{array}{l}\text { Changes in DOC } \\
\text { productivity over four } \\
\text { decades }\end{array}\end{array}$ \\
\hline Coulson & 1988 & N. England & Biodiversity & $\begin{array}{l}\text { Upland } \\
\text { mixed }\end{array}$ & $\mathrm{P}$ & $\begin{array}{l}\text { The structure and } \\
\text { importance of invertebrate } \\
\text { communities on peatlands } \\
\text { and moorlands, and effects } \\
\text { of environmental and } \\
\text { management changes. In } \\
\text { Usher and Thompson - } \\
\text { Ecological change in the } \\
\text { uplands }\end{array}$ \\
\hline $\begin{array}{l}\text { Curtis \& } \\
\text { Corrigan }\end{array}$ & 1990 & Scotland & Biodiversity & $\begin{array}{l}\text { Upland } \\
\text { mixed }\end{array}$ & $\mathrm{P}$ & $\begin{array}{l}\text { Peatland spider } \\
\text { communities and land } \\
\text { management on a Scottish } \\
\text { island. }\end{array}$ \\
\hline $\begin{array}{l}\text { Daplyn \& } \\
\text { Ewald }\end{array}$ & 2006 & England & Biodiversity & $\begin{array}{l}\text { Heather } \\
\text { moorland }\end{array}$ & AR & $\begin{array}{l}\text { Birds, burning and grouse } \\
\text { moor management. Hope } \\
\text { Valley: Report to Moors for } \\
\text { the Future. }\end{array}$ \\
\hline $\begin{array}{l}\text { Davies \& } \\
\text { Legg }\end{array}$ & 2008 & $\begin{array}{l}\text { Scottish } \\
\text { Highlands }\end{array}$ & Biodiversity & $\begin{array}{l}\text { Heather } \\
\text { moorland }\end{array}$ & $\mathrm{P}$ & $\begin{array}{l}\text { The effects of traditional } \\
\text { management burning on } \\
\text { lichen diversity }\end{array}$ \\
\hline Davies et al. & 2008 & UK & Review & $\begin{array}{l}\text { Upland } \\
\text { mixed }\end{array}$ & $\mathrm{R}$ & $\begin{array}{l}\text { The future of fire } \\
\text { management in the uplands }\end{array}$ \\
\hline Davies et al. & 2010 & $\begin{array}{l}\text { Scottish } \\
\text { Highlands }\end{array}$ & Biodiversity & $\begin{array}{l}\text { Heather } \\
\text { moorland }\end{array}$ & $\mathrm{R}$ & $\begin{array}{l}\text { Fire intensity, fire severity } \\
\text { and ecosystem response in } \\
\text { heathlands: factors } \\
\text { affecting the regeneration } \\
\text { of Calluna vulgaris }\end{array}$ \\
\hline Davies et al. & 2016 & UK & Review & $\begin{array}{l}\text { Upland } \\
\text { mixed }\end{array}$ & $\mathrm{R}$ & $\begin{array}{l}\text { The role of fire in UK } \\
\text { peatland and moorland } \\
\text { management: the need for } \\
\text { informed, unbiased debate }\end{array}$ \\
\hline
\end{tabular}




\begin{tabular}{|c|c|c|c|c|c|c|}
\hline Ellis & 2008 & Scotland & Water & Wet Heath & $\mathrm{P}$ & $\begin{array}{l}\text { Interactions between } \\
\text { hydrology, burning and } \\
\text { contrasting plant groups } \\
\text { during the millennial-scale } \\
\text { development of sub- } \\
\text { montane wet heath }\end{array}$ \\
\hline Eyre et al. & 2003 & Scotland & Biodiversity & $\begin{array}{l}\text { Upland } \\
\text { mixed }\end{array}$ & $\mathrm{P}$ & $\begin{array}{l}\text { Grouse moor management: } \\
\text { habitat and conservation } \\
\text { implications } \\
\text { invertebrates in southern } \\
\text { Scotland }\end{array}$ \\
\hline Farage et al. & 2009 & Yorkshire & Carbon & $\begin{array}{l}\text { Heather } \\
\text { moorland }\end{array}$ & $\mathrm{P}$ & $\begin{array}{l}\text { Burning management and } \\
\text { carbon sequestation of } \\
\text { upland heather moorland in } \\
\text { the UK }\end{array}$ \\
\hline Garnett et al. & 2000 & Pennines & Carbon & $\begin{array}{c}\text { Blanket } \\
\text { bog }\end{array}$ & $\mathrm{P}$ & $\begin{array}{l}\text { Effects of burning and } \\
\text { grazing on carbon } \\
\text { sequestration in a Pennine } \\
\text { blanket bog, UK. }\end{array}$ \\
\hline Garnett et al. & 2001 & Pennines & Carbon & Moorland & $\mathrm{P}$ & $\begin{array}{l}\text { Terrestrial organic carbon } \\
\text { storage in a British } \\
\text { moorland }\end{array}$ \\
\hline Glaves et al. & 2013 & UK & Review & $\begin{array}{l}\text { Upland } \\
\text { mixed }\end{array}$ & AR & $\begin{array}{l}\text { The effects of managed } \\
\text { burning on upland peatland } \\
\text { biodiversity, carbon and } \\
\text { water }\end{array}$ \\
\hline Grant et al. & 2012 & UK & Review & $\begin{array}{l}\text { Upland } \\
\text { mixed }\end{array}$ & $\mathrm{AR}$ & $\begin{array}{l}\text { The costs and benefits of } \\
\text { grouse moor management } \\
\text { to biodiversity and aspects } \\
\text { of the wider environment: a } \\
\text { review. RSPB Research } \\
\text { Report. }\end{array}$ \\
\hline Gray \& Levy & 2009 & UK & Review & Peatland & $\mathrm{AR}$ & $\begin{array}{l}\text { A review of carbon flux } \\
\text { research in UK peatlands in } \\
\text { relation to fire and the } \\
\text { Cairngorms National Park }\end{array}$ \\
\hline $\begin{array}{l}\text { Grayson et } \\
\text { al. }\end{array}$ & 2008 & N. England & Water & $\begin{array}{l}\text { Upland } \\
\text { mixed }\end{array}$ & $\mathrm{AR}$ & $\begin{array}{l}\text { GIS-based analysis of the } \\
\text { impacts of land } \\
\text { management on colour, } \\
\text { nitrate and pesticides in raw } \\
\text { water }\end{array}$ \\
\hline $\begin{array}{l}\text { Grayson et } \\
\text { al. }\end{array}$ & 2012 & Yorkshire & Water & $\begin{array}{l}\text { Upland } \\
\text { mixed }\end{array}$ & $\mathrm{P}$ & $\begin{array}{l}\text { A GIS based MCE model } \\
\text { for identifying water colour } \\
\text { generation potential in UK } \\
\text { upland drinking water } \\
\text { supply catchments }\end{array}$ \\
\hline Harris et al. & 2006 & Peak District & Biodiversity & Acid heath & AR & $\begin{array}{l}\text { The effects of cool burning } \\
\text { on the vegetation at } \\
\text { Howden and Bamford } \\
\text { Moor in the Peak District. } \\
\text { Report to Moors of the } \\
\text { future }\end{array}$ \\
\hline Harris et al. & $2011 \mathrm{a}$ & Peak District & Carbon & Moorland & $\mathrm{P}$ & $\begin{array}{l}\text { Prescribed fire } \\
\text { characteristics and biomass } \\
\text { reduction on upland } \\
\text { moorland. }\end{array}$ \\
\hline Harris et al. & $2011 b$ & Peak District & Biodiversity & Moorland & $\mathrm{P}$ & $\begin{array}{l}\text { Factors affecting moorland } \\
\text { plant communities and } \\
\text { component species in } \\
\text { relation to prescribed } \\
\text { burning }\end{array}$ \\
\hline $\begin{array}{l}\text { Hobbs \& } \\
\text { Gimingham }\end{array}$ & 1984 & Scotland & Biodiversity & Heathland & $\mathrm{P}$ & $\begin{array}{l}\text { Studies on Fire in Scottish } \\
\text { Heathland Communities .2. } \\
\text { Post-Fire Vegetation } \\
\text { Development. }\end{array}$ \\
\hline Holden et al. & 2012 & UK & Review & Moorland & $\mathrm{R}$ & $\begin{array}{l}\text { The impacts of prescribed } \\
\text { moorland burning on water } \\
\text { colour and dissolved } \\
\text { organic carbon: A critical } \\
\text { synthesis. }\end{array}$ \\
\hline Holden et al. & 2015 & UK & Review & $\begin{array}{c}\text { Blanket } \\
\text { peat }\end{array}$ & $\mathrm{R}$ & $\begin{array}{l}\text { Impacts of prescribed } \\
\text { burning on blanket peat } \\
\text { hydrology }\end{array}$ \\
\hline
\end{tabular}




\begin{tabular}{|c|c|c|c|c|c|c|}
\hline Holmes et al. & 1993 & Wales & Biodiversity & Peatland & $\mathrm{P}$ & $\begin{array}{l}\text { The ground beetle } \\
\text { (Coleoptera, Carabidae) } \\
\text { fauna of welsh peatland } \\
\text { biotopes - factors } \\
\text { influencing the distribution } \\
\text { of ground beetles and } \\
\text { conservation implications }\end{array}$ \\
\hline Imeson & 1971 & Yorkshire & Carbon & Moorland & $\mathrm{P}$ & $\begin{array}{l}\text { Heather Burning and Soil } \\
\text { Erosion on North Yorkshire } \\
\text { Moors }\end{array}$ \\
\hline $\begin{array}{l}\text { Kinako \& } \\
\text { Gimmingham }\end{array}$ & 1980 & Scotland & Carbon & Heathland & $\mathrm{P}$ & $\begin{array}{l}\text { Heather burning and soil } \\
\text { erosion on upland heaths in } \\
\text { Scotland. }\end{array}$ \\
\hline Lance & 1983 & W. Ireland & Biodiversity & $\begin{array}{l}\text { Blanket } \\
\text { bog }\end{array}$ & $\mathrm{P}$ & $\begin{array}{l}\text { Performance of Sheep on } \\
\text { Unburned and Serially } \\
\text { Burned Blanket Bog in } \\
\text { Western Ireland }\end{array}$ \\
\hline Lee et al. & 2013 & N. Pennines & Biodiversity & $\begin{array}{l}\text { Blanket } \\
\text { bog }\end{array}$ & $\mathrm{P}$ & $\begin{array}{l}\text { Long-term effects of } \\
\text { prescribed burning and } \\
\text { low-intensity sheep grazing } \\
\text { on blanket bog plant } \\
\text { communities }\end{array}$ \\
\hline Lindsay & 2010 & UK & Review & $\begin{array}{l}\text { Blanket } \\
\text { bog }\end{array}$ & $\mathrm{AR}$ & $\begin{array}{l}\text { Peatbogs and carbon: a } \\
\text { critical synthesis. }\end{array}$ \\
\hline $\begin{array}{l}\text { Littlewood et } \\
\text { al., }\end{array}$ & 2010 & UK & Biodiversity & Peatland & AR & $\begin{array}{l}\text { Peatland biodiversity. } \\
\text { Edinburgh: Report to IUCN } \\
\text { UK Peatland Programme }\end{array}$ \\
\hline $\begin{array}{l}\text { MacDonald } \\
\text { \& Haysom }\end{array}$ & 1997 & Scotland & Biodiversity & $\begin{array}{l}\text { Heather } \\
\text { moorland }\end{array}$ & AR & \begin{tabular}{lr} 
Heather & moorland \\
management & for \\
lepidoptera. & Information \\
\multicolumn{2}{l}{ and advisory note, No. 58}
\end{tabular} \\
\hline $\begin{array}{l}\text { Mallik \& } \\
\text { FitzPatrick }\end{array}$ & 1996 & Scotland & Biodiversity & $\begin{array}{l}\text { Heather } \\
\text { moorland }\end{array}$ & $\mathrm{P}$ & $\begin{array}{l}\text { Thin section studies of } \\
\text { Calluna heathland soild } \\
\text { subject to prescribed } \\
\text { burning }\end{array}$ \\
\hline Mallik et al. & 1984 & N.E. Scotland & Water & $\begin{array}{l}\text { Heather } \\
\text { moorland }\end{array}$ & $\mathrm{P}$ & $\begin{array}{l}\text { Ecological effects of } \\
\text { heather burning; Water } \\
\text { infiltration, moisture } \\
\text { retention and porosity of } \\
\text { surface soil }\end{array}$ \\
\hline $\begin{array}{l}\text { Maltby \& } \\
\text { Edwards }\end{array}$ & 1984 & Yorkshire & Biodiversity & $\begin{array}{l}\text { Heather } \\
\text { moorland }\end{array}$ & $\mathrm{P}$ & $\begin{array}{l}\text { Microbiological response } \\
\text { to heather burning in } \\
\text { Moorland Management, } \\
\text { North York Moors National } \\
\text { Park }\end{array}$ \\
\hline Marrs et al. & 2004 & N. England & Biodiversity & Moorland & $\mathrm{P}$ & $\begin{array}{l}\text { Control of Molinia } \\
\text { caerulea on upland moors. }\end{array}$ \\
\hline $\begin{array}{l}\text { McDonald et } \\
\text { al. }\end{array}$ & 1991 & Yorkshire & Water & $\begin{array}{l}\text { Upland } \\
\text { mixed }\end{array}$ & $\mathrm{AR}$ & $\begin{array}{l}\text { Discoloured water } \\
\text { investigations. Leeds: } \\
\text { University of Leeds Report } \\
\text { to Yorkshire Water }\end{array}$ \\
\hline $\begin{array}{l}\text { McFerran et } \\
\text { al. }\end{array}$ & 1995 & Scotland & Biodiversity & Heathland & $\mathrm{P}$ & $\begin{array}{l}\text { The impact of burning and } \\
\text { grazing on heathland plants } \\
\text { and invertebrates in } \\
\text { Country Antrim. }\end{array}$ \\
\hline $\begin{array}{l}\text { McVean \& } \\
\text { Ratcliffe }\end{array}$ & 1962 & Scotland & Biodiversity & $\begin{array}{l}\text { Upland } \\
\text { mixed }\end{array}$ & AR & $\begin{array}{l}\text { Plant communities of the } \\
\text { Scottish Highlands. } \\
\text { Monographs of the Nature } \\
\text { Conservancy No.1. HMSO, } \\
\text { Edinburgh }\end{array}$ \\
\hline Miles & 1971 & Scotland & Biodiversity & Moorland & $\mathrm{P}$ & $\begin{array}{l}\text { Burning Molinia-dominant } \\
\text { vegetation for grazing by } \\
\text { red deer. }\end{array}$ \\
\hline Miller & 2008 & N. England & Water & Peatland & $\mathrm{P}$ & $\begin{array}{l}\text { Mechanisms of water } \\
\text { colour release from organic } \\
\text { soils and consequences for } \\
\text { catchment management }\end{array}$ \\
\hline Miller et al. & 1966 & N.E. Scotland & Biodiversity & $\begin{array}{l}\text { Heather } \\
\text { moorland }\end{array}$ & $\mathrm{P}$ & $\begin{array}{l}\text { Heather Performance and } \\
\text { Red Grouse Populations. I. } \\
\text { Visual Estimates of } \\
\text { Heather Performance }\end{array}$ \\
\hline $\begin{array}{l}\text { Mitchell \& } \\
\text { McDonald }\end{array}$ & 1995 & N. Yorkshire & Water & $\begin{array}{l}\text { Heather } \\
\text { moorland }\end{array}$ & $\mathrm{P}$ & $\begin{array}{l}\text { Catchment characterisation } \\
\text { as a tool for upland water } \\
\text { quality management }\end{array}$ \\
\hline
\end{tabular}




\begin{tabular}{|c|c|c|c|c|c|c|}
\hline O’Brien & 2005 & Peak District & Water & Moorland & $\mathrm{P}$ & $\begin{array}{l}\text { An investigation of the } \\
\text { impact of prescribed } \\
\text { moorland burning in the } \\
\text { Derwent catchment upon } \\
\text { discolouration of surface } \\
\text { waters }\end{array}$ \\
\hline O'Brien & 2009 & Midlands & Water & $\begin{array}{c}\text { Blanket } \\
\text { peat }\end{array}$ & $\mathrm{P}$ & $\begin{array}{l}\text { The role of blanket peat } \\
\text { moorland management in } \\
\text { the generation and } \\
\text { amelioration off drought- } \\
\text { induced discolouration of } \\
\text { surface water supplies }\end{array}$ \\
\hline $\begin{array}{l}\text { Orwin \& } \\
\text { Ostle, }\end{array}$ & 2012 & N. Pennines & Biodiversity & Peatland & $\mathrm{P}$ & $\begin{array}{l}\text { Moss species effects on } \\
\text { peatland carbon cycling } \\
\text { after fire. }\end{array}$ \\
\hline $\begin{array}{l}\text { Pearce- } \\
\text { Higgins \& } \\
\text { Grant }\end{array}$ & 2006 & UK & Biodiversity & Moorland & $\mathrm{P}$ & $\begin{array}{l}\text { Relationships between bird } \\
\text { abundance and the } \\
\text { composition and structure } \\
\text { of moorland vegetation. }\end{array}$ \\
\hline $\begin{array}{l}\text { Pearce- } \\
\text { Higgins et al. }\end{array}$ & 2009 & UK & Biodiversity & $\begin{array}{l}\text { Upland } \\
\text { mixed }\end{array}$ & $\mathrm{P}$ & $\begin{array}{l}\text { International importance } \\
\text { and drivers of change of } \\
\text { upland bird populations. In: } \\
\text { Bonn, A., Allott, T., } \\
\text { Hubacek, K. \& Stewart, J. } \\
\text { (eds.) Drivers of } \\
\text { environmental change in } \\
\text { uplands pp 209227. }\end{array}$ \\
\hline Picozzi & 1968 & N.E. Scotland & Biodiversity & $\begin{array}{l}\text { Heather } \\
\text { moorland }\end{array}$ & $\mathrm{AR}$ & $\begin{array}{l}\text { Grouse Bags in Relation to } \\
\text { Management and Geology } \\
\text { of Heather Moors. }\end{array}$ \\
\hline $\begin{array}{l}\text { Pilkington et } \\
\text { al. }\end{array}$ & 2007 & N. Wales & Water & $\begin{array}{l}\text { Heather } \\
\text { moorland }\end{array}$ & $\mathrm{P}$ & $\begin{array}{l}\text { Impacts of burning and } \\
\text { increased nitrogen } \\
\text { deposition on nitrogen } \\
\text { pools and leaching in an } \\
\text { upland moor }\end{array}$ \\
\hline $\begin{array}{l}\text { Ramchunder } \\
\text { et al. }\end{array}$ & 2009 & UK & Review & Peatland & $\mathrm{R}$ & $\begin{array}{l}\text { Environmental effects of } \\
\text { drainage drain blocking and } \\
\text { prescribed vegetation } \\
\text { burning in UK upland } \\
\text { peatlands. }\end{array}$ \\
\hline $\begin{array}{l}\text { Ramchunder } \\
\text { et al. }\end{array}$ & 2013 & N. England & Water & Peatland & $\mathrm{R}$ & $\begin{array}{l}\text { Rotational vegetation } \\
\text { burning effects on peatland } \\
\text { stream ecosystems }\end{array}$ \\
\hline Shaw et al. & 1996 & UK & Review & $\begin{array}{l}\text { Blanket } \\
\text { bog }\end{array}$ & $\mathrm{AR}$ & $\begin{array}{l}\text { Literature review of the } \\
\text { historical effects of burning } \\
\text { and grazing of blanket bog } \\
\text { and upland wet heath }\end{array}$ \\
\hline Sim et al. & 2005 & UK & Biodiversity & $\begin{array}{l}\text { Upland } \\
\text { mixed }\end{array}$ & $\mathrm{P}$ & $\begin{array}{l}\text { Recent changes in the } \\
\text { abundance of British } \\
\text { upland breeding birds. }\end{array}$ \\
\hline Smith et al. & 2001 & Scotland & Biodiversity & $\begin{array}{l}\text { Moorland } \\
\text { mixed }\end{array}$ & $\mathrm{P}$ & $\begin{array}{l}\text { Meadow pipits, red grouse } \\
\text { and the habitat } \\
\text { characteristics of managed } \\
\text { grouse moors }\end{array}$ \\
\hline $\begin{array}{l}\text { Sotherton et } \\
\text { al. }\end{array}$ & 2009 & UK & Biodiversity & $\begin{array}{l}\text { Upland } \\
\text { mixed }\end{array}$ & $\mathrm{P}$ & $\begin{array}{l}\text { Managing uplands for } \\
\text { game and sporting } \\
\text { interests: an industry } \\
\text { perspective. In: Bonn, A., } \\
\text { Allott, T., Hubacek, K. \& } \\
\text { Stewart, J. (eds.) Drivers of } \\
\text { Environmental change in } \\
\text { uplands, pp 241-260 }\end{array}$ \\
\hline Stewart & 2005 & UK & Biodiversity & $\begin{array}{l}\text { Upland } \\
\text { mixed }\end{array}$ & AR & $\begin{array}{l}\text { Applying evidence-based } \\
\text { practice in conservation } \\
\text { management: Lessons from } \\
\text { the first systematic review } \\
\text { and dissemination projects }\end{array}$ \\
\hline Stewart et al. & 2004 & UK & Carbon & $\begin{array}{c}\text { Blanket } \\
\text { bog }\end{array}$ & $\mathrm{AR}$ & $\begin{array}{l}\text { Does burning degrade } \\
\text { blanket bog? Systematic } \\
\text { Review } 1\end{array}$ \\
\hline Tharme et al. & 2001 & UK & Biodiversity & $\begin{array}{l}\text { Heather } \\
\text { moorland }\end{array}$ & $\mathrm{P}$ & $\begin{array}{l}\text { The effect of management } \\
\text { for red grouse shooting on } \\
\text { the population density of }\end{array}$ \\
\hline
\end{tabular}




\begin{tabular}{|c|c|c|c|c|c|c|}
\hline & & & & & & $\begin{array}{l}\text { breeding birds on heather- } \\
\text { dominated moorland }\end{array}$ \\
\hline $\begin{array}{l}\text { Thompson et } \\
\text { al. }\end{array}$ & 1997 & Scotland & Biodiversity & Moorland & AR & $\begin{array}{l}\text { The contribution of game } \\
\text { management to } \\
\text { biodiversity: a review of the } \\
\text { importance of grouse } \\
\text { moors for uplands birds. }\end{array}$ \\
\hline Tucker & 2003 & England & Review & $\begin{array}{l}\text { Upland } \\
\text { mixed }\end{array}$ & $\mathrm{R}$ & $\begin{array}{l}\text { Review of the impacts of } \\
\text { heather and grassland } \\
\text { burning in the uplands on } \\
\text { soils, hydrology and } \\
\text { biodiversity }\end{array}$ \\
\hline Usher & 1992 & Yorkshire & Biodiversity & $\begin{array}{l}\text { Heather } \\
\text { moorland }\end{array}$ & $\mathrm{P}$ & $\begin{array}{l}\text { Managment and diversity } \\
\text { of arthropods in Calluna } \\
\text { heathland Biodiversity and } \\
\text { Conservation, }\end{array}$ \\
\hline Ward et al. & 2007 & Pennines & Carbon & Peatland & $\mathrm{P}$ & $\begin{array}{l}\text { Long-term consequences of } \\
\text { grazing and burning on } \\
\text { northern peatland carbon } \\
\text { dynamics }\end{array}$ \\
\hline $\begin{array}{l}\text { Whittingham } \\
\text { et al. }\end{array}$ & 2001 & N. England & Biodiversity & Moorland & $\mathrm{P}$ & $\begin{array}{l}\text { Habitat selection by golden } \\
\text { plover Pluvialis apricaria } \\
\text { chicks }\end{array}$ \\
\hline $\begin{array}{l}\text { Worrall \& } \\
\text { Adamson }\end{array}$ & 2008 & N. England & Water & $\begin{array}{l}\text { Blanket } \\
\text { bog }\end{array}$ & $\mathrm{P}$ & $\begin{array}{l}\text { The effects of burning and } \\
\text { sheep-graving on soil water } \\
\text { composition in a blanket } \\
\text { bog: evidence from soil } \\
\text { structural change }\end{array}$ \\
\hline Worrall et al. & 2007 & N. England & Water & Peatland & $\mathrm{P}$ & $\begin{array}{l}\text { The effects of burning and } \\
\text { sheep-grazing on water } \\
\text { table depth and soil water } \\
\text { quality in a upland peat }\end{array}$ \\
\hline Worrall et al. & $2010 \mathrm{a}$ & UK & Review & Peatland & AR & $\begin{array}{l}\text { Impacts of burning } \\
\text { management on peatlands }\end{array}$ \\
\hline Worrall et al. & $2010 b$ & UK & Carbon & Peatland & $\mathrm{P}$ & $\begin{array}{l}\text { Assessing the probability of } \\
\text { carbon and greenhouse gas } \\
\text { benefit from the } \\
\text { management of peat soils. }\end{array}$ \\
\hline Worrall et al. & $2013 a$ & Peak District & Water & $\begin{array}{l}\text { Heather } \\
\text { peatland }\end{array}$ & $\mathrm{P}$ & $\begin{array}{l}\text { Effects of managed burning } \\
\text { in comparison with } \\
\text { vegetation cutting on } \\
\text { dissolved organic carbon } \\
\text { concentration in peat soils }\end{array}$ \\
\hline Worrall et al. & $2013 b$ & Peak District & Carbon & Moorland & $\mathrm{P}$ & $\begin{array}{l}\text { Controls upon biomass } \\
\text { losses and char production } \\
\text { from prescribed burning on } \\
\text { UK moorland }\end{array}$ \\
\hline $\begin{array}{l}\text { Yallop \& } \\
\text { Clutterbuck }\end{array}$ & 2009 & N. England & Water & Heathland & $\mathrm{P}$ & $\begin{array}{l}\text { Land management as a } \\
\text { factor controlling dissolved } \\
\text { organic carbon release from } \\
\text { upland peat soils 1: Spatial } \\
\text { variation in DOC } \\
\text { productivity }\end{array}$ \\
\hline Yallop et al. & 2006 & England & Review & $\begin{array}{l}\text { Upland } \\
\text { mixed }\end{array}$ & AR & $\begin{array}{l}\text { The extent and intensity of } \\
\text { management burning in the } \\
\text { English uplands }\end{array}$ \\
\hline Yallop et al. & 2010 & UK & Water & Peatland & $\mathrm{R}$ & $\begin{array}{l}\text { Increases in humic } \\
\text { dissolved organic carbon } \\
\text { export from upland peat } \\
\text { catchments: the role of } \\
\text { temperature, declining } \\
\text { sulphur deposition and } \\
\text { changes in land } \\
\text { management }\end{array}$ \\
\hline Yallop et al. & 2012 & England & Biodiversity & Peatland & $\mathrm{P}$ & $\begin{array}{l}\text { Burning on deep peat and } \\
\text { bog habitat in England: } \\
\text { reconciliation and re- } \\
\text { examination of results from } \\
\text { English Nature Research } \\
\text { Reports } 667,698 \text { and } \\
\text { unpublished data. }\end{array}$ \\
\hline
\end{tabular}




\section{ii) Supplementary material: Chapter 3}

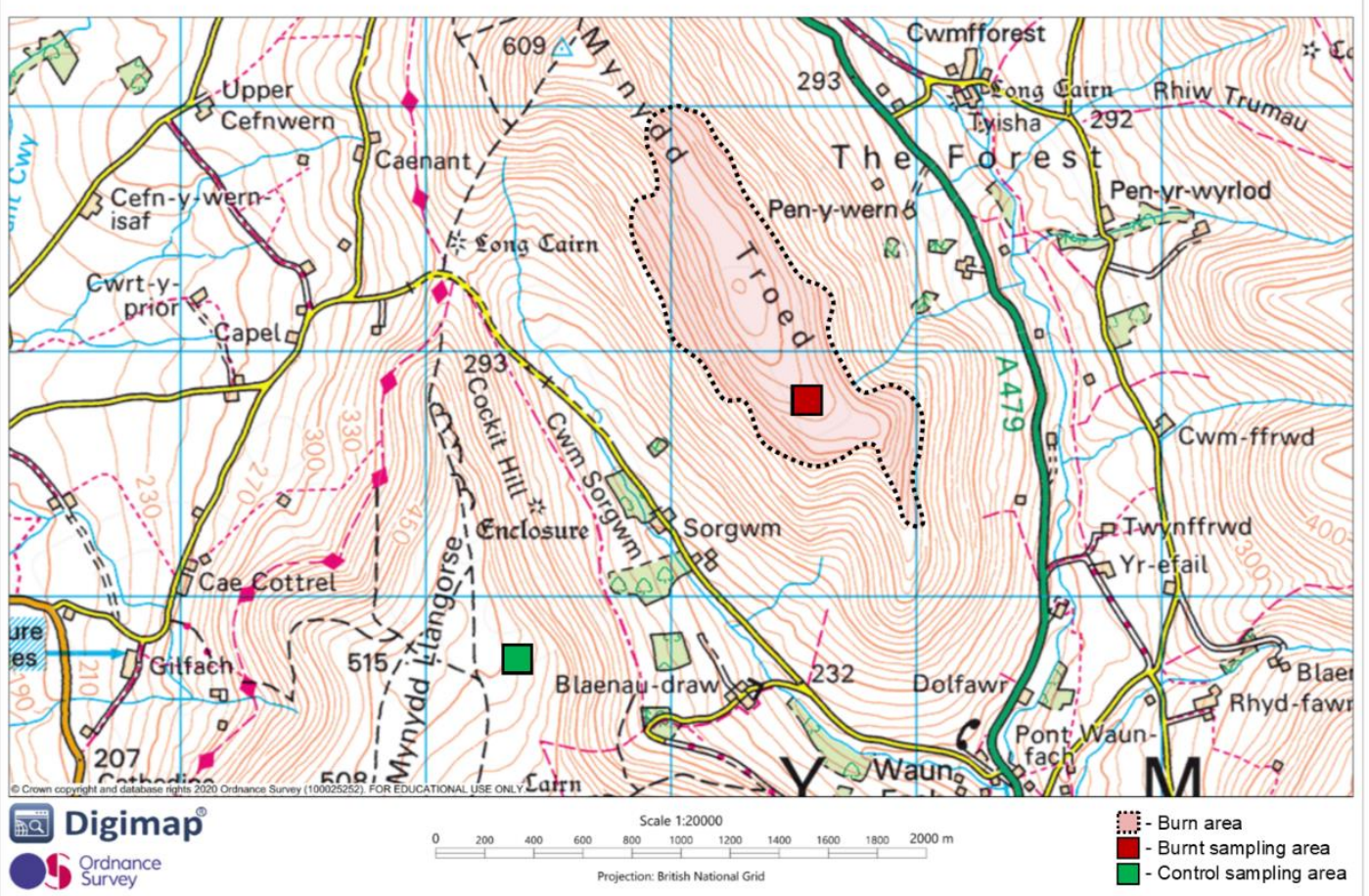

Supplementary Figure 3.1: Overview of Site A in the Llangorse region. Polygons indicate the approximate location and area of the 2018 fire event and the two sampling areas.

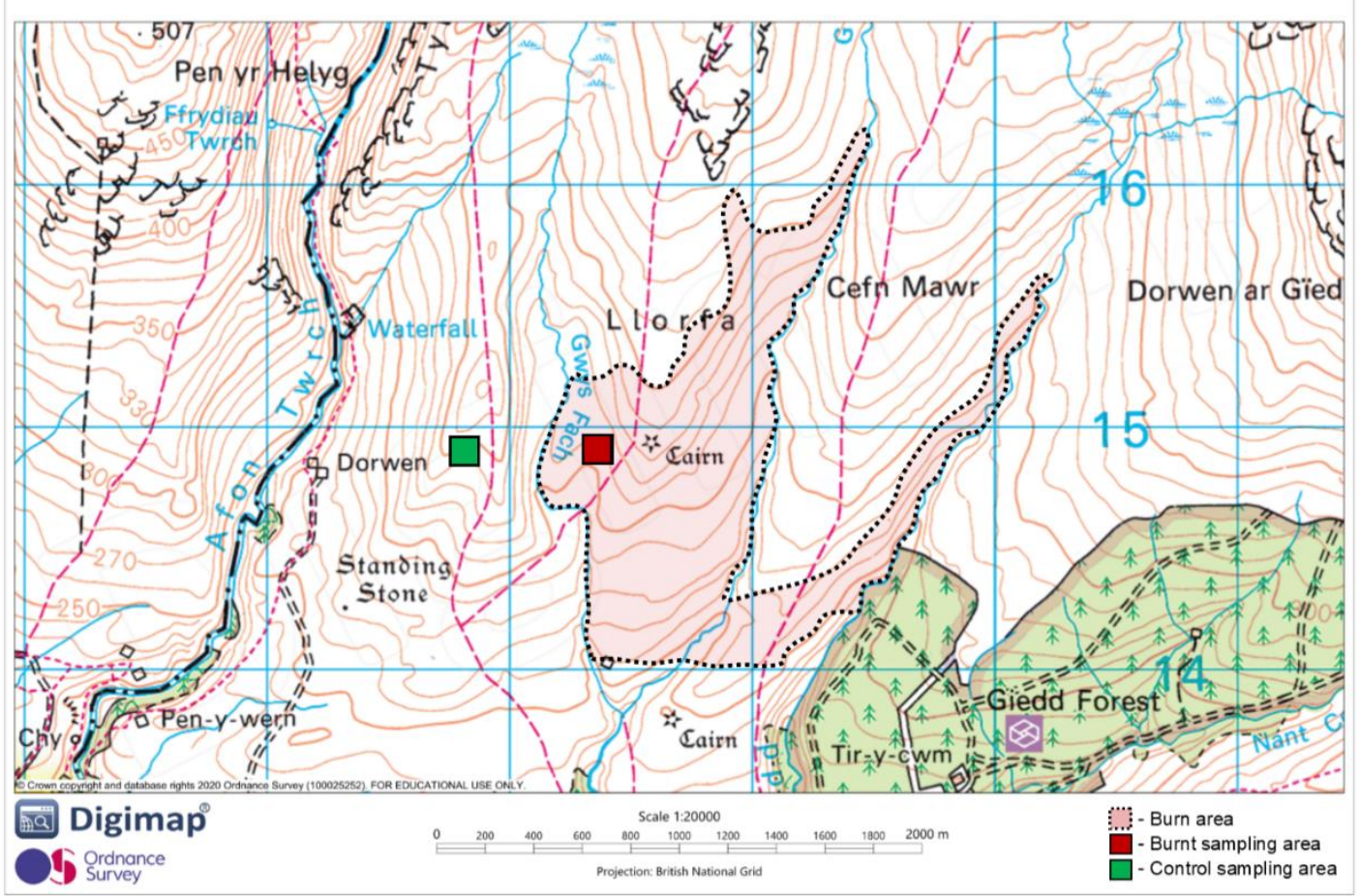

Supplementary Figure 3.2: Overview of Site B in the Cwmgiedd region. Polygons indicate the approximate location and area of the 2015 fire event and the two sampling areas. 


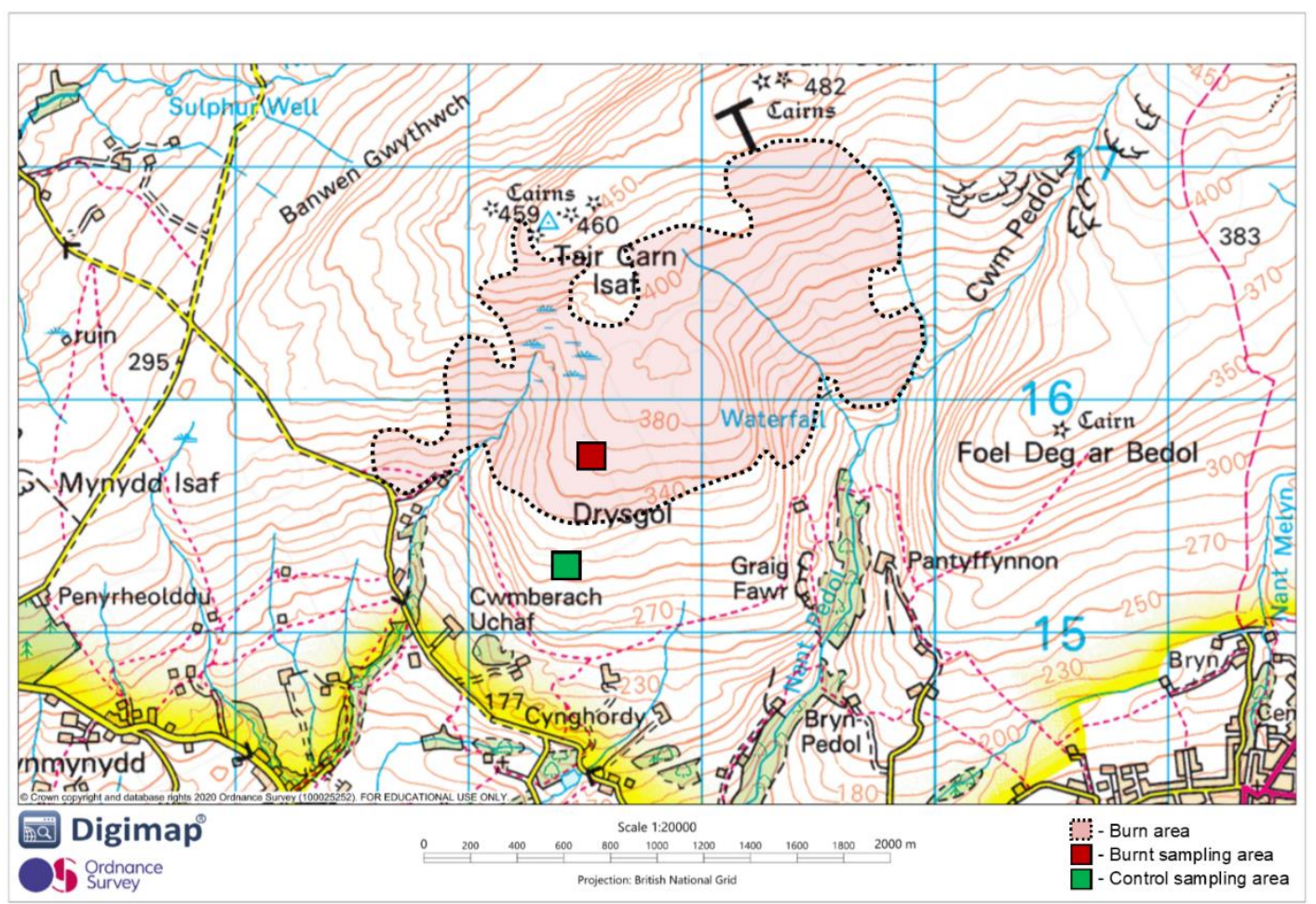

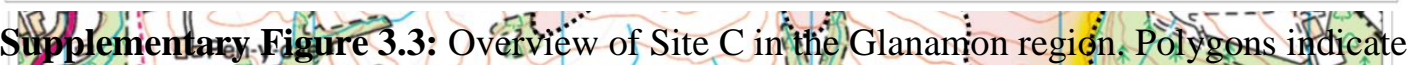
the approximate loeation andrarea of the 2011 fire event and the two sampling arease =

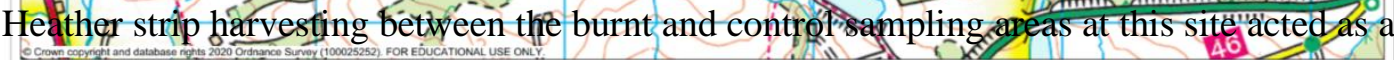

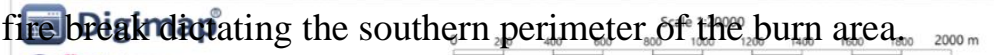
If $\begin{gathered}\text { Ordnance } \\ \text { Survey }\end{gathered}$

Supplementary Figure 3.4: Overview of Site D in the Penderyn region. Polygons indicate the approximate location and area of the 2007 fire event and the two sampling areas. 
Supplementary Table 3.1: Species cover data for each sampling area. Cover (\%) data combines canopy and ground layer survey data averaged for each species and site. The standard deviation (shown in brackets) has been provided for each averaged species cover value. Species have been divided into functional groups for ease of interpretation. Sampling area species richness (alpha diversity) and diversity (Shannon-Wiener Diversity: S-W diversity) have been provided alongside site beta diversity.

\begin{tabular}{|c|c|c|c|c|c|c|c|c|c|}
\hline \multirow[b]{2}{*}{ Group } & \multirow[b]{2}{*}{ Species } & \multicolumn{2}{|c|}{ Site A } & \multicolumn{2}{|c|}{ Site B } & \multicolumn{2}{|c|}{ Site C } & \multicolumn{2}{|c|}{ Site D } \\
\hline & & $<1$-year & Unburnt & 3-years & Unburnt & 7-years & Unburnt & 11-years & Unburnt \\
\hline \multirow{5}{*}{ 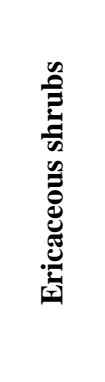 } & Calluna vulgaris & $0(1)$ & 80 (17) & $18(14)$ & $70(8)$ & $45(27)$ & $63(20)$ & $50(25)$ & $45(41)$ \\
\hline & Empetrum nigrum & 0 & 0 & 0 & 0 & 0 & 0 & 0 & $3(9)$ \\
\hline & Erica tetralix & 0 & 0 & $15(9)$ & 0 & 0 & 23 (19) & $6(6)$ & $8(12)$ \\
\hline & Erica cinerea & 0 & 0 & $1(2)$ & 0 & $1(3)$ & 0 & 0 & 0 \\
\hline & $\begin{array}{l}\text { Vaccinium } \\
\text { myrtillus }\end{array}$ & $7(7)$ & $25(15)$ & $5(4)$ & $17(4)$ & $13(7)$ & $15(10)$ & $16(12)$ & $11(12)$ \\
\hline \multirow{9}{*}{ 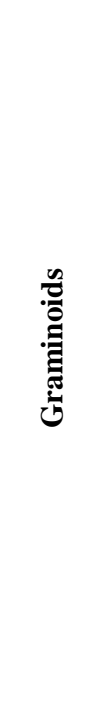 } & Agrostis capillaris & $1(3)$ & $4(4)$ & 0 & $1(3)$ & $1(3)$ & $0.1(0)$ & $0.4(1)$ & $2(4)$ \\
\hline & $\begin{array}{l}\text { Deschampsia } \\
\text { flexuosa }\end{array}$ & $1(1)$ & $1(2)$ & $0(1)$ & $2(3)$ & $3(5)$ & 0 & 0 & $5(14)$ \\
\hline & $\begin{array}{l}\text { Eriophorum } \\
\text { vaginatum }\end{array}$ & 0 & 0 & $1(4)$ & 0 & $1(1)$ & 0 & $1(1)$ & $1(2)$ \\
\hline & Festuca ovina & 0 & 0 & $0(1)$ & $0(1)$ & $1(3)$ & 0 & $0.1(0)$ & $6(10)$ \\
\hline & Juncus acutiflorus & 0 & 0 & $4(5)$ & 0 & $3(3)$ & 0 & 0 & 0 \\
\hline & Juncus squarrosus & 0 & 0 & 0 & 0 & 0 & 0 & $8(1)$ & 0 \\
\hline & Molinia caerulea & $2(3)$ & 0 & $24(17)$ & $3(6)$ & $29(24)$ & 0 & $30(21)$ & $28(33)$ \\
\hline & Nardus stricta & 0 & 0 & $16(15)$ & $7(10)$ & 0 & 0 & $0(3)$ & 0 \\
\hline & $\begin{array}{l}\text { Trichophorum } \\
\text { cespitosum }\end{array}$ & 0 & 0 & $7(5)$ & 0 & $3(5)$ & 0 & $1(2)$ & $1(3)$ \\
\hline \multirow{4}{*}{ 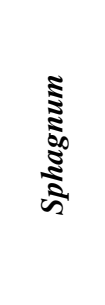 } & Sphagnum fallax & 0 & 0 & 0 & $2(6)$ & 0 & 0 & 0 & 0 \\
\hline & $\begin{array}{l}\text { Sphagnum } \\
\text { palustre }\end{array}$ & 0 & 0 & 0 & 0 & 0 & 0 & 0 & $3(9)$ \\
\hline & $\begin{array}{l}\text { Sphagnum } \\
\text { subnitens }\end{array}$ & 0 & 0 & $4(8)$ & 0 & 0 & 0 & $8(23)$ & $8(20)$ \\
\hline & $\begin{array}{l}\text { Sphagnum } \\
\text { tenellum }\end{array}$ & 0 & 0 & $1(4)$ & 0 & 0 & 0 & 0 & 0 \\
\hline \multirow{5}{*}{ 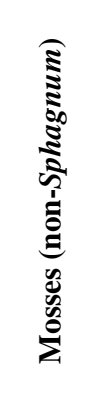 } & $\begin{array}{l}\text { Aulacomnium } \\
\text { palustre }\end{array}$ & 0 & $1(3)$ & 0 & 0 & 0 & 0 & 0 & 0 \\
\hline & $\begin{array}{l}\text { Campylopus } \\
\text { introflexus }\end{array}$ & 0 & 0 & $2(4)$ & 0 & $2(4)$ & 0 & $3(12)$ & 0 \\
\hline & $\begin{array}{l}\text { Dicranum } \\
\text { scoparium }\end{array}$ & 0 & $1(2)$ & $1(3)$ & $3(5)$ & $2(3)$ & 0 & 0 & $4(10)$ \\
\hline & Feather moss (N/A) & 0 & 0 & 0 & 0 & 0 & 0 & 0.1 & $0.4(1)$ \\
\hline & $\begin{array}{l}\text { Hylocomium } \\
\text { splendens }\end{array}$ & 0 & $2(4)$ & 0 & 0 & 0 & 0 & 0 & 0 \\
\hline
\end{tabular}




\begin{tabular}{|c|c|c|c|c|c|c|c|c|c|}
\hline & $\begin{array}{l}\text { Hypnum } \\
\text { jutlandicum }\end{array}$ & $1(2)$ & $10(12)$ & $16(13)$ & $20(13)$ & $8(9)$ & $23(12)$ & $12(20)$ & $32(26)$ \\
\hline \multirow{6}{*}{ 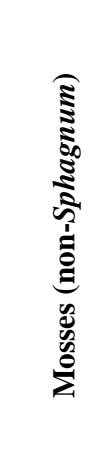 } & $\begin{array}{l}\text { Pleurozium } \\
\text { schreberi }\end{array}$ & 0 & $7(6)$ & $1(3)$ & $0(1)$ & $2(4)$ & $1(2)$ & 0 & $2(6)$ \\
\hline & $\begin{array}{l}\text { Polytrichum } \\
\text { commune }\end{array}$ & 0 & 0 & 0 & $1(3)$ & $12(20)$ & $0.4(1)$ & 0 & 0 \\
\hline & $\begin{array}{l}\text { Pseudoscleropodi } \\
\text { um purum }\end{array}$ & 0 & $3(5)$ & 0 & 0 & 0 & 0 & 0 & $2(7)$ \\
\hline & $\begin{array}{l}\text { Racomitrum } \\
\text { lanuginosum }\end{array}$ & 0 & 0 & 0 & $1(4)$ & 0 & 0 & 0 & 0 \\
\hline & $\begin{array}{l}\text { Rhytidiadelphus } \\
\text { loreus }\end{array}$ & 0 & $1(3)$ & 0 & $1(4)$ & $1(4)$ & $1(3)$ & 0 & 0 \\
\hline & $\begin{array}{l}\text { Rhytidiadelphus } \\
\text { squarrosus }\end{array}$ & $2(4)$ & $11(6)$ & 0 & $10(13)$ & $2(1)$ & $2(4)$ & $0.4(1)$ & $6(12)$ \\
\hline \multirow{3}{*}{ } & $\begin{array}{l}\text { Cladonia } \\
\text { chlorophaea }\end{array}$ & 0 & 0 & 0 & $2(3)$ & $0.1(1)$ & $0.3(0)$ & 0 & 0 \\
\hline & $\begin{array}{l}\text { Cladonia } \\
\text { portentosa }\end{array}$ & 0 & 0 & 0 & $2(5)$ & 0 & $0.4(1)$ & 0 & $1(2)$ \\
\hline & Lichen (N/A) & 0 & 0 & 0 & $1(1)$ & 0 & 0 & 0 & 0 \\
\hline 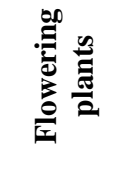 & Potentilla erecta & 0 & 0 & 0 & $1(4)$ & $1(3)$ & $0.2(0)$ & 0 & $2(2)$ \\
\hline \multirow{2}{*}{ 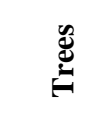 } & Quercus robur & 0 & 0 & 0 & 0 & 0 & $0.4(1)$ & 0 & $0.1(0)$ \\
\hline & Sorbus aucuparia & 0 & 0 & 0 & $0.2(0)$ & 0 & $1(4)$ & 0 & 0 \\
\hline \multicolumn{2}{|c|}{ Species richness } & 7 & 13 & 18 & 20 & 19 & 13 & 15 & 21 \\
\hline \multicolumn{2}{|c|}{$S-W$ diversity } & $\begin{array}{c}0.65 \pm \\
0.51\end{array}$ & $\begin{array}{c}1.33 \pm \\
0.16\end{array}$ & $\begin{array}{c}1.76 \pm \\
0.20\end{array}$ & $\begin{array}{c}1.41 \pm \\
0.23\end{array}$ & $\begin{array}{l}1.53 \pm \\
0.28\end{array}$ & $\begin{array}{c}1.34 \pm \\
0.22\end{array}$ & $\begin{array}{l}1.2 \pm \\
0.3\end{array}$ & $\begin{array}{c}1.34 \pm \\
0.38\end{array}$ \\
\hline \multicolumn{2}{|c|}{ Beta diversity } & \multicolumn{2}{|c|}{8} & \multicolumn{2}{|c|}{18} & \multicolumn{2}{|c|}{14} & \multicolumn{2}{|c|}{12} \\
\hline
\end{tabular}

Supp. Table 3.1: (continued) 
Supplementary Table 3.2: Details of the post-hoc pairwise ("emmeans") analysis of the linear model output to assess differences in sampling area diversity. P-value adjustment using the studentised range statistic, Tukey's 'Honest Significant Difference' method used here for comparing a family of 8 estimates with 88 degrees of freedom.

\begin{tabular}{|c|c|c|c|c|}
\hline & Estimate & SE & t-ratio & p-value \\
\hline SiteA:Burnt - SiteA:Unburnt & -0.68 & 0.13 & -5.18 & $<0.05$ \\
\hline SiteA:Burnt - SiteB:Burnt & -1.10 & 0.13 & -8.34 & $<0.05$ \\
\hline SiteA:Burnt - SiteB:Unburnt & -0.77 & 0.13 & -5.85 & $<0.05$ \\
\hline SiteA:Burnt - SiteC:Burnt & -0.84 & 0.13 & -6.39 & $<0.05$ \\
\hline SiteA:Burnt - SiteC:Unburnt & -0.60 & 0.13 & -4.55 & $<0.05$ \\
\hline SiteA:Burnt - SiteD:Burnt & -0.55 & 0.13 & -4.18 & $<0.05$ \\
\hline SiteA:Burnt - SiteD:Unburnt & -0.70 & 0.13 & -5.32 & $<0.05$ \\
\hline SiteA:Unburnt - SiteB:Burnt & -0.42 & 0.13 & -3.16 & $<0.05$ \\
\hline SiteA:Unburnt - SiteB:Unburnt & -0.09 & 0.13 & -0.67 & 1.00 \\
\hline SiteA:Unburnt - SiteC:Burnt & -0.16 & 0.13 & -1.21 & 0.93 \\
\hline SiteA:Unburnt - SiteC:Unburnt & 0.08 & 0.13 & 0.64 & 1.00 \\
\hline SiteA:Unburnt - SiteD:Burnt & 0.13 & 0.13 & 1.00 & 0.97 \\
\hline SiteA:Unburnt - SiteD:Unburnt & -0.02 & 0.13 & -0.14 & 1.00 \\
\hline SiteB:Burnt - SiteB:Unburnt & 0.33 & 0.13 & 2.50 & 0.21 \\
\hline SiteB:Burnt - SiteC:Burnt & 0.26 & 0.13 & 1.95 & 0.52 \\
\hline SiteB:Burnt - SiteC:Unburnt & 0.50 & 0.13 & 3.80 & $<0.05$ \\
\hline SiteB:Burnt - SiteD:Burnt & 0.55 & 0.13 & 4.17 & $<0.05$ \\
\hline SiteB:Burnt - SiteD:Unburnt & 0.40 & 0.13 & 3.02 & 0.06 \\
\hline SiteB:Unburnt - SiteC:Burnt & -0.07 & 0.13 & -0.54 & 1.00 \\
\hline SiteB:Unburnt - SiteC:Unburnt & 0.17 & 0.13 & 1.30 & 0.90 \\
\hline
\end{tabular}




\begin{tabular}{l|cccc} 
SiteB:Unburnt - SiteD:Burnt & 0.22 & 0.13 & 1.67 & 0.71 \\
SiteB:Unburnt - SiteD:Unburnt & 0.07 & 0.13 & 0.53 & 1.00 \\
SiteC:Burnt - SiteC:Unburnt & 0.24 & 0.13 & 1.85 & 0.59 \\
SiteC:Burnt - SiteD:Burnt & 0.29 & 0.13 & 2.21 & 0.35 \\
SiteC:Burnt - SiteD:Unburnt & 0.14 & 0.13 & 1.07 & 0.96 \\
SiteC:Unburnt - SiteD:Burnt & 0.05 & 0.13 & 0.37 & 1.00 \\
SiteC:Unburnt - SiteD:Unburnt & -0.10 & 0.13 & -0.78 & 0.99 \\
SiteD:Burnt - SiteD:Unburnt & -0.15 & 0.13 & -1.15 & 0.94 \\
\hline
\end{tabular}

Supp. Table 3.2: (continued) 
Supplementary Table 3.3: Overall species scores derived by Non-metric multidimensional scaling analysis (NMDS). Figures provided are vector values fitted to species scores, with associated $\mathrm{r}^{2}$ and degree of significance (Pr) for each species included in NMDS analysis.

\begin{tabular}{|c|c|c|c|c|}
\hline Species & NMDS1 & NMDS2 & $\mathbf{r}^{2}$ & $\operatorname{Pr}(>\mathbf{r})$ \\
\hline Agrostis capillaris & -0.44 & 0.90 & 0.23 & $<0.05$ \\
\hline Aulacomnium palustre & -0.72 & 0.69 & 0.01 & 0.60 \\
\hline Calluna vulgaris & -0.29 & 0.96 & 0.15 & $<0.05$ \\
\hline Campylopus introflexus & 0.99 & -0.15 & 0.02 & 0.47 \\
\hline Cladonia chlorophaea & 0.10 & 0.99 & 0.05 & 0.08 \\
\hline Cladonia portentosa & -0.39 & 0.92 & 0.05 & 0.11 \\
\hline Deschampsia flexuosa & -0.97 & 0.25 & 0.02 & 0.44 \\
\hline Dicranum scoparium & -0.17 & 0.99 & 0.09 & $<0.05$ \\
\hline Empetrum nigrum & -0.07 & 1.00 & 0.07 & 0.05 \\
\hline Erica cinerea & 0.91 & 0.42 & 0.11 & $<0.05$ \\
\hline Erica tetralix & 0.87 & -0.50 & 0.26 & $<0.05$ \\
\hline Eriophorum vaginatum & 0.98 & 0.18 & 0.07 & $<0.05$ \\
\hline Festuca ovina & 0.65 & -0.76 & 0.03 & 0.25 \\
\hline Hylocomium splendens & -0.57 & 0.82 & 0.05 & 0.12 \\
\hline Hypnum jutlandicum & 0.59 & 0.81 & 0.05 & 0.09 \\
\hline Juncus acutiflorus & 0.80 & 0.61 & 0.20 & $<0.05$ \\
\hline Juncus squarrosus & 0.40 & -0.92 & 0.02 & 0.40 \\
\hline Molinia caerulea & 0.67 & -0.74 & 0.47 & $<0.05$ \\
\hline Nardus stricta & 0.70 & 0.72 & 0.18 & $<0.05$ \\
\hline Pleurozium schreberi & -0.12 & 0.99 & 0.20 & $<0.05$ \\
\hline Polytrichum commune & 0.99 & -0.11 & 0.01 & 0.74 \\
\hline Potentilla erecta & 0.08 & 1.00 & 0.01 & 0.67 \\
\hline Pseudoscleropodium purum & -0.68 & 0.73 & 0.06 & 0.07 \\
\hline Quercus robur & 0.13 & 0.99 & 0.01 & 0.61 \\
\hline Racomitrum lanuginosum & -0.30 & 0.95 & 0.05 & 0.11 \\
\hline Rhytidiadelphus loreus & -1.00 & -0.07 & 0.00 & 0.82 \\
\hline Rhytidiadelphus squarrosus & -0.37 & 0.93 & 0.38 & $<0.05$ \\
\hline Sorbus aucuparia & -0.06 & 1.00 & 0.01 & 0.69 \\
\hline Sphagnum fallax & 0.22 & 0.98 & 0.01 & 0.64 \\
\hline Sphagnum palustre & 0.75 & -0.66 & 0.04 & 0.19 \\
\hline Sphagnum subnitens & 0.83 & -0.56 & 0.10 & $<0.05$ \\
\hline Sphagnum tenellum & 0.89 & 0.45 & 0.04 & 0.14 \\
\hline Trichophorum cespitosum & 0.99 & -0.14 & 0.28 & $<0.05$ \\
\hline Vaccinium myrtillus & -0.99 & 0.17 & 0.08 & $<0.05$ \\
\hline
\end{tabular}


Supplementary Table 3.4: Details of the post-hoc pairwise analysis following the vegetation community composition NMDS. P-value adjustment using the studentised range statistic, Tukey's 'Honest Significant Difference' method which accounts for multiple testing.

\begin{tabular}{|c|c|c|c|c|}
\hline & Difference & Lower & Upper & p-value \\
\hline SiteA:Burnt - SiteA:Unburnt & -0.30 & -0.45 & -0.14 & $<0.05$ \\
\hline SiteA:Burnt - SiteB:Burnt & -0.16 & -0.31 & 0.00 & $<0.05$ \\
\hline SiteA:Burnt - SiteB:Unburnt & -0.28 & -0.43 & -0.12 & $<0.05$ \\
\hline SiteA:Burnt - SiteC:Burnt & -0.14 & -0.30 & 0.02 & $<0.05$ \\
\hline SiteA:Burnt - SiteC:Unburnt & -0.28 & -0.43 & -0.12 & $<0.05$ \\
\hline SiteA:Burnt - SiteD:Burnt & -0.21 & -0.37 & -0.06 & $<0.05$ \\
\hline SiteA:Burnt - SiteD:Unburnt & -0.03 & -0.19 & 0.12 & 1.00 \\
\hline SiteA:Unburnt - SiteB:Burnt & 0.14 & -0.02 & 0.30 & 0.11 \\
\hline SiteA:Unburnt - SiteB:Unburnt & 0.02 & -0.14 & 0.17 & 1.00 \\
\hline SiteA:Unburnt - SiteC:Burnt & 0.16 & 0.00 & 0.31 & 0.05 \\
\hline SiteA:Unburnt - SiteC:Unburnt & 0.02 & -0.14 & 0.18 & 1.00 \\
\hline SiteA:Unburnt - SiteD:Burnt & 0.09 & -0.07 & 0.24 & 0.68 \\
\hline SiteA:Unburnt - SiteD:Unburnt & 0.27 & 0.11 & 0.42 & $<0.05$ \\
\hline SiteB:Burnt - SiteB:Unburnt & -0.12 & -0.28 & 0.03 & 0.24 \\
\hline SiteB:Burnt - SiteC:Burnt & 0.02 & -0.14 & 0.17 & 1.00 \\
\hline SiteB:Burnt - SiteC:Unburnt & -0.12 & -0.28 & 0.03 & 0.25 \\
\hline SiteB:Burnt - SiteD:Burnt & -0.05 & -0.21 & 0.10 & 0.96 \\
\hline SiteB:Burnt - SiteD:Unburnt & 0.12 & -0.03 & 0.28 & 0.22 \\
\hline SiteB:Unburnt - SiteC:Burnt & 0.14 & -0.02 & 0.29 & 0.12 \\
\hline SiteB:Unburnt - SiteC:Unburnt & 0.00 & -0.16 & 0.16 & 1.00 \\
\hline
\end{tabular}




\begin{tabular}{l|llll} 
SiteB:Unburnt - SiteD:Burnt & 0.07 & -0.09 & 0.22 & 0.88 \\
SiteB:Unburnt - SiteD:Unburnt & 0.25 & 0.09 & 0.40 & $<0.05$ \\
SiteC:Burnt - SiteC:Unburnt & -0.14 & -0.29 & 0.02 & 0.12 \\
SiteC:Burnt - SiteD:Burnt & -0.07 & -0.23 & 0.08 & 0.84 \\
SiteC:Burnt - SiteD:Unburnt & 0.11 & -0.05 & 0.26 & 0.40 \\
SiteC:Unburnt - SiteD:Burnt & 0.07 & -0.09 & 0.22 & 0.88 \\
SiteC:Unburnt - SiteD:Unburnt & 0.25 & 0.09 & 0.40 & $<0.05$ \\
SiteD:Burnt - SiteD:Unburnt & 0.18 & 0.02 & 0.34 & $<0.05$ \\
\hline
\end{tabular}

Supp. Table 3.4: (continued) 


\section{iii) Supplementary material: Chapter 4}

Supplementary Table 4.1: Details of the nested linear model of bulk density (BD) as a function of site:status and depth (see subsection 4.2.8. for full analytical details). Adjusted $\mathrm{R}^{2}$ was 0.52 and p-value of $<0.05$ on 15 degrees of freedom. The notation * indicates significant p-value interaction at the $95 \%$ confidence level. The notation $S 2.5$ represents the $2.5-5 \mathrm{~cm}$ soil depth layer.

\begin{tabular}{l|cccc}
\hline & Estimate & Std. Error & t-value & p-value \\
\hline (Intercept) & -0.45 & 0.21 & -2.17 & $<0.05^{*}$ \\
Depth [S2.5] & 0.67 & 0.29 & 2.27 & $<0.05^{*}$ \\
SiteA:Burnt & 0.70 & 0.29 & 2.38 & $<0.05^{*}$ \\
SiteA:Unburnt & 1.22 & 0.29 & 4.16 & $<0.05^{*}$ \\
SiteB:Burnt & -0.76 & 0.29 & -2.58 & $<0.05^{*}$ \\
SiteB:Unburnt & -0.06 & 0.29 & -0.22 & 0.83 \\
SiteC:Burnt & -0.26 & 0.29 & -0.89 & 0.38 \\
SiteC:Unburnt & 0.17 & 0.29 & 0.57 & 0.57 \\
SiteD:Burnt & -0.33 & 0.29 & -1.12 & 0.26 \\
SiteD:Unburnt & $\mathrm{NA}$ & $\mathrm{NA}$ & $\mathrm{NA}$ & $\mathrm{NA}$ \\
SiteA:Burnt: S2.5 & 0.18 & 0.42 & 0.44 & 0.66 \\
SiteA:Unburnt: S2.5 & -0.11 & 0.42 & -0.27 & 0.79 \\
SiteB:Burnt: S2.5 & -0.23 & 0.42 & -0.54 & 0.59 \\
SiteB:Unburnt: S2.5 & 0.20 & 0.42 & 0.48 & 0.63 \\
SiteC:Burnt: S2.5 & -0.26 & 0.42 & -0.62 & 0.53 \\
SiteC:Unburnt: S2.5 & 0.46 & 0.42 & 1.12 & 0.27 \\
SiteD:Burnt: S2.5 & 0.29 & 0.42 & 0.69 & 0.49 \\
SiteD:Unburnt: S2.5 & $\mathrm{NA}$ & $\mathrm{NA}$ & $\mathrm{NA}$ & $\mathrm{NA}$ \\
\hline & & & & \\
& & & & \\
\hline
\end{tabular}


Supplementary Table 4.2: Details of the post-hoc pairwise ("emmeans") analysis of the linear model output to assess differences in sampling area soil bulk density (BD). P-value adjustment using the studentised range statistic, Tukey's 'Honest Significant Difference' method used here for comparing a family of 16 estimates with 176 degrees of freedom. The notation S0 represents the $0-2.5 \mathrm{~cm}$ soil depth layer. S2.5 represents the $2.5-5 \mathrm{~cm}$ soil depth layer.

\begin{tabular}{|c|c|c|c|c|}
\hline & Estimate & SE & t-ratio & p-value \\
\hline SiteA:Burnt S0 - SiteA:Unburnt S0 & -0.53 & 0.29 & -1.79 & 0.92 \\
\hline SiteA:Burnt S0 - SiteB:Burnt S0 & 1.46 & 0.29 & 4.95 & $<0.05$ \\
\hline SiteA:Burnt S0 - SiteB:Unburnt S0 & 0.76 & 0.29 & 2.59 & 0.41 \\
\hline SiteA:Burnt S0 - SiteC:Burnt S0 & 0.96 & 0.29 & 3.26 & 0.09 \\
\hline SiteA:Burnt S0 - SiteC:Unburnt S0 & 0.53 & 0.29 & 1.81 & 0.91 \\
\hline SiteA:Burnt S0 - SiteD:Burnt S0 & 1.03 & 0.29 & 3.49 & 0.05 \\
\hline SiteA:Burnt S0 - SiteD:Unburnt S0 & 0.70 & 0.29 & 2.38 & 0.57 \\
\hline SiteA:Burnt S0 - SiteA:Burnt S2.5 & -0.85 & 0.29 & -2.88 & 0.23 \\
\hline SiteA:Burnt S0 - SiteA:Unburnt S2.5 & -1.08 & 0.29 & -3.67 & $<0.05$ \\
\hline SiteA:Burnt S0 - SiteB:Burnt S2.5 & 1.02 & 0.29 & 3.46 & 0.05 \\
\hline SiteA:Burnt S0 - SiteB:Unburnt S2.5 & -0.10 & 0.29 & -0.35 & 1.00 \\
\hline SiteA:Burnt S0 - SiteC:Burnt S2.5 & 0.55 & 0.29 & 1.88 & 0.88 \\
\hline SiteA:Burnt S0 - SiteC:Unburnt S2.5 & -0.60 & 0.29 & -2.04 & 0.80 \\
\hline SiteA:Burnt S0 - SiteD:Burnt S2.5 & 0.07 & 0.29 & 0.25 & 1.00 \\
\hline SiteA:Burnt S0 - SiteD:Unburnt S2.5 & 0.03 & 0.29 & 0.11 & 1.00 \\
\hline SiteA:Unburnt S0 - SiteB:Burnt S0 & 1.98 & 0.29 & 6.74 & $<0.05$ \\
\hline SiteA:Unburnt S0 - SiteB:Unburnt S0 & 1.29 & 0.29 & 4.38 & $<0.05$ \\
\hline SiteA:Unburnt S0 - SiteC:Burnt S0 & 1.48 & 0.29 & 5.05 & $<0.05$ \\
\hline SiteA:Unburnt S0 - SiteC:Unburnt S0 & 1.06 & 0.29 & 3.60 & $<0.05$ \\
\hline SiteA:Unburnt S0 - SiteD:Burnt S0 & 1.55 & 0.29 & 5.28 & $<0.05$ \\
\hline SiteA:Unburnt S0 - SiteD:Unburnt S0 & 1.22 & 0.29 & 4.16 & $<0.05$ \\
\hline SiteA:Unburnt S0 - SiteA:Burnt S2.5 & -0.32 & 0.29 & -1.10 & 1.00 \\
\hline SiteA:Unburnt S0 - SiteA:Unburnt S2.5 & -0.55 & 0.29 & -1.88 & 0.88 \\
\hline SiteA:Unburnt S0 - SiteB:Burnt S2.5 & 1.54 & 0.29 & 5.24 & $<0.05$ \\
\hline SiteA:Unburnt S0 - SiteB:Unburnt S2.5 & 0.42 & 0.29 & 1.44 & 0.99 \\
\hline SiteA:Unburnt S0 - SiteC:Burnt S2.5 & 1.08 & 0.29 & 3.66 & $<0.05$ \\
\hline SiteA:Unburnt S0 - SiteC:Unburnt S2.5 & -0.07 & 0.29 & -0.25 & 1.00 \\
\hline
\end{tabular}




\begin{tabular}{|c|c|c|c|c|}
\hline SiteA:Unburnt S0 - SiteD:Burnt S2.5 & 0.60 & 0.29 & 2.04 & 0.80 \\
\hline SiteA:Unburnt S0 - SiteD:Unburnt S2.5 & 0.56 & 0.29 & 1.90 & 0.87 \\
\hline SiteB:Burnt S0 - SiteB:Unburnt S0 & -0.69 & 0.29 & -2.36 & 0.58 \\
\hline SiteB:Burnt S0 - SiteC:Burnt S0 & -0.50 & 0.29 & -1.69 & 0.95 \\
\hline SiteB:Burnt S0 - SiteC:Unburnt S0 & -0.92 & 0.29 & -3.15 & 0.13 \\
\hline SiteB:Burnt S0 - SiteD:Burnt S0 & -0.43 & 0.29 & -1.46 & 0.99 \\
\hline SiteB:Burnt S0 - SiteD:Unburnt S0 & -0.76 & 0.29 & -2.58 & 0.42 \\
\hline SiteB:Burnt S0 - SiteA:Burnt S2.5 & -2.30 & 0.29 & -7.84 & $<0.05$ \\
\hline SiteB:Burnt S0 - SiteA:Unburnt S2.5 & -2.53 & 0.29 & -8.62 & $<0.05$ \\
\hline SiteB:Burnt S0 - SiteB:Burnt S2.5 & -0.44 & 0.29 & -1.50 & 0.98 \\
\hline SiteB:Burnt S0 - SiteB:Unburnt S2.5 & -1.56 & 0.29 & -5.30 & $<0.05$ \\
\hline SiteB:Burnt S0 - SiteC:Burnt S2.5 & -0.90 & 0.29 & -3.08 & 0.15 \\
\hline SiteB:Burnt S0 - SiteC:Unburnt S2.5 & -2.05 & 0.29 & -6.99 & $<0.05$ \\
\hline SiteB:Burnt S0 - SiteD:Burnt S2.5 & -1.38 & 0.29 & -4.70 & $<0.05$ \\
\hline SiteB:Burnt S0 - SiteD:Unburnt S2.5 & -1.42 & 0.29 & -4.84 & $<0.05$ \\
\hline SiteB:Unburnt S0 - SiteC:Burnt S0 & 0.20 & 0.29 & 0.67 & 1.00 \\
\hline SiteB:Unburnt S0 - SiteC:Unburnt S0 & -0.23 & 0.29 & -0.79 & 1.00 \\
\hline SiteB:Unburnt S0 - SiteD:Burnt S0 & 0.26 & 0.29 & 0.90 & 1.00 \\
\hline SiteB:Unburnt S0 - SiteD:Unburnt S0 & -0.06 & 0.29 & -0.22 & 1.00 \\
\hline SiteB:Unburnt S0 - SiteA:Burnt S2.5 & -1.61 & 0.29 & -5.48 & $<0.05$ \\
\hline SiteB:Unburnt S0 - SiteA:Unburnt S2.5 & -1.84 & 0.29 & -6.26 & $<0.05$ \\
\hline SiteB:Unburnt S0 - SiteB:Burnt S2.5 & 0.25 & 0.29 & 0.86 & 1.00 \\
\hline SiteB:Unburnt S0 - SiteB:Unburnt S2.5 & -0.86 & 0.29 & -2.94 & 0.21 \\
\hline SiteB:Unburnt S0 - SiteC:Burnt S2.5 & -0.21 & 0.29 & -0.72 & 1.00 \\
\hline SiteB:Unburnt S0 - SiteC:Unburnt S2.5 & -1.36 & 0.29 & -4.63 & 0.00 \\
\hline SiteB:Unburnt S0 - SiteD:Burnt S2.5 & -0.69 & 0.29 & -2.34 & 0.59 \\
\hline SiteB:Unburnt S0 - SiteD:Unburnt S2.5 & -0.73 & 0.29 & -2.48 & 0.49 \\
\hline SiteC:Burnt S0 - SiteC:Unburnt S0 & -0.43 & 0.29 & -1.45 & 0.99 \\
\hline SiteC:Burnt S0 - SiteD:Burnt S0 & 0.07 & 0.29 & 0.23 & 1.00 \\
\hline SiteC:Burnt S0 - Site D:Unburnt S0 & -0.26 & 0.29 & -0.89 & 1.00 \\
\hline SiteC:Burnt S0 - SiteA:Burnt S2.5 & -1.80 & 0.29 & -6.14 & $<0.05$ \\
\hline SiteC:Burnt S0 - SiteA:Unburnt S2.5 & -2.04 & 0.29 & -6.93 & $<0.05$ \\
\hline SiteC:Burnt S0 - SiteB:Burnt S2.5 & 0.06 & 0.29 & 0.20 & 1.00 \\
\hline SiteC:Burnt S0 - SiteB:Unburnt S2.5 & -1.06 & 0.29 & -3.61 & 0.03 \\
\hline SiteC:Burnt S0 - SiteC:Burnt S2.5 & -0.41 & 0.29 & -1.39 & 0.99 \\
\hline
\end{tabular}




\begin{tabular}{|c|c|c|c|c|}
\hline SiteC:Burnt S0 - SiteC:Unburnt S2.5 & -1.56 & 0.29 & -5.30 & $<0.05$ \\
\hline SiteC:Burnt S0 - SiteD:Burnt S2.5 & -0.88 & 0.29 & -3.01 & 0.18 \\
\hline SiteC:Burnt S0 - SiteD:Unburnt S2.5 & -0.93 & 0.29 & -3.15 & 0.12 \\
\hline SiteC:Unburnt S0 - SiteD:Burnt S0 & 0.50 & 0.29 & 1.69 & 0.95 \\
\hline SiteC:Unburnt S0 - Site D:Unburnt S0 & 0.17 & 0.29 & 0.57 & 1.00 \\
\hline SiteC:Unburnt S0 - SiteA:Burnt S2.5 & -1.38 & 0.29 & -4.69 & $<0.05$ \\
\hline SiteC:Unburnt S0 - SiteA:Unburnt S2.5 & -1.61 & 0.29 & -5.48 & $<0.05$ \\
\hline SiteC:Unburnt S0 - SiteB:Burnt S2.5 & 0.48 & 0.29 & 1.65 & 0.96 \\
\hline SiteC:Unburnt S0 - SiteB:Unburnt S2.5 & -0.63 & 0.29 & -2.16 & 0.73 \\
\hline SiteC:Unburnt S0 - SiteC:Burnt S2.5 & 0.02 & 0.29 & 0.07 & 1.00 \\
\hline SiteC:Unburnt S0 - SiteC:Unburnt S2.5 & -1.13 & 0.29 & -3.85 & $<0.05$ \\
\hline SiteC:Unburnt S0 - SiteD:Burnt S2.5 & -0.46 & 0.29 & -1.56 & 0.97 \\
\hline SiteC:Unburnt S0 - SiteD:Unburnt S2.5 & -0.50 & 0.29 & -1.70 & 0.94 \\
\hline SiteD:Burnt S0 - SiteD:Unburnt S0 & -0.33 & 0.29 & -1.12 & 1.00 \\
\hline SiteD:Burnt S0 - SiteA:Burnt S2.5 & -1.87 & 0.29 & -6.38 & $<0.05$ \\
\hline SiteD:Burnt S0 - SiteA:Unburnt S2.5 & -2.10 & 0.29 & -7.16 & $<0.05$ \\
\hline SiteD:Burnt S0 - SiteB:Burnt S2.5 & -0.01 & 0.29 & -0.04 & 1.00 \\
\hline SiteD:Burnt S0 - SiteB:Unburnt S2.5 & -1.13 & 0.29 & -3.84 & $<0.05$ \\
\hline SiteD:Burnt S0 - SiteC:Burnt S2.5 & -0.47 & 0.29 & -1.62 & 0.96 \\
\hline SiteD:Burnt S0 - SiteC:Unburnt S2.5 & -1.62 & 0.29 & -5.53 & $<0.05$ \\
\hline SiteD:Burnt S0 - SiteD:Burnt S2.5 & -0.95 & 0.29 & -3.24 & 0.10 \\
\hline SiteD:Burnt S0 - SiteD:Unburnt S2.5 & -0.99 & 0.29 & -3.38 & 0.07 \\
\hline SiteD:Unburnt S0 - SiteA:Burnt S2.5 & -1.54 & 0.29 & -5.26 & $<0.05$ \\
\hline SiteD:Unburnt S0 - SiteA:Unburnt S2.5 & -1.77 & 0.29 & -6.04 & $<0.05$ \\
\hline SiteD:Unburnt S0 - SiteB:Burnt S2.5 & 0.32 & 0.29 & 1.08 & 1.00 \\
\hline SiteD:Unburnt S0 - SiteB:Unburnt S2.5 & -0.80 & 0.29 & -2.72 & 0.33 \\
\hline SiteD:Unburnt S0 - SiteC:Burnt S2.5 & -0.15 & 0.29 & -0.50 & 1.00 \\
\hline SiteD:Unburnt S0 - SiteC:Unburnt S2.5 & -1.30 & 0.29 & -4.41 & $<0.05$ \\
\hline SiteD:Unburnt S0 - SiteD:Burnt S2.5 & -0.62 & 0.29 & -2.12 & 0.75 \\
\hline SiteD:Unburnt S0 - SiteD:Unburnt S2.5 & -0.67 & 0.29 & -2.27 & 0.65 \\
\hline SiteA:Burnt S2.5 - SiteA:Unburnt S2.5 & -0.23 & 0.29 & -0.79 & 1.00 \\
\hline SiteA:Burnt S2.5 - SiteB:Burnt S2.5 & 1.86 & 0.29 & 6.34 & $<0.05$ \\
\hline SiteA:Burnt S2.5 - SiteB:Unburnt S2.5 & 0.75 & 0.29 & 2.54 & 0.45 \\
\hline SiteA:Burnt S2.5 - SiteC:Burnt S2.5 & 1.40 & 0.29 & 4.76 & $<0.05$ \\
\hline SiteA:Burnt S2.5 - SiteC:Unburnt S2.5 & 0.25 & 0.29 & 0.85 & 1.00 \\
\hline
\end{tabular}




\begin{tabular}{|c|c|c|c|c|}
\hline SiteA:Burnt S2.5 - SiteD:Burnt S2.5 & 0.92 & 0.29 & 3.14 & 0.13 \\
\hline SiteA:Burnt S2.5 - SiteD:Unburnt S2.5 & 0.88 & 0.29 & 2.99 & 0.18 \\
\hline SiteA:Unburnt S2.5 - SiteB:Burnt S2.5 & 2.09 & 0.29 & 7.12 & $<0.05$ \\
\hline SiteA:Unburnt S2.5 - SiteB:Unburnt S2.5 & 0.98 & 0.29 & 3.32 & 0.08 \\
\hline SiteA:Unburnt S2.5 - SiteC:Burnt S2.5 & 1.63 & 0.29 & 5.54 & $<0.05$ \\
\hline SiteA:Unburnt S2.5 - SiteC:Unburnt S2.5 & 0.48 & 0.29 & 1.63 & 0.96 \\
\hline SiteA:Unburnt S2.5 - SiteD:Burnt S2.5 & 1.15 & 0.29 & 3.92 & $<0.05$ \\
\hline SiteA:Unburnt S2.5 - SiteD:Unburnt S2.5 & 1.11 & 0.29 & 3.78 & $<0.05$ \\
\hline SiteB:Burnt S2.5 - SiteB:Unburnt S2.5 & -1.12 & 0.29 & -3.80 & $<0.05$ \\
\hline SiteB:Burnt S2.5 - SiteC:Burnt S2.5 & -0.46 & 0.29 & -1.58 & 0.97 \\
\hline SiteB:Burnt S2.5 - SiteC:Unburnt S2.5 & -1.61 & 0.29 & -5.49 & $<0.05$ \\
\hline SiteB:Burnt S2.5 - SiteD:Burnt S2.5 & -0.94 & 0.29 & -3.20 & 0.11 \\
\hline SiteB:Burnt S2.5 - SiteD:Unburnt S2.5 & -0.98 & 0.29 & -3.35 & 0.07 \\
\hline SiteB:Unburnt S2.5 - SiteC:Burnt S2.5 & 0.65 & 0.29 & 2.22 & 0.68 \\
\hline SiteB:Unburnt S2.5 - SiteC:Unburnt S2.5 & -0.50 & 0.29 & -1.69 & 0.95 \\
\hline SiteB:Unburnt S2.5 - SiteD:Burnt S2.5 & 0.18 & 0.29 & 0.60 & 1.00 \\
\hline SiteB:Unburnt S2.5 - SiteD:Unburnt S2.5 & 0.13 & 0.29 & 0.46 & 1.00 \\
\hline SiteC:Burnt S2.5 - SiteC:Unburnt S2.5 & -1.15 & 0.29 & -3.91 & $<0.05$ \\
\hline SiteC:Burnt S2.5 - SiteD:Burnt S2.5 & -0.48 & 0.29 & -1.63 & 0.96 \\
\hline SiteC:Burnt S2.5 - SiteD:Unburnt S2.5 & -0.52 & 0.29 & -1.77 & 0.92 \\
\hline SiteC:Unburnt S2.5 - SiteD:Burnt S2.5 & 0.67 & 0.29 & 2.29 & 0.63 \\
\hline SiteC:Unburnt S2.5 - SiteD:Unburnt S2.5 & 0.63 & 0.29 & 2.15 & 0.73 \\
\hline SiteD:Burnt S2.5 - SiteD:Unburnt S2.5 & -0.04 & 0.29 & -0.14 & 1.00 \\
\hline
\end{tabular}

Supp. Table 4.2: (continued) 
Supplementary Table 4.3: Details of the nested linear model of water holding capacity (WHC) as a function of site:status and depth (see subsection 4.2.8. for full analytical details). Adjusted $\mathrm{R}^{2}$ was 0.52 and $\mathrm{p}$-value of $<0.05$ on 15 degrees of freedom. The notation * indicates significant p-value interaction at the $95 \%$ confidence level. The notation S2.5 represents the 2.5-5 cm soil depth layer.

\begin{tabular}{l|cccc}
\hline & Estimate & Std. Error & t-value & p-value \\
\hline (Intercept) & -0.42 & 0.21 & -2.02 & $<0.05^{*}$ \\
Depth [S2.5] & 0.64 & 0.30 & 2.18 & $<0.05^{*}$ \\
SiteA:Burnt & 0.68 & 0.30 & 2.30 & $<0.05^{*}$ \\
SiteA:Unburnt & 1.16 & 0.30 & 3.94 & $<0.05^{*}$ \\
SiteB:Burnt & -0.82 & 0.30 & -2.77 & $<0.05^{*}$ \\
SiteB:Unburnt & -0.10 & 0.30 & -0.32 & 0.75 \\
SiteC:Burnt & -0.26 & 0.30 & -0.90 & 0.37 \\
SiteC:Unburnt & 0.15 & 0.30 & 0.51 & 0.61 \\
SiteD:Burnt & -0.34 & 0.30 & -1.14 & 0.25 \\
SiteD:Unburnt & $\mathrm{NA}$ & $\mathrm{NA}$ & $\mathrm{NA}$ & $\mathrm{NA}$ \\
SiteA:Burnt: S2.5 & 0.19 & 0.42 & 0.46 & 0.65 \\
SiteA:Unburnt: S2.5 & -0.07 & 0.42 & -0.17 & 0.87 \\
SiteB:Burnt: S2.5 & -0.22 & 0.42 & -0.53 & 0.60 \\
SiteB:Unburnt: S2.5 & 0.22 & 0.42 & 0.53 & 0.60 \\
SiteC:Burnt: S2.5 & -0.23 & 0.42 & -0.54 & 0.59 \\
SiteC:Unburnt: S2.5 & 0.45 & 0.42 & 1.09 & 0.28 \\
SiteD:Burnt: S2.5 & 0.30 & 0.42 & 0.72 & 0.47 \\
SiteD:Unburnt: S2.5 & $\mathrm{NA}$ & $\mathrm{NA}$ & $\mathrm{NA}$ & $\mathrm{NA}$ \\
\hline & & & & \\
\hline
\end{tabular}


Supplementary Table 4.4: Details of the post-hoc pairwise ("emmeans") analysis of the linear model output to assess differences in sampling area soil water holding capacity (WHC). P-value adjustment using the studentised range statistic, Tukey's 'Honest Significant Difference' method used here for comparing a family of 16 estimates with 176 degrees of freedom. The notation S0 represents the 0-2.5 cm soil depth layer. S2.5 represents the 2.5-5 $\mathrm{cm}$ soil depth layer.

\begin{tabular}{|c|c|c|c|c|}
\hline & Estimate & SE & t-ratio & p-value \\
\hline SiteA:Burnt S0 - SiteA:Unburnt S0 & -0.87 & 0.35 & -2.49 & 0.48 \\
\hline SiteA:Burnt S0 - SiteB:Burnt S0 & -1.42 & 0.35 & -4.09 & $<0.05$ \\
\hline SiteA:Burnt S0 - SiteB:Unburnt S0 & -1.12 & 0.35 & -3.21 & 0.11 \\
\hline SiteA:Burnt S0 - SiteC:Burnt S0 & -1.24 & 0.35 & -3.57 & $<0.05$ \\
\hline SiteA:Burnt S0 - SiteC:Unburnt S0 & -0.69 & 0.35 & -1.97 & 0.84 \\
\hline SiteA:Burnt S0 - SiteD:Burnt S0 & -1.43 & 0.35 & -4.11 & $<0.05$ \\
\hline SiteA:Burnt S0 - SiteD:Unburnt S0 & -1.26 & 0.35 & -3.62 & $<0.05$ \\
\hline SiteA:Burnt S0 - SiteA:Burnt S2.5 & 0.33 & 0.35 & 0.96 & 1.00 \\
\hline SiteA:Burnt S0 - SiteA:Unburnt S2.5 & -0.11 & 0.35 & -0.31 & 1.00 \\
\hline SiteA:Burnt S0 - SiteB:Burnt S2.5 & -0.94 & 0.35 & -2.70 & 0.34 \\
\hline SiteA:Burnt S0 - SiteB:Unburnt S2.5 & -0.56 & 0.35 & -1.60 & 0.97 \\
\hline SiteA:Burnt S0 - SiteC:Burnt S2.5 & -0.70 & 0.35 & -2.01 & 0.82 \\
\hline SiteA:Burnt S0 - SiteC:Unburnt S2.5 & 0.36 & 0.35 & 1.03 & 1.00 \\
\hline SiteA:Burnt S0 - SiteD:Burnt S2.5 & -1.16 & 0.35 & -3.34 & 0.07 \\
\hline SiteA:Burnt S0 - SiteD:Unburnt S2.5 & -0.75 & 0.35 & -2.16 & 0.72 \\
\hline SiteA:Unburnt S0 - SiteB:Burnt S0 & -0.56 & 0.35 & -1.59 & 0.97 \\
\hline SiteA:Unburnt S0 - SiteB:Unburnt S0 & -0.25 & 0.35 & -0.72 & 1.00 \\
\hline SiteA:Unburnt S0 - SiteC:Burnt S0 & -0.38 & 0.35 & -1.08 & 1.00 \\
\hline SiteA:Unburnt S0 - SiteC:Unburnt S0 & 0.18 & 0.35 & 0.52 & 1.00 \\
\hline SiteA:Unburnt S0 - SiteD:Burnt S0 & -0.56 & 0.35 & -1.62 & 0.96 \\
\hline SiteA:Unburnt S0 - SiteD:Unburnt S0 & -0.39 & 0.35 & -1.13 & 1.00 \\
\hline SiteA:Unburnt S0 - SiteA:Burnt S2.5 & 1.20 & 0.35 & 3.45 & 0.05 \\
\hline SiteA:Unburnt S0 - SiteA:Unburnt S2.5 & 0.76 & 0.35 & 2.18 & 0.71 \\
\hline SiteA:Unburnt S0 - SiteB:Burnt S2.5 & -0.07 & 0.35 & -0.20 & 1.00 \\
\hline SiteA:Unburnt S0 - SiteB:Unburnt S2.5 & 0.31 & 0.35 & 0.89 & 1.00 \\
\hline SiteA:Unburnt S0 - SiteC:Burnt S2.5 & 0.17 & 0.35 & 0.48 & 1.00 \\
\hline SiteA:Unburnt S0 - SiteC:Unburnt S2.5 & 1.23 & 0.35 & 3.52 & $<0.05$ \\
\hline
\end{tabular}




\begin{tabular}{|c|c|c|c|c|}
\hline SiteA:Unburnt S0 - SiteD:Burnt S2.5 & -0.30 & 0.35 & -0.85 & 1.00 \\
\hline SiteA:Unburnt S0 - SiteD:Unburnt S2.5 & 0.12 & 0.35 & 0.33 & 1.00 \\
\hline SiteB:Burnt S0 - SiteB:Unburnt S0 & 0.31 & 0.35 & 0.88 & 1.00 \\
\hline SiteB:Burnt S0 - SiteC:Burnt S0 & 0.18 & 0.35 & 0.52 & 1.00 \\
\hline SiteB:Burnt S0 - SiteC:Unburnt S0 & 0.74 & 0.35 & 2.11 & 0.75 \\
\hline SiteB:Burnt S0 - SiteD:Burnt S0 & -0.01 & 0.35 & -0.02 & 1.00 \\
\hline SiteB:Burnt S0 - SiteD:Unburnt S0 & 0.16 & 0.35 & 0.47 & 1.00 \\
\hline SiteB:Burnt S0 - SiteA:Burnt S2.5 & 1.76 & 0.35 & 5.05 & $<0.05$ \\
\hline SiteB:Burnt S0 - SiteA:Unburnt S2.5 & 1.32 & 0.35 & 3.78 & $<0.05$ \\
\hline SiteB:Burnt S0 - SiteB:Burnt S2.5 & 0.49 & 0.35 & 1.39 & 0.99 \\
\hline SiteB:Burnt S0 - SiteB:Unburnt S2.5 & 0.87 & 0.35 & 2.49 & 0.49 \\
\hline SiteB:Burnt S0 - SiteC:Burnt S2.5 & 0.72 & 0.35 & 2.08 & 0.78 \\
\hline SiteB:Burnt S0 - SiteC:Unburnt S2.5 & 1.78 & 0.35 & 5.11 & $<0.05$ \\
\hline SiteB:Burnt S0 - SiteD:Burnt S2.5 & 0.26 & 0.35 & 0.75 & 1.00 \\
\hline SiteB:Burnt S0 - SiteD:Unburnt S2.5 & 0.67 & 0.35 & 1.93 & 0.86 \\
\hline SiteB:Unburnt S0 - SiteC:Burnt S0 & -0.12 & 0.35 & -0.36 & 1.00 \\
\hline SiteB:Unburnt S0 - SiteC:Unburnt S0 & 0.43 & 0.35 & 1.24 & 1.00 \\
\hline SiteB:Unburnt S0 - SiteD:Burnt S0 & -0.31 & 0.35 & -0.90 & 1.00 \\
\hline SiteB:Unburnt S0 - SiteD:Unburnt S0 & -0.14 & 0.35 & -0.41 & 1.00 \\
\hline SiteB:Unburnt S0 - SiteA:Burnt S2.5 & 1.45 & 0.35 & 4.17 & $<0.05$ \\
\hline SiteB:Unburnt S0 - SiteA:Unburnt S2.5 & 1.01 & 0.35 & 2.90 & 0.22 \\
\hline SiteB:Unburnt S0 - SiteB:Burnt S2.5 & 0.18 & 0.35 & 0.52 & 1.00 \\
\hline SiteB:Unburnt S0 - SiteB:Unburnt S2.5 & 0.56 & 0.35 & 1.61 & 0.96 \\
\hline SiteB:Unburnt S0 - SiteC:Burnt S2.5 & 0.42 & 0.35 & 1.20 & 1.00 \\
\hline SiteB:Unburnt S0 - SiteC:Unburnt S2.5 & 1.48 & 0.35 & 4.24 & $<0.05$ \\
\hline SiteB:Unburnt S0 - SiteD:Burnt S2.5 & -0.05 & 0.35 & -0.13 & 1.00 \\
\hline SiteB:Unburnt S0 - SiteD:Unburnt S2.5 & 0.37 & 0.35 & 1.05 & 1.00 \\
\hline SiteC:Burnt S0 - SiteC:Unburnt S0 & 0.56 & 0.35 & 1.60 & 0.97 \\
\hline SiteC:Burnt S0 - SiteD:Burnt S0 & -0.19 & 0.35 & -0.54 & 1.00 \\
\hline SiteC:Burnt S0 - Site D:Unburnt S0 & -0.02 & 0.35 & -0.05 & 1.00 \\
\hline SiteC:Burnt S0 - SiteA:Burnt S2.5 & 1.58 & 0.35 & 4.53 & $<0.05$ \\
\hline SiteC:Burnt S0 - SiteA:Unburnt S2.5 & 1.14 & 0.35 & 3.26 & 0.09 \\
\hline SiteC:Burnt S0 - SiteB:Burnt S2.5 & 0.30 & 0.35 & 0.87 & 1.00 \\
\hline SiteC:Burnt S0 - SiteB:Unburnt S2.5 & 0.69 & 0.35 & 1.97 & 0.84 \\
\hline SiteC:Burnt S0 - SiteC:Burnt S2.5 & 0.54 & 0.35 & 1.56 & 0.97 \\
\hline
\end{tabular}




\begin{tabular}{|c|c|c|c|c|}
\hline SiteC:Burnt S0 - SiteC:Unburnt S2.5 & 1.60 & 0.35 & 4.59 & $<0.05$ \\
\hline SiteC:Burnt S0 - SiteD:Burnt S2.5 & 0.08 & 0.35 & 0.23 & 1.00 \\
\hline SiteC:Burnt S0 - SiteD:Unburnt S2.5 & 0.49 & 0.35 & 1.41 & 0.99 \\
\hline SiteC:Unburnt S0 - SiteD:Burnt S0 & -0.74 & 0.35 & -2.13 & 0.74 \\
\hline SiteC:Unburnt S0 - Site D:Unburnt S0 & -0.57 & 0.35 & -1.64 & 0.96 \\
\hline SiteC:Unburnt S0 - SiteA:Burnt S2.5 & 1.02 & 0.35 & 2.93 & 0.21 \\
\hline SiteC:Unburnt S0 - SiteA:Unburnt S2.5 & 0.58 & 0.35 & 1.67 & 0.95 \\
\hline SiteC:Unburnt S0 - SiteB:Burnt S2.5 & -0.25 & 0.35 & -0.72 & 1.00 \\
\hline SiteC:Unburnt S0 - SiteB:Unburnt S2.5 & 0.13 & 0.35 & 0.37 & 1.00 \\
\hline SiteC:Unburnt S0 - SiteC:Burnt S2.5 & -0.01 & 0.35 & -0.04 & 1.00 \\
\hline SiteC:Unburnt S0 - SiteC:Unburnt S2.5 & 1.05 & 0.35 & 3.00 & 0.18 \\
\hline SiteC:Unburnt S0 - SiteD:Burnt S2.5 & -0.48 & 0.35 & -1.37 & 0.99 \\
\hline SiteC:Unburnt S0 - SiteD:Unburnt S2.5 & -0.06 & 0.35 & -0.18 & 1.00 \\
\hline SiteD:Burnt S0 - SiteD:Unburnt S0 & 0.17 & 0.35 & 0.49 & 1.00 \\
\hline SiteD:Burnt S0 - SiteA:Burnt S2.5 & 1.77 & 0.35 & 5.07 & $<0.05$ \\
\hline SiteD:Burnt S0 - SiteA:Unburnt S2.5 & 1.32 & 0.35 & 3.80 & $<0.05$ \\
\hline SiteD:Burnt S0 - SiteB:Burnt S2.5 & 0.49 & 0.35 & 1.41 & 0.99 \\
\hline SiteD:Burnt S0 - SiteB:Unburnt S2.5 & 0.87 & 0.35 & 2.51 & 0.47 \\
\hline SiteD:Burnt S0 - SiteC:Burnt S2.5 & 0.73 & 0.35 & 2.10 & 0.77 \\
\hline SiteD:Burnt S0 - SiteC:Unburnt S2.5 & 1.79 & 0.35 & 5.13 & $<0.05$ \\
\hline SiteD:Burnt S0 - SiteD:Burnt S2.5 & 0.27 & 0.35 & 0.77 & 1.00 \\
\hline SiteD:Burnt S0 - SiteD:Unburnt S2.5 & 0.68 & 0.35 & 1.95 & 0.85 \\
\hline SiteD:Unburnt S0 - SiteA:Burnt S2.5 & 1.60 & 0.35 & 4.58 & $<0.05$ \\
\hline SiteD:Unburnt S0 - SiteA:Unburnt S2.5 & 1.15 & 0.35 & 3.31 & 0.08 \\
\hline SiteD:Unburnt S0 - SiteB:Burnt S2.5 & 0.32 & 0.35 & 0.92 & 1.00 \\
\hline SiteD:Unburnt S0 - SiteB:Unburnt S2.5 & 0.70 & 0.35 & 2.02 & 0.81 \\
\hline SiteD:Unburnt S0 - SiteC:Burnt S2.5 & 0.56 & 0.35 & 1.61 & 0.97 \\
\hline SiteD:Unburnt S0 - SiteC:Unburnt S2.5 & 1.62 & 0.35 & 4.64 & $<0.05$ \\
\hline SiteD:Unburnt S0 - SiteD:Burnt S2.5 & 0.10 & 0.35 & 0.28 & 1.00 \\
\hline SiteD:Unburnt S0 - SiteD:Unburnt S2.5 & 0.51 & 0.35 & 1.46 & 0.99 \\
\hline SiteA:Burnt S2.5 - SiteA:Unburnt S2.5 & -0.44 & 0.35 & -1.27 & 1.00 \\
\hline SiteA:Burnt S2.5 - SiteB:Burnt S2.5 & -1.27 & 0.35 & -3.66 & $<0.05$ \\
\hline SiteA:Burnt S2.5 - SiteB:Unburnt S2.5 & -0.89 & 0.35 & -2.56 & 0.43 \\
\hline SiteA:Burnt S2.5 - SiteC:Burnt S2.5 & -1.04 & 0.35 & -2.97 & 0.19 \\
\hline SiteA:Burnt S2.5 - SiteC:Unburnt S2.5 & 0.02 & 0.35 & 0.06 & 1.00 \\
\hline
\end{tabular}




\begin{tabular}{|c|c|c|c|c|}
\hline SiteA:Burnt S2.5 - SiteD:Burnt S2.5 & -1.50 & 0.35 & -4.30 & $<0.05$ \\
\hline SiteA:Burnt S2.5 - SiteD:Unburnt S2.5 & -1.09 & 0.35 & -3.12 & 0.13 \\
\hline SiteA:Unburnt S2.5 - SiteB:Burnt S2.5 & -0.83 & 0.35 & -2.39 & 0.56 \\
\hline SiteA:Unburnt S2.5 - SiteB:Unburnt S2.5 & -0.45 & 0.35 & -1.29 & 1.00 \\
\hline SiteA:Unburnt S2.5 - SiteC:Burnt S2.5 & -0.59 & 0.35 & -1.70 & 0.94 \\
\hline SiteA:Unburnt S2.5 - SiteC:Unburnt S2.5 & 0.46 & 0.35 & 1.33 & 0.99 \\
\hline SiteA:Unburnt S2.5 - SiteD:Burnt S2.5 & -1.06 & 0.35 & -3.03 & 0.17 \\
\hline SiteA:Unburnt S2.5 - SiteD:Unburnt S2.5 & -0.64 & 0.35 & -1.85 & 0.89 \\
\hline SiteB:Burnt S2.5 - SiteB:Unburnt S2.5 & 0.38 & 0.35 & 1.09 & 1.00 \\
\hline SiteB:Burnt S2.5 - SiteC:Burnt S2.5 & 0.24 & 0.35 & 0.68 & 1.00 \\
\hline SiteB:Burnt S2.5 - SiteC:Unburnt S2.5 & 1.30 & 0.35 & 3.72 & $<0.05$ \\
\hline SiteB:Burnt S2.5 - SiteD:Burnt S2.5 & -0.22 & 0.35 & -0.65 & 1.00 \\
\hline SiteB:Burnt S2.5 - SiteD:Unburnt S2.5 & 0.19 & 0.35 & 0.54 & 1.00 \\
\hline SiteB:Unburnt S2.5 - SiteC:Burnt S2.5 & -0.14 & 0.35 & -0.41 & 1.00 \\
\hline SiteB:Unburnt S2.5 - SiteC:Unburnt S2.5 & 0.92 & 0.35 & 2.63 & 0.39 \\
\hline SiteB:Unburnt S2.5 - SiteD:Burnt S2.5 & -0.61 & 0.35 & -1.74 & 0.93 \\
\hline SiteB:Unburnt S2.5 - SiteD:Unburnt S2.5 & -0.19 & 0.35 & -0.56 & 1.00 \\
\hline SiteC:Burnt S2.5 - SiteC:Unburnt S2.5 & 1.06 & 0.35 & 3.04 & 0.16 \\
\hline SiteC:Burnt S2.5 - SiteD:Burnt S2.5 & -0.46 & 0.35 & -1.33 & 0.99 \\
\hline SiteC:Burnt S2.5 - SiteD:Unburnt S2.5 & -0.05 & 0.35 & -0.15 & 1.00 \\
\hline SiteC:Unburnt S2.5 - SiteD:Burnt S2.5 & -1.52 & 0.35 & -4.37 & $<0.05$ \\
\hline SiteC:Unburnt S2.5 - SiteD:Unburnt S2.5 & -1.11 & 0.35 & -3.18 & 0.11 \\
\hline SiteD:Burnt S2.5 - SiteD:Unburnt S2.5 & 0.41 & 0.35 & 1.18 & 1.00 \\
\hline
\end{tabular}


Supplementary Table 4.5: Details of the nested linear model of $\mathrm{pH}$ as a function of site:status and depth (see subsection 4.2.8. for full analytical details). Adjusted $\mathrm{R}^{2}$ was 0.66 and p-value of $<0.05$ on 15 degrees of freedom. The notation * indicates significant $\mathrm{p}$-value interaction at the 95\% confidence level. The notation S2.5 represents the $2.5-5 \mathrm{~cm}$ soil depth layer.

\begin{tabular}{l|cccc}
\hline & Estimate & Std. Error & t-value & p-value \\
\hline (Intercept) & 0.16 & 0.17 & 0.94 & 0.35 \\
Depth [S2.5] & 0.10 & 0.24 & 0.40 & 0.69 \\
SiteA:Burnt & 1.40 & 0.24 & 5.76 & $<0.05^{*}$ \\
SiteA:Unburnt & -1.29 & 0.24 & -5.30 & $<0.05^{*}$ \\
SiteB:Burnt & -0.33 & 0.24 & -1.34 & 0.18 \\
SiteB:Unburnt & -1.27 & 0.24 & -5.22 & $<0.05^{*}$ \\
SiteC:Burnt & 0.47 & 0.24 & 1.92 & 0.06 \\
SiteC:Unburnt & 0.67 & 0.24 & 2.77 & $<0.05^{*}$ \\
SiteD:Burnt & 0.08 & 0.24 & 0.34 & 0.73 \\
SiteD:Unburnt & $\mathrm{NA}$ & $\mathrm{NA}$ & $\mathrm{NA}$ & $\mathrm{NA}$ \\
SiteA:Burnt: S2.5 & -1.77 & 0.34 & -5.17 & $<0.05^{*}$ \\
SiteA:Unburnt: S2.5 & -0.16 & 0.34 & -0.46 & 0.64 \\
SiteB:Burnt: S2.5 & -0.13 & 0.34 & -0.37 & 0.71 \\
SiteB:Unburnt: S2.5 & -0.21 & 0.34 & -0.60 & 0.55 \\
SiteC:Burnt: S2.5 & -0.26 & 0.34 & -0.77 & 0.44 \\
SiteC:Unburnt: S2.5 & -0.05 & 0.34 & -0.15 & 0.88 \\
SiteD:Burnt: S2.5 & -0.50 & 0.34 & -1.45 & 0.15 \\
SiteD:Unburnt: S2.5 & $\mathrm{NA}$ & $\mathrm{NA}$ & $\mathrm{NA}$ & $\mathrm{NA}$ \\
\hline & & & & \\
\hline
\end{tabular}


Supplementary Table 4.6: Details of the post-hoc pairwise ("emmeans") analysis of the linear model output to assess differences in sampling area soil $\mathrm{pH}$. P-value adjustment using the studentised range statistic, Tukey's 'Honest Significant Difference' method used here for comparing a family of 16 estimates with 176 degrees of freedom. The notation S0 represents the $0-2.5 \mathrm{~cm}$ soil depth layer. $\mathrm{S} 2.5$ represents the $2.5-5 \mathrm{~cm}$ soil depth layer.

\begin{tabular}{|c|c|c|c|c|}
\hline & Estimate & SE & t-ratio & p-value \\
\hline SiteA:Burnt S0 - SiteA:Unburnt S0 & 2.69 & 0.24 & 11.06 & $<0.05$ \\
\hline SiteA:Burnt S0 - SiteB:Burnt S0 & 1.73 & 0.24 & 7.10 & $<0.05$ \\
\hline SiteA:Burnt S0 - SiteB:Unburnt S0 & 2.67 & 0.24 & 10.98 & $<0.05$ \\
\hline SiteA:Burnt S0 - SiteC:Burnt S0 & 0.93 & 0.24 & 3.85 & $<0.05$ \\
\hline SiteA:Burnt S0 - SiteC:Unburnt S0 & 0.73 & 0.24 & 2.99 & 0.18 \\
\hline SiteA:Burnt S0 - SiteD:Burnt S0 & 1.32 & 0.24 & 5.42 & $<0.05$ \\
\hline SiteA:Burnt S0 - SiteD:Unburnt S0 & 1.40 & 0.24 & 5.76 & $<0.05$ \\
\hline SiteA:Burnt S0 - SiteA:Burnt S2.5 & 1.68 & 0.24 & 6.91 & $<0.05$ \\
\hline SiteA:Burnt S0 - SiteA:Unburnt S2.5 & 2.75 & 0.24 & 11.32 & $<0.05$ \\
\hline SiteA:Burnt S0 - SiteB:Burnt S2.5 & 1.76 & 0.24 & 7.24 & $<0.05$ \\
\hline SiteA:Burnt S0 - SiteB:Unburnt S2.5 & 2.78 & 0.24 & 11.44 & $<0.05$ \\
\hline SiteA:Burnt S0 - SiteC:Burnt S2.5 & 1.10 & 0.24 & 4.54 & $<0.05$ \\
\hline SiteA:Burnt S0 - SiteC:Unburnt S2.5 & 0.68 & 0.24 & 2.80 & 0.28 \\
\hline SiteA:Burnt S0 - SiteD:Burnt S2.5 & 1.72 & 0.24 & 7.08 & $<0.05$ \\
\hline SiteA:Burnt S0 - SiteD:Unburnt S2.5 & 1.30 & 0.24 & 5.37 & $<0.05$ \\
\hline SiteA:Unburnt S0 - SiteB:Burnt S0 & -0.96 & 0.24 & -3.95 & $<0.05$ \\
\hline SiteA:Unburnt S0 - SiteB:Unburnt S0 & -0.02 & 0.24 & -0.08 & 1.00 \\
\hline SiteA:Unburnt S0 - SiteC:Burnt S0 & -1.75 & 0.24 & -7.21 & $<0.05$ \\
\hline SiteA:Unburnt S0 - SiteC:Unburnt S0 & -1.96 & 0.24 & -8.07 & $<0.05$ \\
\hline SiteA:Unburnt S0 - SiteD:Burnt S0 & -1.37 & 0.24 & -5.64 & $<0.05$ \\
\hline SiteA:Unburnt S0 - SiteD:Unburnt S0 & -1.29 & 0.24 & -5.30 & $<0.05$ \\
\hline SiteA:Unburnt S0 - SiteA:Burnt S2.5 & -1.01 & 0.24 & -4.15 & $<0.05$ \\
\hline SiteA:Unburnt S0 - SiteA:Unburnt S2.5 & 0.06 & 0.24 & 0.26 & 1.00 \\
\hline SiteA:Unburnt S0 - SiteB:Burnt S2.5 & -0.93 & 0.24 & -3.82 & $<0.05$ \\
\hline SiteA:Unburnt S0 - SiteB:Unburnt S2.5 & 0.09 & 0.24 & 0.38 & 1.00 \\
\hline SiteA:Unburnt S0 - SiteC:Burnt S2.5 & -1.58 & 0.24 & -6.52 & $<0.05$ \\
\hline SiteA:Unburnt S0 - SiteC:Unburnt S2.5 & -2.01 & 0.24 & -8.26 & $<0.05$ \\
\hline SiteA:Unburnt S0 - SiteD:Burnt S2.5 & -0.97 & 0.24 & -3.98 & $<0.05$ \\
\hline
\end{tabular}




\begin{tabular}{|c|c|c|c|c|}
\hline SiteA:Unburnt S0 - SiteD:Unburnt S2.5 & -1.38 & 0.24 & -5.69 & $<0.05$ \\
\hline SiteB:Burnt S0 - SiteB:Unburnt S0 & 0.94 & 0.24 & 3.88 & $<0.05$ \\
\hline SiteB:Burnt S0 - SiteC:Burnt S0 & -0.79 & 0.24 & -3.26 & 0.09 \\
\hline SiteB:Burnt S0 - SiteC:Unburnt S0 & -1.00 & 0.24 & -4.12 & $<0.05$ \\
\hline SiteB:Burnt S0 - SiteD:Burnt S0 & -0.41 & 0.24 & -1.68 & 0.95 \\
\hline SiteB:Burnt S0 - SiteD:Unburnt S0 & -0.33 & 0.24 & -1.34 & 0.99 \\
\hline SiteB:Burnt S0 - SiteA:Burnt S2.5 & -0.05 & 0.24 & -0.19 & 1.00 \\
\hline SiteB:Burnt S0 - SiteA:Unburnt S2.5 & 1.02 & 0.24 & 4.22 & $<0.05$ \\
\hline SiteB:Burnt S0 - SiteB:Burnt S2.5 & 0.03 & 0.24 & 0.13 & 1.00 \\
\hline SiteB:Burnt S0 - SiteB:Unburnt S2.5 & 1.05 & 0.24 & 4.33 & $<0.05$ \\
\hline SiteB:Burnt S0 - SiteC:Burnt S2.5 & -0.62 & 0.24 & -2.57 & 0.43 \\
\hline SiteB:Burnt S0 - SiteC:Unburnt S2.5 & -1.05 & 0.24 & -4.30 & $<0.05$ \\
\hline SiteB:Burnt S0 - SiteD:Burnt S2.5 & -0.01 & 0.24 & -0.03 & 1.00 \\
\hline SiteB:Burnt S0 - SiteD:Unburnt S2.5 & -0.42 & 0.24 & -1.74 & 0.93 \\
\hline SiteB:Unburnt S0 - SiteC:Burnt S0 & -1.73 & 0.24 & -7.14 & $<0.05$ \\
\hline SiteB:Unburnt S0 - SiteC:Unburnt S0 & -1.94 & 0.24 & -7.99 & $<0.05$ \\
\hline SiteB:Unburnt S0 - SiteD:Burnt S0 & -1.35 & 0.24 & -5.56 & $<0.05$ \\
\hline SiteB:Unburnt S0 - SiteD:Unburnt S0 & -1.27 & 0.24 & -5.22 & $<0.05$ \\
\hline SiteB:Unburnt S0 - SiteA:Burnt S2.5 & -0.99 & 0.24 & -4.07 & $<0.05$ \\
\hline SiteB:Unburnt S0 - SiteA:Unburnt S2.5 & 0.08 & 0.24 & 0.34 & 1.00 \\
\hline SiteB:Unburnt S0 - SiteB:Burnt S2.5 & -0.91 & 0.24 & -3.75 & $<0.05$ \\
\hline SiteB:Unburnt S0 - SiteB:Unburnt S2.5 & 0.11 & 0.24 & 0.45 & 1.00 \\
\hline SiteB:Unburnt S0 - SiteC:Burnt S2.5 & -1.57 & 0.24 & -6.44 & $<0.05$ \\
\hline SiteB:Unburnt S0 - SiteC:Unburnt S2.5 & -1.99 & 0.24 & -8.18 & $<0.05$ \\
\hline SiteB:Unburnt S0 - SiteD:Burnt S2.5 & -0.95 & 0.24 & -3.90 & $<0.05$ \\
\hline SiteB:Unburnt S0 - SiteD:Unburnt S2.5 & -1.36 & 0.24 & -5.61 & $<0.05$ \\
\hline SiteC:Burnt S0 - SiteC:Unburnt S0 & -0.21 & 0.24 & -0.86 & 1.00 \\
\hline SiteC:Burnt S0 - SiteD:Burnt S0 & 0.38 & 0.24 & 1.57 & 0.97 \\
\hline SiteC:Burnt S0 - Site D:Unburnt S0 & 0.47 & 0.24 & 1.92 & 0.87 \\
\hline SiteC:Burnt S0 - SiteA:Burnt S2.5 & 0.74 & 0.24 & 3.07 & 0.15 \\
\hline SiteC:Burnt S0 - SiteA:Unburnt S2.5 & 1.82 & 0.24 & 7.47 & $<0.05$ \\
\hline SiteC:Burnt S0 - SiteB:Burnt S2.5 & 0.82 & 0.24 & 3.39 & 0.06 \\
\hline SiteC:Burnt S0 - SiteB:Unburnt S2.5 & 1.84 & 0.24 & 7.59 & $<0.05$ \\
\hline SiteC:Burnt S0 - SiteC:Burnt S2.5 & 0.17 & 0.24 & 0.69 & 1.00 \\
\hline SiteC:Burnt S0 - SiteC:Unburnt S2.5 & -0.25 & 0.24 & -1.04 & 1.00 \\
\hline
\end{tabular}




\begin{tabular}{|c|c|c|c|c|}
\hline SiteC:Burnt S0 - SiteD:Burnt S2.5 & 0.79 & 0.24 & 3.23 & 0.10 \\
\hline SiteC:Burnt S0 - SiteD:Unburnt S2.5 & 0.37 & 0.24 & 1.52 & 0.98 \\
\hline SiteC:Unburnt S0 - SiteD:Burnt S0 & 0.59 & 0.24 & 2.43 & 0.53 \\
\hline SiteC:Unburnt S0 - Site D:Unburnt S0 & 0.67 & 0.24 & 2.77 & 0.29 \\
\hline SiteC:Unburnt S0 - SiteA:Burnt S2.5 & 0.95 & 0.24 & 3.92 & $<0.05$ \\
\hline SiteC:Unburnt S0 - SiteA:Unburnt S2.5 & 2.02 & 0.24 & 8.33 & $<0.05$ \\
\hline SiteC:Unburnt S0 - SiteB:Burnt S2.5 & 1.03 & 0.24 & 4.25 & $<0.05$ \\
\hline SiteC:Unburnt S0 - SiteB:Unburnt S2.5 & 2.05 & 0.24 & 8.45 & $<0.05$ \\
\hline SiteC:Unburnt S0 - SiteC:Burnt S2.5 & 0.38 & 0.24 & 1.55 & 0.98 \\
\hline SiteC:Unburnt S0 - SiteC:Unburnt S2.5 & -0.05 & 0.24 & -0.19 & 1.00 \\
\hline SiteC:Unburnt S0 - SiteD:Burnt S2.5 & 0.99 & 0.24 & 4.09 & $<0.05$ \\
\hline SiteC:Unburnt S0 - SiteD:Unburnt S2.5 & 0.58 & 0.24 & 2.38 & 0.57 \\
\hline SiteD:Burnt S0 - SiteD:Unburnt S0 & 0.08 & 0.24 & 0.34 & 1.00 \\
\hline SiteD:Burnt S0 - SiteA:Burnt S2.5 & 0.36 & 0.24 & 1.49 & 0.98 \\
\hline SiteD:Burnt S0 - SiteA:Unburnt S2.5 & 1.43 & 0.24 & 5.90 & $<0.05$ \\
\hline SiteD:Burnt S0 - SiteB:Burnt S2.5 & 0.44 & 0.24 & 1.82 & 0.91 \\
\hline SiteD:Burnt S0 - SiteB:Unburnt S2.5 & 1.46 & 0.24 & 6.02 & $<0.05$ \\
\hline SiteD:Burnt S0 - SiteC:Burnt S2.5 & -0.21 & 0.24 & -0.88 & 1.00 \\
\hline SiteD:Burnt S0 - SiteC:Unburnt S2.5 & -0.64 & 0.24 & -2.62 & 0.39 \\
\hline SiteD:Burnt S0 - SiteD:Burnt S2.5 & 0.40 & 0.24 & 1.66 & 0.95 \\
\hline SiteD:Burnt S0 - SiteD:Unburnt S2.5 & -0.01 & 0.24 & -0.05 & 1.00 \\
\hline SiteD:Unburnt S0 - SiteA:Burnt S2.5 & 0.28 & 0.24 & 1.15 & 1.00 \\
\hline SiteD:Unburnt S0 - SiteA:Unburnt S2.5 & 1.35 & 0.24 & 5.56 & $<0.05$ \\
\hline SiteD:Unburnt S0 - SiteB:Burnt S2.5 & 0.36 & 0.24 & 1.47 & 0.98 \\
\hline SiteD:Unburnt S0 - SiteB:Unburnt S2.5 & 1.38 & 0.24 & 5.67 & $<0.05$ \\
\hline SiteD:Unburnt S0 - SiteC:Burnt S2.5 & -0.30 & 0.24 & -1.23 & 1.00 \\
\hline SiteD:Unburnt S0 - SiteC:Unburnt S2.5 & -0.72 & 0.24 & -2.96 & 0.20 \\
\hline SiteD:Unburnt S0 - SiteD:Burnt S2.5 & 0.32 & 0.24 & 1.32 & 0.99 \\
\hline SiteD:Unburnt S0 - SiteD:Unburnt S2.5 & -0.10 & 0.24 & -0.40 & 1.00 \\
\hline SiteA:Burnt S2.5 - SiteA:Unburnt S2.5 & 1.07 & 0.24 & 4.41 & $<0.05$ \\
\hline SiteA:Burnt S2.5 - SiteB:Burnt S2.5 & 0.08 & 0.24 & 0.32 & 1.00 \\
\hline SiteA:Burnt S2.5 - SiteB:Unburnt S2.5 & 1.10 & 0.24 & 4.52 & $<0.05$ \\
\hline SiteA:Burnt S2.5 - SiteC:Burnt S2.5 & -0.58 & 0.24 & -2.38 & 0.57 \\
\hline SiteA:Burnt S2.5 - SiteC:Unburnt S2.5 & -1.00 & 0.24 & -4.11 & $<0.05$ \\
\hline SiteA:Burnt S2.5 - SiteD:Burnt S2.5 & 0.04 & 0.24 & 0.17 & 1.00 \\
\hline
\end{tabular}




\begin{tabular}{|c|c|c|c|c|}
\hline SiteA:Burnt S2.5 - SiteD:Unburnt S2.5 & -0.38 & 0.24 & -1.54 & 0.98 \\
\hline SiteA:Unburnt S2.5 - SiteB:Burnt S2.5 & -0.99 & 0.24 & -4.08 & $<0.05$ \\
\hline SiteA:Unburnt S2.5 - SiteB:Unburnt S2.5 & 0.03 & 0.24 & 0.12 & 1.00 \\
\hline SiteA:Unburnt S2.5 - SiteC:Burnt S2.5 & -1.65 & 0.24 & -6.78 & $<0.05$ \\
\hline SiteA:Unburnt S2.5 - SiteC:Unburnt S2.5 & -2.07 & 0.24 & -8.52 & $<0.05$ \\
\hline SiteA:Unburnt S2.5 - SiteD:Burnt S2.5 & -1.03 & 0.24 & -4.24 & 0.00 \\
\hline SiteA:Unburnt S2.5 - SiteD:Unburnt S2.5 & -1.45 & 0.24 & -5.95 & $<0.05$ \\
\hline SiteB:Burnt S2.5 - SiteB:Unburnt S2.5 & 1.02 & 0.24 & 4.20 & $<0.05$ \\
\hline SiteB:Burnt S2.5 - SiteC:Burnt S2.5 & -0.66 & 0.24 & -2.70 & 0.34 \\
\hline SiteB:Burnt S2.5 - SiteC:Unburnt S2.5 & -1.08 & 0.24 & -4.43 & $<0.05$ \\
\hline SiteB:Burnt S2.5 - SiteD:Burnt S2.5 & -0.04 & 0.24 & -0.16 & 1.00 \\
\hline SiteB:Burnt S2.5 - SiteD:Unburnt S2.5 & -0.45 & 0.24 & -1.87 & 0.89 \\
\hline SiteB:Unburnt S2.5 - SiteC:Burnt S2.5 & -1.68 & 0.24 & -6.90 & $<0.05$ \\
\hline SiteB:Unburnt S2.5 - SiteC:Unburnt S2.5 & -2.10 & 0.24 & -8.63 & $<0.05$ \\
\hline SiteB:Unburnt S2.5 - SiteD:Burnt S2.5 & -1.06 & 0.24 & -4.36 & $<0.05$ \\
\hline SiteB:Unburnt S2.5 - SiteD:Unburnt S2.5 & -1.47 & 0.24 & -6.07 & $<0.05$ \\
\hline SiteC:Burnt S2.5 - SiteC:Unburnt S2.5 & -0.42 & 0.24 & -1.74 & 0.93 \\
\hline SiteC:Burnt S2.5 - SiteD:Burnt S2.5 & 0.62 & 0.24 & 2.54 & 0.45 \\
\hline SiteC:Burnt S2.5 - SiteD:Unburnt S2.5 & 0.20 & 0.24 & 0.83 & 1.00 \\
\hline SiteC:Unburnt S2.5 - SiteD:Burnt S2.5 & 1.04 & 0.24 & 4.28 & $<0.05$ \\
\hline SiteC:Unburnt S2.5 - SiteD:Unburnt S2.5 & 0.62 & 0.24 & 2.57 & 0.43 \\
\hline SiteD:Burnt S2.5 - SiteD:Unburnt S2.5 & -0.42 & 0.24 & -1.71 & 0.94 \\
\hline
\end{tabular}


Supplementary Table 4.7: Details of the nested linear model of water drop penetration (WDPT) as a function of site:status and depth $(0,2.5 \mathrm{~cm}$ and $5 \mathrm{~cm}$ depths) (see subsection 4.2.8. for full analytical details). Adjusted $\mathrm{R}^{2}$ was 0.33 and $\mathrm{p}$-value of $<0.05$ on 23 degrees of freedom. The notation * indicates significant p-value interaction at the $95 \%$ confidence level. The notation S2.5 represents the $2.5 \mathrm{~cm}$ soil depth. S5 represents the $5 \mathrm{~cm}$ soil depth.

\begin{tabular}{|c|c|c|c|c|}
\hline & Estimate & Std. Error & t-value & p-value \\
\hline (Intercept) & -0.24 & 0.24 & -1.00 & 0.32 \\
\hline Depth [S2.5] & -0.39 & 0.34 & -1.15 & 0.25 \\
\hline Depth [S5] & 0.55 & 0.34 & 1.64 & 0.10 \\
\hline SiteA:Burnt & -0.91 & 0.34 & -2.68 & $<0.05^{*}$ \\
\hline SiteA:Unburnt & -0.27 & 0.34 & -0.80 & 0.42 \\
\hline SiteB:Burnt & -0.34 & 0.34 & -1.02 & 0.31 \\
\hline SiteB:Unburnt & -0.30 & 0.34 & -0.88 & 0.38 \\
\hline SiteC:Burnt & 0.24 & 0.34 & 0.72 & 0.47 \\
\hline SiteC:Unburnt & 1.07 & 0.34 & 3.17 & $<0.05 *$ \\
\hline SiteD:Burnt & 0.25 & 0.34 & 0.74 & 0.46 \\
\hline SiteD:Unburnt & NA & NA & NA & NA \\
\hline SiteA:Burnt: S2.5 & 0.87 & 0.48 & 1.82 & $<0.05^{*}$ \\
\hline SiteA:Unburnt: S2.5 & 0.62 & 0.48 & 1.31 & 0.19 \\
\hline SiteB:Burnt: S2.5 & 0.46 & 0.48 & 0.96 & 0.34 \\
\hline SiteB:Unburnt: S2.5 & 0.67 & 0.48 & 1.40 & 0.16 \\
\hline SiteC:Burnt: S2.5 & 0.45 & 0.48 & 0.95 & 0.34 \\
\hline SiteC:Unburnt: S2.5 & 0.37 & 0.48 & 0.78 & 0.44 \\
\hline SiteD:Burnt: S2.5 & 0.48 & 0.48 & 1.01 & 0.31 \\
\hline SiteD:Unburnt: S2.5 & NA & NA & NA & NA \\
\hline SiteA:Burnt: S5 & 0.66 & 0.48 & 1.39 & 0.17 \\
\hline SiteA:Unburnt: S5 & 0.42 & 0.48 & 0.88 & 0.38 \\
\hline SiteB:Burnt: S5 & 0.05 & 0.48 & 0.11 & 0.92 \\
\hline SiteB:Unburnt: S5 & 0.17 & 0.48 & 0.36 & 0.72 \\
\hline SiteC:Burnt: S5 & 0.42 & 0.48 & 0.89 & 0.37 \\
\hline
\end{tabular}




\begin{tabular}{l|cccc} 
SiteC:Unburnt: S5 & -0.43 & 0.48 & -0.91 & 0.37 \\
SiteD:Burnt: S5 & -0.12 & 0.48 & -0.25 & 0.80 \\
SiteD:Unburnt: S5 & NA & NA & NA & NA \\
\hline
\end{tabular}

Supp. Table 4.7: (continued) 
Supplementary Table 4.8: Details of the post-hoc pairwise ("emmeans") analysis of the linear model output to assess differences in sampling area soil water drop penetration (WDPT). P-value adjustment using the studentised range statistic, Tukey's 'Honest Significant Difference' method used here for comparing a family of 24 estimates with 264 degrees of freedom. The notation S0 represents the soil surface layer $(0 \mathrm{~cm}$ soil depth). S2.5 represents the $2.5 \mathrm{~cm}$ soil depth. $\mathrm{S} 5$ represents the $5 \mathrm{~cm}$ soil depth.

\begin{tabular}{|c|c|c|c|c|}
\hline & Estimate & $\mathbf{S E}$ & t-ratio & p-value \\
\hline SiteA:Burnt S0 - SiteA:Unburnt S0 & -2.53 & 1.61 & -1.57 & 1.00 \\
\hline SiteA:Burnt S0 - SiteB:Burnt S0 & -2.42 & 1.61 & -1.50 & 1.00 \\
\hline SiteA:Burnt S0 - SiteB:Unburnt S0 & -2.50 & 1.61 & -1.55 & 1.00 \\
\hline SiteA:Burnt S0 - SiteC:Burnt S0 & -4.94 & 1.61 & -3.07 & 0.26 \\
\hline SiteA:Burnt S0 - SiteC:Unburnt S0 & -10.28 & 1.61 & -6.38 & $<0.05$ \\
\hline SiteA:Burnt S0 - SiteD:Burnt S0 & -6.04 & 1.61 & -3.75 & $<0.05$ \\
\hline SiteA:Burnt S0 - SiteD:Unburnt S0 & -4.92 & 1.61 & -3.05 & 0.27 \\
\hline SiteA:Burnt S0 - SiteA:Burnt S2.5 & -2.46 & 1.61 & -1.53 & 1.00 \\
\hline SiteA:Burnt S0 - SiteA:Unburnt S2.5 & -3.87 & 1.61 & -2.40 & 0.75 \\
\hline SiteA:Burnt S0 - SiteB:Burnt S2.5 & -2.57 & 1.61 & -1.59 & 1.00 \\
\hline SiteA:Burnt S0 - SiteB:Unburnt S2.5 & -4.62 & 1.61 & -2.87 & 0.39 \\
\hline SiteA:Burnt S0 - SiteC:Burnt S2.5 & -5.44 & 1.61 & -3.38 & 0.12 \\
\hline SiteA:Burnt S0 - SiteC:Unburnt S2.5 & -10.43 & 1.61 & -6.47 & $<0.05$ \\
\hline SiteA:Burnt S0 - SiteD:Burnt S2.5 & -5.64 & 1.61 & -3.50 & 0.09 \\
\hline SiteA:Burnt S0 - SiteD:Unburnt S2.5 & -3.23 & 1.61 & -2.01 & 0.94 \\
\hline SiteA:Burnt S0 - SiteA:Burnt S5 & -6.20 & 1.61 & -3.84 & $<0.05$ \\
\hline SiteA:Burnt S0 - SiteA:Unburnt S5 & -8.10 & 1.61 & -5.03 & $<0.05$ \\
\hline SiteA:Burnt S0 - SiteB:Burnt S5 & -5.55 & 1.61 & -3.44 & 0.10 \\
\hline SiteA:Burnt S0 - SiteB:Unburnt S5 & -6.67 & 1.61 & -4.14 & $<0.05$ \\
\hline SiteA:Burnt S0 - SiteC:Burnt S5 & -9.21 & 1.61 & -5.71 & $<0.05$ \\
\hline SiteA:Burnt S0 - SiteC:Unburnt S5 & -10.29 & 1.61 & -6.38 & $<0.05$ \\
\hline SiteA:Burnt S0 - SiteD:Burnt S5 & -7.09 & 1.61 & -4.40 & $<0.05$ \\
\hline SiteA:Burnt S0 - SiteD:Unburnt S5 & -6.62 & 1.61 & -4.11 & $<0.05$ \\
\hline SiteA:Unburnt S0 - SiteB:Burnt S0 & 0.11 & 1.61 & 0.07 & 1.00 \\
\hline SiteA:Unburnt S0 - SiteB:Unburnt S0 & 0.03 & 1.61 & 0.02 & 1.00 \\
\hline SiteA:Unburnt S0 - SiteC:Burnt S0 & -2.41 & 1.61 & -1.50 & 1.00 \\
\hline SiteA:Unburnt S0 - SiteC:Unburnt S0 & -7.75 & 1.61 & -4.81 & $<0.05$ \\
\hline
\end{tabular}




\begin{tabular}{|c|c|c|c|c|}
\hline SiteA:Unburnt S0 - SiteD:Burnt S0 & -3.51 & 1.61 & -2.18 & 0.88 \\
\hline SiteA:Unburnt S0 - SiteD:Unburnt S0 & -2.39 & 1.61 & -1.48 & 1.00 \\
\hline SiteA:Unburnt S0 - SiteA:Burnt S2.5 & 0.07 & 1.61 & 0.05 & 1.00 \\
\hline SiteA:Unburnt S0 - SiteA:Unburnt S2.5 & -1.33 & 1.61 & -0.83 & 1.00 \\
\hline SiteA:Unburnt S0 - SiteB:Burnt S2.5 & -0.04 & 1.61 & -0.02 & 1.00 \\
\hline SiteA:Unburnt S0 - SiteB:Unburnt S2.5 & -2.09 & 1.61 & -1.30 & 1.00 \\
\hline SiteA:Unburnt S0 - SiteC:Burnt S2.5 & -2.91 & 1.61 & -1.81 & 0.98 \\
\hline SiteA:Unburnt S0 - SiteC:Unburnt S2.5 & -7.90 & 1.61 & -4.90 & $<0.05$ \\
\hline SiteA:Unburnt S0 - SiteD:Burnt S2.5 & -3.11 & 1.61 & -1.93 & 0.96 \\
\hline SiteA:Unburnt S0 - SiteD:Unburnt S2.5 & -0.70 & 1.61 & -0.44 & 1.00 \\
\hline SiteA:Unburnt S0 - SiteA:Burnt S5 & -3.66 & 1.61 & -2.27 & 0.83 \\
\hline SiteA:Unburnt S0 - SiteA:Unburnt S5 & -5.57 & 1.61 & -3.46 & 0.10 \\
\hline SiteA:Unburnt S0 - SiteB:Burnt S5 & -3.02 & 1.61 & -1.87 & 0.97 \\
\hline SiteA:Unburnt S0 - SiteB:Unburnt S5 & -4.14 & 1.61 & -2.57 & 0.62 \\
\hline SiteA:Unburnt S0 - SiteC:Burnt S5 & -6.68 & 1.61 & -4.14 & $<0.05$ \\
\hline SiteA:Unburnt S0 - SiteC:Unburnt S5 & -7.76 & 1.61 & -4.81 & $<0.05$ \\
\hline SiteA:Unburnt S0 - SiteD:Burnt S5 & -4.55 & 1.61 & -2.83 & 0.42 \\
\hline SiteA:Unburnt S0 - SiteD:Unburnt S5 & -4.09 & 1.61 & -2.54 & 0.65 \\
\hline SiteB:Burnt S0 - SiteB:Unburnt S0 & -0.08 & 1.61 & -0.05 & 1.00 \\
\hline SiteB:Burnt S0 - SiteC:Burnt S0 & -2.53 & 1.61 & -1.57 & 1.00 \\
\hline SiteB:Burnt S0 - SiteC:Unburnt S0 & -7.86 & 1.61 & -4.88 & $<0.05$ \\
\hline SiteB:Burnt S0 - SiteD:Burnt S0 & -3.62 & 1.61 & -2.25 & 0.84 \\
\hline SiteB:Burnt S0 - SiteD:Unburnt S0 & -2.50 & 1.61 & -1.55 & 1.00 \\
\hline SiteB:Burnt S0 - SiteA:Burnt S2.5 & -0.04 & 1.61 & -0.02 & 1.00 \\
\hline SiteB:Burnt S0 - SiteA:Unburnt S2.5 & -1.45 & 1.61 & -0.90 & 1.00 \\
\hline SiteB:Burnt S0 - SiteB:Burnt S2.5 & -0.15 & 1.61 & -0.09 & 1.00 \\
\hline SiteB:Burnt S0 - SiteB:Unburnt S2.5 & -2.20 & 1.61 & -1.37 & 1.00 \\
\hline SiteB:Burnt S0 - SiteC:Burnt S2.5 & -3.03 & 1.61 & -1.88 & 0.97 \\
\hline SiteB:Burnt S0 - SiteC:Unburnt S2.5 & -8.01 & 1.61 & -4.97 & $<0.05$ \\
\hline SiteB:Burnt S0 - SiteD:Burnt S2.5 & -3.23 & 1.61 & -2.00 & 0.94 \\
\hline SiteB:Burnt S0 - SiteD:Unburnt S2.5 & -0.81 & 1.61 & -0.51 & 1.00 \\
\hline SiteB:Burnt S0 - SiteA:Burnt S5 & -3.78 & 1.61 & -2.34 & 0.78 \\
\hline SiteB:Burnt S0 - SiteA:Unburnt S5 & -5.69 & 1.61 & -3.53 & 0.08 \\
\hline SiteB:Burnt S0 - SiteB:Burnt S5 & -3.13 & 1.61 & -1.94 & 0.96 \\
\hline SiteB:Burnt S0 - SiteB:Unburnt S5 & -4.25 & 1.61 & -2.64 & 0.57 \\
\hline
\end{tabular}




\begin{tabular}{|c|c|c|c|c|}
\hline SiteB:Burnt S0 - SiteC:Burnt S5 & -6.79 & 1.61 & -4.21 & $<0.05$ \\
\hline SiteB:Burnt S0 - SiteC:Unburnt S5 & -7.87 & 1.61 & -4.88 & $<0.05$ \\
\hline SiteB:Burnt S0 - SiteD:Burnt S5 & -4.67 & 1.61 & -2.90 & 0.37 \\
\hline SiteB:Burnt S0 - SiteD:Unburnt S5 & -4.20 & 1.61 & -2.61 & 0.59 \\
\hline SiteB:Unburnt S0 - SiteC:Burnt S0 & -2.45 & 1.61 & -1.52 & 1.00 \\
\hline SiteB:Unburnt S0 - SiteC:Unburnt S0 & -7.78 & 1.61 & -4.83 & $<0.05$ \\
\hline SiteB:Unburnt S0 - SiteD:Burnt S0 & -3.54 & 1.61 & -2.20 & 0.87 \\
\hline SiteB:Unburnt S0 - SiteD:Unburnt S0 & -2.42 & 1.61 & -1.50 & 1.00 \\
\hline SiteB:Unburnt S0 - SiteA:Burnt S2.5 & 0.04 & 1.61 & 0.03 & 1.00 \\
\hline SiteB:Unburnt S0 - SiteA:Unburnt S2.5 & -1.37 & 1.61 & -0.85 & 1.00 \\
\hline SiteB:Unburnt S0 - SiteB:Burnt S2.5 & -0.07 & 1.61 & -0.04 & 1.00 \\
\hline SiteB:Unburnt S0 - SiteB:Unburnt S2.5 & -2.12 & 1.61 & -1.32 & 1.00 \\
\hline SiteB:Unburnt S0 - SiteC:Burnt S2.5 & -2.95 & 1.61 & -1.83 & 0.98 \\
\hline SiteB:Unburnt S0 - SiteC:Unburnt S2.5 & -7.93 & 1.61 & -4.92 & $<0.05$ \\
\hline SiteB:Unburnt S0 - SiteD:Burnt S2.5 & -3.15 & 1.61 & -1.95 & 0.96 \\
\hline SiteB:Unburnt S0 - SiteD:Unburnt S2.5 & -0.73 & 1.61 & -0.46 & 1.00 \\
\hline SiteB:Unburnt S0 - SiteA:Burnt S5 & -3.70 & 1.61 & -2.29 & 0.82 \\
\hline SiteB:Unburnt S0 - SiteA:Unburnt S5 & -5.61 & 1.61 & -3.48 & 0.09 \\
\hline SiteB:Unburnt S0 - SiteB:Burnt S5 & -3.05 & 1.61 & -1.89 & 0.97 \\
\hline SiteB:Unburnt S0 - SiteB:Unburnt S5 & -4.17 & 1.61 & -2.59 & 0.61 \\
\hline SiteB:Unburnt S0 - SiteC:Burnt S5 & -6.71 & 1.61 & -4.16 & $<0.05$ \\
\hline SiteB:Unburnt S0 - SiteC:Unburnt S5 & -7.79 & 1.61 & -4.83 & $<0.05$ \\
\hline SiteB:Unburnt S0 - SiteD:Burnt S5 & -4.59 & 1.61 & -2.85 & 0.41 \\
\hline SiteB:Unburnt S0 - SiteD:Unburnt S5 & -4.12 & 1.61 & -2.56 & 0.63 \\
\hline SiteC:Burnt S0 - SiteC:Unburnt S0 & -5.34 & 1.61 & -3.31 & 0.14 \\
\hline SiteC:Burnt S0 - SiteD:Burnt S0 & -1.09 & 1.61 & -0.68 & 1.00 \\
\hline SiteC:Burnt S0 - SiteD:Unburnt S0 & 0.03 & 1.61 & 0.02 & 1.00 \\
\hline SiteC:Burnt S0 - SiteA:Burnt S2.5 & 2.49 & 1.61 & 1.54 & 1.00 \\
\hline SiteC:Burnt S0 - SiteA:Unburnt S2.5 & 1.08 & 1.61 & 0.67 & 1.00 \\
\hline SiteC:Burnt S0 - SiteB:Burnt S2.5 & 2.38 & 1.61 & 1.48 & 1.00 \\
\hline SiteC:Burnt S0 - SiteB:Unburnt S2.5 & 0.32 & 1.61 & 0.20 & 1.00 \\
\hline SiteC:Burnt S0 - SiteC:Burnt S2.5 & -0.50 & 1.61 & -0.31 & 1.00 \\
\hline SiteC:Burnt S0 - SiteC:Unburnt S2.5 & -5.48 & 1.61 & -3.40 & 0.11 \\
\hline SiteC:Burnt S0 - SiteD:Burnt S2.5 & -0.70 & 1.61 & -0.43 & 1.00 \\
\hline SiteC:Burnt S0 - SiteD:Unburnt S2.5 & 1.71 & 1.61 & 1.06 & 1.00 \\
\hline
\end{tabular}




\begin{tabular}{|c|c|c|c|c|}
\hline SiteC:Burnt S0 - SiteA:Burnt S5 & -1.25 & 1.61 & -0.78 & 1.00 \\
\hline SiteC:Burnt S0 - SiteA:Unburnt S5 & -3.16 & 1.61 & -1.96 & 0.95 \\
\hline SiteC:Burnt S0 - SiteB:Burnt S5 & -0.61 & 1.61 & -0.38 & 1.00 \\
\hline SiteC:Burnt S0 - SiteB:Unburnt S5 & -1.72 & 1.61 & -1.07 & 1.00 \\
\hline SiteC:Burnt S0 - SiteC:Burnt S5 & -4.27 & 1.61 & -2.65 & 0.56 \\
\hline SiteC:Burnt S0 - SiteC:Unburnt S5 & -5.35 & 1.61 & -3.32 & 0.14 \\
\hline SiteC:Burnt S0 - SiteD:Burnt S5 & -2.14 & 1.61 & -1.33 & 1.00 \\
\hline SiteC:Burnt S0 - SiteD:Unburnt S5 & -1.68 & 1.61 & -1.04 & 1.00 \\
\hline SiteC:Unburnt S0 - SiteD:Burnt S0 & 4.24 & 1.61 & 2.63 & 0.57 \\
\hline SiteC:Unburnt S0 - SiteD:Unburnt S0 & 5.37 & 1.61 & 3.33 & 0.14 \\
\hline SiteC:Unburnt S0 - SiteA:Burnt S2.5 & 7.82 & 1.61 & 4.85 & $<0.05$ \\
\hline SiteC:Unburnt S0 - SiteA:Unburnt S2.5 & 6.42 & 1.61 & 3.98 & $<0.05$ \\
\hline SiteC:Unburnt S0 - SiteB:Burnt S2.5 & 7.72 & 1.61 & 4.79 & $<0.05$ \\
\hline SiteC:Unburnt S0 - SiteB:Unburnt S2.5 & 5.66 & 1.61 & 3.51 & 0.08 \\
\hline SiteC:Unburnt S0 - SiteC:Burnt S2.5 & 4.84 & 1.61 & 3.00 & 0.30 \\
\hline SiteC:Unburnt S0 - SiteC:Unburnt S2.5 & -0.15 & 1.61 & -0.09 & 1.00 \\
\hline SiteC:Unburnt S0 - SiteD:Burnt S2.5 & 4.64 & 1.61 & 2.88 & 0.39 \\
\hline SiteC:Unburnt S0 - SiteD:Unburnt S2.5 & 7.05 & 1.61 & 4.37 & $<0.05$ \\
\hline SiteC:Unburnt S0 - SiteA:Burnt S5 & 4.09 & 1.61 & 2.54 & 0.65 \\
\hline SiteC:Unburnt S0 - SiteA:Unburnt S5 & 2.18 & 1.61 & 1.35 & 1.00 \\
\hline SiteC:Unburnt S0 - SiteB:Burnt S5 & 4.73 & 1.61 & 2.94 & 0.35 \\
\hline SiteC:Unburnt S0 - SiteB:Unburnt S5 & 3.61 & 1.61 & 2.24 & 0.84 \\
\hline SiteC:Unburnt S0 - SiteC:Burnt S5 & 1.07 & 1.61 & 0.67 & 1.00 \\
\hline SiteC:Unburnt S0 - SiteC:Unburnt S5 & -0.01 & 1.61 & -0.01 & 1.00 \\
\hline SiteC:Unburnt S0 - SiteD:Burnt S5 & 3.20 & 1.61 & 1.98 & 0.95 \\
\hline SiteC:Unburnt S0 - SiteD:Unburnt S5 & 3.66 & 1.61 & 2.27 & 0.83 \\
\hline SiteD:Burnt S0 - SiteD:Unburnt S0 & 1.12 & 1.61 & 0.70 & 1.00 \\
\hline SiteD:Burnt S0 - SiteA:Burnt S2.5 & 3.58 & 1.61 & 2.22 & 0.86 \\
\hline SiteD:Burnt S0 - SiteA:Unburnt S2.5 & 2.17 & 1.61 & 1.35 & 1.00 \\
\hline SiteD:Burnt S0 - SiteB:Burnt S2.5 & 3.47 & 1.61 & 2.15 & 0.89 \\
\hline SiteD:Burnt S0 - SiteB:Unburnt S2.5 & 1.42 & 1.61 & 0.88 & 1.00 \\
\hline SiteD:Burnt S0 - SiteC:Burnt S2.5 & 0.59 & 1.61 & 0.37 & 1.00 \\
\hline SiteD:Burnt S0 - SiteC:Unburnt S2.5 & -4.39 & 1.61 & -2.72 & 0.50 \\
\hline SiteD:Burnt S0 - SiteD:Burnt S2.5 & 0.39 & 1.61 & 0.24 & 1.00 \\
\hline SiteD:Burnt S0 - SiteD:Unburnt S2.5 & 2.81 & 1.61 & 1.74 & 0.99 \\
\hline
\end{tabular}




\begin{tabular}{|c|c|c|c|c|}
\hline SiteD:Burnt S0 - SiteA:Burnt S5 & -0.16 & 1.61 & -0.10 & 1.00 \\
\hline SiteD:Burnt S0 - SiteA:Unburnt S5 & -2.07 & 1.61 & -1.28 & 1.00 \\
\hline SiteD:Burnt S0 - SiteB:Burnt S5 & 0.49 & 1.61 & 0.30 & 1.00 \\
\hline SiteD:Burnt S0 - SiteB:Unburnt S5 & -0.63 & 1.61 & -0.39 & 1.00 \\
\hline SiteD:Burnt S0 - SiteC:Burnt S5 & -3.17 & 1.61 & -1.97 & 0.95 \\
\hline SiteD:Burnt S0 - SiteC:Unburnt S5 & -4.25 & 1.61 & -2.64 & 0.57 \\
\hline SiteD:Burnt S0 - SiteD:Burnt S5 & -1.05 & 1.61 & -0.65 & 1.00 \\
\hline SiteD:Burnt S0 - SiteD:Unburnt S5 & -0.59 & 1.61 & -0.36 & 1.00 \\
\hline SiteD:Unburnt S0 - SiteA:Burnt S2.5 & 2.46 & 1.61 & 1.53 & 1.00 \\
\hline SiteD:Unburnt S0 - SiteA:Unburnt S2.5 & 1.05 & 1.61 & 0.65 & 1.00 \\
\hline SiteD:Unburnt S0 - SiteB:Burnt S2.5 & 2.35 & 1.61 & 1.46 & 1.00 \\
\hline SiteD:Unburnt S0 - SiteB:Unburnt S2.5 & 0.29 & 1.61 & 0.18 & 1.00 \\
\hline SiteD:Unburnt S0 - SiteC:Burnt S2.5 & -0.53 & 1.61 & -0.33 & 1.00 \\
\hline SiteD:Unburnt S0 - SiteC:Unburnt S2.5 & -5.51 & 1.61 & -3.42 & 0.11 \\
\hline SiteD:Unburnt S0 - SiteD:Burnt S2.5 & -0.73 & 1.61 & -0.45 & 1.00 \\
\hline SiteD:Unburnt S0 - SiteD:Unburnt S2.5 & 1.68 & 1.61 & 1.05 & 1.00 \\
\hline SiteD:Unburnt S0 - SiteA:Burnt S5 & -1.28 & 1.61 & -0.79 & 1.00 \\
\hline SiteD:Unburnt S0 - SiteA:Unburnt S5 & -3.19 & 1.61 & -1.98 & 0.95 \\
\hline SiteD:Unburnt S0 - SiteB:Burnt S5 & -0.63 & 1.61 & -0.39 & 1.00 \\
\hline SiteD:Unburnt S0 - SiteB:Unburnt S5 & -1.75 & 1.61 & -1.09 & 1.00 \\
\hline SiteD:Unburnt S0 - SiteC:Burnt S5 & -4.29 & 1.61 & -2.66 & 0.55 \\
\hline SiteD:Unburnt S0 - SiteC:Unburnt S5 & -5.37 & 1.61 & -3.33 & 0.14 \\
\hline SiteD:Unburnt S0 - SiteD:Burnt S5 & -2.17 & 1.61 & -1.35 & 1.00 \\
\hline SiteD:Unburnt S0 - SiteD:Unburnt S5 & -1.71 & 1.61 & -1.06 & 1.00 \\
\hline SiteA:Burnt S2.5- SiteA:Unburnt S2.5 & -1.41 & 1.61 & -0.87 & 1.00 \\
\hline SiteA:Burnt S2.5- SiteB:Burnt S2.5 & -0.11 & 1.61 & -0.07 & 1.00 \\
\hline SiteA:Burnt S2.5- SiteB:Unburnt S2.5 & -2.16 & 1.61 & -1.34 & 1.00 \\
\hline SiteA:Burnt S2.5- SiteC:Burnt S2.5 & -2.99 & 1.61 & -1.85 & 0.98 \\
\hline SiteA:Burnt S2.5- SiteC:Unburnt S2.5 & -7.97 & 1.61 & -4.94 & $<0.05$ \\
\hline SiteA:Burnt S2.5- SiteD:Burnt S2.5 & -3.19 & 1.61 & -1.98 & 0.95 \\
\hline SiteA:Burnt S2.5- SiteD:Unburnt S2.5 & -0.77 & 1.61 & -0.48 & 1.00 \\
\hline SiteA:Burnt S2.5- SiteA:Burnt S5 & -3.74 & 1.61 & -2.32 & 0.80 \\
\hline SiteA:Burnt S2.5- SiteA:Unburnt S5 & -5.65 & 1.61 & -3.50 & 0.09 \\
\hline SiteA:Burnt S2.5- SiteB:Burnt S5 & -3.09 & 1.61 & -1.92 & 0.96 \\
\hline SiteA:Burnt S2.5- SiteB:Unburnt S5 & -4.21 & 1.61 & -2.61 & 0.59 \\
\hline
\end{tabular}


$-6.75$

SiteA:Burnt S2.5- SiteC:Unburnt S5

SiteA:Burnt S2.5- SiteD:Burnt S5

SiteA:Burnt S2.5- SiteD:Unburnt S5

SiteA:Unburnt S2.5- SiteB:Burnt S2.5

SiteA:Unburnt S2.5- SiteB:Unburnt S2.5

SiteA:Unburnt S2.5- SiteC:Burnt S2.5

SiteA:Unburnt S2.5- SiteC:Unburnt S2.5

SiteA:Unburnt S2.5- SiteD:Burnt S2.5

SiteA:Unburnt S2.5- SiteD:Unburnt S2.5

SiteA:Unburnt S2.5- SiteA:Burnt S5

SiteA:Unburnt S2.5- SiteA:Unburnt S5

SiteA:Unburnt S2.5- SiteB:Burnt S5

SiteA:Unburnt S2.5- SiteB:Unburnt S5

SiteA:Unburnt S2.5- SiteC:Burnt S5

SiteA:Unburnt S2.5- SiteC:Unburnt S5

SiteA:Unburnt S2.5- SiteD:Burnt S5

SiteA:Unburnt S2.5- SiteD:Unburnt S5

SiteB:Burnt S2.5- SiteB:Unburnt S2.5

SiteB:Burnt S2.5- SiteC:Burnt S2.5

SiteB:Burnt S2.5- SiteC:Unburnt S2.5

SiteB:Burnt S2.5- SiteD:Burnt S2.5

SiteB:Burnt S2.5- SiteD:Unburnt S2.5

SiteB:Burnt S2.5- SiteA:Burnt S5

SiteB:Burnt S2.5- SiteA:Unburnt S5

SiteB:Burnt S2.5- SiteB:Burnt S5

SiteB:Burnt S2.5- SiteB:Unburnt S5

SiteB:Burnt S2.5- SiteC:Burnt S5

SiteB:Burnt S2.5- SiteC:Unburnt S5

SiteB:Burnt S2.5- SiteD:Burnt S5

SiteB:Burnt S2.5- SiteD:Unburnt S5

SiteB:Unburnt S2.5- SiteC:Burnt S2.5

SiteB:Unburnt S2.5- SiteC:Unburnt S2.5

SiteB:Unburnt S2.5- SiteD:Burnt S2.5

SiteB:Unburnt S2.5- SiteD:Unburnt S2.5
$-7.83$

$-4.63$

$-4.17$

1.30

$-0.76$

$-1.58$

$-6.56$

$-1.78$

0.63

$-2.33$

$-4.24$

$-1.69$

$-2.80$

$-5.34$

$-6.42$

$-3.22$

$-2.76$

$-2.06$

$-2.88$

$-7.86$

$-3.08$

$-0.67$

$-3.63$

$-5.54$

$-2.98$

$-4.10$

$-6.64$

$-7.72$

$-4.52$

$-4.06$

$-0.82$

$-5.81$

$-1.02$

1.39
1.61

1.61

1.61

1.61

1.61

1.61

1.61

1.61

1.61

1.61

1.61

1.61

1.61

1.61

1.61

1.61

1.61

1.61

1.61

1.61

1.61

1.61

1.61

1.61

1.61

1.61

1.61

1.61

1.61

1.61

1.61

1.61

1.61

1.61

1.61
$-4.19$

$<0.05$

$-4.86$

$<0.05$

$-2.87$

0.39

$-2.58$

0.61

0.81

1.00

$-0.47$

1.00

$-0.98$

1.00

$-4.07$

$<0.05$

$-1.10$

1.00

0.39

1.00

$-1.45$

1.00

$-2.63$

0.58

$-1.05$

1.00

$-1.74$

0.99

$-3.32$

0.14

$-3.99$

$<0.05$

$-2.00$

0.94

$-1.71$

0.99

$-1.28$

1.00

$-1.79$

0.98

$-4.88$

$<0.05$

$-1.91$

0.97

$-0.41$

1.00

$-2.25$

0.84

$-3.44$

0.10

$-1.85$

0.98

$-2.54$

0.64

$-4.12$

$<0.05$

$-4.79$

$<0.05$

$-2.80$

0.44

$-2.52$

0.66

1.00

0.06

1.00

1.00 
SiteB:Unburnt S2.5- SiteA:Burnt S5

SiteB:Unburnt S2.5- SiteA:Unburnt S5

SiteB:Unburnt S2.5- SiteB:Burnt S5

SiteB:Unburnt S2.5- SiteB:Unburnt S5

SiteB:Unburnt S2.5- SiteC:Burnt S5

SiteB:Unburnt S2.5- SiteC:Unburnt S5

SiteB:Unburnt S2.5- SiteD:Burnt S5

SiteB:Unburnt S2.5- SiteD:Unburnt S5

SiteC:Burnt S2.5- SiteC:Unburnt S2.5

SiteC:Burnt S2.5- SiteD:Burnt S2.5

SiteC:Burnt S2.5- SiteD:Unburnt S2.5

SiteC:Burnt S2.5- SiteA:Burnt S5

SiteC:Burnt S2.5- SiteA:Unburnt S5

SiteC:Burnt S2.5- SiteB:Burnt S5

SiteC:Burnt S2.5- SiteB:Unburnt S5

SiteC:Burnt S2.5- SiteC:Burnt S5

SiteC:Burnt S2.5- SiteC:Unburnt S5

SiteC:Burnt S2.5- SiteD:Burnt S5

SiteC:Burnt S2.5- SiteD:Unburnt S5

SiteC:Unburnt S2.5- SiteD:Burnt S2.5

SiteC:Unburnt S2.5- SiteD:Unburnt S2.5

SiteC:Unburnt S2.5- SiteA:Burnt S5

SiteC:Unburnt S2.5- SiteA:Unburnt S5

SiteC:Unburnt S2.5- SiteB:Burnt S5

SiteC:Unburnt S2.5- SiteB:Unburnt S5

SiteC:Unburnt S2.5- SiteC:Burnt S5

SiteC:Unburnt S2.5- SiteC:Unburnt S5

SiteC:Unburnt S2.5- SiteD:Burnt S5

SiteC:Unburnt S2.5- SiteD:Unburnt S5

SiteD:Burnt S2.5- SiteD:Unburnt S2.5

SiteD:Burnt S2.5- SiteA:Burnt S5

SiteD:Burnt S2.5- SiteA:Unburnt S5

SiteD:Burnt S2.5- SiteB:Burnt S5

SiteD:Burnt S2.5- SiteB:Unburnt S5

SiteD:Burnt S2.5- SiteC:Burnt S5
$-1.57$

1.61

$-0.98$

1.00

$-3.48$

1.61

$-2.16$

0.89

$-0.93$

1.61

$-0.58$

1.00

$-2.05$

1.61

$-1.27$

1.00

$-4.59$

1.61

$-2.85$

0.41

$-5.67$

1.61

$-3.52$

0.08

$-2.46$

1.61

$-1.53$

1.00

$-2.00$

1.61

$-1.24$

1.00

$-4.98$

1.61

$-3.09$

0.25

$-0.20$

1.61

$-0.12$

1.00

2.21

1.61

1.37

1.00

$-0.75$

1.61

$-0.47$

1.00

$-2.66$

1.61

$-1.65$

0.99

$-0.11$

1.61

$-0.07$

1.00

$-1.22$

1.61

$-0.76$

1.00

$-3.77$

1.61

$-2.34$

0.79

$-4.85$

1.61

$-3.01$

0.30

$-1.64$

1.61

$-1.02$

1.00

$-1.18$

1.61

$-0.73$

1.00

4.78

1.61

2.97

0.32

7.20

1.61

4.46

$<0.05$

4.23

1.61

2.63

0.58

2.32

1.61

1.44

1.00

4.88

1.61

3.03

0.29

3.76

1.61

2.33

0.79

1.22

1.61

0.76

1.00

0.14

1.61

0.09

1.00

3.34

1.61

2.07

0.92

3.80

1.61

2.36

0.77

2.41

1.61

1.50

1.00

$-0.55$

1.61

$-0.34$

1.00

$-2.46$

1.61

$-1.53$

1.00

0.09

1.61

0.06

1.00

$-1.02$

1.61

$-0.64$

1.00

$-3.57$

1.61

$-2.21$

0.86 
SiteD:Burnt S2.5- SiteC:Unburnt S5

SiteD:Burnt S2.5- SiteD:Burnt S5

SiteD:Burnt S2.5- SiteD:Unburnt S5

SiteD:Unburnt S2.5- SiteA:Burnt S5

SiteD:Unburnt S2.5- SiteA:Unburnt S5

SiteD:Unburnt S2.5- SiteB:Burnt S5

SiteD:Unburnt S2.5- SiteB:Unburnt S5

SiteD:Unburnt S2.5- SiteC:Burnt S5

SiteD:Unburnt S2.5- SiteC:Unburnt S5

SiteD:Unburnt S2.5- SiteD:Burnt S5

SiteD:Unburnt S2.5- SiteD:Unburnt S5

SiteA:Burnt S5- SiteA:Unburnt S5

SiteA:Burnt S5- SiteB:Burnt S5

SiteA:Burnt S5- SiteB:Unburnt S5

SiteA:Burnt S5- SiteC:Burnt S5

SiteA:Burnt S5- SiteC:Unburnt S5

SiteA:Burnt S5- SiteD:Burnt S5

SiteA:Burnt S5- SiteD:Unburnt S5

SiteA:Unburnt S5- SiteB:Burnt S5

SiteA:Unburnt S5- SiteB:Unburnt S5

SiteA:Unburnt S5- SiteC:Burnt S5

SiteA:Unburnt S5- SiteC:Unburnt S5

SiteA:Unburnt S5- SiteD:Burnt S5

SiteA:Unburnt S5- SiteD:Unburnt S5

SiteB:Burnt S5- SiteB:Unburnt S5

SiteB:Burnt S5- SiteC:Burnt S5

SiteB:Burnt S5- SiteC:Unburnt S5

SiteB:Burnt S5- SiteD:Burnt S5

SiteB:Burnt S5- SiteD:Unburnt S5

SiteB:Unburnt S5- SiteC:Burnt S5

SiteB:Unburnt S5- SiteC:Unburnt S5

SiteB:Unburnt S5- SiteD:Burnt S5

SiteB:Unburnt S5- SiteD:Unburnt S5

SiteC:Burnt S5- SiteC:Unburnt S5

SiteC:Burnt S5- SiteD:Burnt S5
1.61

$-2.88$

0.38

1.61

$-0.90$

1.00

1.61

$-0.61$

1.00

1.61

$-1.84$

0.98

1.61

$-3.02$

0.29

1.61

$-1.44$

1.00

$-2.13$

0.90

$-3.71$

0.05

$-4.38$

0.00

$-2.39$

0.75

$-2.10$

0.91

$-1.18$

1.00

0.40

1.00

$-0.29$

1.00

$-1.87$

0.97

$-2.54$

0.64

$-0.55$

1.00

$-0.27$

1.00

1.58

1.00

0.89

1.00

$-0.69$

1.00

$-1.36$

1.00

0.63

1.00

0.92

1.00

$-0.69$

1.00

1.61

$-2.27$

0.83

$-2.94$

0.34

$-0.95$

1.00

$-0.67$

1.00

$-1.58$

1.00

$-2.25$

0.84

1.00

$-0.26$

1.00

1.00

1.00 


\begin{tabular}{l|cccc} 
SiteC:Burnt S5- SiteD:Unburnt S5 & 2.59 & 1.61 & 1.61 & 1.00 \\
SiteC:Unburnt S5- SiteD:Burnt S5 & 3.20 & 1.61 & 1.99 & 0.95 \\
SiteC:Unburnt S5- SiteD:Unburnt S5 & 3.67 & 1.61 & 2.28 & 0.83 \\
SiteD:Burnt S5- SiteD:Unburnt S5 & 0.46 & 1.61 & 0.29 & 1 \\
\hline
\end{tabular}

Supp. Table 4.8: (continued) 
Supplementary Table 4.9: Average soil moisture expressed as volumetric water content (VWC) across all sampling areas and both soil depths (0-2.5 and 2.5-5 $\mathrm{cm}$ depth) $(\mathrm{n}=12$ per sampling location). Standard deviation for each value is provided in brackets. Site identification divided into: Site $=$ Site A, Site B, Site C, Site D; Status = Burnt $(<1$-year, 3years, 7-years, 11-years post-fire), Unburnt ( $>25$-years post-fire); Depth $=0-25 \mathrm{~cm}, 2.5-5 \mathrm{~cm}$ ).

\begin{tabular}{|c|c|c|c|c|c|c|c|c|c|}
\hline & & \multicolumn{2}{|c|}{ Site A } & \multicolumn{2}{|c|}{ Site B } & \multicolumn{2}{|c|}{ Site C } & \multicolumn{2}{|c|}{ Site D } \\
\hline & & $<1$-year & Unburnt & 3 -years & Unburnt & 7-years & Unburnt & 11-years & Unburnt \\
\hline 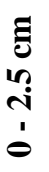 & $\operatorname{VWC}(\%)$ & $16.2(3)$ & $16.9(4)$ & $16.4(4)$ & $18(3)$ & $18.4(3)$ & $10.3(4)$ & $19(1)$ & $15.5(5)$ \\
\hline $\begin{array}{l}\Xi \\
\text { in } \\
\text { n' } \\
\text { ñ } \\
\text { in }\end{array}$ & $\operatorname{VWC}(\%)$ & $18.1(2)$ & $13.9(2)$ & $16(3)$ & $18.5(4)$ & $20(2)$ & $11(4)$ & $20.2(3)$ & $18.1(3)$ \\
\hline
\end{tabular}




\section{Bibliography}

Abraham, J., Dowling, K., and Florentine, S., 2017. Risk of post-fire metal mobilization into surface water resources: A review. Science of the Total Environment 599, 1740-1750. https://doi.org/10.1016/j.scitotenv.2017.05.096

Abrantes, N., Pereira, R., Soares, A.M.V.M., and Gonçalves, F., 2008. Evaluation of the ecotoxicological impact of the pesticide Lasso ${ }^{\circledR}$ on non-target freshwater species, through leaching from nearby agricultural fields, using terrestrial model ecosystems. Water, Air, and Soil Pollution 192, 211-220.

https://doi.org/10.1007/s11270-008-9648-5

Aerts, R., and de Caluwe, H., 1989. Aboveground productivity and nutrient turnover of Molinia caerulea along an experimental gradient of nutrient availability.

Oikos 54, 320-324. https://doi.org/10.2307/3565292

Aerts, R., Berendse, F., de Caluwe, H., and Schmitz, M., 1990. Competition in heathland along an experimental gradient of nutrient availability. Oikos 57, 310-318. https://doi.org/10.2307/3565959

Albertson, K., Aylen, J., Cavan, G., and McMorrow, J., 2010. Climate change and the future occurrence of moorland wildfires in the Peak District of the UK. Climate Research 45, 105-118. https://doi.org/10.3354/cr00926

Alcañiz, M., Outeiro, L., Francos, M., and Úbeda, X., 2018. Effects of prescribed fires on soil properties: A review. Science of the Total Environment 613-614, 944-957. https://doi.org/10.1016/j.scitotenv.2017.09.144

Alcañiz, M., Outeiro, L., Francos, M., Farguell, J., and Úbeda, X., 2016. Long-term dynamics of soil chemical properties after a prescribed fire in a Mediterranean forest (Montgrí Massif, Catalonia, Spain). Science of the Total Environment 572, 1329-1335. https://doi.org/10.1016/j.scitotenv.2016.01.115

Alexander, M.E. and Cole, F.V., 2001. Rating fire danger in Alaska ecosystems: CFFDRS provides an invaluable guide to systematically evaluating burning conditions. Fireline, 12(4), pp.2-3.

Allen, H.D., 2008. Fire: Plant functional types and patch mosaic burning in fire- 
prone ecosystems. Progress in Physical Geography 32, 421-437.

https://doi.org/10.1177/0309133308096754

Allen, K.A., Denelle, P., Ruiz, F.M.S., Santana, V.M., and Marrs, R.H., 2016.

Prescribed moorland burning meets good practice guidelines: A monitoring case study using aerial photography in the Peak District, UK. Ecological Indicators 62, 76-85. https://doi.org/10.1016/j.ecolind.2015.11.030

Allen, K.A., Harris, M.P.K., and Marrs, R.H., 2013. Matrix modelling of prescribed burning in Calluna vulgaris-dominated moorland: Short burning rotations minimize carbon loss at increased wildfire frequencies. Journal of Applied Ecology 50, 614-624. https://doi.org/10.1111/1365-2664.12075

Allen, S.E., 1964. Chemical Aspects of Heather Burning. Journal of Applied Ecology 1, 347-367. https://doi.org/10.2307/2401318

Al-Shammary, A.A.G., Kouzani, A.Z., Kaynak, A., Khoo, S.Y., Norton, M., and Gates, W., 2018. Soil bulk density estimation methods: a review. Pedosphere 28, 581-596. https://doi.org/doi:10.1016/S1002-0160(18)60034-7

Álvarez, E., Fernández-Marcos, M.L., Monterroso, C., and Fernández-Sanjurjo, M.J., 2005. Application of aluminium toxicity indices to soils under various forest species. Forest Ecology and Management 211, 227-239. https://doi.org/doi.org/10.1016/j.foreco.2005.02.044

Andela, N., Morton, D.C., Giglio, L., Chen, Y., Van Der Werf, G.R., Kasibhatla, P.S., DeFries, R.S., Collatz, G.J., Hantson, S., and Kloster, S., 2017. A humandriven decline in global burned area. Science 356, 1356-1362. https://doi.org/10.1126/science.aal4108

Anderson, M.J., 2001. A new method for non-parametric multivariate analysis of variance. Austral Ecology 26: 32-46

Anderson, M.J., 2006 Distance-based tests for homogeneity of multivariate dispersions. Biometrics 62, 245--253.

Antonsen, H., and Olsson, P.A., 2005. Relative importance of burning, mowing and species translocation in the restoration of a former boreal hayfield: Responses of plant diversity and the microbial community. Journal of Applied Ecology 42, 
337-347. https://doi.org/10.1111/j.1365-2664.2005.01023.x

Armstrong, A., Holden, J., Luxton, K., and Quinton, J.N., 2012. Multi-scale relationship between peatland vegetation type and dissolved organic carbon concentration. Ecological Engineering 47, 182-188.

https://doi.org/10.1016/j.ecoleng.2012.06.027

Arocena, J.M., and Opio, C., 2003. Prescribed fire-induced changes in properties of sub-boreal forest soils. Geoderma 113, 1-16. https://doi.org/doi.org/10.1016/S0016-7061(02)00312-9

Ashby, M. and Heinemeyer, A., 2019a. Prescribed burning impacts on ecosystem services in the British uplands: a methodological critique of the EMBER project. Journal of Applied Ecology. 00:1-9. https://doi.org/10.1111/13652664.13476

Ashby, M.A. and Heinemeyer, A., 2019b. Whither scientific debate? A rebuttal of "Contextualising UK moorland burning studies: geographical versus potential sponsorship-bias effects on research conclusions" by Brown and Holden (bioRxiv 2019; 731117).

Averis, A.M., Averis, A.B.G., Birks, H.J.B., Horsfield, D., Thompson, D.B.A., and Yeo, M.J.M., 2014. An illustrated guide to British upland vegetation, 2nd ed, Joint Nature Conservation Committee (JNCC). Pelagic Publishing, Exeter.

Bárcenas-Moreno, G., and Bååth, E., 2009. Bacterial and fungal growth in soil heated at different temperatures to simulate a range of fire intensities. Soil Biology and Biochemistry 41, 2517-2526.

Bárcenas-Moreno, G., García-Orenes, F., Mataix-Solera, J., Mataix-Beneyto, J., and Bååth, E., 2011. Soil microbial recolonisation after a fire in a Mediterranean forest. Biology and Fertility of soils 47, 261-272.

Barratt, B.I.P., Tozer, P.A., Wiedemer, R.L., Ferguson, C.M., and Johnstone, P.D., 2006. Effect of Fire on Microarthropods in New Zealand Indigenous Grassland. Rangeland Ecology \& Management 59, 383-391. https://doi.org/https://doi.org/10.2111/05-190R1.1

Bartoli, A., Gerdol, R., and Massari, G., 1991. Soil fungi succession in a 
Mediterranean" macchia" after fire. Revue d'Ecologie et de Biologie du Sol (France).

Batjes, N.H., 1996. Development of a world data set of soil water retention properties using pedotransfer rules. Geoderma, 71(1-2), pp.31-52.

https://doi.org/10.1016/0016-7061(95)00089-5

BBC News, 2011. Swinley Forest fire "largest in Berkshire's history" [WWW

Document]. URL https://www.bbc.co.uk/news/uk-england-berkshire-13292400 (accessed 1.15.20).

BBC News, 2019. Saddleworth Moor fire: Harmful fumes reached Irish Sea [WWW Document]. URL https://www.bbc.co.uk/news/uk-england-49897399 (accessed 1.15.20).

Beharry-Borg, N., Hubacek, K., Termansen, M., Smart, J., Chapman, P.J., Roberoek, B.J.M., Holden, J., Irvine, B.J., Kirkby, M.J., Ashley, D., Chapman, D.S., Quinn, C.H., Reed, M.S., and Kay, P., 2009. Determining the socio-economic implications of different land management strategies in Yorkshire Water's catchments. Leeds.

Bento-Gonçalves, A., Vieira, A., Úbeda, X., and Martin, D., 2012. Fire and soils: key concepts and recent advances. Geoderma 191, 3-13.

Bisdom, E.B.A., Dekker, L.W., and Schoute, J.F.T., 1993. Water repellency of sieve fractions from sandy soils and relationships with organic material and soil structure, in: Soil Structure/Soil Biota Interrelationships. Elsevier, pp. 105-118. https://doi.org/doi.org/10.1016/B978-0-444-81490-6.50013-3

Bixby, R.J., Cooper, S.D., Gresswell, R.E., Brown, L.E., Dahm, C.N., and Dwire, K.A., 2015a. Fire effects on aquatic ecosystems: an assessment of the current state of the science. Freshwater Science 34, 1340-1350. https://doi.org/10.1086/684073

Bixby, R.J., Cooper, S.D., Gresswell, R.E., Brown, L.E., Dahm, C.N., and Dwire, K.A., 2015b. Fire effects on aquatic ecosystems: an assessment of the current state of the science. Freshwater Science 34, 1340-1350. https://doi.org/10.1086/684073 
Bladon, K.D., Emelko, M.B., Silins, U., and Stone, M., 2014. Wildfire and the future of water supply. Environmental Science and Technology 48, 8936-8943. https://doi.org/10.1021/es500130g

Bladon, K.D., Silins, U., Wagner, M.J., Stone, M., Emelko, M.B., Mendoza, C.A., Devito, K.J., and Boon, S., 2008. Wildfire impacts on nitrogen concentration and production from headwater streams in southern Alberta's Rocky Mountains. Canadian Journal of Forest Research 38, 2359-2371. https://doi.org/10.1139/X08-071

Blake, W.H., Wallbrink, P.J., and Droppo, I.G., 2009. Sediment aggregation and water quality in wildfire-affected river basins. Marine and Freshwater Research 60, 653-659. https://doi.org/10.1071/mf08068

Blanco-Canqui, H., and Lal, R., 2010. Soil resilience and conservation, in: Principles of Soil Conservation and Management. Springer, pp. 425-447. https://doi.org/doi.org/10.1007/978-1-4020-8709-7_16

Bodí, M.B., Cerda, A., Mataix-Solera, J., and Doerr, S.H., 2012. Review of Fire Effects on Vegetation and Soil in the Mediterranean Basin 58, 439-442.

Bodí, M.B., Doerr, S.H., Cerdà, A., and Mataix-Solera, J., 2012. Hydrological effects of a layer of vegetation ash on underlying wettable and water repellent soil. Geoderma 191, 14-23.

Bodí, M.B., Martin, D.A., Balfour, V.N., Santín, C., Doerr, S.H., Pereira, P., Cerdà, A., and Mataix-Solera, J., 2014. Wildland fire ash: Production, composition and eco-hydro-geomorphic effects. Earth-Science Reviews 130, 103-127. https://doi.org/10.1016/j.earscirev.2013.12.007

Bodí, M.B., Mataix-Solera, J., Doerr, S.H., and Cerdà, A., 2011. The wettability of ash from burned vegetation and its relationship to Mediterranean plant species type, burn severity and total organic carbon content. Geoderma 160, 599-607.

Boelter, A.M., Lamming, F.N., Farag, A.M., and Bergman, H.L., 1992. Environmental effects of saline oil-field discharges on surface waters. Environmental Toxicology and Chemistry 11, 1187-1195. https://doi.org/10.1002/etc.5620110815 
Boerner, R.E.J., Huang, J., and Hart, S.C., 2009. Impacts of Fire and Fire Surrogate treatments on forest soil properties: a meta-analytical approach. Ecological Applications 19, 338-358.

Bonanomi, G., Legg, C., and Mazzoleni, S., 2005. Autoinhibition of germination and seedling establishment by leachate of Calluna vulgaris leaves and litter.

Community Ecology 6, 203-208. https://doi.org/10.1556/comec.6.2005.2.8

Bond, W.J., and Midgley, J.J., 2001. Ecology of sprouting in woody plants: The persistence niche. Trends in Ecology and Evolution 16, 45-51. https://doi.org/10.1016/S0169-5347(00)02033-4

Bonn, A., Allott, T., Hubacek, K., and Stewart, J., 2009. Drivers of environmental change in uplands. Routledge, London and New York.

Bormann, H. and Klaassen, K., 2008. Seasonal and land use dependent variability of soil hydraulic and soil hydrological properties of two Northern German soils. Geoderma, 145(3-4), pp.295-302. https://doi.org/10.1016/j.geoderma.2008.03.017

Bowman, D.M.J.S., Balch, J.K., Artaxo, P., Bond, W.J., Carlson, J.M., Cochrane, M.A., D’Antonio, C.M., DeFries, R.S., Doyle, J.C., Harrison, S.P., Johnston, F.H., Keeley, J.E., Krawchuk, M.A., Kull, C.A., Marston, J.B., Moritz, M.A., Prentice, I.C., Roos, C.I., Scott, A.C., Swetnam, T.W., Van Der Werf, G.R., and Pyne, S.J., 2009. Fire in the earth system. Science 324, 481-484. https://doi.org/10.1126/science.1163886

Box, G. E. P., \& Cox, D. R. (1964). An Analysis of Transformations (with discussion). Journal of the Royal Statistical Society. Series B (Methodological), 26(2), 211-252.

Box, G.E. and Cox, D.R., 1964. An analysis of transformations. Journal of the Royal Statistical Society: Series B (Methodological), 26(2), pp.211-243. https://doi.org/10.1111/j.2517-6161.1964.tb00553.x

Braithwaite, N.T., and Mallik, A.U., 2012. Edge effects of wildfire and riparian buffers along boreal forest streams. Journal of Applied Ecology 49, 192-201. https://doi.org/10.1111/j.1365-2664.2011.02076.x 
British Geological Survey, 2018. Geology of Britain viewer [WWW Document]. Natural Environment Research Council. URL

http://mapapps.bgs.ac.uk/geologyofbritain/home.html (accessed 12.4.18).

Brito, D.Q., Passos, C.J.S., Muniz, D.H.F., and Oliveira-Filho, E.C., 2017. Aquatic ecotoxicity of ashes from Brazilian savanna wildfires. Environmental Science and Pollution Research 24, 19671-19682. https://doi.org/10.1007/s11356-0179578-0

Britton, A., Marrs, R., Pakeman, R., and Carey, P., 2003. The influence of soil-type, drought and nitrogen addition on interactions between Calluna vulgaris and Deschampsia flexuosa: Implications for heathland regeneration. Plant Ecology 166, 93-105. https://doi.org/10.1023/A:1023248407408

Brown, A., and Bainbridge, I.P., 1990. Grouse moors and upland breeding birds, in: Heaths and Moorland: Cultural Landscapes. HMSO, UK, Edinburgh, pp. 51-66.

Brown, L.E. and Holden, J., 2019. Contextualising UK moorland burning studies: geographical versus potential sponsorship-bias effects on research conclusions. BioRxiv, p.731117. https://doi.org/10.1101/731117

Brown, L.E., Holden, J., Palmer, S.M., Johnston, K., Ramchunder, S.J., and Grayson, R., 2015. Effects of fire on the hydrology, biogeochemistry, and ecology of peatland river systems. Freshwater Science 34, 1406-1425. https://doi.org/10.1086/683426

Brown, L.E., Johnston, K., Palmer, S.M., Aspray, K.L., and Holden, J., 2013. River ecosystem response to prescribed vegetation burning on blanket peatland. PLoS ONE 8. https://doi.org/10.1371/journal.pone.0081023

Brys, R., Jacquemyn, H., and De Blust, G., 2005. Fire increases aboveground biomass, seed production and recruitment success of Molinia caerulea in dry heathland. Acta Oecologica 28, 299-305. https://doi.org/10.1016/j.actao.2005.05.008

Buddle, C.M., Langor, D.W., Pohl, G.R., and Spence, J.R., 2006. Arthropod responses to harvesting and wildfire: implications for emulation of natural disturbance in forest management. Biological Conservation 128, 346-357. 
Bundt, M., Krauss, M., Blaser, P., and Wilcke, W., 2001. Forest Fertilization with Wood Ash: Effect on the Distribution and Storage of Polycyclic Aromatic Hydrocarbons (PAHs) and Polychlorinated Biphenyls (PCBs). Journal of Environmental Quality 30, 1296-1304.

Burkle, L.A., Myers, J.A., Belote, R.T., and Peters, D.P.C., 2015. Wildfire disturbance and productivity as drivers of plant species diversity across spatial scales. Ecosphere 6, 1-14. https://doi.org/10.1890/ES15-00438.1

Burrows, N., and McCaw, L., 2013. Prescribed burning in southwestern Australian forests. Frontiers in Ecology and the Environment 11. https://doi.org/10.1890/120356

Butler, O.M., Elser, J.J., Lewis, T., Mackey, B., and Chen, C., 2018. The phosphorus-rich signature of fire in the soil-plant system: a global metaanalysis. Ecology Letters 21, 335-344. https://doi.org/10.1111/ele.12896

Butler, O.M., Elser, J.J., Lewis, T., Maunsell, S.C., Rezaei Rashti, M., and Chen, C., 2020. The multi-element stoichiometry of wet eucalypt forest is transformed by recent, frequent fire. Plant and Soil 447, 447-461. https://doi.org/10.1007/s11104-019-04397-z

Cade-Menun, B.J., Berch, S.M., Preston, C.M., and Lavkulich, L.M., 2000. Phosphorus forms and related soil chemistry of Podzolic soils on northern Vancouver Island. II. The effects of clear-cutting and burning. Canadian Journal of Forest Research 30, 1726-1741. https://doi.org/doi.org/10.1139/x00099

Calladine, J., Critchley, C.N.R., Baker, D., Towers, J. and Thiel, A., 2014. Conservation management of moorland: a case study of the effectiveness of a combined suite of management prescriptions which aim to enhance breeding bird populations. Bird Study, 61(1), pp.56-72. https://doi.org/10.1080/00063657.2013.876615

Calvo, L., Tárrega, R., and Luis, E., 2012. Changes of Species Richness in Heathland Communities over 15 Years following Disturbances. International Journal of Forestry Research 2012, 1-12. https://doi.org/10.1155/2012/547120 
Calvo, L., Tárrega, R., Luis, E., Valbuena, L., and Marcos, E., 2005. Recovery after experimental cutting and burning in three shrub communities with different dominant species. Plant Ecology. https://doi.org/10.1007/s11258-005-0200-z

Campbell, G.S., and Campbell, C.S., 2005. Water content and potential measurement. Encyclopedia of Soils in the Environment 253-257. https://doi.org/https://doi.org/10.1016/B0-12-348530-4/00502-6

Campbell, G.S., Jungbauer, J.D., Bidlake, W.R., and Hungerford, R.D., 1994. Predicting the effect of temperature on soil thermal conductivity. Soil Science 158, 307-313. https://doi.org/10.1097/00010694-199411000-00001

Campo, J., Gimeno-García, E., Andreu, V., González-Pelayo, O., and Rubio, J.L., 2008. Aggregation of under canopy and bare soils in a Mediterranean environment affected by different fire intensities. Catena 74, 212-218.

Campos, I., Abrantes, N., Vidal, T., Bastos, A.C., Gonçalves, F., and Keizer, J.J., 2012. Assessment of the toxicity of ash-loaded runoff from a recently burnt eucalypt plantation. European Journal of Forest Research 131, 1889-1903. https://doi.org/10.1007/s10342-012-0640-7

Caon, L., Vallejo, V.R., Ritsema, C.J., and Geissen, V., 2014. Effects of wildfire on soil nutrients in Mediterranean ecosystems. Earth-Science Reviews 139, 47-58.

Capogna, F., Persiani, A.M., Maggi, O., Dowgiallo, G., Puppi, G., and Manes, F., 2009. Effects of different fire intensities on chemical and biological soil components and related feedbacks on a Mediterranean shrub (Phillyrea angustifolia L.). Plant ecology 204, 155-171.

Cerdà, A., and Doerr, S.H., 2005. Influence of vegetation recovery on soil hydrology and erodibility following fire: an 11-year investigation. International Journal of Wildland Fire 14, 423-437. https://doi.org/10.1071/WF05044

Cerdà, A., and Doerr, S.H., 2008. The effect of ash and needle cover on surface runoff and erosion in the immediate post-fire period. Catena 74, 256-263.

Certini, G., 2005. Effects of fire on properties of forest soils: a review. Oecologia 143, 1-10. https://doi.org/10.1007/s00442-004-1788-8

Chambers, F.M., Cloutman, E.W., Daniell, J.R.G., Mauquoy, D., and Jones, P.S., 
2013. Long-term ecological study (palaeoecology) to chronicle habitat degradation and inform conservation ecology: an exemplar from the Brecon Beacons, South Wales. Biodiversity and Conservation 22, 719-736. https://doi.org/10.1007/s10531-013-0441-4

Chapman, D.S., Termansen, M., Quinn, C.H., Jin, N., Bonn, A., Cornell, S.J., Fraser, E.D.G., Hubacek, K., Kunin, W.E., and Reed, M.S., 2009. Modelling the coupled dynamics of moorland management and upland vegetation. Journal of Applied Ecology 46, 278-288. https://doi.org/10.1111/j.13652664.2009.01618.x

Chapman, H.D., 1965. Cation-Exchange Capacity. Methods of Soil Analysis, Agronomy Monographs. https://doi.org/doi:10.2134/agronmonogr9.2.c6

Chapman, P.J., McDonald, A.T., Tyson, R., Palmer, S.M., Mitchell, G., and Irvine, B., 2010. Changes in water colour between 1986 and 2006 in the headwaters of the River Nidd, Yorkshire, UK. Biogeochemistry 101, 281-294. https://doi.org/10.1007/s10533-010-9474-X

Chen, H., Chow, A.T., Li, X.W., Ni, H.G., Dahlgren, R.A., Zeng, H., and Wang, J.J., 2018. Wildfire Burn Intensity Affects the Quantity and Speciation of Polycyclic Aromatic Hydrocarbons in Soils. ACS Earth and Space Chemistry 2, 12621270. https://doi.org/10.1021/acsearthspacechem.8b00101

Chen, Y., McNamara, N.P., Dumont, M.G., Bodrossy, L., Stralis-Pavese, N., and Murrell, J.C., 2008. The impact of burning and Calluna removal on belowground methanotroph diversity and activity in a peatland soil. Applied Soil Ecology 40, 291-298. https://doi.org/10.1016/j.apsoil.2008.05.008

CHIFM, 2008. Committee on hydrologic impacts of forest management. Hydrologic Effects of a Changing Forest Landscape. Washington DC.

Chow, A.T., Tanji, K.K., and Gao, S., 2003. Production of dissolved organic carbon (DOC) and trihalomethane (THM) precursor from peat soils. Water Research 37, 4475-4485. https://doi.org/10.1016/S0043-1354(03)00437-8

Clarke, P.J., Lawes, M.J., Midgley, J.J., Lamont, B.B., Ojeda, F., Burrows, G.E., Enright, N.J., and Knox, K.J.E., 2013. Resprouting as a key functional trait: 
How buds, protection and resources drive persistence after fire. New Phytologist 197, 19-35. https://doi.org/10.1111/nph.12001

Clay, G.D., Worrall, F., and Aebischer, N.J., 2012. Does prescribed burning on peat soils influence DOC concentrations in soil and runoff waters? Results from a 10year chronosequence. Journal of Hydrology 448-449, 139-148. https://doi.org/10.1016/j.jhydrol.2012.04.048

Clay, G.D., Worrall, F., and Fraser, E.D.G., 2009a. Effects of managed burning upon dissolved organic carbon (DOC) in soil water and runoff water following a managed burn of a UK blanket bog. Journal of Hydrology 367, 41-51. https://doi.org/10.1016/j.jhydrol.2008.12.022

Clay, G.D., Worrall, F., and Fraser, E.D.G., 2010a. Compositional changes in soil water and runoff water following managed burning on a UK upland blanket bog. Journal of Hydrology 380, 135-145. https://doi.org/10.1016/j.jhydrol.2009.10.030

Clay, G.D., Worrall, F., and Rose, R., 2010b. Carbon budgets of an upland blanket bog managed by prescribed fire. Journal of Geophysical Research: Biogeosciences 115, 1-14. https://doi.org/10.1029/2010JG001331

Clay, G.D., Worrall, F., Clark, E. and Fraser, E.D., 2009b. Hydrological responses to managed burning and grazing in an upland blanket bog. Journal of Hydrology, 376, 486-495. https://doi.org/10.1016/j.jhydrol.2009.07.055

Clément, B., and Touffet, J., 1981. Vegetation dynamics in Brittany heathlands after fire. Vegetatio 46, 157-166. https://doi.org/10.1007/BF00118393

Clement, B., and Touffet, J., 1990. Plant strategies and secondary succession on Brittany heathlands after severe fire. Journal of Vegetation Science 1, 195-202. https://doi.org/10.2307/3235658

Clutterbuck, B., and Yallop, A.R., 2010. Land management as a factor controlling dissolved organic carbon release from upland peat soils 2: Changes in DOC productivity over four decades. Science of the Total Environment 408, 61796191. https://doi.org/10.1016/j.scitotenv.2010.08.038

Costa, M.R., Calvão, A.R., and Aranha, J., 2014. Linking wildfire effects on soil and 
water chemistry of the Marão River watershed, Portugal, and biomass changes detected from Landsat imagery. Applied Geochemistry 44, 93-102. https://doi.org/10.1016/j.apgeochem.2013.09.009

Coulson, J.., 1988. The structure and importance of invertebrate communities on peatlands and moorlands, and effects of environmental and management changes.

Covington, W.W., and Sackett, S.S., 1992. Soil mineral nitrogen changes following prescribed burning in ponderosa pine. Forest Ecology and Management 54, $175-191$.

Covington, W.W., DeBano, L.F., and Huntsberger, T.G., 1991. Soil nitrogen changes associated with slash pile burning in pinyon-juniper woodlands. Forest Science 37, 347-355.

Cox, F.R., 1994. Current phosphorus availability indices: Characteristics and shortcomings. Soil testing: Prospects for improving nutrient recommendations 40. Soil Science Society of America Special Publication. Madison, WI. https://doi.org/10.2136/sssaspecpub40.c6

Coyle, D.R., Nagendra, U.J., Taylor, M.K., Campbell, J.H., Cunard, C.E., Joslin, A.H., Mundepi, A., Phillips, C.A., and Callaham Jr, M.A., 2017. Soil fauna responses to natural disturbances, invasive species, and global climate change: Current state of the science and a call to action. Soil Biology and Biochemistry 110, 116-133.

Cranfield University, 2018. The Soils Guide - Soilscapes [WWW Document]. Cranfield Soil and Agrifood Institute. URL www.landis.org.uk (accessed 4.5.18).

Crowhurst, E., 2015. Fire Statistics Monitor: England April 2013 to March 2014, Fire and Rescue Statistical Release.

Cummings, D.C., Fuhlendorf, S.D., and Engle, D.M., 2007. Is Altering Grazing Selectivity of Invasive Forage Species With Patch Burning More Effective Than Herbicide Treatments?, Rangeland Ecology Management, (2007). https://doi.org/10.2111/1551-5028(2007)60[253:IAGSOI]2.0.CO;2 
D’Ascoli, R., Rutigliano, F.A., De Pascale, R.A., Gentile, A., and De Santo, A.V., 2005. Functional diversity of the microbial community in Mediterranean maquis soils as affected by fires. International Journal of Wildland Fire 14, 355-363.

Daplyn, J., Ewald, J., and Manor, B., 2006. Birds, burning and grouse moor management. Unpublished report to Moors for the Future.

Davies G.M., and Legg C.J., 2016. Regional variation in fire weather controls the reported occurrence of Scottish wildfires. PeerJ 4:e2649. https://doi.org/10.7717/peerj.2649

Davies, G.M., and Legg, C.J., 2011. Fuel Moisture Thresholds in the Flammability of Calluna vulgaris. Fire Technology 47, 421-436. https://doi.org/10.1007/s10694010-0162-0

Davies, G.M., Gray, A., Hamilton, A., and Legg, C.J., 2008a. The future of fire management in the British uplands. International Journal of Biodiversity Science \& Management 4, 127-147. https://doi.org/10.3843/biodiv.4.3:1

Davies, G.M., Gray, A., Rein, G., and Legg, C.J., 2013. Peat consumption and carbon loss due to smouldering wildfire in a temperate peatland. Forest Ecology and Management 308, 169-177. https://doi.org/10.1016/j.foreco.2013.07.051

Davies, G.M., Hamilton, A., Smith, A., and Legg, C.J., 2008b. Using visual obstruction to estimate heathland fuel load and structure. International Journal of Wildland Fire 17, 380-389. https://doi.org/10.1071/WF07021

Davies, G.M., Kettridge, N., Stoof, C.R., Gray, A., Ascoli, D., Fernandes, P.M., Marrs, R., Allen, K.A., Doerr, S.H., Clay, G.D., Mcmorrow, J., and Vandvik, V., 2016. The role of fire in UK peatland and moorland management: the need for informed, unbiased debate. Philosophical Transactions of the Royal Society B: Biological Sciences 371. https://doi.org/10.1098/rstb.2015.0342

Davies, G.M., Legg, C.J., Smith, A.A., and MacDonald, A.J., 2009. Rate of spread of fires in Calluna vulgaris-dominated moorlands. Journal of Applied Ecology 46, 1054-1063. https://doi.org/10.1111/j.1365-2664.2009.01681.x

Davies, G.M., Smith, A.A., MacDonald, J.A., Bakker, D.J., and Legg, J.C., 2010. Fire intensity, fire severity and ecosystem response in heathlands: Factors 
affecting the regeneration of Calluna vulgaris. Journal of Applied Ecology 47, 356-365. https://doi.org/10.1111/j.1365-2664.2010.01774.x

De Deyn, G.B., Cornelissen, J.H.C., and Bardgett, R.D., 2008. Plant functional traits and soil carbon sequestration in contrasting biomes. Ecology letters 11, 516531. https://doi.org/10.1111/j.1461-0248.2008.01164.x

De Graaf, M.C.C., Bobbink, R., Smits, N.A.C., Van Diggelen, R., and Roelofs, J.G.M., 2009. Biodiversity, vegetation gradients and key biogeochemical processes in the heathland landscape. Biological Conservation 142, 2191-2201. https://doi.org/10.1016/j.biocon.2009.04.020

De Groot, W.J., 1998, April. Interpreting the Canadian forest fire weather index (FWI) system. In Proc. of the Fourth Central Region Fire Weather Committee Scientific and Technical Seminar.

De Jong, M.C., Wooster, M.J. and McCall, F.F., 2016. Calibration and evaluation of the Canadian Forest Fire Weather Index (FWI) System for improved wildland fire danger rating in the United Kingdom. Natural Hazards and Earth System Sciences, 16(5), p.1217.

DeBano, F.L, DeBano, L.F., Neary, D.G., and Ffolliott, P.F., 1998. Fire effects on ecosystems. John Wiley \& Sons.

DeBano, F.L., 1991. The effect of fire on soil properties. In: Harvey, Alan E.; Neuenschwander, Leon F., compilers. Proceedings-management and productivity of western-montane forest soils; 1990 April 10-12; Boise, ID. Gen. Tech. Rep. INT-280. Ogden, UT: US Department of Agriculture, Forest Service, Intermountain 280, 151-156.

DeBano, L.F., 2000. The role of fire and soil heating on water repellency in wildland environments: a review. Journal of hydrology, 231, pp.195-206. https://doi.org/10.1016/S0022-1694(00)00194-3

DEFRA, 2007. The Heather and Grass Burning Code.

Dekker, L.W. and Ritsema, C.J., 1994. How water moves in a water repellent sandy soil: 1. Potential and actual water repellency. Water Resources Research, 30(9), pp.2507-2517. https://doi.org/10.1029/94WR00749 
Department for Business Energy and Industrial Strategy (DBEIS), 2017. UK Greenhouse Gas Emissions - 2015 [online].

Diaz, O.A., Reddy, K.R., and Moore, P.A., 1994. Solubility of inorganic phosphorus in stream water as influenced by $\mathrm{pH}$ and calcium concentration. Water Research 28, 1755-1763. https://doi.org/10.1016/0043-1354(94)90248-8

Dixon, P., 2003. VEGAN, a package of R functions for community ecology. Journal of Vegetation Science 14, 927-930. https://doi.org/10.1111/j.16541103.2003.tb02228.x

Dobson, A. J. 1990. An Introduction to Generalized Linear Models. London: Chapman and Hall.

Dodgshon, R.A., and Almered, G., 2006. Heather moorland in the Scottish Highlands : the history of a cultural landscape , 1600 e 1880. Journal of Historical Geography 32, 21-37. https://doi.org/10.1016/j.jhg.2005.01.002

Doerr, S.H. and Thomas, A.D., 2000. The role of soil moisture in controlling water repellency: new evidence from forest soils in Portugal. Journal of Hydrology, 231, pp.134-147. doi:10.1016/s0022-1694(00)00190-6

Doerr, S.H., and Cerdà, A., 2005. Fire effects on soil system functioning: new insights and future challenges. International Journal of Wildland Fire 14, 339342.

Doerr, S.H., Blake, W.H., Shakesby, R.A., Stagnitti, F., Vuurens, S.H., Humphreys, G.S., and Wallbrink, P., 2004. Heating effects on water repellency in Australian eucalypt forest soils and their value in estimating wildfire soil temperatures. International Journal of Wildland Fire 13, 157-163. https://doi.org/doi.org/10.1071/WF03051

Doerr, S.H., Cerdà, A., and Bryant, R., 2008. The role of ash in carbon fluxes in fireaffected environments, in: Geophysical Research Abstracts.

Doerr, S.H., Shakesby, R.A., and Walsh, R.P.D., 1998. Spatial variability of soil hydrophobicity in fire-prone eucalyptus and pine forests, Portugal. Soil Science 163, 313-324.

Doerr, S.H., Shakesby, R.A., and Walsh, R.P.D., 2000. Soil water repellency: Its 
causes, characteristics and hydro-geomorphological significance. Earth Science Reviews 51, 33-65. https://doi.org/10.1016/S0012-8252(00)00011-8

Doerr, S.H., Shakesby, R.A., Blake, W.H., Chafer, C.J., Humphreys, G.S., and Wallbrink, P.J., 2006. Effects of differing wildfire severities on soil wettability and implications for hydrological response. Journal of Hydrology 319, 295311. https://doi.org/10.1016/j.jhydrol.2005.06.038

Douglas, D.J., Beresford, A., Selvidge, J., Garnett, S., Buchanan, G.M., Gullett, P. and Grant, M.C., 2017. Changes in upland bird abundances show associations with moorland management. Bird Study, 64(2), pp.242-254. https://doi.org/10.1080/00063657.2017.1317326

Douglas, D.J., Buchanan, G.M., Thompson, P., Amar, A., Fielding, D.A., Redpath, S.M. and Wilson, J.D., 2015. Vegetation burning for game management in the UK uplands is increasing and overlaps spatially with soil carbon and protected areas. Biological Conservation, 191, pp.243-250.

Downing, E., and Coe, S., 2018. Brexit: Future UK agriculture policy. Briefing paper: CBP 8218, Health. London.

Durgin, P.B., and Vogelsang, P.J., 1984. Dispersion of kaolinite by water extracts of Douglas-fir ash. Canadian Journal of Soil Science 64, 439-443.

Earl, S.R., and Blinn, D.W., 2003. Effects of wildfire ash on water chemistry and biota. Freshwater Biology 48, 1015-1030.

Enell, A., Fuhrman, F., Lundin, L., Warfvinge, P., and Thelin, G., 2008. Polycyclic aromatic hydrocarbons in ash: Determination of total and leachable concentrations. Environmental Pollution 152, 285-292. https://doi.org/10.1016/j.envpol.2007.06.055

European Commission, 2020a. Global Wildfire Information System - Annual country statistics for the United Kingdom [online]. URL https://gwis.jrc.ec.europa.eu/static/gwis.statistics.portal/countriesestimates/EU/GB (accessed 1.20.20).

European Commission, 2020b. European Forest Fire Information System - Statistics for the United Kingdom (2009-2019) [online]. URL 
https://effis.jrc.ec.europa.eu/static/effis_stats/effis-estimates/GB

Evans, C.D., Monteith, D.T., and Cooper, D.M., 2005. Long-term increases in surface water dissolved organic carbon: observations, possible causes and environmental impacts. Environmental pollution 137, 55-71.

Evans, C.D., Page, S.E., Jones, T., Moore, S., Gauci, V., Laiho, R., Hruška, J., Allott, T.E., Billett, M.F., Tipping, E. and Freeman, C., 2014. Contrasting vulnerability of drained tropical and high-latitude peatlands to fluvial loss of stored carbon. Global Biogeochemical Cycles, 28(11), pp.1215-1234. https://doi.org/10.1002/2013GB004782

Eyre, M.D., Luff, M.L., and Woodward, J.C., 2003. Grouse moor management: Habitat and conservation implications for invertebrates in southern Scotland. Journal of Insect Conservation 7, 21-32. https://doi.org/10.1023/A:1024714506587

Fagúndez, J., 2013. Heathlands confronting global change: Drivers of biodiversity loss from past to future scenarios. Annals of Botany 111, 151-172. https://doi.org/10.1093/aob/mcs257

Farage, P., Ball, A., Mcgenity, T.J., Whitby, C., and Pretty, J., 2009. Burning management and carbon sequestration of upland heather moorland in the UK. Australian Journal of Soil Research 47, 351-361. https://doi.org/10.1071/SR08095

Fayos, C.B., 1997. The roles of texture and structure in the water retention capacity of burnt Mediterranean soils with varying rainfall. Catena 31, 219-236.

Fedje, K., Ekberg, C., Skarnemark, G., and Steenari, B.M., 2010. Removal of hazardous metals from MSW fly ash-An evaluation of ash leaching methods. Journal of Hazardous Materials 173, 310-317. https://doi.org/10.1016/j.jhazmat.2009.08.094

Fenton, J.H.C., 2008. A postulated natural origin for the open landscape of upland Scotland. Plant Ecology and Diversity 1, 115-127. https://doi.org/10.1080/17550870802260624

Fernandes, P.M., and Loureiro, C.A., 2010. Handbook to plan and use prescribed 
burning in Europe 45. https://doi.org/10.1017/CBO9781107415324.004

Fernandes, P.M., Davies, G.M., Ascoli, D., Fernández, C., Moreira, F., Rigolot, E., Stoof, C.R., Vega, J.A., and Molina, D., 2013. Prescribed burning in southern Europe: Developing fire management in a dynamic landscape. Frontiers in Ecology and the Environment 11. https://doi.org/10.1890/120298

Ferreira, A.J.D., Coelho, C. de O.A., Ritsema, C.J., Boulet, A.K., and Keizer, J.J., 2008. Soil and water degradation processes in burned areas: lessons learned from a nested approach. Catena 74, 273-285.

Ferreira, A.J.D., Coelho, C.O.A., Boulet, A.K., and Lopes, F.P., 2005. Temporal patterns of solute loss following wildfires in Central Portugal. International Journal of Wildland Fire 14, 401-412. https://doi.org/10.1071/wf05043

Fire and Rescue Service, 2020. Wildfire statistics for Wales (2009-2019).

Fisher, R.F., and Binkley, D., 2013. Ecology and management of forest soils. WileyBlackwell, Oxford.

Fonseca, F., de Figueiredo, T., Nogueira, C., and Queirós, A., 2017. Effect of prescribed fire on soil properties and soil erosion in a Mediterranean mountain area. Geoderma 307, 172-180. https://doi.org/10.1016/j.geoderma.2017.06.018

Forestry Commission, 2019. Wildfire statistics for England. Bristol.

Forgeard, F. and Frenot, Y., 1996. Effects of burning on heathland soil chemical properties: an experimental study on the effect of heating and ash deposits. Journal of Applied Ecology, pp.803-811. https://doi.org/10.2307/2404950

Fox, J and Weisberg, S., 2019b. Companion to Applied Regression Functions to Accompany; An R Companion to Applied Regression, Third Edition, Sage publications.

Fox, J. and Weisberg, S. 2019a. An R Companion to Applied Regression, Third Edition, Sage publications.

Fox, J., 2016. Applied Regression Analysis and Generalized Linear Models, Third Edition. Sage.

França, F., Louzada, J., Korasaki, V., Griffiths, H., Silveira, J.M. and Barlow, J., 
2016. Do space-for-time assessments underestimate the impacts of logging on tropical biodiversity? An Amazonian case study using dung beetles. Journal of Applied Ecology 53(4), 1098-1105. https://doi.org/10.1111/1365-2664.12657

Franco, C.M.M., Clarke, P.J., Tate, M.E. and Oades, J.M., 2000. Hydrophobic properties and chemical characterisation of natural water repellent materials in Australian sands. Journal of Hydrology, 231, pp.47-58.

https://doi.org/10.1016/S0022-1694(00)00182-7

Franços, M., Úbeda, X., Pereira, P., and Alcañiz, M., 2018. Long-term impact of wildfire on soils exposed to different fire severities. A case study in Cadiretes Massif (NE Iberian Peninsula). Science of the Total Environment 615, 664-671. https://doi.org/10.1016/j.scitotenv.2017.09.311

Franklin, N.M., Stauber, J.L., Markich, S.J., and Lim, R.P., 2000. pH-dependent toxicity of copper and uranium to a tropical freshwater alga (Chlorella spp.). Aquatic Toxicology 48, 275-289. https://doi.org/10.1016/S0166445X(99)00042-9

Freeman, C., Evans, C.D., Monteith, D.T., Reynolds, B., and Fenner, N., 2001. Export of organic carbon from peat soils. Nature 412, 785.

Freitas, E.C., and Rocha, O., 2011. Acute and chronic effects of sodium and potassium on the tropical freshwater cladoceran Pseudosida ramosa. Ecotoxicology 20, 88-93. https://doi.org/10.1007/s10646-010-0559-z

Friedrich, U., von Oheimb, G., Dziedek, C., Kriebitzsch, W.-U., Selbmann, K., and Härdtle, W., 2011. Mechanisms of purple moor-grass (Molinia caerulea) encroachment in dry heathland ecosystems with chronic nitrogen inputs. Environmental Pollution 159, 3553-3559. https://doi.org/10.1016/j.envpol.2011.08.010

Frišták, V., Laughinghouse, H.D., Packová, A., Graser, M., and Soja, G., 2019. Monitoring of methylated naphthalenes in sludge-derived pyrogenic carbonaceous materials. Chemosphere 217, 456-462. https://doi.org/10.1016/j.chemosphere.2018.11.030

Fu, W., Tunney, H., \& Zhang, C. 2010. Spatial variation of soil nutrients in a dairy 
farm and its implications for site-specific fertilizer application. Soil and Tillage Research, 106(2), 185-193. doi:10.1016/j.still.2009.12.001

Fuhlendorf, S.D., and Engle, D.M., 2001. Restoring heterogeneity on rangelands: ecosystem management based on evolutionary grazing patterns: we propose a paradigm that enhances heterogeneity instead of homogeneity to promote biological diversity and wildlife habitat on rangelands grazed by lives. BioScience 51, 625-632.

Fyfe, R.M., Brown, A.G., and Rippon, S.J., 2003. Mid- to late-Holocene vegetation history of Greater Exmoor, UK: Estimating the spatial extent of human-induced vegetation change. Vegetation History and Archaeobotany 12, 215-232. https://doi.org/10.1007/s00334-003-0018-3

Gabet, E.J., and Sternberg, P., 2008. The effects of vegetative ash on infiltration capacity, sediment transport, and the generation of progressively bulked debris flows. Geomorphology 101, 666-673.

García, R.R., Fraser, M.D., Celaya, R., Ferreira, L.M.M., García, U., and Osoro, K., 2013. Grazing land management and biodiversity in the Atlantic European heathlands: A review. Agroforestry Systems 87, 19-43. https://doi.org/10.1007/s10457-012-9519-3

Gardner, W.H., 1986. Water content, in: Klute, A. (Ed.), Methods of Soil Analysis: Part 1 Physical and Mineralogical Methods. Wiley Online Library, pp. 493-544. https://doi.org/doi.org/10.2136/sssabookser5.1.2ed.c21

Garnett, M.H., Ineson, P., and Stevenson, A.C., 2000. Effects of burning and grazing on carbon sequestration in a Pennine blanket bog, UK. Holocene 10, 729-736. https://doi.org/10.1191/09596830094971

Garnett, M.H., Ineson, P., Stevenson, A.C., and Howard, D.C., 2001. Terrestrial organic carbon storage in a British moorland. Global Change Biology 7, 375388. https://doi.org/10.1046/j.1365-2486.2001.00382.x

Gazzard, R., McMorrow, J., and Policy, A.J.W., 2016. Wildfire policy and management in England: an evolving response from Fire and Rescue Services. Forestry and Cross-Sector Groups 371, 1696. 
https://doi.org/10.1098/rstb.2015.0341

Gharun, M., Possell, M., Bell, T.L., and Adams, M.A., 2017. Optimisation of fuel reduction burning regimes for carbon, water and vegetation outcomes. Journal of Environmental Management 203, 157-170.

https://doi.org/10.1016/j.jenvman.2017.07.056

Gifford, S., Dunstan, R.H., O’Connor, W., Roberts, T., and Toia, R., 2004. Pearl aquaculture - profitable environmental remediation? Science of the total environment 319, 27-37.

Giglio, L., Boschetti, L., Roy, D.P., Humber, M.L., and Justice, C.O., 2018. The Collection 6 MODIS burned area mapping algorithm and product. Remote Sensing of Environment 217, 72-85. https://doi.org/10.1016/j.rse.2018.08.005

Giglio, L., Randerson, J.T., and Van Der Werf, G.R., 2013. Analysis of daily, monthly, and annual burned area using the fourth-generation global fire emissions database (GFED4). Journal of Geophysical Research:

Biogeosciences. https://doi.org/10.1002/jgrg.20042

Gill, D.D., 2004. The impacts of forest fires on drinking water quality.

Gimingham, C.H., Hobbs, R.J. and Mallik, A.U., 1981. Community dynamics in relation to management of heathland vegetation in Scotland. In Vegetation dynamics in grasslans, healthlands and mediterranean ligneous formations (pp. 149-155). Springer, Dordrecht.

Giovannini, G., and Lucchesi, S., 1997. Modifications induced in soil physicochemical parameters by experimental fires at different intensities. Soil Science 162, 479-486.

Giovannini, G., Lucchesi, S., and Giachetti, M., 1988. Effect of heating on some physical and chemical parameters related to soil aggregation and erodibility. Soil Science 146, 255-261.

Glaves, D., 2015. Molinia caerulea in upland habitats : a Natural England perspective on the perceived issue of ' over-dominance ,' in: National Trust. pp. 56-70.

Glaves, D.J., Haycock, N.E., Costigan, P., Coulson, J.C., Marrs, R.H., Robertson, P.A., and Younger, J., 2005. Defra review of the heather and grass burning 
regulations and code: Science Panel assessment of the effects of burning on biodiversity, soils and hydrology. Unpublished report to Defra.

Glaves, D.J., Morecroft, M., Fitzgibbon, C., Lepitt, P., Owen, M., and Phillips, S., 2013. The effects of managed burning on upland peatland biodiversity, carbon and water. Peterborough.

Goldammer, J.G., and Bruce, M.A., 2004. The use of prescribed fire in the land management of western and Baltic Europe: An overview. International Forest Fire News 30, 2-13.

Gómez-Rey, M.X., and González-Prieto, S.J., 2014. Short and medium-term effects of a wildfire and two emergency stabilization treatments on the availability of macronutrients and trace elements in topsoil. Science of the total environment 493, 251-261.

Gómez-Rey, M.X., Couto-Vázquez, A., García-Marco, S., and González-Prieto, S.J., 2013. Impact of fire and post-fire management techniques on soil chemical properties. Geoderma 195, 155-164.

Gonino, G., Branco, P., Benedito, E., Ferreira, M.T., and Santos, J.M., 2019a. Shortterm effects of wildfire ash exposure on behaviour and hepatosomatic condition of a potamodromous cyprinid fish, the Iberian barbel Luciobarbus bocagei (Steindachner, 1864). Science of the Total Environment 665, 226-234. https://doi.org/10.1016/j.scitotenv.2019.02.108

Gonino, G.M.R., Figueiredo, B.R.S., Manetta, G.I., Zaia Alves, G.H., and Benedito, E., 2019b. Fire increases the productivity of sugarcane, but it also generates ashes that negatively affect native fish species in aquatic systems. Science of the Total Environment 664, 215-221.

https://doi.org/10.1016/j.scitotenv.2019.02.022

González-Pérez, J.A., González-Vila, F.J., Almendros, G., and Knicker, H., 2004. The effect of fire on soil organic matter - A review. Environment International 30, 855-870. https://doi.org/10.1016/j.envint.2004.02.003

Goodfellow, S., 1998. The use, impact and control of fire on Dartmoor: an overview. Dartmoor National Park Authority, Bovey Tracey, Devon, UK. 
Gorissen, S., Mallinson, J., Greenlees, M., and Shine, R., 2015. The impact of fire regimes on populations of an endangered lizard in montane south-eastern A ustralia. Austral Ecology 40, 170-177.

Grace, J., 2004. Understanding and managing the global carbon cycle. Journal of Ecology 92, 189-202.

Granged, A.J.P., Jordán, A., Zavala, L.M., Muñoz-Rojas, M., and Mataix-Solera, J., 2011b. Short-term effects of experimental fire for a soil under eucalyptus forest (SE Australia). Geoderma 167-168, 125-134. https://doi.org/10.1016/j.geoderma.2011.09.011

Granged, A.J.P., Zavala, L.M., Jordán, A., and Bárcenas-Moreno, G., 2011a. Postfire evolution of soil properties and vegetation cover in a Mediterranean heathland after experimental burning: A 3-year study. Geoderma 164, 85-94. https://doi.org/10.1016/j.geoderma.2011.05.017

Granström, A., and Schimmel, J., 1993. Heat effects on seeds and rhizomes of a selection of boreal forest plants and potential reaction to fire. Oecologia 94, 307-313. https://doi.org/10.1007/BF00317103

Grant, M., Mallord, J., Stephen, L., and Thompson, P.S., 2012. The costs and benefits of grouse moor management to biodiversity and aspects of the wider environment : a review.

Grau-Andrés, R., Davies, G.M., Gray, A., Scott, E.M., and Waldron, S., 2018. Fire severity is more sensitive to low fuel moisture content on Calluna heathlands than on peat bogs. Science of the Total Environment 616-617, 1261-1269. https://doi.org/10.1016/j.scitotenv.2017.10.192

Grau-Andrés, R., Davies, G.M., Waldron, S., Scott, E.M., and Gray, A., 2019a. Increased fire severity alters initial vegetation regeneration across Callunadominated ecosystems. Journal of Environmental Management 231, 10041011. https://doi.org/10.1016/j.jenvman.2018.10.113

Grau-Andrés, R., Gray, A., and Davies, G.M., 2017 Sphagnum abundance and photosynthetic capacity show rapid short-term recovery following managed burning, Plant Ecology \& Diversity, 10:4, 353-359, DOI: 
Grau-Andrés, R., Gray, A., Davies, G.M., Scott, E.M., and Waldron, S., 2019b.

Burning increases post-fire carbon emissions in a heathland and a raised bog, but experimental manipulation of fire severity has no effect. Journal of Environmental Management 233, 321-328.

https://doi.org/10.1016/j.jenvman.2018.12.036

Gray, A., and Levy, P., 2009. A review of carbon flux research in UK peatlands in relation to fire and the Cairngorms national park 44, 1-34.

Grayson, R., Kay, P., Foulger, M., and Gledhill, S., 2012. A GIS based MCE model for identifying water colour generation potential in UK upland drinking water supply catchments. Journal of Hydrology 420-421, 37-45. https://doi.org/10.1016/j.jhydrol.2011.11.018

Grayson, R., Kay, P., Holden, A., Whelan, M., Hannam, J., Hallett, S., Foulger, M., and Gledhill, S., 2008. GIS-based analysis of the impacts of land management on colour, nitrate and pesticides in raw water. Final Report for Yorkshire Water. University of Leeds, Leeds.

Gritten, R., 2012. Conservation Assessment of Heathland in the Upland Fringes (Ffridd Zone) of the Snowdonia National Park.

Grogan, P., Burns, T.D., and Chapin Iii, F.S., 2000. Fire effects on ecosystem nitrogen cycling in a Californian bishop pine forest. Oecologia 122, 537-544. https://doi.org/doi.org/10.1007/s004420050977

Grubb, P.J., and Hopkins, A.J.M., 1986. Resilience at the level of the plant community, in: Resilience in Mediterranean-Type Ecosystems. Springer, pp. 21-38. https://doi.org/doi.org/10.1007/978-94-009-4822-8_3

Guerrero, C., Mataix-Solera, J., Navarro-Pedreño, J., García-Orenes, F., and Gómez, I., 2001. Different patterns of aggregate stability in burned and restored soils. Arid Land Research and Management 15, 163-171.

Hageman, P.L., 2007. US Geological Survey field leach test for assessing water reactivity and leaching potential of mine wastes, soils, and other geologic and environmental materials. https://doi.org/10.3133/tm5D3 
Hallema, D.W., Sun, G., Caldwell, P. V., Norman, S.P., Cohen, E.C., Liu, Y., Bladon, K.D., and McNulty, S.G., 2018. Burned forests impact water supplies. Nature Communications 9, 1307. https://doi.org/10.1038/s41467-018-03735-6

Hand, D. J., and Taylor, C. C., 1987. Multivariate Analysis of Variance and Repeated Measures: A Practical Approach for Behavioural Scientists. Chapman and Hall.

Harper, A.R., Doerr, S.H., Santin, C., Froyd, C.A., and Sinnadurai, P., 2018. Prescribed fire and its impacts on ecosystem services in the UK. Science of the Total Environment 624, 691-703. doi.org/10.1016/j.scitotenv.2017.12.161

Harper, A.R., Santin, C., Doerr, S.H., Froyd, C.A., Albini, D., Otero, X.L., Viñas, L., and Pérez-Fernández, B., 2019. Chemical composition of wildfire ash produced in contrasting ecosystems and its toxicity to Daphnia magna. International Journal of Wildland Fire. https://doi.org/10.1071/WF18200

Harper, C.A., Ford, W.M., Lashley, M.A., Moorman, C.E., and Stambaugh, M.C., 2016. Fire effects on wildlife in the Central Hardwoods and Appalachian regions, USA. Fire Ecology 12, 127-159.

Harper, K.A., Macdonald, E.S., Burton, P.J., Chen Jiquan, Brosofske, Kimberley, D., Saunders, Sari, C., Euskirchen, E.S., Roberts, D., Jaiteh, M.S., and Esseen, P.A., 2004. Edge influence on forest structure and composition in fragmented landscapes. Conservation Biology 19, 768-782. https://doi.org/10.4018/978-159904-099-8.ch010

Harris, M.P.., Allen, K.., Le Duc, M.., Eyre, G., and Marrs, R.., 2011b. Prescribed fire characteristics and biomass reduction on upland moorland. Aspects of Applied Biology 171-177.

Harris, M.P.K., Allen, K.A., McAllister, H.A., Eyre, G., Le Duc, M.G., and Marrs, R.H., 2011a. Factors affecting moorland plant communities and component species in relation to prescribed burning. Journal of Applied Ecology 48, 14111421. https://doi.org/10.1111/j.1365-2664.2011.02052.x

Hawley, G., Anderson, P., Gash, M., Smith, P., Higham, N., Alonso, I., Ede, J., and Holloway, J., 2008. Impacts of heathland restoration and re-creation techniques 
on soil characteristics and the historical environment, Natural England Research Report - NERR010.

Heinemeyer, A., Asena, Q., Burn, W.L. and Jones, A.L., 2018. Peatland carbon stocks and burn history: Blanket bog peat core evidence highlights charcoal impacts on peat physical properties and long-term carbon storage. Geo: Geography and Environment, 5(2), p.e00063. https://doi.org/10.1002/geo2.63

Heip, C.H.R., Herman, P.M.J., and Soetaert, K., 1998. Indices of diversity and evenness. Oceanis 24, 61-88.

Hellou, J., Leonard, J., Collier, T.K., and Ariese, F., 2006. Assessing PAH exposure in feral finfish from the Northwest Atlantic. Marine Pollution Bulletin 52, 433441. https://doi.org/10.1016/j.marpolbul.2005.11.012

Helmke, P.A., and Sparks, D.L., 1996. Lithium, sodium, potassium, rubidium, and cesium. Methods of Soil Analysis: Part 3 Chemical Methods 5, 551-574. https://doi.org/doi.org/10.2136/sssabookser5.3.c19

Hester, A.J. and Sydes, C., 1992. Changes in burning of Scottish heather moorland since the 1940s from aerial photographs. Biological Conservation, 60(1), pp.2530. https://doi.org/10.1016/0006-3207(92)90795-O

Hewelke, E., Szatyłowicz, J., Gnatowski, T. and Oleszczuk, R., 2016. Effects of soil water repellency on moisture patterns in a degraded sapric histosol. Land Degradation \& Development, 27(4), pp.955-964. https://doi.org/10.1002/ldr.2305

Hill, M.O., 1973. Diversity and evenness: a unifying notation and its consequences. Ecology 54, 427-432. https://doi.org/10.2307/1934352

Hinojosa, M.B., Parra, A., Laudicina, V.A., and Moreno, J.M., 2016. Post-fire soil functionality and microbial community structure in a Mediterranean shrubland subjected to experimental drought. Science of the Total Environment 573, 11781189.

Hobbs, R.J. and Legg, C.J., 1984. Markov models and initial floristic composition in heathland vegetation dynamics. Vegetatio, 56(1), pp.31-43. https://doi.org/10.1007/BF00036134 
Hobbs, R.J., and Gimingham, C.H., 1984. Studies on Fire in Scottish Heathland Communities II . Post-Fire Vegetation Development 72, 585-610. https://doi.org/10.2307/2260069

Hoke, R.A., Giesy, J.P., Zabik, M., and Unger, M., 1993. Toxicity of Sediments and Sediment Pore Waters from the Grand Calumet River-Indiana Harbor, Indiana Area of Concern. Ecotoxicology and Environmental Safety 26, 86-112. https://doi.org/10.1006/eesa.1993.1042

Holden, J., 2005. Controls of soil pipe frequency in upland blanket peat. Journal of Geophysical Research: Earth Surface 110.

Holden, J., Chapman, P.J. and Labadz, J.C., 2004. Artificial drainage of peatlands: hydrological and hydrochemical process and wetland restoration. Progress in physical geography, 28(1), pp.95-123. https://doi.org/10.1191/0309133304pp403ra

Holden, J., Chapman, P.J., Palmer, S.M., Kay, P., and Grayson, R., 2012. The impacts of prescribed moorland burning on water colour and dissolved organic carbon: A critical synthesis. Journal of Environmental Management 101, 92103. https://doi.org/10.1016/j.jenvman.2012.02.002

Holden, J., Shotbolt, L., Bonn, A., Burt, T.P., Chapman, P.J., Dougill, A.J., Fraser, E.D.G., Hubacek, K., Irvine, B., and Kirkby, M.J., 2007. Environmental change in moorland landscapes. Earth-Science Reviews 82, 75-100.

Holden, S.R., Rogers, B.M., Treseder, K.K., and Randerson, J.T., 2016. Fire severity influences the response of soil microbes to a boreal forest fire. Environmental Research Letters 11, 35004.

Hooper, D.U., Chapin, F.S., Ewel, J.J., Hector, A., Inchausti, P., Lavorel, S., Lawton, J.H., Lodge, D.M., Loreau, M., Naeem, S., Schmid, B., Setälä, H., Symstad, A.J., Vandermeer, J., and Wardle, D.A., 2005. Effects of biodiversity on ecosystem functioning: A consensus of current knowledge. Ecological Monographs 75, 3-35. https://doi.org/10.1890/04-0922

Hope, C., 2017. Discussion on the restrictions imposed by the legal prescribed burn seasons in the UK. 
Hubbert, K.R., Preisler, H.K., Wohlgemuth, P.M., Graham, R.C., and Narog, M.G., 2006. Prescribed burning effects on soil physical properties and soil water repellency in a steep chaparral watershed, southern California, USA. Geoderma 130, 284-298. https://doi.org/doi.org/10.1016/j.geoderma.2005.02.001

Imeson, A.C., 1971. Heather burning and soil erosion on the North Yorkshire Moors. Journal of Applied Ecology 537-542.

Imeson, A.C., Verstraten, J.M., van Mulligen, E.J., and Sevink, J., 1992. The effects of fire and water repellency on infiltration and runoff under Mediterranean type forest. Catena 19, 345-361. https://doi.org/10.1016/0341-8162(92)90008-Y

Ingersoll, C.G., Dwyer, F.J., Burch, S.A., Nelson, M.K., Buckler, D.R., and Hunn, J.B., 1992. The use of freshwater and saltwater animals to distinguish between the toxic effects of salinity and contaminants in irrigation drain water. Environmental Toxicology and Chemistry 11, 503-511. https://doi.org/10.1002/etc.5620110408

IPCC, 2000. IPCC Special Report on Emission Scenarios, (Intergovernmental Panel on Climate Change) Cambridge University Press. https://doi.org/10.1017/CBO9781107415324.004

Jacquemyn, H., Brys, R., and Neubert, M.G., 2005. Fire increases invasive spread of Molinia caerulea mainly through changes in demographic parameters.

Ecological Applications 15, 2097-2108. https://doi.org/10.1890/04-1762

Jenkins, G.J., Murphy, J.M., Sexton, D.M.H., Lowe, J.A., Jones, P. and Kilsby, C.G., UK Climate Projections: Briefing report; Met Office; Exeter; UK., 2009. http://ukclimateprojections.defra.gov.uk/images/stories/briefing_pdfs/UKCP09_ Briefing. pdf.

JNCC, 2008. UK Biodiversity Action Plan Priority Habitat Descriptions - Upland Heathland. Peterborough.

JNCC, 2009. Common Standards Monitoring guidance for upland habitats. Peterborough. https://doi.org/ISSN 1743-8160

JNCC, 2019a. European dry heaths (4030) - Description and characteristics [WWW Document]. URL https://sac.jncc.gov.uk/habitat/H4030/ (accessed 1.20.18). 
JNCC, 2019b. Forth Report by the United Kingdom under Article 17: H4030 European dry heaths. Peterborough.

Johnsond E.A., and Miyanishid K., 2008. Testing the assumptions of chronosequences in succession. Ecology Letters 11, 419-431. https://doi.org/10.1111/j.1461-0248.2008.01173.x

Jollands, M., Morris, J., and Moffat, A., 2011. Wildfires in Wales 1-107.

Jolly, W.M., Cochrane, M.A., Freeborn, P.H., Holden, Z.A., Brown, T.J., Williamson, G.J., and Bowman, D.M.J.S., 2015. Climate-induced variations in global wildfire danger from 1979 to 2013. Nature Communications. https://doi.org/10.1038/ncomms8537

Jones, P.S., 2005. Burning on blanket bog: a scientific perspective. In: Guidelines for burning and cutting dwarf-shrub vegetation on lowland and upland heath and blanket bog. Bangor.

Jordán, A., Zavala, L.M., Mataix-Solera, J., Nava, A.L., and Alanís, N., 2011. Effect of fire severity on water repellency and aggregate stability on Mexican volcanic soils. Catena $\mathbf{8 4}$, 136-147.

Jost, L., 2007. Partitioning diversity into independent alpha and beta components. Ecology 88, 2427-2439. https://doi:10.1890/06-1736.1.

Jung, C., Kim, J.W., Marquardt, T., and Kaczmarek, S., 2010. Species richness of soil gamasid mites (Acari: Mesostigmata) in fire-damaged mountain sites. Journal of Asia-Pacific Entomology 13, 233-237.

Jung, H.Y., Hogue, T.S., Rademacher, L.K., and Meixner, T., 2009. Impact of wildfire on source water contributions in Devil Creek, CA: Evidence from endmember mixing analysis. Hydrological Processes 23, 183-200. https://doi.org/10.1002/hyp.7132

Kahmen, S., Poschlod, P., and Schreiber, K.-F., 2002. Conservation management of calcareous grasslands. Changes in plant species composition and response of functional traits during 25 years. Biological Conservation 104, 319-328.

Kallis, G., and Butler, D., 2001. The EU water framework directive: measures and implications. Water policy 3, 125-142. 
Kamprath, E.J. and Watson, M.E. 1980. Conventional soil and tissue tests for assessing the phosphorus status of soil. In F.E. Khasawneh, E.C. Sample, and E.J. Kamprath, Eds. The Role of Phosphorus in Agriculture. American Society of Agronomy, Madison, WI, 433-469. https://doi.org/10.2134/1980.roleofphosphorus.c17

Katsvairo, T., Cox, W.J. and van Es, H., 2002. Tillage and rotation effects on soil physical characteristics. Agronomy Journal, 94(2), pp.299-304. https://doi.org/10.2134/agronj2002. 2990

Kayll, A.J., and Gimingham, C.H., 1965. Vegetative regeneration of Calluna vulgaris after fire 53, 729-734. https://doi.org/10.2307/2257631

Keeley, J.E., 2009. Fire intensity, fire severity and burn severity: a brief review and suggested usage. International Journal of Wildland Fire 18, 116-126. https://doi.org/doi.org/10.1071/WF07049

Keeley, J.E., Pausas, J.G., Rundel, P.W., Bond, W.J., and Bradstock, R.A., 2011. Fire as an evolutionary pressure shaping plant traits. Trends in Plant Science 16, 406-411. https://doi.org/10.1016/j.tplants.2011.04.002

Keiluweit, M., Kleber, M., Sparrow, M.A., Simoneit, B.R.T., and Prahl, F.G., 2012. Solvent-extractable polycyclic aromatic hydrocarbons in biochar: Influence of pyrolysis temperature and feedstock. Environmental Science and Technology 46, 9333-9341. https://doi.org/10.1021/es302125k

Keith, L.H., 2015. The Source of U.S. EPA's Sixteen PAH Priority Pollutants. Polycyclic Aromatic Compounds 35, 147-160. https://doi.org/10.1080/10406638.2014.892886

Kelly, R., Montgomery, W.I., and Reid, N., 2018. Differences in soil chemistry remain following wildfires on temperate heath and blanket bog sites of conservation concern. Geoderma 315, 20-26. https://doi.org/10.1016/j.geoderma.2017.11.016

Kempers, A.J., 1974. Determination of sub-microquantities of ammonium and nitrates in soils with phenol, sodiumnitroprusside and hypochlorite. Geoderma 12, 201-206. https://doi.org/10.1016/0016-7061(74)90068-8 
Kennard, D.K., and Gholz, H.L., 2001. Effects of high-and low-intensity fires on soil properties and plant growth in a Bolivian dry forest. Plant and Soil 234, 119129. https://doi.org/doi.org/10.1023/A:1010507414994

Kesler, S.E., 2003. Eh-pH diagrams for geochemistry. Geochimica et Cosmochimica Acta 53, 763. https://doi.org/10.1016/0016-7037(89)90020-3

Ketterings, Q., Reid, S., Rao, R., and Czymmek, K., 2007. Cation Exchange Capacity: Agronomy Fact Sheet Series. Cornell University.

Kettridge, N., Humphrey, R.E., Smith, J.E., Lukenbach, M.C., Devito, K.J., Petrone, R.M. and Waddington, J.M., 2014. Burned and unburned peat water repellency: Implications for peatland evaporation following wildfire. Journal of Hydrology, 513, pp.335-341. https://doi.org/10.1016/j.jhydrol.2014.03.019

Kettridge, N., Turetsky, M.R., Sherwood, J.H., Thompson, D.K., Miller, C.A., Benscoter, B.W., Flannigan, M.D., Wotton, B.M., and Waddington, J.M., 2015. Moderate drop in water table increases peatland vulnerability to post-fire regime shift. Scientific Reports 5, 8063. https://doi.org/10.1038/srep08063

Khanna, P.K., Raison, R.J., and Falkiner, R.A., 1994. Chemical properties of ash derived from Eucalyptus litter and its effects on forest soils. Forest Ecology and Management 66, 107-125. https://doi.org/10.1016/0378-1127(94)90151-1

Kim, E.J., Choi, S.D., and Chang, Y.S., 2011. Levels and patterns of polycyclic aromatic hydrocarbons (PAHs) in soils after forest fires in South Korea. Environmental Science and Pollution Research 18, 1508-1517. https://doi.org/10.1007/s11356-011-0515-3

Kim, E.J., Oh, J.-E., and Chang, Y.-S., 2003. Effects of forest fire on the level and distribution of PCDD/Fs and PAHs in soil. Science of the Total Environment 311, 177-189.

Kinako, P.D.S., and Gimingham, C.H., 1980. Heather burning and soil erosion on upland heaths in Scotland. Journal of Environmental Management 10, 277-284.

Kirkham, F.W., 2001. Nitrogen uptake and nutrient limitation in six hill moorland species in relation to atmospheric nitrogen deposition in England and Wales. Journal of Ecology 89, 1041-1053. https://doi.org/doi.org/10.1111/j.1365- 
Kleijn, D., Bekker, R.M., Bobbink, R., De Graaf, M.C.C., and Roelofs, J.G.M., 2008. In search for key biogeochemical factors affecting plant species persistence in heathland and acidic grasslands: A comparison of common and rare species. Journal of Applied Ecology 45, 680-687. https://doi.org/10.1111/j.13652664.2007.01444.x

Knicker, H., 2007. How does fire affect the nature and stability of soil organic nitrogen and carbon? A review. Biogeochemistry 85, 91-118.

Köhler, B., Gigon, A., Edwards, P.J., Krüsi, B., Langenauer, R., Lüscher, A., and Ryser, P., 2005. Changes in the species composition and conservation value of limestone grasslands in Northern Switzerland after 22 years of contrasting managements. Perspectives in Plant Ecology, Evolution and Systematics 7, 5167.

Krawchuk, M.A., Moritz, M.A., Parisien, M.A., Van Dorn, J., and Hayhoe, K., 2009. Global pyrogeography: The current and future distribution of wildfire. PLoS ONE 4, 5102. https://doi.org/10.1371/journal.pone.0005102

Krishnaraj, S.J., Baker, T.G., Polglase, P.J., Volkova, L., and Weston, C.J., 2016. Prescribed fire increases pyrogenic carbon in litter and surface soil in lowland Eucalyptus forests of south-eastern Australia. Forest Ecology and Management 366, 98-105. https://doi.org/10.1016/j.foreco.2016.01.038

Kruskal, J.B., 1964. Multidimensional scaling by optimizing goodness of fit to a nonmetric hypothesis. Psychometrika 29, 1-27. https://doi.org/10.1007/BF02289565

Lamont, B.B., Enright, N.J., and He, T., 2011. Fitness and evolution of resprouters in relation to fire. Plant Ecology 212, 1945-1957. https://doi.org/10.1007/s11258011-9982-3

Lashley, M.A., Chitwood, M.C., Kays, R., Harper, C.A., DePerno, C.S., and Moorman, C.E., 2015. Prescribed fire affects female white-tailed deer habitat use during summer lactation. Forest Ecology and Management 348, 220-225.

Lavoie, M., Starr, G., Mack, M.C., Martin, T.A., and Gholz, H.L., 2010. Effects of a 
prescribed fire on understory vegetation, carbon pools, and soil nutrients in a longleaf pine-slash pine forest in Florida. Natural Areas Journal 30, 82-94. https://doi.org/doi.org/10.3375/043.030.0109

Lawson, B.D., Frandsen, W.H., Hawkes, B.C. and Dalrymple, G.N., 1997. Probability of sustained smoldering ignition for some boreal forest duff types. Canadian Forest Service, Northern Forestry Centre, Edmonton, Alberta, For. Manage. Forest Management Note, 63.

Lee, H., Alday, J.G., Rose, R.J., O’Reilly, J., and Marrs, R.H., 2013. Long-term effects of rotational prescribed burning and low-intensity sheep grazing on blanket-bog plant communities. Journal of Applied Ecology 50, 625-635. https://doi.org/10.1111/1365-2664.12078

Legg, A.C.J., Maltby, E., and Proctor, M.C.F., 1992. The Ecology of Severe Moorland Fire on the North York Moors : Seed Distribution and Seedling Establishment of Calluna Vulgaris Published by : British Ecological Society Stable URL : http://www.jstor.org/stable/2260863. Journal of Ecology 80, 737752.

Leifeld, J., Alewell, C., Badger, C., Kruger, J.., Mueller, C.W., Sommer, M., Steffens, M., and Szidat, S., 2017. Pyrogenic carbon contributes substantially to carbon storage in intact and degraded northern peatlands. Land Degradation \& Development.

Lenth, R., Singmann, H., Love, J., Buerkner, P. and Herve, M., 2018. Emmeans: Estimated marginal means, aka least-squares means. R package version, 1(1), p.3.

Lewis, S.A., Wu, J.Q., and Robichaud, P.R., 2006. Assessing burn severity and comparing soil water repellency, Hayman Fire, Colorado. Hydrological Processes: An International Journal 20, 1-16. https://doi.org/doi.org/10.1002/hyp.5880

Liira, J., Issak, M., Jõgar, Ü., Mändoja, M., and Zobel, M., 2009. Restoration management of a floodplain meadow and its cost-effectiveness - the results of a 6-year experiment, in: Annales Botanici Fennici. BioOne, pp. 397-408. 
Lindsay, J., 2010. Peatbogs and Carbon: A critical synthesis RSPB Scotland.

Littlewood, N., Anderson, P., Artz, R., Bragg, O., Lunt, P., and Land, M., 2010. Peatland Biodiversity: Scientific Review. IUCN UK Peatland Programme"s Commission of Inquiry on Peatlands 1-35.

Littlewood, N.A., Mason, T.H., Hughes, M., Jaques, R., Whittingham, M.J. and Willis, S.G., 2019. The influence of different aspects of grouse moorland management on nontarget bird assemblages. Ecology and evolution, 9(19), pp.11089-11101. https://doi.org/10.1002/ece3.5613

Liu, Y., Stanturf, J., and Goodrick, S., 2010. Trends in global wildfire potential in a changing climate. Forest Ecology and Management 259, 685-697. https://doi.org/10.1016/j.foreco.2009.09.002

Lukenbach, M.C., Devito, K.J., Kettridge, N., Petrone, R.M., and Waddington, J.M., 2015. Hydrogeological controls on post-fire moss recovery in peatlands. Journal of Hydrology 530, 405-418. https://doi.org/10.1016/j.jhydrol.2015.09.075

Lunt, P., Allot, T., Anderson, P., Buckler, M., Coupar, A., Jones, P., Labadz, J., Worrall, P., and Evans, M., 2010. Impacts of peatland restoration. Scientific Review commissioned by IUCN UK Peatland Programme Commission of Inquiry into Peatland Restoration.

Macadam, A.M., 1987. Effects of broadcast slash burning on fuels and soil chemical properties in the sub-boreal spruce zone of central British Columbia. Canadian Journal of Forest Research 17, 1577-1584.

MacDonald, A.J., and Haysom, K., 1997. Heather moorland management for lepidoptera. Information and advisory note. Battleby.

Mace, G.M., Norris, K., and Fitter, A.H., 2012. Biodiversity and ecosystem services: a multilayered relationship. Trends in ecology \& evolution 27, 19-26.

Mallik, A.U., 1985. Soil water repellency in regularly burned Calluna heathlands: Comparison of three measuring techniques. Journal of Environmental Management 20, 207-218.

Mallik, A.U., and Gimingham, C.H., 1983. Regeneration of heathland plants 
following burning. Vegetatio 53, 45-58. https://doi.org/10.1007/BF00039771

Malmström, A., 2012. Life-history traits predict recovery patterns in Collembola species after fire: A 10 year study. Applied Soil Ecology 56, 35-42. https://doi.org/10.1016/j.apsoil.2012.02.007

Malmström, A., Persson, T., Ahlström, K., Gongalsky, K.B., and Bengtsson, J., 2009. Dynamics of soil meso- and macrofauna during a 5-year period after clear-cut burning in a boreal forest. Applied Soil Ecology 43, 61-74. https://doi.org/10.1016/j.apsoil.2009.06.002

Maltby, E., Legg, C.J., and Proctor, M.C.F., 1990. The Ecology of Severe Moorland Fire on the North York Moors : Effects of the 1976 Fires, and Subsequent Surface and Vegetation Development. Journal of Ecology 78, 490-518. https://doi.org/10.2307/2261126

Marais, K.E., Pratt, R.B., Jacobs, S.M., Jacobsen, A.L., and Esler, K.J., 2014. Postfire regeneration of resprouting mountain fynbos shrubs: Differentiating obligate resprouters and facultative seeders. Plant Ecology 215, 195-208. https://doi.org/10.1007/s11258-013-0289-4

Måren, I.E., Janovský, Z., Spindelböck, J.P., Daws, M.I., Kaland, P.E., and Vandvik, V., 2010. Prescribed burning of northern heathlands: Calluna vulgaris germination cues and seed-bank dynamics. Plant Ecology 207, 245-256. https://doi.org/10.1007/s11258-009-9669-1

Marlon, J.R., Bartlein, P.J., Carcaillet, C., Gavin, D.G., Harrison, S.P., Higuera, P.E., Joos, F., Power, M.J., and Prentice, I.C., 2008. Climate and human influences on global biomass burning over the past two millennia. Nature Geoscience. https://doi.org/10.1038/ngeo313

Marrs, R.H., Galtress, K., Tong, C., Blackbird, S.J., Heyes, T.J., Pakeman, R.J., and Le Duc, M.G., 2007. Conflicts between competing conservation goals, biodiversity or ecosystem services: quantification of element losses and species recruitment using a moorland-bracken model system. Journal of Environmental Management 85, 1034-1047. https://doi.org/10.1016/ jenvman.11.011.

Marrs, R.H., Marsland, E., Lingard, R., Appleby, P.G., Piliposyan, G.T., Rose, R.J., 
O’Reilly, J., Milligan, G., Allen, K.A., Alday, J.G. and Santana, V., 2019 b.

Author Correction: Experimental evidence for sustained carbon sequestration in fire-managed, peat moorlands. Nature Geoscience 12, 148.

https://doi.org/10.1038/s41561-019-0303-0

Marrs, R.H., Marsland, E.L., Lingard, R., Appleby, P.G., Piliposyan, G.T., Rose, R.J., O’Reilly, J., Milligan, G., Allen, K.A., Alday, J.G. and Santana, V., 2019a. Experimental evidence for sustained carbon sequestration in fire-managed, peat moorlands. Nature Geoscience, 12(2), pp.108-112. https://doi.org/10.1038/s41561-018-0266-6

Marrs, R.H., Phillips, J.D.P., Todd, P.A., Ghorbani, J., and Le Duc, M.G., 2004. Control of Molinia caerulea on upland moors. Journal of Applied Ecology 41, 398-411. https://doi.org/10.1111/j.0021-8901.2004.00901.x

Martin, D.A., and Moody, J.A., 2001. Comparison of soil infiltration rates in burned and unburned mountainous watersheds. Hydrological Processes 15, 2893-2903.

Mast, M.A., and Clow, D.W., 2008. Effects of 2003 wildfires on stream chemistry in Glacier National Park, Montana. Hydrological Processes 22, 5013-5023. https://doi.org/10.1002/hyp.7121

Mataix-Solera, J., Cerdà, A., Arcenegui, V., Jordán, A., and Zavala, L.M., 2011. Fire effects on soil aggregation: A review. Earth-Science Reviews 109, 44-60. https://doi.org/10.1016/j.earscirev.2011.08.002

Mataix-Solera, J., Guerrero, C., García-Orenes, F., Bárcenas, G.M., Torres, M.P., and Barcenas, M., 2009. Forest fire effects on soil microbiology. Fire effects on soils and restoration strategies 5, 133-175.

Mataix-Solera, J., Navarro, M.A., Zornoza, R., Guerrero, C., Gómez, I., GarcíaOrenes, F., and Bárcenas, G.M., 2008. Fire effects on soil organic carbon in turn affecting physical, chemical and biochemical soil properties, in: Geophysical Research Abstracts. p. 1280.

McDonald, A.T., Mitchell, G.N., Naden, P.S., and Martin, D.S.J., 1991. Discoloured water investigations. Final report to Yorkshire Water plc 432.

McFerran, D.M., McAdam, J.H., and Montgomery, W.I., 1995. The impact of 
burning and grazing on heathland plants and invertebrates in County Antrim, in: Biology and Environment: Proceedings of the Royal Irish Academy. JSTOR, pp. 1-17.

McMorrow, J., 2011. Wildfire in the United Kingdom: Status and key issues. Proceedings of the Second Conference on the Human Dimensions of Wildland Fire 13.

McMorrow, J., Lindley, S., and Aylen, J., 2009. Moorland wildfire risk, visitors and climate change: patterns, prevention and policy, in: Drivers of Environmental Change in Uplands. Routledge, pp. 432-459.

McVean, D.N., and Ratcliffe, D.A., 1962. Plant communities of the Scottish Highlands. A study of Scottish mountain, moorland and forest vegetation. Plant communities of the Scottish Highlands. A study of Scottish mountain, moorland and forest vegetation.

Medina, L., Kreutzmann, A.K., Rojas-Perilla, N. and Castro, P., 2019. The R Package trafo for Transforming Linear Regression Models. $R$ Journal, 9(2).

Meloun, M., Sáňka, M., Němec, P., Křítková, S., \& Kupka, K. 2005. The analysis of soil cores polluted with certain metals using the Box-Cox transformation. Environmental Pollution, 137(2), 273-280. doi:10.1016/j.envpol.2005.01.027

Mermut, A.R., Luk, S.H., Römkens, M.J.M., and Poesen, J.W.A., 1997. Soil loss by splash and wash during rainfall from two loess soils. Geoderma 75, 203-214.

Miller, C.J., 2008. Mechanisms of water colour release from organic soils and consequences for catchment management.

Milligan, G., Rose, R.J., O’Reilly, J., and Marrs, R.H., 2018. Effects of rotational prescribed burning and sheep grazing on moorland plant communities: Results from a 60-year intervention experiment. Land Degradation and Development 29, 1397-1412. https://doi.org/10.1002/ldr.2953

Moffat, A., Morison, J., Nicoll, B., and Bain, V., 2012. Climate Change Risk Assessment for the Forestry Sector.

Mohamed, A., Härdtle, W., Jirjahn, B., Niemeyer, T., and Von Oheimb, G., 2007. Effects of prescribed burning on plant available nutrients in dry heathland 
ecosystems. Plant Ecology 189, 279-289. https://doi.org/10.1007/s11258-0069183-7

Mohamed, B.F. and Gimingham, C.H., 1970. The morphology of vegetative regeneration in Calluna vulgaris. New Phytologist, 69(3), pp.743-750. https://doi.org/10.1111/j.1469-8137.1970.tb02459.x

Molina, M., Fuentes, R., Calderón, R., Escudey, M., Avendaño, K., Gutiérrez, M., and Chang, A.C., 2007. Impact of forest fire ash on surface charge characteristics of Andisols. Soil science 172, 820-834.

Monbiot, G., 2016. Meet the conservationists who believe that burning is good for wildlife. The Guardian.

Moore, P.A., Lukenbach, M.C., Kettridge, N., Petrone, R.M., Devito, K.J. and Waddington, J.M., 2017. Peatland water repellency: Importance of soil water content, moss species, and burn severity. Journal of Hydrology, 554, pp.656665. https://doi.org/10.1016/j.jhydrol.2017.09.036

Moritz, M.A., Morais, M.E., Summerell, L.A., Carlson, J.M., and Doyle, J., 2005. Wildfires, complexity, and highly optimized tolerance. Proceedings of the National Academy of Sciences. https://doi.org/10.1073/pnas.0508985102

Mount, D.R., Gulley, D.D., Hockett, J.R., Garrison, T.D., and Evans, J.M., 1997. Statistical models to predict the toxicity of major ions to Ceriodaphnia dubia, Daphnia magna and Pimephales promelas (fathead minnows). Environmental Toxicology and Chemistry 16, 2009-2019. https://doi.org/10.1897/15515028(1997)016<2009:SMTPTT>2.3.CO;2

Murphy, J., and Riley, P.., 1986. The analysis of agricultural materials, Reference Book 427, Ministry of Agriculture, Fisheries and Food. HMSO, UK.

Musset, M.L., 2006. Current Approaches in the Statistical analysis of Ecotoxicity data.

Natural England, 2001. The upland management handbook (SC26).

Natural England, 2009. Mapping values: the vital nature of our uplands. http://publications.naturalengland.org.uk/publication/47001 
Neary, D.G., Ryan, K.C., and DeBano, L.F., 2005. Wildland fire in ecosystems: effects of fire on soils and water. Gen. Tech. Rep. RMRS-GTR-42-vol. 4. Ogden, UT: US Department of Agriculture, Forest Service, Rocky Mountain Research Station. 250 p. 42.

Nikinmaa, M., 2014. An introduction to aquatic toxicology. Elsevier.

Noble, A., Palmer, S.M., Glaves, D.J., Crowle, A., and Holden, J., 2019. Peatland vegetation change and establishment of re-introduced Sphagnum moss after prescribed burning. Biodiversity and Conservation 28, 939-952. https://doi.org/10.1007/s10531-019-01703-0

Normand, S., Treier, U.A., Randin, C., Vittoz, P., Guisan, A., and Svenning, J., 2009. Importance of abiotic stress as a range-limit determinant for European plants: insights from species responses to climatic gradients. Global Ecology and Biogeography 18, 437-449. https://doi.org/10.1111/j.1466-8238.2009.00451

Nunes, B., Silva, V., Campos, I., Pereira, J.L., Pereira, P., Keizer, J.J., Gonçalves, F., and Abrantes, N., 2017. Off-site impacts of wildfires on aquatic systems Biomarker responses of the mosquitofish Gambusia holbrooki. Science of the Total Environment 581-582, 305-313. https://doi.org/10.1016/j.scitotenv.2016.12.129

Nunes, J., Doerr, S., and Sheridan, G., 2018. Assessing water contamination risk from vegetation fires: Challenges, opportunities and a framework for progress. Hydrological Processes 32, 687-694. https://doi.org/doi.org/10.1002/hyp.11434

O'Brien, H., 2009. The role of blanket peat moorland management in the generation and amelioration of discolouration of surface water supplies.

O’Brien, H., Labadz, J.C., and Butcher, D.P., 2006. An Investigation of the Impact of Prescribed Moorland Burning in the Derwent Catchment Upon Discolouration of Surface Waters. Report to Moors for the Future. Nottingham Trent University.

OECD, 2004. OECD Guideline for testing of chemicals - Daphnia spp., acute immobilisation test.

Oksanen, J., Blanchet, F.G., Kindt, R., Legendre, P., Minchin, P.R., O’hara, R.B., 
Simpson, G.L., Solymos, P., Stevens, M.H.H., and Wagner, H., 2019. Vegan: community ecology pachage. Community ecology package, version.

Oliveira-Filho, E.C., Brito, D.Q., Dias, Z.M.B., Guarieiro, M.S., Carvalho, E.L., Fascineli, M.L., Niva, C.C., and Grisolia, C.K., 2018. Effects of ashes from a Brazilian savanna wildfire on water, soil and biota: An ecotoxicological approach. Science of the Total Environment 618, 101-111. https://doi.org/10.1016/j.scitotenv.2017.11.051

Olivella, M.A., Ribalta, T.G., De Febrer, A.R., Mollet, J.M., and De Las Heras, F.X.C., 2006. Distribution of polycyclic aromatic hydrocarbons in riverine waters after Mediterranean forest fires. Science of the Total Environment 355, 156-166. https://doi.org/10.1016/j.scitotenv.2005.02.033

Oliver, T.H., Heard, M.S., Isaac, N.J.B., Roy, D.B., Procter, D., Eigenbrod, F., Freckleton, R., Hector, A., Orme, C.D.L., Petchey, O.L., Proença, V., Raffaelli, D., Suttle, K.B., Mace, G.M., Martín-López, B., Woodcock, B.A., and Bullock, J.M., 2015. Biodiversity and Resilience of Ecosystem Functions. Trends in Ecology and Evolution 30, 673-684. https://doi.org/10.1016/j.tree.2015.08.009

Olsen, S.R., Cole, V., Watanabe, F.S., and Dean, L.A., 1954. Estimation of available phosphorus in soils by extraction with sodium bicarbonate.,(United States Department of Agriculture: Washington, DC). DC, USA, Circular 939.

Oswald, B.P., Davenport, D., and Neuenschwander, L.F., 1998. Effects of slash pile burning on the physical and chemical soil properties of Vassar soils. Journal of Sustainable Forestry 8, 75-86.

Pausas, J.G., and Keeley, J.E., 2014. Evolutionary ecology of resprouting and seeding in fire-prone ecosystems. New Phytologist 204, 55-65. https://doi.org/10.1111/nph.12921

Pausas, J.G., Llovet, J., Rodrigo, A., and Vallejo, R., 2008. Are wildfires a disaster in the Mediterranean basin? - A review Vegetation changes Shrublands dominated by resprouting species. International Journal of Wildland Fire 17, $713-723$.

Pearce-Higgins, J.W., and Grant, M.C., 2006. Relationships between bird abundance 
and the composition and structure of moorland vegetation. Bird Study 53, 112125. https://doi.org/10.1080/00063650609461424

Pechony, O., and Shindell, D.T., 2010. Driving forces of global wildfires over the past millennium and the forthcoming century. Proceedings of the National Academy of Sciences of the United States of America. https://doi.org/10.1073/pnas.1003669107

Pellegrini, A.F.A., Ahlström, A., Hobbie, S.E., Reich, P.B., Nieradzik, L.P., Staver, A.C., Scharenbroch, B.C., Jumpponen, A., Anderegg, W.R.L., and Randerson, J.T., 2018. Fire frequency drives decadal changes in soil carbon and nitrogen and ecosystem productivity. Nature 553, 194.

Pepper, I.L., and Brusseau, M.L., 2019. Chapter 2 - Physical-Chemical Characteristics of Soils and the Subsurface, in: Brusseau, M.L., Pepper, I.L., and Gerba, C.P.B.T.-E. and P.S. (Third E. (Eds.), Environmental and Pollution Science (Third Edition). Academic Press, pp. 9-22. https://doi.org/https://doi.org/10.1016/B978-0-12-814719-1.00002-1

Peralta-Videa, J.R., Lopez, M.L., Narayan, M., Saupe, G., and Gardea-Torresdey, J., 2009. The biochemistry of environmental heavy metal uptake by plants: Implications for the food chain. International Journal of Biochemistry and Cell Biology 41, 1665-1677. https://doi.org/10.1016/j.biocel.2009.03.005

Pereira, P., and Úbeda, X., 2010. Spatial distribution of heavy metals released from ashed after a wildfire. Journal of Environmental Engineering and Landscape Management 18, 13-22. https://doi.org/10.3846/jeelm.2010.02

Pereira, P., Cerdà, A., Úbeda, X., Mataix-Solera, J., and Rein, G., 2019. Fire Effects on Soil Properties. CSIRO PUBLISHING.

Pereira, P., Francos, M., Brevik, E.C., Ubeda, X., and Bogunovic, I., 2018. Post-fire soil management. Current Opinion in Environmental Science and Health 5, 2632. https://doi.org/10.1016/j.coesh.2018.04.002

Pereira, P., Úbeda, X., and Martin, D.A., 2012. Fire severity effects on ash chemical composition and water-extractable elements. Geoderma 191, 105-114. https://doi.org/10.1016/j.geoderma.2012.02.005 
Pereira, P., Ubeda, X., Martin, D., Mataix-Solera, J., and Guerrero, C., 2011. Effects of a low severity prescribed fire on water-soluble elements in ash from a cork oak (Quercus suber) forest located in the northeast of the Iberian Peninsula. Environmental Research 111, 237-247. https://doi.org/10.1016/j.envres.2010.09.002

Pereira, P., Úbeda, X., Martin, D., Mataix-Solera, J., Cerdà, A., and Burguet, M., 2014. Wildfire effects on extractable elements in ash from a Pinus pinaster forest in Portugal. Hydrological Processes 28, 3681-3690. https://doi.org/10.1002/hyp.9907

Pérez-Fernández, B., Viñas, L., Franco, M.Á., and Bargiela, J., 2015. PAHs in the Ría de Arousa (NW Spain): A consideration of PAHs sources and abundance. Marine Pollution Bulletin 95, 155-165. https://doi.org/10.1016/j.marpolbul.2015.04.028

Perry, R.W., Rudolph, D.C., and Thill, R.E., 2012. Effects of short-rotation controlled burning on amphibians and reptiles in pine woodlands. Forest ecology and management 271, 124-131.

Peterson, R.A. and Cavanaugh, J.E., 2019. Ordered quantile normalization: a semiparametric transformation built for the cross-validation era, Journal of Applied Statistics, 47:13-15. 2312-2327. DOI: 10.1080/02664763.2019.1630372

Peterson, R.A., 2019. bestNormalize: Normalizing Transformation Functions. URL https://CRAN.Rproject.org/package=bestNormalize. R package version 3.1.

Pickett, S.T.A., 1989. Space-for-time substitution as an alternative to long-term studies. In G.E. Likens (Ed.) Long-term studies in ecology (pp. 110-135). New York, NY: Springer

Pilliod, D.S., Bury, R.B., Hyde, E.J., Pearl, C.A., and Corn, P.S., 2003. Fire and amphibians in North America. Forest Ecology and Management 178, 163-181. https://doi.org/10.1016/S0378-1127(03)00060-4

Pitman, R.M., 2006. Wood ash use in forestry - A review of the environmental impacts. Forestry 79, 563-588. https://doi.org/10.1093/forestry/cp1041

Pivello, V.R., Oliveras, I., Miranda, H.S., Haridasan, M., Sato, M.N., and Meirelles, 
S.T., 2010. Effect of fires on soil nutrient availability in an open savanna in Central Brazil. Plant and Soil 337, 111-123.

https://doi.org/doi.org/10.1007/s11104-010-0508-x

Plumlee, G.S., Martin, D. a, Hoefen, T., Kokaly, R., Eckberg, A., Meeker, G.P., Adams, M., Anthony, M., and Lamothe, P.J., 2007. Preliminary Analytical Results for Ash and Burned Soils from the October 2007 Southern California wildfires, U.S. Geological Survey Open-File Report.

Prats, S.A., dos Santos Martins, M.A., Malvar, M.C., Ben-Hur, M., and Keizer, J.J., 2014. Polyacrylamide application versus forest residue mulching for reducing post-fire runoff and soil erosion. Science of the total environment 468, 464-474.

Prieto-Fernández, A., Acea, M.J., and Carballas, T., 1998. Soil microbial and extractable $\mathrm{C}$ and $\mathrm{N}$ after wildfire. Biology and Fertility of Soils 27, 132-142.

Prieto-Fernandez, A., Villar, M.C., Carballas, M., and Carballas, T., 1993. Shortterm effects of a wildfire on the nitrogen status and its mineralization kinetics in an Atlantic forest soil. Soil Biology and Biochemistry 25, 1657-1664.

Pywell, R.F., Meek, W.R., Webb, N.R., Putwain, P.D., and Bullock, J.M., 2011. Long-term heathland restoration on former grassland: The results of a 17-year experiment. Biological Conservation 144, 1602-1609. https://doi.org/10.1016/j.biocon.2011.02.010

Rackham, O., 1986. The history of the countryside. Dent London.

Radea, C., Kazanis, D., and Arianoutsou, M., 2010. Effects of fire history upon soil macroarthropod communities in Pinus halepensis stands in Attica, Greece. Israel Journal of Ecology \& Evolution 56, 165-179.

Raison, R.J., Khanna, P.K., and Jacobsen, K.L.S., 2009. Effects of Fire on Forest Nutrient Cycles Joan Romanya and Isabel Serrasolses, in: Fire Effects on Soils and Restoration Strategies. CRC Press, pp. 241-272.

Ramage, B.S., Sheil, D., Salim, H.M., Fletcher, C., Mustafa, N.Z.A., Luruthusamay, J.C., Harrison, R.D., Butod, E., Dzulkiply, A.D., Kassim, A.R. and Potts, M.D., 2013. Pseudoreplication in tropical forests and the resulting effects on biodiversity conservation. Conservation Biology, 27(2), 364-372. 
https://doi.org/10.1111/cobi.12004

Ramchunder, S.J., Brown, L.E., and Holden, J., 2009. Environmental effects of drainage, drain-blocking and prescribed vegetation burning in UK upland peatlands. Progress in Physical Geography 33, 49-79.

https://doi.org/10.1177/0309133309105245

Ramchunder, S.J., Brown, L.E., and Holden, J., 2013. Rotational vegetation burning effects on peatland stream ecosystems. Journal of Applied Ecology 50, 636648. https://doi.org/10.1111/1365-2664.12082

Ratajczak, Z., Nippert, J.B., and Collins, S.L., 2012. Woody encroachment decreases diversity across North American grasslands and savannas. Ecology 93, 697703.

Rau, B.M., Blank, R.R., Chambers, J.C., and Johnson, D.W., 2007. Prescribed fire in a Great Basin sagebrush ecosystem: dynamics of soil extractable nitrogen and phosphorus. Journal of Arid Environments 71, 362-375.

Reed, M.S., Bonn, A., Slee, W., Beharry-Borg, N., Birch, J., Brown, I., Burt, T.P., Chapman, D., Chapman, P.J., Clay, G.D., Cornell, S.J., Fraser, E.D.G., Glass, J.H., Holden, J., Hodgson, J.A., Hubacek, K., Irvine, B., Jin, N., Kirkby, M.J., Kunin, W.E., Moore, O., Moseley, D., Prell, C., Price, M.F., Quinn, C.H., Redpath, S., Reid, C., Stagl, S., Stringer, L.C., Termansen, M., Thorp, S., Towers, W., and Worrall, F., 2009. The future of the uplands. Land Use Policy 26, 204-216. https://doi.org/10.1016/j.landusepol.2009.09.013

Reid, W. V, Mooney, H.A., Cropper, A., Capistrano, D., Carpenter, S.R., Chopra, K., Dasgupta, P., Dietz, T., Duraiappah, A.K., and Hassan, R., 2005. Ecosystems and human well-being-Synthesis: A report of the Millennium Ecosystem Assessment. Island Press, Washington DC.

Rey-Salgueiro, L., Martínez-Carballo, E., Merino, A., Vega, J.A., Fonturbel, M.T., and Simal-Gandara, J., 2018. Polycyclic Aromatic Hydrocarbons in Soil Organic Horizons Depending on the Soil Burn Severity and Type of Ecosystem. Land Degradation and Development 29, 2112-2123. https://doi.org/10.1002/ldr.2806 
Richardson, J.L., and Hole, F.D., 1978. Influence of Vegetation on Water Repellency in Selected Western Wisconsin Soils1. Soil Science Society of America Journal 42, 465-467. https://doi.org/10.2136/sssaj1978.03615995004200030018x

Ries, L., Fletcher, R.J., Battin, J., and Sisk, T.D., 2004. Ecological Responses to Habitat Edges: Mechanisms, Models, and Variability Explained. Annual Review of Ecology, Evolution, and Systematics 35, 491-522. https://doi.org/10.1146/annurev.ecolsys.35.112202.130148

Rivas, Y., Huygens, D., Knicker, H., Godoy, R., Matus, F., and Boeckx, P., 2012. Soil nitrogen dynamics three years after a severe Araucaria-Nothofagus forest fire. Austral Ecology 37, 153-163.

Robertson, G.S., Newborn, D., Richardson, M. and Baines, D., 2017. Does rotational heather burning increase red grouse abundance and breeding success on moors in northern England?. Wildlife Biology, 2017(SP1). https://doi.org/10.2981/wlb.00227

Robertson, P.A., Park, K.J. and Barton, A.F., 2001. Loss of heather Calluna vulgaris moorland in the Scottish uplands: the role of red grouse Lagopus lagopus scoticus management. Wildlife Biology, 7(3), pp.11-16. https://doi.org/10.2981/wlb.2001.004

Robinson, L., and Thorn, I., 2009. Toxicology and Ecotoxicology in Chemical Safety Assessment, Toxicology and Ecotoxicology in Chemical Safety Assessment. https://doi.org/10.1002/9781444305494

Rodwell, J.S., 1991. British Plant Communities: Volume 2, Mires and Heaths. Cambridge University Press.

Rogers, B.M., Balch, J.K., Goetz, S., Lehmann, C.E.R., and Turetsky, M., 2020. Focus on changing fire regimes: Interactions with climate, ecosystems, and society. Environmental Research Letters. https://doi.org/10.1088/17489326/ab6d3a

Rousk, J., Brookes, P.C., and Bååth, E., 2009. Contrasting soil pH effects on fungal and bacterial growth suggest functional redundancy in carbon mineralization. Appl. Environ. Microbiol. 75, 1589-1596. 
Ryan, K.C., Knapp, E.E., and Varner, J.M., 2013. Prescribed fire in North American forests and woodlands: History, current practice, and challenges. Frontiers in Ecology and the Environment 11. https://doi.org/10.1890/120329

Rydin, H., and Jeglum, J.K., 2006. The biology of peatlands. Oxford University Press, Oxford, UK.

Santín, C., and Doerr, S., 2019. Carbon, in: Pereira, P., Mataix-Solera, J., Ubeda, X., Rein, G., and Cerdà, A. (Eds.), Fire Effects on Soil Properties. CSIRO PUBLISHING, pp. 115-128.

Santín, C., and Doerr, S.H., 2016. Fire effects on soils: The human dimension. Philosophical Transactions of the Royal Society B: Biological Sciences 371, 28-34. https://doi.org/10.1098/rstb.2015.0171

Santín, C., Doerr, S.H., Kane, E.S., Masiello, C.A., Ohlson, M., de la Rosa, J.M., Preston, C.M., and Dittmar, T., 2016. Towards a global assessment of pyrogenic carbon from vegetation fires. Global Change Biology 22, 76-91. https://doi.org/10.1111/gcb.12985

Santín, C., Doerr, S.H., Merino, A., Bucheli, T.D., Bryant, R., Ascough, P., Gao, X., and Masiello, C.A., 2017. Carbon sequestration potential and physicochemical properties differ between wildfire charcoals and slow-pyrolysis biochars. Scientific Reports 7, 11233. https://doi.org/10.1038/s41598-017-10455-2

Santín, C., Doerr, S.H., Otero, X.L., and Chafer, C.J., 2015. Quantity, composition and water contamination potential of ash produced under different wildfire severities. Environmental Research 142, 297-308.

https://doi.org/10.1016/j.envres.2015.06.041

Santín, C., Otero, X.L., Doerr, S.H., and Chafer, C.J., 2018. Impact of a moderate/high-severity prescribed eucalypt forest fire on soil phosphorous stocks and partitioning. Science of the Total Environment 621, 1103-1114. https://doi.org/10.1016/j.scitotenv.2017.10.116

Savage, S.M., 1974. Mechanism of fire-induced water repellency in soil. Soil Science Society of America Journal, 38(4), pp.652-657.

https://doi.org/10.2136/sssaj1974.036159950038000 40033x 
Savage, S.M., Osborn, J., Letey, J. and Heaton, C., 1972. Substances contributing to fire-induced water repellency in soils. Soil Science Society of America Journal, 36(4), pp.674-678. https://doi.org/10.2136/sssaj1972.03615995003600040047x

Schafer, J.L., and Mack, M.C., 2010. Short-term effects of fire on soil and plant nutrients in palmetto flatwoods. Plant and Soil 334, 433-447. https://doi.org/10.1007/s11104-010-0394-2

Schank, J.C. and Koehnle, T.J., 2009. Pseudoreplication is a pseudoproblem. Journal of comparative psychology, 123(4), 421. https://doi.org/10.1037/a0013579

Scharlemann, J.P.W., Tanner, E.V.J., Hiederer, R., and Kapos, V., 2014. Global soil carbon: Understanding and managing the largest terrestrial carbon pool. Carbon Management 5, 81-91. https://doi.org/10.4155/cmt.13.77

Schepers, L., Haest, B., Veraverbeke, S., Spanhove, T., Borre, J. Vanden, and Goossens, R., 2014. Burned area detection and burn severity assessment of a heathland fire in belgium using airborne imaging spectroscopy (APEX). Remote Sensing 6, 1803-1826. https://doi.org/10.3390/rs6031803

Schimmel, J., and Granstrom, A., 1996. Fire severity and vegetation response in the boreal Swedish forest. Ecology 77, 1436-1450. https://doi.org/10.2307/2265541

Schoenau, J.J. and O'Halloran, I.P., 2008. Sodium bicarbonate-extractable phosphorus. In Carter, M.R. and Gregorich, E.G. ed. Soil sampling and methods of analysis. Canadian Society of Soil Science. CRC Press. Second edition. 8994. https://doi.org/ 10.1017/S0014479708006546

Scholze, M., Knorr, W., Arnell, N.W., and Prentice, I.C., 2006. A climate-change risk analysis for world ecosystems. Proceedings of the National Academy of Sciences 103, 13116-13120. https://doi.org/10.1073/pnas.0601816103

Schulze, E.-D., Wirth, C., and Heimann, M., 2000. Managing forests after Kyoto. Science 289, 2058-2059.

Schurbon, J.M., and Fauth, J.E., 2003. Effects of Prescribed Burning on Amphibian Diversity in a Southeastern U.S. National Forest\rEfectos de Quemas Prescritas sobre la Diversidad de Anfibios en un Parque Nacional en el Sureste de E.U.A. Conservation Biology 17, 1338. 
Schwilk, D.W., and Kerr, B., 2002. Genetic niche-hiking: An alternative explanation for the evolution of flammability. Oikos 99, 431-442. https://doi.org/10.1034/j.1600-0706.2002.11730.x

Scott, A.C., 2000. The Pre-Quaternary history of fire. Palaeogeography, palaeoclimatology, palaeoecology 164, 281-329.

Scott, A.C., and Glasspool, I.J., 2006. The diversification of Paleozoic fire systems and fluctuations in atmospheric oxygen concentration. Proceedings of the National Academy of Sciences 103, 10861-10865. https://doi.org/10.1073/pnas.0604090103

Scott, A.C., Bowman, D.M.J.S., Bond, W.J., Pyne, S.J., and Alexander, M.E., 2014. Fire on earth: an introduction. John Wiley \& Sons.

Scott, G., and Crunkilton, R.L., 2005. Acute and chronic toxicity of nitrate to fathead minnows (pimephales promelas), ceriodephnia dubia and daphnia magna. Environmental Toxicology and Chemistry 19, 2918. https://doi.org/10.1897/1551-5028(2000)019<2918:aacton>2.0.co;2

Searle, S.R., Speed, F.M. and Milliken, G.A., 1980. Population marginal means in the linear model: an alternative to least squares means. The American Statistician 34(4), pp.216-221. https://doi:10.1080/00031305.1980.10483031

SEERAD, 2001. The muirburn code: A guide to good practice. Edinburgh.

SEERAD, 2007. Estimating carbon in organic soils sequestration and emissions (ECOSSE). Edinburgh.

Serrasolsas, I., and Khanna, P.K., 1995. Changes in heated and autoclaved forest soils of SE Australia. II. Phosphorus and phosphatase activity. Biogeochemistry 29, 25-41. https://doi.org/doi.org/10.1007/BF00002592

Shakesby, R.A., 2011. Post-wildfire soil erosion in the Mediterranean: review and future research directions. Earth-science reviews 105, 71-100.

Shakesby, R.A., and Doerr, S.H., 2006. Wildfire as a hydrological and geomorphological agent. Earth-Science Reviews 74, 269-307. https://doi.org/10.1016/j.earscirev.2005.10.006 
Shakesby, R.A., Bento, C.P.M., Ferreira, C.S.S., Ferreira, A.J.D., Stoof, C.R., Urbanek, E., and Walsh, R.P.D., 2015. Impacts of prescribed fire on soil loss and soil quality: an assessment based on an experimentally-burned catchment in central Portugal. Catena 128, 278-293.

https://doi.org/doi.org/10.1016/j.catena.2013.03.012

Sillasoo, Ü., Väliranta, M., and Tuittila, E.S., 2011. Fire history and vegetation recovery in two raised bogs at the Baltic Sea. Journal of Vegetation Science 22, 1084-1093. https://doi.org/10.1111/j.1654-1103.2011.01307.x

Silva, V., Pereira, J.L., Campos, I., Keizer, J.J., Gonçalves, F., and Abrantes, N., 2015. Toxicity assessment of aqueous extracts of ash from forest fires. Catena 135, 401-408. https://doi.org/10.1016/j.catena.2014.06.021

Simplício, N., Muniz, D., Rocha, F., Martins, D., Dias, Z., Farias, B., and OliveiraFilho, E., 2016. Comparative Analysis between Ecotoxicity of Nitrogen-, Phosphorus-, and Potassium-Based Fertilizers and Their Active Ingredients. Toxics 5, 2. https://doi.org/10.3390/toxics5010002

Smart, R.P., Holden, J., Dinsmore, K.J., Baird, A.J., Billett, M.F., Chapman, P.J., and Grayson, R., 2013. The dynamics of natural pipe hydrological behaviour in blanket peat. Hydrological Processes 27, 1523-1534.

https://doi.org/10.1002/hyp.9242

Smith, A.A., Redpath, S.M., Campbell, S.T., and Thirgood, S.J., 2001. Meadow pipits, red grouse and the habitat characteristics of managed grouse moors. Journal of Applied Ecology 38, 390-400. https://doi.org/10.1046/j.13652664.2001.00601

Smith, H.G., Sheridan, G.J., Lane, P.N.J., Nyman, P., and Haydon, S., 2011. Wildfire effects on water quality in forest catchments: A review with implications for water supply. Journal of Hydrology 396, 170-192. https://doi.org/10.1016/j.jhydrol.2010.10.043

Smith, S.M., Newman, S., Garrett, P.B. and Leeds, J.A., 2001. Differential effects of surface and peat fire on soil constituents in a degraded wetland of the northern Florida Everglades. Journal of Environmental Quality, 30(6), pp.1998-2005. https://doi.org/10.2134/jeq2001.1998 
Smithson, P., Addison, K., and Atkinson, K., 2013. Fundamentals of the physical environment - Fourth Edition. Routledge.

Sparks, D.L., Page, A.L., Helmke, P.A., Loeppert, R.H., Soltanpour, P.N., and Tabatabai, M.A., 1996. Methods of soil analysis. Part 3. Chemical methods. SSSA Book Ser. 5. SSSA, Madison, WI. Methods of soil analysis. Part 3. Chemical methods. SSSA Book Ser. 5. SSSA, Madison, WI. https://doi.org/doi.org/10.2136/sssabookser5.3.c19

SPSS, I., 2007. SPSS (Version 15.0)[Computer software].

Stein, E.D., Brown, J.S., Hogue, T.S., Burke, M.P., and Kinoshita, A., 2012.

Stormwater contaminant loading following southern California wildfires.

Environmental Toxicology and Chemistry 31, 2625-2638.

https://doi.org/10.1002/etc.1994

Stevenson, A.C. and Rhodes, A.N., 2000. Palaeoenvironmental evaluation of the importance of fire as a cause for Calluna loss in the British Isles.

Palaeogeography, Palaeoclimatology, Palaeoecology, 164(1-4), pp.195-206. https://doi.org/10.1016/S0031-0182(00)00186-3

Stewart, G.B., Coles, C.F., and Pullin, A.S., 2004. Systematic Review No. 1 Does Burning Degrade Blanket Bog? Systematic Review No. 1. Collaboration for Environmental Evidence., Centre for Evidence-Based Conservation. Birmingham.

Stewart, G.B., Coles, C.F., and Pullin, A.S., 2005. Applying evidence-based practice in conservation management: Lessons from the first systematic review and dissemination projects. Biological Conservation 126, 270-278. https://doi.org/10.1016/j.biocon.2005.06.003

Stiernström, S., Lindé, M., Hemström, K., Wik, O., Ytreberg, E., Bengtsson, B.E., and Breitholtz, M., 2013. Improved understanding of key elements governing the toxicity of energy ash eluates. Waste Management 33, 842-849. https://doi.org/10.1016/j.wasman.2012.12.008

Stokes, K.E., Allchin, A.E., Bullock, J.M., and Watkinson, A.R., 2004. Population responses of Ulex shrubs to fire in a lowland heath community. Journal of 
Vegetation Science 15, 505-514. https://doi.org/10.1111/j.16541103.2004.tb02289.x

Stoof, C.R., Wesseling, J.G. and Ritsema, C.J., 2010. Effects of fire and ash on soil water retention. Geoderma, 159(3-4), pp.276-285.

https://doi.org/10.1016/j.geoderma.2010.08.002

Stroud, D.A., Chambers, D., Cook, S., Buxton, N., Fraser, B., Clement, P., Lewis, P., McLean, I., Baker, H., and Whitehead, S., 2001. The UK SPA Network: Its Scope and Content, Three Volumes. JNCC, Peter Burk, UK.

Stumm, W. and Morgan, J.., 2013. Aquatic chemistry: chemical equilibria and rates in natural waters, Choice Reviews Online. https://doi.org/10.5860/choice.336312

Sulwiński, M., Mętrak, M., and Suska-Malawska, M., 2017. Long-term fire effects of the drained open fen on organic soils. Archives of Environmental Protection 43, 11-19. https://doi.org/10.1515/aep-2017-0002

Sundström, E., Magnusson, T. and Hånell, B., 2000. Nutrient conditions in drained peatlands along a north-south climatic gradient in Sweden. Forest Ecology and Management, 126(2), pp.149-161. https://doi.org/10.1016/S03781127(99)00098-5

Tavşanoğlu, Ç., and Pausas, J.G., 2018. A functional trait database for Mediterranean Basin plants. Scientific data 5. https://doi.org/10.1038/sdata.2018.135

Taylor, E.S., Levy, P.E., and Gray, A., 2017 The recovery of Sphagnum capillifolium following exposure to temperatures of simulatedmoorland fires: a glasshouse experiment, Plant Ecology \& Diversity, 10:1, 77-88, DOI: $10.1080 / 17550874.2017 .1302017$

Tecle, A., and Neary, D., 2015. Water Quality Impacts of Forest Fires. Journal of Pollution Effects \& Control 03. https://doi.org/10.4172/2375-4397.1000140

Terefe, T., Mariscal-Sancho, I., Peregrina, F., and Espejo, R., 2008. Influence of heating on various properties of six Mediterranean soils. A laboratory study. Geoderma 143, 273-280.

Tharme, A.P., Green, R.E., Baines, D., Bainbridge, I.P., and O’Brien, M., 2001. The 
effect of management for red grouse shooting on the population density of breeding birds on heather-dominated moorland. Journal of Applied Ecology 38, 439-457. https://doi.org/10.1046/j.1365-2664.2001.00597

Thomas, G.W., 1996. Soil pH and soil acidity. Methods of soil analysis: part 3 chemical methods 5, 475-490. https://doi.org/doi.org/10.2136/sssabookser5.3.c16

Thompson, D.B.A., Macdonald, A.J., Marsden, J.H., and Galbraith, C.A., 1995. Upland heather moorland in Great Britain: nature conservation. Biological Conservation 71, 163-178. https://doi.org/10.1016/0006-3207(94)00043-P

Tian, Q., Guo, B., Nakama, S., and Sasaki, K., 2018. Distributions and Leaching Behaviors of Toxic Elements in Fly Ash. ACS Omega 3, 13055-13064. https://doi.org/10.1021/acsomega.8b02096

Tsai, K.P., Uzun, H., Karanfil, T., and Chow, A.T., 2017. Dynamic Changes of Disinfection Byproduct Precursors following Exposures of Microcystis aeruginosa to Wildfire Ash Solutions. Environmental Science and Technology 51, 8272-8282. https://doi.org/10.1021/acs.est.7b01541

Tucker, G., 2003a. Review of the impacts of heather and grassland burning in the uplands on soils, hydrology and biodiversity, English Nature Research Report No: 550.

Tucker, G., 2003b. Review of the impacts of heather and grass burning in the uplands on soils, hydrology and biodiversity, English Nature Research Reports.

Turetsky, M.R., Benscoter, B., Page, S., Rein, G., Van Der Werf, G.R. and Watts, A., 2015. Global vulnerability of peatlands to fire and carbon loss. Nature Geoscience, 8(1), pp.11-14. https://doi.org/10.1038/ngeo2325

Turner, M.G., Smithwick, E.A.H., Metzger, K.L., Tinker, D.B., and Romme, W.H., 2007. Inorganic nitrogen availability after severe stand-replacing fire in the Greater Yellowstone ecosystem. Proceedings of the National Academy of Sciences 104, 4782-4789.

UK Soil Observatory, 2018. UK soil environment viewer [WWW Document]. British Ecological Society. URL http://mapapps2.bgs.ac.uk/ukso/home.html 
(accessed 4.12.18).

Ulery, A.L., Graham, R.C., and Amrhein, C., 1993. Wood-ash composition and soil pH following intense burning. Soil science 156, 358-364.

USEPA - United States Environmental Protection Agency, 2016. EPA - OCSPP 850.1010: Aquatic Invertebrate Acute Toxicity Test, Freshwater Daphnids.

Usher, M.B., 1992. Management and diversity of arthropods inCalluna heathland. Biodiversity \& Conservation 1, 63-79.

Valkó, O., Deák, B., Magura, T., Török, P., Kelemen, A., Tóth, K., Horváth, R., Nagy, D.D., Debnár, Z., Zsigrai, G., Kapocsi, I., and Tóthmérész, B., 2016. Supporting biodiversity by prescribed burning in grasslands - A multi-taxa approach. Science of the Total Environment 572, 1377-1384. https://doi.org/10.1016/j.scitotenv.2016.01.184

Valkó, O., Török, P., Deák, B., and Tóthmérész, B., 2014. Review: Prospects and limitations of prescribed burning as a management tool in European grasslands. Basic and Applied Ecology 15, 26-33. https://doi.org/10.1016/j.baae.2013.11.002

Van Reeuwijk, L.P., 2002. Technical Paper -Procedures for soil analysis, Procedures for Soil Analysis. https://doi.org/10.1016/j.postcomstud.2006.09.001

Van Wagner, C.E. 1987. Development and structure of the Canadian forest fire weather index system. Canadian Forestry Service: Ottawa. Forest Technology Report 35. http://cfs.nrcan.gc.ca/pubwarehouse/pdfs/19927.pdf

Van Wagner, C.E. and T.L. Pickett. 1985. Equations and FORTRAN program for the Canadian Forest Fire Weather Index System. Canadian Forestry Service: Ottawa, Ontario Forest Technology Report 33. 18 p. http://cfs.nrcan.gc.ca/pubwarehouse/pdfs/19973.pdf

Veeraswamy, A., Galea, E.R., Filippidis, L., Lawrence, P.J., Haasanen, S., Gazzard, R.J., and Smith, T.E.L., 2018. The simulation of urban-scale evacuation scenarios with application to the Swinley forest fire. Safety Science 102, 178193. https://doi.org/10.1016/j.ssci.2017.07.015

Velle, L.G., and Vandvik, V., 2014. Succession after prescribed burning in coastal 
Calluna heathlands along a 340-km latitudinal gradient. Journal of Vegetation Science 25, 546-558. https://doi.org/10.1111/jvs.12100

Velle, L.G., Nilsen, L.S., and Vandvik, V., 2012. The age of Calluna stands moderates post-fire regeneration rate and trends in northern Calluna heathlands. Applied Vegetation Science 15, 119-128. https://doi.org/10.1111/j.1654109X.2011.01144

Velle, L.G., Nilsen, L.S., Norderhaug, A., and Vandvik, V., 2014. Does prescribed burning result in biotic homogenization of coastal heathlands? Global Change Biology 20, 1429-1440. https://doi.org/10.1111/gcb.12448

Venterink, H.O., Kardel, I., Kotowski, W., Peeters, W. and Wassen, M.J., 2009. Long-term effects of drainage and hay-removal on nutrient dynamics and limitation in the Biebrza mires, Poland. Biogeochemistry, 93(3), pp.235-252. https://doi.org/10.1007/s10533-009-9300-5

Verma, S., and Jayakumar, S., 2012. Impact of forest fire on physical, chemical and biological properties of soil: A review. Proceedings of the International Academy of Ecology and Environmental Sciences 2, 168.

Vila-Escalé, M., Vegas-Vilarrúbia, T., and Prat, N., 2007. Release of polycyclic aromatic compounds into a Mediterranean creek (Catalonia, NE Spain) after a forest fire. Water Research 41, 2171-2179. https://doi.org/10.1016/j.watres.2006.07.029

Viñas, L., Franco, M.A., and González, J.J., 2009. Polycyclic aromatic hydrocarbon composition of sediments in the Ría de Vigo (NW Spain). Archives of Environmental Contamination and Toxicology 57, 42-49. https://doi.org/10.1007/s00244-008-9230-6

Vogelmann, E.S., Reichert, J.M., Prevedello, J., Consensa, C.O.B., Oliveira, A.É., Awe, G.O. and Mataix-Solera, J., 2013. Threshold water content beyond which hydrophobic soils become hydrophilic: The role of soil texture and organic matter content. Geoderma, 209, pp.177-187. https://doi.org/10.1016/j.geoderma.2013.06.019

Voroney, P., 2019. Chapter 4 - Soils for Pasture Management, in: Sharpe, P.B.T.- 
H.P.M. (Ed.), Horse Pasture Managment. Academic Press, pp. 65-79. https://doi.org/https://doi.org/10.1016/B978-0-12-812919-7.00004-4

Walter, K., Don, A., Tiemeyer, B., and Freibauer, A., 2016. Determining soil bulk density for carbon stock calculations: a systematic method comparison. Soil Science Society of America Journal 80, 579-591.

https://doi.org/doi:10.2136/sssaj2015.11.0407

Wang, C., Wang, G., Wang, Y., Rafique, R., Ma, L., Hu, L., and Luo, Y., 2016. Fire alters vegetation and soil microbial community in alpine meadow. Land Degradation \& Development 27, 1379-1390.

Wang, G., Yu, X., Bao, K., Xing, W., Gao, C., Lin, Q. and Lu, X., 2015. Effect of fire on phosphorus forms in Sphagnum moss and peat soils of ombrotrophic bogs. Chemosphere, 119, pp.1329-1334. https://doi.org/10.1016/j.chemosphere.2014.01.084

Wang, X., Parisien, M.-A., Taylor, S.W., Candau, J.-N., Stralberg, D., Marshall, G.A., Little, J.M., and Flannigan, M.D., 2017. Projected changes in daily fire spread across Canada over the next century. Environmental Research Letters 12, 25005. https://doi.org/10.1088/1748-9326/aa5835

Wang, X., Wotton, B.M., Cantin, A.S., Parisien, M.A., Anderson, K., Moore, B. and Flannigan, M.D., 2017. cffdrs: an R package for the Canadian forest fire danger rating system. Ecological Processes, 6(1), p.5. https://doi.org/10.1186/s13717017-0070-Z

Ward, S.E., Bardgett, R.D., McNamara, N.P., Adamson, J.K., and Ostle, N.J., 2007. Long-term consequences of grazing and burning on northern peatland carbon dynamics. Ecosystems 10, 1069-1083. https://doi.org/10.1007/s10021-0079080-5

Ward, S.E., Bardgett, R.D., McNamara, N.P., and Ostle, N.J., 2009. Plant functional group identity influences short-term peatland ecosystem carbon flux: Evidence from a plant removal experiment. Functional Ecology 23, 454-462. https://doi.org/10.1111/j.1365-2435.2008.01521

Webb, N.R., 2008. The traditional management of European heathlands. Journal of 
Applied Ecology 35, 987-990. https://doi.org/10.1111/j.1365-

2664.1998.tb00020

Weiner, E.R., and Group, F., 2007. Applications of Environmental Aquatic A Practical Guide, Applications of Environmental Aquatic Chemistry A Practical Guide. https://doi.org/10.1201/9781420008371

Welsh Government, 2008. The Heather and Grass Burning Code for Wales. Cardiff.

Welsh Government, 2017. Securing Wales Future: Transiting from the European Union to a new relationship with Europe. Cardiff.

Welsh Government, 2018. Brexit and our land: Securing the future for welsh farming. Cardiff.

Welsh Government, 2019. Glastir Advanced: Rules Booklet 1. Cardiff.

Wessel, A.T., 1988. On using the effective contact angle and the water drop penetration time for classification of water repellency in dune soils. Earth Surface Processes and Landforms 13, 555-561. https://doi.org/doi.org/10.1002/espp.3290130609

Wessel, W.W., Tietema, A., Beier, C., Emmett, B.A., Peñuelas, J., and Riis-Nielsen, T., 2004. A qualitative ecosystem assessment for different shrublands in western Europe under impact of climate change. Ecosystems 7, 662-671. https://doi.org/10.1007/s10021-004-0219-3

Wesseling, J.G., Stoof, C.R., Ritsema, C.J., Oostindie, K. and Dekker, L.W., 2009. The effect of soil texture and organic amendment on the hydrological behaviour of coarse-textured soils. Soil use and management, 25(3), pp.274-283. https://doi.org/10.1111/j.1475-2743.2009.00224.x

Whitehead, S.C., and Baines, D., 2018. Moorland vegetation responses following prescribed burning on blanket peat. International Journal of Wildland Fire 27, 658-664. https://doi.org/10.1071/wf18019

Whittaker, E., \& Gimingham, C., 1962. The Effects of Fire on Regeneration of Calluna Vulgaris (L.) Hull. from Seed. Journal of Ecology, 50(3), 815-822. doi:10.2307/2257484 
Wicklow, D.T., 1988. Parallels in the development of post-fire fungal and herb communities. Proceedings of the Royal Society of Edinburgh, Section B: Biological Sciences 94, 87-95.

Wilde, K.L., Stauber, J.L., Markich, S.J., Franklin, N.M., and Brown, P.L., 2006. The effect of $\mathrm{pH}$ on the uptake and toxicity of copper and zinc in a tropical freshwater alga (Chlorella spp.). Archives of Environmental Contamination and Toxicology 51, 174-185. https://doi.org/10.1007/s00244-004-0256-0

Wilkinson, J.F., and Miller, R.H., 1978. Investigation and Treatment of Localized Dry Spots on Sand Golf Greens 1. Agronomy Journal 70, 299-304.

Woods, S.W., and Balfour, V.N., 2010. The effects of soil texture and ash thickness on the post-fire hydrological response from ash-covered soils. Journal of Hydrology 393, 274-286.

World Health Organization, 2011. Guidelines for drinking-water quality - 4th edition. https://doi.org/10.1016/S1462-0758(00)00006-6

Worrall, F., and Adamson, J.K., 2008. The effect of burning and sheep grazing on soil water composition in a blanket bog: evidence for soil structural changes? Hydrological Processes 22, 2531-2541. https://doi.org/10.1002/hyp

Worrall, F., Armstrong, A., and Adamson, J.K., 2007. The effects of burning and sheep-grazing on water table depth and soil water quality in a upland peat. Journal of Hydrology 339, 1-14. https://doi.org/10.1016/j.jhydrol.2006.12.025

Worrall, F., Bell, M.J., and Bhogal, A., 2010b. Assessing the probability of carbon and greenhouse gas benefit from the management of peat soils. Science of the Total Environment 408, 2657-2666. https://doi.org/10.1016/j.scitotenv.2010.01.033

Worrall, F., Clay, G., Marrs, R., and Reed, M., 2010a. Impacts of Burning Management on Peatlands. IUCN, UK Peatland Programme, Durham 1-41.

Worrall, F., Clay, G.D., and May, R., 2013b. Controls upon biomass losses and char production from prescribed burning on UK moorland. Journal of Environmental Management 120, 27-36. https://doi.org/10.1016/j.jenvman.2013.01.030

Worrall, F., Reed, M., Warburton, J., and Burt, T., 2003. Carbon budget for a British 
upland peat catchment. Science of the Total Environment 312, 133-146.

Worrall, F., Rowson, J., and Dixon, S., 2013a. Effects of managed burning in comparison with vegetation cutting on dissolved organic carbon concentrations in peat soils. Hydrological Processes 27, 3994-4003. https://doi.org/10.1002/hyp.9474

Wotton, B.M., Flannigan, M.D., and Marshall, G.A., 2017. Potential climate change impacts on fire intensity and key wildfire suppression thresholds in Canada. Environmental Research Letters 12, 95003. https://doi.org/10.1088/17489326/aa7e6e

Wynne-Jones, S., 2013. Connecting payments for ecosystem services and agrienvironment regulation: An analysis of the Welsh Glastir Scheme. Journal of Rural Studies 31, 77-86. https://doi.org/10.1016/j.jrurstud.2013.01.004

Xue, L., Li, Q., and Chen, H., 2014. Effects of a wildfire on selected physical, chemical and biochemical soil properties in a Pinus massoniana forest in South China. Forests 5, 2947-2966. https://doi.org/doi.org/10.3390/f5122947

Yallop, A.R., and Clutterbuck, B., 2009. Land management as a factor controlling dissolved organic carbon release from upland peat soils 1: Spatial variation in DOC productivity. Science of the Total Environment 407, 3803-3813. https://doi.org/10.1016/j.scitotenv.2009.03.012

Yallop, A.R., Clutterbuck, B., and Thacker, J., 2010. Increases in humic dissolved organic carbon export from upland Peat catchments: The role of temperature, declining sulphur deposition and changes in land management. Climate Research 45, 43-56. https://doi.org/10.3354/cr00884

Yallop, A.R., Thacker, J.I., Thomas, G., Stephens, M., Clutterbuck, B., Brewer, T., and Sannier, C.A.D., 2006. The extent and intensity of management burning in the English uplands. Journal of Applied Ecology 43, 1138-1148. https://doi.org/10.1111/j.1365-2664.2006.01222

Yallop, A.R., Thomas, G., Thacker, J., Brewer, T., and Sannier, C., 2005. A History of Burning as a Management Tool in the English Uplands: 1: Estimates of the Areal Extent of Management Burning in English Uplands. English Nature. 
Yallop, A.R., White, S.M., and Clutterbuck, B., 2008. Evidence for a mechanism driving recent observed trends in dissolved organic carbon release from upland peat soils. Aspects of Applied Biology 85, 127-132.

Yang, J., Tian, H., Tao, B., Ren, W., Kush, J., Liu, Y., and Wang, Y., 2014. Spatial and temporal patterns of global burned area in response to anthropogenic and environmental factors: Reconstructing global fire history for the 20th and early 21 st centuries. Journal of Geophysical Research: Biogeosciences 119, 249-263. https://doi.org/10.1002/2013JG002532

Yousaf, B., Liu, G., Wang, R., Abbas, Q., Imtiaz, M., and Liu, R., 2017. Investigating the biochar effects on C-mineralization and sequestration of carbon in soil compared with conventional amendments using the stable isotope (813C) approach. Gcb Bioenergy 9, 1085-1099. https://doi.org/doi.org/10.1111/gcbb.12401

Zaitsev, A.S., Gongalsky, K.B., Malmström, A., Persson, T., and Bengtsson, J., 2016. Why are forest fires generally neglected in soil fauna research? A minireview. Applied Soil Ecology 98, 261-271. https://doi.org/10.1016/j.apsoil.2015.10.012

Zavala, L.M., De Celis, R., and Jordán, A., 2014. How wildfires affect soil properties. A brief review. Cuadernos de Investigación Geográfica 40, 311. https://doi.org/10.18172/cig.2522

Zavala, L.M., Granged, A.J., Jordán, A. and Bárcenas-Moreno, G., 2010. Effect of burning temperature on water repellency and aggregate stability in forest soils under laboratory conditions. Geoderma, 158(3-4), pp.366-374. https://doi.org/10.1016/j.geoderma.2010.06.004

Zisman, W.A., 1964. Relation of the Equilibrium Contact Angle to Liquid and Solid Constitution. American Chemical Society 43, 1-51. https://doi.org/10.1021/ba1964-0043.ch001 